15 Army Corps =ngineers

LIBRARY rways Experiment USE ONLY on
US-CE-C Property of the

United States Government

\title{
Flow-Induced Vibration Experiments for a 1:25-Scale-Model Flat Wicket Gate
}

by Mostafiz R. Chowdhury, Robert L. Hall, Eileen Pesantes

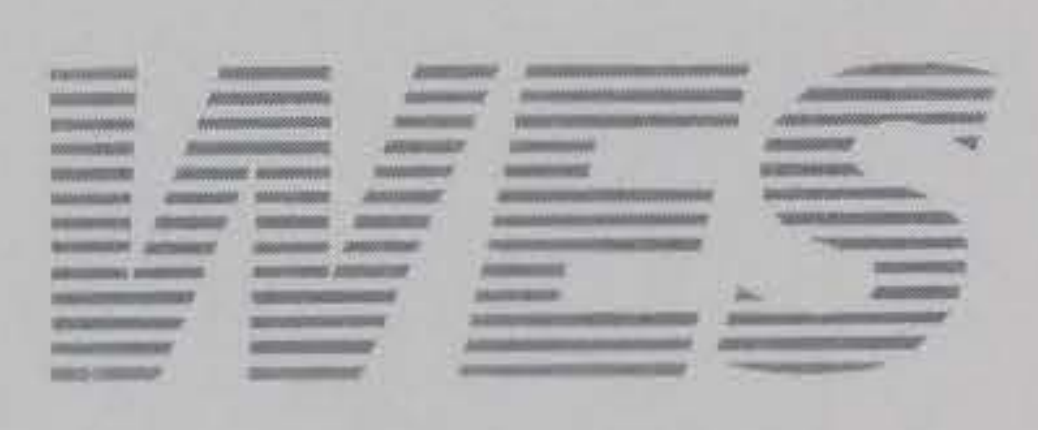

Approved For Public Release; Distribution Is Unlimited

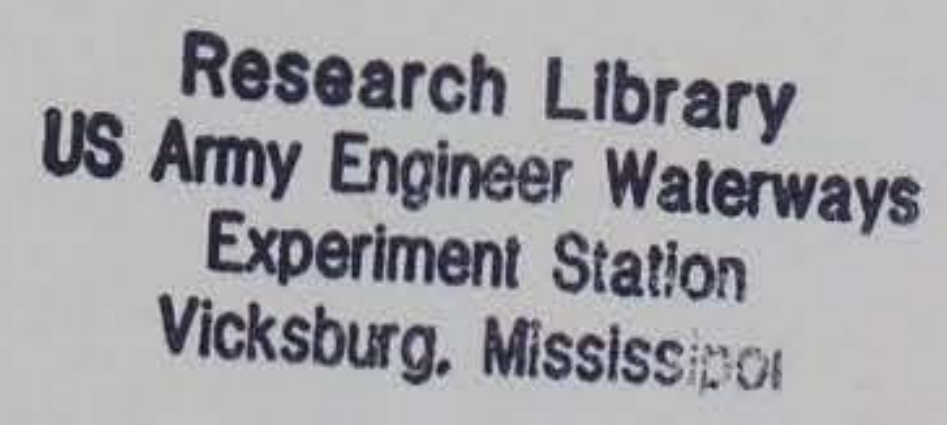

Prepared for Headquarters, U.S. Army Corps of Engineers and U.S. Army Engineer District, Louisville 
The contents of this report are not to be used for advertising, publication, or promotional purposes. Citation of trade names does not constitute an official endorsement or approval of the use of such commercial products.

The findings of this report are not to be construed as an official Department of the Army position, unless so designated by other authorized documents. 


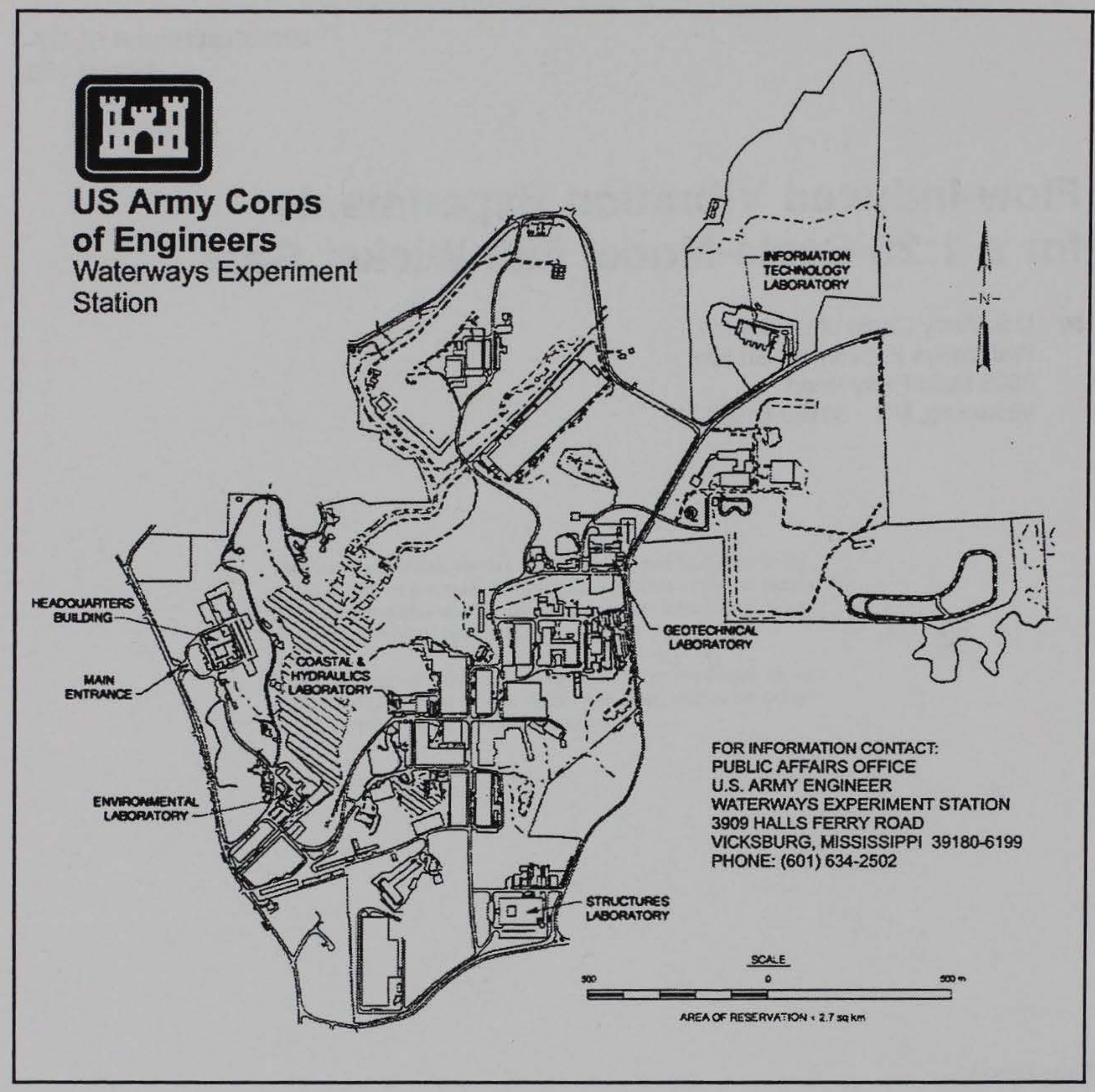

Waterways Experiment Station Cataloging-in-Publication Data

Chowdhury, Mostafiz R.

Flow-induced vibration experiments for a 1:25-scale-model flat wicket gate / by Mostafiz

R. Chowdhury, Robert L. Hall, Eileen Pesantes; prepared for U.S. Army Corps of Engineers ; monitored by U.S. Army Engineer District, Louisville.

247 p. : ill. ; $28 \mathrm{~cm}$.- (Technical report ; SL-97-4)

Includes bibliographical references.

1. Hydraulic gates -- Vibration. 2. Hydraulic structures. 3. Streamflow. I. Hall, Robert L. II. Pesantes, Eileen. III. United States. Army. Corps of Engineers. Louisville District. IV. U.S. Army Engineer Waterways Experiment Station. V. Structures Laboratory (U.S. Army Engineer Waterways Experiment Station) VI. Title. VII. Series: Technical report (U.S. Army Engineer Waterways Experiment Station); SL-97-4.

TA7 W34 no.SL-97-4 


\section{Contents}

Preface $\ldots \ldots \ldots \ldots \ldots \ldots \ldots \ldots \ldots \ldots \ldots \ldots \ldots \ldots \ldots, v$

Conversion Factors, Non-SI to SI Units of Measurement $\ldots \ldots \ldots \ldots \ldots$ vi

1 -Introduction $\ldots \ldots \ldots \ldots \ldots \ldots \ldots \ldots \ldots \ldots \ldots \ldots \ldots$

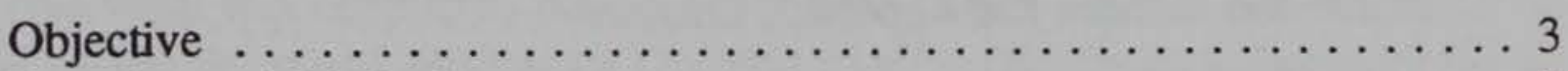

Experimental Method .......................... 3

Experimental outline $\ldots \ldots \ldots \ldots \ldots \ldots \ldots \ldots \ldots \ldots \ldots \ldots \ldots$

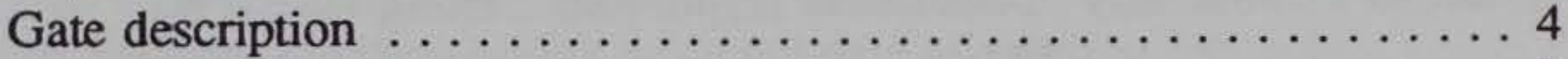

Instrumentation and test setup $\ldots \ldots \ldots \ldots \ldots \ldots \ldots \ldots$

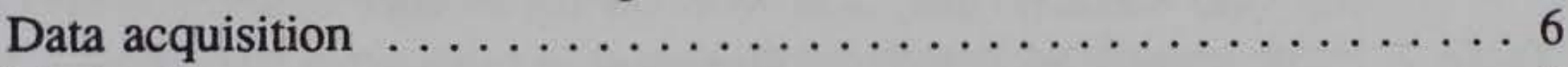

Limitations . . . . . . . . . . . . . . . . 7

Experimental conditions $\ldots \ldots \ldots \ldots \ldots \ldots \ldots \ldots \ldots$

2-Flow Data Analyses for the 1:25 Scale-Model Wicket Gate ....... 11

Data Analysis for the Flat Gate with and without the Approach

Channel . . . . . . . . . . . . . . . . . . . . 11

Time-domain data comparison $\ldots \ldots \ldots \ldots \ldots \ldots \ldots \ldots \ldots \ldots$

Frequency-domain signature analysis $\ldots \ldots \ldots \ldots \ldots \ldots \ldots \ldots \ldots$

Experimental Data Analysis for the Flat and Curved Gates ....... 23

Time-domain data comparison $\ldots \ldots \ldots \ldots \ldots \ldots \ldots \ldots \ldots \ldots \ldots$

Frequency-domain signature analysis $\ldots \ldots \ldots \ldots \ldots \ldots \ldots \ldots \ldots \ldots \ldots$

Experimental modal test - dry condition $\ldots \ldots \ldots \ldots \ldots \ldots .23$

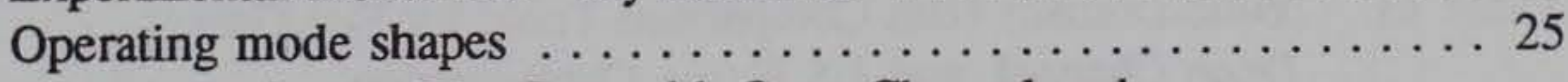

Data Analysis for the Flat Gate with Open Channel and

1:5 Flume Configuration ...................... 27

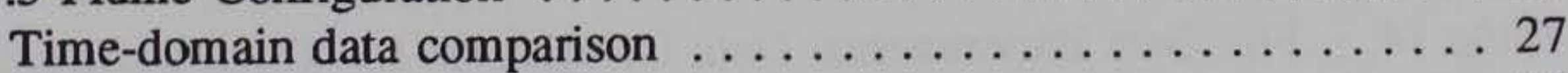

Frequency-domain data comparison $\ldots \ldots \ldots \ldots \ldots \ldots \ldots 28$

3-Verification of Experimental Results and Estimation of Design

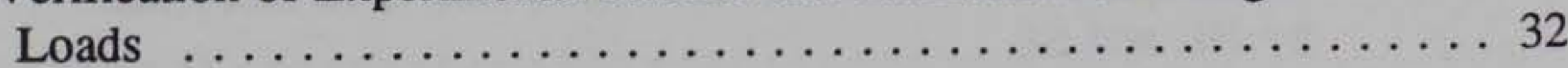

Repeatability of Experimental Data $\ldots \ldots \ldots \ldots \ldots \ldots \ldots \ldots \ldots \ldots \ldots \ldots$

Design Load . . . . . . . . . . . . . . . . . . . 34

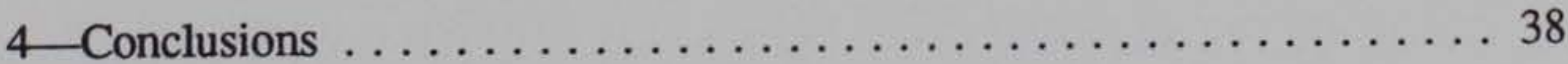

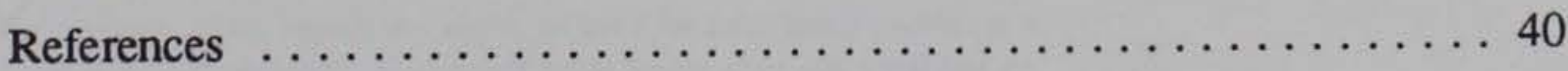


Appendix A: Selected Raw Data on 1:25 Olmsted Flat Gate

Wicket Model

Figures 1-33

SF 298

\section{List of Tables}

Table 1a. Instrumentation List for the 1:25 Olmsted Flat Gate Wicket

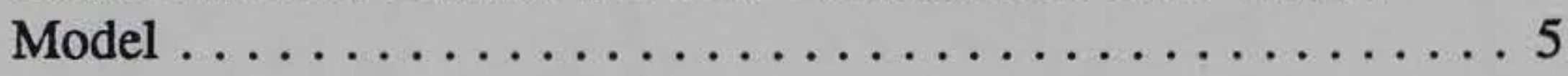

Table 1b. Typical Calibration Values for Response Channels . . . . . . . 8

Table 2. Experiment Data Designation List $\ldots \ldots \ldots \ldots \ldots \ldots$

Table 3. Time-Domain Data Comparison Table for Flat Gate with and without the Approach Channel $\ldots \ldots \ldots \ldots \ldots \ldots$

Table 4. Summary of Statistical Hypothesis Testing for Set \#1 . . . . 14

Table 5. Summary of Statistical Hypothesis Testing for Set \#2 . . . 15

Table 6. Summary of Statistical Hypothesis Testing for Set \#2 . . . . 16

Table 7. Summary of Statistical Hypothesis Testing for Set \#3 . . . . 17

Table 8. Summary of Statistical Hypothesis Testing for Set \#4 . . . . 18

Table 9. A Comparison of Responses for Flat Gate with and without the Approach Channel . . . . . . . . . . . . . 19

Table 10. Frequency-Domain Response Comparison for Flat Gate with and without the Approach Channel .......... 22

Table 11. Summary of Statistical Hypothesis Testing for Flat and Curved Gates ...................... 24

Table 12. Mode Shape Comparison for Flat and Curved Gates . . . . . 25

Table 13. Time-Domain Data Comparison Table for Flat Gate, Open Channel, and 1:5 Flume Configuration

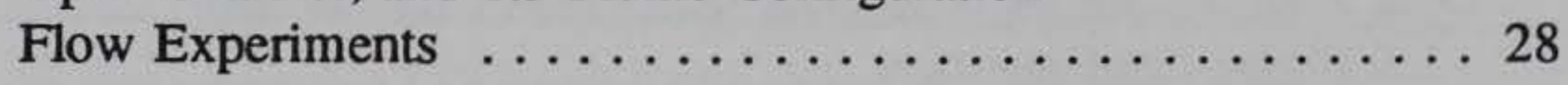

Table 14. Flat Gate Experimental Data Comparison for Three Different Flow Configurations . . . . . . . . . . . . . . . 29

Table 15. A Comparison of 1:25 Flat Gate Response Data Recorded by $\mathrm{HL}$ and $\mathrm{SL} \ldots \ldots \ldots \ldots \ldots \ldots \ldots \ldots \ldots \ldots$

Table 16. Design Load Verification Table ............... 36 


\section{Preface}

This work was sponsored by the U.S. Army Engineer District, Louisville, in support of the Olmsted Navigational Models Study program. Mr. Rick Schultz was the program monitor.

This work was conducted during the period August 1993 to November 1994 by the Structural Mechanics Division (SMD), Structures Laboratory (SL), U.S. Army Engineer Waterways Experiment Station (WES), under the direct supervision of Dr. Mostafiz R. Chowdhury, SMD. Mr. Terry Warren, Instrumentation Services Division (ISD), provided data acquisition and data reduction/management support for the flow test. Mr. Wallace Guy and Mr. Joe Ables, ISD, operated and managed the data acquisition system. Mr. Homer Greer, ISD, was the overall coordinator for the ISD services. Their efforts were invaluable and greatly appreciated.

This work was performed by Dr. Chowdhury, Dr. Robert L. Hall, and Ms. Eileen Pesantes, SMD, under the general supervision of Mr. Bryant Mather, Director, SL; Mr. John T. Ehrgott, Assistant Director, SL; Dr. Jimmy Balsara, SMD; Dr. Reed Mosher, Chief, SMD; and Dr. Hall, Chief, Structural Analysis Group, SMD.

At the time of publication of this report, Director of WES was Dr. Robert W. Whalin. Commander was COL Bruce K. Howard, EN. 


\section{Conversion Factors, Non-SI to SI Units of Measurement}

Non-SI units of measurement used in this report can be converted to SI units as follows:

\begin{tabular}{||l|l|l||}
\hline Multiply & By & To Obtain \\
\hline \hline degrees (angle) & 0.01745329 & radians \\
\hline feet & 0.3048 & metres \\
\hline inches & 0.0254 & metres \\
\hline pounds (force) & 4.4484 & newton \\
\hline pounds (mass) & 0.453515 & kilograms \\
\hline pounds (force) per square inch & 0.006894757 & megapascals \\
\hline square inches & 0.00064516 & square metres \\
\hline
\end{tabular}




\section{Introduction}

The U.S. Army Engineer Waterways Experiment Station (WES) has been investigating two scale models (1:25 and 1:5) of hydraulically operated wickets to assist the U.S. Army Engineer District, Louisville (ORL), in the final design for permanent gates to be built for the Olmsted Dam. The Olmsted Locks and Dams will replace Locks and Dams 52 and 53 on the lower Ohio River which have oak wicket gates that are raised and lowered by a steam-powered boat (Soast 1994).

The location of Olmsted Project is one of the busiest barge traffic routes in the nation. The new locks and dam project is located below Paducah, KY, at Mile 964.4 on the Ohio River, 16 miles from the confluence of the Ohio and Mississippi Rivers. This reach of the Ohio River is particularly strategic in that it provides a connection between the Ohio, Tennessee, Cumberland, and Mississippi rivers. The project is planned for twin $1,200-\mathrm{ft}$ by $110-\mathrm{ft}$ lock chambers with a design lift of $21 \mathrm{ft}$ and a 2,200-ft movable portion which includes 220 remotely operated, hydraulically actuated wicket gates. The remaining 426-foot dam will include a fixed weir section extending to the Kentucky shore. In the raised position, the wicket gates will be used to regulate the level of the navigable pool. In the lowered position, the gates will provide a navigable pass (Lance 1992).

The current operating proposal calls for the wicket gates to be raised in groups of five with five gate gaps until 220 gates are raised. Flow over the top of any gate is not anticipated except during its raising or lowering operation. The five gate gaps will then be closed by raising two gates simultaneously or one gate at a time. In each case, the gate or gates to be moved will be the end gates. To maintain a uniform flow pattern in the river, as many as $\mathbf{4 4}$ gates will be simultaneously and continuously operated in a manner that subjects the gates to hydraulic conditions that will create uneven hydraulic loading and may produce gate vibrations. In addition, during the raising or lowering operations, additional hydraulic conditions will occur that could also induce gate vibrations. A large amount of gate manipulation is expected during the low-flow periods when the gates will be in use due to the major powerhouse-controlled inflows into Olmsted Reservoir which come from the Tennessee and Cumberland rivers (Elder 1992). 
The Olmsted wicket model studies began in January 1990 when ORL tasked WES with the development of a 1:25-scale curved gate model of the Olmsted Locks and Dam. Since then, two additional models were developed: a 1:25-scale flat gate and a 1:5-scale flat gate. These physical models have been used to investigate the flow-induced vibrational response of Olmsted wicket gates and have also helped researchers to better understand the complexities involved in the fluid-structure interaction problem affecting them. The Olmsted wicket model studies also include a prototype test facility in the Smithland Dam on the Ohio River (Snowberger 1995). This facility will test the physical performances of various mechanical/electrical/hydraulic systems proposed for the Olmsted Dam. Dam Prototype facility at Smithland consists of an approach channel to simulate the open river flow condition for the Olmsted Dam. WES studied the 1:25 wicket model in support of the model studies for the Olmsted wickets.

The purposes of the 1:25 flat gate model are to enhance the understanding of the structural as well as hydraulic behavior of wicket gates and to support the design of the 1:5 intermediate model. Experimentation was conducted to model the flume configuration for the 1:5 model being built at WES and the approach channel for a prototype structure being built by ORL at Smithland Locks and Dams. These model studies investigated the potential differences in hydraulic conditions between the open channel, approach channel, and the 1:5 flume configuration.

In this report, the flow-induced vibrational response of the 1:25 Olmsted flat gate is analyzed for three different river models: the Olmsted Dam, the Smithland Dam, and the flume configuration for the 1:5 model. The Olmsted model simulated the open channel river flow conditions of the Olmsted navigational pass (dam) in the Ohio River, whereas the Smithland analysis represented the approach channel conditions of the prototype gate test facility. The main objective of the first two studies is to determine any variations in the flow-induced vibrational characteristics of the gate with and without the approach channel for equivalent Smithland Dam navigation pool conditions relative to the Olmsted Dam pool elevations. The 1:25 model of the flume configuration for the 1:5 model placed in the 1:25 flat gate model is evaluated to determine the effectiveness of partial river modeling for the intermediate scale model. An insignificant variation in the dynamics of open and approach channel flow conditions would support the use of an approach channel on the prototype test to represent the actual open channel flow condition. Similarly, any deviation of the 1:5 flume configuration model results from that of the open river model would indicate deficiencies and the limitations of the 1:5 model in simulating the actual flow pattern of the Olmsted Dam. Another purpose of this study is to compare the flow experimental results of the flat gate with those of the curved gate and to determine the effects that geometry changes reflect in the dynamics of the gate.

The curved gate with a dissimilar geometry was used previously for the same Olmsted navigational model mentioned above (March and Elder 1992). The experimental modal parameters of the gate for dry conditions are also 
compared for the flat and curved gates. Any dependency of the geometric shape on regulating the dynamics of the gate will be identified from this comparison. The operating deflected shapes are presented to visualize the actual flow-induced vibrational patterns of the gate and to diagnose any possible resonant problems.

\section{Objective}

The objectives of this study are to:

a. Determine the variations in the flow-induced vibrational characteristics of the flat gate with and without the approach channel for equivalent Smithland pool conditions relative to the Olmsted pool elevations.

b. Determine the variation in the flow-induced vibrational behaviors of the 1:25 flat gate for the open-river condition and the 1:5 flume configuration placed in the 1:25 model.

c. Compare the flow-induced vibrational experimental results of the flat gate with that of the curved gate.

d. Identify the effect of the fundamental modes on the dynamics of the gate.

\section{Experimental Method}

\section{Experimental outline}

A 1:25 scale model of the Olmsted Wicket Dam was constructed at WES, initially for the purpose of conducting scour studies (WES 1991a). The model was then modified to include an instrumented gate (WES 1991b) to allow the study of forces expected to occur in the lifting rod and on the hinges and to investigate designs developed to provide aeration to the nappe when the gate is partially open. The transient dynamic loads which have been observed in the 1:25 model have been of great concern throughout the model study. Several previous efforts have investigated the source of dynamic loads and their implications or the design and operation of the Olmsted Wicket Dam (WES 1991a; Simpson and Solomon 1992; Elder and March 1992). Considering the recommendations provided for the 1:25-scale curved gate model study, a flat gate geometry of the wicket was selected for further investigation. The geometry of the curved gate was modified to mitigate oscillation and the "bouncing" of the gate upon its hydraulic system, resulting from aeration of the nappe. For this model, a total of 92 wicket gates were reproduced, and one of them was instrumented. 
Experiments for the 1:25-scale flat gate were conducted in the fall of 1993 for the Olmsted and Smithland Dam conditions. Figures 1a and $1 \mathrm{~b}$ show the front and back views of the 1:25 flat gate model for the Olmsted wickets. The Olmsted model simulates the open channel river flow conditions of the Olmsted Navigational Pass in the Ohio River. Figure 2 shows the Olmsted 1:25 flat gate river model. The Smithland Dam represents the approach channel condition of the prototype test facility. A five-gate-width river model as shown in Figure 3 was used to simulate the open channel flow condition in the Smithland river model.

In the summer of 1994, WES constructed a flume configuration to simulate the 12-gate-width river section for the 1:5 model, in the 1:25 flat gate river model. Figure 4 shows the 1:5 flume configuration placed in the 1:25 model. The experimental data for the 1:25 flat gate for the 1:5 flume configuration were recorded to measure the effects of partial modeling of the river section instead of a full river model in the 1:5 flat gate simulation test.

\section{Gate description}

An operational wicket in a fully raised position regulates navigational pool in the upstream side of the river. A shaft supported wicket in its operational position is shown in Figure 1. Out of a total of 92 scaled gates in the open channel river model, \#47 gate was the scaled model for the Olmsted wicket. The rest of the gates were dummy gates such that the upstream surface area of each gate was scaled properly. The skin plate on the up-stream side of the wicket model provides an 11.75 -in. $\times 4.4$-in flat surface area.

For the scaled gate, the skin plate is mounted on the top flanges of the main supporting I-beams running longitudinally at the middle of the gate width. In addition to the two I-beams, both edges of the skin plate are mounted on channels on both sides of the I-beams. Each beam has a depth of about 0.8 in. As seen in Figure $1 \mathrm{~b}$, seven transverse stiffener plates are effectively used to increase the plate stability and torsional rigidity of the wicket model.

An E-type, single-ended, 7/8-in $\times 6$-in., no-tail stainless steel cylinder was used to operate the gate. The hydraulically operated cylinder was driven by a remotely controlled computer. The main part of the shaft rod is $3 / 8 \mathrm{in}$. in diameter with an overall length of 8.09 in. The top end of the shaft is pin connected to the hinge-pin mounting plate securely fastened to the downstream flanges of the I-beams. The bottom of the wicket is attached to the base through two sets of hinges.

Although scaled 1:25 flat gate model replicated the general dimensions of the prototype gate, it is not an elastic similitude model since an exact scaling of the thickness and construction details was not physically achievable. Moreover, the wicket design changed many times during the operation of the 1:25 model. Many of the construction details in the current prototype design 
are not available in the scaled model. Brass was used for the 1:25 scaled gate instead of steel which will be used for the prototype design. The gate weighs $1.747 \mathrm{lb}$ and it has a nominal moment of inertia about its transverse axis of about 0.018 in $^{4}$.

\section{Instrumentation and experimental setup}

The scaled gate shown in Figure 1 was used to measure the flow-induced dynamic structural responses due to a three-gate gap river flow configuration. Previously, the 1:25-curved gate physical model study indicated that the threegate gap flow configuration was the most severe case with highest load on the hinges and on the shaft (WES 1991a,b). Therefore, the three-gate gap configuration was considered for studying the dynamics of the model. The gate was instrumented with four accelerometers (PCB Model 353B68), five strain gauge load cells (two for each of the hinges and one for the shaft), two pressure transducers (DRUCK Model PDCR-200), and a displacement transducer. Table 1a provides a general outline of the instruments and their specific uses. Measurements from the displacement transducers were used to determine gate rotation. The pressure transducers gave upstream and downstream pressure measurements. Two load cells at each hinge measured the vertical and horizontal reaction forces. A positive shaft load represented a compressive load in the shaft requiring an increase in operating pressure in the hydraulic system. For the hinge loads, vertical loads acting downward were assumed to have a negative sign, and a negative horizontal hinge load corresponded to a thrust acting downstream.

\begin{tabular}{|c|c|c|c|c|c|c|}
\hline \multicolumn{7}{|c|}{$\begin{array}{l}\text { Table 1a } \\
\text { Instrumentation List for the 1:25 Olmsted Flat Gate Wicket Model (for position } \\
\text { see Figure 6) }\end{array}$} \\
\hline Sensor & Type & Model & $\begin{array}{l}\text { Sampling } \\
\text { Rate }\end{array}$ & $\begin{array}{l}\text { Cut-Off } \\
\text { Fre- } \\
\text { quency }\end{array}$ & Purpose & Applications \\
\hline Accelerometers (4) & PCB & $353 \mathrm{~B} 68$ & 2,000 & 1,000 & $\begin{array}{l}\text { To measure the } \\
\text { dynamic motion } \\
\text { of the gate. }\end{array}$ & $\begin{array}{l}\text { Model Analysis } \\
\text { To predict and } \\
\text { compare responses. } \\
\text { Operating deflected } \\
\text { shapes. }\end{array}$ \\
\hline $\begin{array}{l}\text { Load Cells (5) } \\
\text { (one for the shaft } \\
\text { and four at the } \\
\text { hinges) }\end{array}$ & In-house & & 2,000 & 1,000 & $\begin{array}{l}\text { To measure } \\
\text { reaction forces } \\
\text { in the bottom } \\
\text { hinges and } \\
\text { shaft load. }\end{array}$ & $\begin{array}{r}\text { To compare } \\
\text { responses. }\end{array}$ \\
\hline $\begin{array}{l}\text { Pressure } \\
\text { Transducers (2) }\end{array}$ & DRUCK & PDCR-200 & 2,000 & 1,000 & $\begin{array}{l}\text { To measure } \\
\text { pressure } \\
\text { distributions. }\end{array}$ & $\begin{array}{r}\text { To compare } \\
\text { responses. }\end{array}$ \\
\hline
\end{tabular}

The location of the instruments for the flat gate is shown in Figure 6. Note that except for the midspan accelerometers, all transducer locations for the flat 
and curved gates were identical. Four accelerometers (ACC1, ACC2, ACC3, and ACC4) were used for the flat gate as opposed to six on the curved gate. Midspan accelerometer locations were closer to the base of the gate for the flat gate than for the curved gate. Pressure gauge locations (P1 and P2) were almost identical for both cases. Pressure gauge, P1, was mounted on the upstream side, and P2 was mounted on the downstream side of the gate.

\section{Data acquisition}

The data acquisition system for the Olmsted 1:25 Model Study consisted of a personal computer (PC) for data storage, data processing, and process control, an analog-to-digital converter (ADC), a digital-to-analog converter (DAC), and signal conditioning amplifiers. The PC consisted of a 33- MHz $486 \mathrm{CPU}$ machine, 8 Mbytes of RAM, 200- Mbytes hard disk drive, 5.25- and 3.5-in. floppy diskette drives, a 90-Mbytes Bernoulli removable disk drive, and software for data acquisition and gate position control.

The ADC and DAC were both part of a printed circuit board that plugged into an expansion slot of the PC. The ADC was a 12-bit device with an input voltage range of -5 to $+5 \mathrm{~V}$. Thirty-two input signals could be interfaced by means of the onboard multiplexer. Maximum total throughput specified by the manufacturer was 90,000 samples per second. The DAC was a 12-bit device with an output voltage range of -10 to $+10 \mathrm{~V}$. It had two outputs and the manufacturer specified an update rate of 90,000 updates per second.

The block diagram shown in Figure 7 presents the data-acquiring network system for the flat gate model. The operating condition for the hydraulic system was similar to the one used for the curved gate. For more information on the data acquisition system, refer to WES Data Report (U.S. Army Engineer Waterways Experiment Station 1991). All instruments were calibrated in the laboratory prior to installing them onto the gate. A static load reference test was conducted at the beginning of each test day to measure the accuracy, sensitivity, and connectivity of the load cells. This test was conducted by placing a known input load $(3.56 \mathrm{lb})$ on the top of the gate and checking the static equilibrium of the system by equating the input and output reaction forces (shaft and vertical reactions). All sensors were again initialized (set to zero) corresponding to a static upstream and downstream pool elevation of $302 \mathrm{ft}^{1}$ The recorded accelerations represented the actual accelerations that the gate experienced due to the flow; whereas the load cells and the pressure transducers measured responses with reference to the static pool head. Actual responses for these transducers, therefore, consisted of measured dynamic and initial static responses. The flow-induced pressure readings, for example, can be obtained by adding the pressure gauge reading with the static pressure head corresponding to a $302-\mathrm{ft}$ pool elevation.

1 All elevations (el) cited herein are in feet as referred to in National Geodetic Vertical Datum (NGVD) of 1929. 


\section{Limitations}

Experiments presented in this report were conducted between November 1993 to July 1994. Though the instruments were calibrated during the beginning of each experiment series, the measured responses during the experiment had been subject to time-dependent drift of the mechanical and electrical devices. It is assumed that the relative comparison of results, such as the data for with and without an approach channel, would be affected very little due to such a random drift because of the presence of drifts for all test cases. A preand postcalibration of the response channels for a fixed configuration was used to detect such errors resulting from instrumentation drift. Experiments were repeated when pre- and postcalibration results differed by more than 0.5 units of respective response magnitudes.

Recorded experimental results were also subject to an error associated with the gate-rotation measurement accuracy. This error resulted from a slight deviation in the actual orientation of the operating gate from the recorded angular position. A minimum incremental step $( \pm 0.5 \mathrm{deg})$ used to operate the system caused this error.

A 60-cycle background noise was detected for the experiments presented in this report. An experiment was conducted to identify the source and measure the amplitude and the frequency contents of the background noise. In this experiment, all cables were unplugged from the analyzer, and a 350-ohm dummy gauge input at a gain of 6,200 was used for the shaft channel. The experiment showed the $60 \mathrm{~Hz}$ signal and its harmonics in the frequency domain (see auto spectra plots in the next chapter), which was primarily due to a power source problem in the data acquisition system. This experiment verified that the spikes shown in the frequency domain analysis, particularly for shaft load, are the result of such a background noise and not a structural response. These spikes are less noticeable in the FRF data for the remaining channels because of the lower gains of these channels. Since the error was present for all cases, the relative comparison of data will not be affected by this error.

The signal-to-noise ratio for the shaft load was very low compared to the other channels used for the data acquisition system used in the experiments presented. A typical calibration for the flow experiment is shown below in Table $1 \mathrm{~b}$. A low sensitivity (1-V signal per 10-lb load) of the shaft channel, along with a high gain factor, made it impossible to eliminate very low amplitude noise from the recorded data (30-mv peak/peak signal from the power source). As a result, the shaft load was contaminated by harmonic spikes more than the other channels as shown in the frequency domain analysis for the data presented in this report.

A slight misalignment of the bottom hinges and a random lateral tilting of the clevis attached to the cylinder rod, connecting the gate to the cylinder, caused nonuniform distributions of reaction forces at the bottom hinges. This 


\begin{tabular}{|c|c|c|c|c|}
\hline \multicolumn{5}{|c|}{$\begin{array}{l}\text { Table 1b } \\
\text { Typical Calibration Values for Response Channels }\end{array}$} \\
\hline $\begin{array}{l}\text { Response } \\
\text { Channel }\end{array}$ & $\begin{array}{l}\text { ADC } \\
\text { Magnitude }\end{array}$ & $\begin{array}{l}\text { Engineering } \\
\text { Units }\end{array}$ & $\begin{array}{l}\text { Signal Level } \\
\text { volts }\end{array}$ & $\begin{array}{l}\text { Amplification } \\
\text { Factor, Gain }\end{array}$ \\
\hline Shaft load & $-1,080$ & $-26.47 \mathrm{lb}$ & 2.6367 & 6,000 \\
\hline R/vertical hinge & $-1,634$ & $-5.903 \mathrm{lb}$ & 3.9893 & 2,100 \\
\hline $\mathrm{R} /$ horizontal hinge & $-1,642$ & $-5.939 \mathrm{lb}$ & 4.0088 & 2,100 \\
\hline L/vertical hinge & $-1,637$ & $-5.976 \mathrm{lb}$ & 3.9966 & 2,100 \\
\hline Lhorizontal hinge & $-1,635$ & $-5.971 \mathrm{lb}$ & 3.9917 & 2,100 \\
\hline DCDT & 2,247 & $5.02 \mathrm{in.}$ & 5.4858 & 100 \\
\hline U/S pressure & $-1,430$ & 12.693 in. & 3.4912 & 730 \\
\hline $\mathrm{D} / \mathrm{S}$ pressure & $-1,431$ & 12.2945 in. & 3.4937 & 730 \\
\hline Acc1 & 455 & $1.0 \mathrm{~g}$ & 1.1108 & 100 \\
\hline Acc2 & 445 & $1.0 \mathrm{~g}$ & 1.0864 & 100 \\
\hline Acc3 & 445 & $1.0 \mathrm{~g}$ & 1.0864 & 100 \\
\hline
\end{tabular}

phenomenon was experimentally verified by observing the unequal bottom hinge reaction forces due to a symmetric load applied to the gate. Experiment \#2370 presented in Appendix A confirms such variation in the reaction forces due to known symmetric load applied to the gate. A lateral shift of the clevis due to its freedom to rotate about the longitudinal axis of the gate, as observed during the experiment, was one of the reasons for developing uneven hinge reactions. This movement caused horizontal forces at the bottom hinges of the gate. An equilibrium of the moment caused by the lateral forces thus required nonuniform vertical reactions at the hinges. Therefore, a fluctuation in the reaction forces is expected during the course of the study.

\section{Experimental conditions}

After calibrating the system for a constant pool and tail water elevation, the gate was raised at a particular position and the data were recorded for $30 \mathrm{sec}$. The recorded angular positions were kept identical for both flat and curved gates. The experiment numbers corresponding to open and approach channels, and the flat and curved gates are presented in Table 2. All 6,000 series experiments represent the results for the flat gate with an open channel flow configuration (Olmsted). The 7,000 series experiments were conducted for the flat gate with an approach channel and flume configuration (Smithland Prototype). The 1,000 series refers to the results for the curved gate with an open channel flow condition. All experiments were conducted for a three-gate gap configuration with the test gate being the middle one. Set \#2 was repeated for two 
Table 2

Experiment Data Designation List

\begin{tabular}{|c|c|c|c|c|c|c|}
\hline \multirow{2}{*}{$\begin{array}{l}\text { Experiment } \\
\text { Set \# }\end{array}$} & \multicolumn{2}{|c|}{ Water Level, ft } & \multirow[b]{2}{*}{ Status } & \multirow{2}{*}{$\begin{array}{l}\text { Angular } \\
\text { Position Deg }\end{array}$} & \multicolumn{2}{|c|}{ Experiment Numbers } \\
\hline & Olmsted & Smithland & & & Without & With \\
\hline Set \#1 & $\begin{array}{l}\text { P.E. }=300 \\
\text { T.W.E. }=279\end{array}$ & $\begin{array}{l}\text { P.E. }=325.5 \\
\text { T.W.E. }=304.5\end{array}$ & $\begin{array}{l}\text { Fixed } \\
\text { 3-Gate Gap }\end{array}$ & $\begin{array}{r}-2 \\
27 \\
30 \\
50 \\
60 \\
\end{array}$ & $\begin{array}{l}6,005 \\
6,006 \\
6,007 \\
6,008 \\
6,009 \\
\end{array}$ & $\begin{array}{l}7,008 \\
7,009 \\
7,010 \\
7,011 \\
7,013 \\
\end{array}$ \\
\hline Set \#2 & & & $\begin{array}{l}\text { Operational } \\
\text { 3-Gate Gap }\end{array}$ & $\begin{array}{l}67 \text { to } 40 \\
45 \text { to } 25 \\
30 \text { to }-2 \\
-2 \text { to } 30 \\
25 \text { to } 45 \\
40 \text { to } 67 \\
\end{array}$ & $\begin{array}{l}6,010 \\
6,011 \\
6,012 \\
6,013 \\
6,014 \\
6,015 \\
\end{array}$ & $\begin{array}{l}7,014 \\
7,015 \\
7,016 \\
7,017 \\
7,018 \\
7,019 \\
\end{array}$ \\
\hline Set \#3 & $\begin{array}{l}\text { P.E. }=299 \\
\text { T.W.E. }=276.5\end{array}$ & $\begin{array}{l}\text { P.E. }=324.5 \\
\text { T.W.E. = } 302\end{array}$ & $\begin{array}{l}\text { Fixed } \\
\text { 3-Gate Gap }\end{array}$ & $\begin{array}{l}-2 \\
27 \\
30 \\
50 \\
60\end{array}$ & $\begin{array}{l}6,016 \\
6,018 \\
6,019 \\
6,020 \\
6,021 \\
\end{array}$ & $\begin{array}{l}7,002 \\
7,004 \\
7,005 \\
7,006 \\
7,007\end{array}$ \\
\hline Set \#4 & $\begin{array}{l}\text { P.E. }=296.5 \\
\text { T.W.E. }=285.5\end{array}$ & $\begin{array}{l}\text { P.E. }=322 \\
\text { T.W.E. }=311\end{array}$ & $\begin{array}{l}\text { Fixed } \\
\text { 3-Gate Gap }\end{array}$ & $\begin{array}{r}-2 \\
27 \\
27 \\
30 \\
50 \\
60 \\
\end{array}$ & $\begin{array}{l}6,022 \\
6,023 \\
6,024 \\
6,025 \\
6,026 \\
6,027 \\
\end{array}$ & $\begin{array}{l}7,044-45 \\
7,046 \\
7,047 \\
7,048-49 \\
7,050-51 \\
7,052-53 \\
\end{array}$ \\
\hline \multicolumn{7}{|c|}{ b. Information Data Sheet for the Flat and Curved Gate Flow Results } \\
\hline \multirow{2}{*}{$\begin{array}{l}\text { Flow } \\
\text { Condition }\end{array}$} & \multirow[b]{2}{*}{ Water Level, ft } & \multirow[b]{2}{*}{ Status } & \multirow{2}{*}{$\begin{array}{l}\text { Angular } \\
\text { Position Deg }\end{array}$} & \multicolumn{3}{|c|}{ Experiment Numbers } \\
\hline & & & & Flat & Curved & \\
\hline 3-Gate Gap & $\begin{array}{l}\text { P.E. }=301.5 \\
\text { T.W.E. }=278\end{array}$ & Fixed & $\begin{array}{l}30 \\
50 \\
60 \\
\end{array}$ & $\begin{array}{l}6,002 \\
6,003 \\
6,004 \\
\end{array}$ & $\begin{array}{l}1,060 \\
1,068 \\
1,071 \\
\end{array}$ & \\
\hline \multicolumn{7}{|c|}{$\begin{array}{c}\text { c. Information Data Sheet for Open Channel and 1:5 Flume } \\
\text { Configuration Flow Results for the 1:25 Flat Gate }\end{array}$} \\
\hline \multirow[b]{2}{*}{$\begin{array}{l}\text { Experiment } \\
\text { Set \# }\end{array}$} & \multirow[b]{2}{*}{ Water Level, ft } & \multirow[b]{2}{*}{ Status } & \multirow[b]{2}{*}{$\begin{array}{l}\text { Angular } \\
\text { Position Deg }\end{array}$} & \multicolumn{3}{|c|}{ Experiment Numbers } \\
\hline & & & & $\begin{array}{l}\text { Open } \\
\text { Channel }\end{array}$ & 1:5 Flume C & nfiguration \\
\hline Set \#5 & $\begin{array}{l}\text { P.E. }=300 \\
\text { T.W.E. }=279\end{array}$ & Fixed & $\begin{array}{r}-2 \\
27 \\
30 \\
50 \\
60 \\
\end{array}$ & $\begin{array}{l}6,005 \\
6,006 \\
6,007 \\
6,008 \\
6,009 \\
\end{array}$ & $\begin{array}{l}7,071 \\
7,072\left(20^{\circ}\right) \\
7,073\left(39^{\circ}\right) \\
7,074 \\
7,075 \\
\end{array}$ & \\
\hline Set \#6 & $\begin{array}{l}\text { P.E. }=299 \\
\text { T.W.E. }=276.5\end{array}$ & Fixed & $\begin{array}{r}-2 \\
27 \\
30 \\
50 \\
60 \\
\end{array}$ & $\begin{array}{l}6,016 \\
6,018 \\
6,019 \\
6,020 \\
6,021 \\
\end{array}$ & $\begin{array}{l}7,077 \\
7,078\left(20^{\circ}\right) \\
7,079\left(39^{\circ}\right) \\
7,080 \\
7,081\end{array}$ & \\
\hline Set \#7 & $\begin{array}{l}\text { P.E. }=296.5 \\
\text { T.W.E. }=285.5\end{array}$ & Fixed & $\begin{array}{r}-2 \\
27 \\
30 \\
50 \\
60\end{array}$ & $\begin{array}{l}6,022 \\
6,024 \\
6,025 \\
6,026 \\
6,027\end{array}$ & $\begin{array}{l}7,084 \\
7,085\left(20^{\circ}\right) \\
7,086\left(39^{\circ}\right) \\
7,087 \\
7,088\end{array}$ & \\
\hline
\end{tabular}


sequences of gate operations, one going up and another coming down. Set \#4, for the approach channel condition, was repeated for each fixed position of the gate as shown in Table 2.

Appendix A presents the time-domain raw data for selected experiments shown in Table 2. Each set of data includes a status sheet and 14 plots of measured responses. The status sheet outlines the configurations and a description of responses for all channels. In these figures, the responses are plotted as a function of time. Gate rotation corresponding to a time instance can be obtained by using the DCDT(Direct Current Displacement Transducer) versus time plot. DCDT had measured the extension of the cylinder rod from the down position as the gate was lifted. By using the trigonometrical relationships, the gate rotation can be obtained from the measured displacement transducer reading. Figure 8 shows the schematic dimensions of the 1:25 flat gate model. 


\section{Flow Data Analyses for the 1:25 Scale-Model Wicket Gate}

\section{Data Analysis for the Flat Gate with and without the Approach Channel}

The raw data presented in Appendix A were analyzed in the time- and frequency-domains using the MATLAB (The Math Works 1993) and Structural Dynamic Research Corporation's (SDRC) IDEAS-TEST module (SDRC 1994). The measurement units for the pressure gauges and the accelerometers were converted from inches and g's to pounds per square inch and inches per second ${ }^{2}$, respectively, unless mentioned.

\section{Time-domain data comparison}

The variations of the average magnitudes and the ranges (maximum and minimum) for sensor responses recorded with and without the approach channel are presented in Figures 9 to 12. In these figures, the recorded responses (raw data, such that the pressure is presented in reference to a constant static head as mentioned before) for fixed gate positions, for example $-2,30,50$, $60 \mathrm{deg}$, are compared for the experiments shown in Table 2a. The response pattern for both groups is summarized in Table 3. In these tables, an apparent deviation of the response magnitudes is identified by comparing the corresponding plots in Figures 9 to 12.

A study of these plots suggests that the time-domain average magnitudes for the shaft load and pressures slightly varied between the cases compared in these plots. The mean value of the accelerations remained almost steady for both restricted (approach channel condition) and open channel flow conditions. Except for the right vertical hinge reactions, the rest of the reactions forces generally did not differ significantly due to a change in the flow pattern. The reason for such an inconsistency in the hinge reactions is not quite clear, however, it may be attributed to the drifting and misalignment problems in the system as discussed earlier. 


\begin{tabular}{|c|c|c|c|c|}
\hline \multicolumn{5}{|c|}{$\begin{array}{l}\text { Table } 3 \\
\text { Time-Domain Data Comparison Table for Flat Gate with and without the } \\
\text { Approach Channel }\end{array}$} \\
\hline \multirow[b]{2}{*}{$\begin{array}{l}\text { Response } \\
\text { Channel }\end{array}$} & \multicolumn{4}{|c|}{$\begin{array}{l}\text { Any Noticeable Changes in the Time Domain } \\
\text { (average, minimum, and maximum) Magnitudes? }\end{array}$} \\
\hline & $\begin{array}{l}\text { Set No. } 1 \\
\text { Pool EI }=300^{\prime} \\
\text { Tail W/EI }=279^{\prime} \\
\text { Fixed Position }\end{array}$ & $\begin{array}{l}\text { Set No. } 2 \\
\text { Pool El }=300^{\prime} \\
\text { Tail W/EI }=279^{\prime} \\
\text { Operational }\end{array}$ & $\begin{array}{l}\text { Set No. } 3 \\
\text { Pool EI }=299^{\prime} \\
\text { Tail W/EI }=276.5^{\prime} \\
\text { Fixed Position }\end{array}$ & $\begin{array}{l}\text { Set No. } 4 \\
\text { Pool EI }=296.5^{\prime} \\
\text { Tail W/EI }=285.5^{\prime} \\
\text { Fixed Position }\end{array}$ \\
\hline Shaft load & No & No & Yes@ @ $27^{\circ}$ and $30^{\circ}$ & No \\
\hline $\mathrm{R} /$ vertical hinge & Yes & Yes & No (except @ 30) & Yes \\
\hline R/horiz. hinge & No & No & No & No \\
\hline L/vertical hinge & Yes $\left(\min @ 27^{\circ}\right)$ & No & No (except @ 30) & $\begin{array}{l}\text { Yes (@27 and } \\
\left.30^{\circ}\right)\end{array}$ \\
\hline Lhoriz. hinge & Yes (max @ 27) & No & Yes & $\begin{array}{l}\text { Yes (@ } 27 \text { and } \\
\left.30^{\circ}\right)\end{array}$ \\
\hline Upstream pressure & No & Slightly & $\begin{array}{l}\text { No (except @ } 30^{\circ} \text {, } \\
\text { min and max only) }\end{array}$ & Yes \\
\hline Downstream pressure & No & No & $\begin{array}{l}\text { No (except @ } 30^{\circ} \text {, } \\
\text { min only) }\end{array}$ & No \\
\hline Acceleration No. 1 & $\begin{array}{l}\text { Yes } \\
\text { (max and min @ } \\
\left.27^{\circ}\right)\end{array}$ & $\begin{array}{l}\text { Yes (max only when } \\
\text { lowering down, max } \\
\text { and min @ 2-30 } \\
\text { when raising up) }\end{array}$ & No (except @ 30) & $\begin{array}{l}\text { Yes (min and max } \\
@ 27 \text { and } 30^{\circ} \text { only) }\end{array}$ \\
\hline Acceleration No. 2 & $\begin{array}{l}\text { Yes } \\
\text { (max and } \min @ \\
\left.27^{\circ}\right)\end{array}$ & $\begin{array}{l}\text { Yes (max only when } \\
\text { lowering down, max } \\
\text { and min when raising } \\
\text { up) }\end{array}$ & $\begin{array}{l}\text { No (except @ } 30^{\circ} \text {, } \\
\text { min and max only) }\end{array}$ & $\begin{array}{l}\text { Yes (min and max } \\
\left.@ 27^{\circ}\right)\end{array}$ \\
\hline Acceleration No. 3 & $\begin{array}{l}\text { Yes } \\
\text { ( } m a x \text { and } \min @ \\
27^{\circ} \text { and } 60^{\circ} \text { ) }\end{array}$ & $\begin{array}{l}\text { Yes (min only when } \\
\text { lowering down, max } \\
\text { and min when raising } \\
\text { up) }\end{array}$ & $\begin{array}{l}\text { No (except @ } 30^{\circ} \text {, } \\
\text { min and max only) }\end{array}$ & $\begin{array}{l}\text { Yes (max and } \min \\
\left.\text { @ } 27 \text { and } 30^{\circ}\right)\end{array}$ \\
\hline \multicolumn{5}{|c|}{$\begin{array}{l}\text { Remarks } \\
\text { (A comparison of responses for approach channel and open channel result sets.) }\end{array}$} \\
\hline Response Channel & \multicolumn{2}{|c|}{ Average Magnitudes } & \multicolumn{2}{|c|}{$\begin{array}{l}\text { Standard Deviation at the Turbulent } \\
\text { Region }\end{array}$} \\
\hline Shaft load & \multicolumn{2}{|c|}{$\begin{array}{l}\text { Higher for open channel (a maximum } \\
\text { difference of } 14 \% \text { ) }\end{array}$} & \multicolumn{2}{|c|}{ Higher for approach channel } \\
\hline Vertical reactions & \multicolumn{2}{|l|}{ No consistent result } & \multicolumn{2}{|c|}{ Higher for approach channel } \\
\hline Horz. reactions & \multicolumn{2}{|c|}{ Pretty close to each other } & \multicolumn{2}{|c|}{ More fluctuations for approach channel } \\
\hline $\begin{array}{l}\text { Up- and downstream } \\
\text { pressures }\end{array}$ & \multicolumn{2}{|c|}{$\begin{array}{l}\text { Mostly higher for approach channel (Note } \\
\text { that the pressure readings in the plot is in } \\
\text { reference to a static pressure head) }\end{array}$} & \multicolumn{2}{|c|}{ Higher for approach channel } \\
\hline Accelerations & \multicolumn{2}{|l|}{ Close to each other } & \multicolumn{2}{|c|}{ Higher for approach channel } \\
\hline
\end{tabular}


Though the average accelerations for both cases were identical, the maximum and minimum values (dynamic response) deviated significantly from each other mostly during turbulance. Some structural response fluctuations were expected because of unsteady flow patterns and water depths during the approach channel test. The control of water depth for the approach channel test was more critical than that of the open channel test. During the approach channel experiments, a settling time, depending upon the steadiness of the water level, was allowed to adjust the water level. The nonsteady flow pattem for the approach channel experiment was one of the reason for generating fluctuating flow-induced loads as indicated in Figures 9 to 12. A statistical hypothesis test was also used in support of this conclusion.

A statistical hypothesis test, based on the assumptions that the observations are independent, populations of the samples for each group have normal distributions, and variances for the two independent groups are equal, was used to measure the differences between the two groups. The stated assumptions were valid for the flow experimental results and were verified by comparing the histograms shown in Figure $13 \mathrm{a}-\mathrm{j}$. A normal distribution of the sampling responses is noticeable for both conditions. Response histograms present a deviation as well as distribution of magnitudes of all measured responses for test Set \#3. In general, the 6,000 series experiment (open channel) caused higher shaft reactions than that of the 7,000 series experiment. The standard deviations for the shaft load for corresponding positions, however, agreed reasonably well for the experimental sequence shown in Figure 13. This suggests that the dynamic variation of the shaft load about the mean does not show noticeable difference due to the use of an approach channel. Apparently, downstream pressure and the accelerometer response distributions, as shown in Figure $13 \mathrm{~g}-\mathrm{j}$, did not vary much in magnitudes and shapes.

Tables 4 to 8 present the hypothesis testing for respective test numbers shown in Table 2. This hypothesis test was based on a null hypothesis that the means for the two groups are equal and the alternative that they are not. These tables also present the correlation coefficients which indicate the strength of the relation between the two variables. A higher correlation coefficient reflects a trend of linear relationship between the variables and vice versa. As noted in the conclusion columns of these tables, average magnitudes of pressure gauges, shaft loads, and accelerations, with the exception of accelerations for gage \#3 for Set \#2 (while raising) and pressures for Set \#4, showed no significant variation at 5 percent level of significance. This observation is quite contrary to the observations found in the histogram plots for shaft load (Figure 13a) as discussed earlier. Note that there are variations in average magnitudes as shown in the histogram plots, however, statistically this variation is not significant as suggested by the calculations presented in Tables 4 to 8 . The right vertical reaction force varied significantly for Set \#2 when the gate was raised from -2 to $67 \mathrm{deg}$. A variation in the hinge reactions is believed to be a mechanical error as opposed to a system effect. The hinge transducers were very sensitive to ambient variations ( $1.5 \mathrm{lb}$ per volt) due to the fact that they were well suited for measuring higher loads. 


\begin{tabular}{|c|c|c|c|c|c|}
\hline \multicolumn{6}{|c|}{ Flat Gate with and without Approach Channel, Data taken @ $-2^{\circ}, 27^{\circ}, 30^{\circ}, 50^{\circ}, 60^{\circ}$} \\
\hline $\begin{array}{l}\text { Test } \\
\text { Condi- } \\
\text { tions }\end{array}$ & Parameter & $\begin{array}{l}\text { Critical Region } \\
\alpha=0.05\end{array}$ & T-Value & Conclusion & R-Value \\
\hline \multirow{10}{*}{$\begin{array}{l}\text { P.E. = } \\
300 \mathrm{ft} \\
\text { T.W.E. }= \\
279 \mathrm{ft}\end{array}$} & Shaft load & $-2.13<\triangleright 2.13$ & 0.802 & $\begin{array}{l}\text { Not significantly } \\
\text { different }\end{array}$ & 0.999 \\
\hline & R/vert. hinge & $-2.13<\downarrow 2.13$ & -0.829 & $\begin{array}{l}\text { Not significantly } \\
\text { different }\end{array}$ & 0.797 \\
\hline & $\begin{array}{l}\text { R/horz. } \\
\text { hinge }\end{array}$ & $-2.13<\downarrow 2.13$ & 0.295 & $\begin{array}{l}\text { Not significantly } \\
\text { different }\end{array}$ & 0.996 \\
\hline & $\begin{array}{l}\text { L/vert. } \\
\text { hinge }\end{array}$ & $-2.13<\downarrow 2.13$ & 0.447 & $\begin{array}{l}\text { Not significantly } \\
\text { different }\end{array}$ & 0.998 \\
\hline & Lhorz. hinge & $-2.13<\triangleright 2.13$ & 0.053 & $\begin{array}{l}\text { Not significantly } \\
\text { different }\end{array}$ & 0.877 \\
\hline & U/S pressure & $-2.13<\downarrow 2.13$ & -0.435 & $\begin{array}{l}\text { Not significantly } \\
\text { different }\end{array}$ & 0.993 \\
\hline & D/S pressure & $-2.13<\triangleright 2.13$ & -0.718 & $\begin{array}{l}\text { Not significantly } \\
\text { different }\end{array}$ & 0.999 \\
\hline & ACC. 1 & $-2.13<\downarrow>2.13$ & 0.064 & $\begin{array}{l}\text { Not significantly } \\
\text { different }\end{array}$ & -0.468 \\
\hline & ACC. 2 & $-2.13<\triangleright 2.13$ & -0.063 & $\begin{array}{l}\text { Not significantly } \\
\text { different }\end{array}$ & 0.305 \\
\hline & ACC. 3 & $-2.13<\downarrow 2.13$ & -0.733 & $\begin{array}{l}\text { Not significantly } \\
\text { different }\end{array}$ & 0.980 \\
\hline
\end{tabular}

A numerical comparison of the mean and standard deviation for all response channels for Sets \#1 and 3 is shown in Table 9. The standard deviation is a measure of dispersion of the data about the mean. Also shown in this table are the ratios of respective dynamic magnitudes for the open channel and approach channel flow condition. Ratios of dynamic magnitudes which measure the variations in dynamic responses are obtained by using the equation:

$$
\text { Ratio }=\frac{[\mu+\sigma]_{\text {Open Channel }}}{[\mu+\sigma]_{\text {Approach Channel }}}
$$

where

$$
\begin{aligned}
& \sigma=\text { standard deviation } \\
& \mu=\text { mean value of the response }
\end{aligned}
$$




\begin{tabular}{|c|c|c|c|c|c|}
\hline \multicolumn{6}{|c|}{$\begin{array}{l}\text { Table } 5 \\
\text { Summary of Statistical Hypothesis Testing for Set \#2 }\end{array}$} \\
\hline \multicolumn{6}{|c|}{$\begin{array}{l}\text { Flat Gate with and without Approach Channel Decreasing Angle } \\
\left.\left.\text { (Data taken @ } 67^{\circ}-40^{\circ}, 45^{\circ}-25^{\circ}, 30^{\circ}-2^{\circ}\right)\right) \\
\end{array}$} \\
\hline $\begin{array}{l}\text { Experimental } \\
\text { Conditions }\end{array}$ & Parameter & $\begin{array}{l}\text { Critical Region } \\
\alpha=0.05\end{array}$ & T-Value & Conclusion & $\begin{array}{l}\text { R- } \\
\text { Value }\end{array}$ \\
\hline \multirow{10}{*}{$\begin{array}{l}\text { P.E. = } \\
300 \mathrm{ft} \\
\text { T.W.E. = } 279 \mathrm{ft} \\
\text { Time: } \\
142 \mathrm{sec}\end{array}$} & Shaft load & $-2.92<\Delta 2.92$ & -1.606 & $\begin{array}{l}\text { Not significantly } \\
\text { different }\end{array}$ & 0.999 \\
\hline & $\mathrm{R} /$ vert. hinge & $-2.92<\Delta 2.92$ & -69.173 & $\begin{array}{l}\text { SIGNIFICANTLY } \\
\text { DIFFERENT }\end{array}$ & 0.999 \\
\hline & R/horz. hinge & $-2.92<\downarrow 2.92$ & 1.250 & $\begin{array}{l}\text { Not significantly } \\
\text { different }\end{array}$ & 0.999 \\
\hline & L/vert. hinge & $-2.92<\bowtie 2.92$ & -0.340 & $\begin{array}{l}\text { Not significantly } \\
\text { different }\end{array}$ & 0.997 \\
\hline & Lhorz. hinge & $-2.92<\downarrow 2.92$ & -1.190 & $\begin{array}{l}\text { Not significantly } \\
\text { different }\end{array}$ & 0.997 \\
\hline & $\mathrm{U} / \mathrm{S}$ pressure & $-2.92<\downarrow>2.92$ & -1.335 & $\begin{array}{l}\text { Not significantly } \\
\text { different }\end{array}$ & 0.997 \\
\hline & $\mathrm{D} / \mathrm{S}$ pressure & $-2.92<t>2.92$ & -1.558 & $\begin{array}{l}\text { Not significantly } \\
\text { different }\end{array}$ & 0.993 \\
\hline & ACC. 1 & $-2.92<t>2.92$ & -0.617 & $\begin{array}{l}\text { Not significantly } \\
\text { different }\end{array}$ & 0.968 \\
\hline & ACC. 2 & $-2.92<\downarrow 2.92$ & -0.692 & $\begin{array}{l}\text { Not significantly } \\
\text { different }\end{array}$ & 0.984 \\
\hline & ACC. 3 & $-2.92<\downarrow 2.92$ & 0.147 & $\begin{array}{l}\text { Not significantly } \\
\text { different }\end{array}$ & 0.999 \\
\hline
\end{tabular}

Table 9 shows that the maximum shaft load dynamic response variation for the open channel is about 9 percent higher than that of the approach channel. As shown in the table, no consistent variation in the ratios of reactions is noticeable. The upper and lower bounds of ratios for the dynamic pressures of open and approach channels are about 7 and -4 percent, respectively. A -4 percent indicates that the approach channel pressure estimation is about 4 percent higher than that of the open channel estimate. Accelerations for the approach channel are consistently greater than that of the open channel. This difference is mainly due to major fluctuations of the flow during the approach channel flow experiment. This phenomenon is indicated by the higher magnitudes of standard deviations for the approach channel than those of the open channel.

This time-domain comparison suggests that the approach channel experimental results differed from that of the open channel. For all practical purposes, however, a general increase in the approach channel estimates of reaction forces and pressures by a maximum of 9 percent would adequately represent the open channel flow condition. Overestimated accelerations for the 


\begin{tabular}{|c|c|c|c|c|c|}
\hline \multirow{2}{*}{\multicolumn{6}{|c|}{$\begin{array}{l}\text { Table } 6 \\
\text { Summary of Statistical Hypothesis Testing for Set \#2 } \\
\begin{array}{c}\text { Flat Gate with and without Approach Channel Increasing Angle } \\
\text { (Data taken @ }-2^{\circ}-30^{\circ}, 25^{\circ}-45^{\circ}, 40^{\circ}-67^{\circ} \text { ) }\end{array}\end{array}$}} \\
\hline & & & & & \\
\hline $\begin{array}{l}\text { Experiment } \\
\text { Conditions }\end{array}$ & Parameter & $\begin{array}{l}\text { Critical Region } \\
\alpha=0.05\end{array}$ & T-Value & Conclusion & R-Value \\
\hline \multirow{10}{*}{$\begin{array}{l}\text { P.E. = } \\
300 \mathrm{ft} \\
\text { T.W.E. = } 279 \\
\mathrm{ft} \\
\text { Time: } \\
142 \mathrm{sec}\end{array}$} & Shaft load & $-2.92<\downarrow 2.92$ & -1.153 & $\begin{array}{l}\text { Not significantly } \\
\text { different }\end{array}$ & 1 \\
\hline & R/vert. hinge & $-2.92<\downarrow 2.92$ & -9.633 & $\begin{array}{l}\text { SIGNIFICANTLY } \\
\text { DIFFERENT }\end{array}$ & 0.999 \\
\hline & R/horz. hinge & $-2.92<\downarrow 2.92$ & 1.372 & $\begin{array}{l}\text { Not significantly } \\
\text { different }\end{array}$ & 0.998 \\
\hline & L/vert. hinge & $-2.92<\triangleright 2.92$ & -0.660 & $\begin{array}{l}\text { Not significantly } \\
\text { different }\end{array}$ & 0.999 \\
\hline & Lhorz. hinge & $-2.92<\downarrow 2.92$ & -0.118 & $\begin{array}{l}\text { Not significantly } \\
\text { different }\end{array}$ & 0.979 \\
\hline & U/S pressure & $-2.92<\downarrow 2.92$ & -1.980 & $\begin{array}{l}\text { Not significantly } \\
\text { different }\end{array}$ & 0.997 \\
\hline & D/S pressure & $-2.92<\downarrow>2.92$ & -1.068 & $\begin{array}{l}\text { Not significantly } \\
\text { different }\end{array}$ & 0.943 \\
\hline & ACC. 1 & $-2.92<\downarrow 2.92$ & -0.282 & $\begin{array}{l}\text { Not significantly } \\
\text { different }\end{array}$ & 0.999 \\
\hline & ACC. 2 & $-2.92<\downarrow 2.92$ & 0.318 & $\begin{array}{l}\text { Not significantly } \\
\text { different }\end{array}$ & 0.998 \\
\hline & ACC. 3 & $-2.92<\downarrow 2.92$ & -3.150 & $\begin{array}{l}\text { SIGNIFICANTLY } \\
\text { DIFFERENT }\end{array}$ & 0.999 \\
\hline
\end{tabular}

approach channel on the contrary may be considered as the conservative estimate of the open channel experimental magnitudes.

\section{Frequency-domain signature analysis}

A frequency-domain signature analysis was used to measure the variations in the operating random signals for the cases mentioned in Table 2. This analysis illustrates two distinct operating random vibrational characteristics of the system. These include the dynamics of the flow and the flow-induced structural motion. The frequency content of the flow and the most dominant frequency of the flow-induced gate vibration are the essence of this study to detect possible resonant vibration problem.

Using IDEAS-TEST module, the time-domain data were converted to the frequency-domain data. A Hanning narrow window with 50 percent overlapping and a frame size of 1,024 samples or $0.49152 \mathrm{sec}$ were used to process 


\begin{tabular}{|c|c|c|c|c|c|}
\hline \multicolumn{6}{|c|}{$\begin{array}{l}\text { Table } 7 \\
\text { Summary of Statistical Hypothesis Testing for Set \#3 }\end{array}$} \\
\hline \multicolumn{6}{|c|}{$\begin{array}{l}\text { Flat Gate with and without Approach Channel } \\
\text { (Data taken @ - } 2^{\circ}, 27^{\circ}, 30^{\circ}, 50^{\circ}, 60^{\circ} \text { ) }\end{array}$} \\
\hline $\begin{array}{l}\text { Experiment } \\
\text { Conditions }\end{array}$ & Parameter & $\begin{array}{l}\text { Critical Region } \\
\alpha=0.05\end{array}$ & T-Value & Conclusion & R-Value \\
\hline \multirow{10}{*}{$\begin{array}{l}\text { P.E. = } \\
299 \mathrm{ft} \\
\text { T.W.E. = } \\
276.5 \mathrm{ft}\end{array}$} & Shaft load & $-2.015<t>2.015$ & 0.9910 & $\begin{array}{l}\text { Not significantly } \\
\text { different }\end{array}$ & 0.999 \\
\hline & R/vert. hinge & $-2.015<\downarrow 2.015$ & -0.478 & $\begin{array}{l}\text { Not significantly } \\
\text { different }\end{array}$ & 0.998 \\
\hline & R/horz. hinge & $-2.015<t>2.015$ & -0.095 & $\begin{array}{l}\text { Not significantly } \\
\text { different }\end{array}$ & 0.992 \\
\hline & L/vert. hinge & $-2.015<\downarrow 2.015$ & 0.294 & $\begin{array}{l}\text { Not significantly } \\
\text { different }\end{array}$ & 0.995 \\
\hline & Lhorz. hinge & $-2.015<\downarrow>2.015$ & -0.103 & $\begin{array}{l}\text { Not significantly } \\
\text { different }\end{array}$ & 0.939 \\
\hline & U/S pressure & $-2.015<\downarrow 2.015$ & 0.202 & $\begin{array}{l}\text { Not significantly } \\
\text { different }\end{array}$ & 0.996 \\
\hline & $D / S$ pressure & $-2.015<\downarrow 2.015$ & 0.010 & $\begin{array}{l}\text { Not significantly } \\
\text { different }\end{array}$ & 0.996 \\
\hline & ACC. 1 & $-2.015<\iota>2.015$ & 0.794 & $\begin{array}{l}\text { Not significantly } \\
\text { different }\end{array}$ & 0.381 \\
\hline & ACC. 2 & $-2.015<\downarrow>2.015$ & -0.194 & $\begin{array}{l}\text { Not significantly } \\
\text { different }\end{array}$ & 0.606 \\
\hline & ACC. 3 & $-2.015<\downarrow 2.015$ & -0.159 & $\begin{array}{l}\text { Not significantly } \\
\text { different }\end{array}$ & 0.839 \\
\hline
\end{tabular}

the time-domain data. The accuracy of this converted data was independently checked by using the MATLAB signature analysis module. The resulting frequency-domain data were presented as Auto- or Power-spectral density (PSD), and quasi Frequency Response Function (FRF). A PSD function reflects the energy content of the response as a function of frequency, and quasi FRF is the ratio of two response signals in the frequency domain. Quasi FRF's were calculated from the fixed reference point $(j)$ and each response point (i) using the equation shown below:

$$
\text { quasi } F R F_{i j}=\frac{G_{i j}(\omega)}{\sqrt{G_{j j}}(\omega)}
$$




\begin{tabular}{|c|c|c|c|c|c|}
\hline \multicolumn{6}{|c|}{$\begin{array}{l}\text { Table } 8 \\
\text { Summary of Statistical Hypothesis Testing for Set \#4 }\end{array}$} \\
\hline \multicolumn{6}{|c|}{$\begin{array}{l}\text { Flat Gate with and without Approach Channel } \\
\left.\text { (Data taken @-2 } 27^{\circ}, 30^{\circ}, 50^{\circ}, 60^{\circ}\right)\end{array}$} \\
\hline $\begin{array}{l}\text { Experiment } \\
\text { Conditions }\end{array}$ & Parameter & $\begin{array}{l}\text { Critical Region } \\
\alpha=0.05\end{array}$ & T-Value & Conclusion & $\begin{array}{l}\text { R- } \\
\text { Value }\end{array}$ \\
\hline \multirow{10}{*}{$\begin{array}{l}\text { P.E. = } \\
296.5 \mathrm{ft} \\
\text { T.W.E. = } \\
285.5 \mathrm{ft}\end{array}$} & Shaft load & $-2.015<\downarrow 2.015$ & 0.485 & $\begin{array}{l}\text { Not significantly } \\
\text { different }\end{array}$ & 0.998 \\
\hline & $\begin{array}{l}\text { R/vert. } \\
\text { hinge }\end{array}$ & $-2.015<\diamond 2.015$ & -1.880 & $\begin{array}{l}\text { Not significantly } \\
\text { different }\end{array}$ & 0.955 \\
\hline & $\begin{array}{l}\text { R/horz. } \\
\text { hinge }\end{array}$ & $-2.015<\downarrow 2.015$ & 0.532 & $\begin{array}{l}\text { Not significantly } \\
\text { different }\end{array}$ & 0.999 \\
\hline & $\begin{array}{l}\text { Lvert. } \\
\text { hinge }\end{array}$ & $-2.015<\downarrow>2.015$ & 0.623 & $\begin{array}{l}\text { Not significantly } \\
\text { different }\end{array}$ & 0.989 \\
\hline & $\begin{array}{l}\text { Lhorz. } \\
\text { hinge }\end{array}$ & $-2.015<\downarrow 2.015$ & -0.367 & $\begin{array}{l}\text { Not significantly } \\
\text { different }\end{array}$ & -0.208 \\
\hline & $\begin{array}{l}\text { U/S } \\
\text { pressure }\end{array}$ & $-2.015<\downarrow>2.015$ & 2.909 & $\begin{array}{l}\text { SIGNIFICANTLY } \\
\text { DIFFERENT }\end{array}$ & 0.999 \\
\hline & $\begin{array}{l}\text { D/S } \\
\text { pressure }\end{array}$ & $-2.015<\downarrow 2.015$ & -2.433 & $\begin{array}{l}\text { SIGNIFICANTLY } \\
\text { DIFFERENT }\end{array}$ & 0.999 \\
\hline & ACC. 1 & $-2.015<\downarrow>2.015$ & -0.080 & $\begin{array}{l}\text { Not significantly } \\
\text { different }\end{array}$ & -0.702 \\
\hline & ACC. 2 & $-2.015<\downarrow 2.015$ & -0.634 & $\begin{array}{l}\text { Not significantly } \\
\text { different }\end{array}$ & -0.102 \\
\hline & ACC. 3 & $-2.015<\downarrow 2.015$ & -0.107 & $\begin{array}{l}\text { Not significantly } \\
\text { different }\end{array}$ & -0.921 \\
\hline
\end{tabular}

where

$$
\begin{aligned}
& G_{i j}(\omega)=\text { crosspower spectrum between reference and response point } \\
& G_{j j}(\omega)=\text { autopower spectrum of reference point }
\end{aligned}
$$

The area underneath the PSD indicates the mean square value of the discrete function. A comparison of PSD's for two random signals would indicate changes in the flow-induced physical phenomena (such as more pressure or loads) between the groups in the frequency domain. A comparison of quasi FRF's would provide information regarding any changes in the system information (the gate performance). For an ideally linear system, the FRF's computed from the two cases (with and without approach channel) would be invariable with no or little deviation. A coherence function provides the correlation strength between the response signals used to compute the FRF's. 


\begin{tabular}{|c|c|c|c|c|c|c|c|c|c|c|}
\hline \multirow{4}{*}{$\begin{array}{l}\text { Table } \\
\text { A Co } \\
\text { Chan } \\
\\
\begin{array}{l}\text { Angle } \\
\text { deg }\end{array}\end{array}$} & $\begin{array}{l}\text { el } \\
\text { el }\end{array}$ & of Rer & onses & or the & Flat C & ate witl & ind $v$ & hout $t$ & Apr & \\
\hline & \multicolumn{5}{|c|}{ Set \#1 } & \multicolumn{5}{|c|}{ Set \#3 } \\
\hline & \multicolumn{2}{|c|}{ Open Channel, A } & \multicolumn{3}{|c|}{ Approach Channel, B } & \multicolumn{2}{|c|}{ Open Channel, A } & \multicolumn{3}{|c|}{ Approach Channel, B } \\
\hline & Mean & $\begin{array}{l}\text { Std. } \\
\text { Dev. }\end{array}$ & Mean & $\begin{array}{l}\text { Std. } \\
\text { Dev. }\end{array}$ & $\begin{array}{l}\text { Ra- } \\
\text { tio } \\
\text { A }^{1}{ }^{1}\end{array}$ & Mean & $\begin{array}{l}\text { Std. } \\
\text { Dev. }\end{array}$ & Mean & $\begin{array}{l}\text { Std. } \\
\text { Dev. }\end{array}$ & $\begin{array}{l}\text { Ratio } \\
\text { A/B }\end{array}$ \\
\hline \multicolumn{11}{|c|}{ Shaft Load } \\
\hline-2 & 7.81 & 0.16 & 7.24 & 0.16 & 1.08 & 7.48 & 0.15 & 6.88 & 0.16 & 1.08 \\
\hline 27 & 16.32 & 0.31 & 15.68 & 0.54 & 1.02 & 16.08 & 0.31 & 14.64 & 0.39 & 1.09 \\
\hline 30 & 15.91 & 0.17 & 15.35 & 0.21 & 1.03 & 15.57 & 0.20 & 14.05 & 0.40 & 1.09 \\
\hline 50 & 11.49 & 0.19 & 11.02 & 0.19 & 1.04 & 10.83 & 0.16 & 10.07 & 0.12 & 1.08 \\
\hline 60 & 10.18 & 0.08 & 9.70 & 0.08 & 1.05 & 9.34 & 0.09 & 8.64 & 0.08 & 1.08 \\
\hline \multicolumn{11}{|c|}{ Right Vertical Hinge } \\
\hline-2 & -2.93 & 0.03 & 0.34 & 0.04 & - & 0.29 & 0.03 & 0.20 & 0.04 & 1.35 \\
\hline 27 & -1.25 & 0.19 & 2.37 & 0.26 & -- & 2.24 & 0.27 & 2.39 & 0.25 & 0.95 \\
\hline 30 & -1.01 & 0.05 & 2.53 & 0.07 & -- & 2.43 & 0.07 & 2.80 & 0.13 & 0.85 \\
\hline 50 & -0.65 & 0.05 & 2.59 & 0.06 & - & 2.69 & 0.05 & 2.93 & 0.04 & 0.92 \\
\hline 60 & -0.68 & 0.03 & 2.68 & 0.02 & -- & 2.48 & 0.03 & 2.72 & 0.03 & 0.91 \\
\hline \multicolumn{11}{|c|}{ Right Horizontal Hinge } \\
\hline-2 & 0.42 & 0.06 & 0.20 & 0.08 & 1.73 & -0.10 & 0.07 & -0.18 & 0.08 & 0.67 \\
\hline 27 & -3.30 & 0.20 & -3.52 & 0.27 & 0.95 & -3.47 & 0.28 & -3.51 & 0.26 & 1.00 \\
\hline 30 & -3.29 & 0.05 & -3.28 & 0.06 & 1.00 & -3.34 & 0.06 & -3.49 & 0.12 & 0.94 \\
\hline 50 & -3.01 & 0.03 & -2.94 & 0.03 & 1.02 & -3.07 & 0.02 & -2.84 & 0.02 & 1.08 \\
\hline 60 & -2.47 & 0.02 & -2.72 & 0.02 & 0.91 & -2.73 & 0.02 & -2.47 & 0.02 & 1.10 \\
\hline \multicolumn{11}{|c|}{ Left Vertical Hinge } \\
\hline-2 & 0.35 & 0.03 & 0.18 & 0.03 & 1.77 & 0.25 & 0.03 & 0.15 & 0.03 & 1.47 \\
\hline 27 & 3.17 & 0.24 & 2.92 & 0.33 & 1.05 & 2.70 & 0.29 & 2.73 & 0.28 & 1.00 \\
\hline 30 & 3.56 & 0.06 & 3.38 & 0.07 & 1.05 & 3.12 & 0.06 & 2.88 & 0.20 & 1.03 \\
\hline 50 & 3.53 & 0.06 & 3.55 & 0.05 & 1.00 & 3.27 & 0.02 & 3.09 & 0.03 & 1.05 \\
\hline 60 & 3.77 & 0.02 & 3.64 & 0.02 & 1.04 & 3.37 & 0.02 & 3.31 & 0.03 & 1.02 \\
\hline \multicolumn{11}{|c|}{ (Sheet 1 of 3 ) } \\
\hline $\mathrm{L}$ & $=$ & $\frac{\sigma] \mathrm{O}}{\mathrm{App}}$ & $\frac{\mathrm{Cha}}{\mathrm{ch} \mathrm{Cl}}$ & & & & & & & \\
\hline
\end{tabular}




\begin{tabular}{|c|c|c|c|c|c|c|c|c|c|c|}
\hline \multirow[b]{3}{*}{$\begin{array}{l}\text { Angle } \\
\text { deg }\end{array}$} & \multicolumn{5}{|c|}{ Set \#1 } & \multicolumn{5}{|c|}{ Set \#3 } \\
\hline & \multicolumn{2}{|c|}{ Open Channel, A } & \multicolumn{3}{|c|}{ Approach Channel, B } & \multicolumn{2}{|c|}{ Open Channel, A } & \multicolumn{3}{|c|}{ Approach Channel, B } \\
\hline & Mean & $\begin{array}{l}\text { Std. } \\
\text { Dev. }\end{array}$ & Mean & $\begin{array}{l}\text { Std. } \\
\text { Dev. }\end{array}$ & $\begin{array}{l}\text { Ra- } \\
\text { tio } \\
\text { A }^{1}{ }^{1}\end{array}$ & Mean & $\begin{array}{l}\text { Std. } \\
\text { Dev. }\end{array}$ & Mean & $\begin{array}{l}\text { Std. } \\
\text { Dev. }\end{array}$ & $\begin{array}{l}\text { Ratio } \\
\text { A/B }\end{array}$ \\
\hline \multicolumn{11}{|c|}{ Left Horizontal Hinge } \\
\hline-2 & -0.50 & 0.06 & -0.90 & 0.08 & 0.57 & -0.34 & 0.07 & -0.68 & 0.08 & 0.54 \\
\hline 27 & -1.44 & 0.25 & -1.35 & 0.30 & 1.03 & -1.30 & 0.31 & -1.03 & 0.26 & 1.25 \\
\hline 30 & -1.38 & 0.07 & -1.42 & 0.08 & 0.97 & -1.33 & 0.07 & -0.91 & 0.14 & 1.34 \\
\hline 50 & -0.79 & 0.04 & -0.80 & 0.03 & 1.00 & -0.68 & 0.03 & -0.70 & 0.03 & 0.97 \\
\hline 60 & -0.63 & 0.02 & -0.44 & 0.03 & 1.40 & -0.26 & 0.02 & -0.46 & 0.03 & 0.59 \\
\hline \multicolumn{11}{|c|}{ Upstream Pressure } \\
\hline-2 & -5.11 & 0.07 & -5.02 & 0.09 & 1.01 & -5.10 & 0.10 & -5.36 & 0.08 & 0.96 \\
\hline 27 & -6.07 & 0.08 & -5.70 & 0.10 & 1.06 & -6.00 & 0.11 & -6.24 & 0.08 & 0.97 \\
\hline 30 & -6.20 & 0.08 & -5.78 & 0.09 & 1.07 & -6.11 & 0.09 & -6.28 & 0.13 & 0.97 \\
\hline 50 & -7.49 & 0.06 & -7.09 & 0.07 & 1.05 & -7.62 & 0.06 & -7.40 & 0.09 & 1.02 \\
\hline 60 & -7.85 & 0.08 & -7.84 & 0.08 & 1.00 & -8.36 & 0.04 & -8.29 & 0.13 & 1.00 \\
\hline \multicolumn{11}{|c|}{ Downstream Pressure } \\
\hline-2 & -9.37 & 0.25 & -9.04 & 0.26 & 1.04 & -9.27 & 0.27 & -9.54 & 0.27 & 0.97 \\
\hline 27 & -14.30 & 0.57 & -13.71 & 0.58 & 1.05 & -13.77 & 0.57 & -13.71 & 0.55 & 1.00 \\
\hline 30 & -13.66 & 0.23 & -13.23 & 0.20 & 1.03 & -13.20 & 0.22 & -13.37 & 0.30 & 0.99 \\
\hline 50 & -11.32 & 0.04 & -11.03 & 0.04 & 1.03 & -11.00 & 0.03 & -10.97 & 0.03 & 1.00 \\
\hline 60 & -11.44 & 0.02 & -11.03 & 0.02 & 1.04 & -11.05 & 0.02 & -10.88 & 0.02 & 1.02 \\
\hline \multicolumn{11}{|c|}{ Accelerometer \#1 } \\
\hline-2 & -0.023 & 0.020 & -0.030 & 0.021 & 0.84 & -0.020 & 0.021 & -0.031 & 0.022 & 0.78 \\
\hline 27 & -0.022 & 0.022 & -0.033 & 0.114 & 0.30 & -0.018 & 0.051 & -0.028 & 0.089 & 0.59 \\
\hline 30 & -0.023 & 0.031 & -0.044 & 0.054 & 0.55 & -0.022 & 0.045 & -0.045 & 0.135 & 0.37 \\
\hline 50 & -0.019 & 0.050 & -0.037 & 0.058 & 0.73 & -0.018 & 0.046 & -0.031 & 0.044 & 0.86 \\
\hline 60 & -0.056 & 0.032 & -0.019 & 0.042 & 1.46 & -0.023 & 0.035 & -0.028 & 0.042 & 0.83 \\
\hline \multicolumn{11}{|c|}{ Accelerometer \#2 } \\
\hline-2 & -0.033 & 0.019 & -0.029 & 0.024 & 0.99 & -0.034 & 0.022 & -0.025 & 0.028 & 1.06 \\
\hline 27 & -0.034 & 0.026 & -0.043 & 0.142 & 0.33 & -0.032 & 0.068 & -0.027 & 0.143 & 0.59 \\
\hline 30 & -0.035 & 0.046 & -0.054 & 0.118 & 0.47 & -0.037 & 0.071 & -0.046 & 0.264 & 0.35 \\
\hline 50 & -0.029 & 0.051 & -0.025 & 0.061 & 0.93 & -0.029 & 0.046 & -0.026 & 0.047 & 1.03 \\
\hline 60 & -0.077 & 0.033 & -0.039 & 0.054 & 1.18 & -0.037 & 0.043 & -0.034 & 0.045 & 1.01 \\
\hline \multicolumn{11}{|c|}{ (Sheet 2 of 3 ) } \\
\hline
\end{tabular}




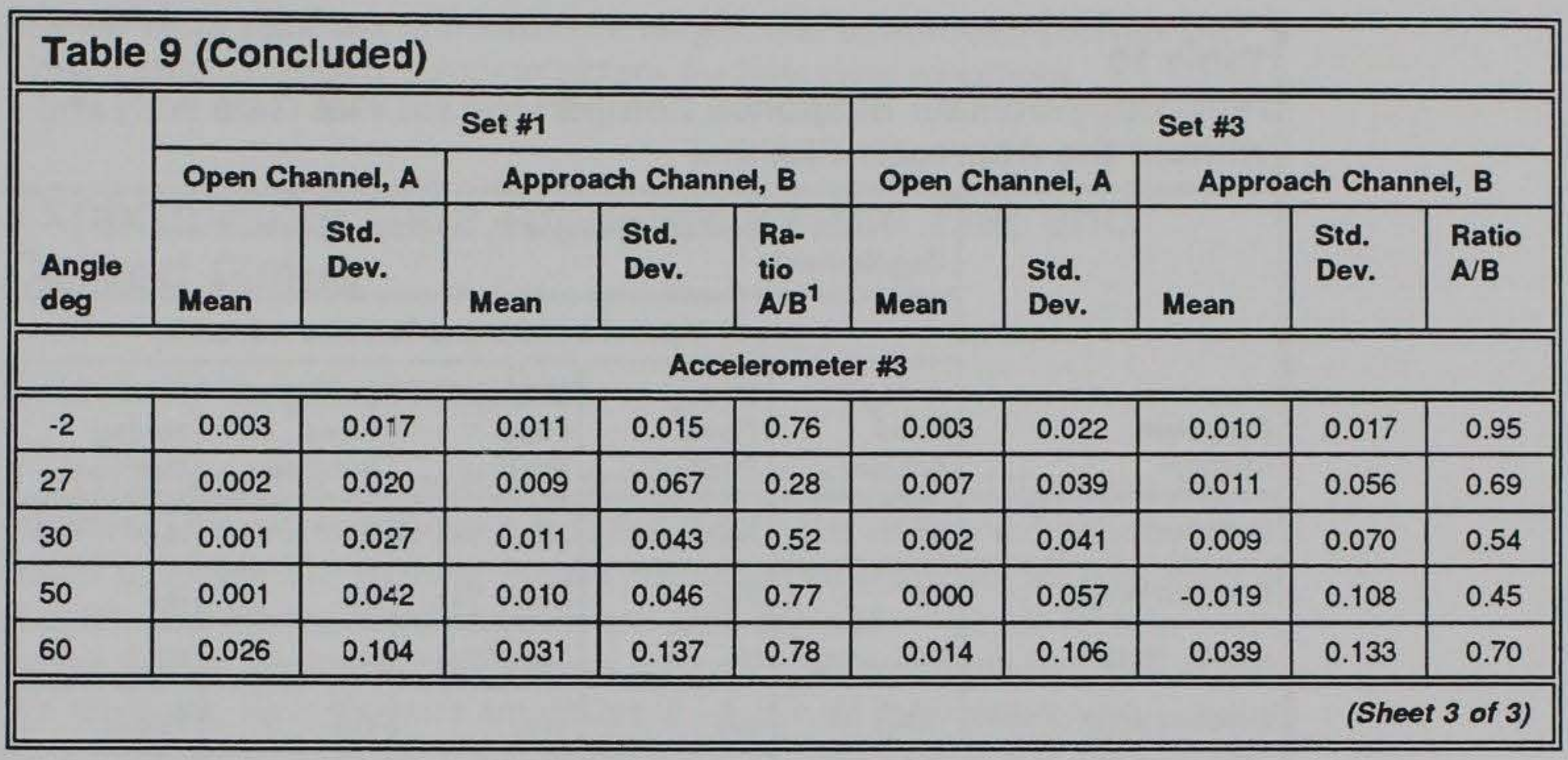

The auto spectra and FRF's for Set \#3 are compared in Figures 14 to 18. Nine auto spectra and FRF comparison plots (with and without the approach channel data) were generated for each fixed position of the gate. For instance, Figures $14 \mathrm{a}-\mathrm{i}$ compare the variations of the responses in the frequency domain when the gate was tested at -2 deg position. Each plot compares the auto spectra for the response channel in the fourth quadrant, reference channel in the third quadrant, quasi FRF in the second quadrant, and coherence function between the reference and response channels in the first quadrant. The FRF's for the response channels were computed with respect to the right vertical hinge (reference channel) of the respective experiment. Note that the shaft load auto spectra consistently show harmonically related spikes for all experiments. This odd harmonic spike is related to a square wave signal recorded from the power source as described in the limitations section of this report. A square wave could result if a sine wave signal is chopped off at certain amplitudes.

The PSD's for the accelerations (system response) show the frequencies of the gate that are being excited by the forcing functions. A similar system response is also noticeable in the quasi FRF's that show the operational vibrational pattern of the gate as a function of frequency. On the contrary, PSD's for the upstream pressure is a good representation of the frequency content for the actual flow.

The auto spectra and FRF's comparison plots for the remaining cases are not included in this report. They showed similar trend as in Set \#3. Table 10 summarizes the frequency-domain differences of the channel responses for Set \#3. Only the apparent differences in the superimposed plots are identified in this table. As noted in the table, only the functions that appeared to have differences are designated by a positive response. It appeared that the response measurements for 27- and 30-deg positions systematically disagreed between the groups. This phenomenon is clearly depicted in Figures 15 and 16. These figures show that the higher frequencies are more dominant in the approach 


\begin{tabular}{|c|c|c|c|c|c|}
\hline \multicolumn{6}{|c|}{$\begin{array}{l}\text { Table } 10 \\
\text { Frequency-Domain Response Comparison for Flat Gate with and } \\
\text { without the Approach Channel }\end{array}$} \\
\hline \multirow[b]{3}{*}{$\begin{array}{l}\text { Response } \\
\text { Channel } \\
\end{array}$} & \multicolumn{5}{|c|}{$\begin{array}{l}\text { Any Noticeable Changes in the Auto Spectrum and FRF } \\
\text { Magnitudes? }\end{array}$} \\
\hline & \multicolumn{5}{|c|}{ Set \#3 (Pool el = $299 \mathrm{ft}$ and Tail W/el $=276.5 \mathrm{ft})$} \\
\hline & $\begin{array}{l}\text {-2-deg } \\
\text { Fixed } \\
\text { Position }\end{array}$ & $\begin{array}{l}\text { 27-deg } \\
\text { Fixed } \\
\text { Position }\end{array}$ & $\begin{array}{l}\text { 30-deg } \\
\text { Fixed } \\
\text { Position }\end{array}$ & $\begin{array}{l}\text { 50-deg } \\
\text { Fixed } \\
\text { Position }\end{array}$ & $\begin{array}{l}\text { 60-deg } \\
\text { Position }\end{array}$ \\
\hline Shaft load & No & Auto - yes & Auto - Yes & No & No \\
\hline $\mathrm{R} /$ vertical hinge & No & Yes & Auto-Yes & No & No \\
\hline$R /$ horiz. hinge & No & No & Auto - Yes & No & No \\
\hline L/vertical hinge & Yes & Yes & Yes & Yes & Yes \\
\hline Lhoriz. hinge & No & No & Auto - Yes & No & No \\
\hline Upstream pressure & Yes & Auto-Yes & Auto - Yes & No & No \\
\hline Downstream pressure & No & No & Auto-Yes & No & No \\
\hline Acceleration \#1 & $\begin{array}{l}\text { No for lower } \\
\text { modes }\end{array}$ & Auto - Yes & Yes & No & No \\
\hline Acceleration \#2 & $\begin{array}{l}\text { No for lower } \\
\text { modes }\end{array}$ & Auto-Yes & Auto-Yes & No & No \\
\hline Acceleration \#3 & No & Auto-Yes & Auto-Yes & No & No \\
\hline Acceleration \#4 & $\begin{array}{l}\text { No data } \\
\text { taken }\end{array}$ & $\begin{array}{l}\text { No data } \\
\text { taken }\end{array}$ & \begin{tabular}{|l} 
No data \\
taken
\end{tabular} & $\begin{array}{l}\text { No data } \\
\text { taken }\end{array}$ & No data \\
\hline
\end{tabular}

channel flow than for the open channel condition. From the dynamic point of view, the simulated approach channel dynamics are the conservative estimate of the open channel results since more disturbances are likely to excite the gate in the former case. This trend was also noticeable in the time-domain data (Table 3). Like the time-domain effects, the left vertical hinge reaction also varied in the frequency domain.

A three-dimensional plot of the power spectra as a function of equally spaced time and frequency was used to generate the time-spectral map as shown in Figures 19 and 20. This time-spectral map was generated by stacking the frequency spectra for equally spaced time-domain data for the flat gate with and without the approach channel. The responses for 27-deg positions are shown in these maps. A time-spectral map is generally used to measure vibration during startup, during periods of changing load, or operation. As shown in the figures, the peaks of the spectra remain fixed as a function of the frequency. This indicates that the operating condition does not change the dynamics of the gate and no nonlinear motion is noticeable at these frequencies. A comparison of time-spectra maps for corresponding channels indicates 
that the shaft, right and left horizontal hinges, and downstream pressure provided similar frequency response pattern for both river conditions.

\section{Experimental Data Analysis for the Flat and Curved Gates}

\section{Time-domain data comparison}

A comparison of the average magnitudes and the ranges (maximum and minimum) for sensor responses recorded for the flat and curved gates is presented in Figure 21. In these figures, the measured responses for both gates at 30-, 50-, and 60-deg fixed positions are superimposed. As seen in these plots, except for the average accelerometers responses, all corresponding sensor average responses for both gates are different. A curved gate consistently provided higher shaft load, pressures, and reaction forces compared to the flat gate for identical gate orientation and flow condition. Curved gate responses are more widely dispersed about the mean than that of the flat gate. This suggests that the responses for the curved gate are amplified more than that of the flat gate due to flow-induced vibration. A summary of the time-domain statistical hypothesis testing showed a significant difference in the measured pressures only (Table 11).

\section{Frequency-domain signature analysis}

The auto spectra and quasi FRF's for the flat and curved gates are compared in Figures 22 to 24 . Only the auto spectra for the corresponding set numbers were superimposed in these plots. These figures show that the response auto spectra for identical flow configurations are different for both gates. It appears that the root mean square (RMS) values for the higher frequencies are more dominant for the flat gate than that of the curved gate. A relative difference in the sampling rate for both gates caused such an appearant mismatch, particularly in the higher-order frequency steps. A sampling rate of $2,000 \mathrm{samples} / \mathrm{sec} / \mathrm{channel}$ was used for the flat gate, while a very low sampling rate of only $500 \mathrm{samples} / \mathrm{sec} / \mathrm{channel}$ was considered during the curved gate tests. As shown in the plots, the lower mode frequencies for the curved gate are more amplified than that of the flat gate.

\section{Experimental modal test - dry condition}

An experimental modal test was performed for the flat gate with two fixed positions, 45 and $65 \mathrm{deg}$. The curved gate was tested for the same positions. This hammer-impacted madal test was conducted to extract the fundamental modes of the gate and to determine their effects on the forced dynamics of the gate. The gate in dry condition was impacted by a modally tuned hammer at each of the 33 nodes (a grid of 11 rows and 3 columns), one at a time, and the 


\begin{tabular}{|c|c|c|c|c|c|}
\hline \multicolumn{6}{|c|}{$\begin{array}{l}\text { Table } 11 \\
\text { Summary of Statistical Hypothesis Testing for Flat and Curved } \\
\text { Gates }\end{array}$} \\
\hline \multicolumn{6}{|c|}{ Flat and Curved Gates Readings, Data taken @ $30^{\circ}, 50^{\circ}, 60^{\circ}$} \\
\hline $\begin{array}{l}\text { Experimental } \\
\text { Conditions }\end{array}$ & Parameter & $\begin{array}{l}\text { Critical Region } \\
\alpha=0.05\end{array}$ & T-Value & Conclusion & R-Value \\
\hline \multirow{11}{*}{$\begin{array}{l}\text { P.E. }= \\
301.5 \mathrm{ft} \\
\text { T.W.E. }=278 \\
\mathrm{ft}\end{array}$} & Shaft load & $-2.92<\downarrow 2.92$ & 0.562 & $\begin{array}{l}\text { Not significantly } \\
\text { different }\end{array}$ & 0.547 \\
\hline & R/vert. hinge & $-2.92<\triangleright 2.92$ & 1.547 & $\begin{array}{l}\text { Not significantly } \\
\text { different }\end{array}$ & 0.961 \\
\hline & $\begin{array}{l}\text { Rhorz. } \\
\text { hinge }\end{array}$ & $-2.92<\triangleright 2.92$ & 0.241 & $\begin{array}{l}\text { Not significantly } \\
\text { different }\end{array}$ & -0.238 \\
\hline & L/vert. hinge & $-2.92<\downarrow 2.92$ & -0.074 & $\begin{array}{l}\text { Not significantly } \\
\text { different }\end{array}$ & 0.744 \\
\hline & Lhorz. hinge & $-2.92<\triangleright 2.92$ & -1.982 & $\begin{array}{l}\text { Not significantly } \\
\text { different }\end{array}$ & 0.721 \\
\hline & $\begin{array}{l}\mathrm{U} / \mathrm{S} \\
\text { pressure }\end{array}$ & $-2.92<t>2.92$ & 3.608 & $\begin{array}{l}\text { SIGNIFICANTLY } \\
\text { DIFFERENT }\end{array}$ & 0.931 \\
\hline & $\begin{array}{l}\mathrm{D} / \mathrm{S} \\
\text { pressure }\end{array}$ & $-2.92<\downarrow 2.92$ & 5.799 & $\begin{array}{l}\text { SIGNIFICANTLY } \\
\text { DIFFERENT }\end{array}$ & -0.523 \\
\hline & ACC. 1 & $-2.92<\downarrow 2.92$ & 0.891 & $\begin{array}{l}\text { Not significantly } \\
\text { different }\end{array}$ & -0.974 \\
\hline & ACC. 2 & $-2.92<\triangleright 2.92$ & 0.990 & $\begin{array}{l}\text { Not significantly } \\
\text { different }\end{array}$ & -0.982 \\
\hline & ACC. 3 & $-2.92<\downarrow 2.92$ & 1.287 & $\begin{array}{l}\text { Not significantly } \\
\text { different }\end{array}$ & -0.319 \\
\hline & ACC. 4 & $-2.92<\triangleright 2.92$ & 2.495 & $\begin{array}{l}\text { Not significantly } \\
\text { different }\end{array}$ & -0.014 \\
\hline
\end{tabular}

data for five channels (four response outputs and one input excitation) for each impact was recorded by a multichannel data acquisition system. The recorded binary data was analyzed by the IDEAS modal analysis module that extracted the modal parameters of the gate. The sampling rate was $2,000 \mathrm{~Hz}$ and the data filtered at a frequency of $1,000 \mathrm{~Hz}$.

Table 12 compares the first five modes for the flat and curved gates. Figure 25 shows the extracted mode shapes of the flat gate. A comparison of the mode shapes indicate that the fundamental dynamic characteristics of the flat gate is substantially different from that of the curved gate. As shown in the table, the torsional frequency for the flat gate was smaller than for the curved gate. The first bounce frequency for the flat gate was higher than that for the curved gate. An increase in the shaft length, while the gate is raised from a 45- to 65-deg position, decreased the bending frequencies in the flat gate. The first torsional stiffness, however, did not change much due to the increase in 


\begin{tabular}{|c|c|c|c|}
\hline \multicolumn{4}{|c|}{$\begin{array}{l}\text { Table } 12 \\
\text { Mode Shape Comparison for Flat and Curved Gates }\end{array}$} \\
\hline Mode Shapes Type & $\begin{array}{l}\text { Curved Gate } \\
\text { 45-deg Position }\end{array}$ & $\begin{array}{l}\text { Flat Gate } \\
\text { 45-deg Position }\end{array}$ & $\begin{array}{l}\text { Flat Gate } \\
\text { 65-deg Position }\end{array}$ \\
\hline $\begin{array}{l}\text { Bouncing } \\
\text { frequency, } \mathrm{Hz} \\
\text { damping, \% }\end{array}$ & $\begin{array}{r}119.93 \\
3.91 \\
\end{array}$ & $\begin{array}{c}179.165 \\
4.19\end{array}$ & $\begin{array}{r}154.07 \\
1.64 \\
\end{array}$ \\
\hline $\begin{array}{l}\text { Torsion } \\
\text { frequency, } \mathrm{Hz} \\
\text { damping, \% }\end{array}$ & $\begin{array}{r}254.75 \\
2.02\end{array}$ & $\begin{array}{r}242.73 \\
1.26 \\
\end{array}$ & $\begin{array}{r}239.24 \\
1.26\end{array}$ \\
\hline $\begin{array}{l}\text { Bending } \\
\text { frequency, } \mathrm{Hz} \\
\text { damping, \% }\end{array}$ & $\begin{array}{r}567.40 \\
1.66\end{array}$ & $\begin{array}{r}375.08 \\
2.83\end{array}$ & $\begin{array}{r}369.81 \\
2.34\end{array}$ \\
\hline $\begin{array}{l}\text { Second torsion } \\
\text { frequency, } \mathrm{Hz} \\
\text { damping, \% }\end{array}$ & $\begin{array}{r}794.82 \\
0.664\end{array}$ & $\begin{array}{r}605.71 \\
1.49\end{array}$ & $\begin{array}{r}649.12 \\
2.68\end{array}$ \\
\hline $\begin{array}{l}\text { Second bending } \\
\text { frequency, } \mathrm{Hz} \\
\text { damping, \% }\end{array}$ & $\begin{array}{r}917.75 \\
2.36\end{array}$ & $\begin{array}{r}902.30 \\
1.88\end{array}$ & \\
\hline Moment of inertia, in. ${ }^{4}$ & 0.00449 & 0.018 & 0.018 \\
\hline Weight of gate, lb & 2.08 & 1.747 & 1.747 \\
\hline Weight of cylinder, lb & 1.485 & 1.485 & 1.485 \\
\hline
\end{tabular}

the shaft length. The second bending frequency for the flat gate at 65-deg position was not distinctly identified by the curve fitting algorithm. An interaction between the shaft-mode and the gate-mode at higher frequencies caused difficulties in obtaining normal gate modes using the curve fitting method. Table 12 also shows the mass and the nominal sectional moment of inertia for both gates.

\section{Operating mode shapes}

The operating deflected shapes (ODS) for the flat gate were analyzed to understand the actual response pattern of the gate during operation. One can think of this ODS as the madem "digital camera" equivalent of the traditional analog stroboscope. These shapes were animated using the IDEAS-TEST module. The IDEAS-TEST module created a frame of deflected shapes for each instance of time response. Four accelerometer readings for the flat gate were used to generate the frame of accelerometer responses. The frames were animated and displayed sequentially as if the structure was vibrating in real time.

The ODS for the gate in the frequency domain were also examined to identify any resonant vibrations (possible troubled area) due to flow-induced vibrations of the gate. A few of the static ODS are shown in Figures 26. A 
snapshot of four accelerometer responses in Experiment \#6020, in the frequency domain, was captured to display the four ODS due to the flow-induced motion of the gate at a 50-deg position. A cross spectrum of the measured accelerometer responses and auto spectra for a fixed reference were considered to generate the transmissibility functions for the gate. Transmissibility functions for each response accelerometers were obtained corresponding to a fixed reference accelerometer using the quasi FRF equation defined earlier in this report. Transmissibility function has an amplitude of a response point itself, and a phase angle that is normalized by the phase of the reference point. The operating shapes were identified by extracting the corresponding amplitude and phase data from each quasi frequency response function.

Figure 27 shows the transmissibility functions for four accelerometers which measured simultaneously responses for the flat gate in Experiment \#6020. Peaks in this plot are the dominant frequency dependent flow-induced operating deflections. These transmissibility functions were consequently used to display the ODS in the frequency domain. A scanning of the ODS's indicated that the gate vibrated with four distinct mode shapes similar to the natural mode shapes identified using the experimental modal analysis. These ODS's, however, occurred in different frequency ranges with respect to the dry modal frequencies for the gate. It was found that the first mode, Bounce, controlled the gate vibration at a frequency of 68 to $84 \mathrm{~Hz}$ during operation. Peaks corresponding to 125 and $148 \mathrm{~Hz}$ show a bounce shape of vibration. Bending shape was noticeable at a frequency of $269 \mathrm{~Hz}$. At frequencies $357,369,402$, and $611 \mathrm{~Hz}$, a combination of second torsion and bending mode of vibration was noticed.

The above observation is not quite adequate to identify the flow-induced resonant vibration problems for the gate. Two distinct effects of the flow, one due to added mass of the partially submerged gate and another due to the flow-induced forcing function, need to be identified to detect the existence of any resonant problem. This is due to the fact that the natural mode of vibration for the operating gate due to added mass affect will shift from the corresponding dry modal frequencies. A resonance problem will exist if one of the operating modes of the gate coincides with one of the natural modes of vibration of the wet gate. This necessitates the measurement of the wet modal information for the operating gate.

A correlation of selected ODS to the extracted dry mode shapes was also measured using the IDEAS-TEST correlation module. The modal assurance criteria (MAC) matrix did not indicate any strong correlation between the groups. An overview of the ODS and its applications were recorded and explained in a video developed by WES (1994). 


\section{Data Analysis for the Flat Gate with Open Channel and 1:5 Flume Configuration}

Three experiments similar to the open channel test configurations were conducted in the 1:25 Olmsted model for the 1:5 flume configuration. Information data sheet for corresponding open channel and 1:5 flume configuration experiments are presented in Table 2 . Unlike the previously mentioned experiments, 1:5 flume configuration experiments were conducted at two different fixed positions based on the shaft load performance during its operation. At about a 20-deg gate position, the test result showed the maximum shaft load during its operation. This maximum shaft load is identified from a test conducted for the entire range of gate operation from -2 to $67 \mathrm{deg}$. A 39-deg position corresponds to a sudden change in the time-history of the shaft response. Altogether, five gate positions were considered for recording data for the 1:5 flume configuration.

\section{Time-domain data comparison}

Time-domain responses for the open channel and 1:5 flume configuration tests are compared in Figures 28 to 30 . Response averages and ranges for three fixed positions are plotted in these figures. In general, the open channel flow condition caused higher average shaft load, not over 10 percent, than that of the 1:5 flume configuration cases. For both cases, fluctuation of shaft load about its mean was not significant. The right vertical average reactions for flume configurations were higher than that of the open channel. As seen in these plots, open channel developed slightly higher average left vertical and right horizontal than those of the flume configuration. For all of these cases, however, the flume configuration showed higher deviation from the respective means. Accelerations for most of the times deviated more for the flume configuration. Table 13 shows an outline of apparent differences between the responses for both flow configurations.

A statistical hypothesis testing was also performed to determine the differences between the respective means of the flow-experimental data obtained for the two river models. Except for the right vertical hinge in Set \#5, no significant difference between the corresponding means was observed at a 5-percent level of significance.

For identical flow and gap configurations, relative deviations in the flowinduced responses for three river models are compared in Table 14. In this table, the ratios of corresponding dynamic responses between the open and approach channels $(\mathrm{A} / \mathrm{B})$, open and flume configurations $(\mathrm{A} / \mathrm{C})$, and approach and flume configurations $(\mathrm{B} / \mathrm{C})$ are presented. The ratios shown in this table are the relative deviation of flow-test responses between the groups compared. Four test sets (\#1, 3, 5, and 6) were used for computing the ratios presented in Table 14. Mean and standard deviations for the 1:5 flume configuration (designated as C) are presented in Table 14, and those of the open and 


\begin{tabular}{|c|c|c|c|}
\hline \multirow{2}{*}{$\begin{array}{l}\text { Response } \\
\text { Channel }\end{array}$} & \multicolumn{3}{|c|}{$\begin{array}{l}\text { Any Noticeable Changes in the Time-Domain } \\
\text { (average, minimum, and maximum) Magnitudes? }\end{array}$} \\
\hline & $\begin{array}{l}\text { Set } \# 5 \\
\text { Pool el }=300^{\prime} \\
\text { Tail W/el }=279^{\prime} \\
\text { Fixed Position }\end{array}$ & $\begin{array}{l}\text { Set \#6 } \\
\text { Pool el = 299' } \\
\text { Tail W/el }=276.5^{\prime} \\
\text { Fixed Position }\end{array}$ & $\begin{array}{l}\text { Set } \# 7 \\
\text { Pool el }=296.5^{\prime} \\
\text { Tail W/el }=285.5^{\prime} \\
\text { Fixed Position }\end{array}$ \\
\hline Shaft load & No & Yes & No \\
\hline $\mathrm{R} /$ vertical hinge & Yes & No & Yes \\
\hline R/horiz. hinge & Yes & Yes & Yes \\
\hline L/vertical hinge & Yes, only @ 50 & Yes, only@ 50 & Yes, except @-2 \\
\hline Lhoriz. hinge & Yes & $\begin{array}{l}\text { Yes } \\
\text { except @ 60 }\end{array}$ & Yes \\
\hline Upstream pressure & No & No & No \\
\hline Downstream pressure & Yes, only @ 50 & No & No \\
\hline Acceleration \#1 & No & $\begin{array}{l}\text { No } \\
\text { except @ 50 }\end{array}$ & $\begin{array}{l}\text { Yes } \\
\text { min and max @ 60 } \\
\text { only }\end{array}$ \\
\hline Acceleration \#2 & No & $\begin{array}{l}\text { No } \\
\text { except @ 50 }\end{array}$ & $\begin{array}{l}\text { Yes, min and max } \\
\text { @ } 60^{\circ}\end{array}$ \\
\hline Acceleration \#3 & Yes, only @ 60 & Yes & Yes \\
\hline Acceleration \#4 & No data taken & No data taken & No data taken \\
\hline
\end{tabular}

approach channels are shown in Table 9. Note that the gate positions for the intermediate test cases for the flume configurations were different from those of the river models (Table 2).

The shaft load ratios for the open and flume configurations indicate that the maximum variation between the group is not over 10 percent. This conclusion disregards the biased responses obtained for the intermediate fixed gate position at $30 \mathrm{deg}$. No consistent variation is found for the reactions and acceleration ratios. The pressures for the open and flume configurations did not vary more than 15 percent of respective values. This extreme deviation in both cases occurred at a 30-deg fixed position. In general, the pressure distributions due to different channel conditions remain almost similar.

\section{Frequency-domain data comparison}

Frequency-domain comparison for open channel and 1:5 flume configuration experiment responses is performed to measure the effects of channel 


\section{Table 14 \\ Flat Gate Experimental Data Comparison for Three Different Flow Configurations (River Models)}

\begin{tabular}{|c|c|c|c|c|c|c|c|c|c|c|}
\hline \multirow[b]{3}{*}{$\begin{array}{l}\text { Angle } \\
\text { deg }\end{array}$} & \multirow{2}{*}{\multicolumn{2}{|c|}{$\begin{array}{c}\text { 1:5 Flume } \\
\text { Configuration, C }\end{array}$}} & \multicolumn{3}{|c|}{ Comparison of } & \multirow{2}{*}{\multicolumn{2}{|c|}{$\begin{array}{c}1: 5 \text { Flume } \\
\text { Configuration, C }\end{array}$}} & \multicolumn{3}{|c|}{ Comparison of } \\
\hline & & & & & & & & & & \\
\hline & Mean & $\begin{array}{l}\text { Std. } \\
\text { Dev. }\end{array}$ & $\begin{array}{l}\text { Ratio }^{1} \\
\text { ABB }\end{array}$ & $\begin{array}{l}\text { Ratio } \\
\text { A/C }\end{array}$ & $\begin{array}{l}\text { Ra- } \\
\text { tio } \\
B / C\end{array}$ & Mean & $\begin{array}{l}\text { Std. } \\
\text { Dev. }\end{array}$ & $\begin{array}{l}\text { Ratio } \\
\text { A/B }\end{array}$ & $\begin{array}{l}\text { Ratio } \\
\text { A/C }\end{array}$ & $\begin{array}{l}\text { Ratio } \\
\text { B/C }\end{array}$ \\
\hline
\end{tabular}

\section{Shaft Load}

\begin{tabular}{|r|r|r|r|r|r||r|r|r|r|r|}
\hline \hline-2 & 7.29 & 0.15 & 1.08 & 1.07 & 0.99 & 7.08 & 0.14 & 1.08 & 1.06 & 0.97 \\
\hline 27 & 17.03 & 0.46 & 1.02 & 0.95 & 0.93 & 15.72 & 0.30 & 1.09 & 1.02 & 0.94 \\
\hline 30 & 13.35 & 0.46 & 1.03 & 1.16 & 1.13 & 12.70 & 0.30 & 1.09 & 1.21 & 1.11 \\
\hline 50 & 11.24 & 0.23 & 1.04 & 1.02 & 0.98 & 10.13 & 0.16 & 1.08 & 1.07 & 0.99 \\
\hline 60 & 9.37 & 0.14 & 1.05 & 1.08 & 1.03 & 8.46 & 0.11 & 1.08 & 1.10 & 1.02 \\
\hline \hline
\end{tabular}

\begin{tabular}{||c|c|c|c|c|c||c|c|c|c|c||}
\hline \multicolumn{10}{|c||}{ Right Vertical Hinge } \\
\hline \hline-2 & -0.21 & 0.04 & -7.75 & 17.07 & -2.20 & 0.04 & 0.03 & 1.35 & 4.29 & 3.18 \\
\hline 27 & 1.64 & 0.58 & -0.41 & -0.48 & 1.18 & 1.39 & 0.14 & 0.95 & 1.64 & 1.72 \\
\hline 30 & 3.10 & 0.20 & -0.37 & -0.29 & 0.79 & 3.13 & 0.11 & 0.85 & 0.77 & 0.90 \\
\hline 50 & 3.19 & 0.09 & -0.23 & -0.18 & 0.81 & 2.68 & 0.05 & 0.92 & 1.00 & 1.09 \\
\hline 60 & 2.73 & 0.04 & -0.24 & -0.24 & 0.97 & 2.42 & 0.03 & 0.91 & 1.02 & 1.12 \\
\hline \hline
\end{tabular}

Right Horizontal Hinge

\begin{tabular}{||l|l|l|l|l|l||r|r|r|r|r|r|}
\hline \hline-2 & 0.29 & 0.08 & 1.73 & 1.33 & 0.77 & 0.43 & 0.06 & 0.67 & 0.35 & .53 \\
\hline 27 & -3.70 & 0.74 & 0.95 & 1.05 & 1.10 & -3.10 & 0.19 & 1.00 & 1.10 & 1.12 \\
\hline 30 & -3.04 & 0.11 & 1.00 & 1.10 & 1.10 & -2.80 & 0.07 & 0.94 & 1.20 & 1.23 \\
\hline 50 & -2.35 & 0.05 & 1.02 & 1.30 & 1.27 & -2.33 & 0.03 & 1.08 & 1.32 & 1.23 \\
\hline 60 & -1.83 & 0.03 & 0.91 & 1.36 & 1.50 & -1.81 & 0.02 & 1.10 & 1.51 & 1.36 \\
\hline \hline
\end{tabular}

\section{Left Vertical Hinge}

\begin{tabular}{|l|l|l|l|l|l||l|l|l|l|l|l||}
\hline \hline-2 & 0.16 & 0.04 & 1.77 & 1.96 & 1.11 & 0.45 & 0.03 & 1.47 & 0.57 & 0.39 \\
\hline 27 & 2.32 & 0.60 & 1.05 & 1.17 & 1.11 & 2.39 & 0.18 & 1.00 & 1.17 & 1.17 \\
\hline 30 & 2.99 & 0.21 & 1.05 & 1.13 & 1.08 & 2.88 & 0.09 & 1.03 & 1.07 & 1.03 \\
\hline 50 & 3.23 & 0.08 & 1.00 & 1.08 & 1.09 & 2.69 & 0.05 & 1.05 & 1.20 & 1.14 \\
\hline 60 & 3.52 & 0.04 & 1.04 & 1.07 & 1.03 & 3.20 & 0.03 & 1.02 & 1.05 & 1.03 \\
\hline \hline
\end{tabular}

Note: Legend: $\mathrm{A}=$ Flow test data for the open channel condition (shown in Table 9); $\mathrm{B}=$ Flow test data for the approach channel condition (shown in Table 9); $\mathbf{C}=$ Flow test data for the 1:5 flume configuration.

$$
\left[\text { Ratio }=\frac{[\mu+\sigma] \text { Open Channel }}{[\mu+\sigma] \text { Approach Channel }}\right]
$$




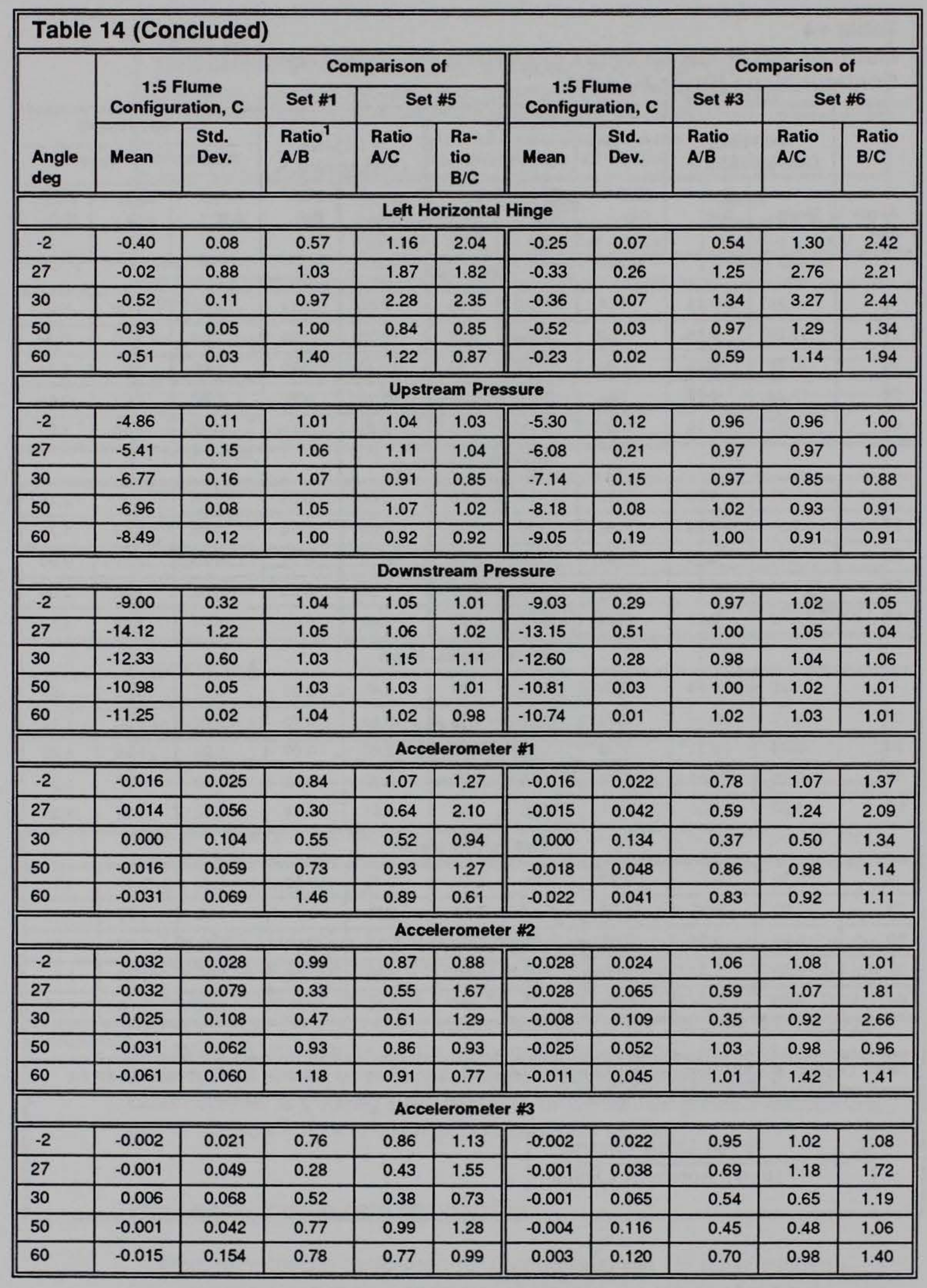


conditions on the dynamic responses of the gate. A study of these plots indicates that there is not an exact resemblance between the corresponding PSD's for the response channels, neither do they show any extreme difference among them. The upstream and downstream pressures, and the shaft-load PSD's, for example, agreed reasonably well with others for both test configurations. The acceleration PSD's for Set \#5 (for 50- and 60-deg positions) and all acceleration PSD's in Set \#6 did not show extreme differences. In general, like the approach channel experiment, the higher frequencies are more dominant in the 1:5 flume configuration spectra than that of the open channel. 


\section{Verification of Experimental Results and Estimation of Design Loads}

\section{Repeatability of Experimental Data}

Two sets of vibrational experimental results for the approach channel flow condition are compared at two different sampling rates. Data, Experiment A, are obtained from fixed gate positions, and data, Experiment B, are obtained for the operational gate while raised from -2 to $67 \mathrm{deg}$. Table 15 shows the repeatability of the data by comparing corresponding responses for the 1:25 flat gate for the approach channel flow condition. Ratios of Experiment B to Experiment $A$ are also shown in this table. No accelerometer data were recorded during Experiment B. Average response magnitudes for the fixed gate positions are obtained from Set \#7044 to 7052 for comparison Set \#1, and Set \#7002 to 7007 are used for comparison Set \#2. Experiment B sampled the flow data at a rate of 100 samples per sec instead of 2,000 samples per sec used for the data presented in this report. They also collected the data for $11.8 \mathrm{~min}$ while raising the gate from a -2 to $67-\mathrm{deg}$ position. Since the data presented in this report were recorded for fixed positions, it was required to read the magnitudes of the response channels for corresponding fixed positions from the continuous data taken by Experiment B.

As shown in the table, the shaft load and pressure gauge readings for both tests agreed reasonably well. The reaction forces, however, provided inconsistent results as expected. Considering the dynamic interaction of the gate while raising, if any, fluctuation of water levels during operation, and the random misalignment of hinges as stated in the limitation section of this report, a deviation of corresponding responses for both river conditions is quite obvious. Furthermore, Experiment A neglects the dynamic fluctuations of individual response by averaging the response about its mean. Most contributing factors for such deviation may be attributed to the maintenance of the water level during the operation; particularly, when the gate was lifted, the upstream water level did not remain constant. In the table, a negative ratio 


\section{Table 15 \\ A Comparison of 1:25 Flat Gate Response Data Recorded by HL and SL}

\begin{tabular}{|c|c|c|c|c|c|c|}
\hline & \multicolumn{3}{|c|}{ Comparison Set \#1 } & \multicolumn{3}{|c|}{ Comparison Set \#2 } \\
\hline & $\begin{array}{l}\text { Average } \\
\text { Value } \\
\text { Experi- } \\
\text { ment B } \\
\text { Ib }^{1}\end{array}$ & $\begin{array}{l}\text { Experi- } \\
\text { ment A } \\
\text { Ib }\end{array}$ & $\begin{array}{l}\text { B/A } \\
\text { Ratio }\end{array}$ & $\begin{array}{l}\text { Average } \\
\text { Value } \\
\text { Recorded } \\
\text { Experi- } \\
\text { ment B } \\
\mathrm{Ib}^{2}\end{array}$ & $\begin{array}{l}\text { Data } \\
\text { Recorded } \\
\text { Experi- } \\
\text { ment A } \\
\text { Ib }\end{array}$ & $\begin{array}{l}\text { Ratio } \\
\text { B/A }\end{array}$ \\
\hline \multicolumn{7}{|c|}{ Shaft Load } \\
\hline at degree -2 & 3.29 & 3.86 & 0.85 & 7.05 & 6.88 & 1.02 \\
\hline at degree 27 & 11.20 & 11.02 & 1.02 & 15.29 & 14.55 & 1.05 \\
\hline at degree 30 & 10.83 & 10.68 & 1.01 & 14.82 & 14.05 & 1.06 \\
\hline at degree 50 & 7.49 & 7.45 & 1.01 & 10.37 & 10.07 & 1.03 \\
\hline at degree 60 & 6.23 & 6.36 & 0.98 & 9.18 & 8.64 & 1.06 \\
\hline \multicolumn{7}{|c|}{ R/Vertical Hinges } \\
\hline at degree -2 & 0.04 & 0.12 & 0.37 & 0.26 & 0.20 & 1.32 \\
\hline at degree 27 & 2.58 & 2.01 & 1.29 & 2.01 & 2.47 & 0.81 \\
\hline at degree 30 & 2.50 & 2.14 & 1.17 & 2.28 & 2.80 & 0.82 \\
\hline at degree 50 & 2.27 & 2.17 & 1.05 & 2.66 & 2.93 & 0.91 \\
\hline at degree 60 & 2.41 & 2.02 & 1.19 & 2.71 & 2.72 & 1.00 \\
\hline \multicolumn{7}{|c|}{ R/Horizontal Hinges } \\
\hline at degree -2 & 0.10 & -0.04 & -2.62 & 0.33 & -0.18 & -1.86 \\
\hline at degree 27 & -2.63 & -3.20 & 0.82 & -3.91 & -3.46 & 1.13 \\
\hline at degree 30 & -2.56 & -3.05 & 0.84 & -3.83 & -3.49 & 1.10 \\
\hline at degree 50 & -2.58 & -2.70 & 0.95 & -3.55 & -2.85 & 1.25 \\
\hline at degree 60 & -2.09 & -2.24 & 0.93 & -3.21 & -2.47 & 1.30 \\
\hline \multicolumn{7}{|c|}{ LNertical Hinges } \\
\hline at degree -2 & -0.12 & 0.13 & -0.87 & 0.12 & 0.15 & 0.78 \\
\hline at degree 27 & 1.62 & 2.01 & 0.81 & 2.81 & 2.78 & 1.01 \\
\hline at degree 30 & 2.10 & 2.18 & 0.96 & 3.13 & 2.88 & 1.09 \\
\hline at degree 50 & 2.33 & 2.29 & 1.02 & 3.49 & 3.09 & 1.13 \\
\hline at degree 60 & 2.43 & 2.49 & 0.98 & 3.71 & 3.31 & 1.12 \\
\hline \multicolumn{7}{|c|}{ (Continued) } \\
\hline $\begin{array}{l}1 \text { An average } \\
\text { Tail Water el = } \\
2 \text { An average } \\
\text { Water el }=276\end{array}$ & $\begin{array}{l}\text { of Experir } \\
5 \mathrm{ft} \text {. } \\
\text { of Experi }\end{array}$ & $\begin{array}{l}\# 2272, \\
\# 2175,\end{array}$ & $\begin{array}{l}2274, \\
2177 .\end{array}$ & $\begin{array}{l}\text { and } 2276 \\
\text { and } 2179\end{array}$ & $\begin{array}{l}\text { ol el }=296 \\
\text { ol el }=299\end{array}$ & ft, \\
\hline
\end{tabular}




\begin{tabular}{|c|c|c|c|c|c|c|}
\hline \multicolumn{7}{|c|}{ Table 15 (Concluded) } \\
\hline & $\begin{array}{l}\text { Average } \\
\text { Value } \\
\text { Experi- } \\
\text { ment B } \\
\mathrm{Ib}^{1}\end{array}$ & $\begin{array}{l}\text { Experi- } \\
\text { ment A } \\
\text { Ib }\end{array}$ & $\begin{array}{l}\text { B/A } \\
\text { Ratio }\end{array}$ & $\begin{array}{l}\text { Average } \\
\text { Value } \\
\text { Recorded } \\
\text { Experi- } \\
\text { ment B } \\
\text { Ib }^{2}\end{array}$ & $\begin{array}{l}\text { Data } \\
\text { Recorded } \\
\text { Experi- } \\
\text { ment A } \\
\text { Ib }\end{array}$ & $\begin{array}{l}\text { Ratio } \\
\text { B/A }\end{array}$ \\
\hline \multicolumn{7}{|c|}{ LHorizontal Hinges } \\
\hline at degree -2 & -0.41 & -0.20 & 2.10 & -0.78 & -0.68 & 1.14 \\
\hline at degree 27 & -0.43 & -0.02 & 18.79 & -0.87 & -0.98 & 0.88 \\
\hline at degree 30 & -0.43 & 0.01 & -60.95 & -0.73 & -0.91 & 0.80 \\
\hline at degree 50 & -0.43 & -0.19 & 2.32 & -0.42 & -0.70 & 0.59 \\
\hline at degree 60 & -0.09 & 0.02 & -4.98 & -0.09 & -0.46 & 0.19 \\
\hline \multicolumn{7}{|c|}{ U/S Pressure } \\
\hline at degree -2 & -5.85 & -6.50 & 0.90 & -5.28 & -5.36 & 0.98 \\
\hline at degree 27 & -7.16 & -8.04 & 0.89 & -6.24 & -6.13 & 1.02 \\
\hline at degree 30 & -7.32 & -7.88 & 0.93 & -6.37 & -6.28 & 1.02 \\
\hline at degree 50 & -8.53 & -9.67 & 0.88 & -7.63 & -7.40 & 1.03 \\
\hline at degree 60 & -9.29 & -10.57 & 0.88 & -8.32 & -8.29 & 1.00 \\
\hline \multicolumn{7}{|c|}{ D/S Pressure } \\
\hline at degree -2 & -7.51 & -7.92 & 0.95 & -9.46 & -9.54 & 0.99 \\
\hline at degree 27 & -12.89 & -12.52 & 1.03 & -14.66 & -13.53 & 1.08 \\
\hline at degree 30 & -12.42 & -12.04 & 1.03 & -13.98 & -13.37 & 1.05 \\
\hline at degree 50 & -10.48 & -10.17 & 1.03 & -11.92 & -10.97 & 1.09 \\
\hline at degree 60 & -10.29 & -10.45 & 0.99 & -11.48 & -10.88 & 1.06 \\
\hline
\end{tabular}

indicates a polarity change which might have resulted due to the low sensitivity and/or a drift in the recorded channel.

\section{Design Load}

The peak values of the reaction forces for the 1:25 flat gate and curved gate for a head difference of $21 \mathrm{ft}$ (Pool el - $300 \mathrm{ft}$, Tail Water el - $279 \mathrm{ft}$ ) are listed in the table shown below. The time-domain data for Experiment \#701719 for the approach channel and 6013-15 for the open channel were used to obtain these peak values. Note that the peak loads shown in the table did not occur at the same operating position. These are the absolute maximum magnitudes for the respective channels, while the gate was raised from -2 to $67 \mathrm{deg}$. 
Most of these largest values, however, occurred in a position when the gate was raised from a 22- to 27-deg position. The critical orientation of the gate that caused the highest shaft load (Peak Response) was identified by scanning the shaft load responses for the entire operating cycle (-2- to 67-deg). Also, shown in this table are the largest peak estimates using the Type I extremevalue distributions (EVD) (Wirsching and Ortiz 1993). Experiment statistics of Experiment \#7097 (1:5 flume configuration, three-gate gap with a head difference of $21 \mathrm{ft}$,) were used to compute the "design" values at a 99.99-percent level for the random variables shown in the table. Estimated design loads used for designing the prototype gate are also listed in this table.

A typical experiment gate response for a head difference of $22.5 \mathrm{ft}$ and a three-gate gap configuration is shown in Figure 31. As shown in the figure, the maximum shaft load occurred at an angle of about $22 \mathrm{deg}$. This angular position of the gate was situated just prior to the formation of air pockets beneath the gate surface. At and after the initiation of such an air gap, the downstream water turbulence forced the gate to vibrate in a low-frequency mode as shown in Figure 31. The fluctuating downstream pressure load occurred during the rise of the gate from 20 to $27 \mathrm{deg}$. A negative downstream pressure indicates a suction on the back of the gate. Vertical reactions increased until the top edge of the gate coincided with the upstream water level such that the overflowing of water over the top of the gate ceased thereafter. As a result of fixed static water depth at the upstream face of the gate, the vertical reactions remained almost steady for the rest of the operating cycle. The shaft load, however, decreased due to its geometrical configuration (angle subtended by the shaft with respect to gate longitudinal axis decreased as the gate was lifted) after resisting maximum operating load. The upstream pressure dropped as the gate was lifted from -2 to $67 \mathrm{deg}$, while the downstream pressure fluctuated during the turbulence of the flow at the onset of air gaps undemeath the wickets. The downstream pressure remained constant after the complete separation of air from the flow at the downstream side of the gate.

Typical responses corresponding to the maximum shaft load for the 1:25 flat gate at a 22-deg position are shown in Figure 32 for Experiment \#7097. As shown in the plots, the time data were recorded for $30 \mathrm{sec}$ for the fixed gate position. Respective auto-spectra for the time-domain responses are shown on the right-hand side of each plot. As shown in Figure 32, the relative amplifications (a ratio of maximum to the average values) of hinge reactions about their respective means are greater than that of the shaft load. Because of the smaller magnitudes of hinge reactions, the base hinge was more susceptible to the low driving flow-induced motion. Note that the statistics for Experiment \#7097 were used to obtain the largest peak estimates using the Type I EVD method.

A conversion factor of $25^{3}$ is used to determine the equivalent 1:25 flat gate design load from the prototype estimate used by the gate designer. Since the pressure gauges were zeroed at $-2 \mathrm{deg}$, the actual pressure for the gauges were obtained by subtracting the initial static head from the gauge reading as 
shown in the table. The missing data for the design loads were not available during the writing of this report.

In Table 16, an assumed maximum static load for the 1:25 flat gate are also presented. The maximum load is computed based on the hydrostatic pressure distribution (Figure 33) on the upstream face of the gate. A surcharge load on the top of the gate, due to overflowing water head, is considered to compute the reaction forces. Thus the calculated load is a conservative estimate of the static load, since the overflowing water depth may be less than the assumed one. The assumed depth equals the difference in water head between the tip of the gate to the upstream water level. Since the depth of water at the gate tip is not known, it is assumed that a constant surcharge load acts on the tip of the gate prior to the formation of the air-gap separation. This separation took place at an angle of about $30 \mathrm{deg}$ as mentioned before.

\begin{tabular}{|c|c|c|c|c|c|c|}
\hline \multicolumn{7}{|c|}{$\begin{array}{l}\text { Table } 16 \\
\text { Design Load Verification Table }\end{array}$} \\
\hline $\begin{array}{l}\text { Response } \\
\text { Channel }\end{array}$ & $\begin{array}{l}\text { 1:25 Flat Gate } \\
\text { Peak Response } \\
\text { for the Approach } \\
\text { Channel } \\
\text { Condition }\end{array}$ & $\begin{array}{l}\text { 1:25 Flat Gate Peak } \\
\text { Response for the } \\
\text { Open Channel } \\
\text { Condition }\end{array}$ & $\begin{array}{l}\text { Design } \\
\text { Load Esti- } \\
\text { mates, } \\
\text { Type I } \\
\text { EVD }\end{array}$ & $\begin{array}{l}\text { Design } \\
\text { Load } \\
\text { Used by } \\
\text { the } \\
\text { Louis- } \\
\text { ville Dis- } \\
\text { trict }\end{array}$ & $\begin{array}{l}1: 25 \\
\text { Curved } \\
\text { Gate } \\
\text { Experi- } \\
\text { ment } \\
\text { Results for } \\
\text { the Open } \\
\text { Channel } \\
\text { Flow } \\
\text { (Peak) }\end{array}$ & $\begin{array}{l}\text { Static } \\
\text { Assumed } \\
\text { Maximum } \\
\text { Load }\end{array}$ \\
\hline $\begin{array}{l}\text { Shaft load } \\
\text { lb }\end{array}$ & 18.391 & 18.2 & 19.855 & & 38.585 & 17.91 \\
\hline $\begin{array}{l}\text { Maximum } \\
\text { vertical } \\
\text { reaction, lb }\end{array}$ & 4.958 on each & 5.05 & $\begin{array}{l}4.252 \text { on } \\
\text { each }\end{array}$ & $\begin{array}{l}11.264 \\
\text { on each }\end{array}$ & $\begin{array}{l}8.5 \text { on } \\
\text { each }\end{array}$ & 1.55 total \\
\hline $\begin{array}{l}\text { Maximum } \\
\text { horizontal } \\
\text { reaction, Ib }\end{array}$ & 5.308 on each & 4.63 on each & $\begin{array}{l}5.514 \text { on } \\
\text { each }\end{array}$ & $\begin{array}{l}7.232 \text { on } \\
\text { each }\end{array}$ & $\begin{array}{l}5.79 \text { on } \\
\text { each }\end{array}$ & 1.67 total \\
\hline $\begin{array}{l}\text { Maximum } \\
\text { accelera- } \\
\text { tion, } g\end{array}$ & 1.21 & 1.881 & 0.4469 & & 3.69 & \\
\hline $\begin{array}{l}\text { Maximum } \\
\text { upstream } \\
\text { pressure } \\
\text { in. of water }\end{array}$ & $\begin{array}{l}(-4.72+11.85)= \\
7.13\end{array}$ & $(-4.75+11.85)=7.10$ & 6.34 & & & \\
\hline $\begin{array}{l}\text { Maximum } \\
\text { down- } \\
\text { stream } \\
\text { pressure } \\
\text { in. of water }\end{array}$ & $\begin{array}{l}(-6.91+12.21)= \\
5.30\end{array}$ & $\begin{array}{l}(-8.96+12.21)= \\
3.25\end{array}$ & 4.846 & & & \\
\hline
\end{tabular}


A study of this data indicates that a substantial amplification of hinge reactions occurred due to the flow-induced vibration of the gate. The shaft load amplification in relation to the maximum static load, however, was affected very little due to the flow-induced vibration. Note that the angular positions of the gate for the 1:25 experimental results and the static maximum load configuration were not identical. 


\section{Conclusions}

The modeling of the approach channel for the prototype facility at Smithland resulted in minor changes to the dynamic pressures, accelerations, and shaft loads for the latest flat wicket gate design. As seen in Table 9, the shaft loads and the dynamic pressures only deviated 9 percent. Simulated shaft loads and pressures, in most of the cases, were smaller for the approach channel than that of the open channel. The average magnitude of the shaft loads were higher and the dispersion about the mean (standard deviation) was smaller for the open channel experiments. Accelerometers for the approach channel experiments consistently provided higher responses than that of the open channel. This difference was due to the fluctuations of the flow during the approach channel flow experiments.

The differences in the hinge reactions varied randomly between the open channel and the approach channel experiments. The inconsistency in the measurement of the hinge reactions is a result from slight misalignment and rotational movement of the clevis attachment to the shaft. These misalignments can be expected in structural models at a 1:25 scale. The 1:25 model does not result in a sufficiently large structure to properly scale the tolerances at the hinge supports.

A comparison of the PSDs for both flow conditions demonstrated that the frequency contents for the approach channel differed from that of the open channel. Particularly during turbulent regions while raising the gates. Higher frequencies were more dominant in the approach channel flow than in the approach channel condition. Therefore, the simulated approach channel results in dynamics loads which represents a conservative load condition.

The curved gate consistently responded with higher shaft loads, pressures, and reaction forces than the flat gate for identical gate positions and flow conditions. The measured structural responses for the curve gate were widely dispersed about their mean values particularly at intermediate positions during the raising of the gate indicating more structural dynamic response than the flat gate. A shape change from a curved gate to the flat gate obviously changed the natural dynamic characteristics of the gate. The torsional frequency for the flat gate was smaller than that of the curved gate. The first bending frequency, however, was higher for the flat gate. This increased dynamic response 
indicates a greater potential for flow induced vibrations for the curved gate than the flat gate design.

As expected, the dry mode shapes differed from the flow-excited mode shapes of the gate. The added mass effects of the hydrodynamic loads results in a shifting of the natural mode shapes. The measurement of the wet model shapes are critical for the development of analytical models to reproduce the correct hydrodynamic loads.

Similar to the approach channel experimental results, the 1:5 flume configuration differed from the open channel results. The open channel experiments provided a maximum of 16 percent higher shaft loads than the $1: 5$ flume configuration only at $30-\mathrm{deg}$ intermediate position. All other positions for the open channel had shaft loads less than 8 percent of the corresponding flume configurations. In general, the downstream and upstream pressure loads agreed well for both cases. The 1:5 flume configuration showed higher fluctuation about the means (a maximum of 74 percent for the reaction forces). Accelerations also deviated more about the mean for the 1:5 flume configurations. In general, like the approach channel experiment, the higher frequencies were more dominant in the 1:5 flume configuration than the other.

The estimated prototype design loads were more conservative than that of the experimentally predicted values obtained from the 1:25 flow-induced vibration experiment for a head difference of $21 \mathrm{ft}$. The relative amplifications ( a ratio of maximum-to-average values) of hinge reactions about their respective means were greater than that of the shaft load. A higher fluctuation occurred due to the occurrence of low magnitude base-hinge reactions during the experiments. As a result of low magnitudes at the base hinges, they were more susceptible to the low driving flow-induced motion than the shaft reaction.

Considering the random nature of the flow, fluctuation of water levels, and mechanical, thermal, and electrical drifting during the experiments, a deviation of corresponding responses for river conditions compared in this report is obvious. The deviation in the corresponding responses presented here, thus, measures such a random error in addition to the actual flow-induced vibrational response changes due to different river conditions. 


\section{References}

Elder, R. A. (1992). "Review of the 1:25 Scale Hydraulic Model Olmsted Wicket Dam," Consulting Hydraulic Engineers, Cincinnati, $\mathrm{OH}$.

Lance, G. R. (1992). "Developing an operating plan for Olmsted Locks and Dam." ASCE Fourth Water Resources Operations Management Workshop, Mobile, AL.

March, T. A., and Elder, R. A. (1992). Review of the 1:25 scale hydraulic model Olmsted Wicket Dam, Report submitted to the U.S. Army Corps of Engineers, Ohio River Division, Cincinnati, $\mathrm{OH}$.

Novak, P., and Cabelka, J. (1981). "Models in hydraulic engineering physical principles and design applications," Pitman Advanced Publishing Program, Boston, MA.

Simpson, M., and Solomon, A. (1992). "Summary report: Olmsted Wicket Dam Project, review of 1/25 Scale Model," Structural Dynamics Research Corporation, Milford, $\mathrm{OH}$.

Snowberger, R. B. (1995). "Olmsted prototype at Smithland, Kentucky." Proceedings of the Corps of Engineers Structural Engineering Conference. San Antonio, TX.

Soast, A. (1994). "Record size lock and dam project gets a soggy launch as rains swell the lower Ohio River for months," Engineering News Record, 24-26.

Structural Dynamics Research Corporation. (1994). IDEAS Master Series, Version 1.3, 2000 Eastman Drive, Milford, OH.

The Math Works, Inc. (1993). MATLAB, 24 Prime Parkway, Natick, MA.

U.S. Army Engineer Waterways Experiment Station. (1991a,b). "Data report, model study of Olmsted Navigational pass," versions a and b, Vicksburg, MS. 
U.S. Army Engineer Waterways Experiment Station. (1994). "Flow-induced vibration analysis of 1:25 flat wicket gate," video report, Vicksburg, MS.

Wirsching, P. H., and Oriz, K. (1993). "Reliability methods in mechanical and structural design." 14th Annual Seminar and Workshop. The University of Arizona, Tucson, AZ. 


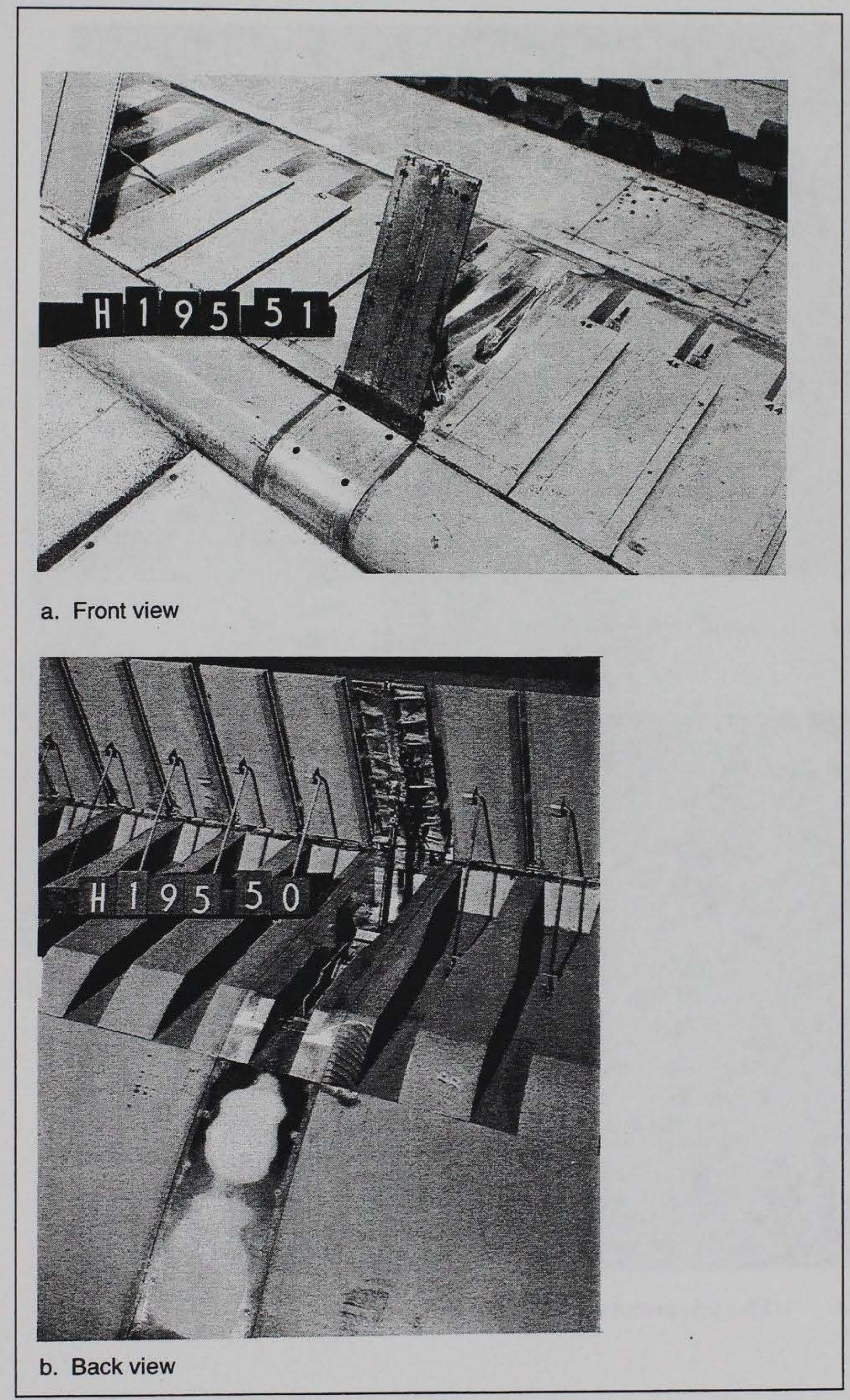

Figure 1. 1:25-scale flat wicket gate model 


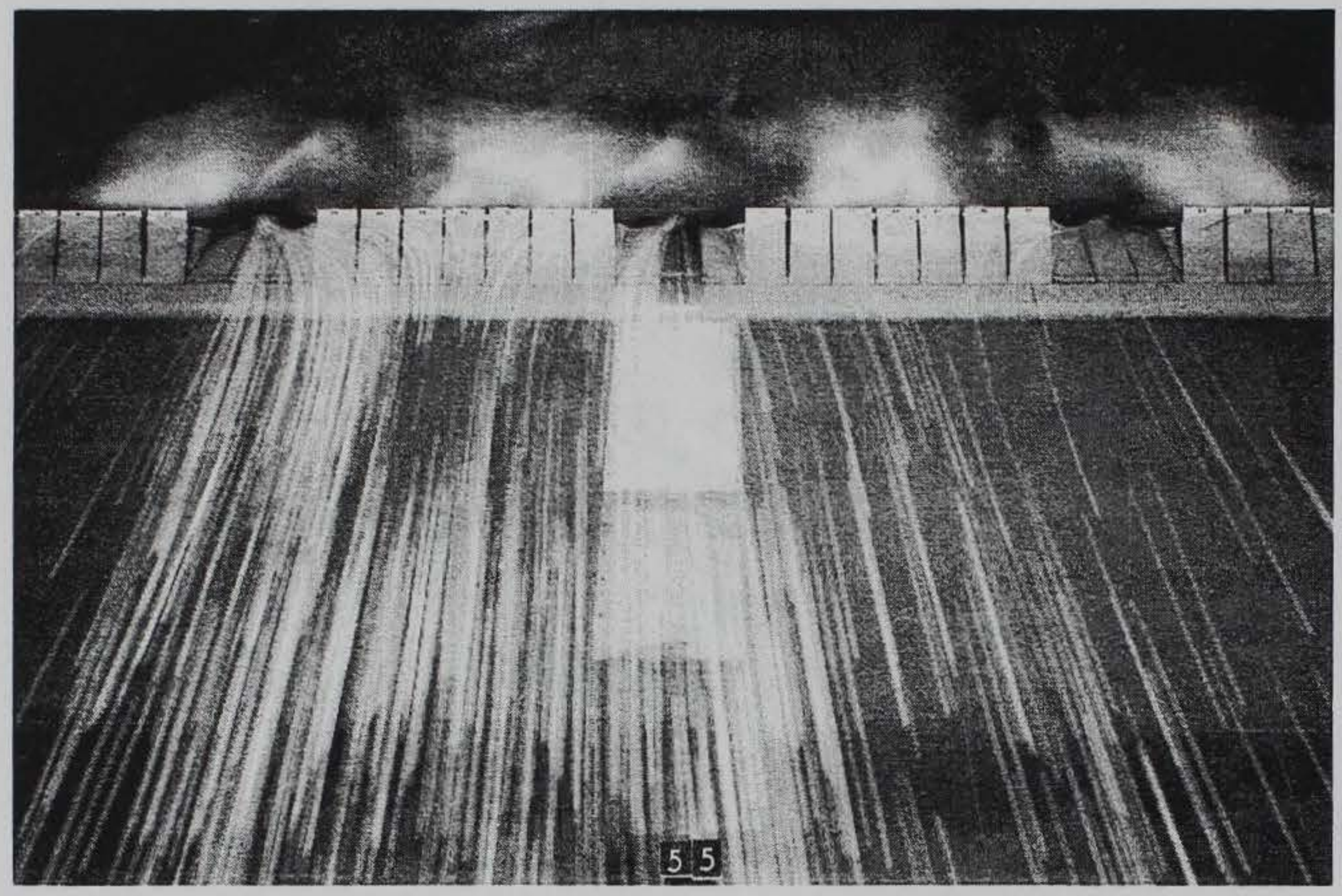

Figure 2. Olmsted navigational pass

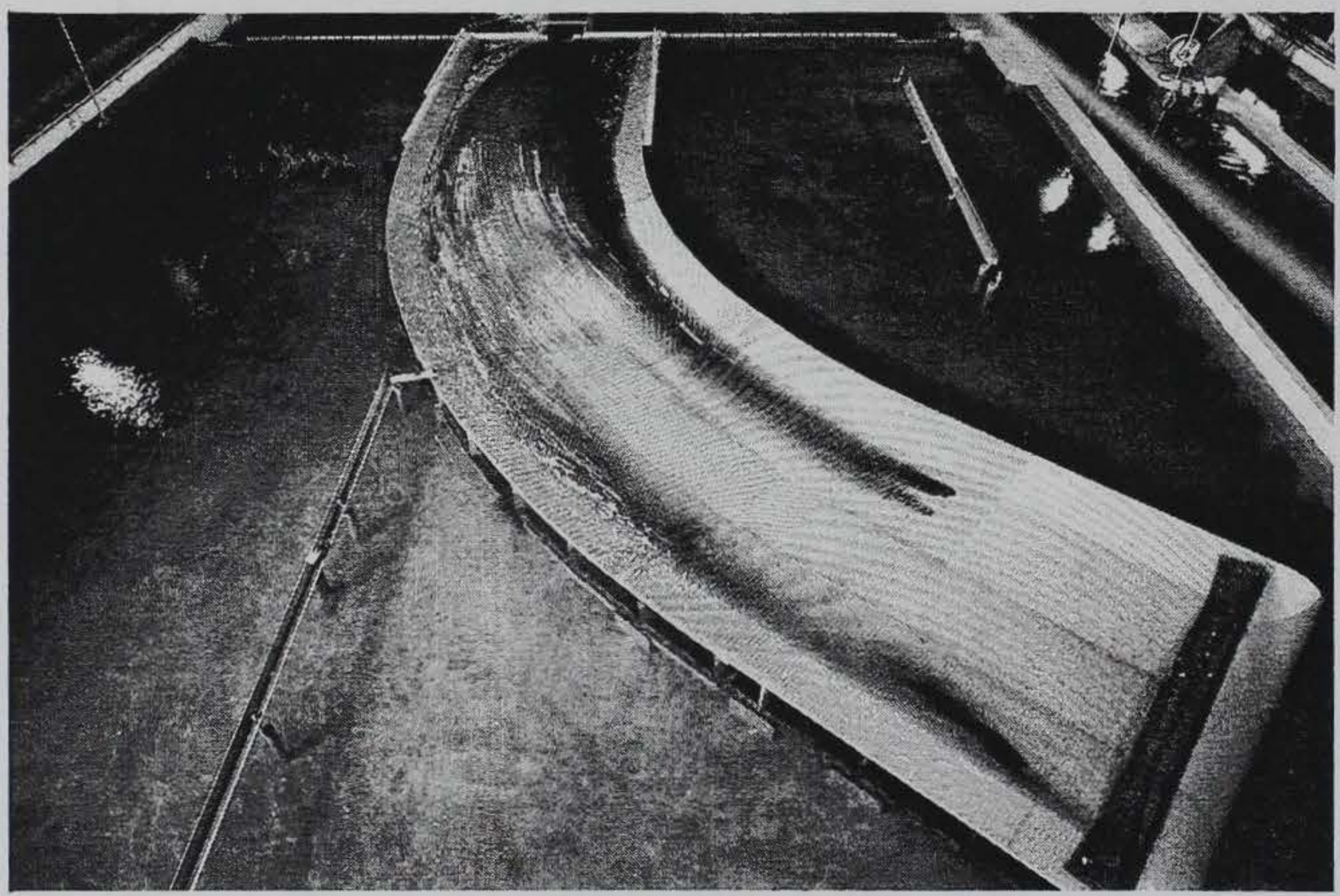

Figure 3. 1:25-scale prototype test facility 


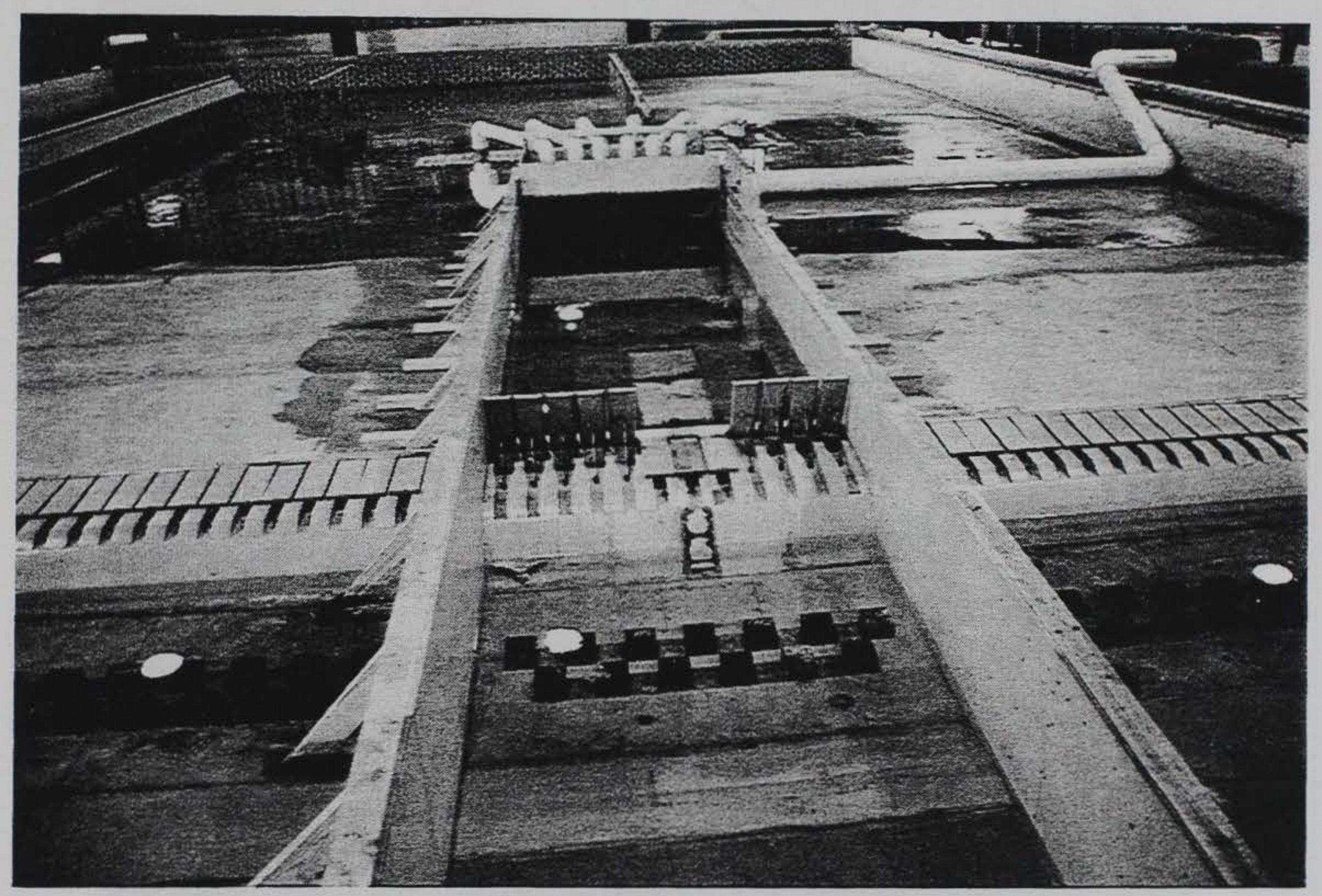

Figure 4. 1:5 Flume configuration placed in the 1:25 model 


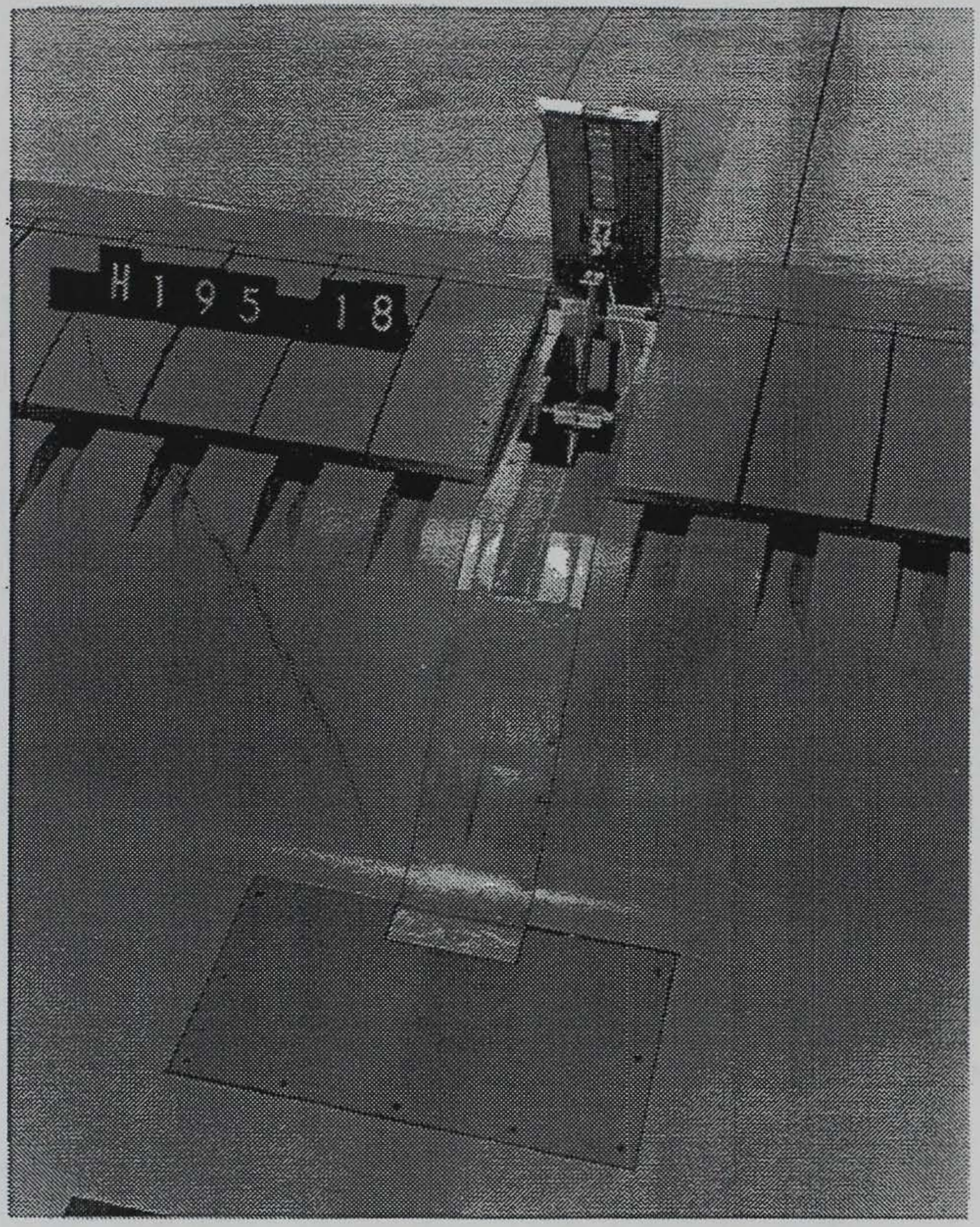

Figure 5. 1:25 curved gate 


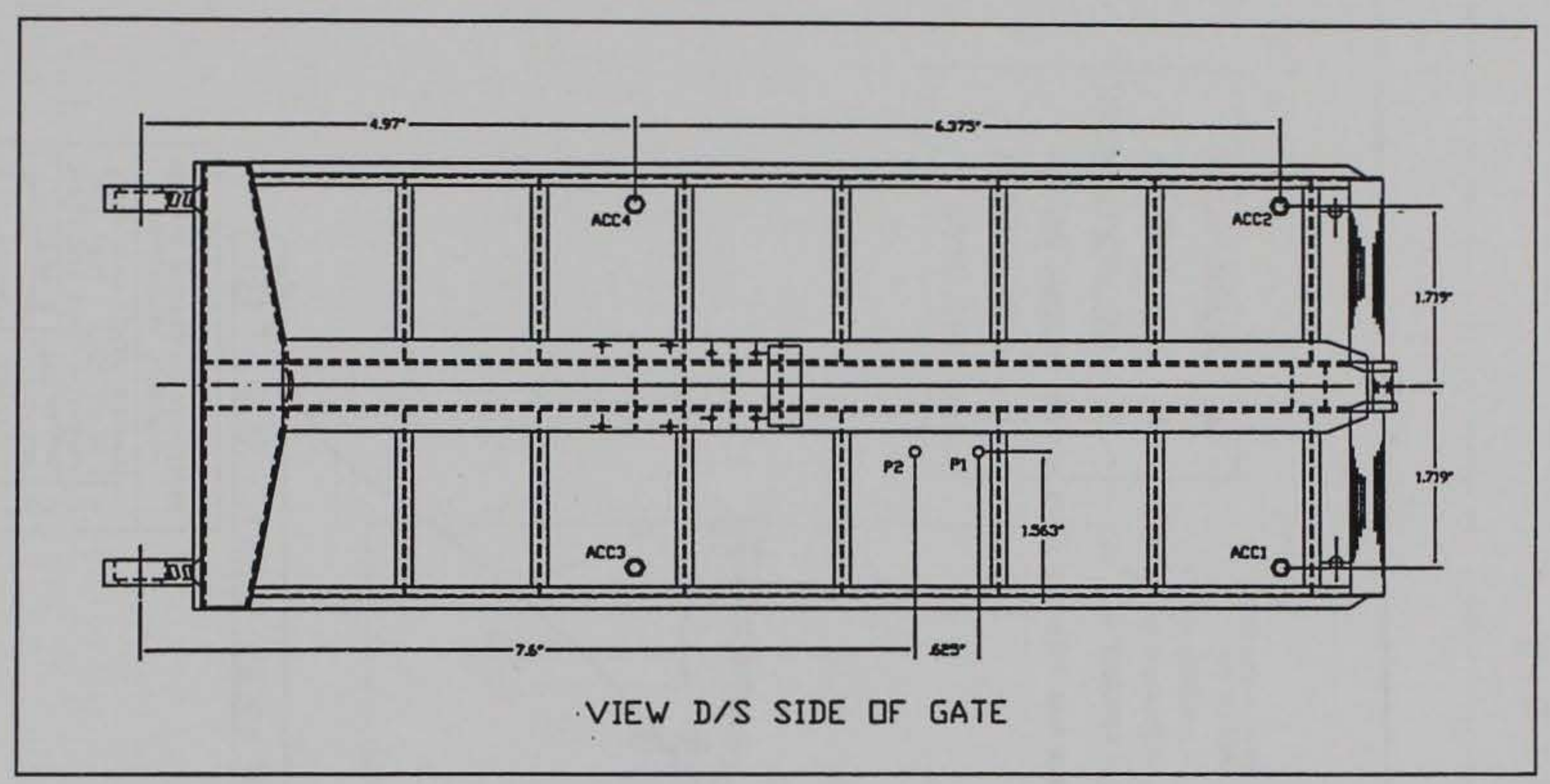

Figure 6. Location of instruments in the flat gate

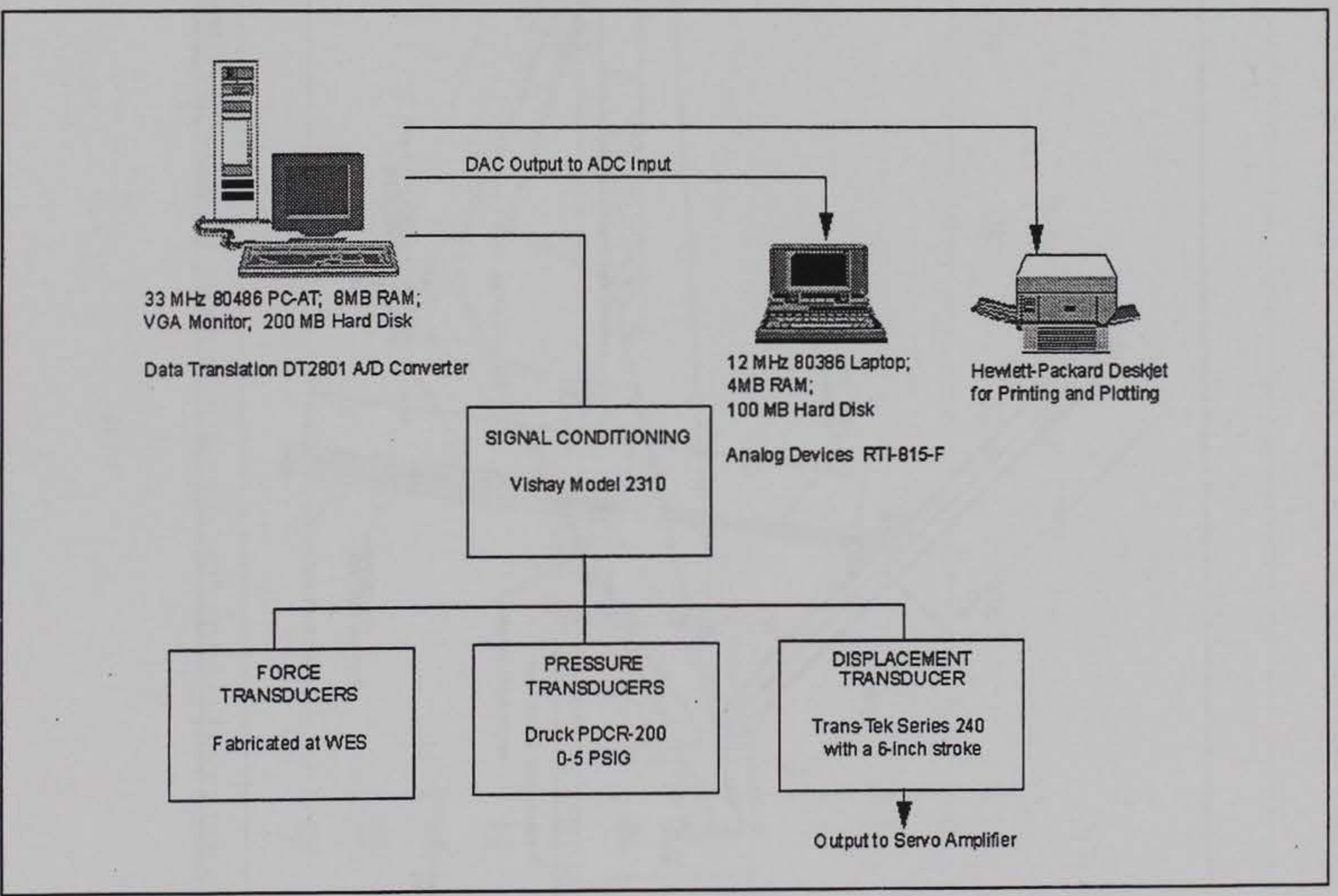

Figure 7. Schematic of data acquisition and analysis system 


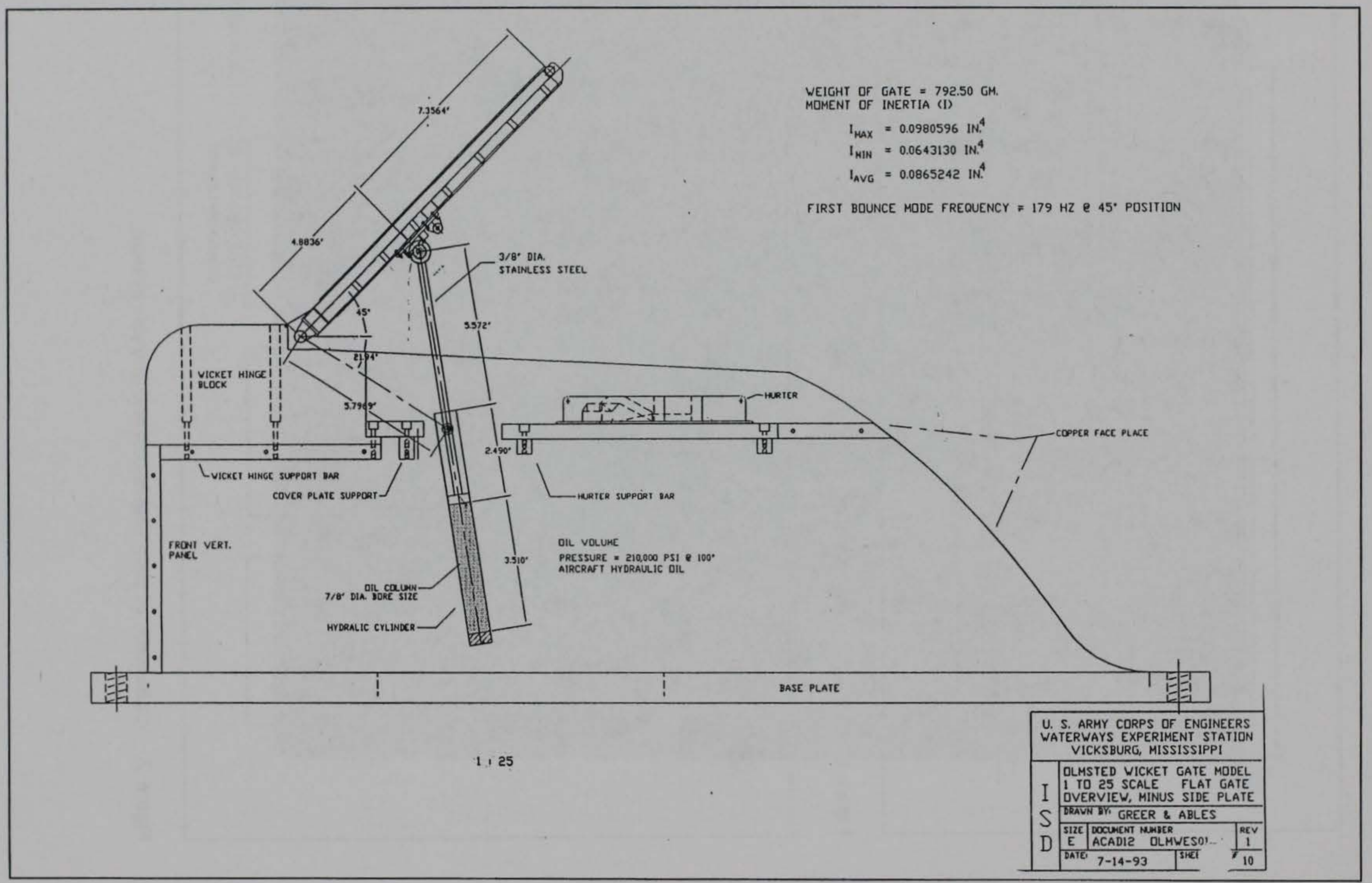

Figure 8. Schematic dimensions of the 1:25 flat gate model 


\section{Shaft Load Readings (with and without Approach Channel) P.E. $=300$ ', T.W.E. $=279$ '}

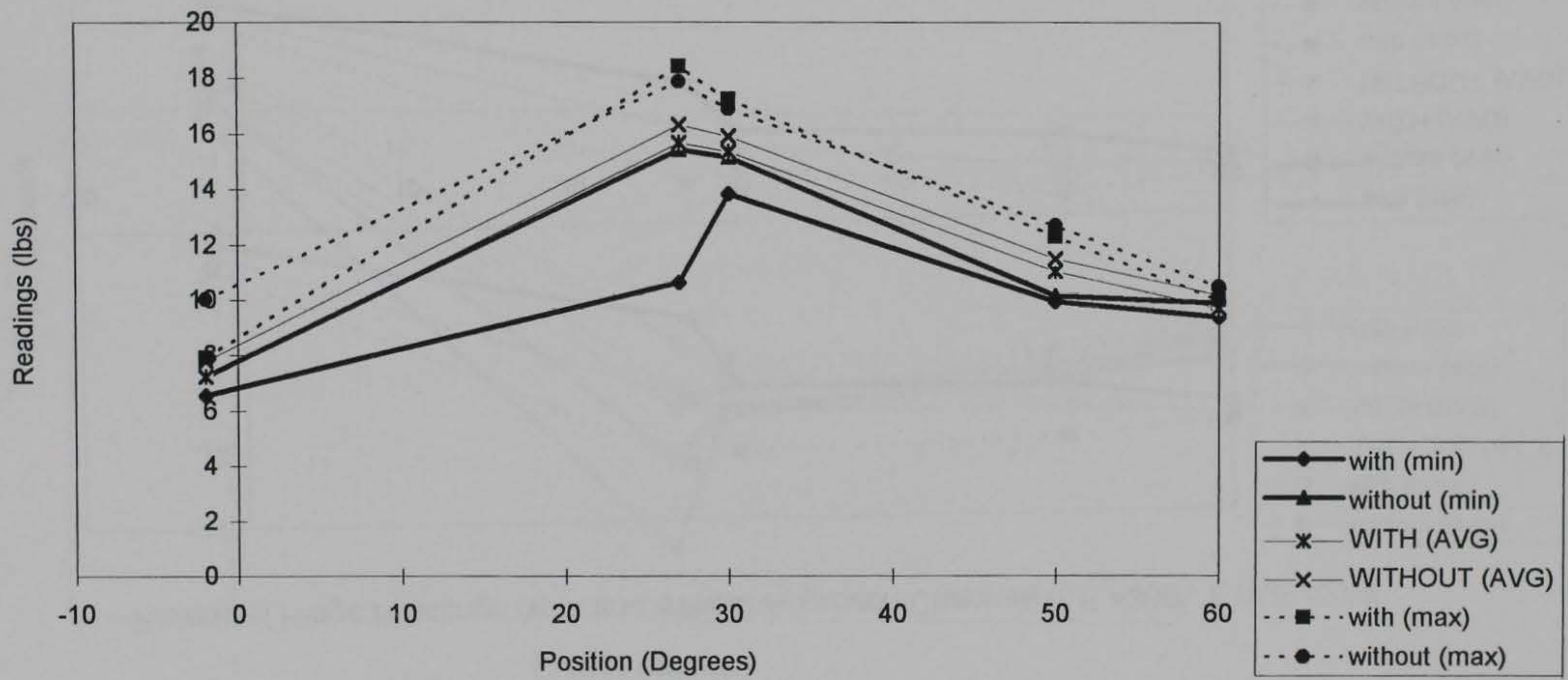

Figure 9. Time-domain data comparison for test set \#1. a. Shaft load readings (Sheet 1 of 10) 
R/Nertical Hinge Readings (with and without Approach Channel) P.E. $=300$ ', T.W.E. $=279$ '

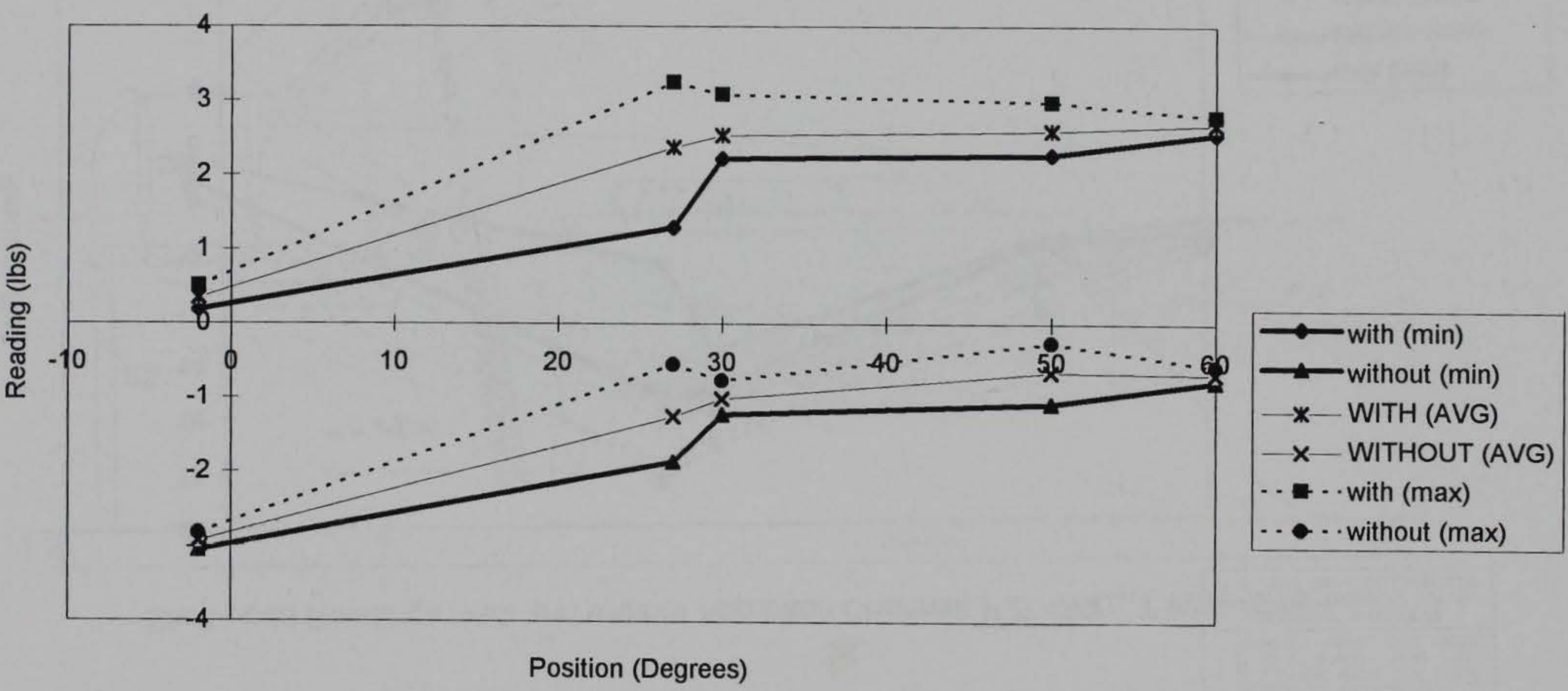

Figure $9 \mathrm{~b}$. Right/vertical hinge readings (Sheet 2 of 10 ) 
R/Horizontal Hinge Readings (with and without Approach Channel) P.E. $=300$ ', T.W.E. $=279$ '

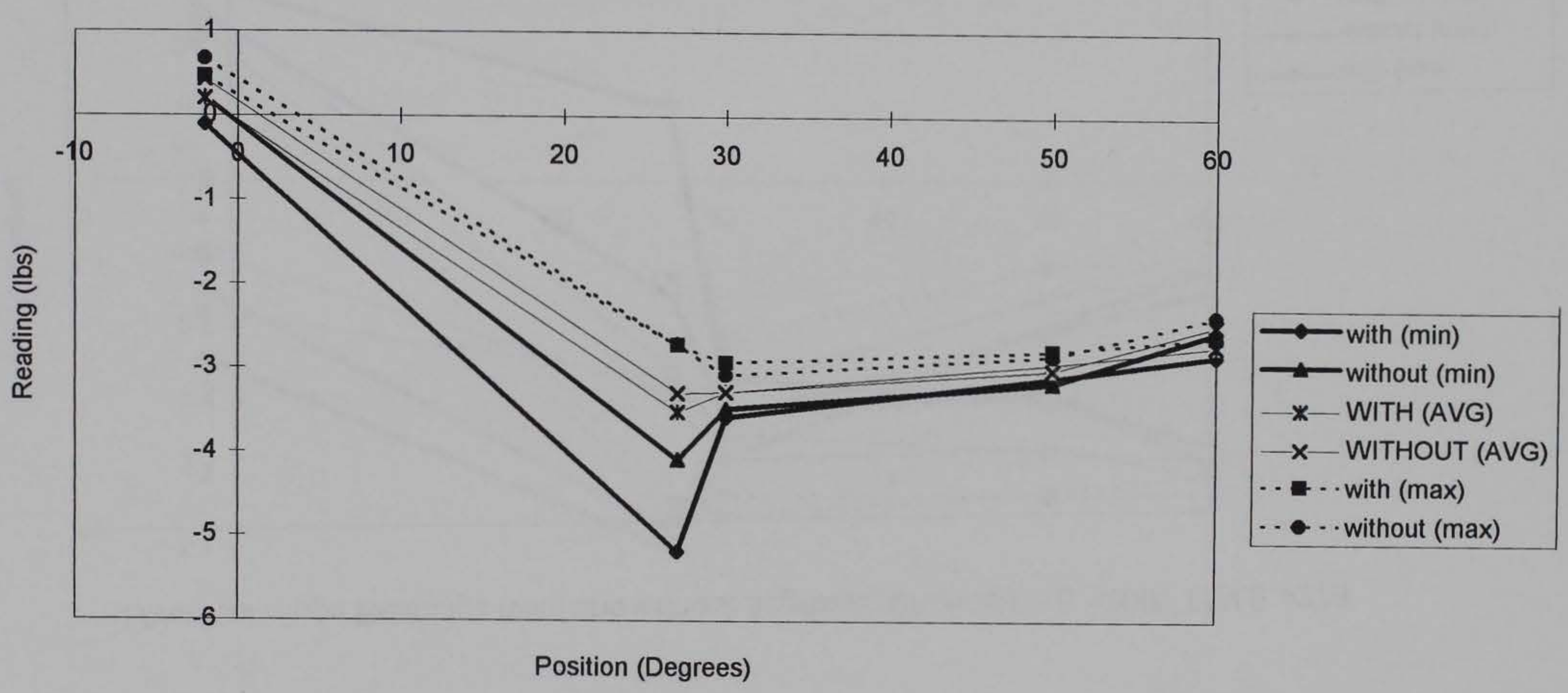

Figure 9c. Right/horizontal hinge readings (Sheet 3 of 10) 
L/Nertical Hinge Readings (with and without Approach Channel) P.E. $=300^{\prime}$, T.W.E. $=279^{\prime}$

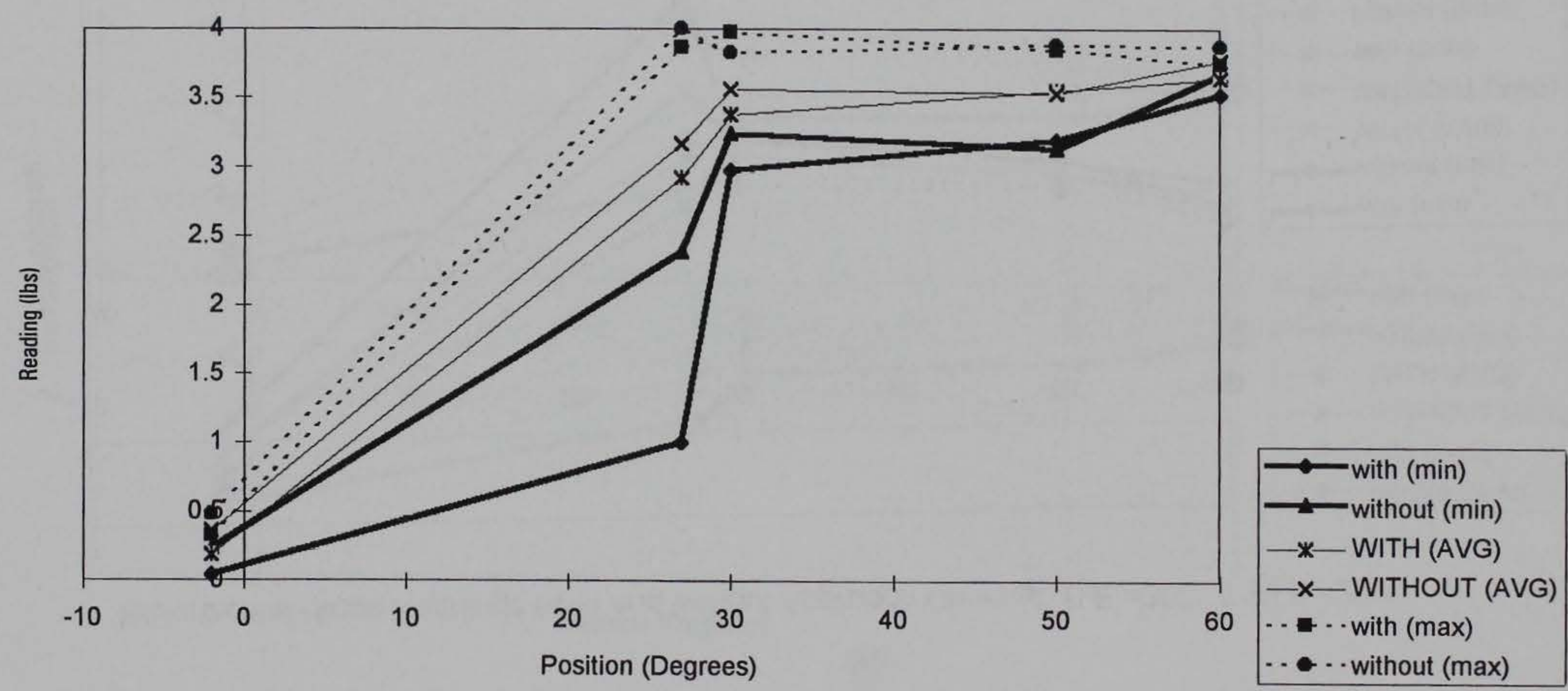

Figure 9d. Left/vertical hinge readings (Sheet 4 of 10) 
L/Horizontal Hinge Readings (with and without Approach Channel) P.E. $=300$ ', T.W.E. $=279$ '

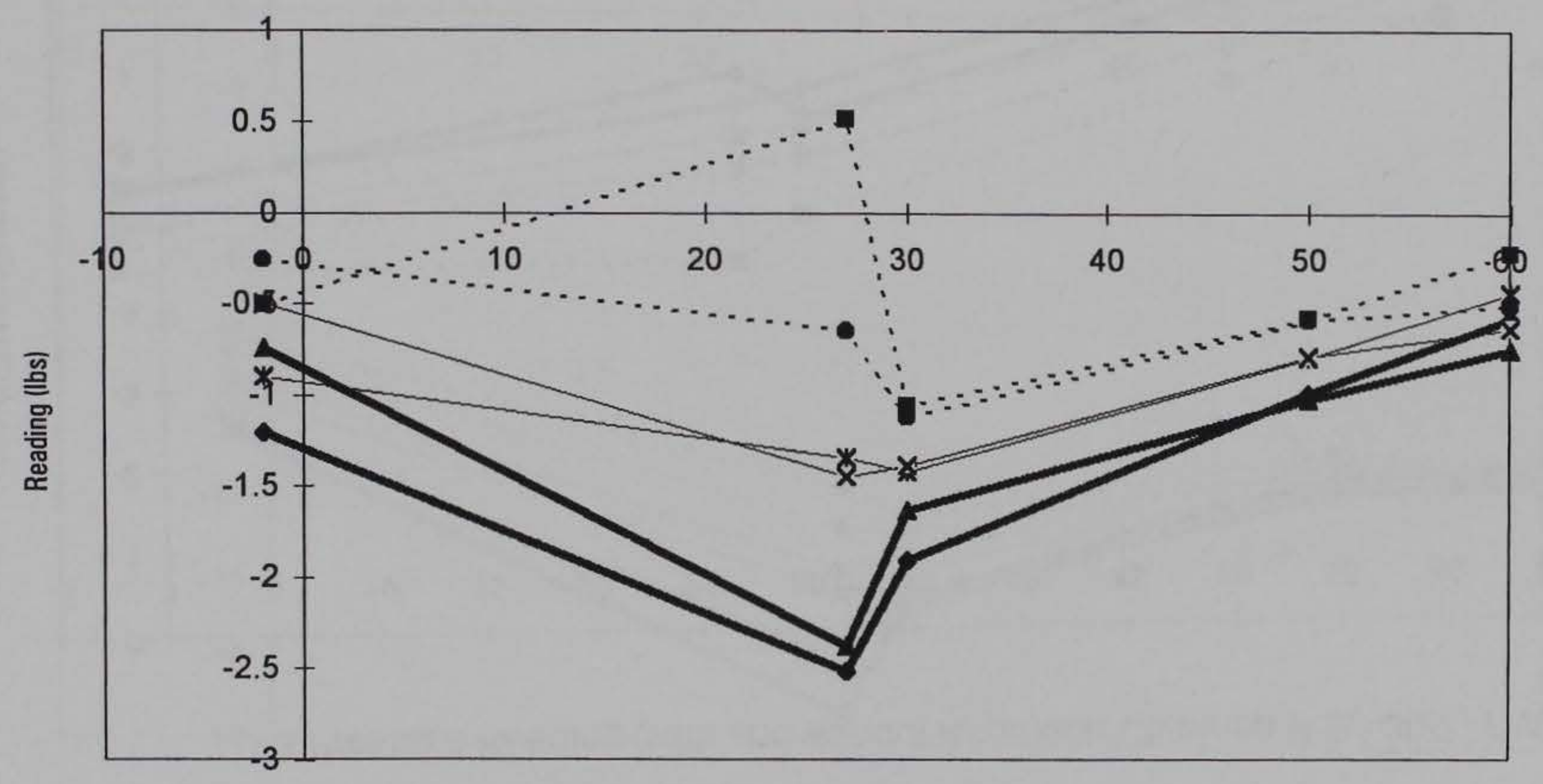

Position (Degrees)

Figure 9e. Left/horizontal hinge readings (Sheet 5 of 10) 


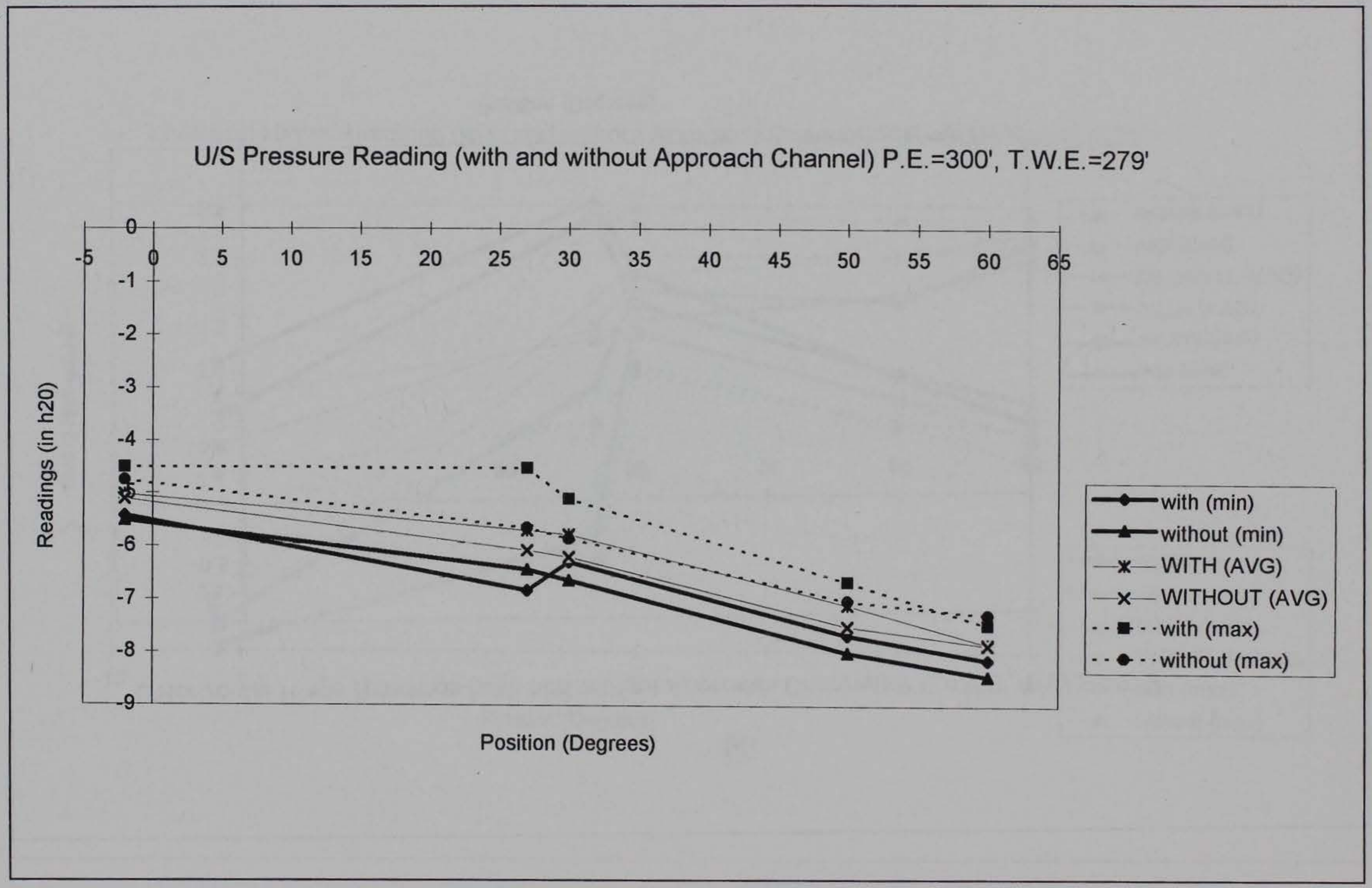

Figure 9f. Upstream pressure reading (Sheet 6 of 10) 


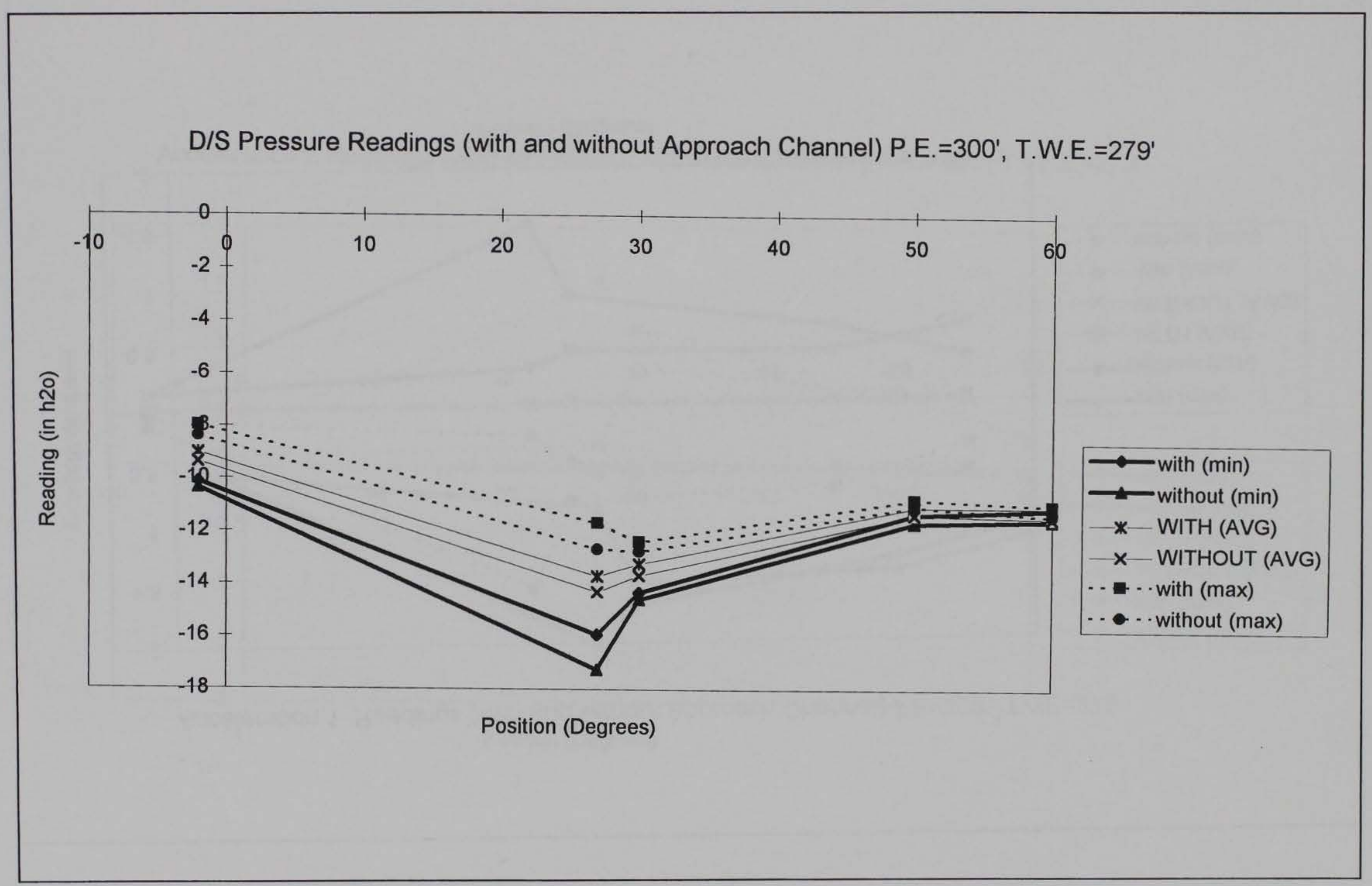

Figure 9g. Downstream pressure readings (Sheet 7 of 10) 
Acceleration 1 Readings (with and without Approach Channel) PE=300', TWE=279'

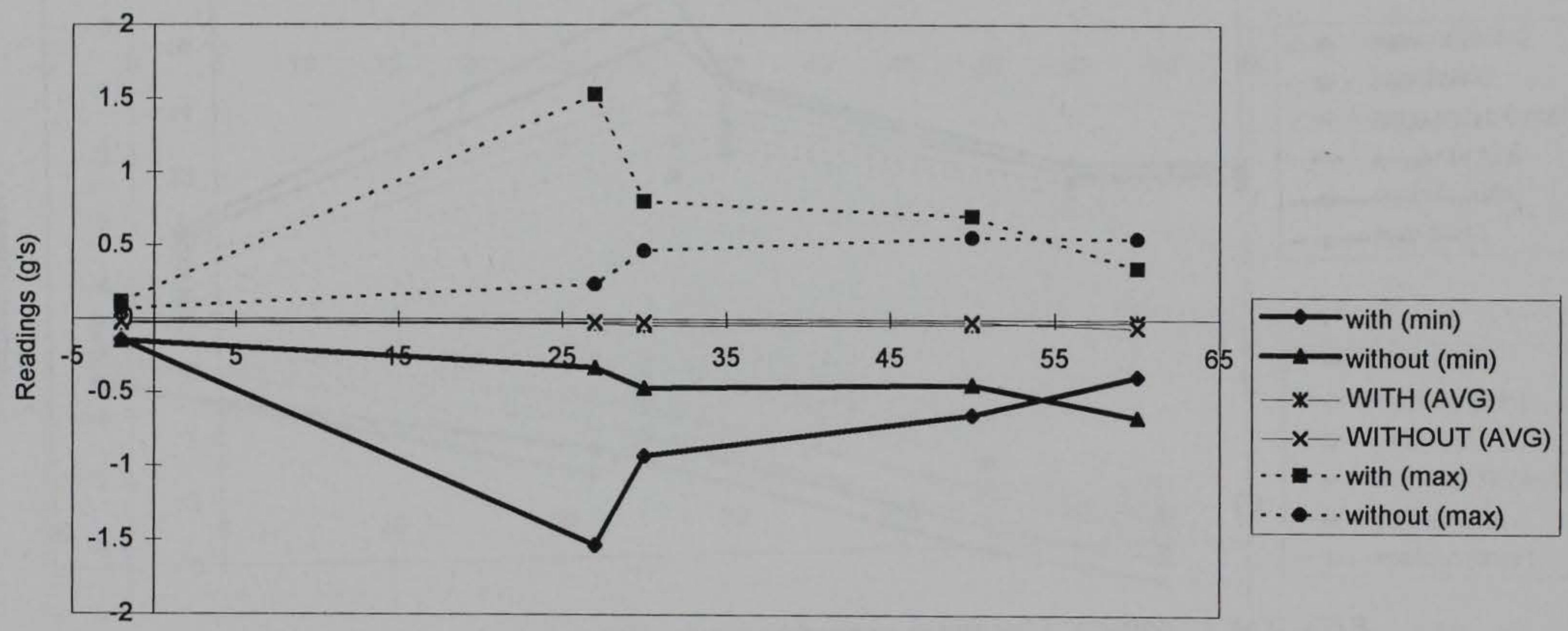

Position (Degrees)

Figure $9 \mathrm{~h}$. Acceleration 1 readings (Sheet 8 of 10 ) 
Acceleration 2 Readings (with and without Approach Channel ) P.E. $=300^{\prime}$, T.W.E. $=279^{\prime}$

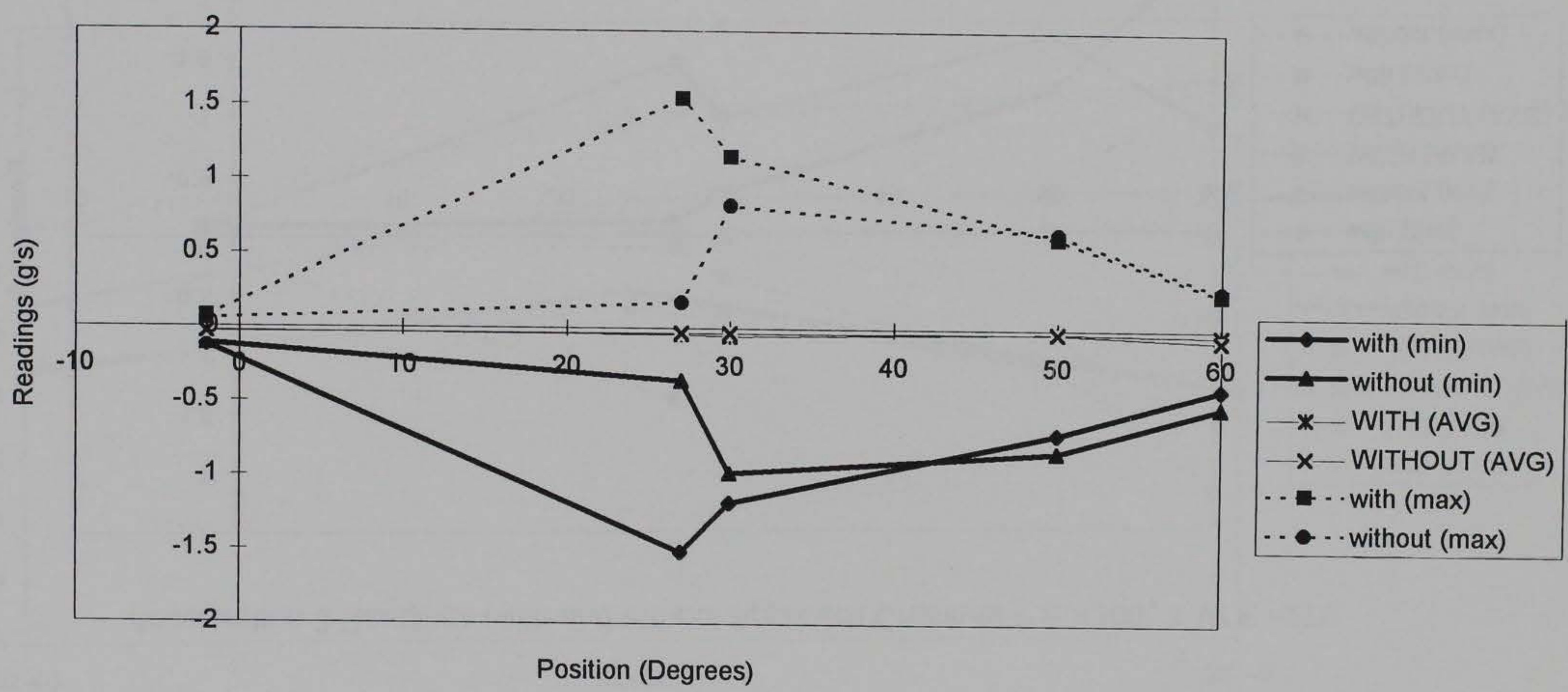

Figure 9i. Acceleration 2 readings (Sheet 9 of 10) 
Acceleration 3 Readings (with and without Approach Channel) P.E. $=300$ ', T.W.E. $=279^{\prime}$

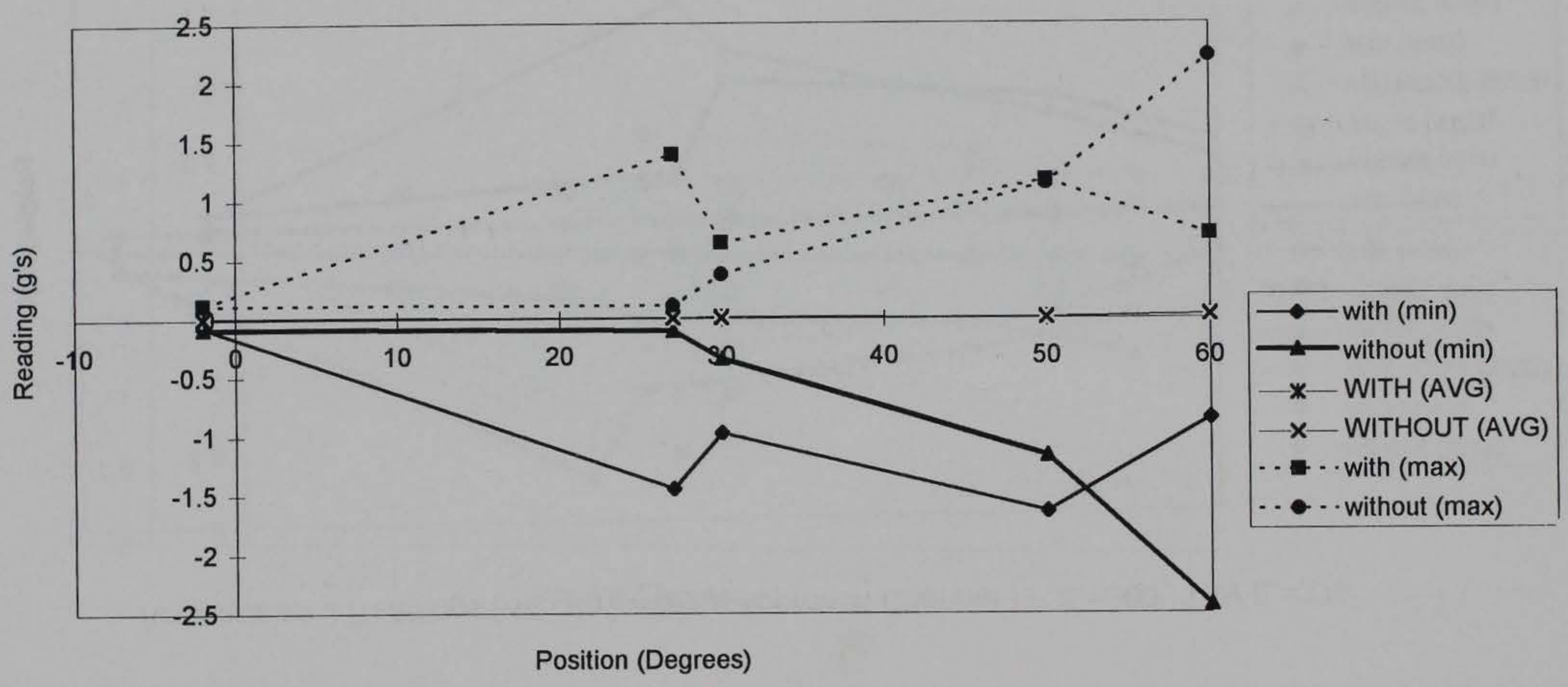

Figure $9 \mathrm{j}$. Acceleration 3 readings (Sheet 10 of 10 ) 


\section{Shaft Load Readings (with and without Approach Channel) Change in Rotation Angle}

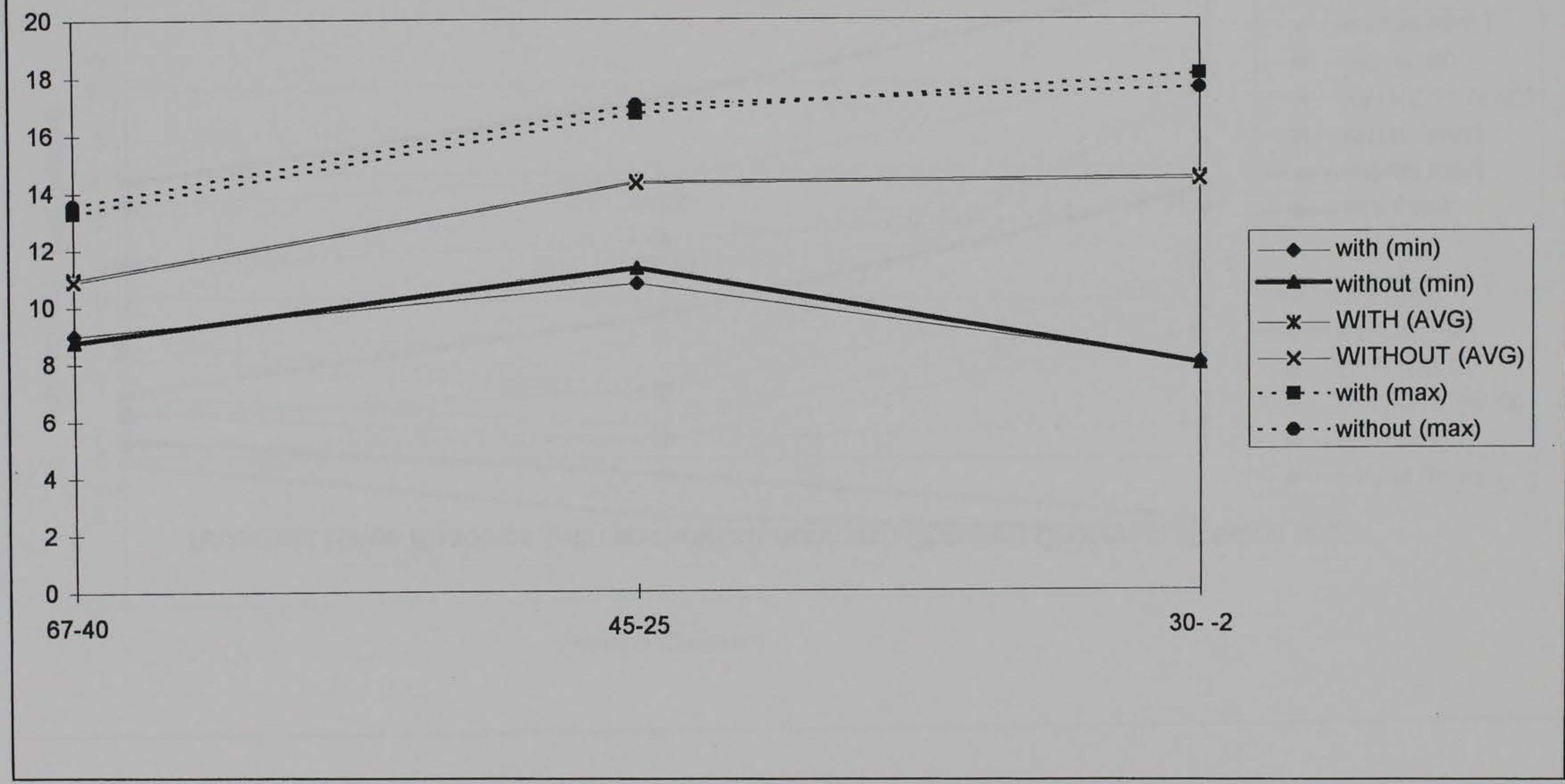

Figure 10. Time-domain data comparison for test set \#2. a. Shape load readings (Sheet 1 of 20) 


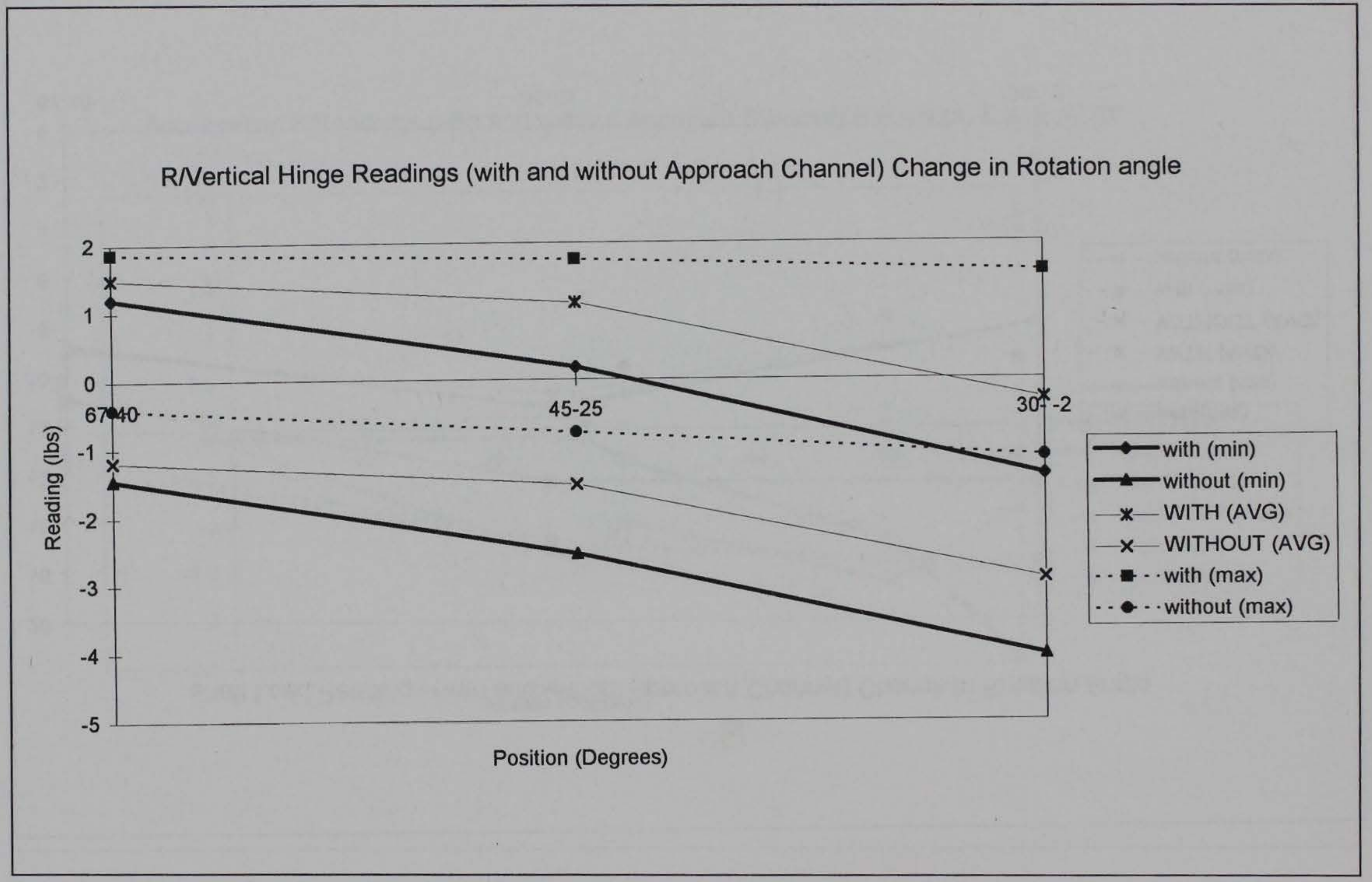

Figure $10 \mathrm{~b}$. Right vertical hinge readings (Sheet 2 of 20) 


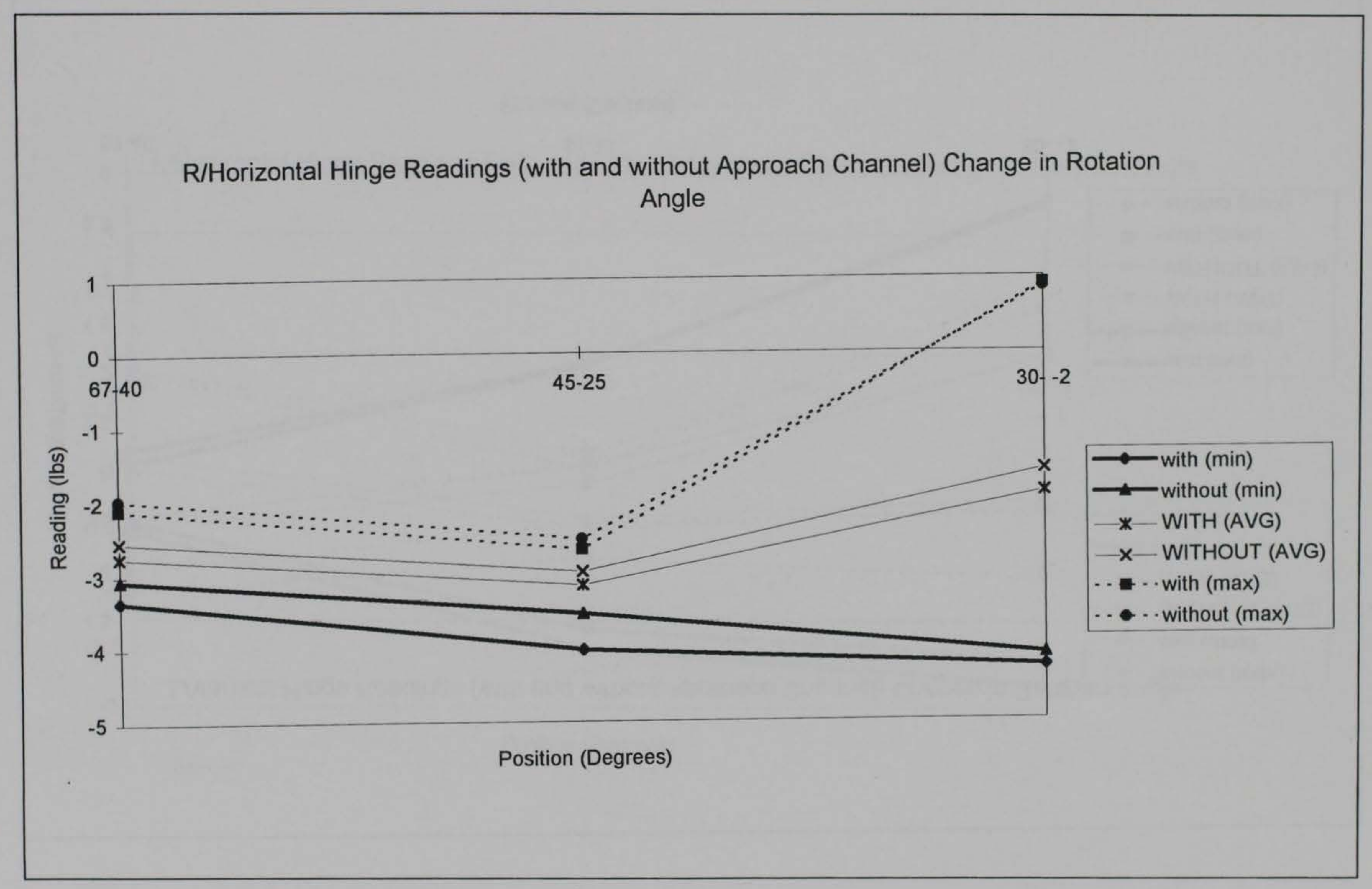

Figure 10c. Right horizontal hinge readings (Sheet 3 of 20) 


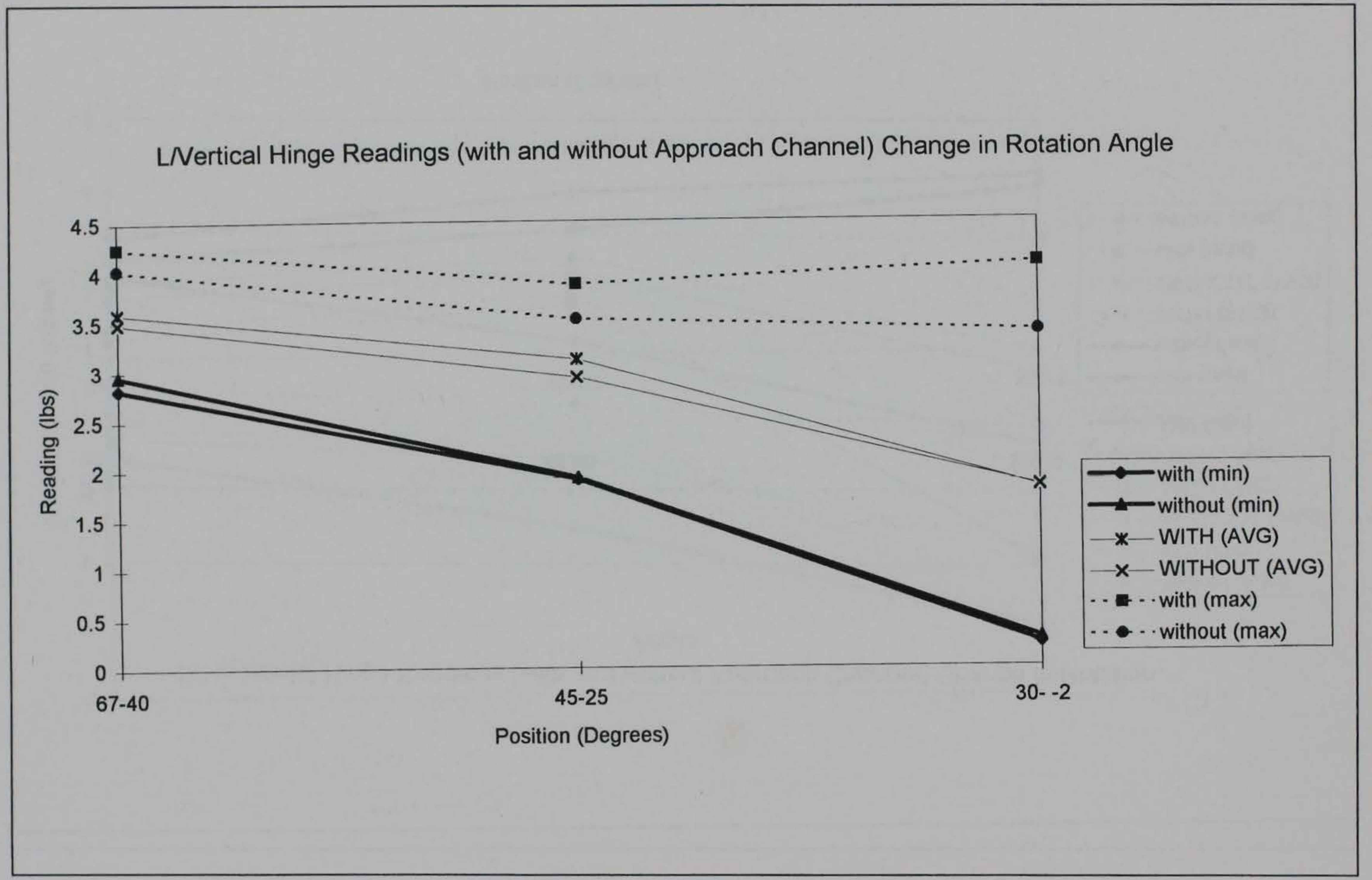

Figure 10d. Left vertical hinge readings (Sheet 4 of 20) 


\section{L/Horizontal Hinge Readings (with and without Approach Channel) Change in Rotation Angle}

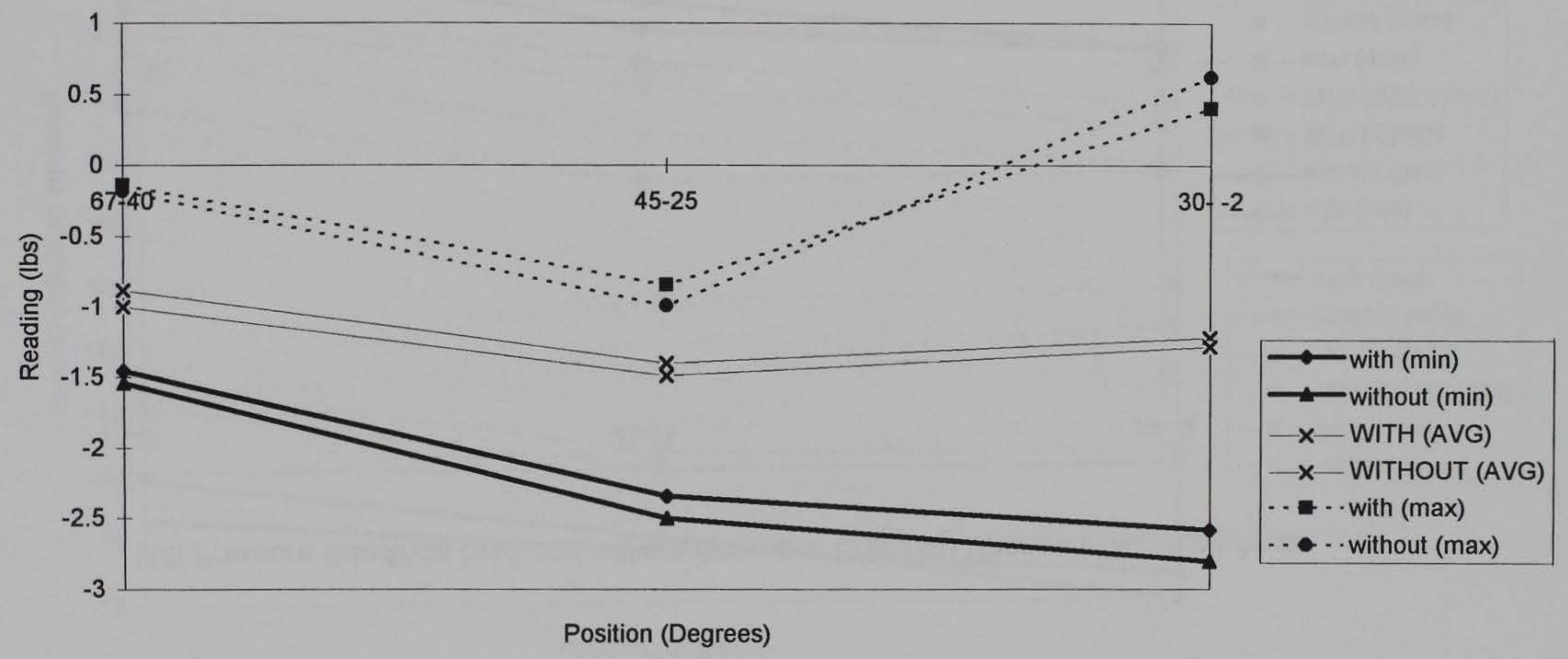

Figure 10e. Left horizontal hinge readings (Sheet 5 of 20) 


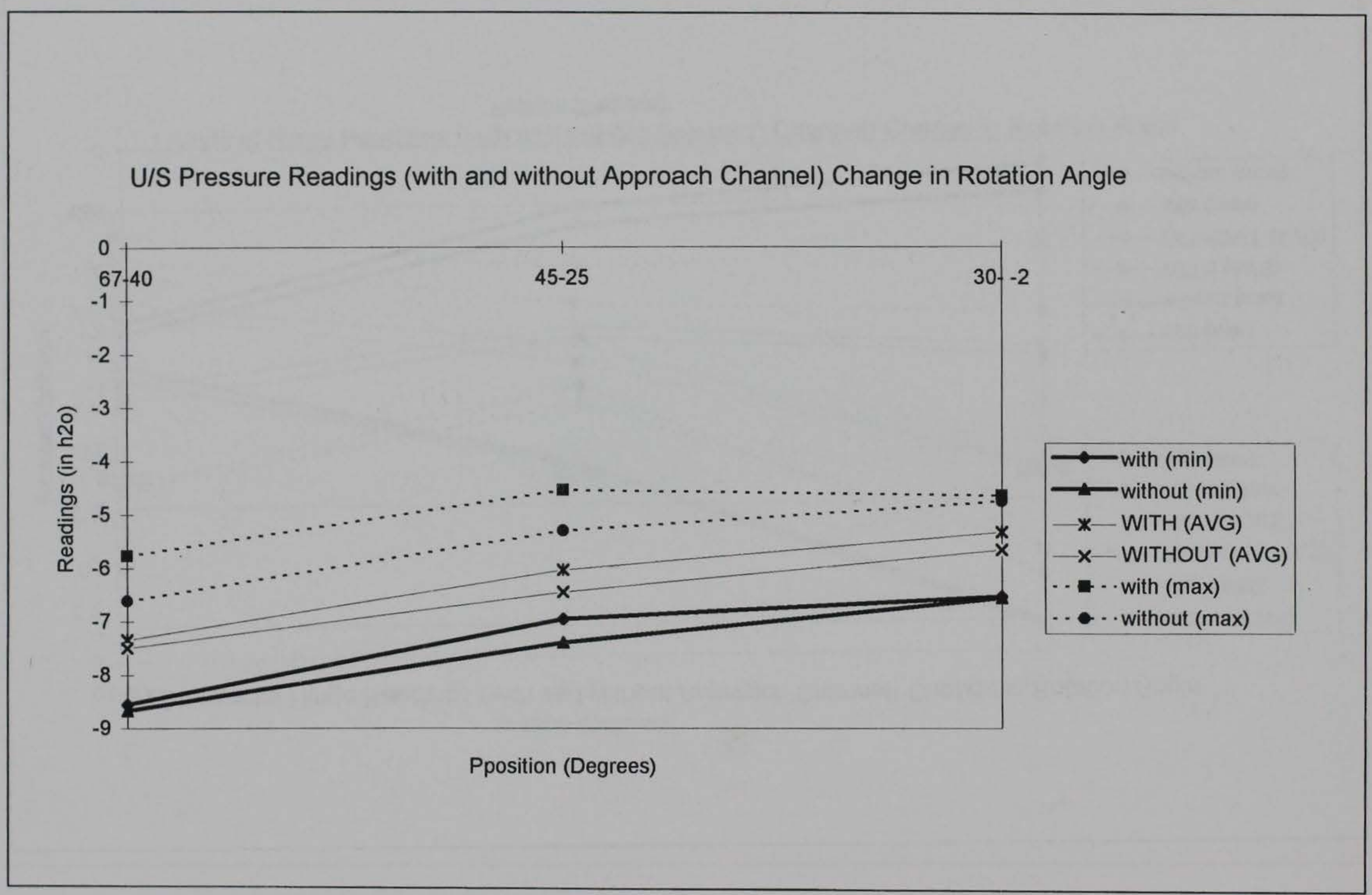

Figure 10 f. Upstream pressure readings (Sheet 6 of 20) 


\section{D/S Pressure Readings (with and without Approach Channel) Change in Rotation Angle}

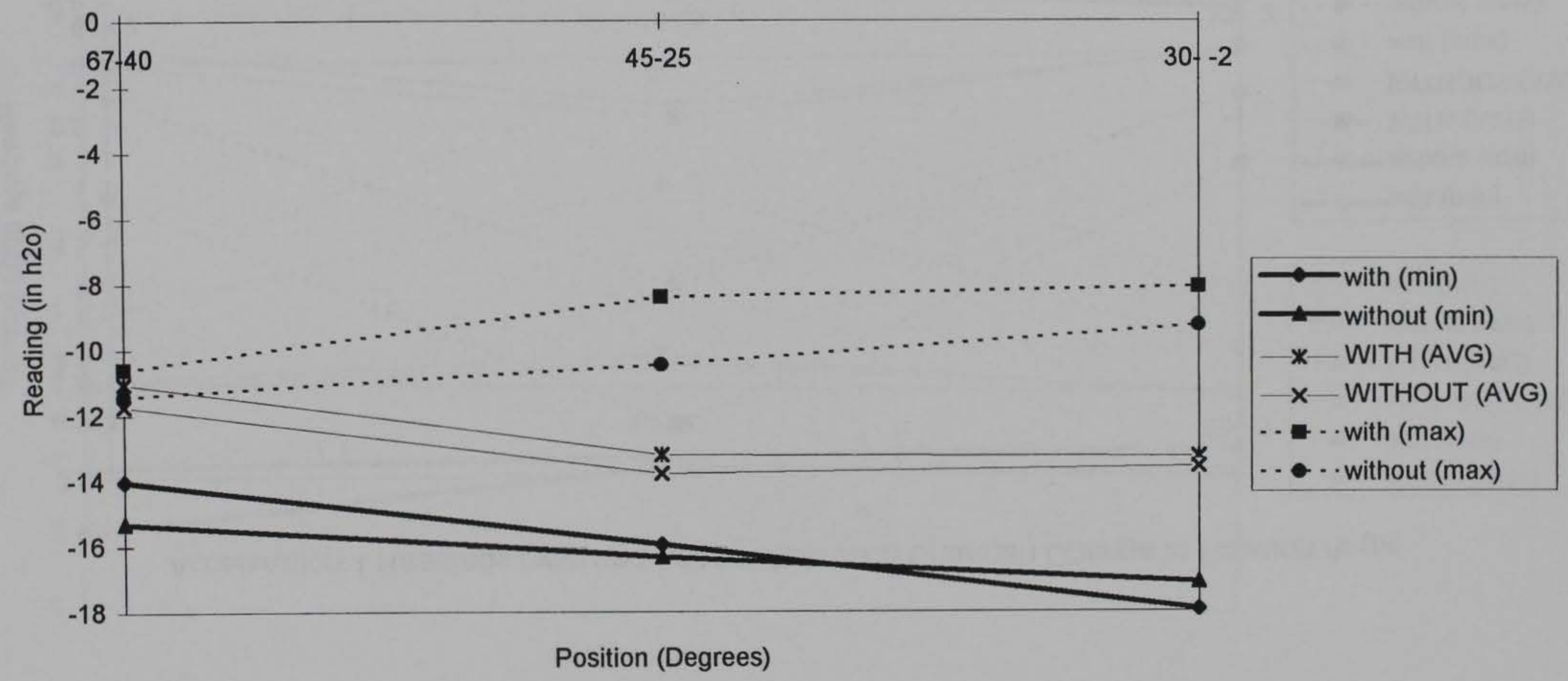

Figure $10 \mathrm{~g}$. Downstream pressure readings (Sheet 7 of 20) 


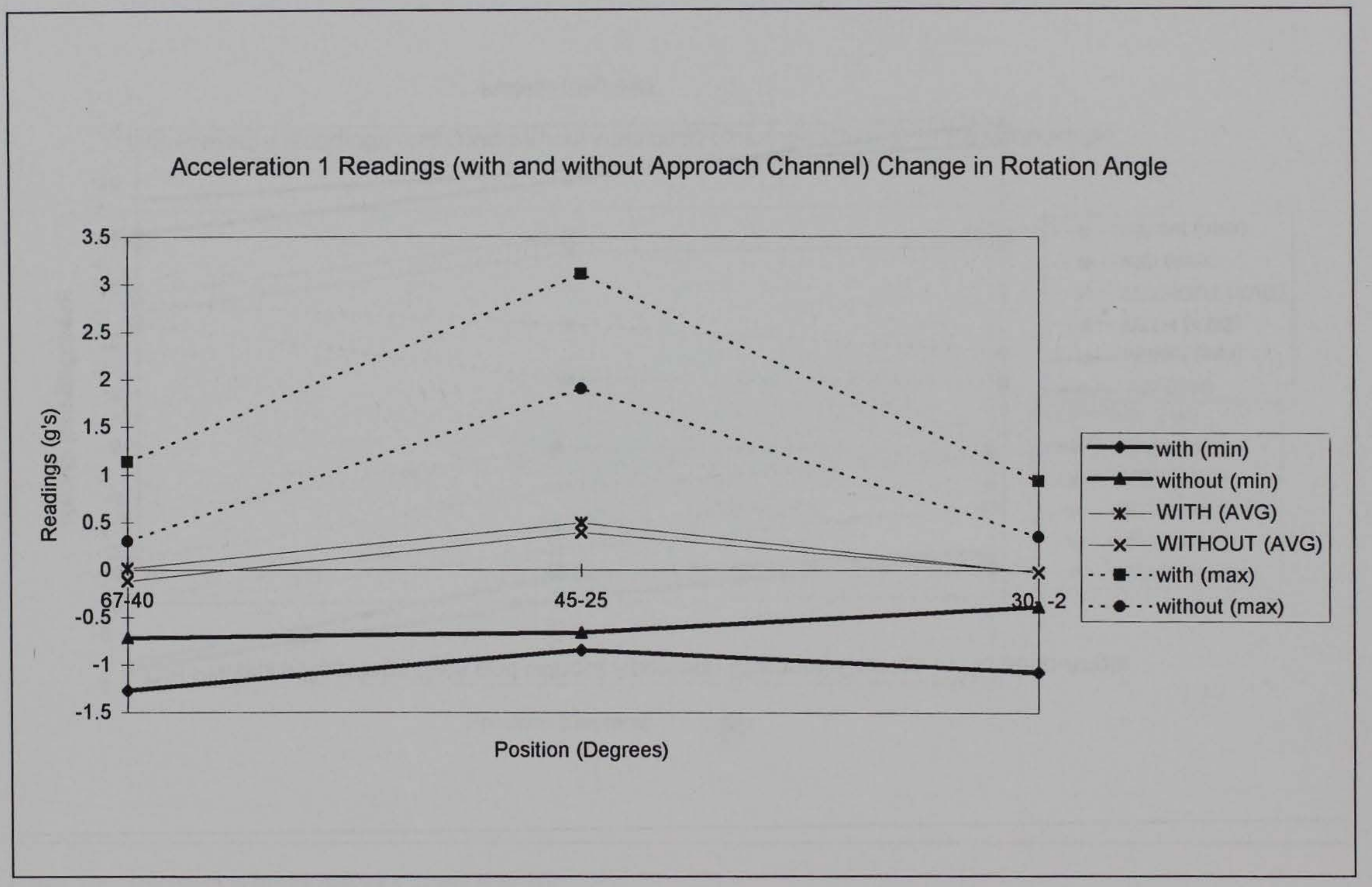

Figure $10 \mathrm{~h}$. Acceleration 1 readings (Sheet 8 of 20) 
Acceleration 2 Readings (with and without Approach Channel) Change in Rotation Angle

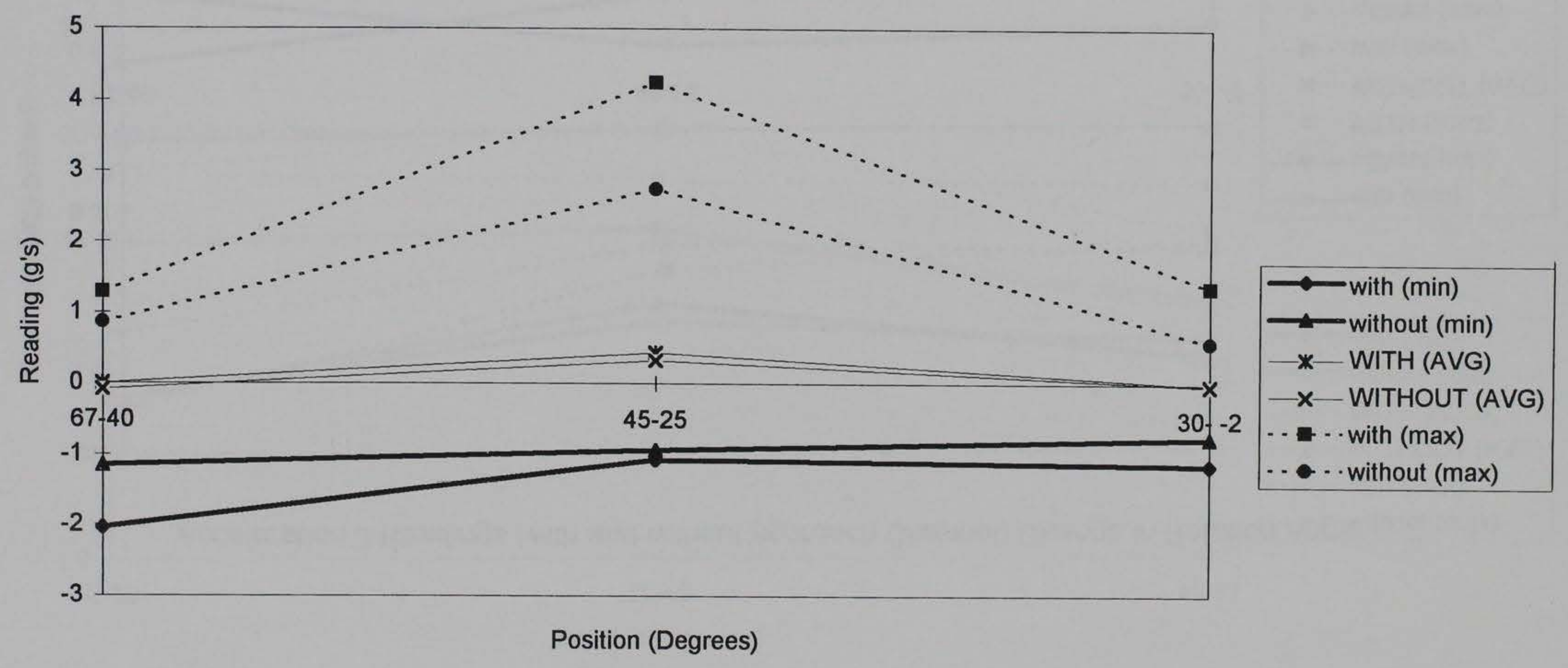

Figure 10i. Acceleration 2 readings (Sheet 9 of 20) 
Acceleration 3 Readings (with and without approach Channel) Change in Rotation Angle

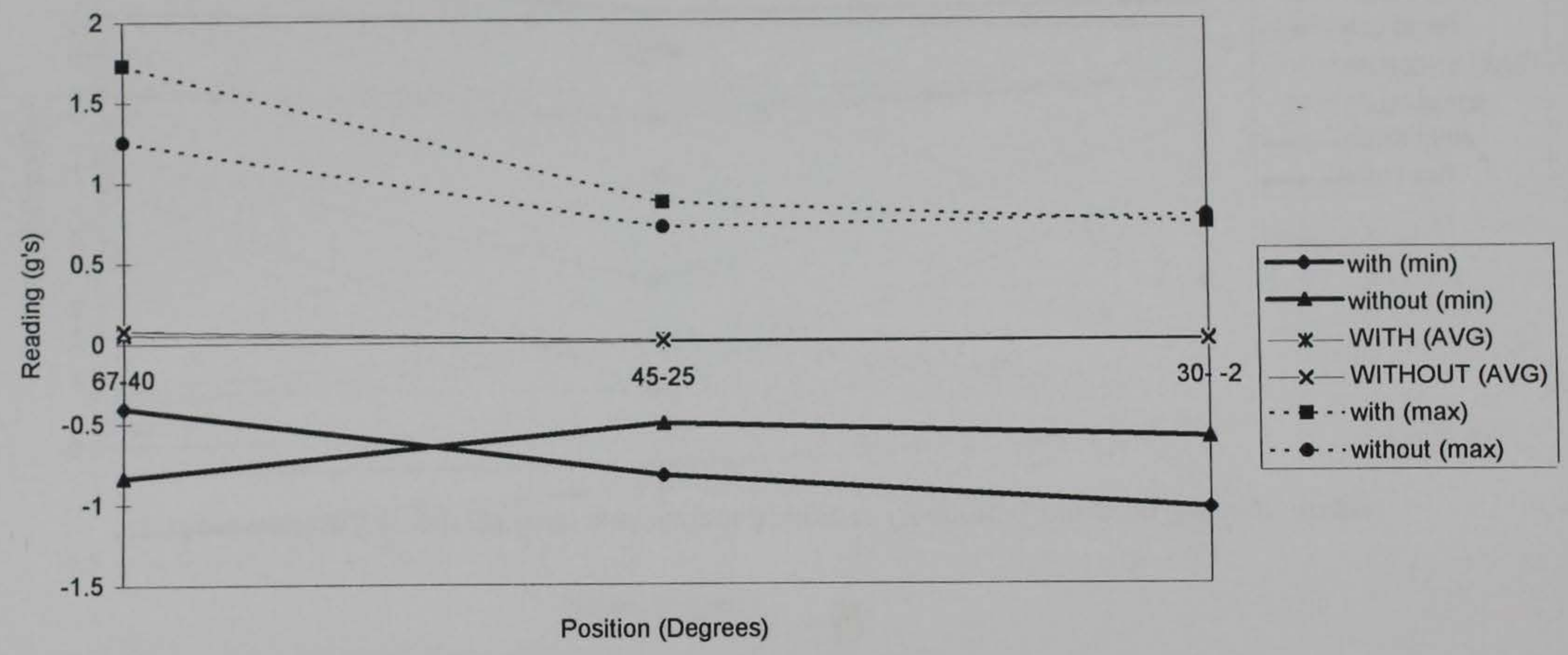

Figure 10j. Acceleration 3 readings (Sheet 10 of 20) 


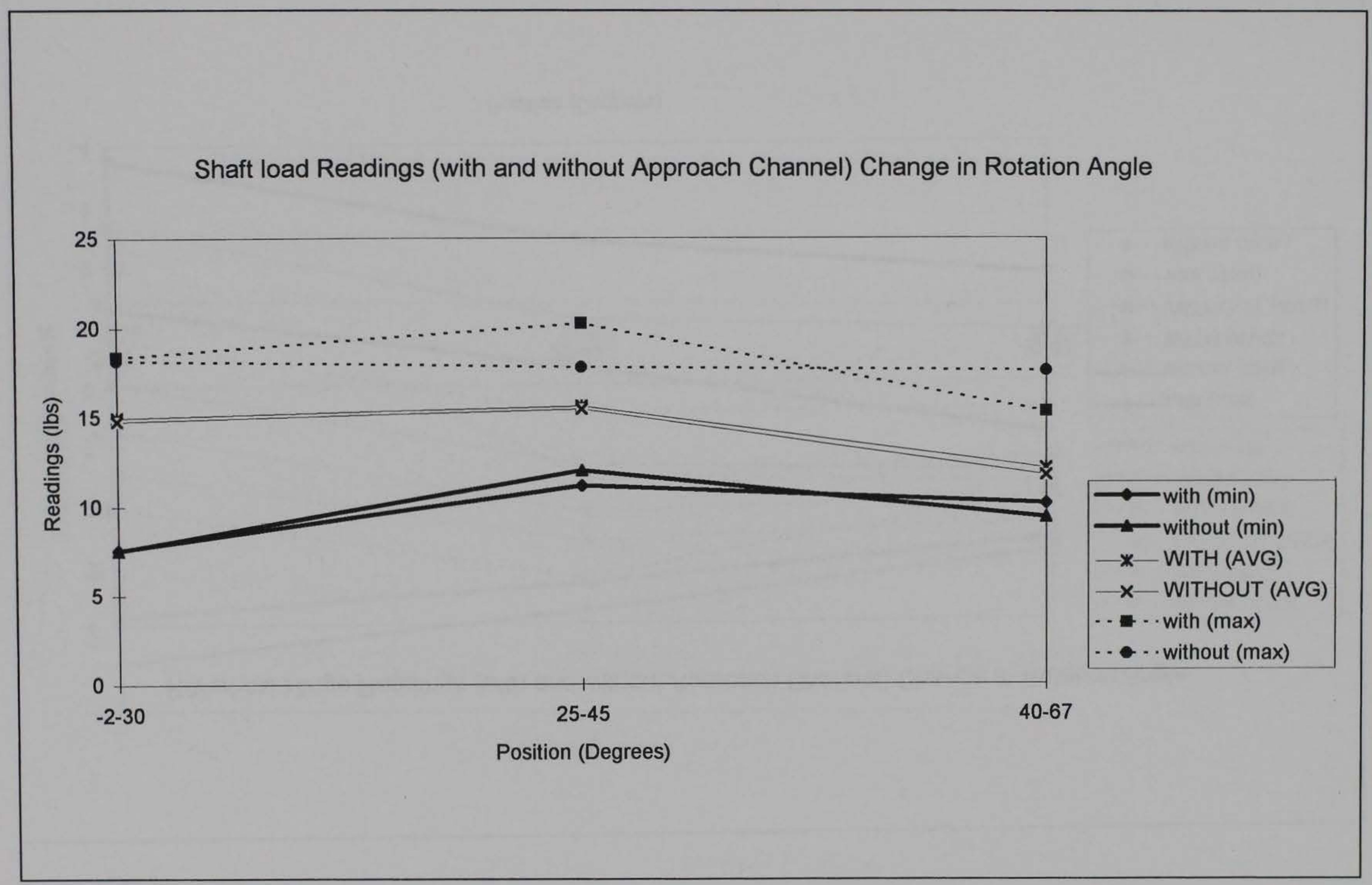

Figure 10k. Shaft load readings (Sheet 11 of 20) 


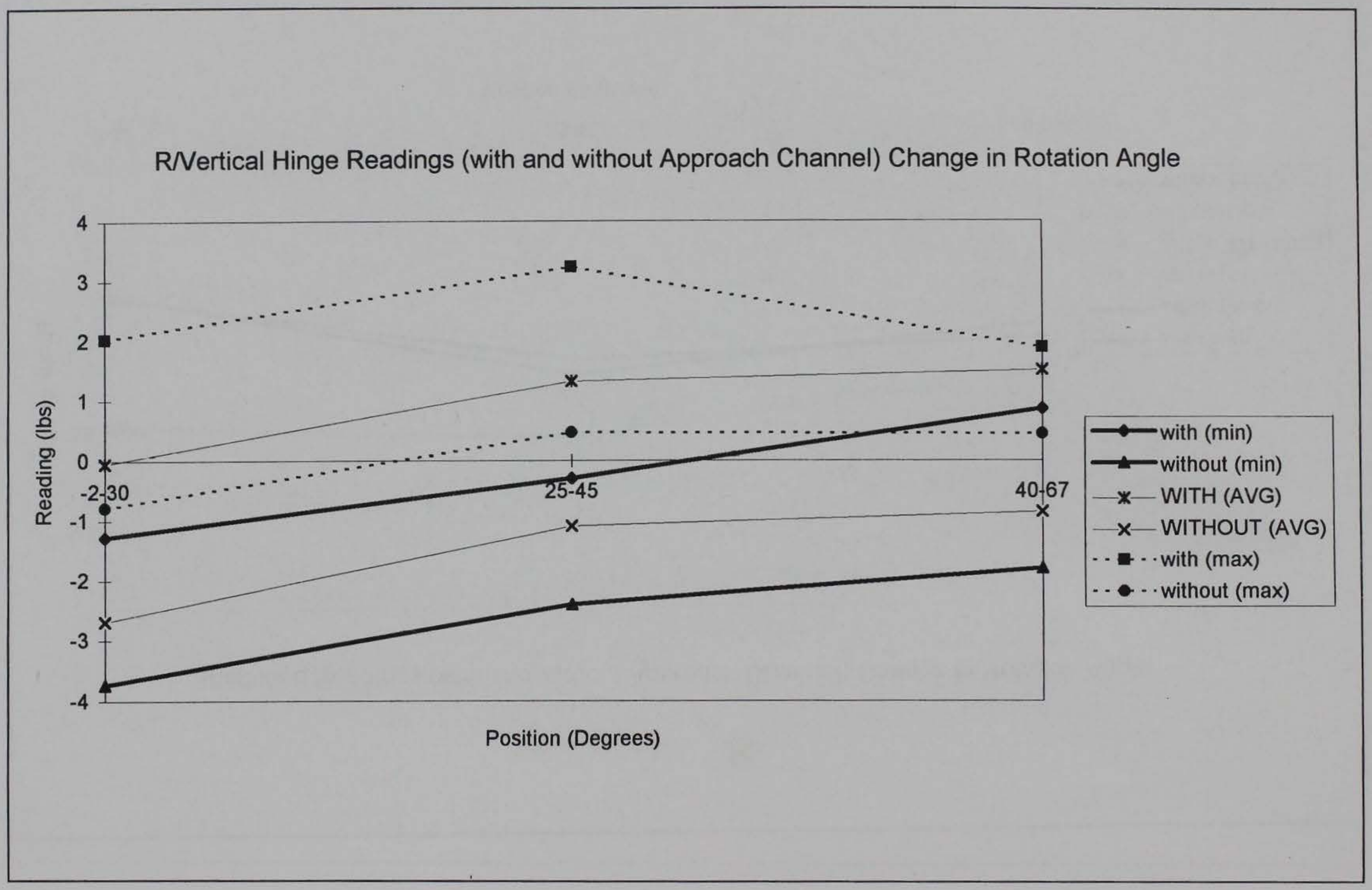

Figure 10I. Right vertical hinge readings (Sheet 12 of 20) 


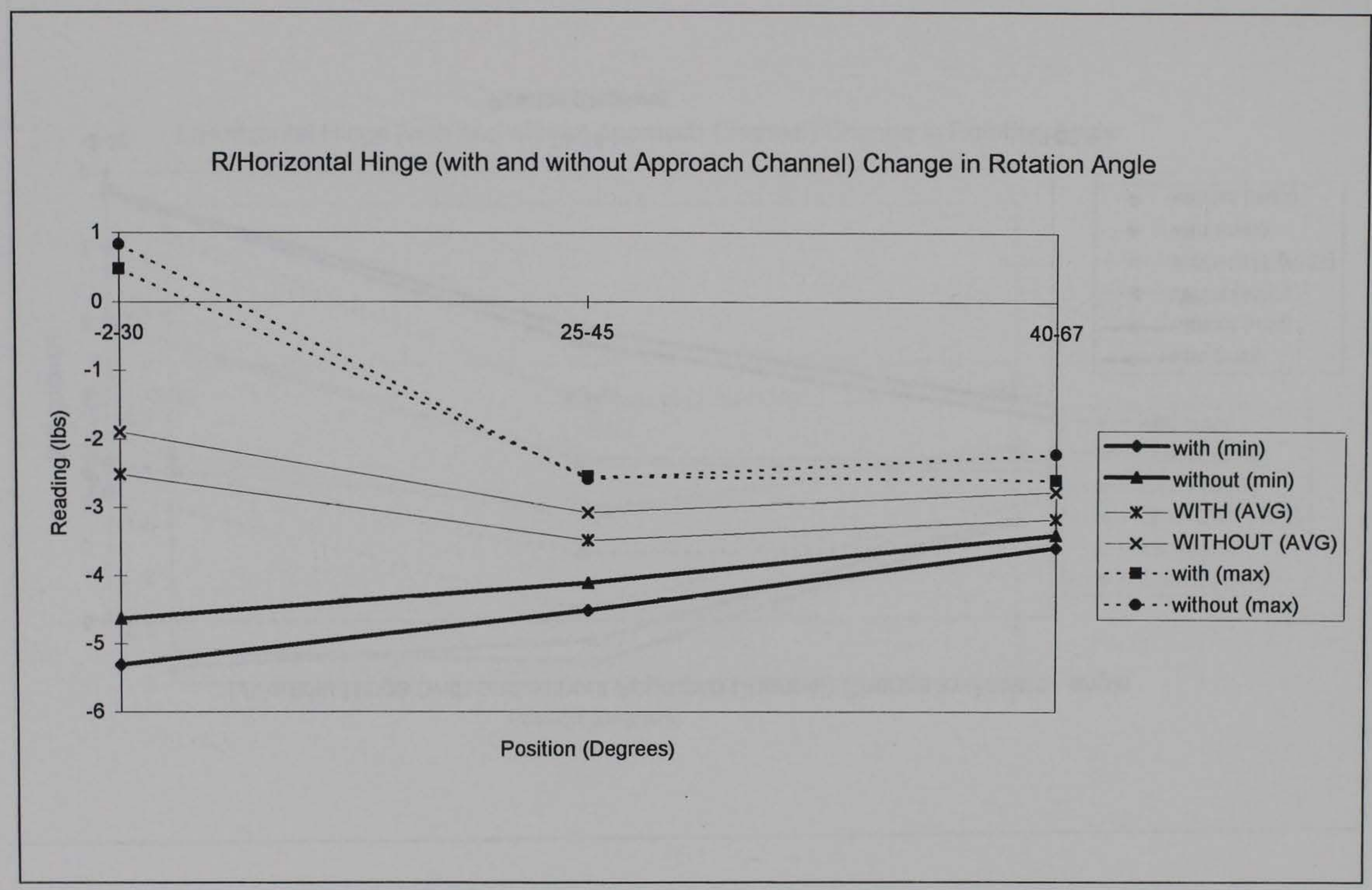

Figure $10 \mathrm{~m}$. Right horizontal hinge (Sheet 13 of 20) 


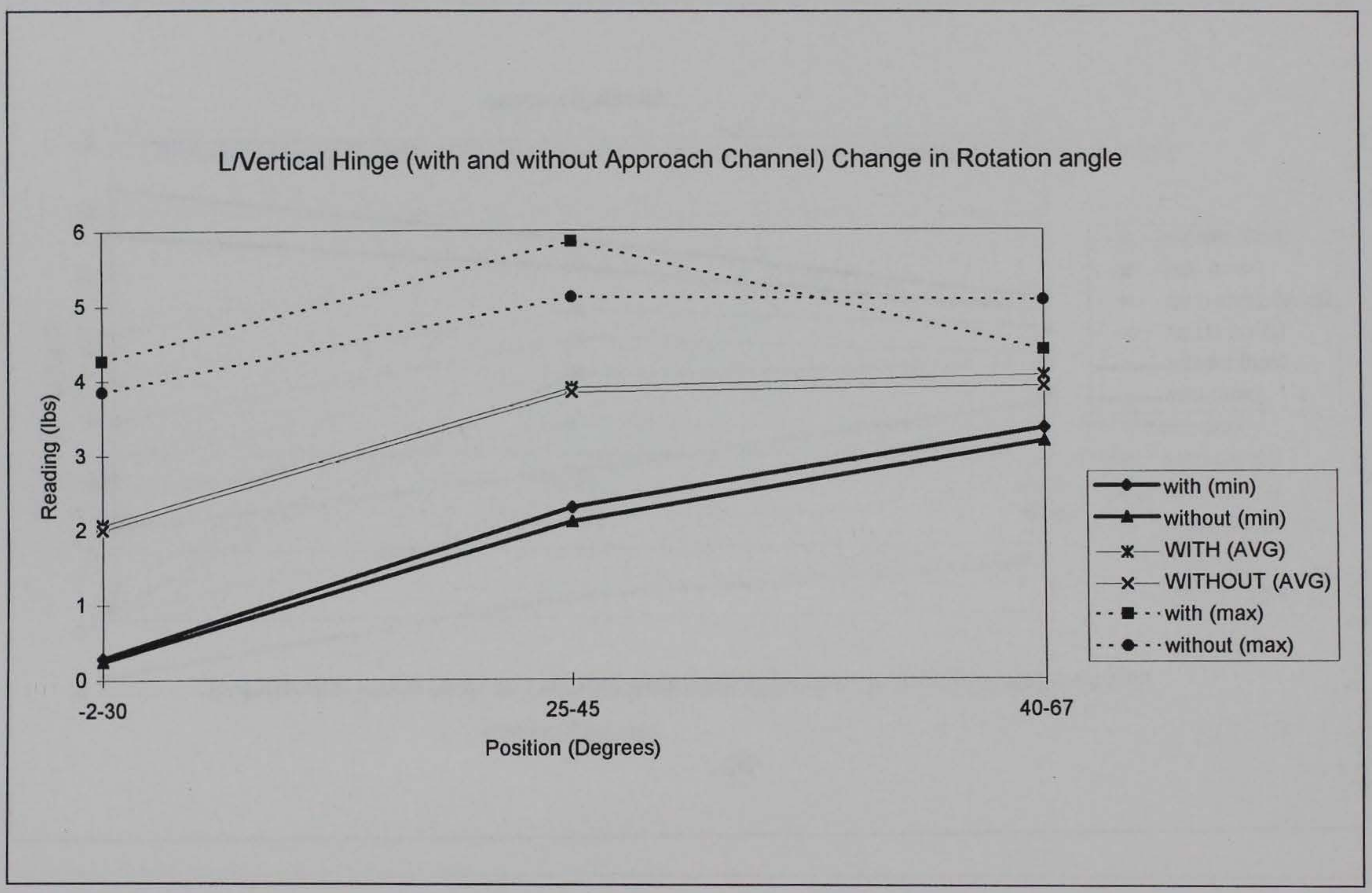

Figure 10n. Left vertical hinge (Sheet 14 of 20) 
L/Horizontal Hinge (with and without Approach Channel) Change in Rotation Angle

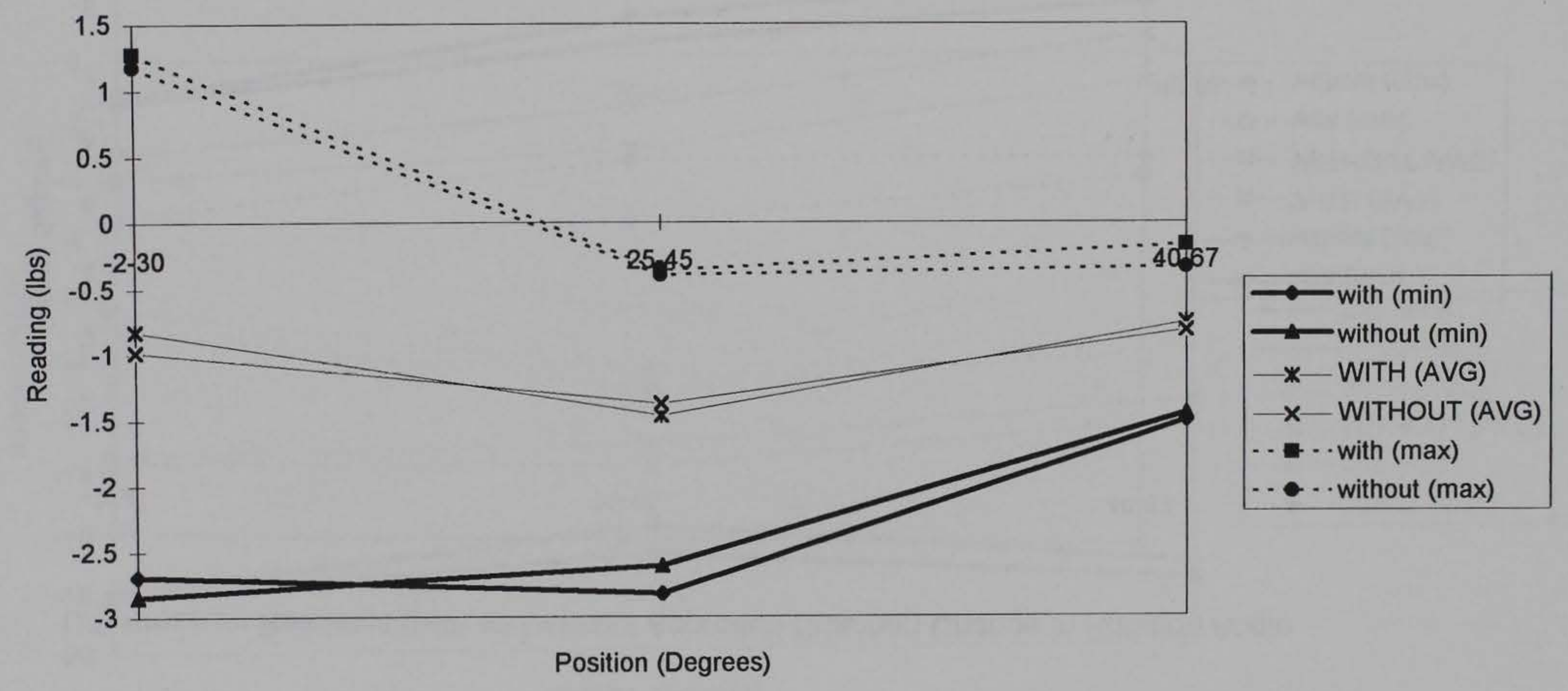

Figure 10o. Left horizontal hinge (Sheet 15 of 20) 
U/S Pressure Readings (with and without Approach Channel) Change in Rotation Angle

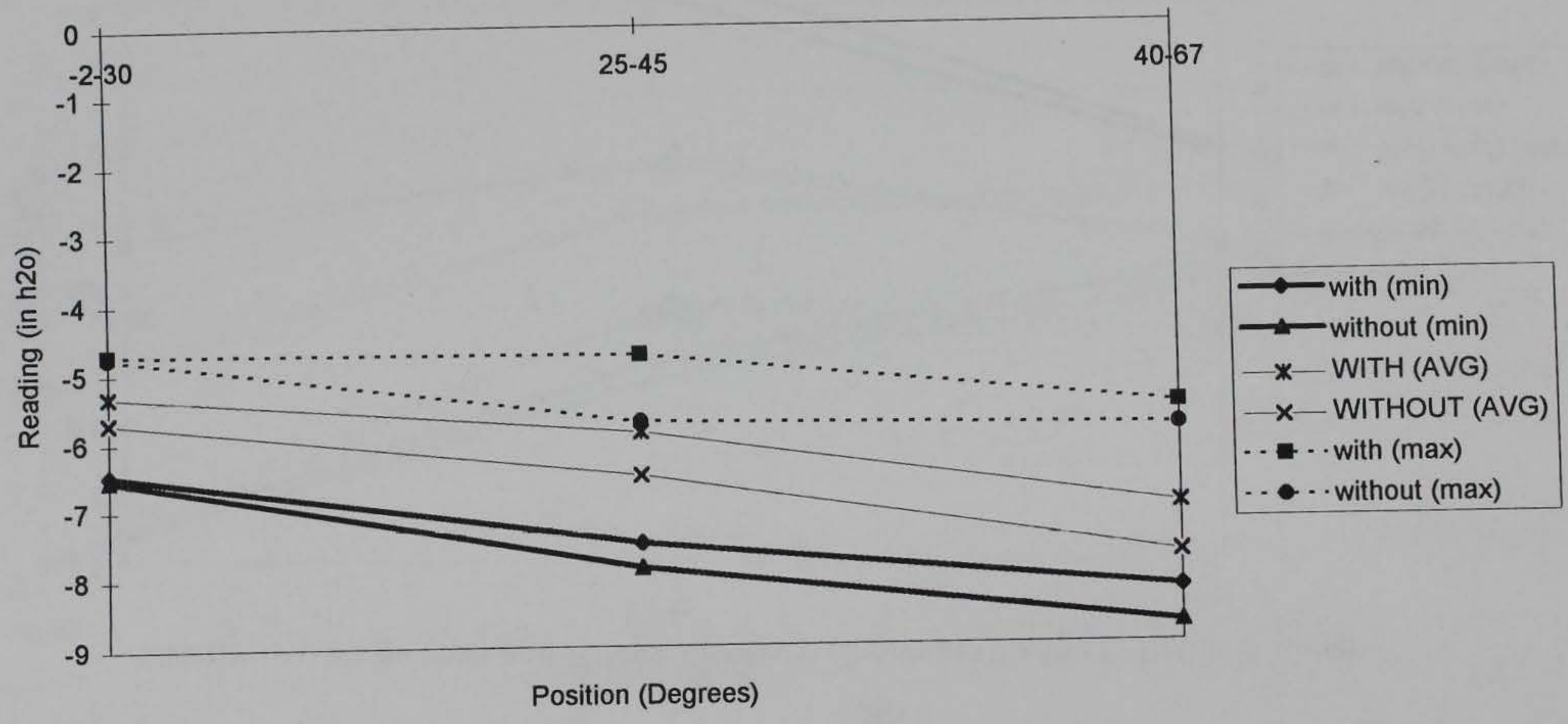

Figure 10p. Upstream pressure readings (Sheet 16 of 20) 


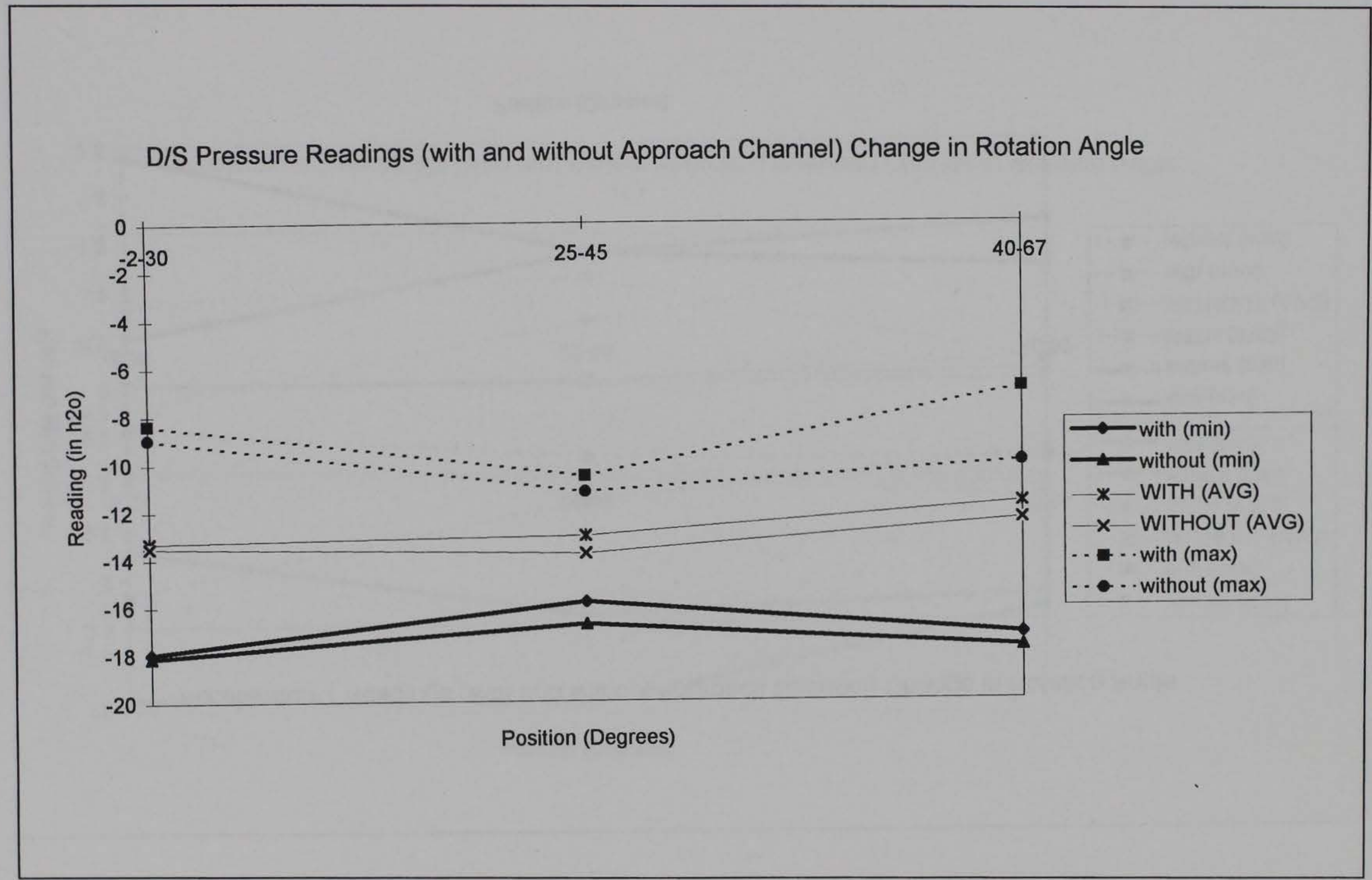

Figure 10q. Downstream pressure readings (Sheet 17 of 20) 


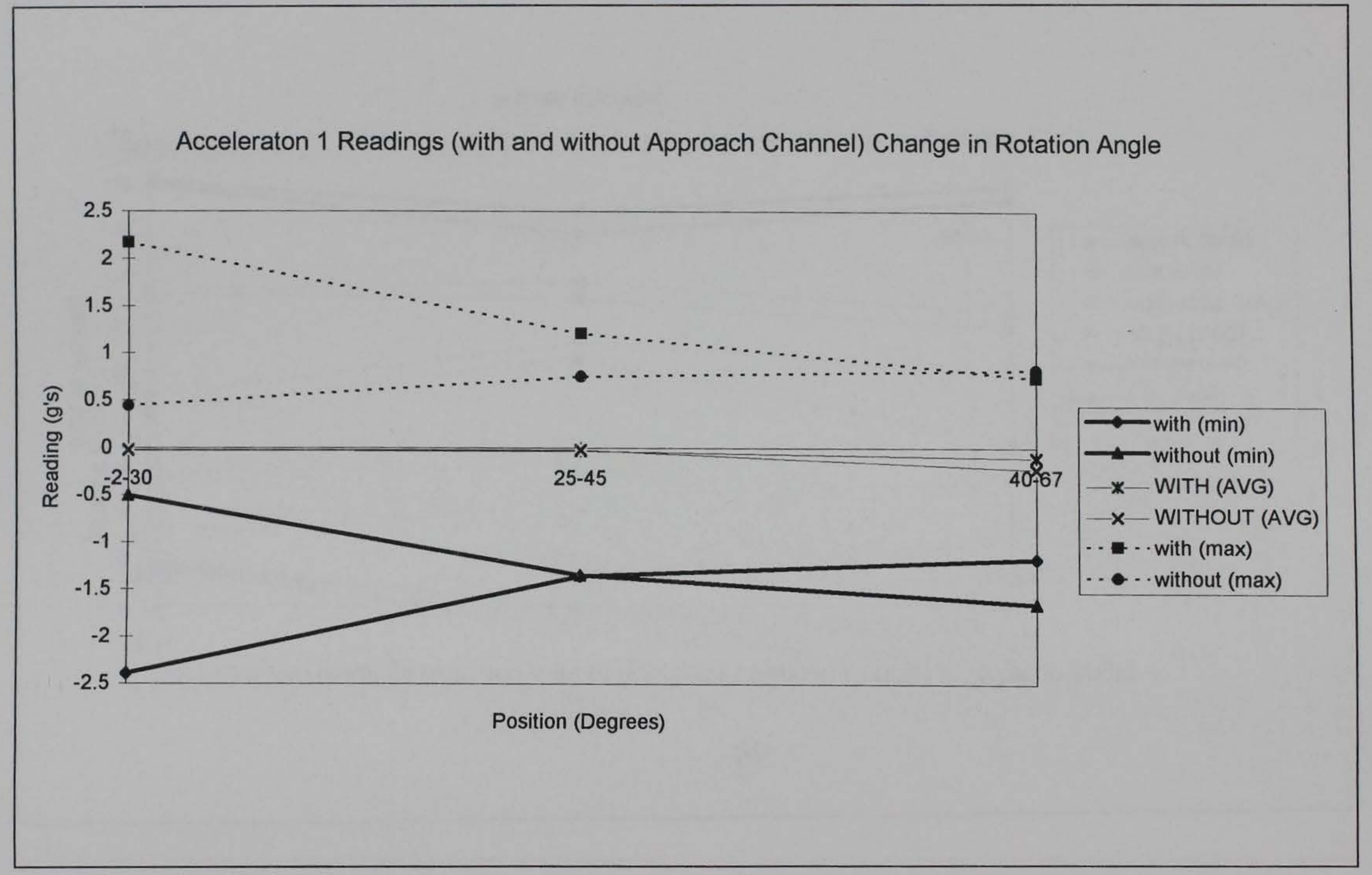

Figure 10r. Acceleration 1 readings (Sheet 18 of 20) 


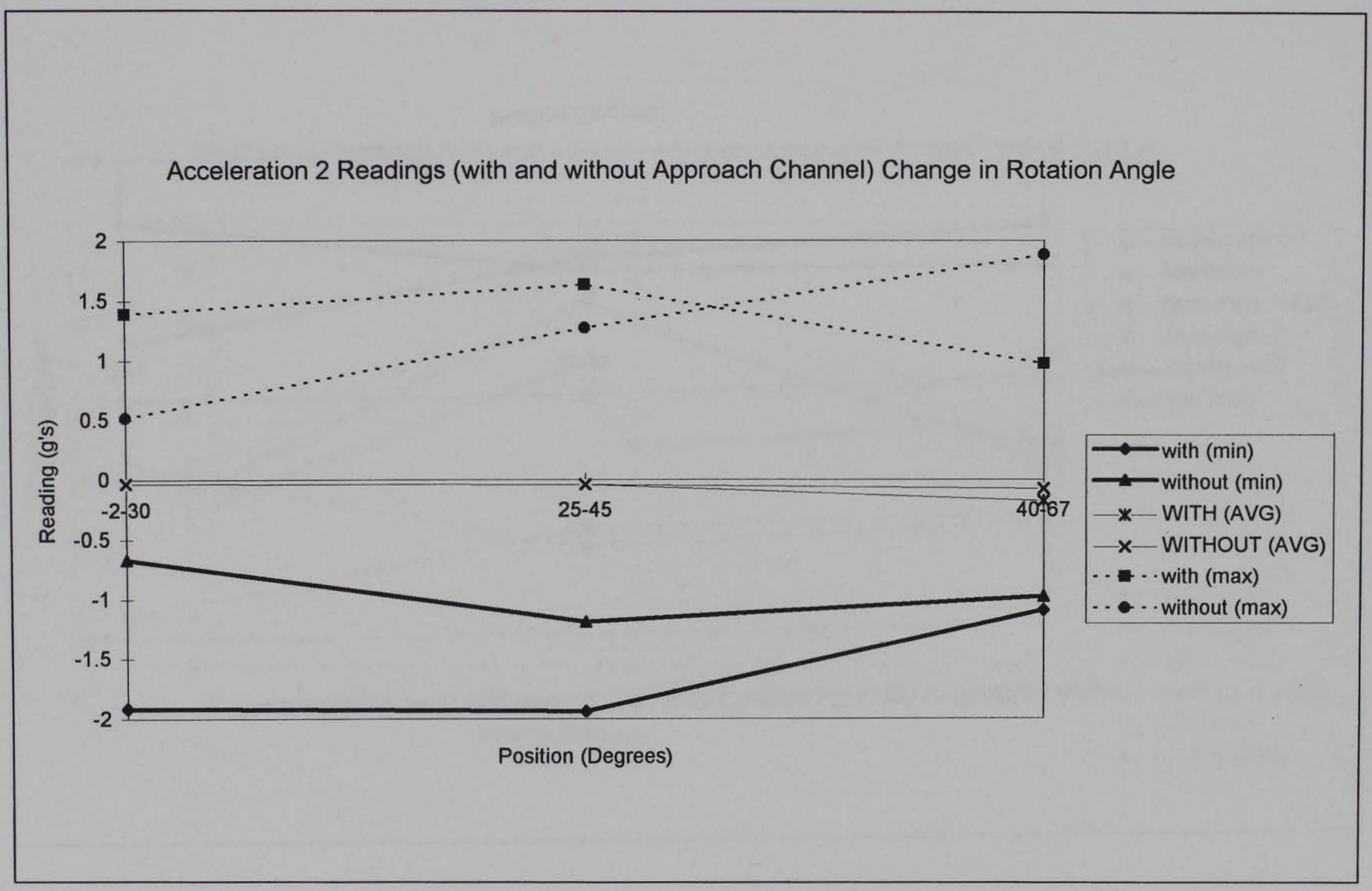

Figure 10s. Acceleration 2 readings (Sheet 19 of 20) 


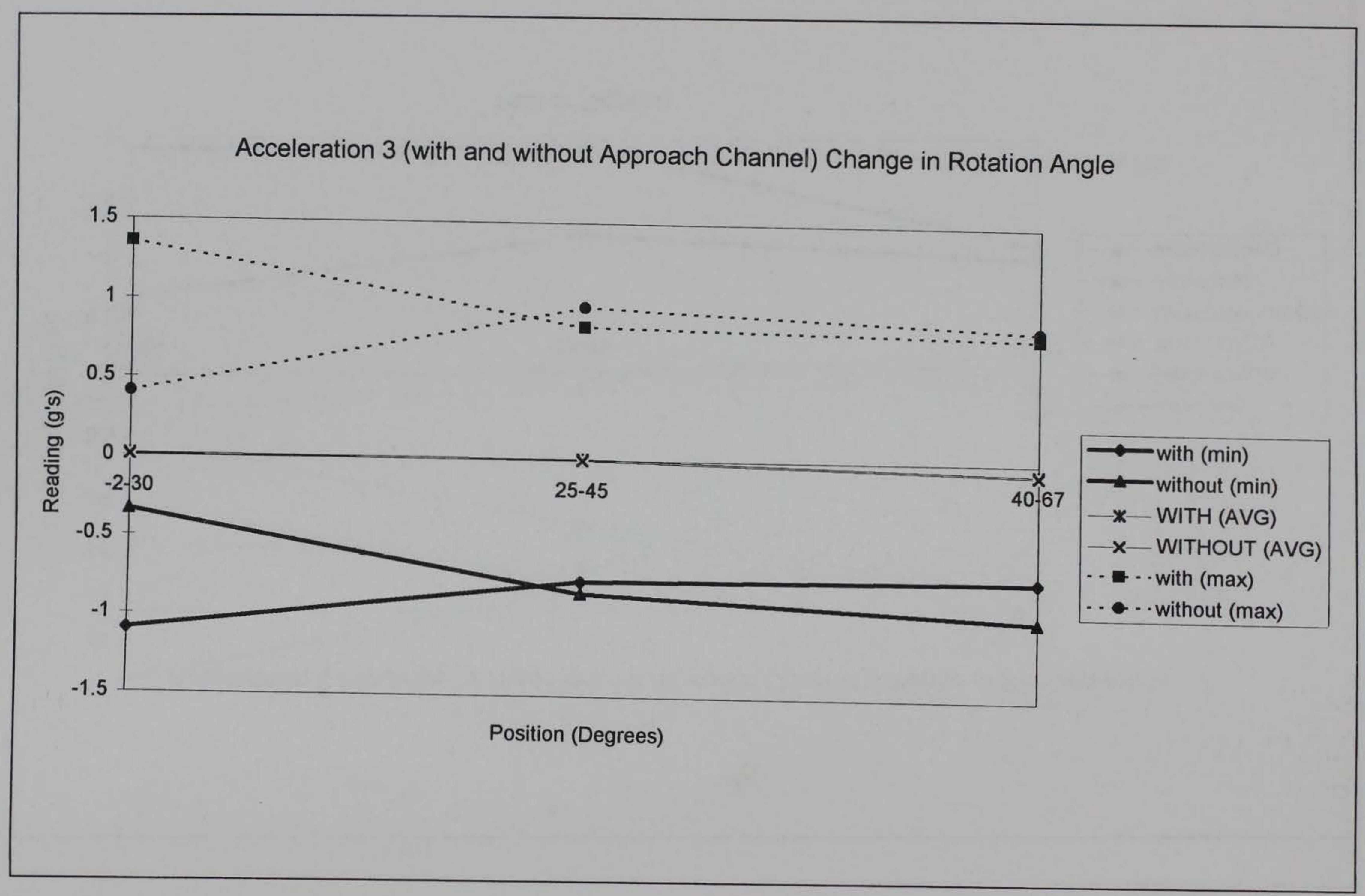

Figure 10t. Acceleration 3 readings (Sheet 20 of 20) 


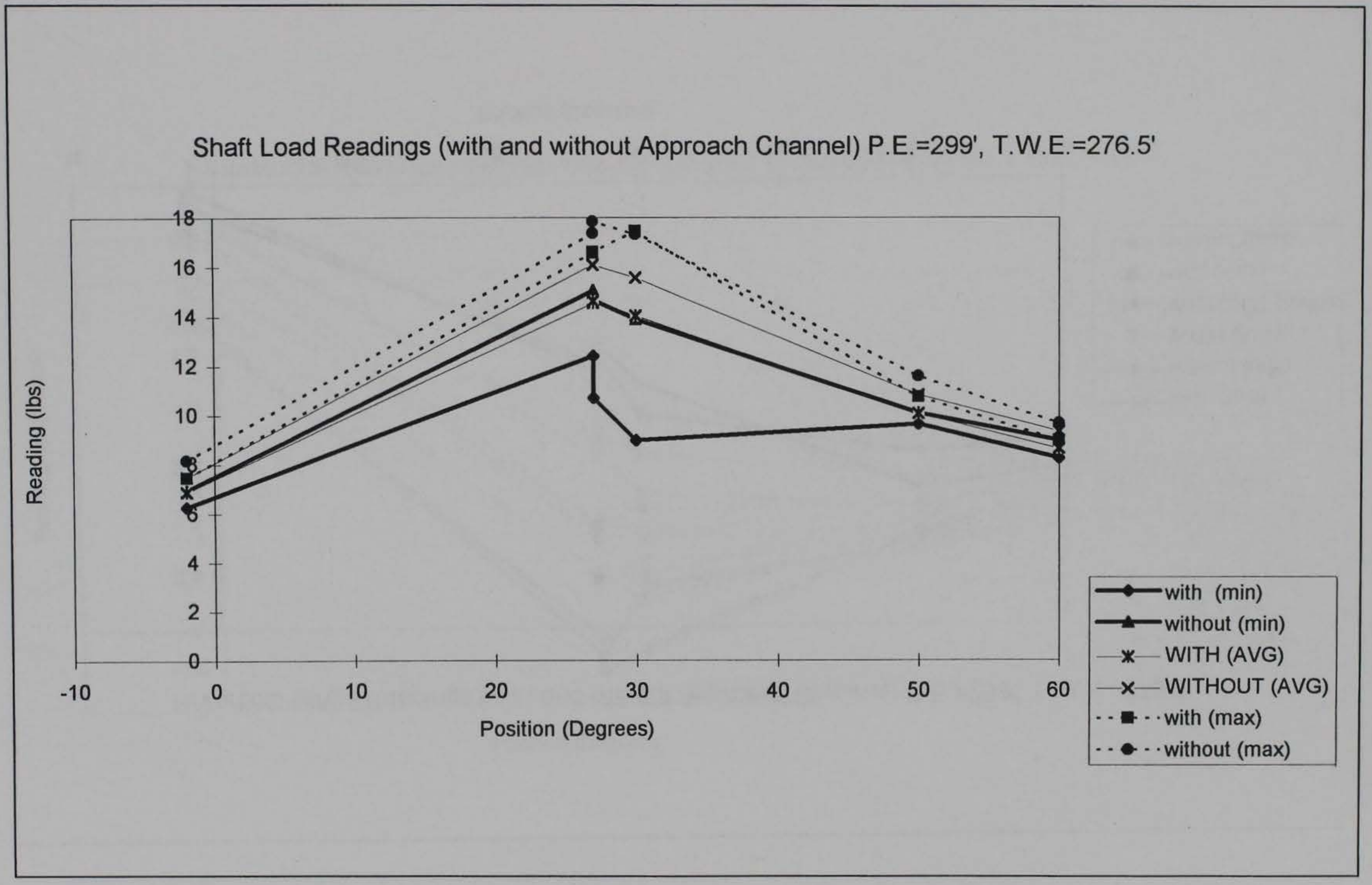

Figure 11. Time-domain data comparison for test set \#3. a. Shaft land readings (Sheet 1 of 10) 


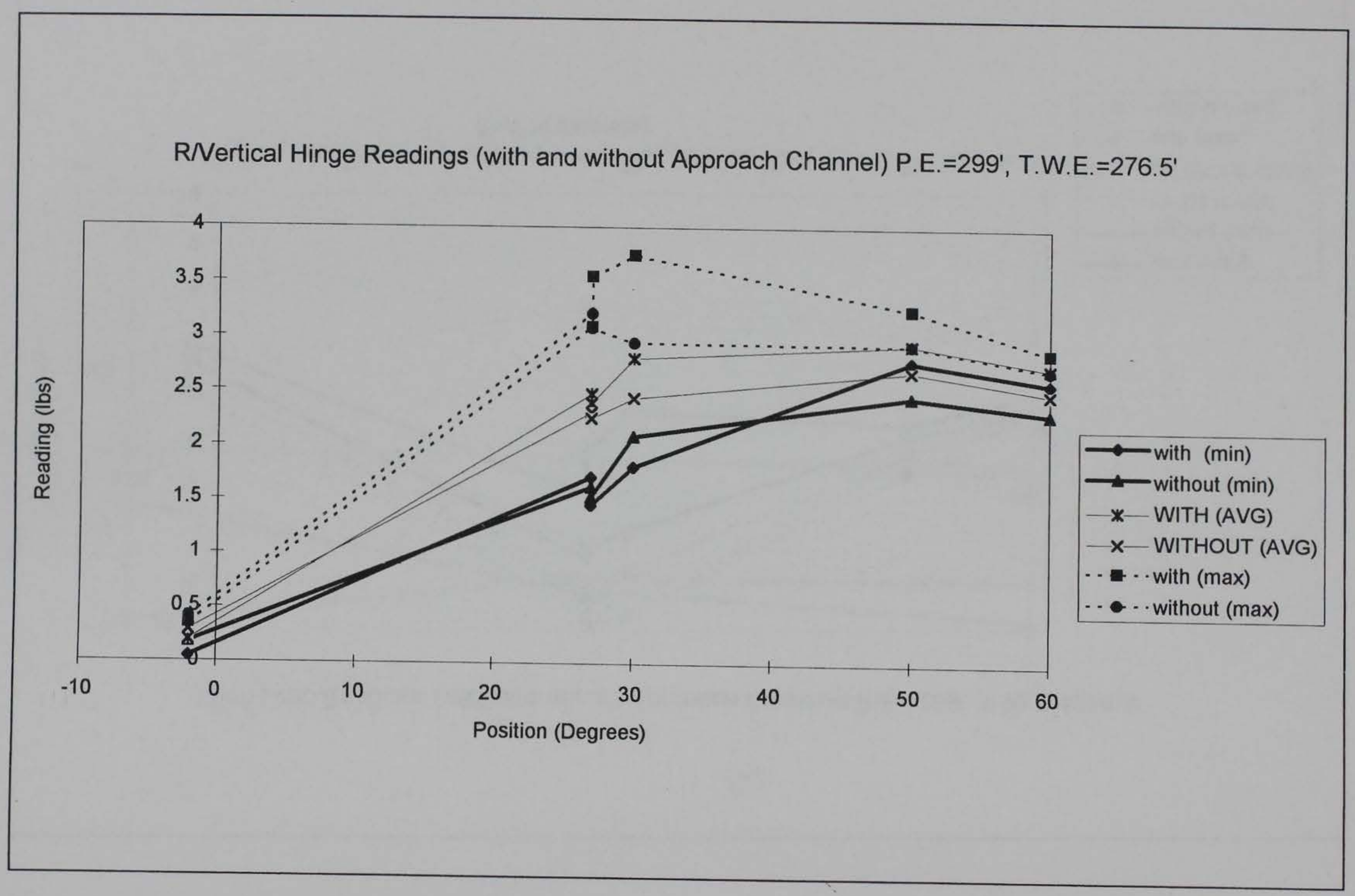

Figure 11b. Right vertical hinge readings (Sheet 2 of 10) 


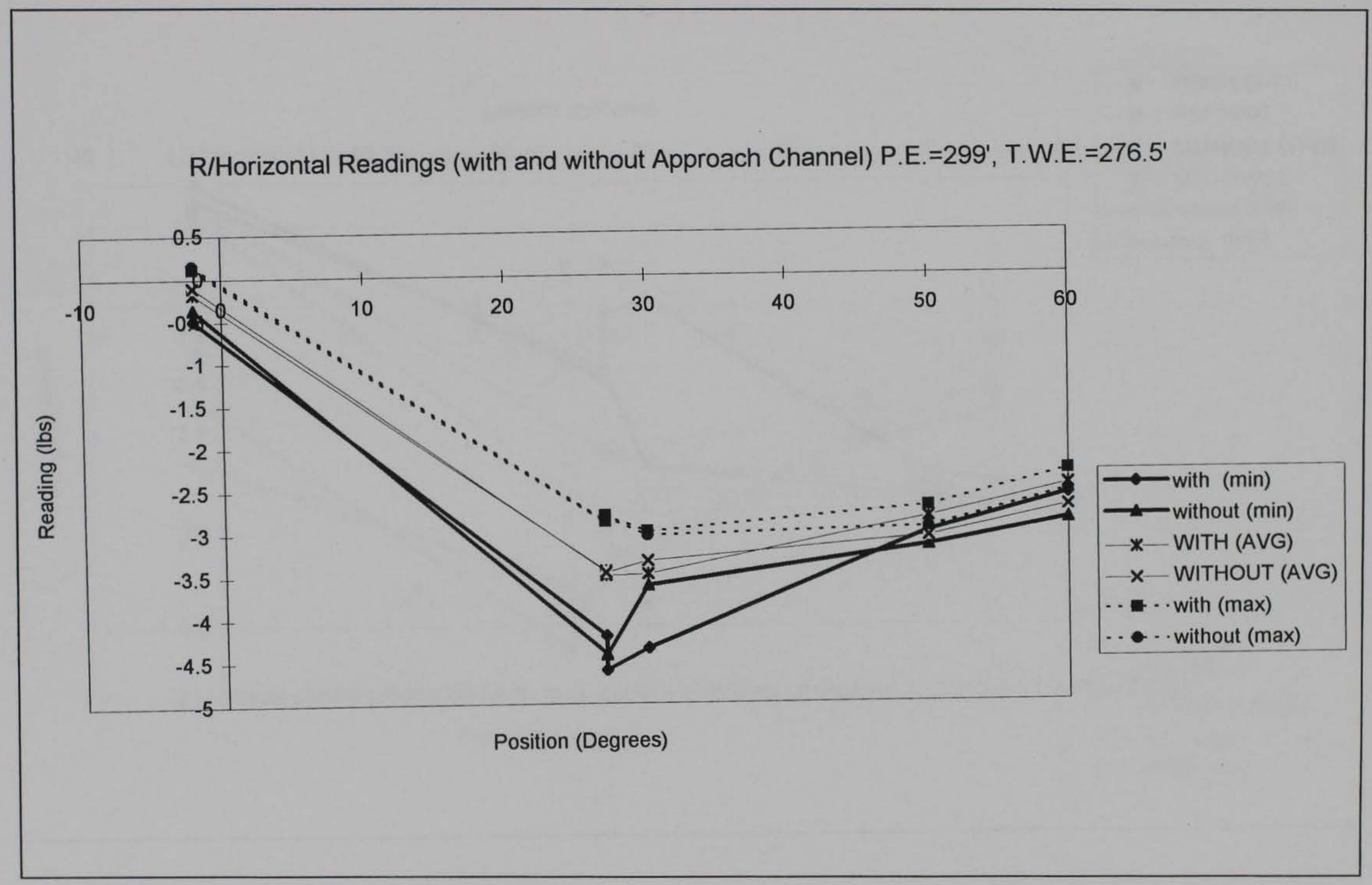

Figure 11c. Right horizontal hinge readings (Sheet 3 of 10) 


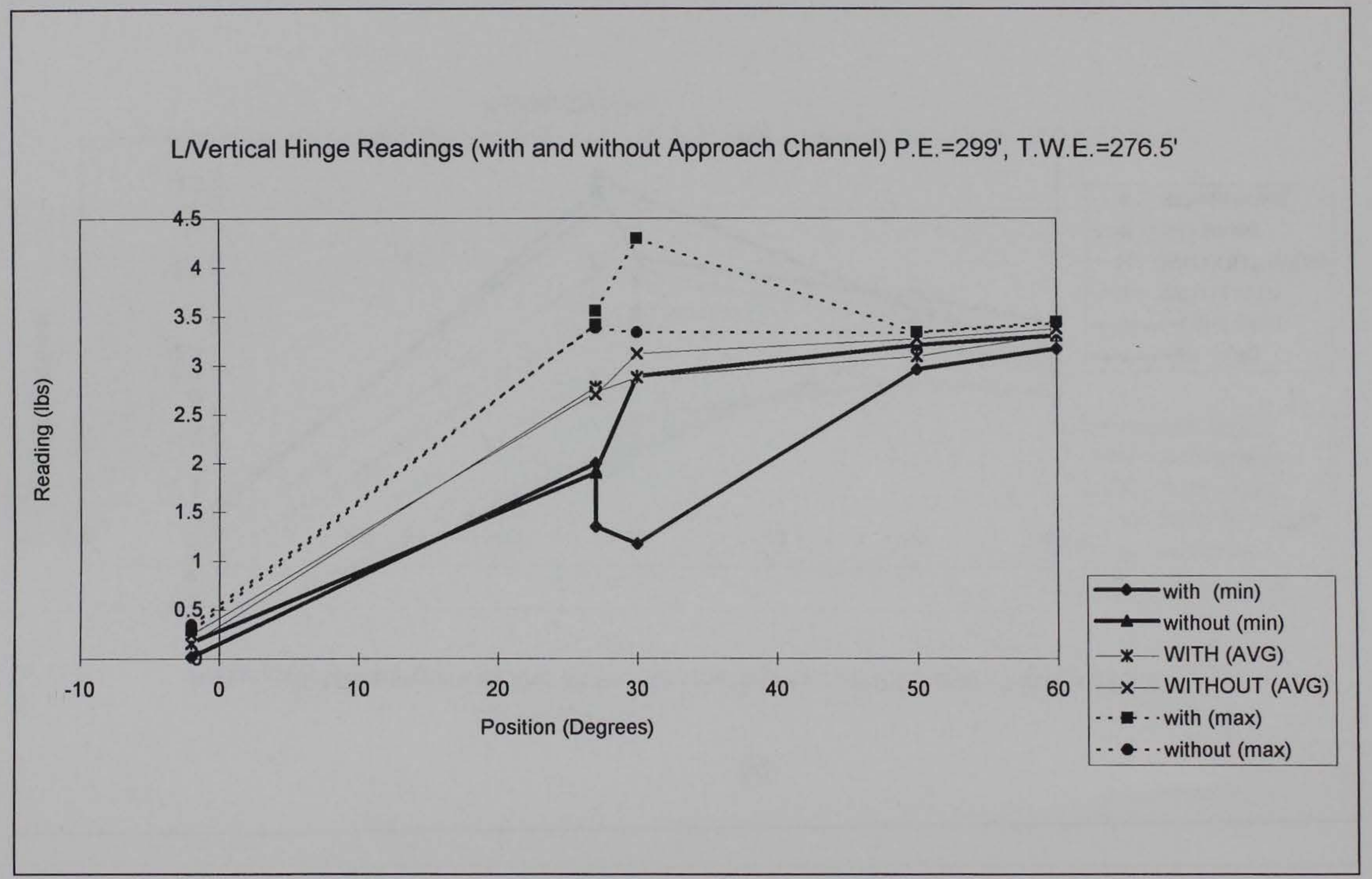

Figure $11 \mathrm{~d}$. Left vertical hinge readings (Sheet 4 of 10) 
L/Horizontal Hinge Readings (with and without Approach Channel) P.E. $=299^{\prime}$, T.W.E. $=276.5^{\prime}$

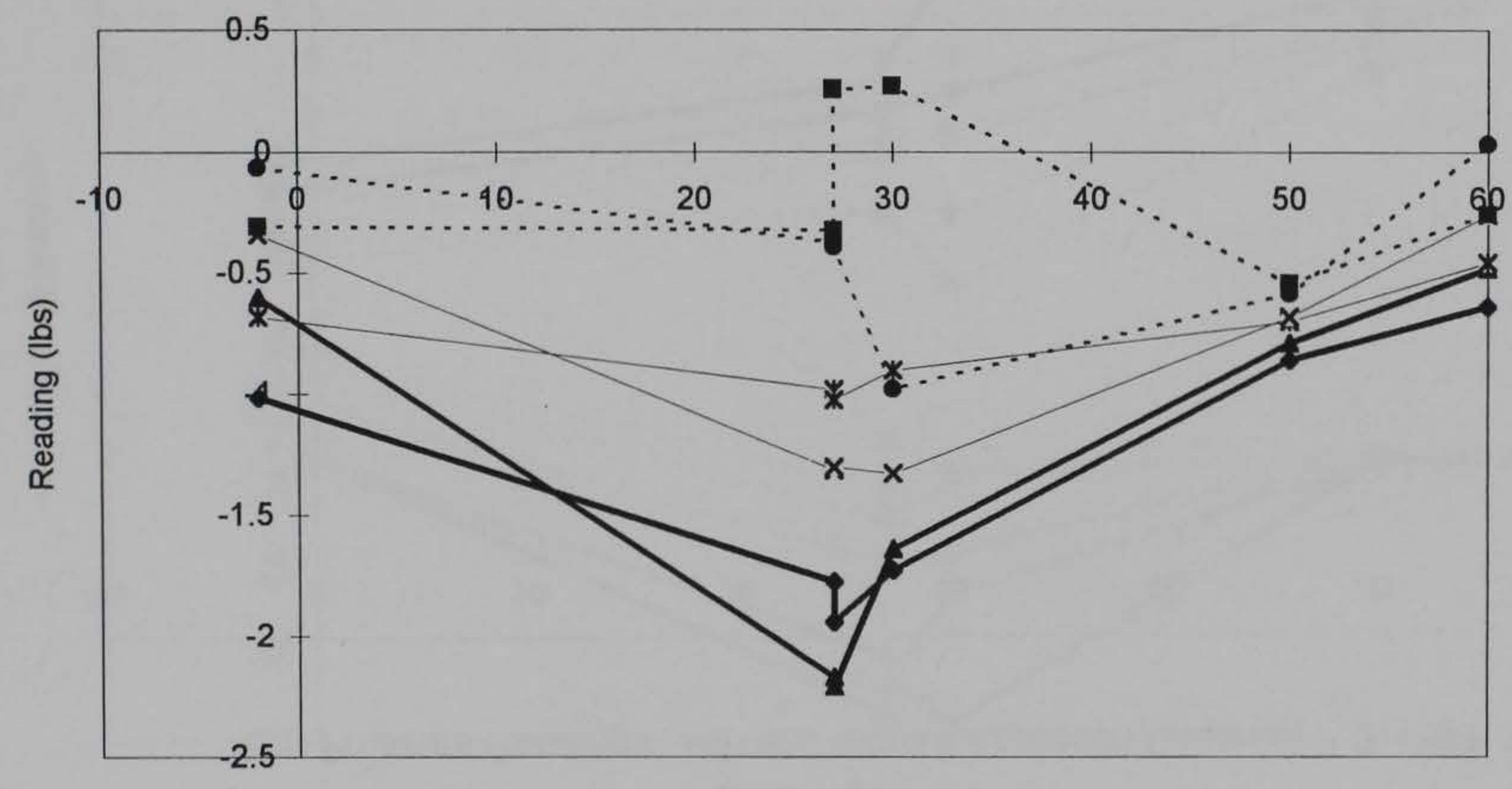

Position (Degrees)

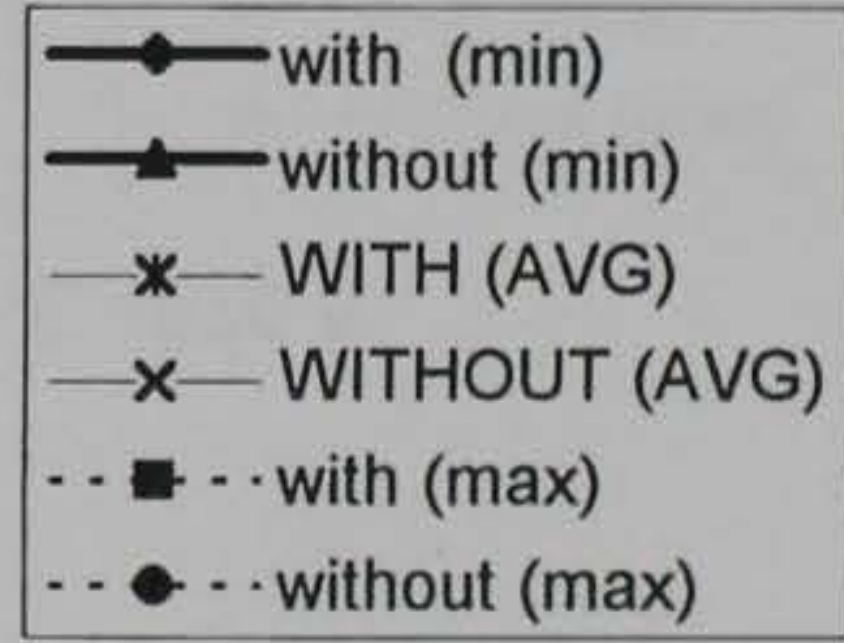

Figure $11 \mathrm{e}$. Left vertical hinge readings (Sheet 5 of 10) 
U/S Pressure Readings (with and without Approach Channel) P.E. $=299^{\prime}$, T.W.E. $=276.5^{\prime}$

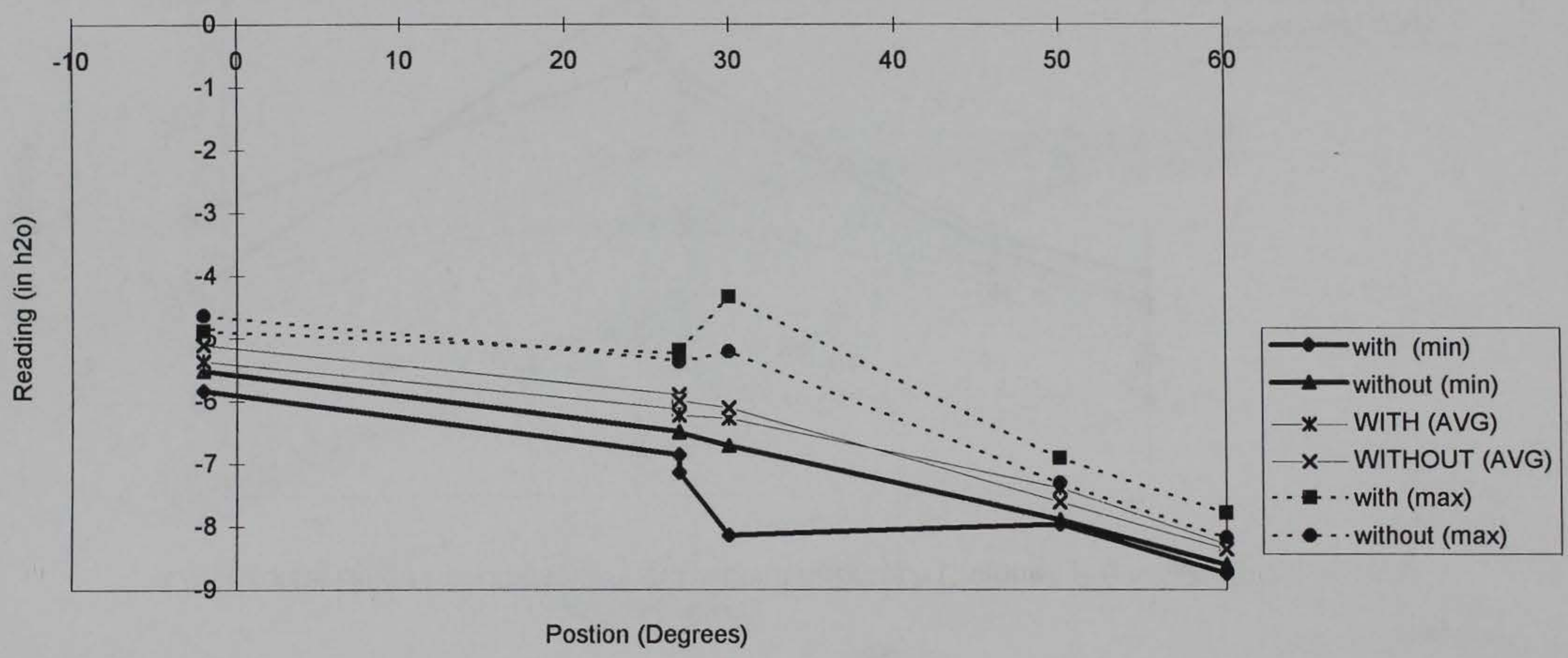

Figure $11 \mathrm{f}$. Upstream pressure readings (Sheet 6 of 10) 


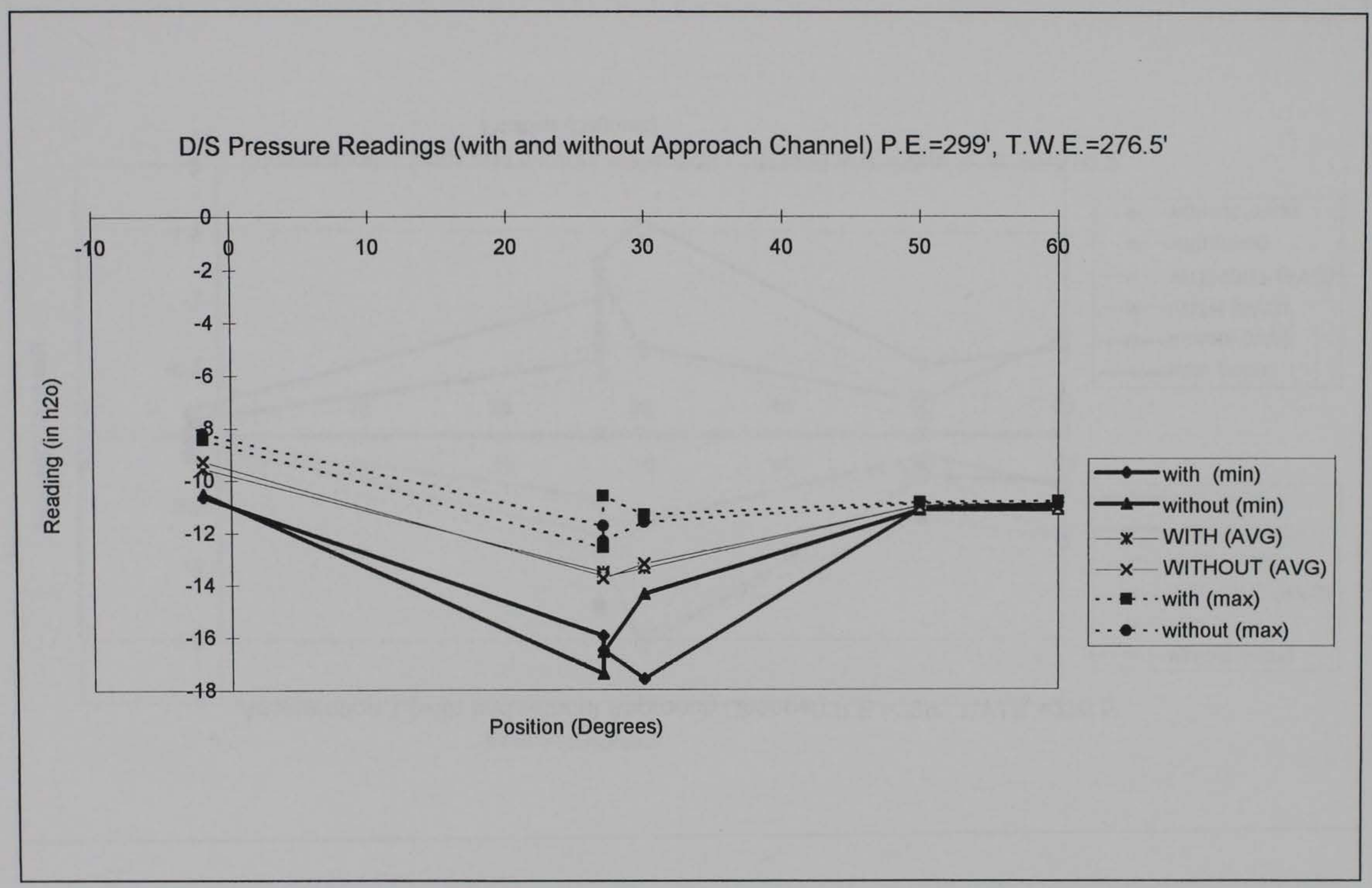

Figure $11 \mathrm{~g}$. Downstream pressure readings (Sheet 7 of 10) 


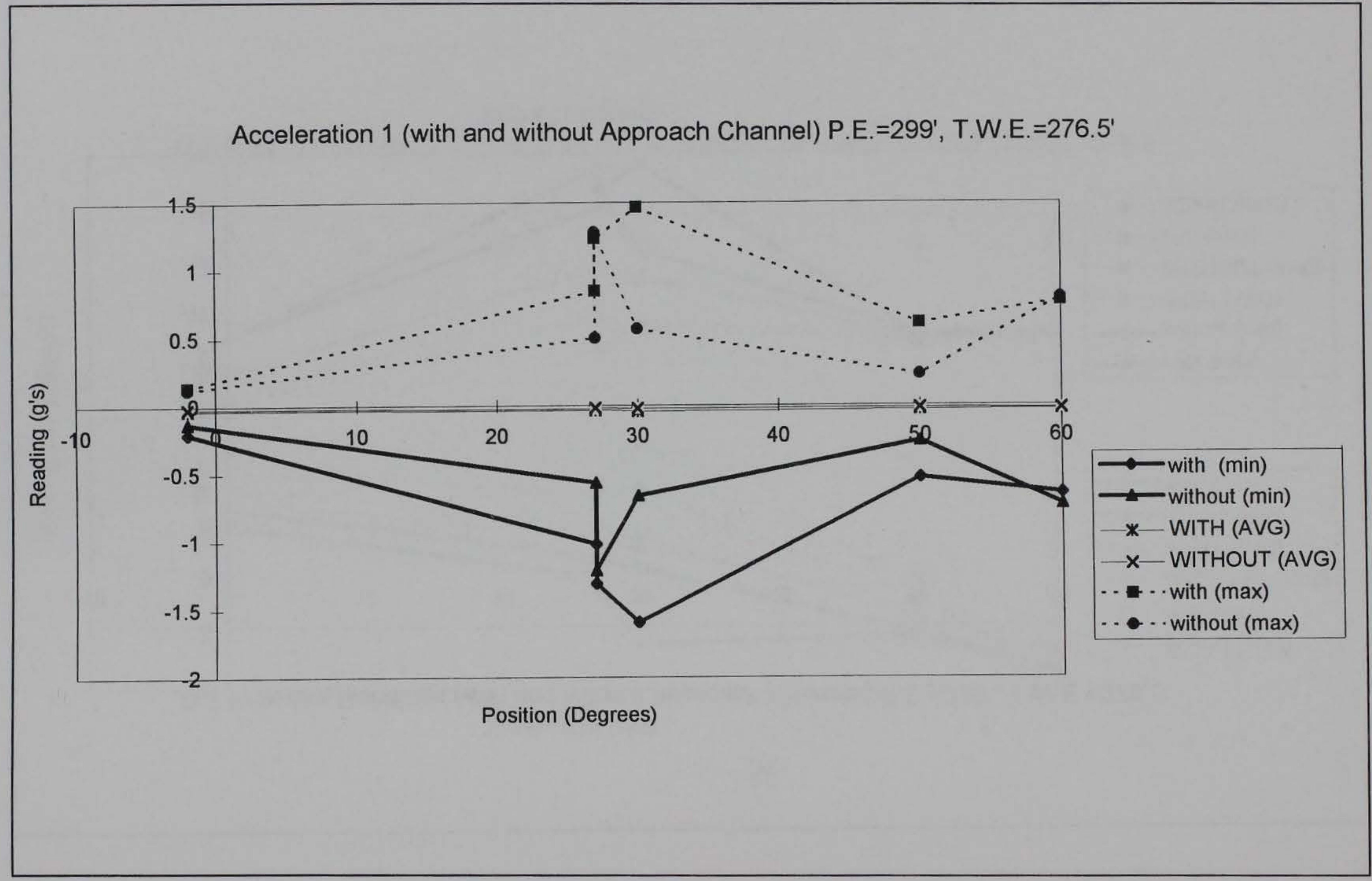

Figure 11 h. Acceleration 1 readings (Sheet 8 of 10) 


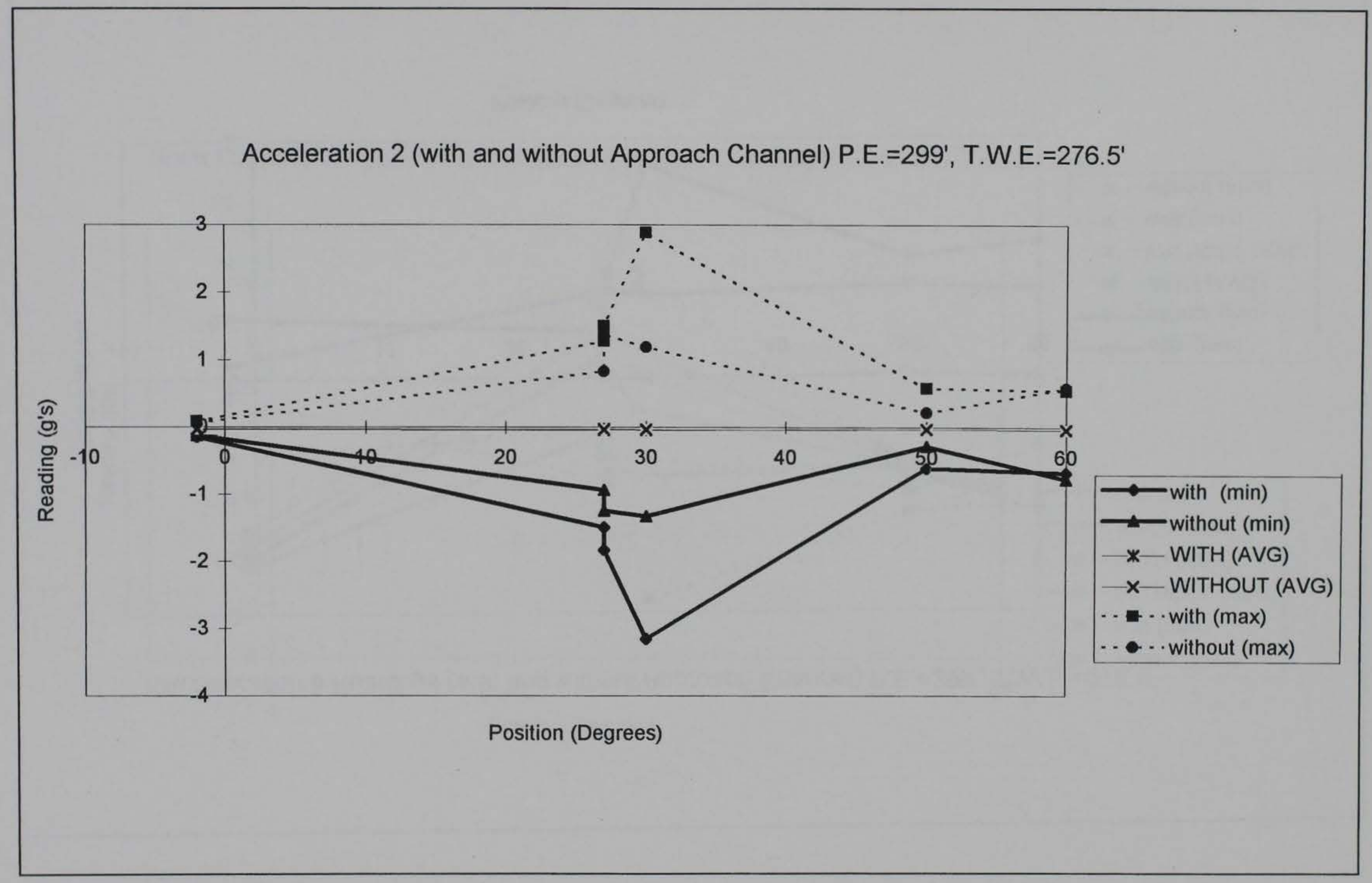

Figure 11i. Acceleration 2 readings (Sheet 9 of 10) 
Acceleration 3 Readings (with and without Approach Channel) P.E. $=299$ ', T.W.E. $=276.5^{\prime}$

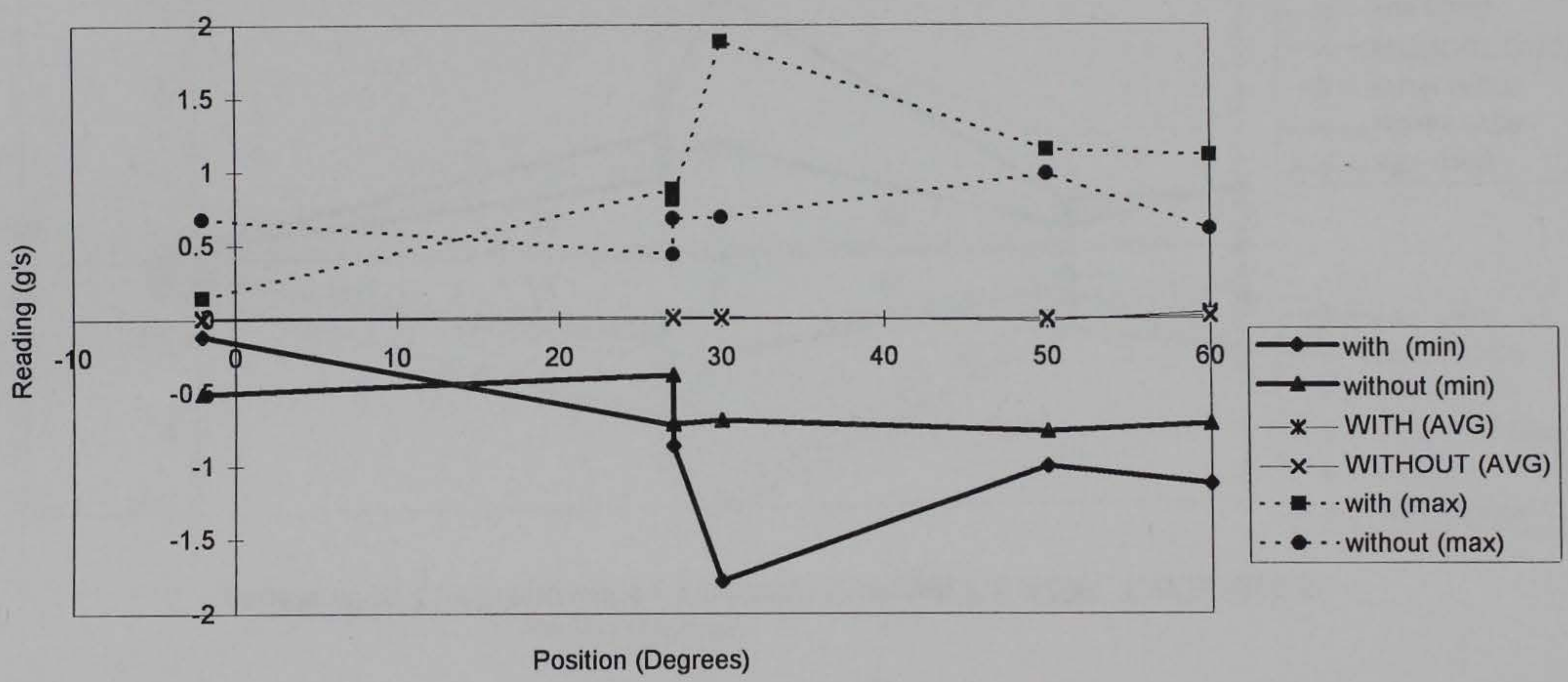

Figure $11 \mathrm{j}$. Acceleration 3 readings (Sheet 10 of 10) 
Shaft Load Readings (with and without Approach Channel) P.E. $=296.5^{\prime}$ T.W.E. $=285.5^{\prime}$
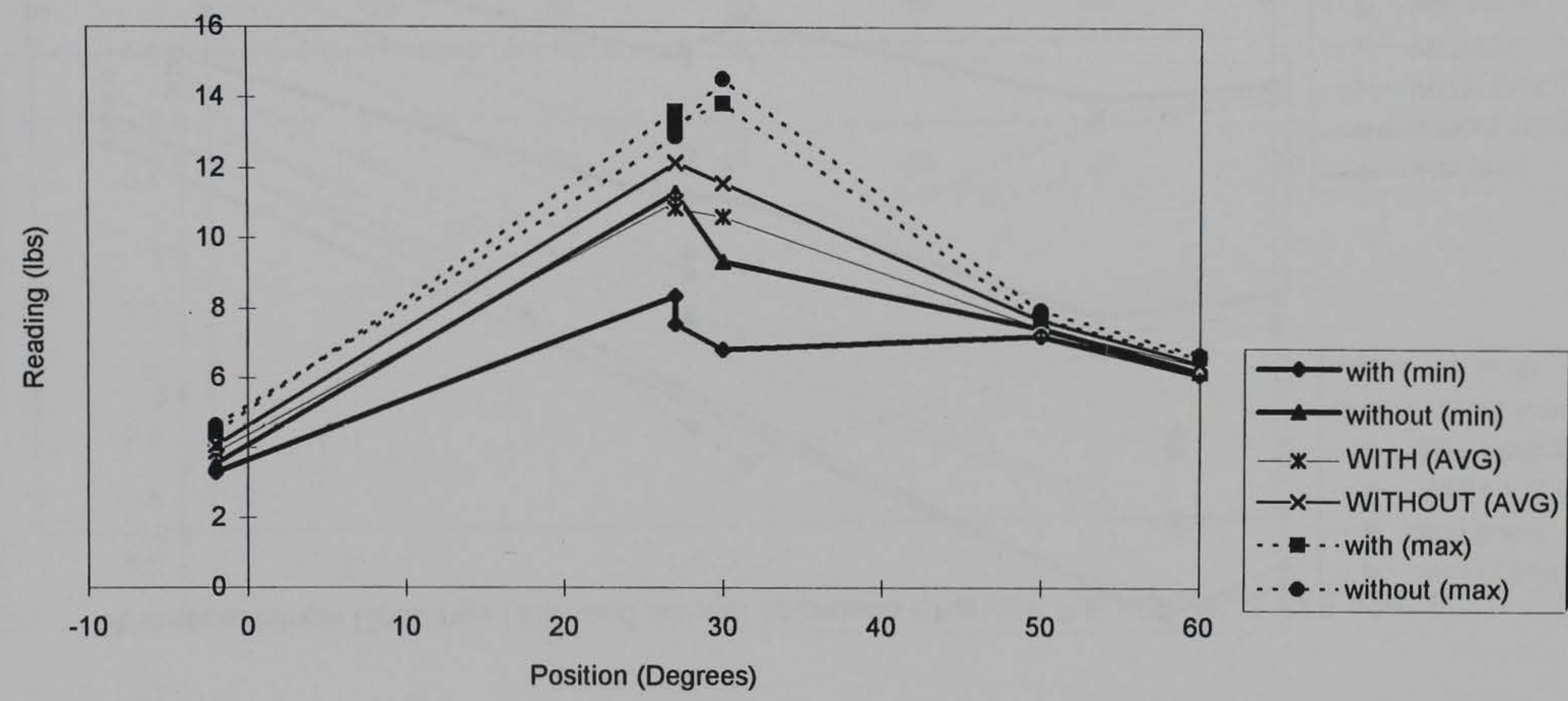

Figure 12. Time-domain data comparison for test set \#4. a. Shaft load readings (Sheet 1 of 10) 
R/Nertical Hinge Readings (with and without Approach Channel) P.E. $=296.5^{\prime}$, T.W.E. $=285.5^{\prime}$

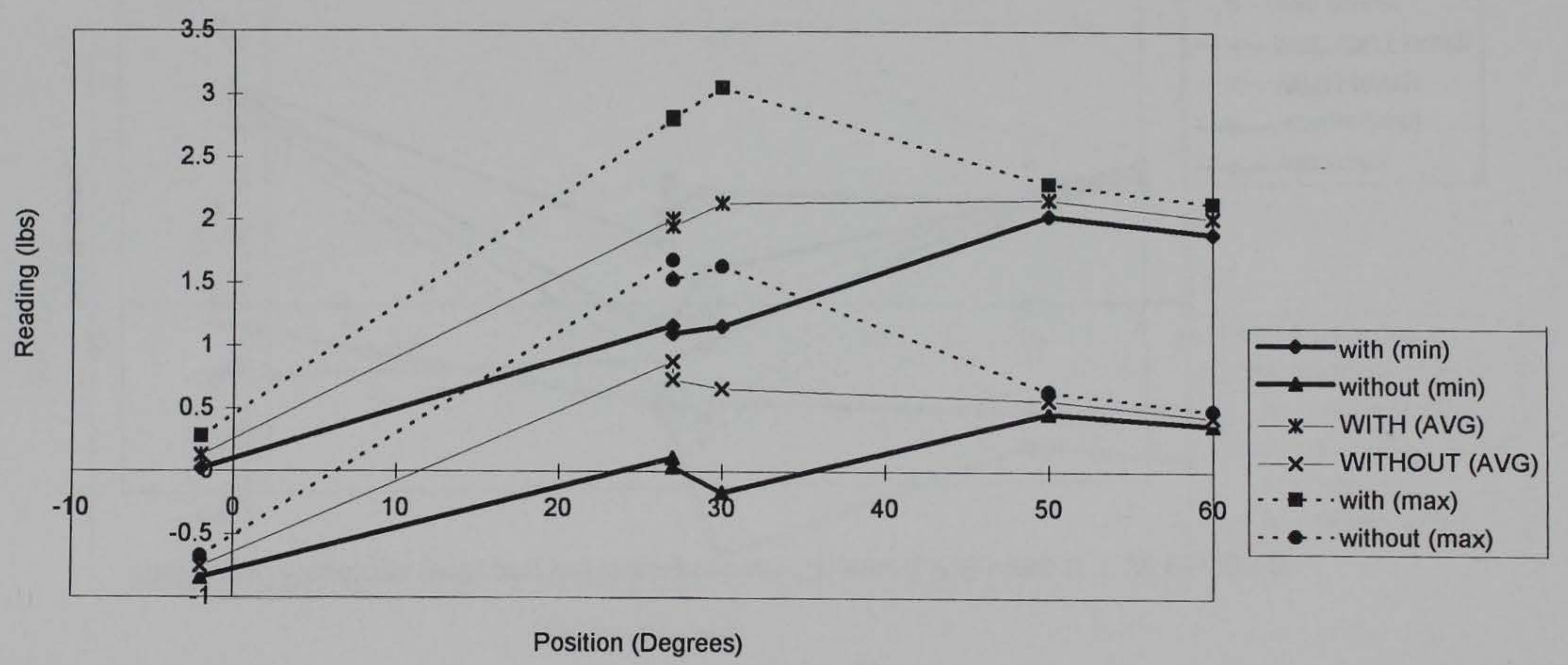

Figure $12 \mathrm{~b}$. Right vertical hinge readings (Sheet 2 of 10) 
R/Horizontal Hinge Readings (with and without Approach Channel) P.E.=296.5', T.W.E. $=285.5^{\prime}$

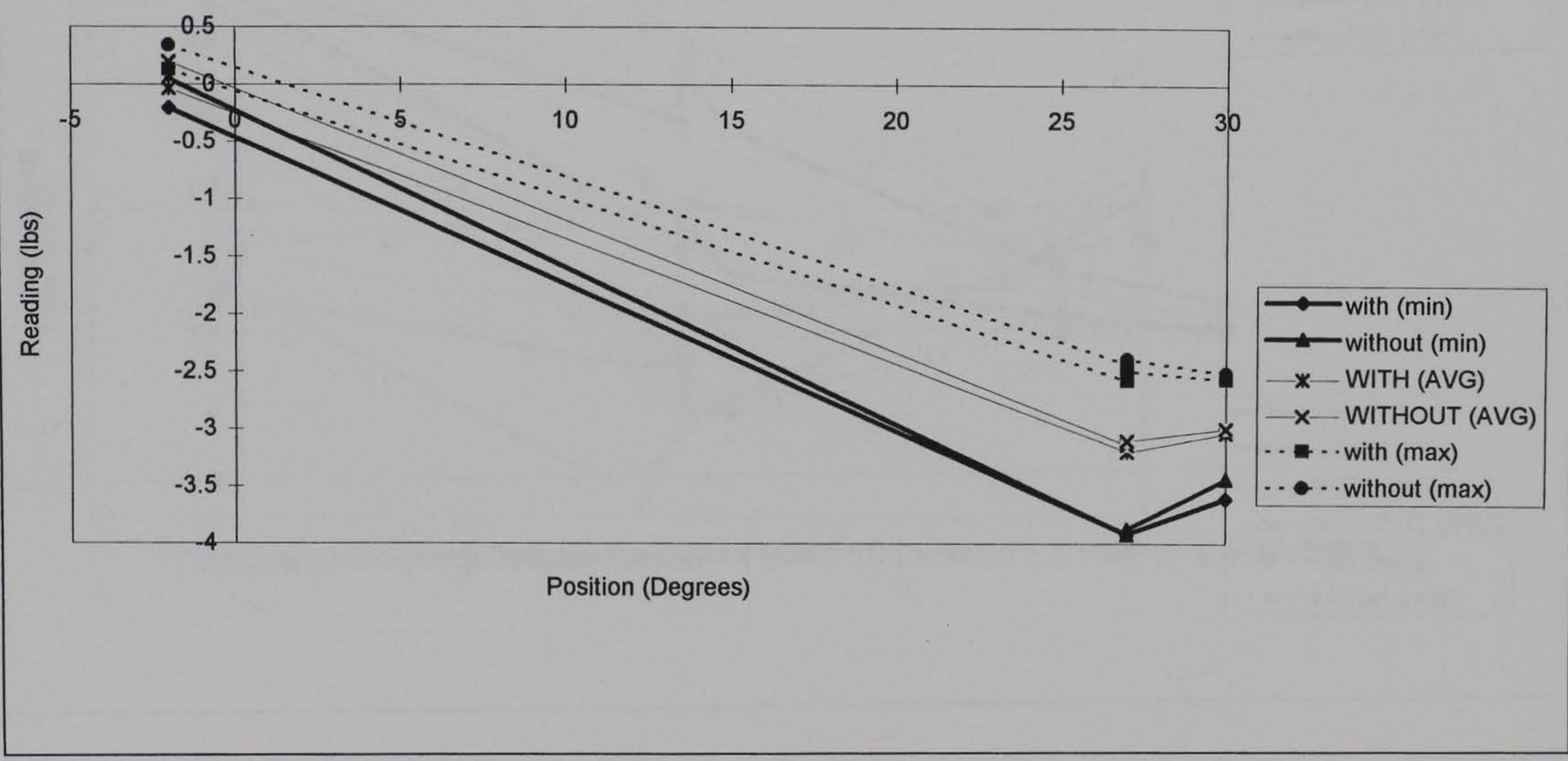

Figure 12c. Right horizontal hinge readings (Sheet 3 of 10) 


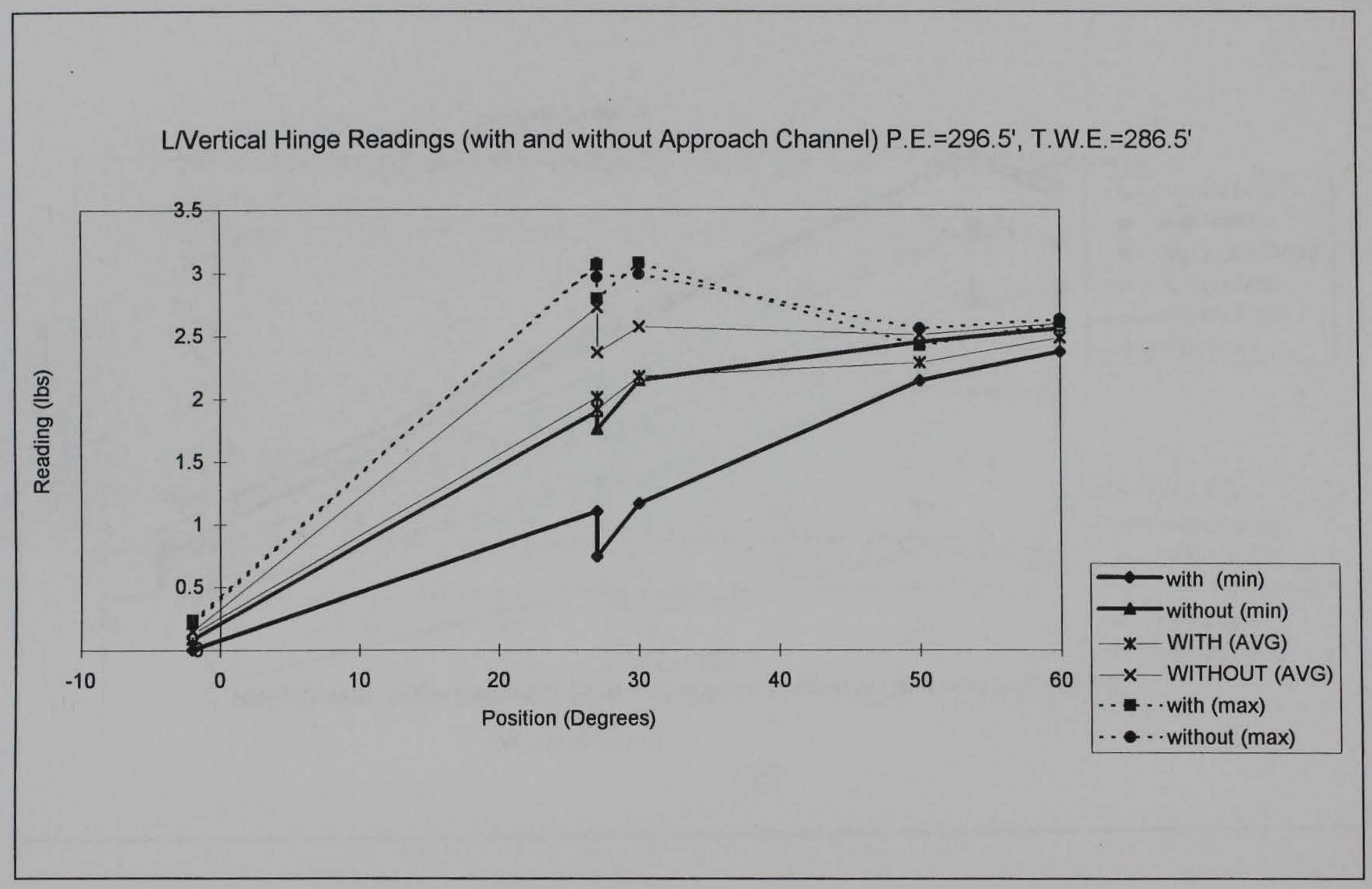

Figure $12 \mathrm{~d}$. Left vertical hinge readings (Sheet 4 of 10) 
L/Horizontal Hinge Readings (with and without Approach Channel) P.E. $=296.5$ ',

T.W.E. $=286.5^{\prime}$
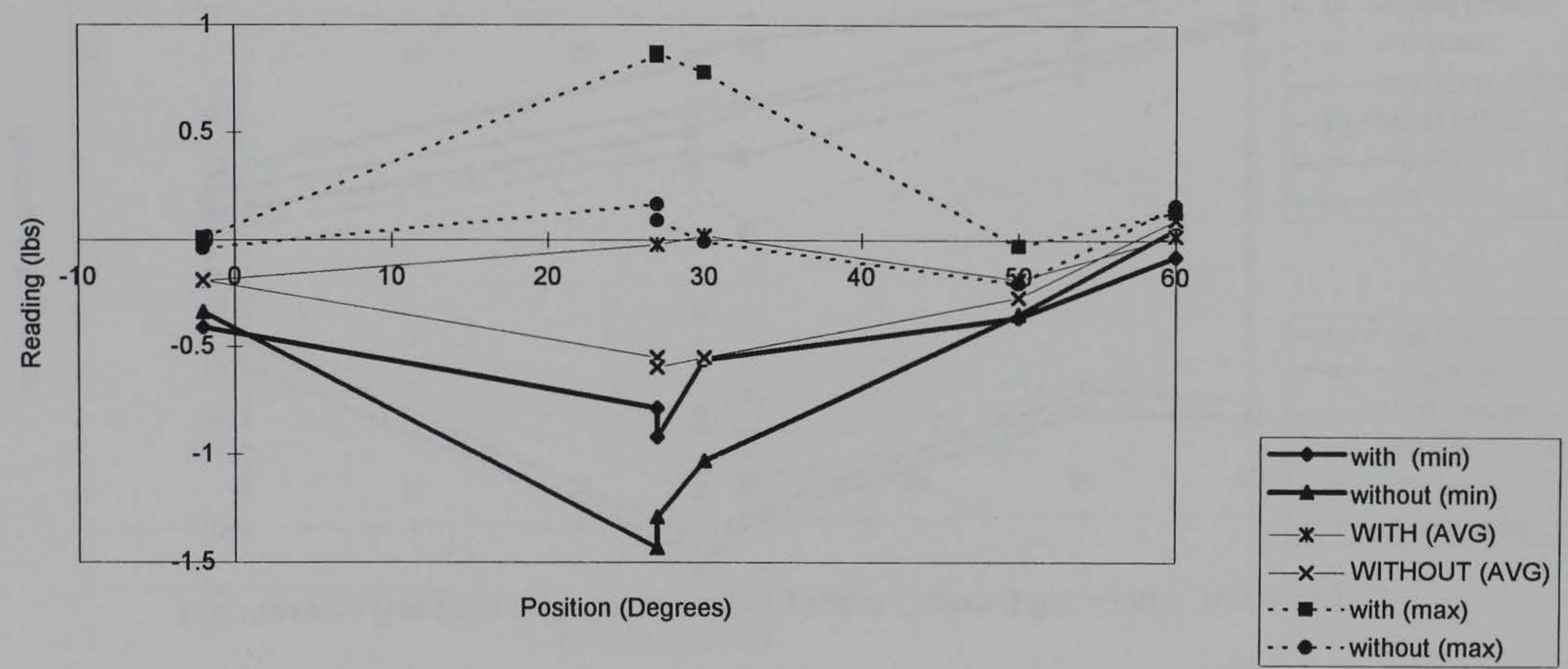

Figure $12 \mathrm{e}$. Left horizontal hinge readings (Sheet 5 of 10) 


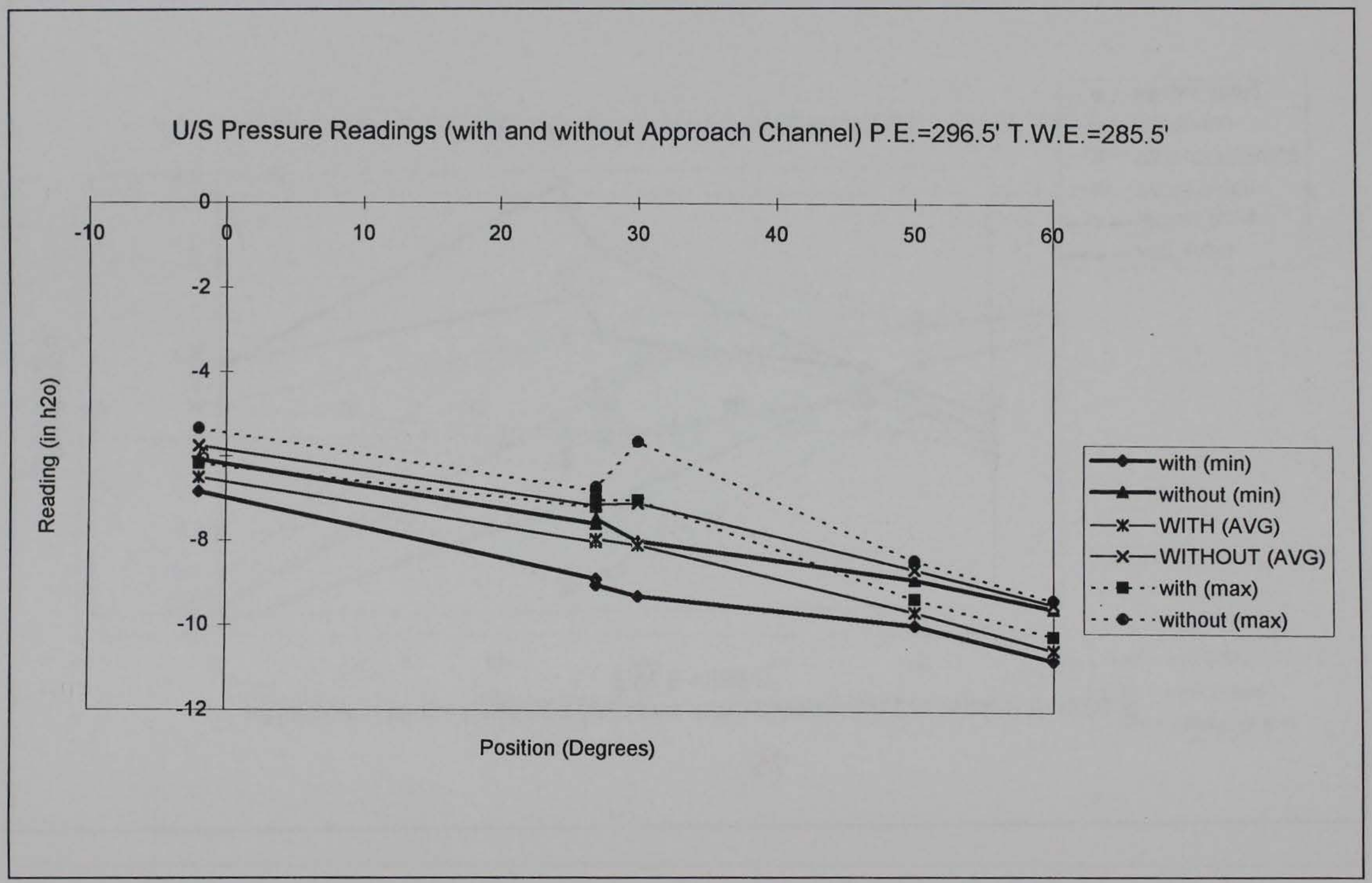

Figure 12f. Upstream pressure readings (Sheet 6 of 10) 


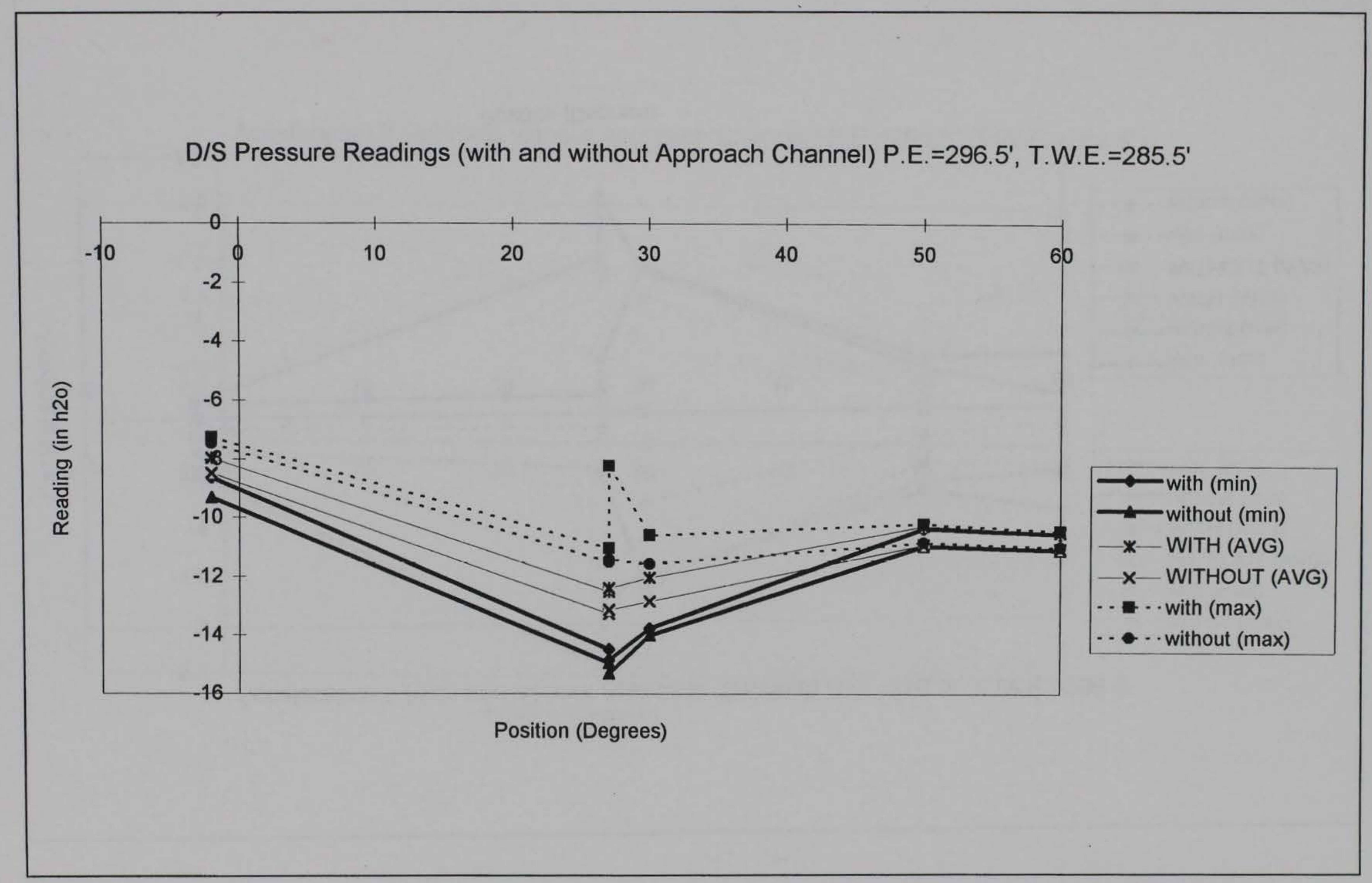

Figure $12 \mathrm{~g}$. Downstream pressure readings (Sheet 7 of 10) 
Acceleration 1 (with and without Approach Channel) P.E. $=296.5^{\prime}$, T.W.E. $=286.5^{\prime}$

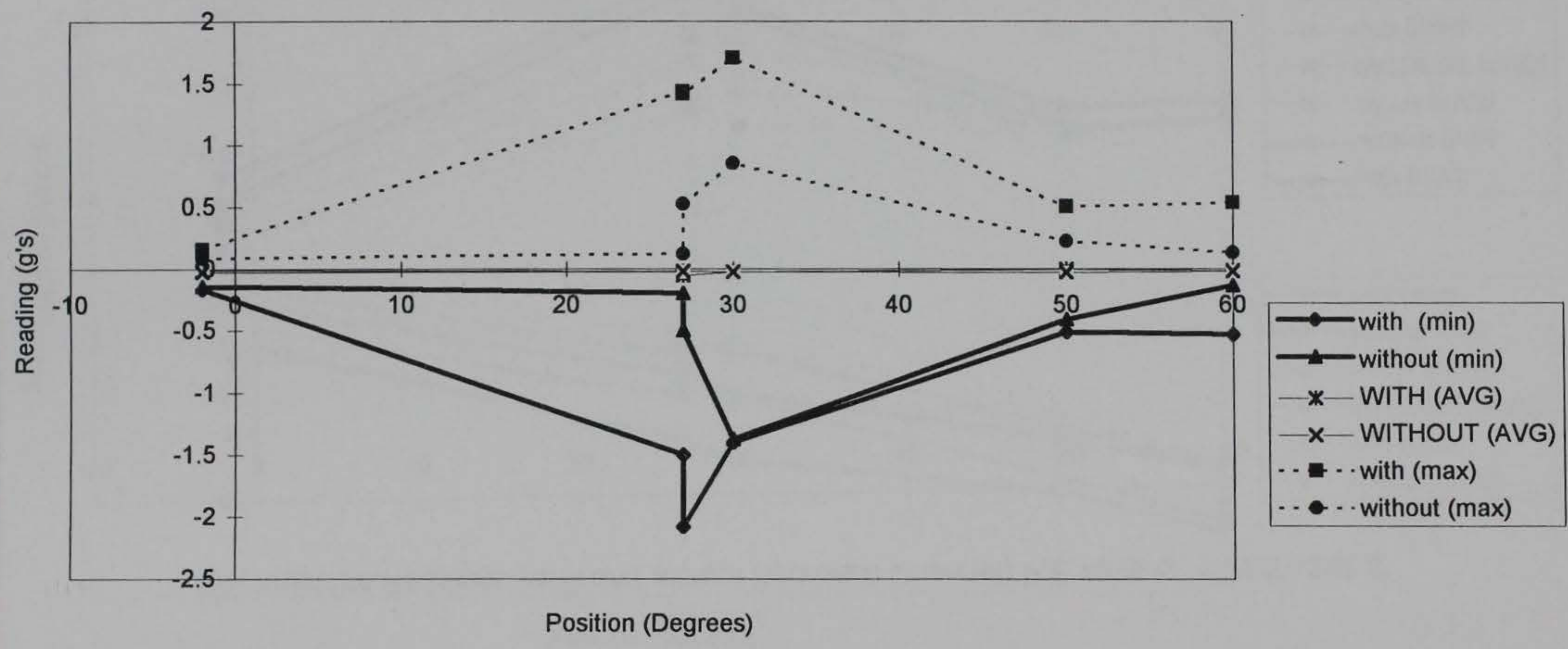

Figure $12 \mathrm{~h}$. Acceleration 1 readings (Sheet 8 of 10) 


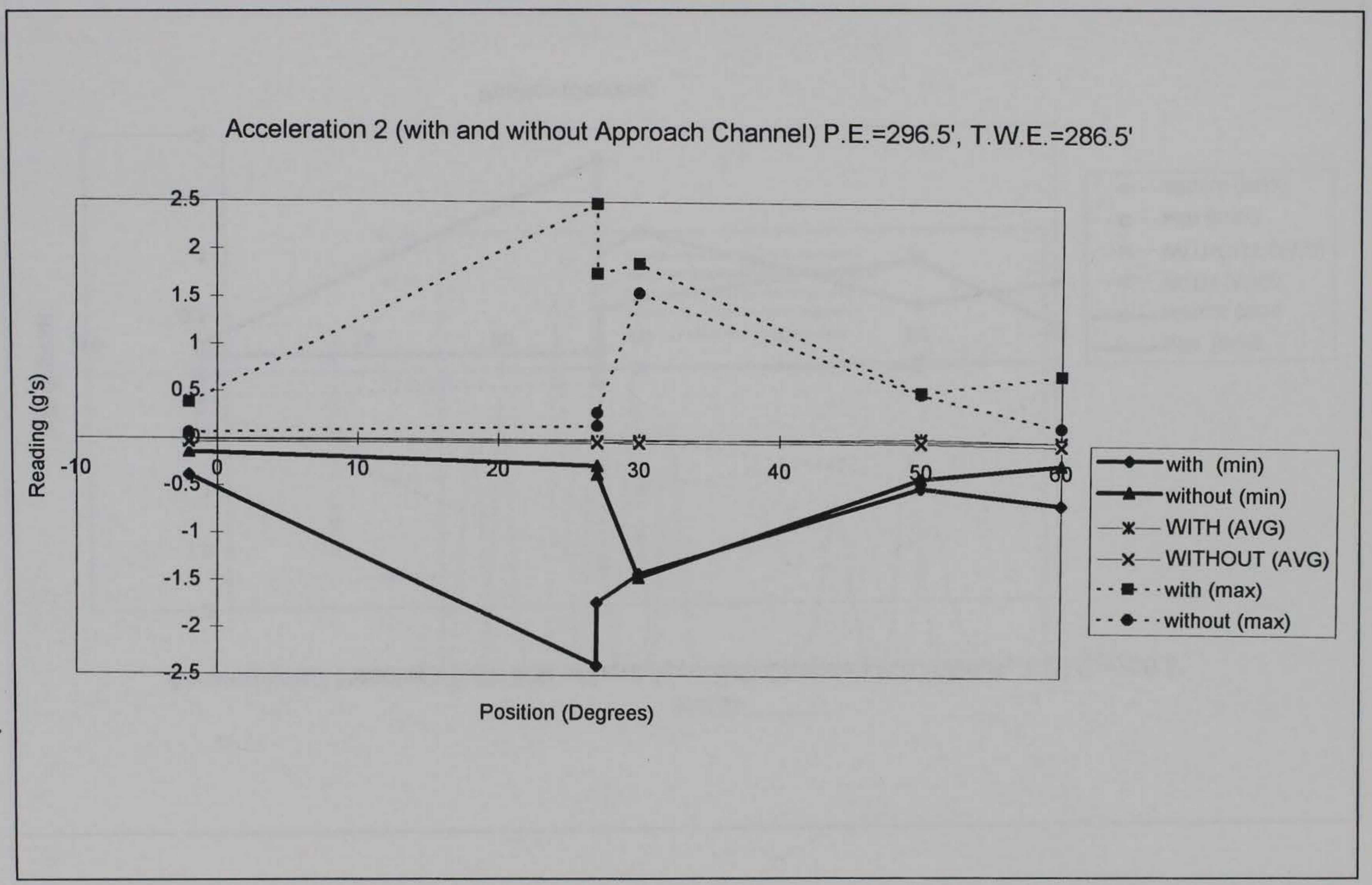

Figure 12i. Acceleration 2 readings (Sheet 9 of 10) 
Acceleration 3 Readings (with and without Approach Channel) P.E. $=296.5^{\prime}$, T.W.E. $=286.5^{\prime}$

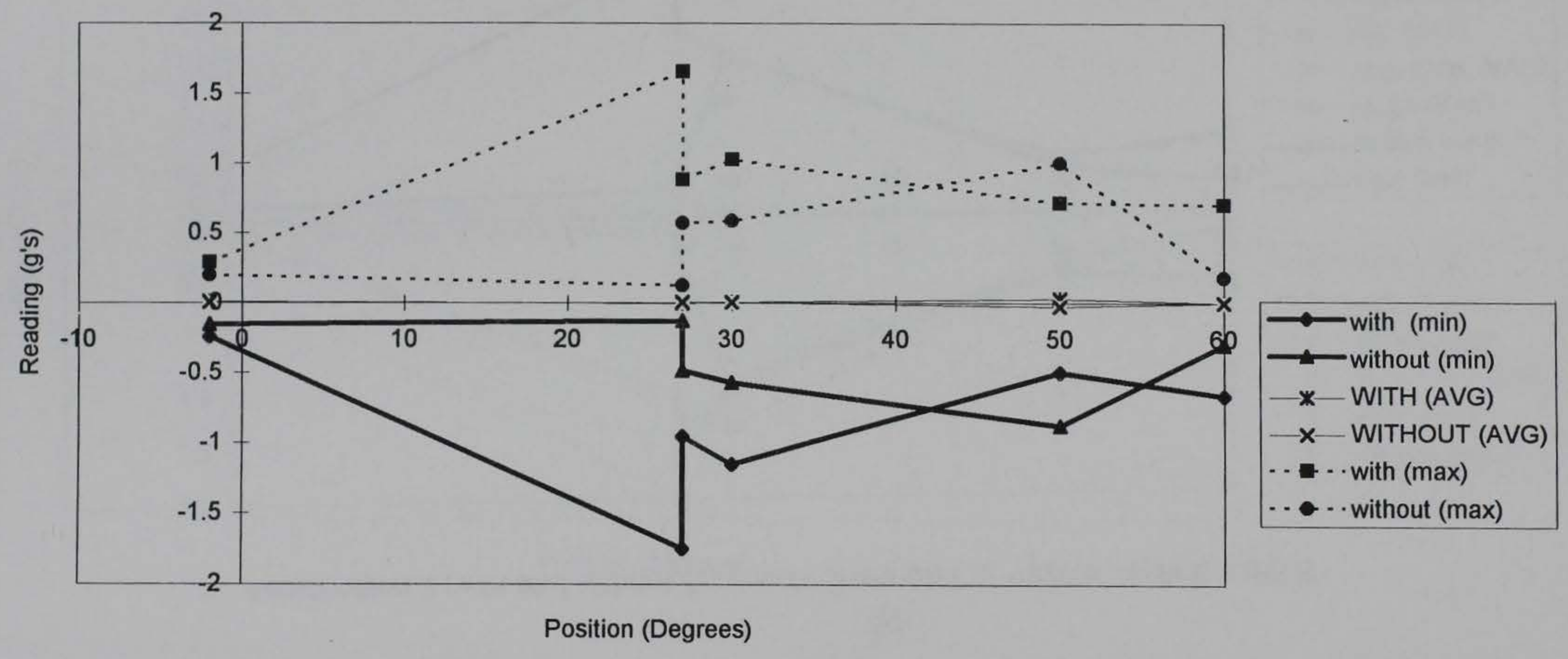

Figure $12 \mathrm{j}$. Acceleration 3 readings (Sheet 10 of 10) 


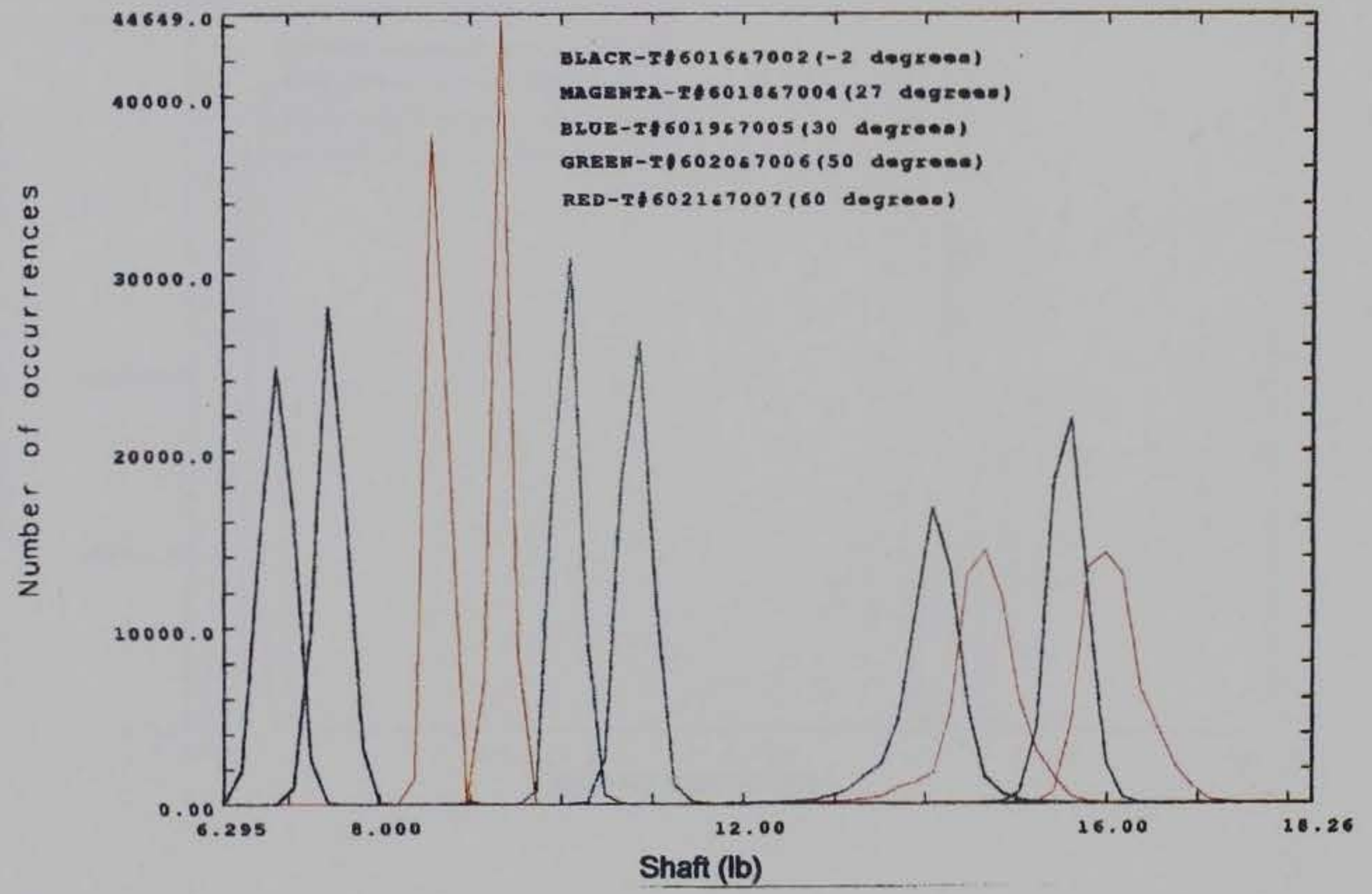

Figure 13. Distribution of response magnitudes for test set \#3. a. Shaft load (Sheet 1 of 10) 


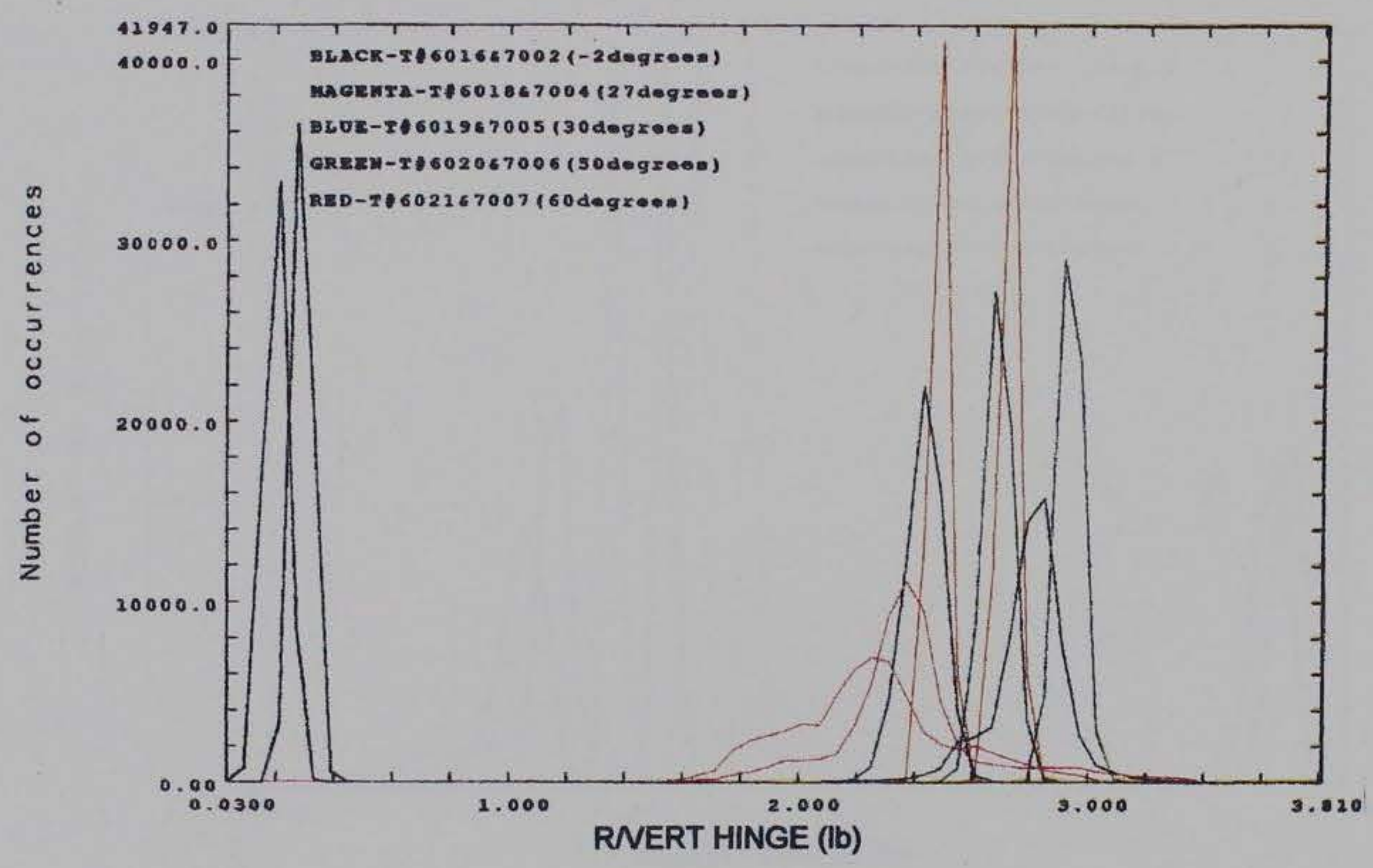

Figure 13b. Right vertical hinge (Sheet 2 of 10 ) 


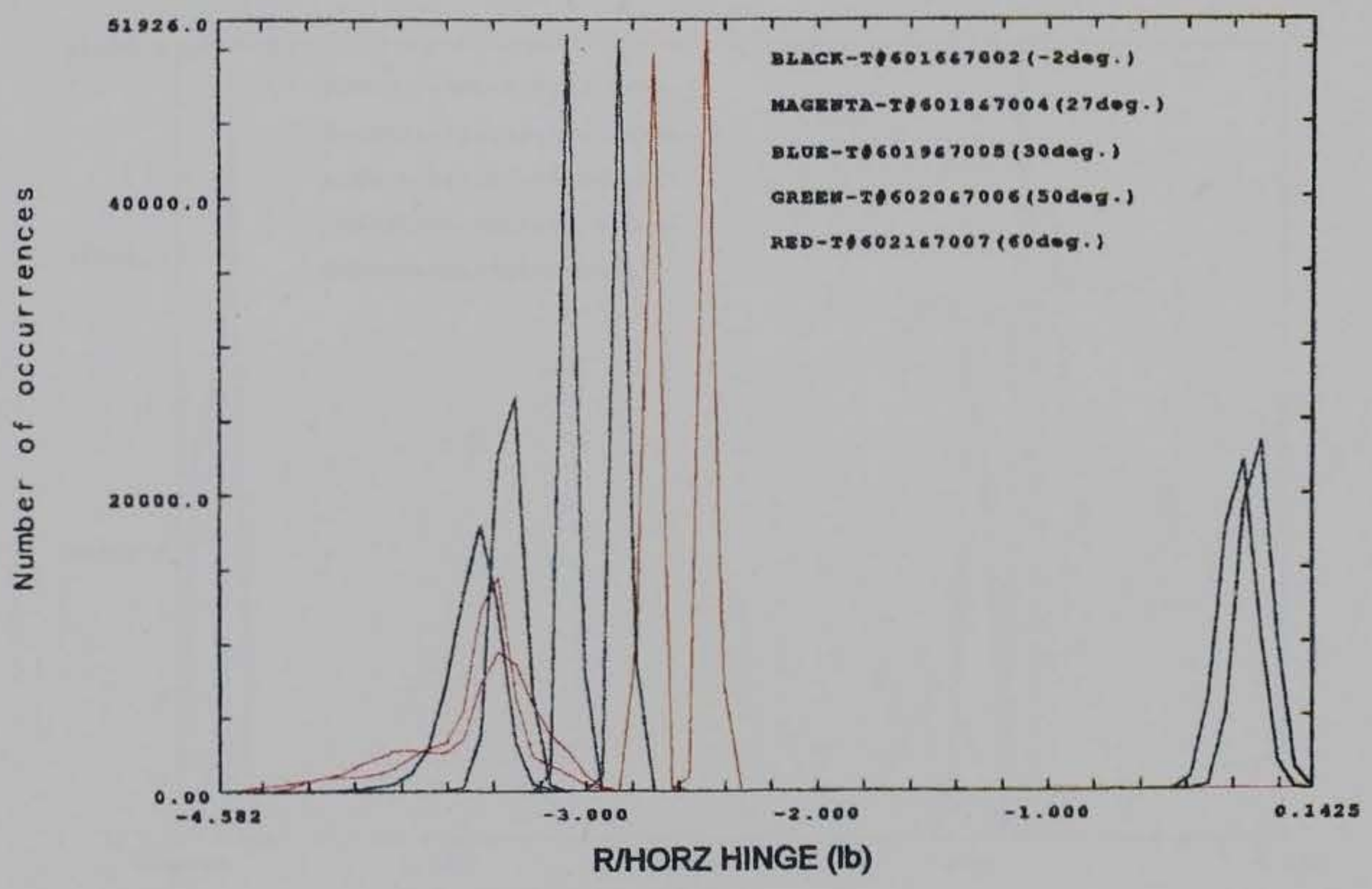

Figure 13c. Right horizontal hinge (Sheet 3 of 10) 


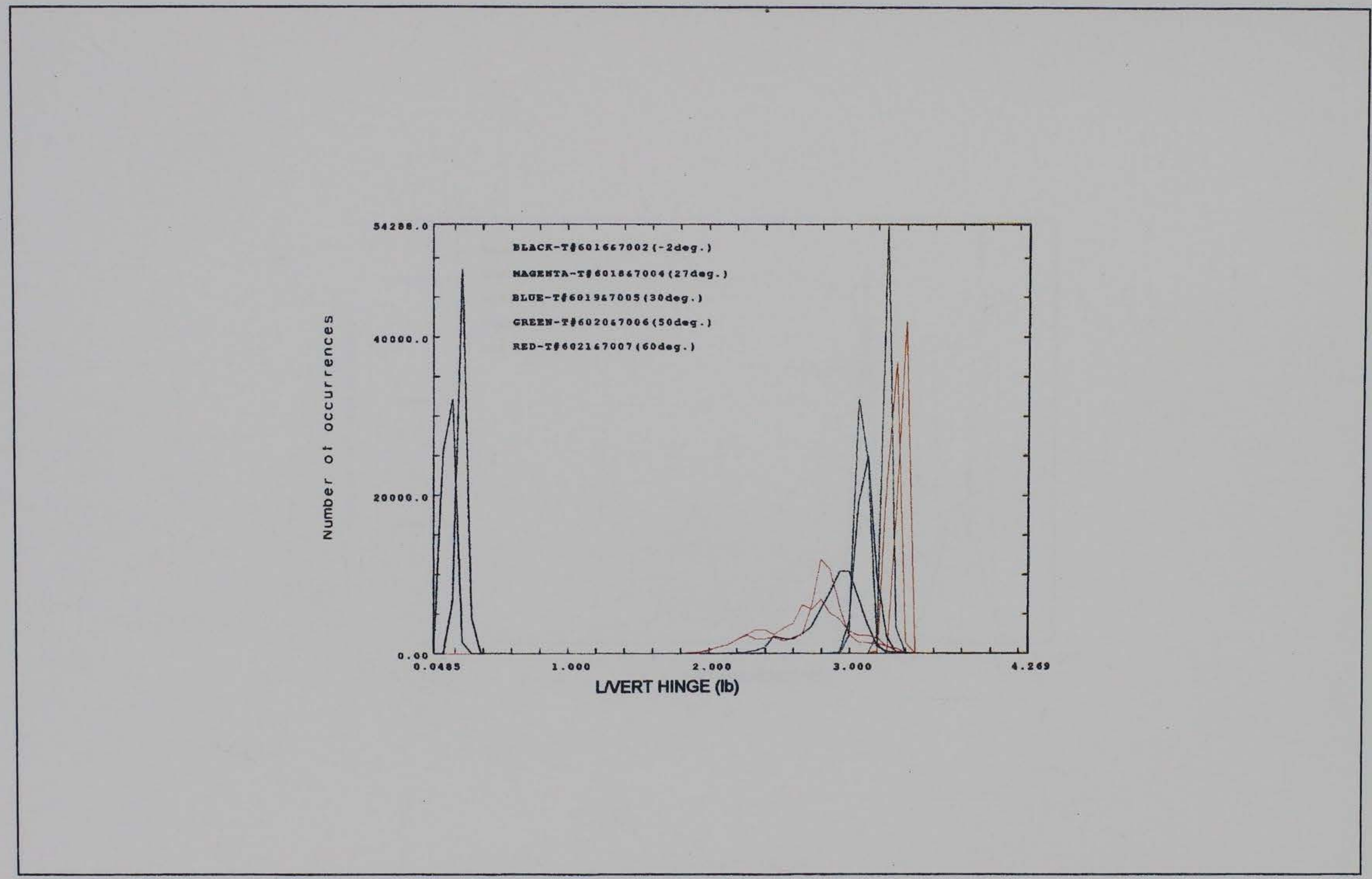

Figure 13d. Left vertical hinge (Sheet 4 of 10) 


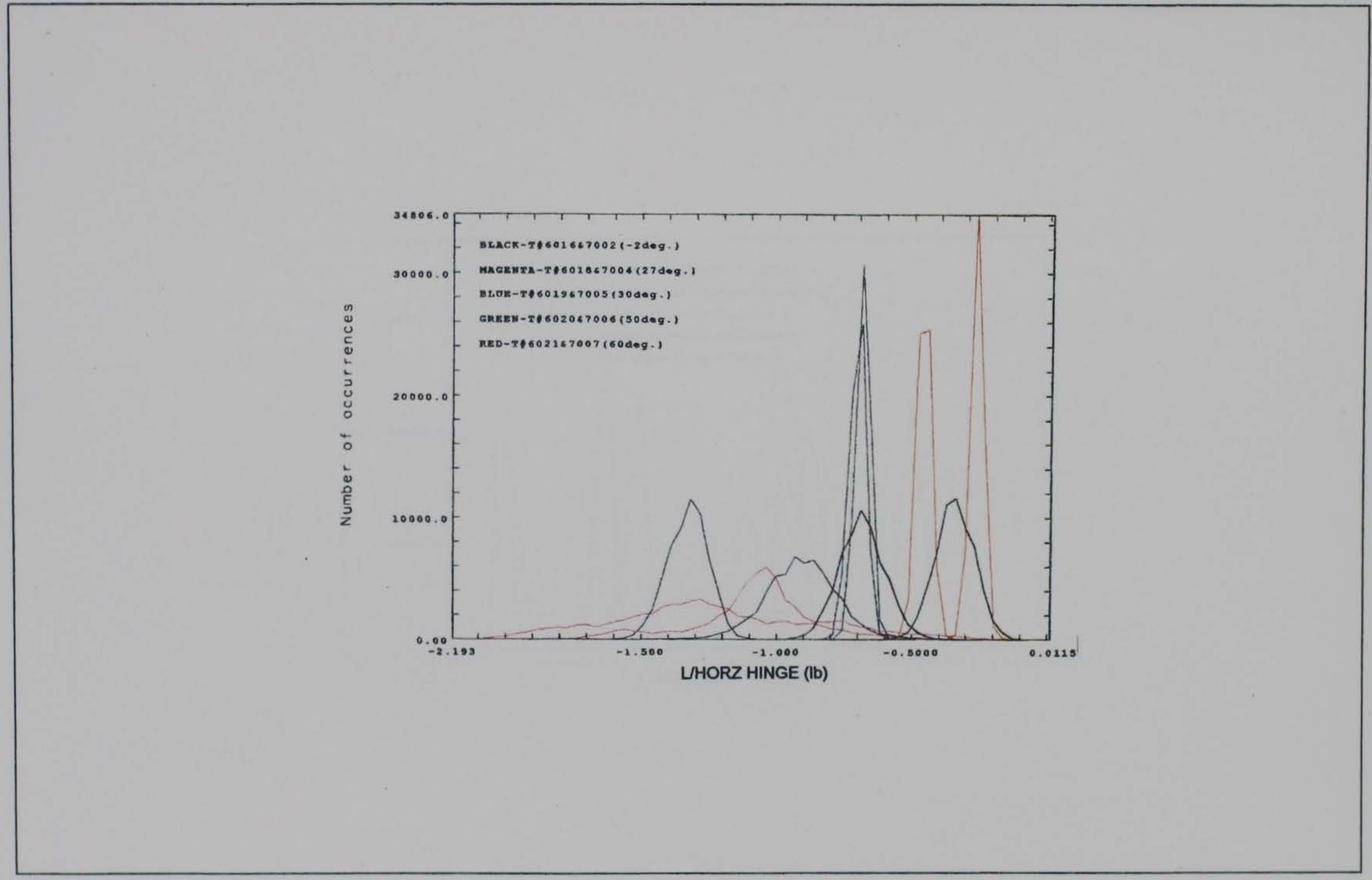

Figure 13e. Left horizontal hinge (Sheet 5 of 10) 


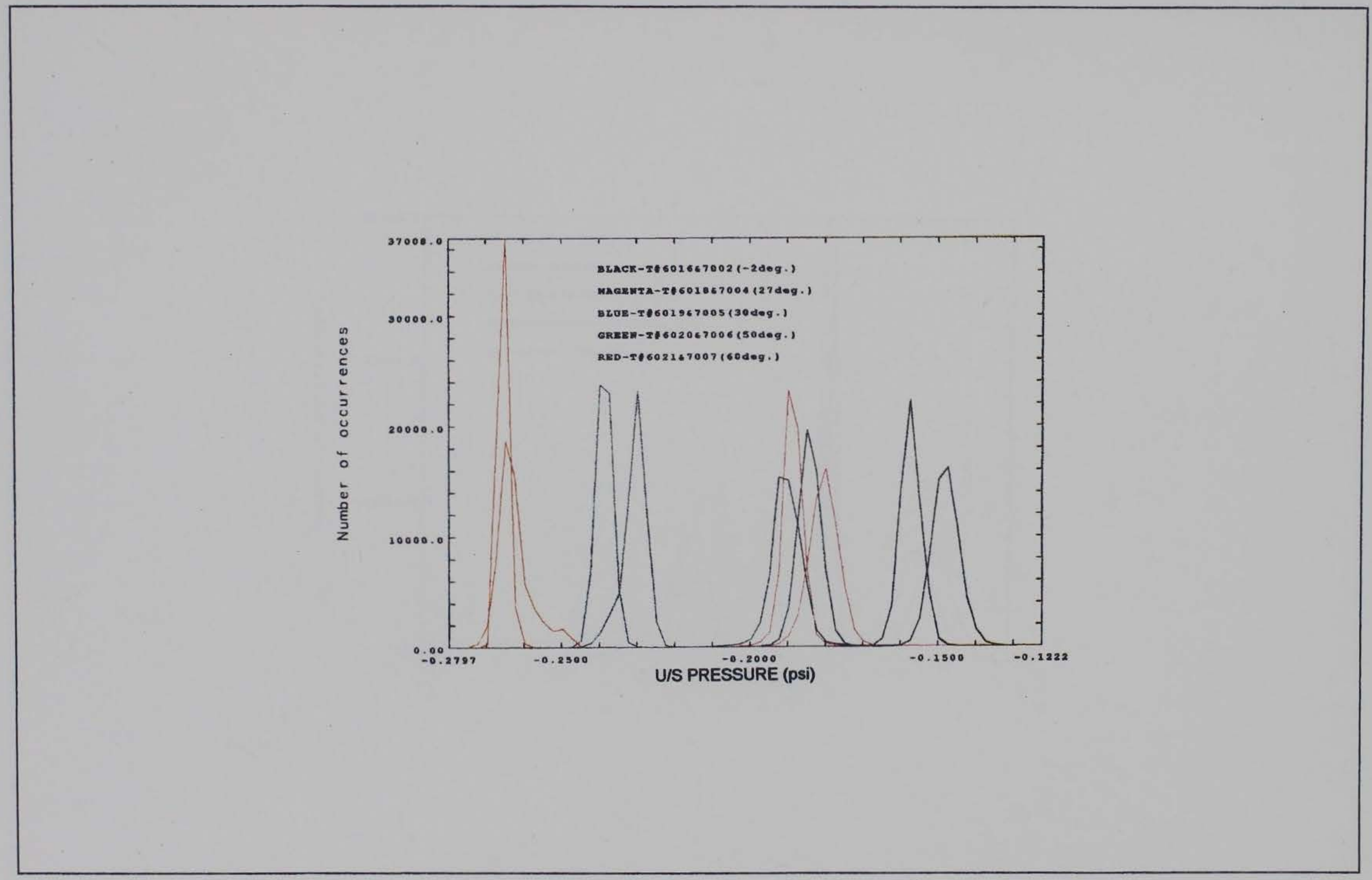

Figure 13f. Upstream pressure $(+0.394)$ (Sheet 6 of 10) 


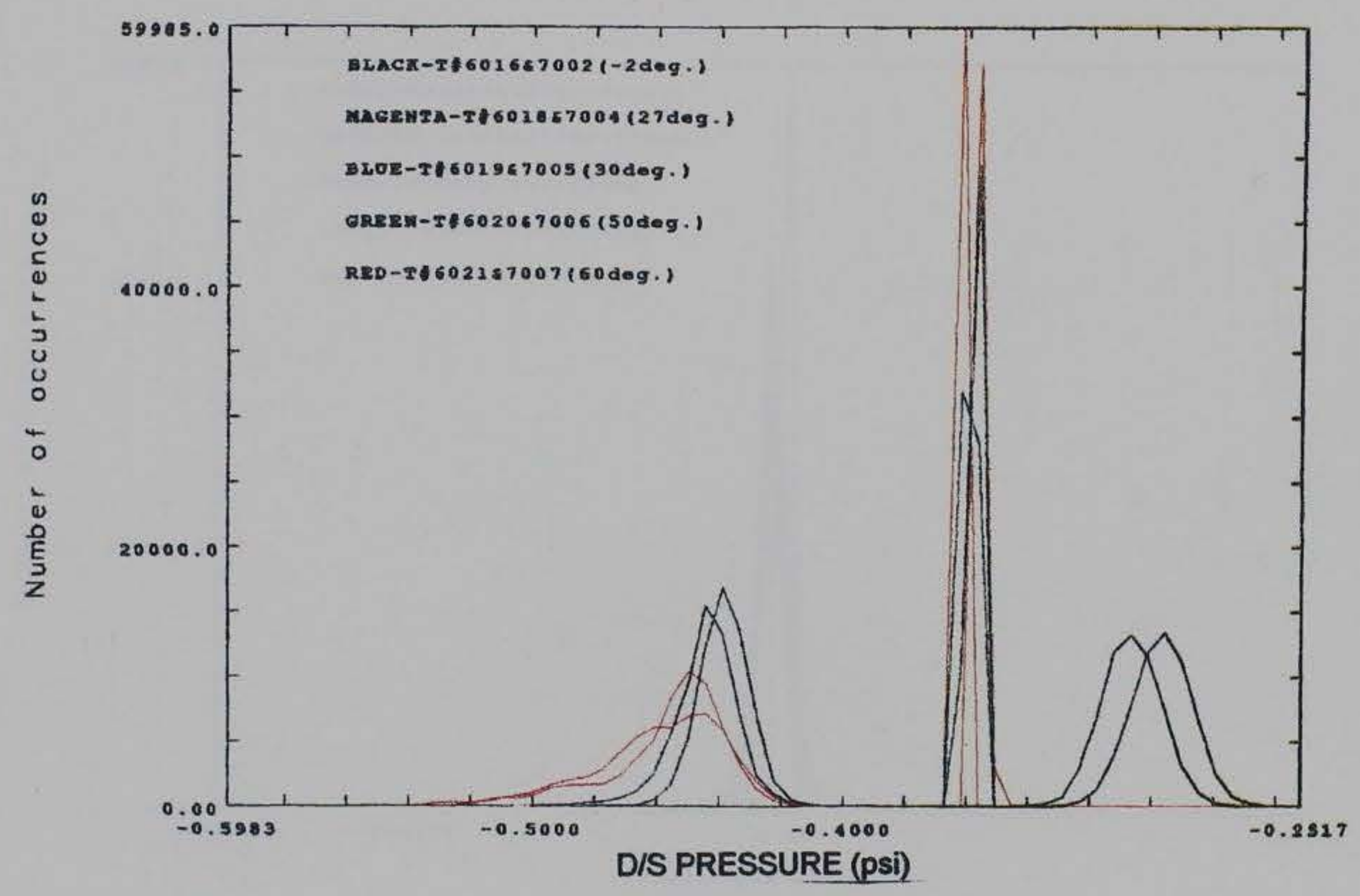

Figure $13 \mathrm{~g}$. Downstream pressure $(+0.4063)$ (Sheet 7 of 10 ) 


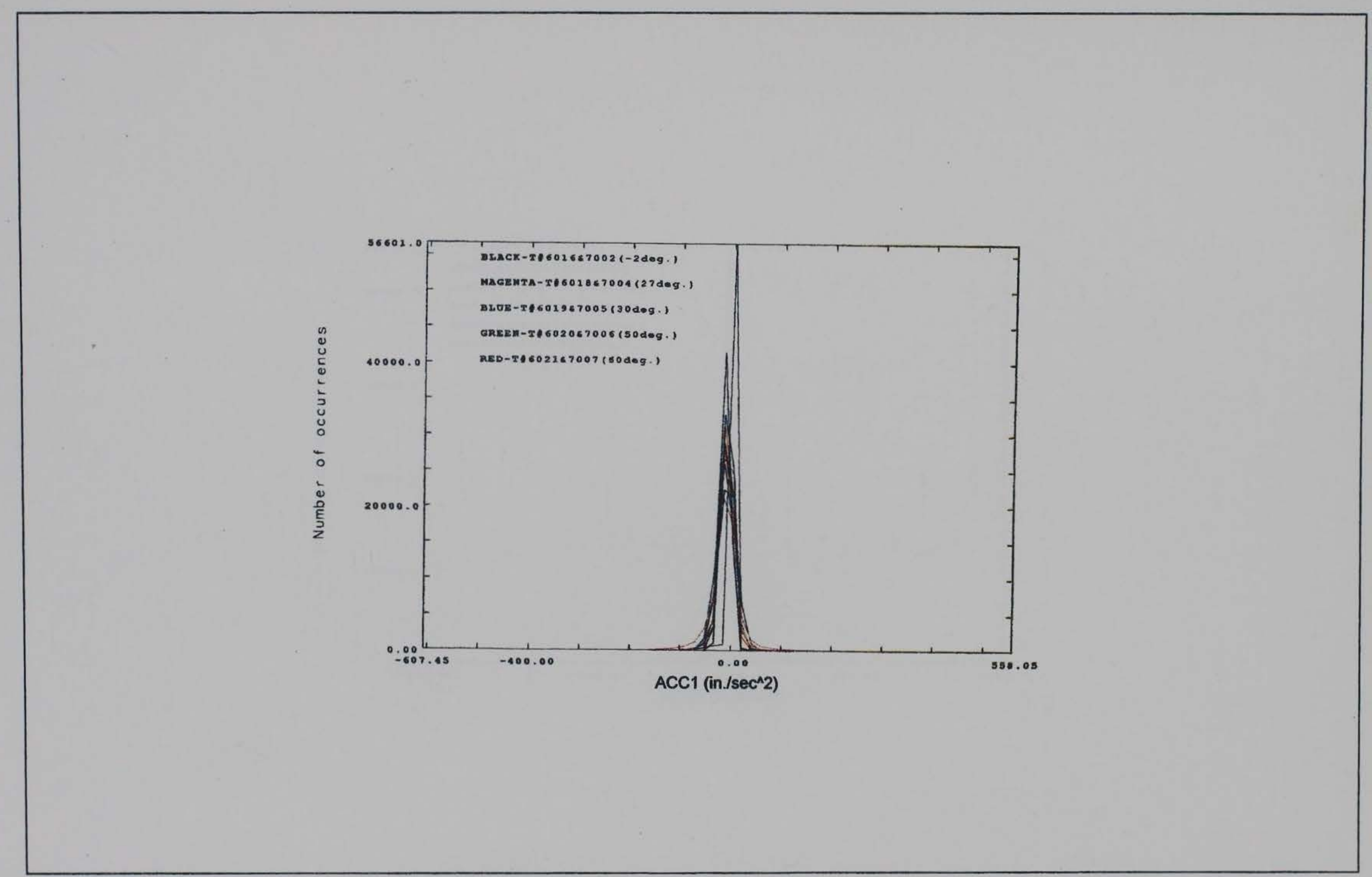

Figure $13 \mathrm{~h}$. Acceleration 1 (Sheet 8 of 10 ) 


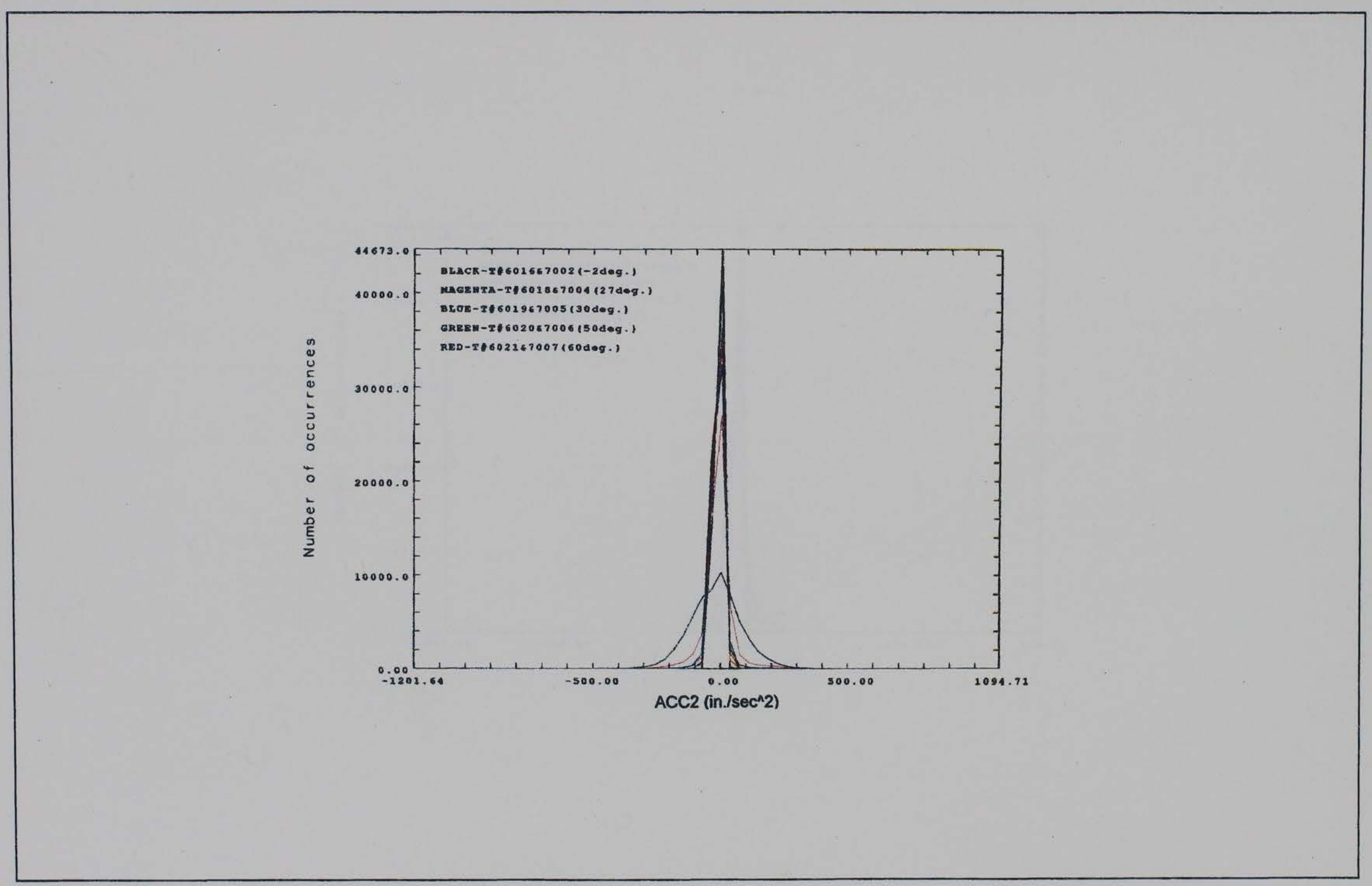

Figure 13i. Acceleration 2 (Sheet 9 of 10) 


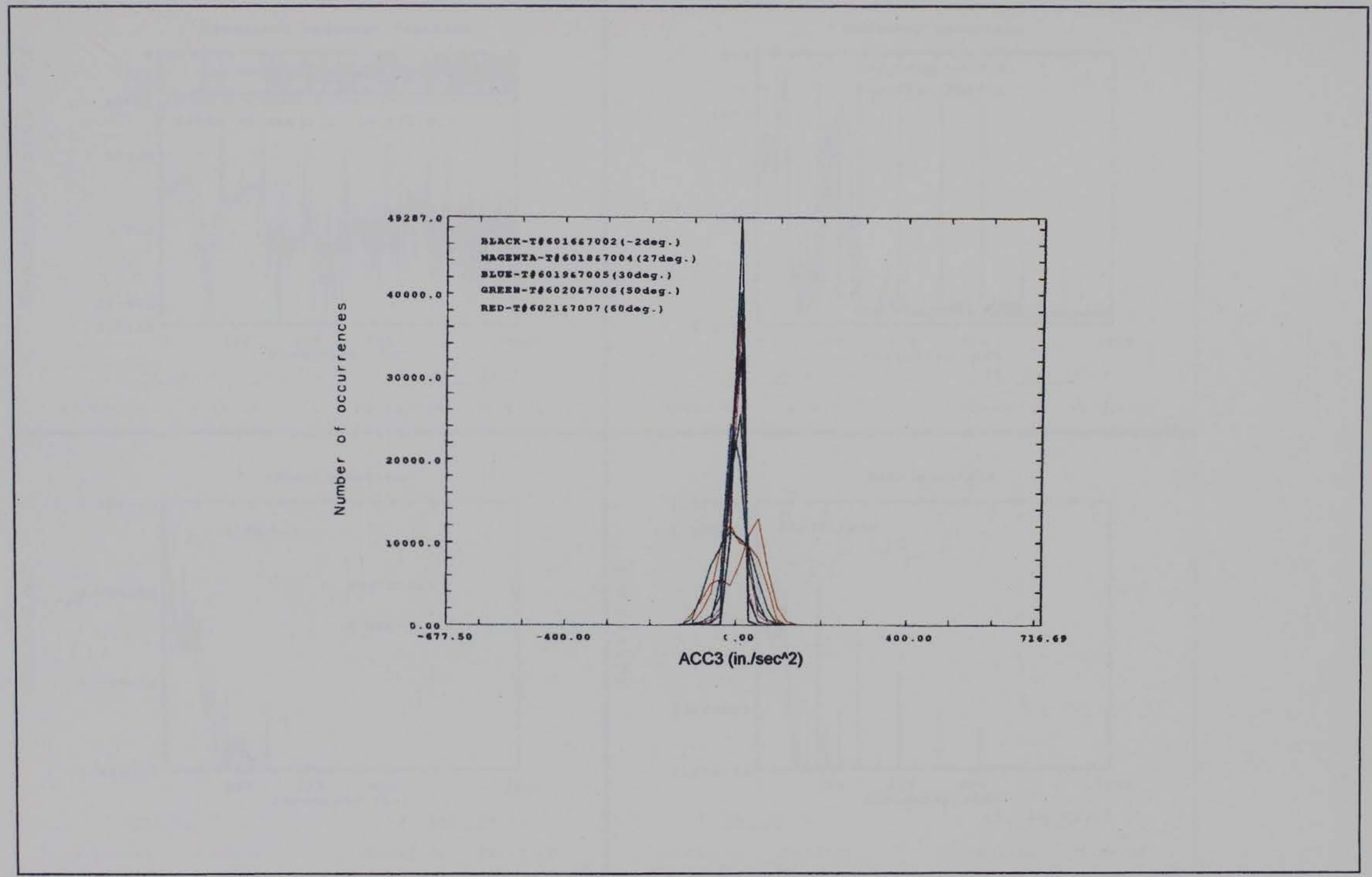

Figure 13j. Acceleration 3 (Sheet 10 of 10) 


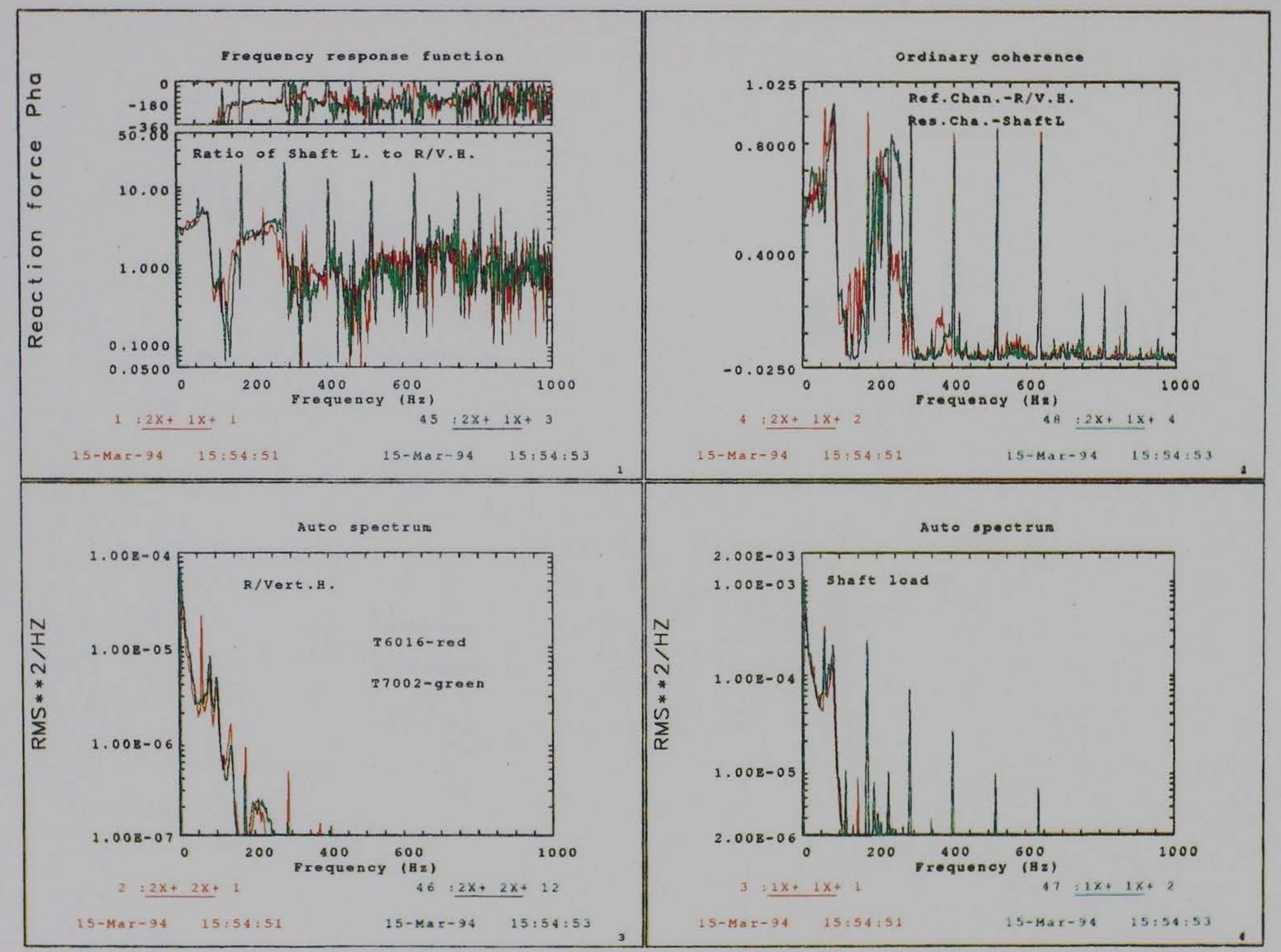

Figure 14. FRF data comparison to test set \#3 $\left(-2^{\circ}\right.$ position). a. Shaft load to right vertical hinge (Sheet 1 of 9 ) 


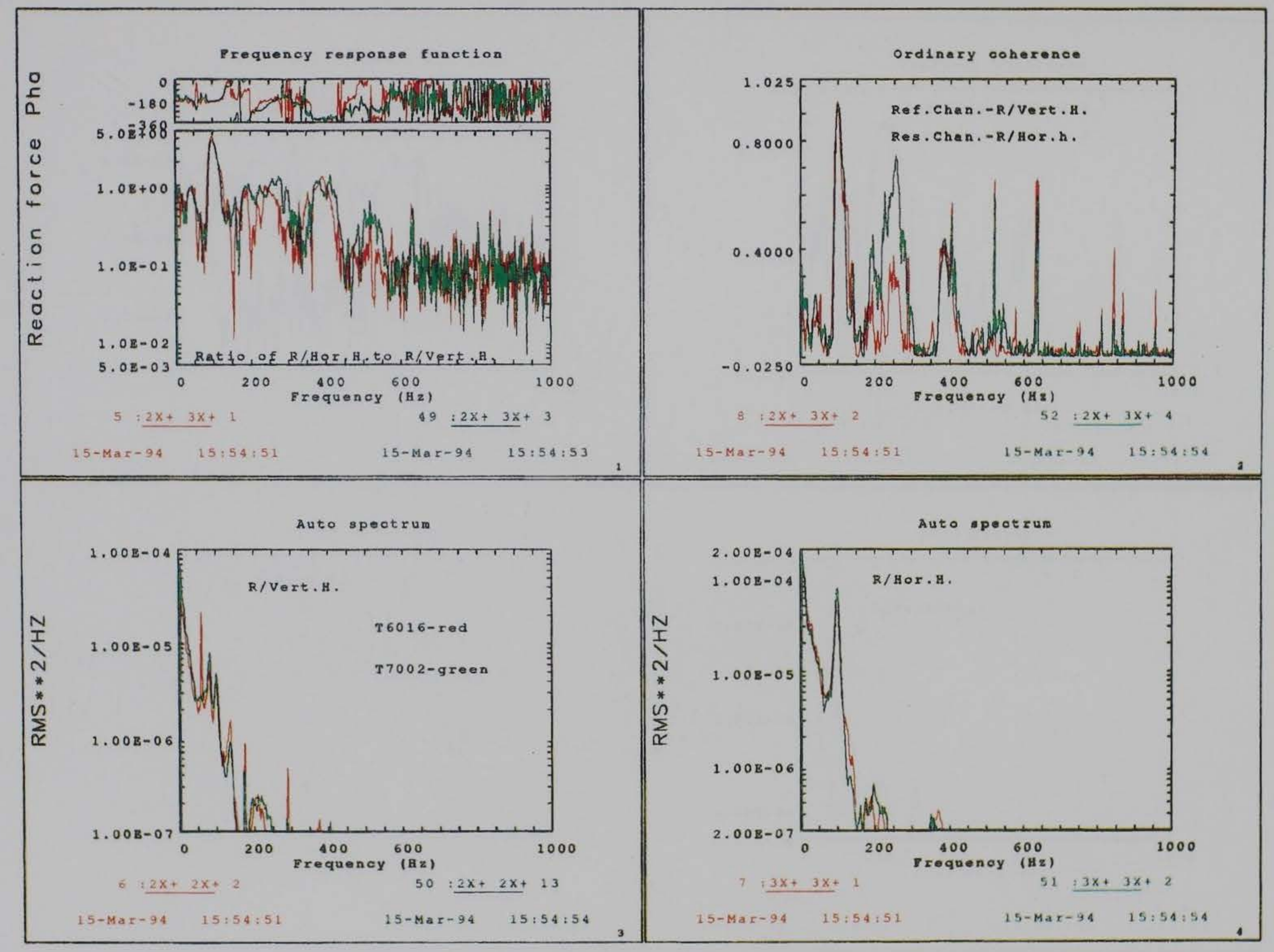

Figure 14b. Right horizontal to right vertical hinge (Sheet 2 of 9) 


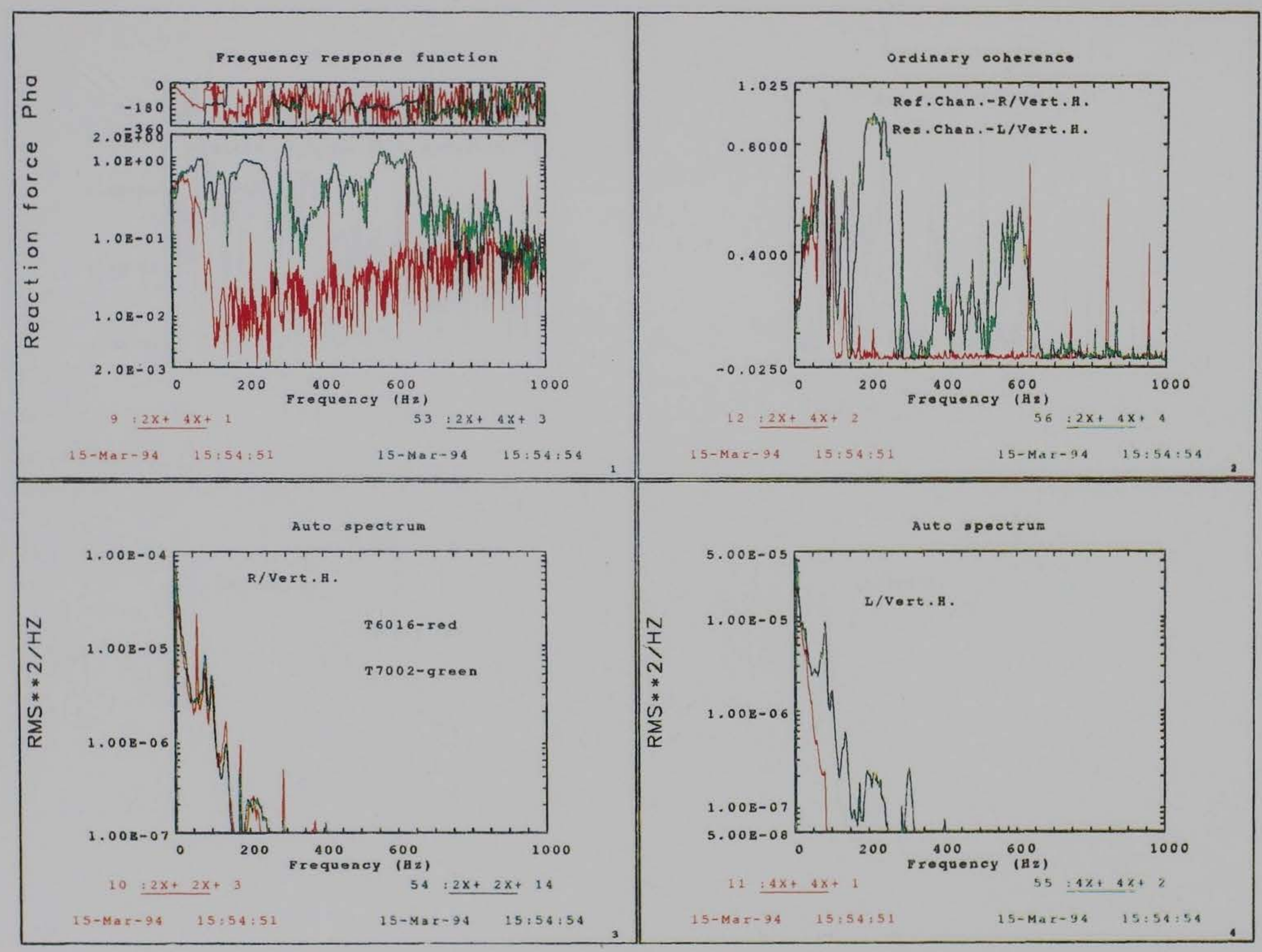

Figure 14c. Left vertical to right vertical hinge (Sheet 3 of 9) 


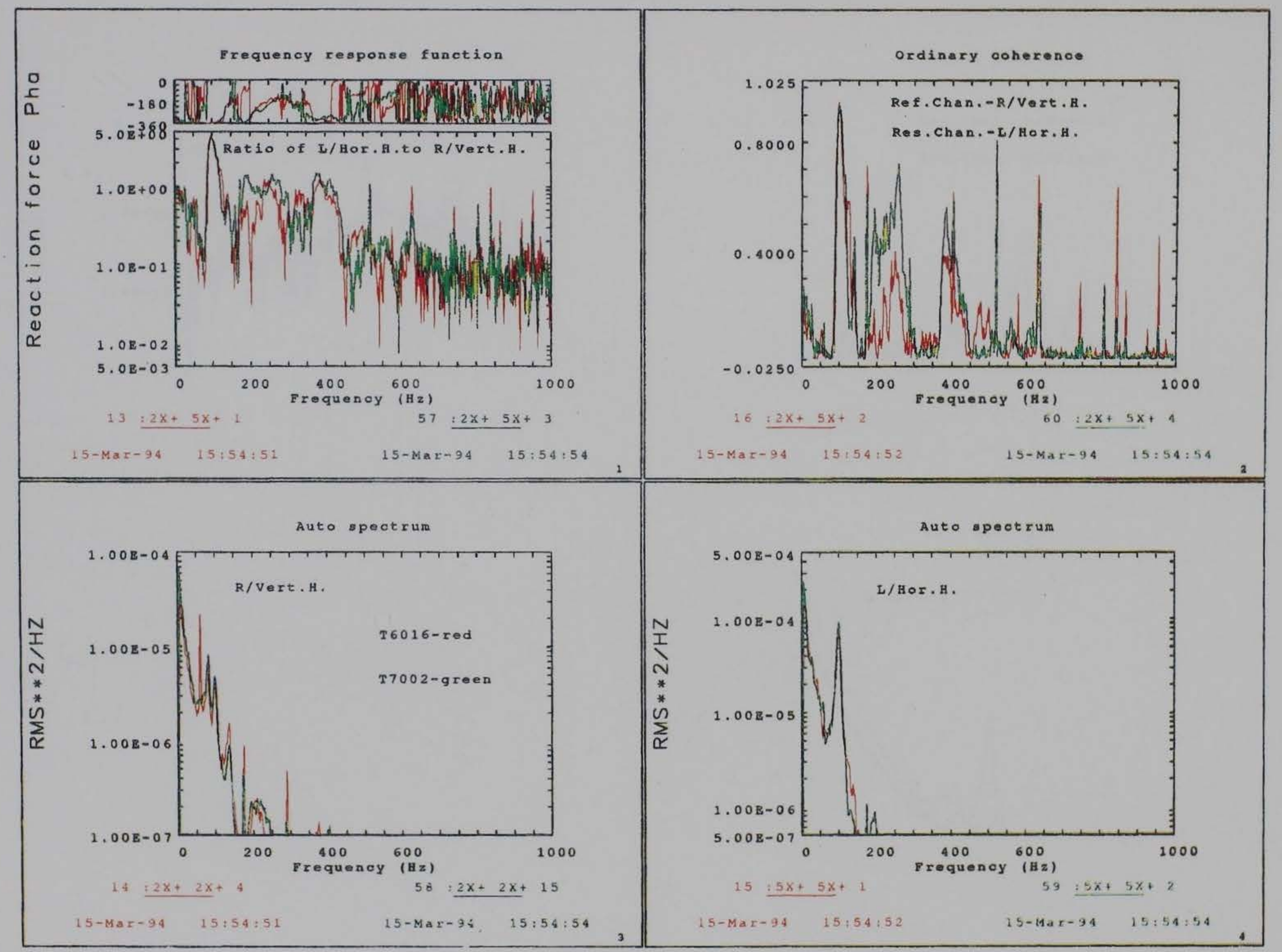

Figure $14 d$. Left horizontal to right vertical hinge (Sheet 4 of 9) 


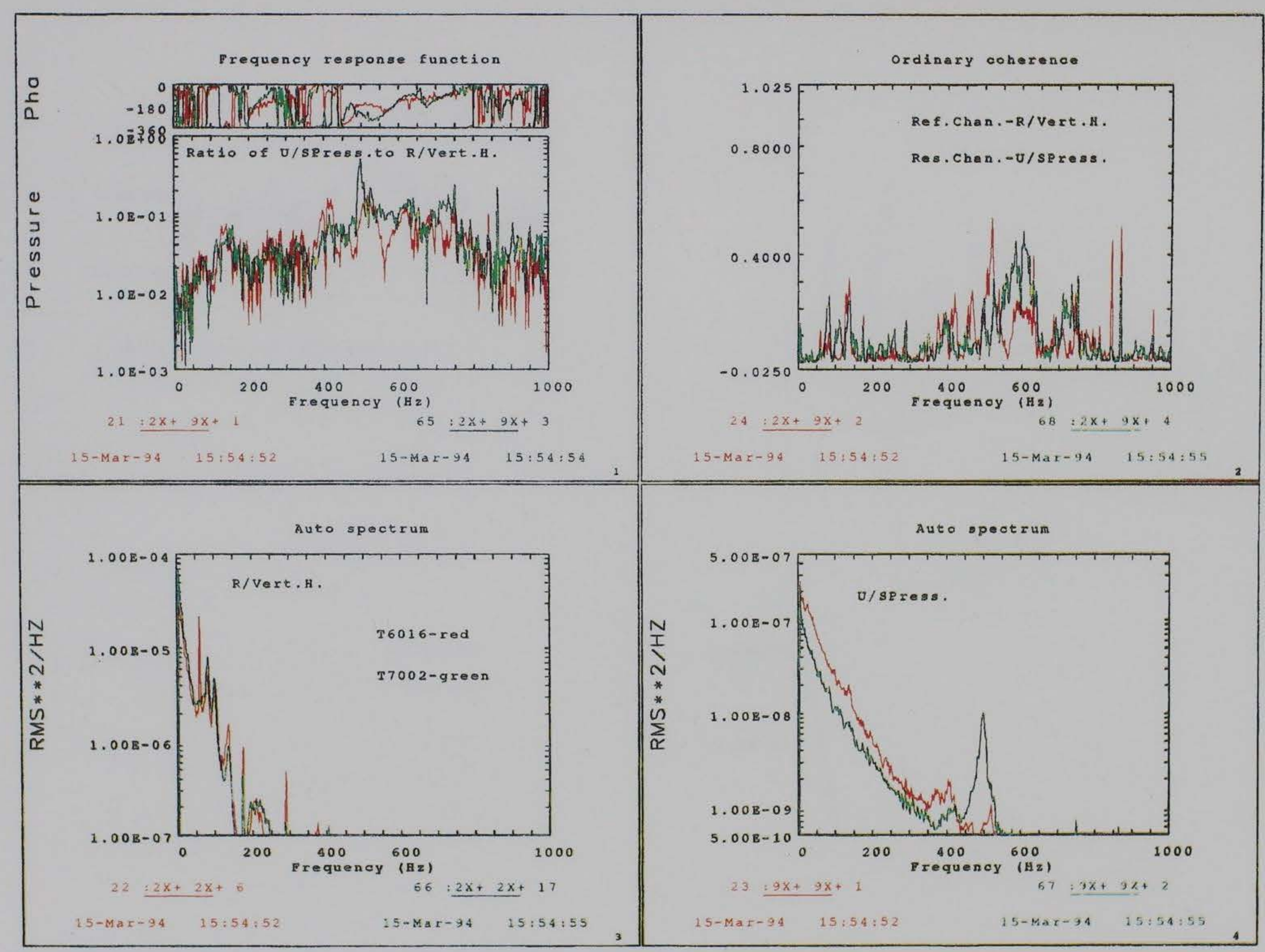

Figure 14e. Upstream pressure to right vertical hinge (Sheet 5 of 9) 


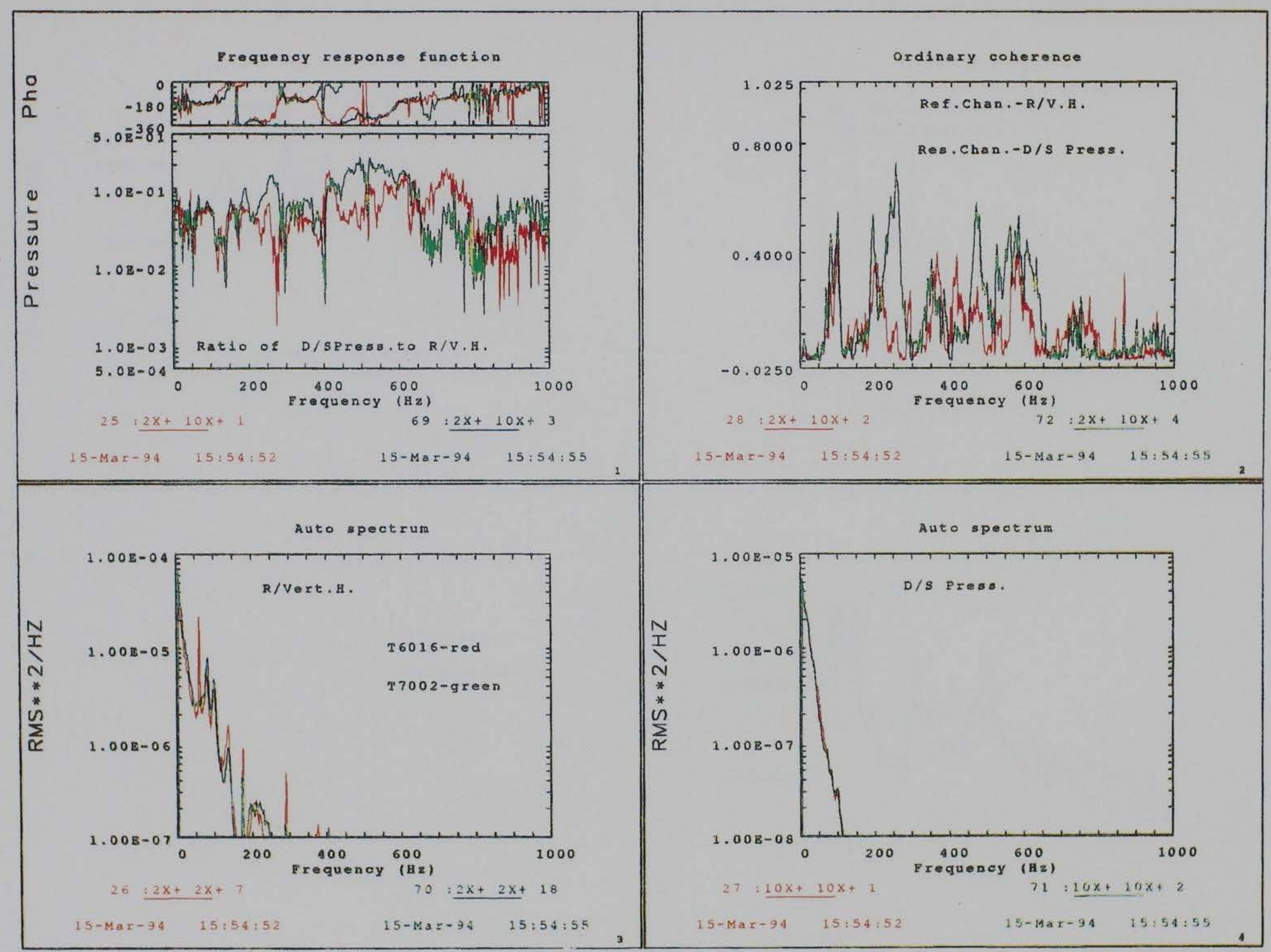

Figure 14f. Downstream pressure to right vertical hinge (Sheet 6 of 9) 


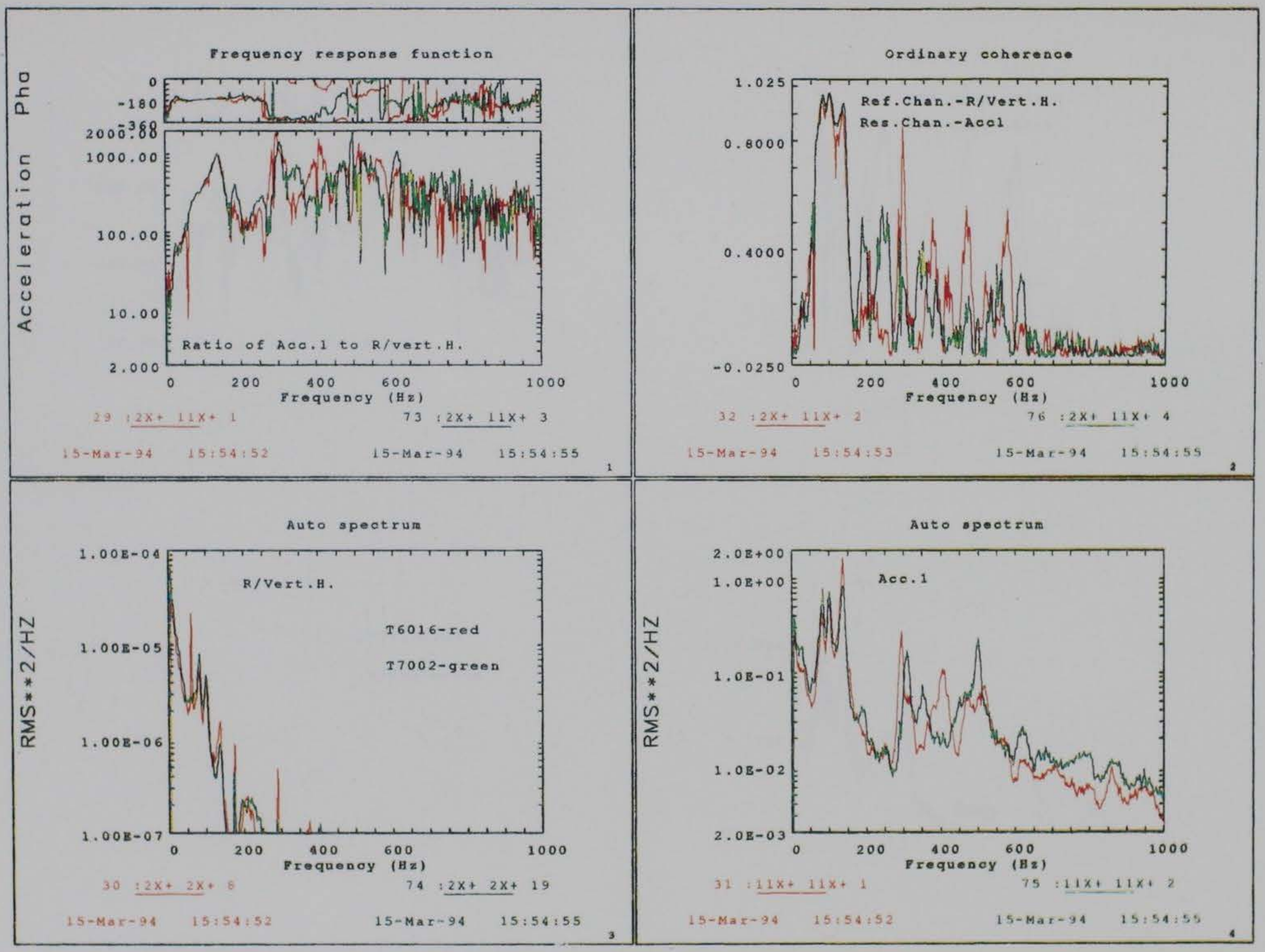

Figure $14 \mathrm{~g}$. Acceleration 1 to right vertical hinge (Sheet 7 of 9) 


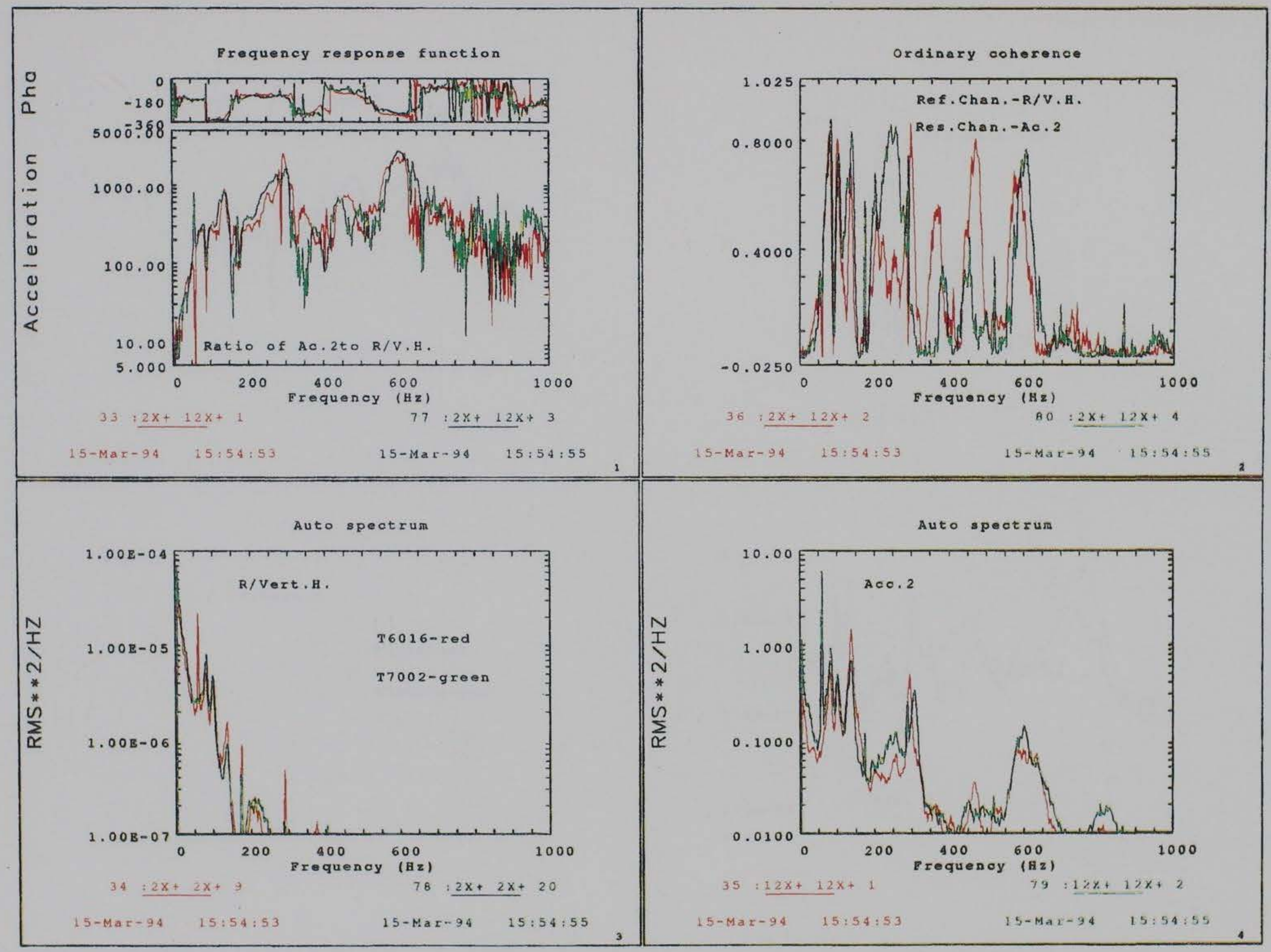

Figure 14h. Acceleration 2 to right vertical hinge (Sheet 8 of 9) 


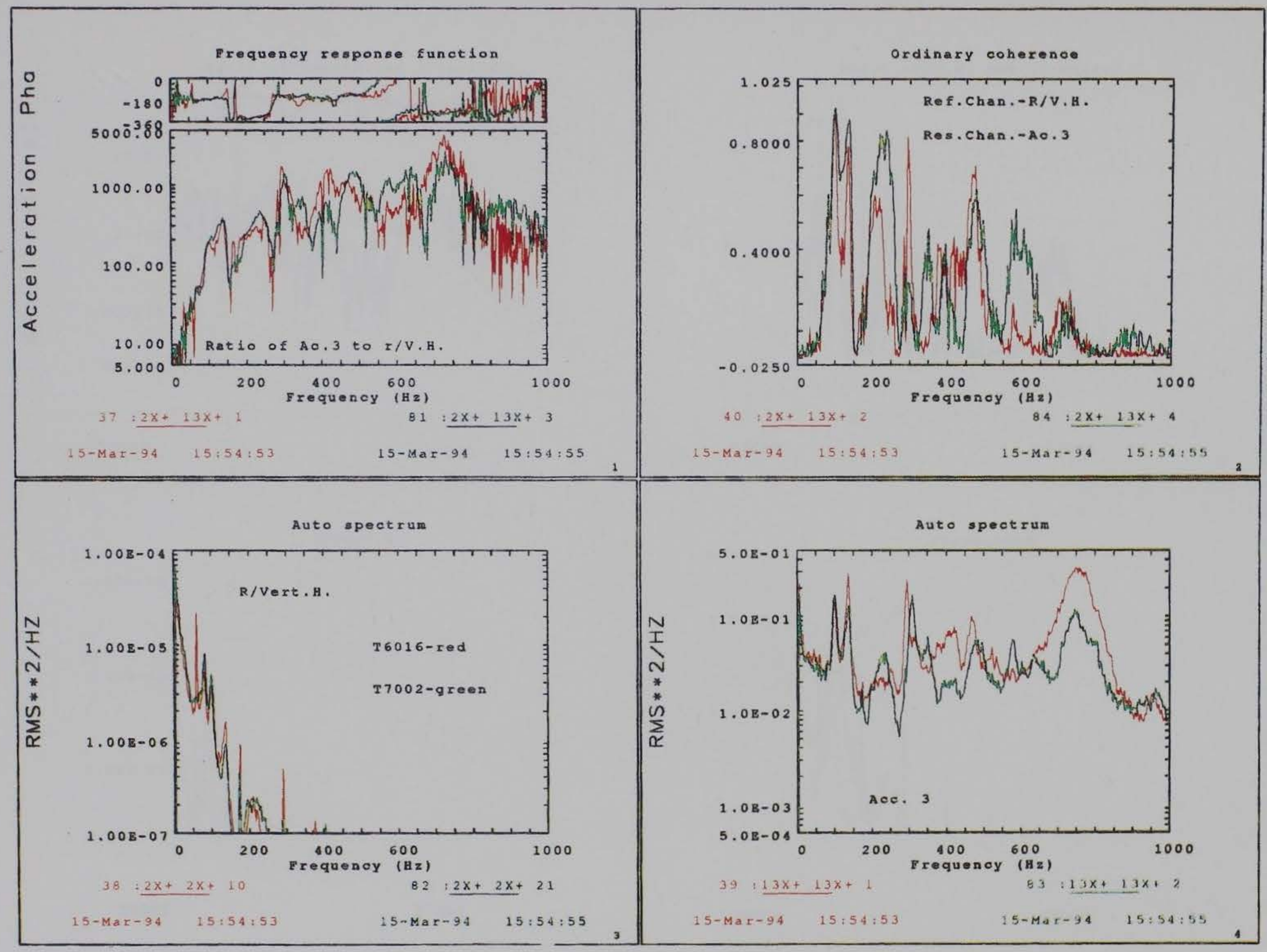

Figure 14i. Acceleration 3 to right vertical hinge (Sheet 9 of 9) 


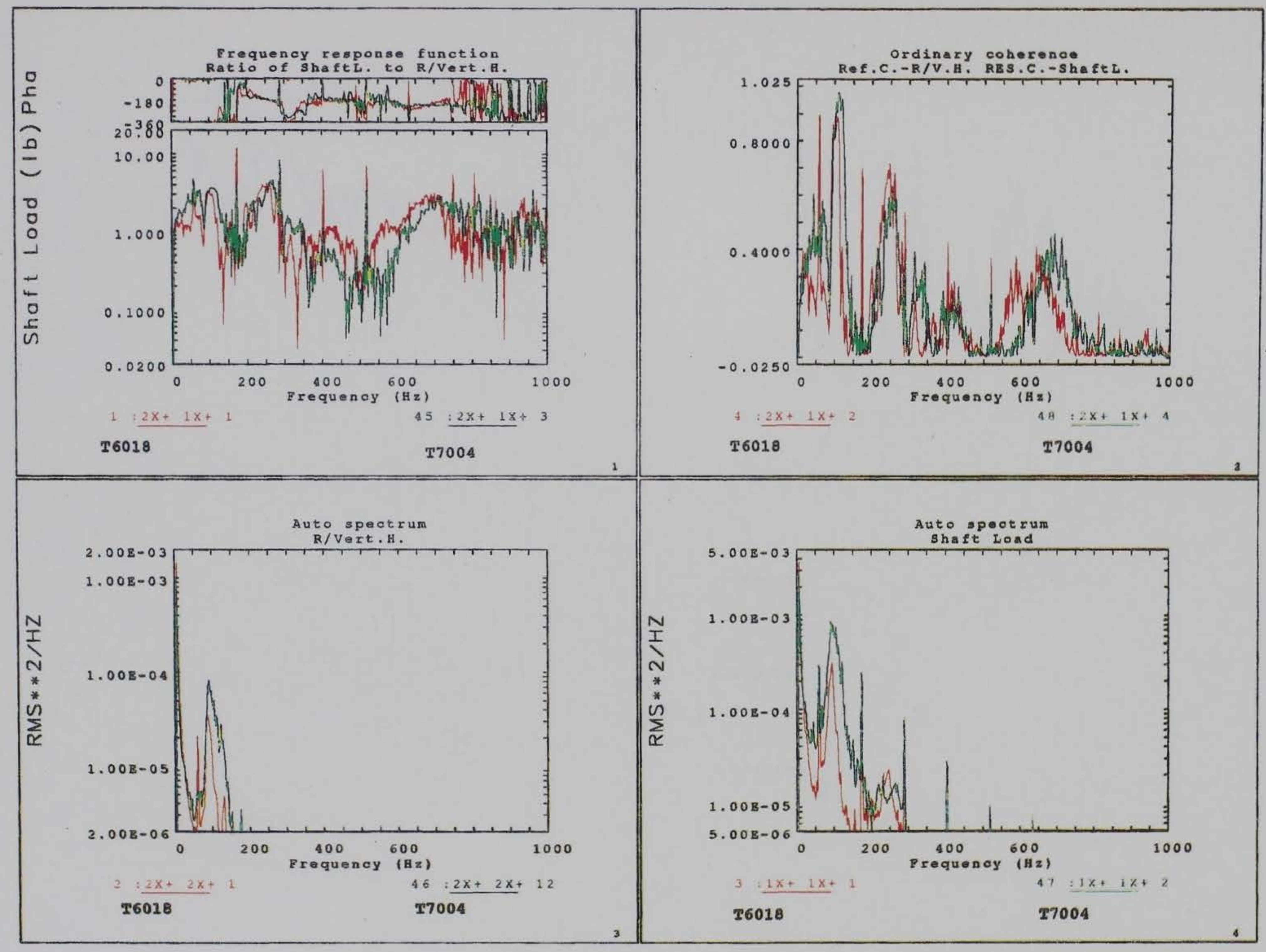

Figure 15. FRF data comparison for test set \#3 $\left(27^{\circ}\right.$ position). a. Shaft load to right vertical hinge (Sheet 1 of 9 ) 


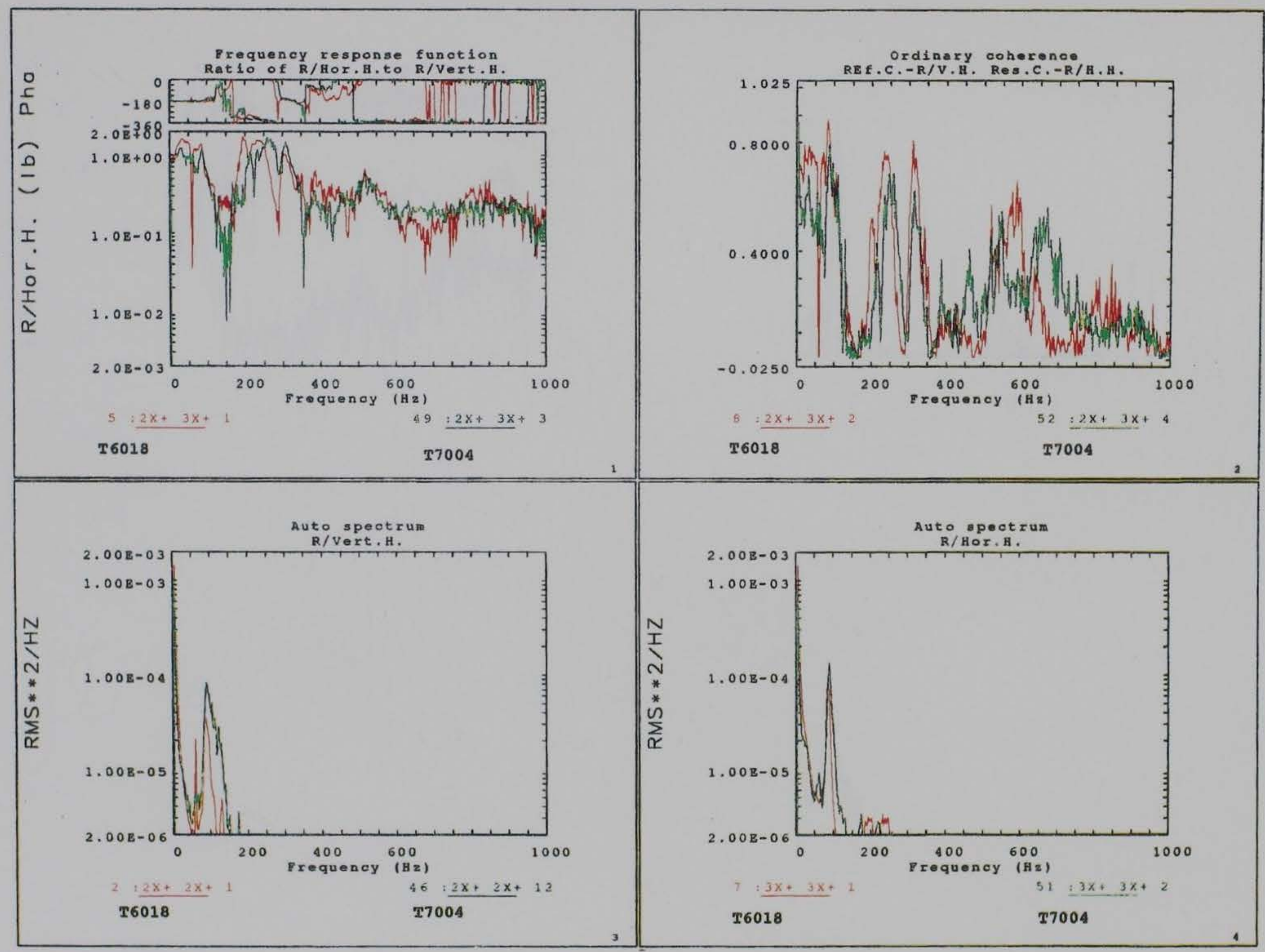

Figure 15b. Right horizontal to right vertical hinge (Sheet 2 of 9) 


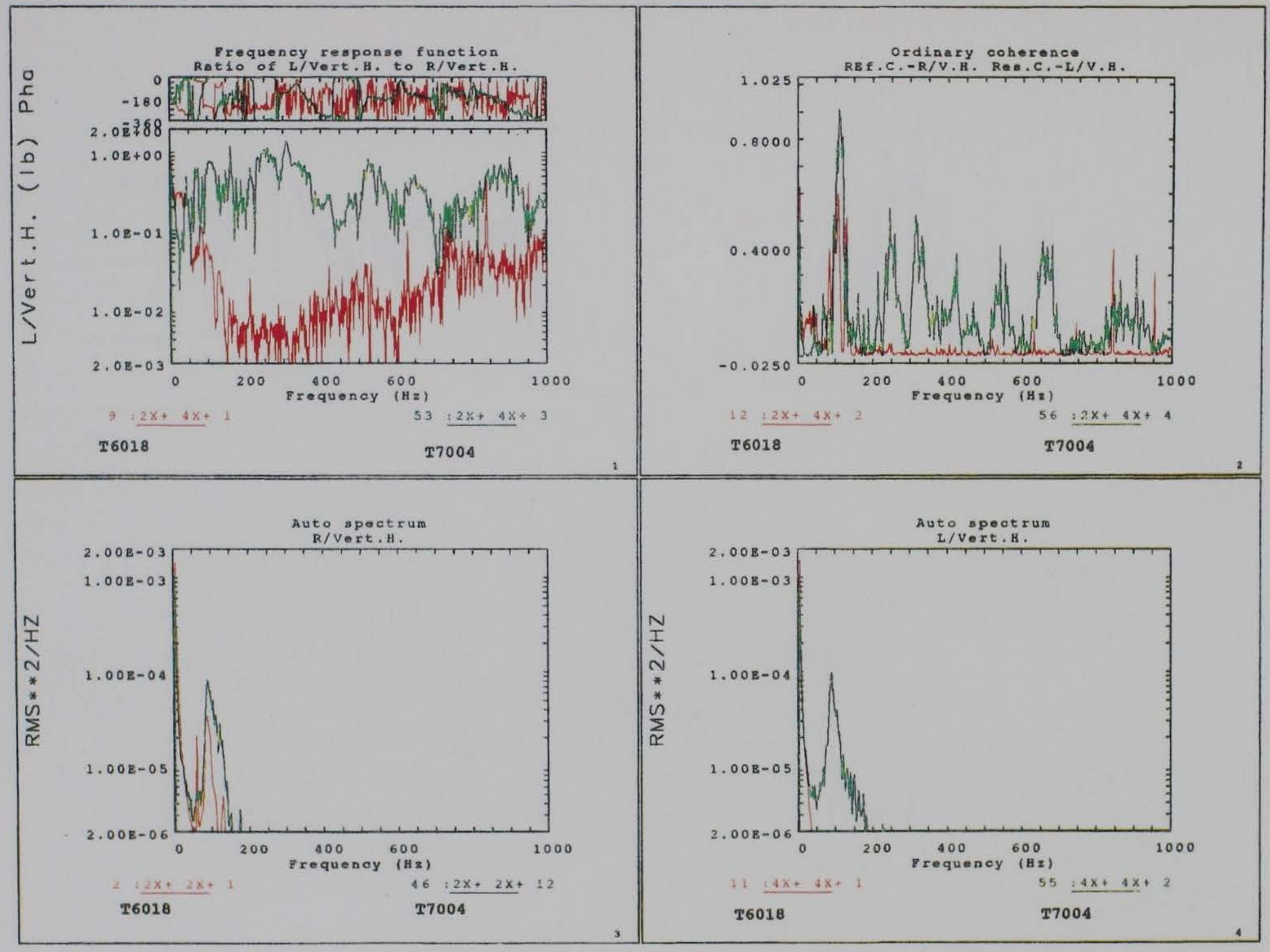

Figure 15c. Left vertical to right vertical hinge (Sheet 3 of 9) 


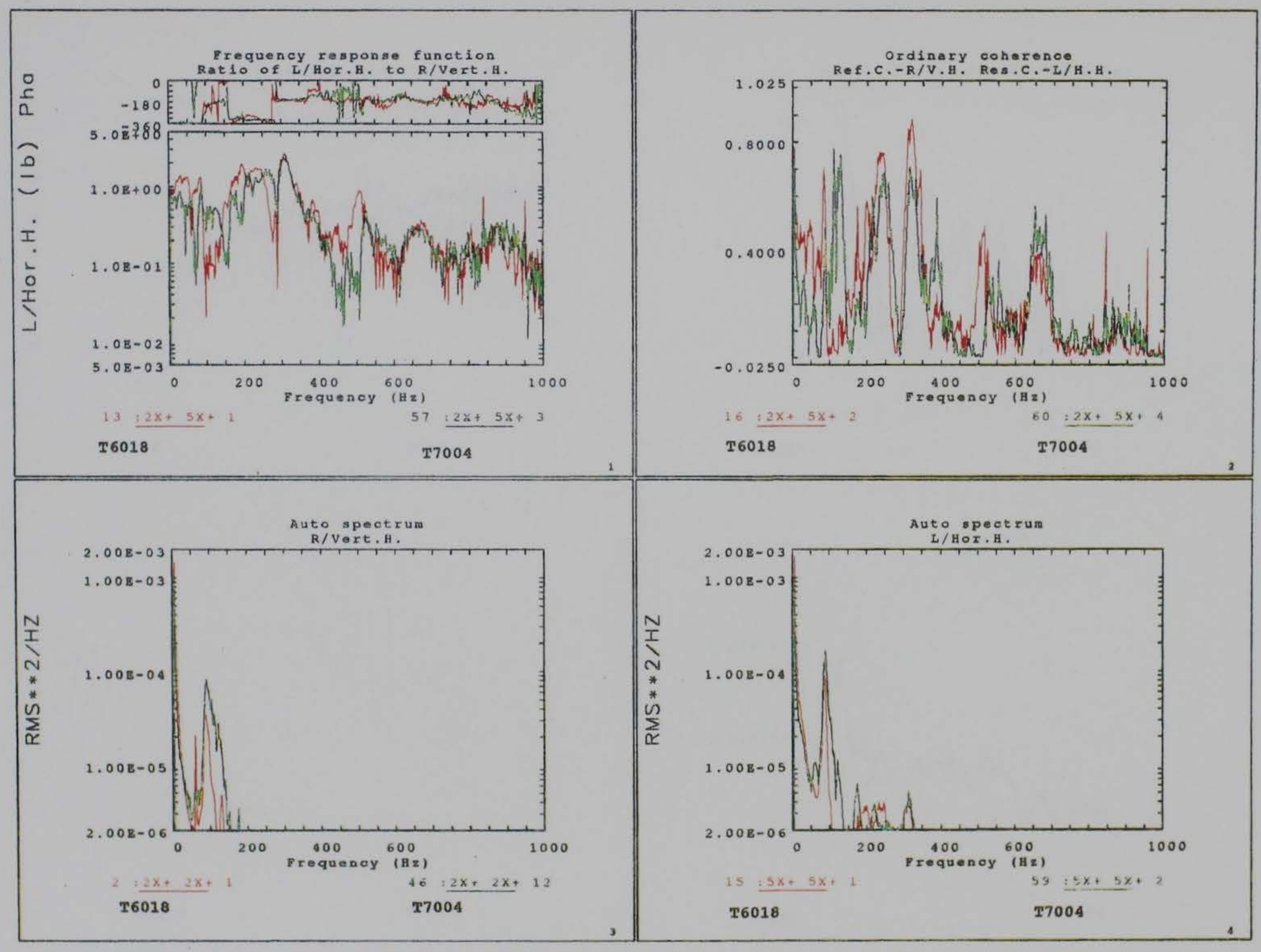

Figure 15d. Left horizontal to right vertical hinge (Sheet 4 of 9) 


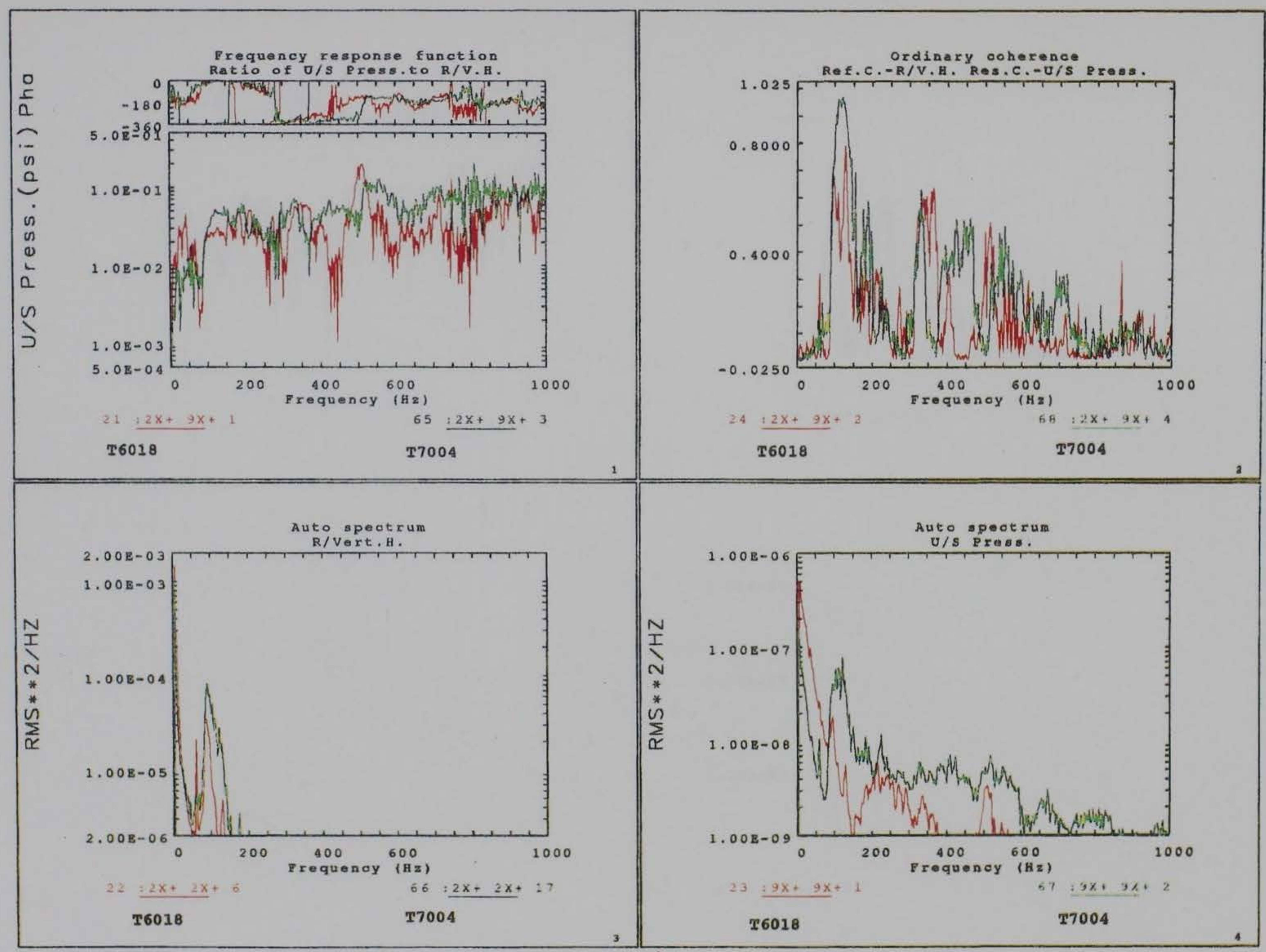

Figure 15e. Upstream pressure to right vertical hinge (Sheet 5 of 9) 


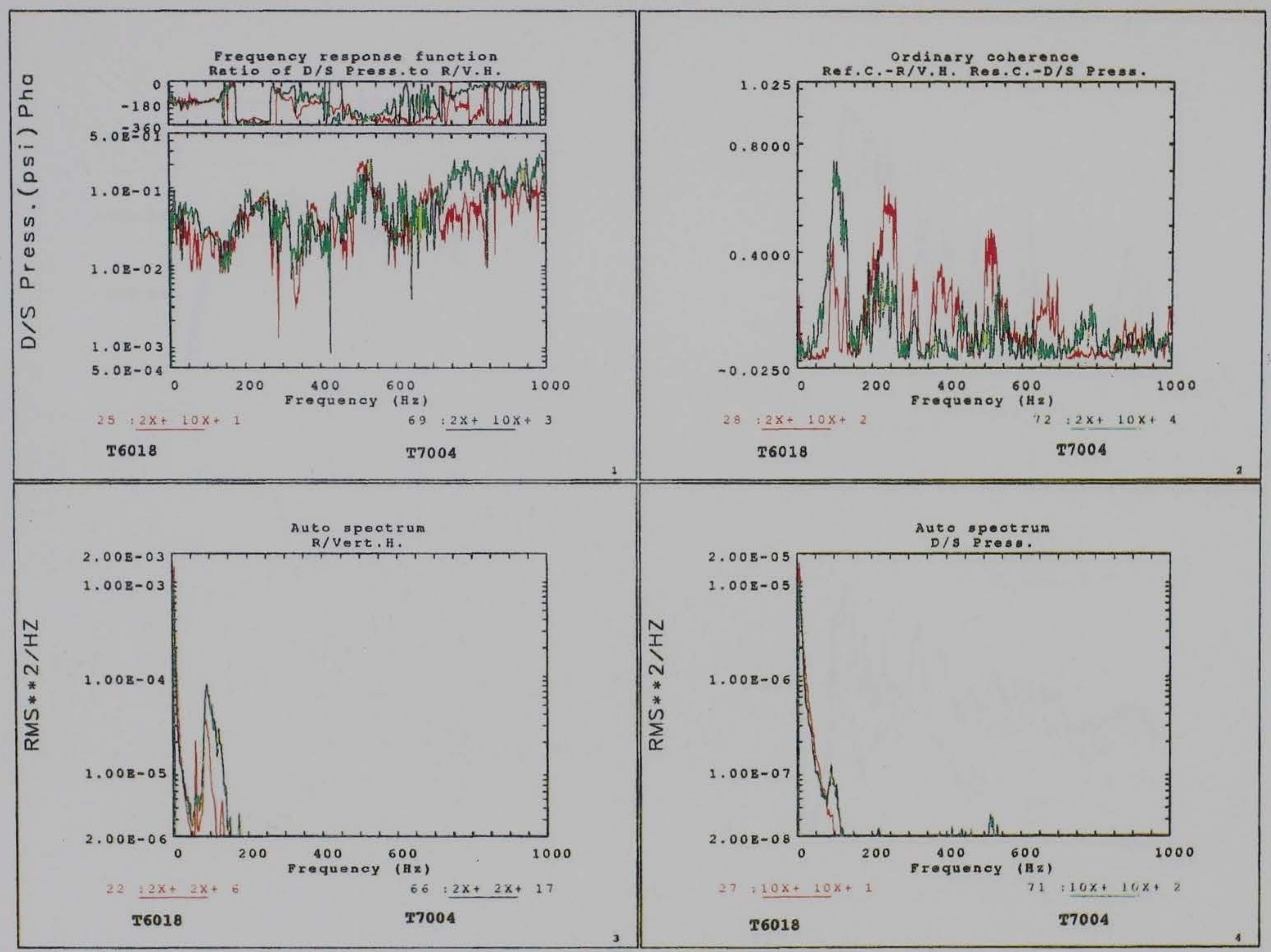

Figure 15f. Downstream pressure to right vertical hinge (Sheet 6 of 9) 


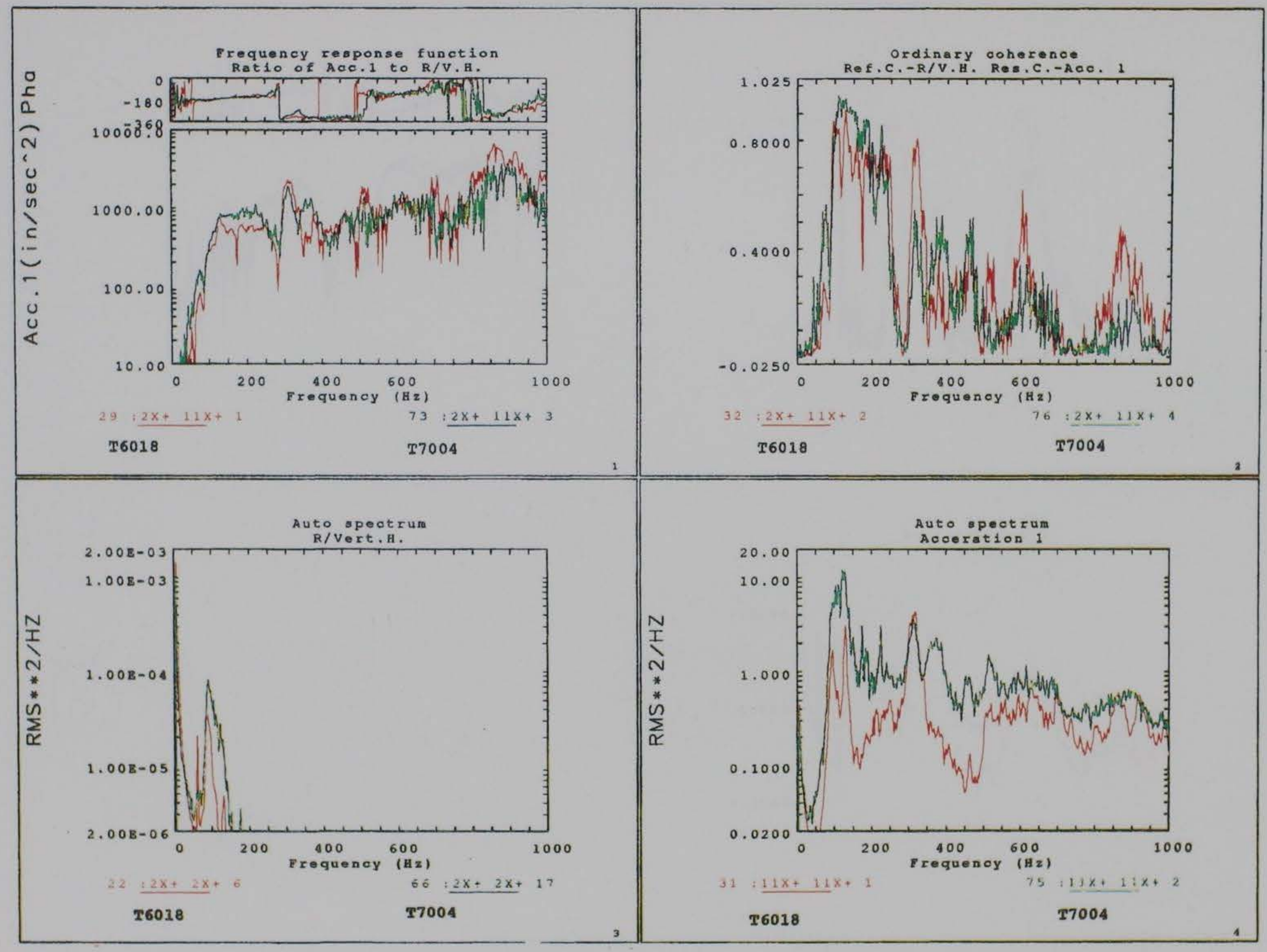

Figure 15g. Acceleration 1 to right vertical hinge (Sheet 7 of 9) 


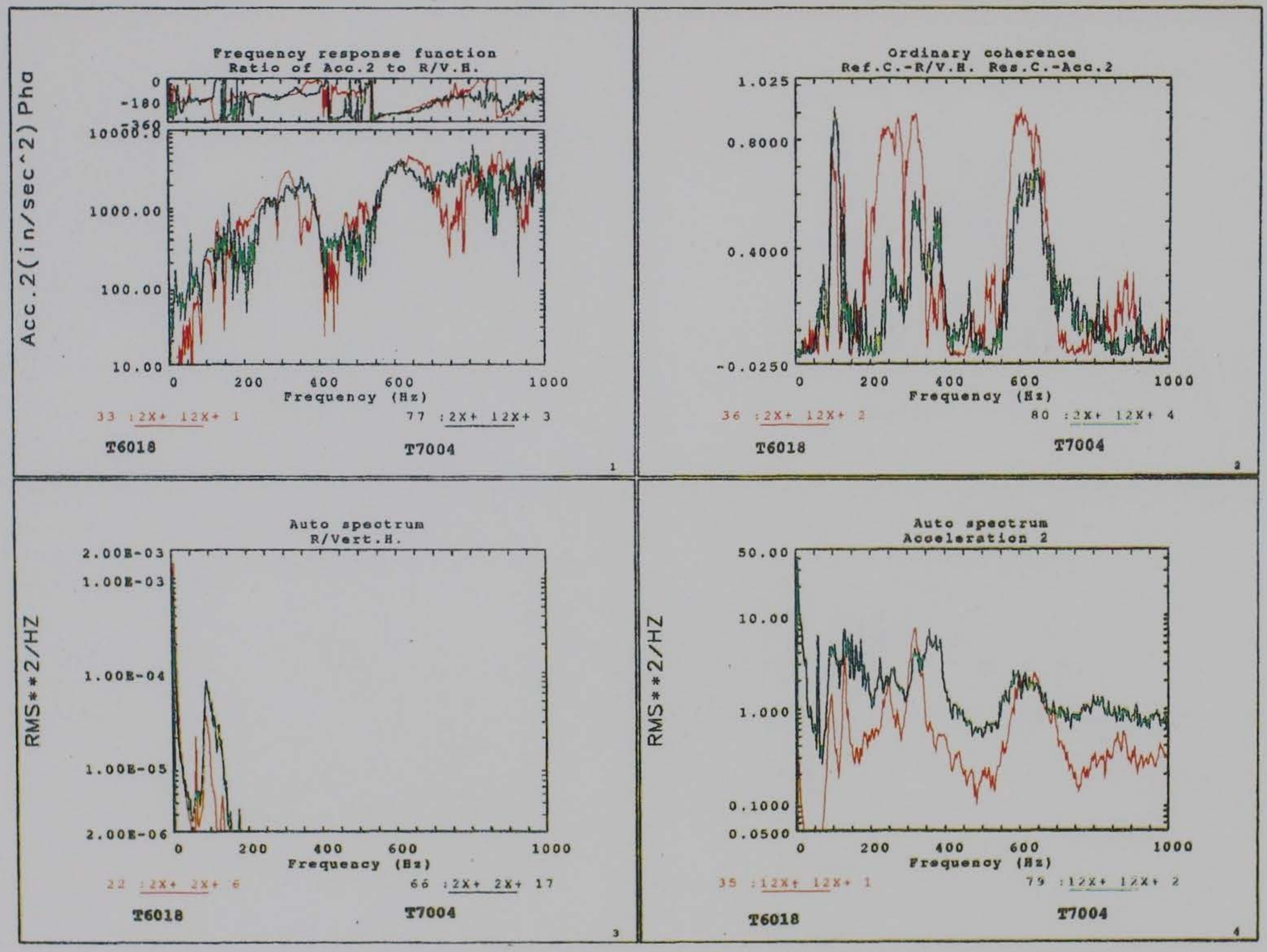

Figure $15 \mathrm{~h}$. Acceleration 2 to right vertical hinge (Sheet 8 of 9) 


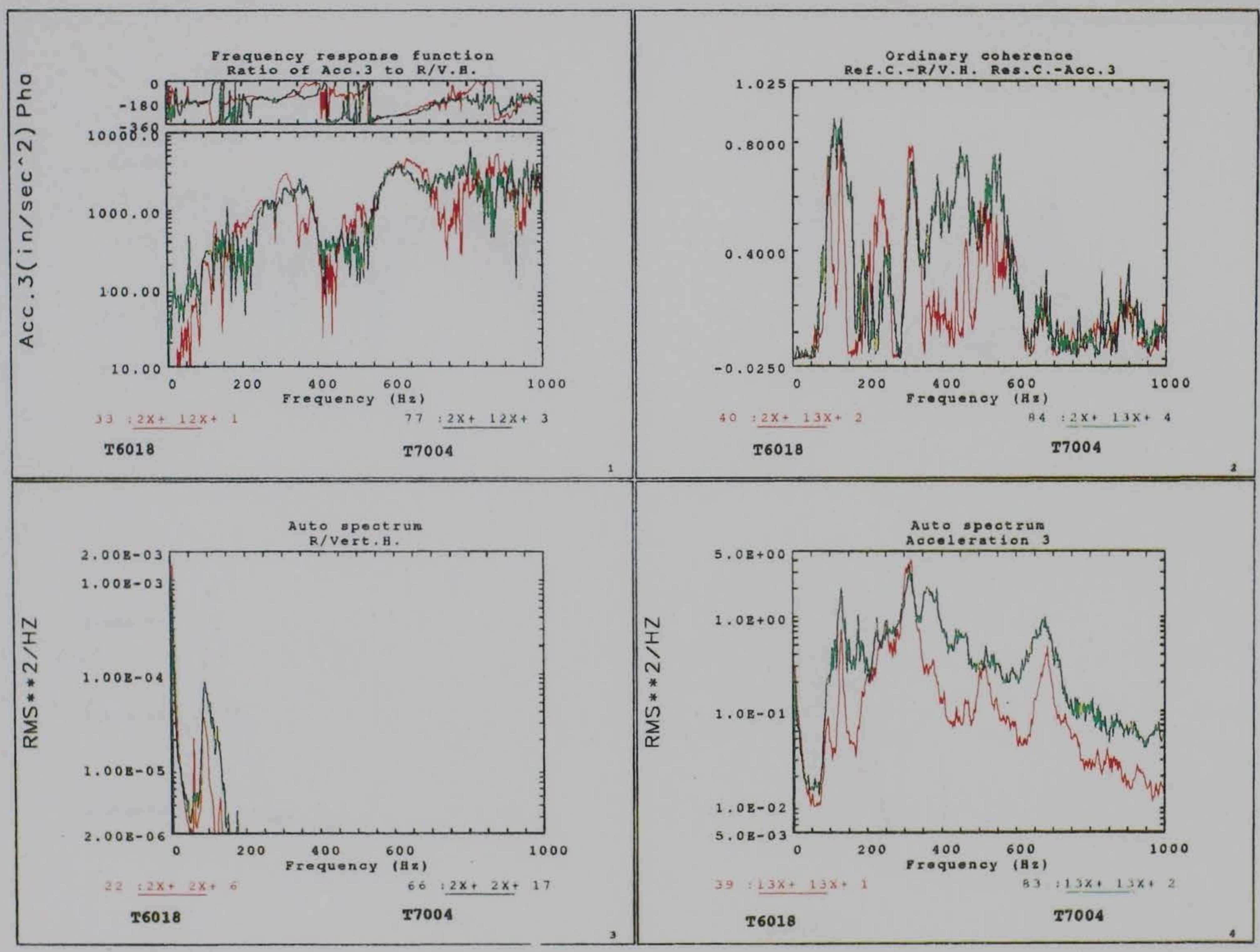

Figure 15i. Acceleration 3 to right vertical hinge (Sheet 9 of 9) 


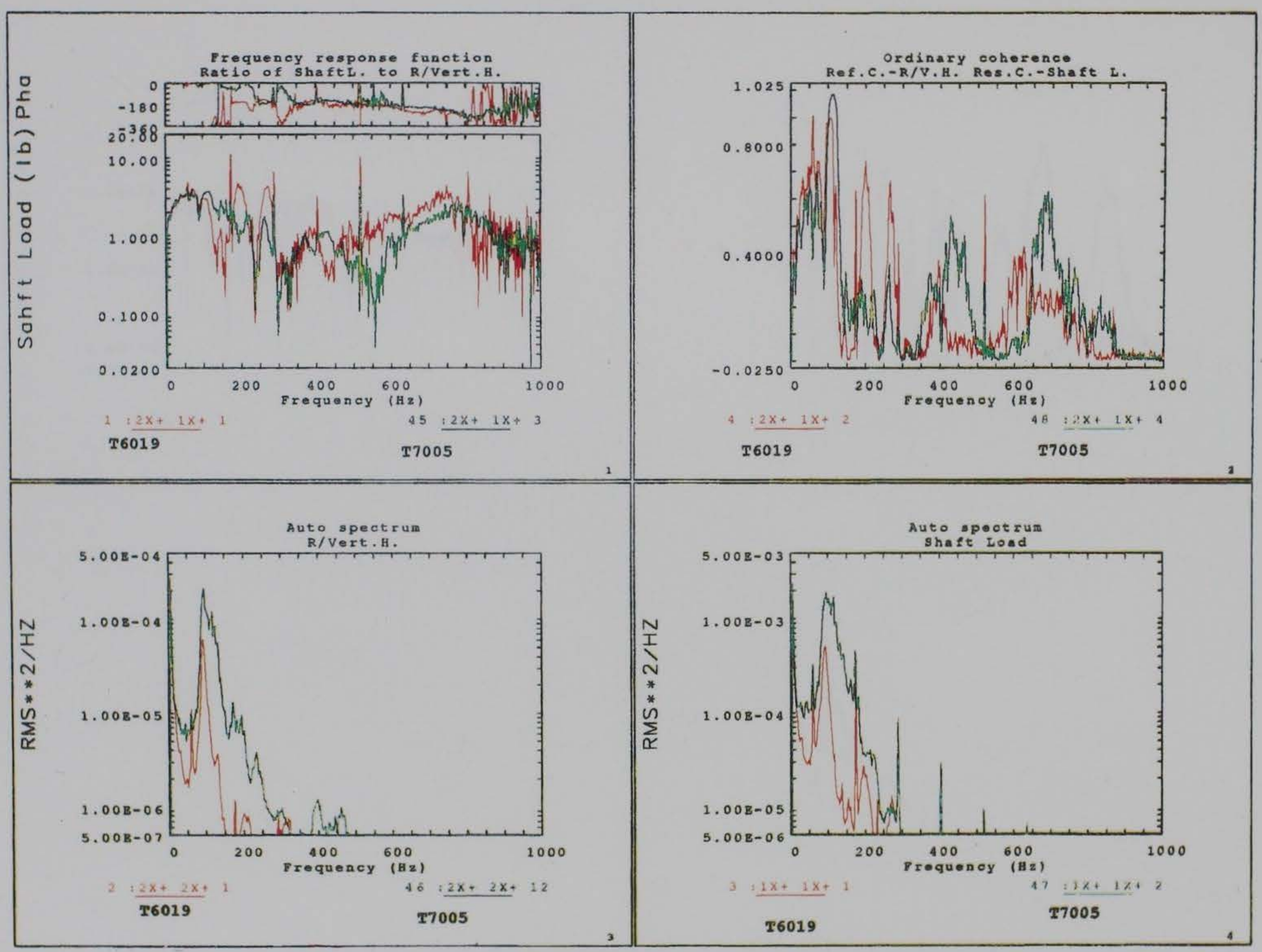

Figure 16. FRF data comparison for test set \#3 $\left(30^{\circ}\right.$ position). a. Shaft load to right vertical hinge (Sheet 1 of 9 ) 


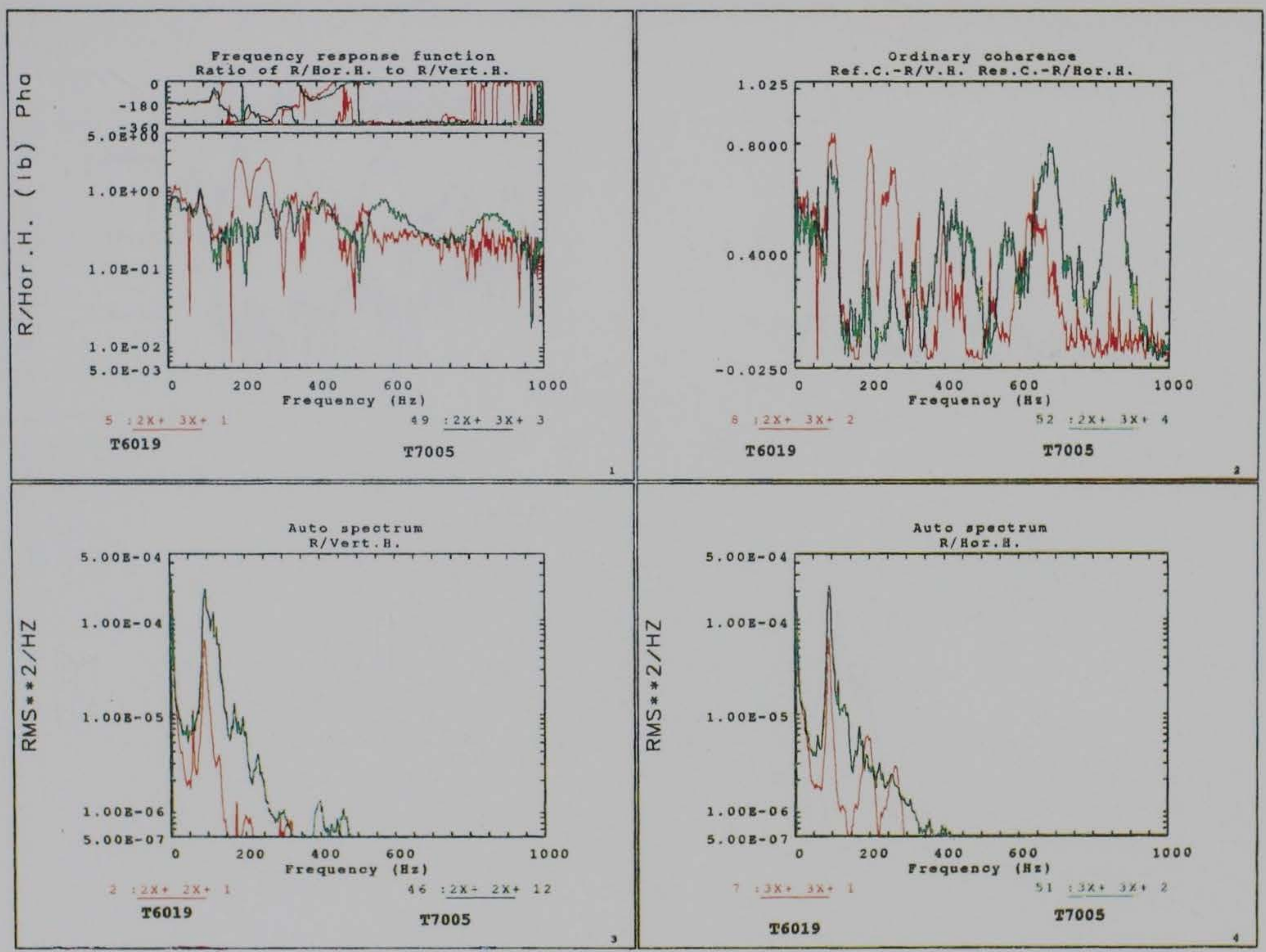

Figure 16b. Right horizontal to right vertical hinge (Sheet 2 of 9) 


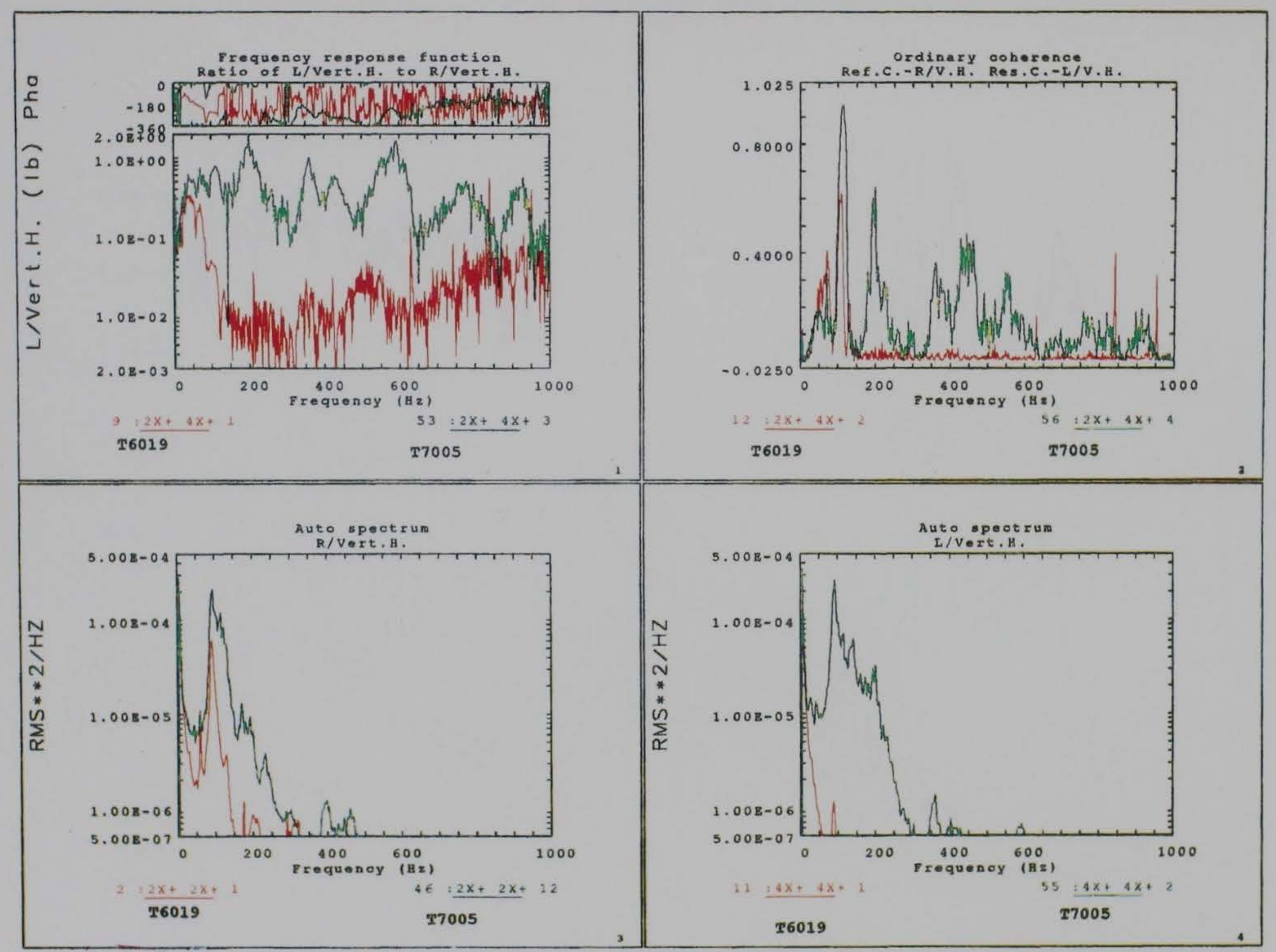

Figure $16 c$. Left vertical to right vertical hinge (Sheet 3 of 9) 


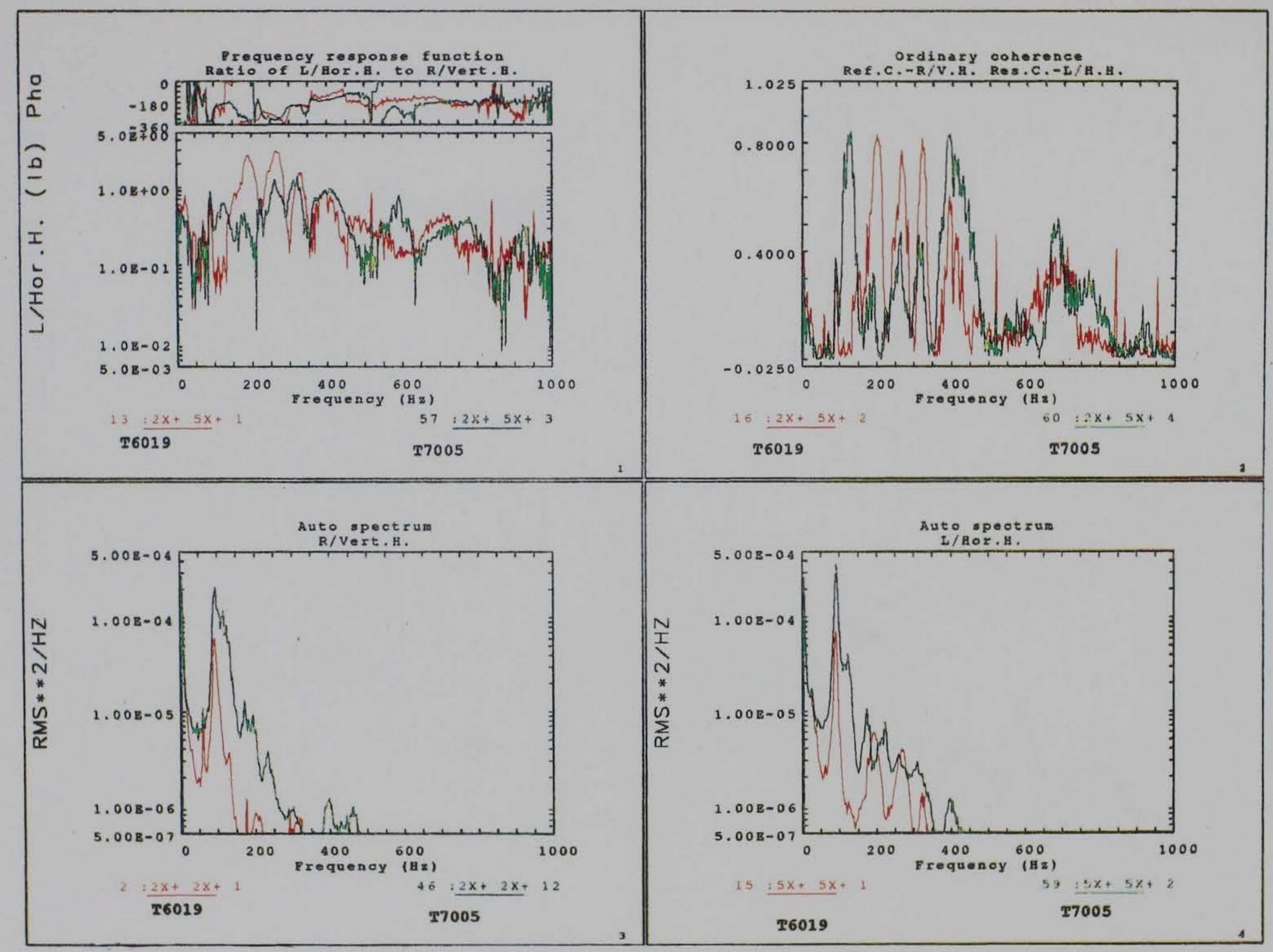

Figure 16d. Left horizontal to right vertical hinge (Sheet 4 of 9) 


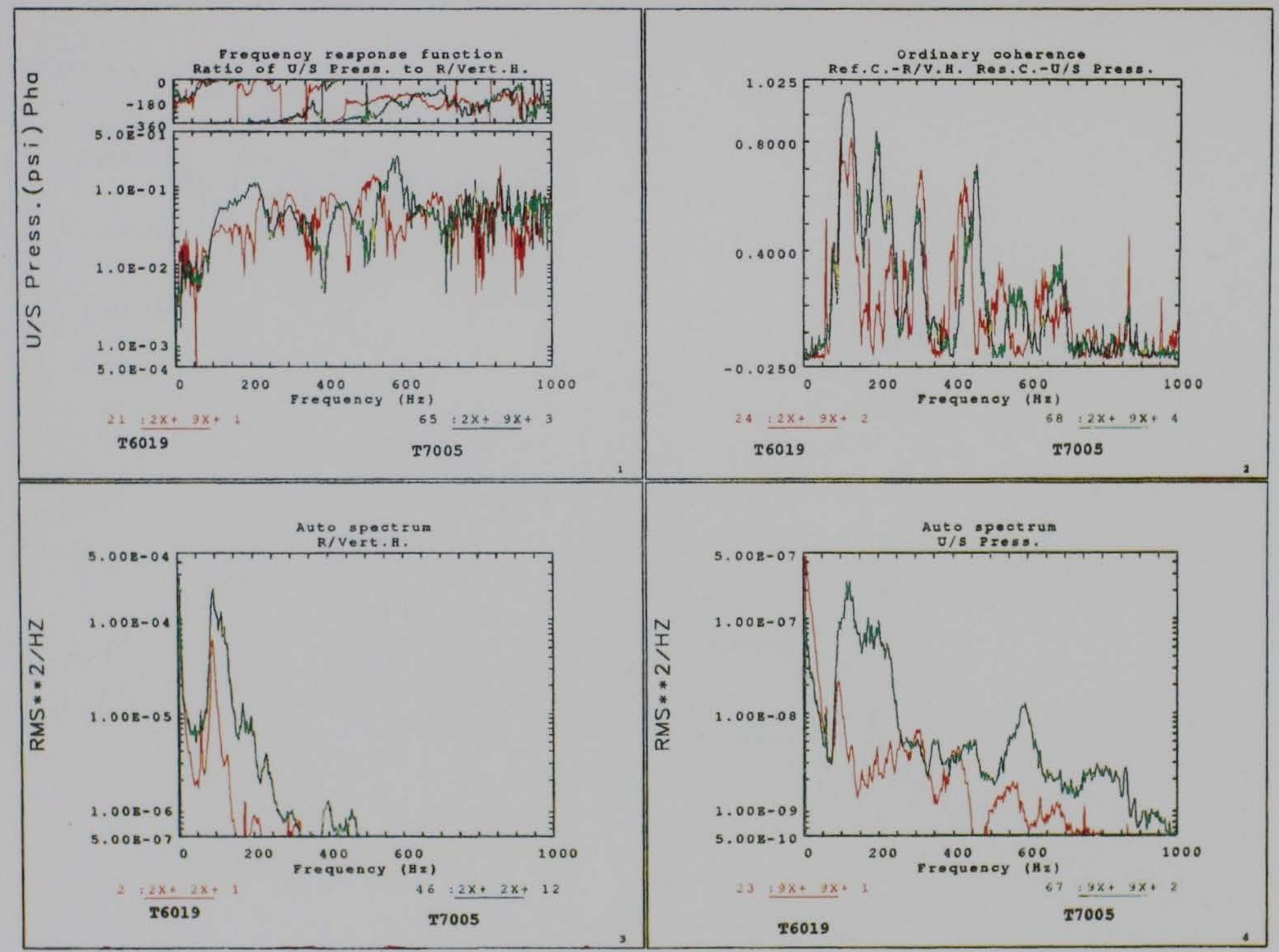

Figure 16e. Upstream pressure to right vertical hinge (Sheet 5 of 9) 


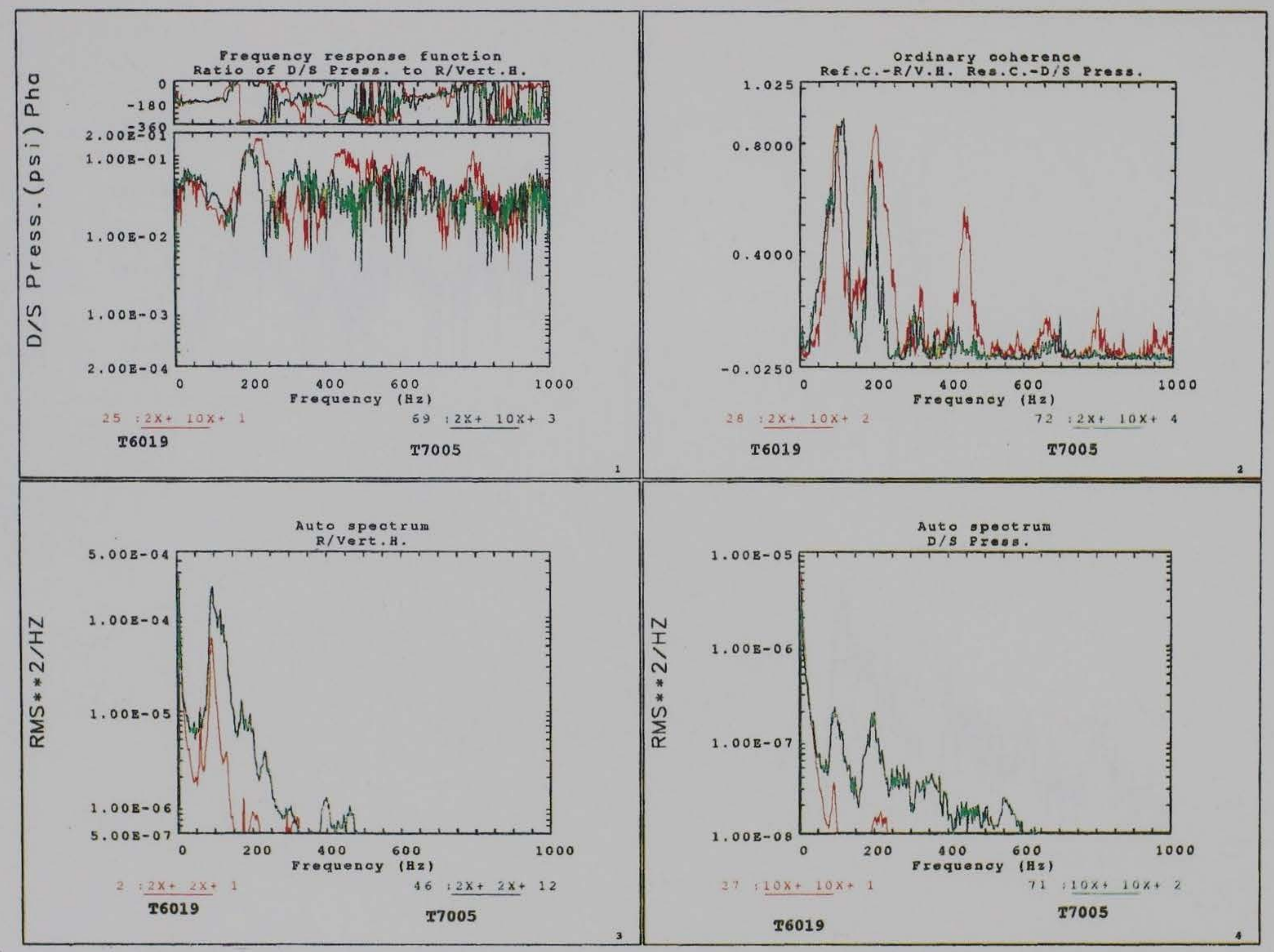

Figure 16f. Downstream pressure to right vertical hinge (Sheet 6 of 9) 


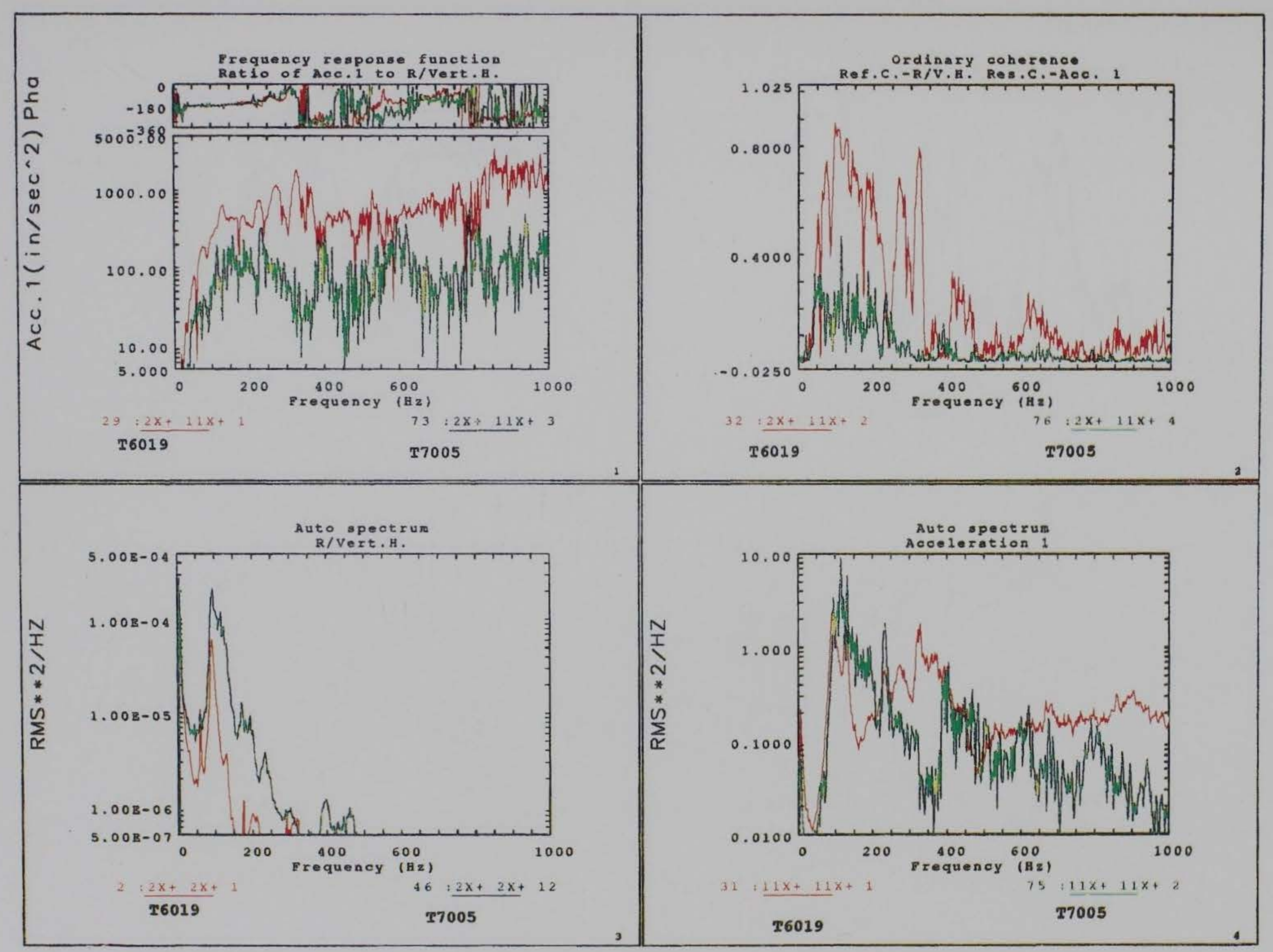

Figure $16 \mathrm{~g}$. Acceleration 1 to right vertical hinge (Sheet 7 of 9) 


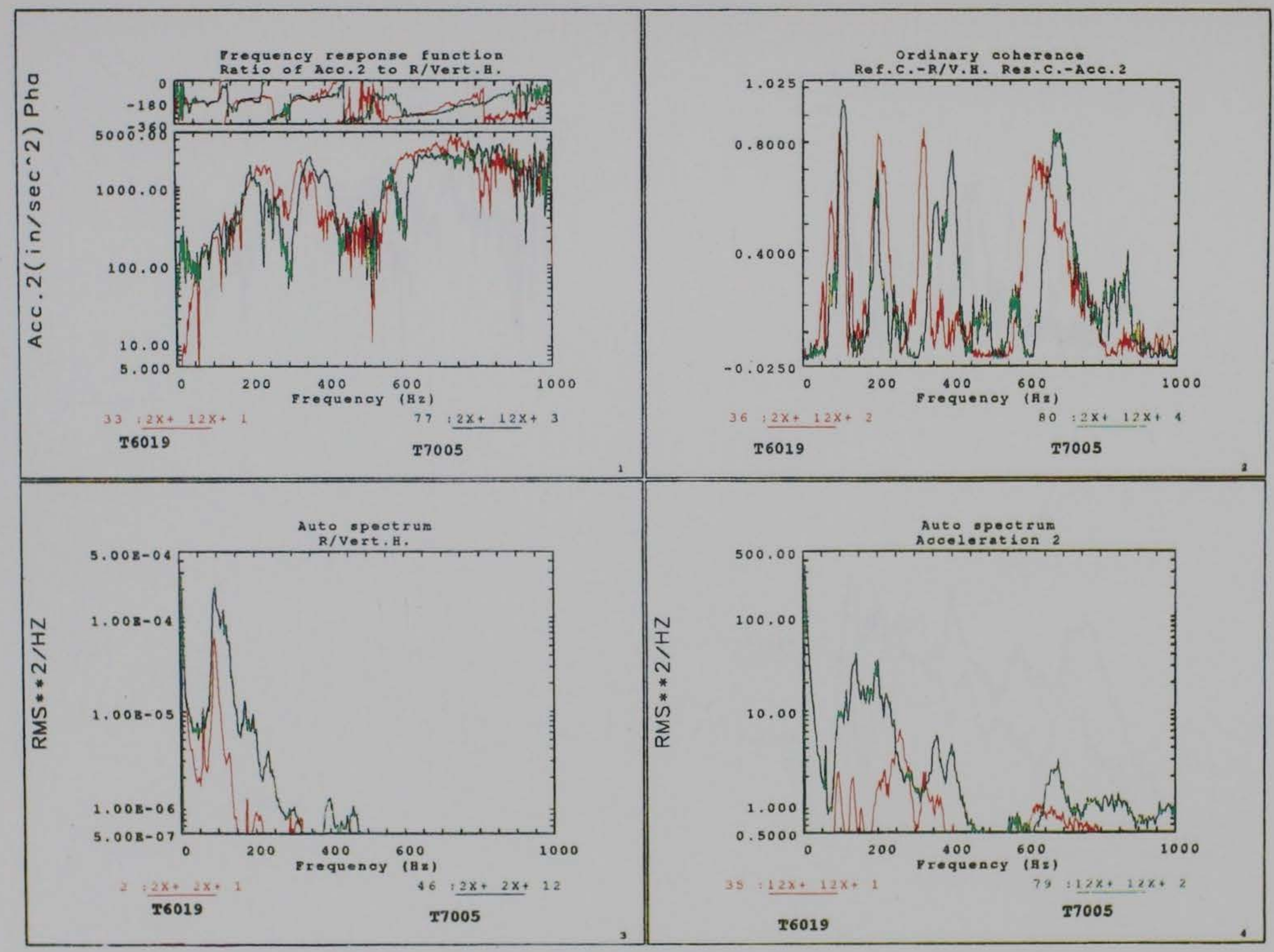

Figure 16h. Acceleration 2 to right vertical hinge (Sheet 8 of 9) 


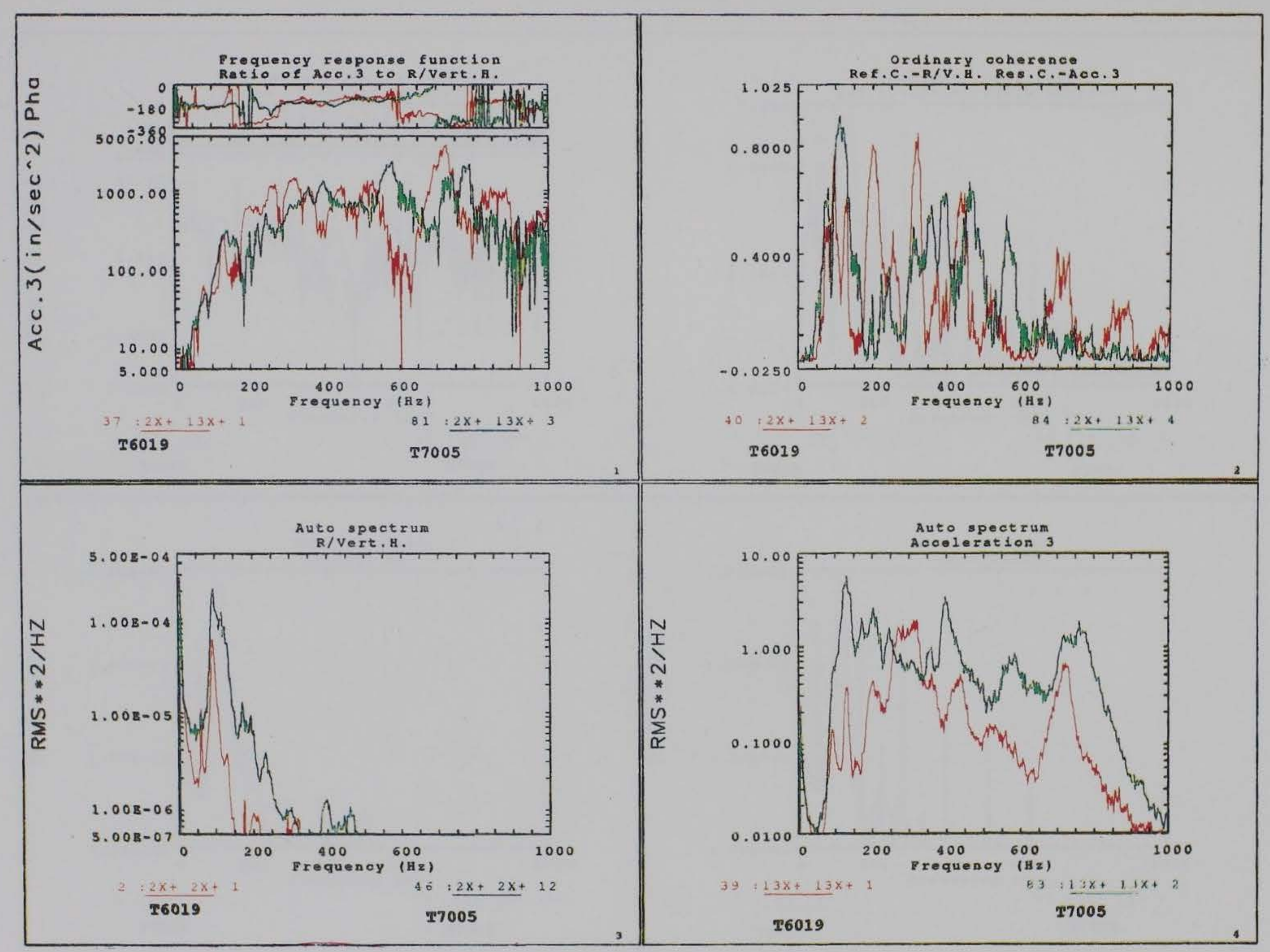

Figure 16i. Acceleration 3 to right vertical hinge (Sheet 9 of 9) 


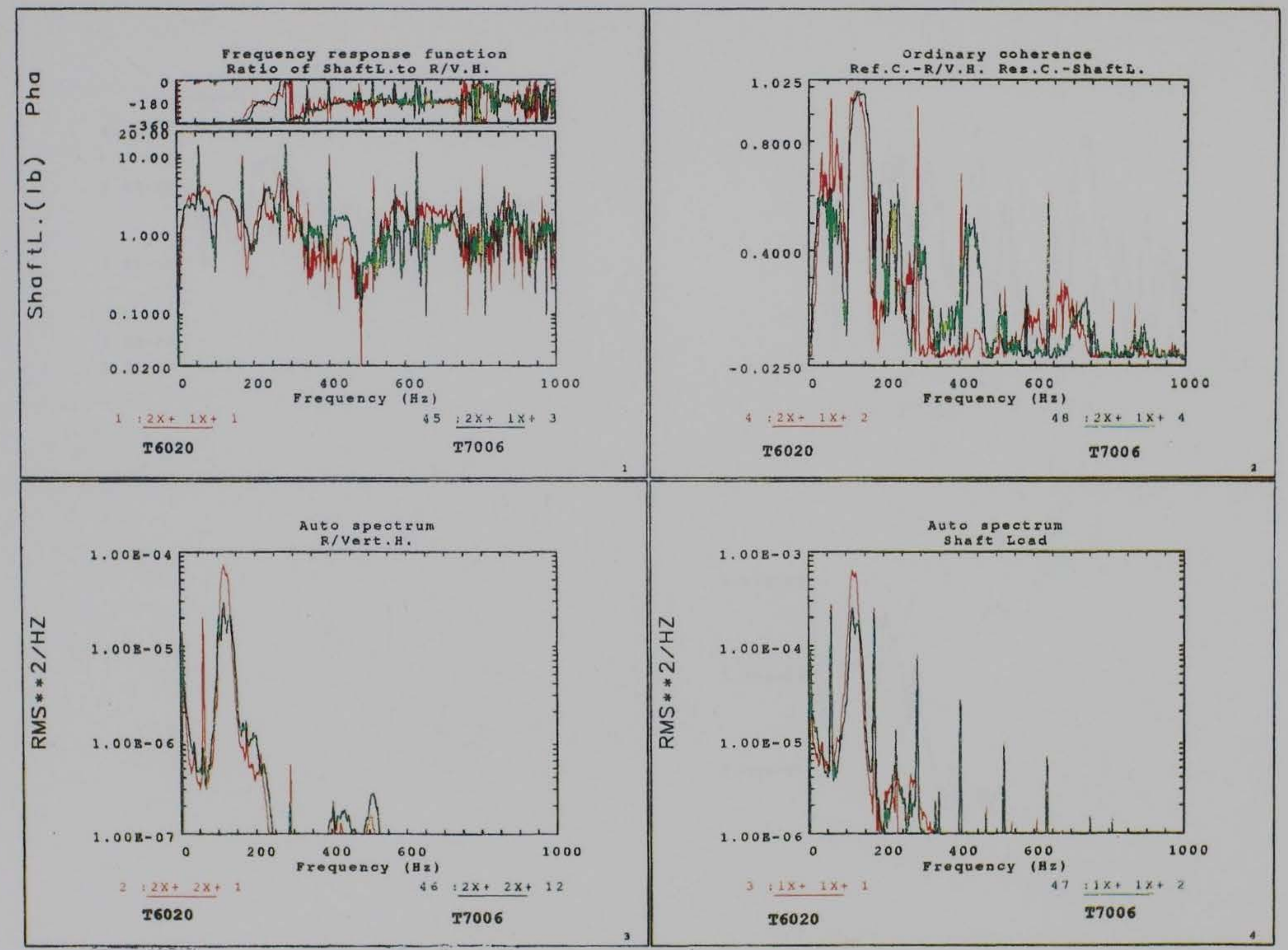

Figure 17. FRF data comparison for test set \#3 $\left(50^{\circ}\right.$ position). a. Shaft load to right vertical hinge (Sheet 1 of 9 ) 


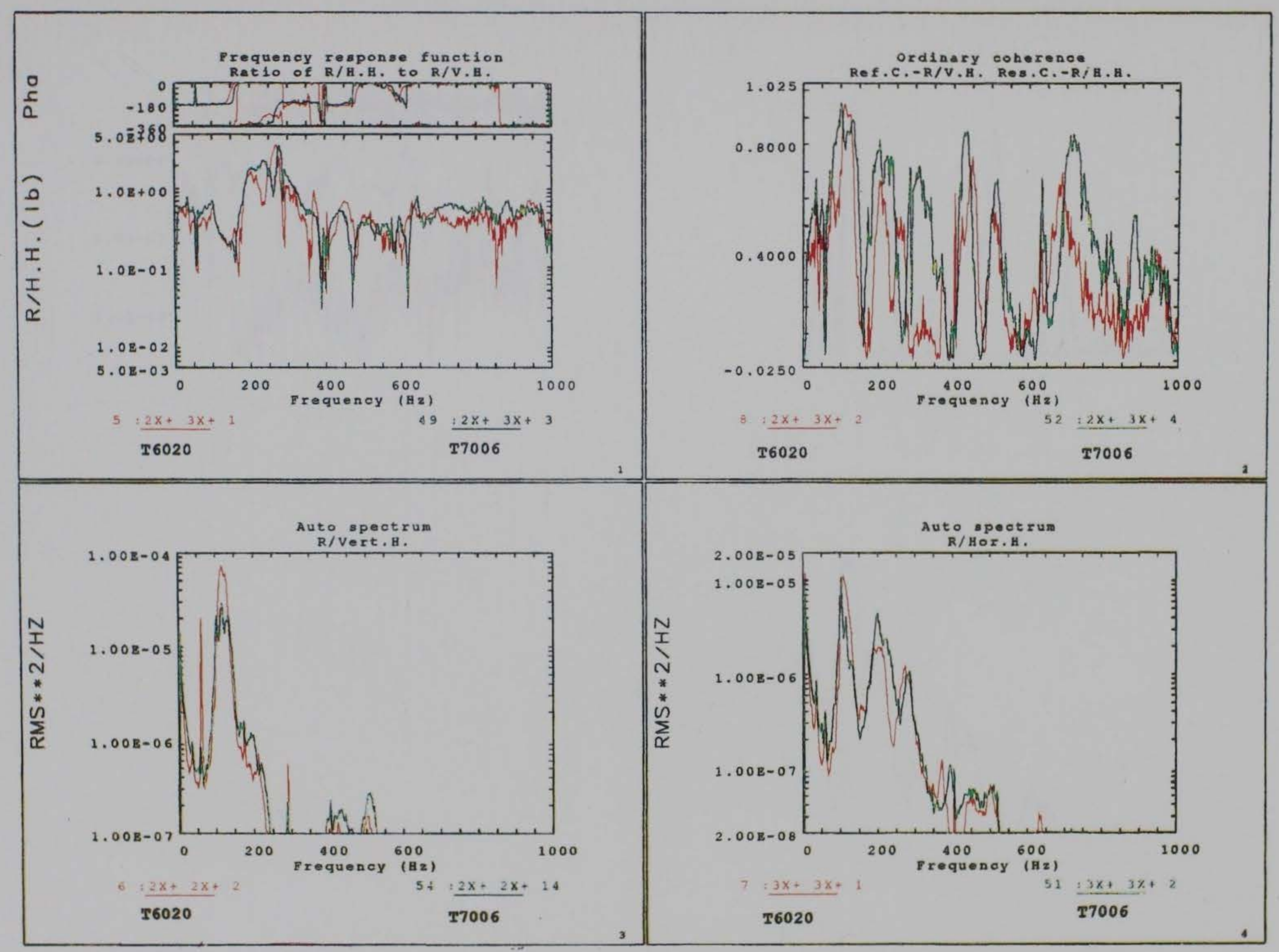

Figure 17b. Right horizontal hinge to right vertical hinge (Sheet 2 of 9) 


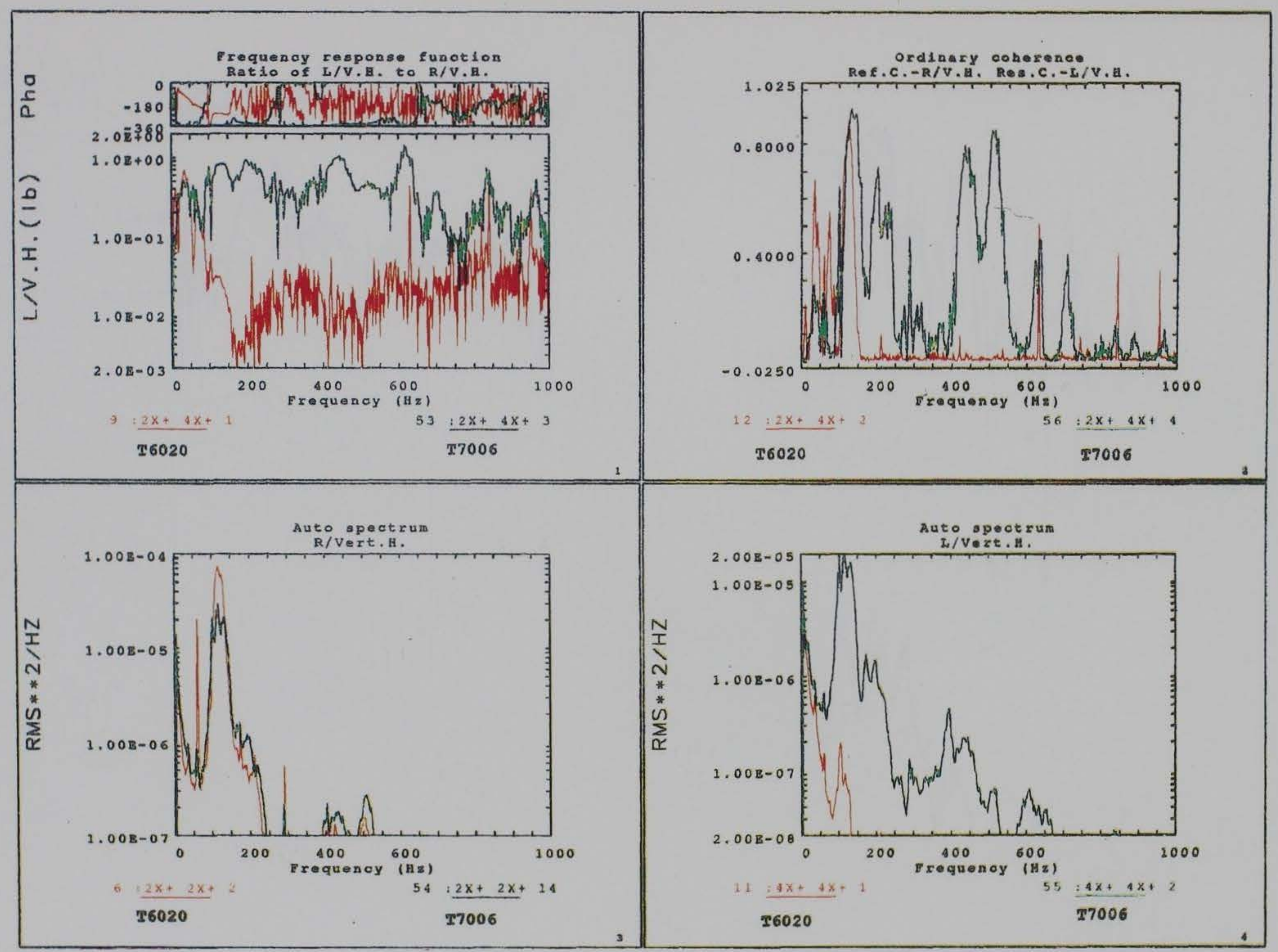

Figure 17c. Left vertical to right vertical hinge (Sheet 3 of 9) 


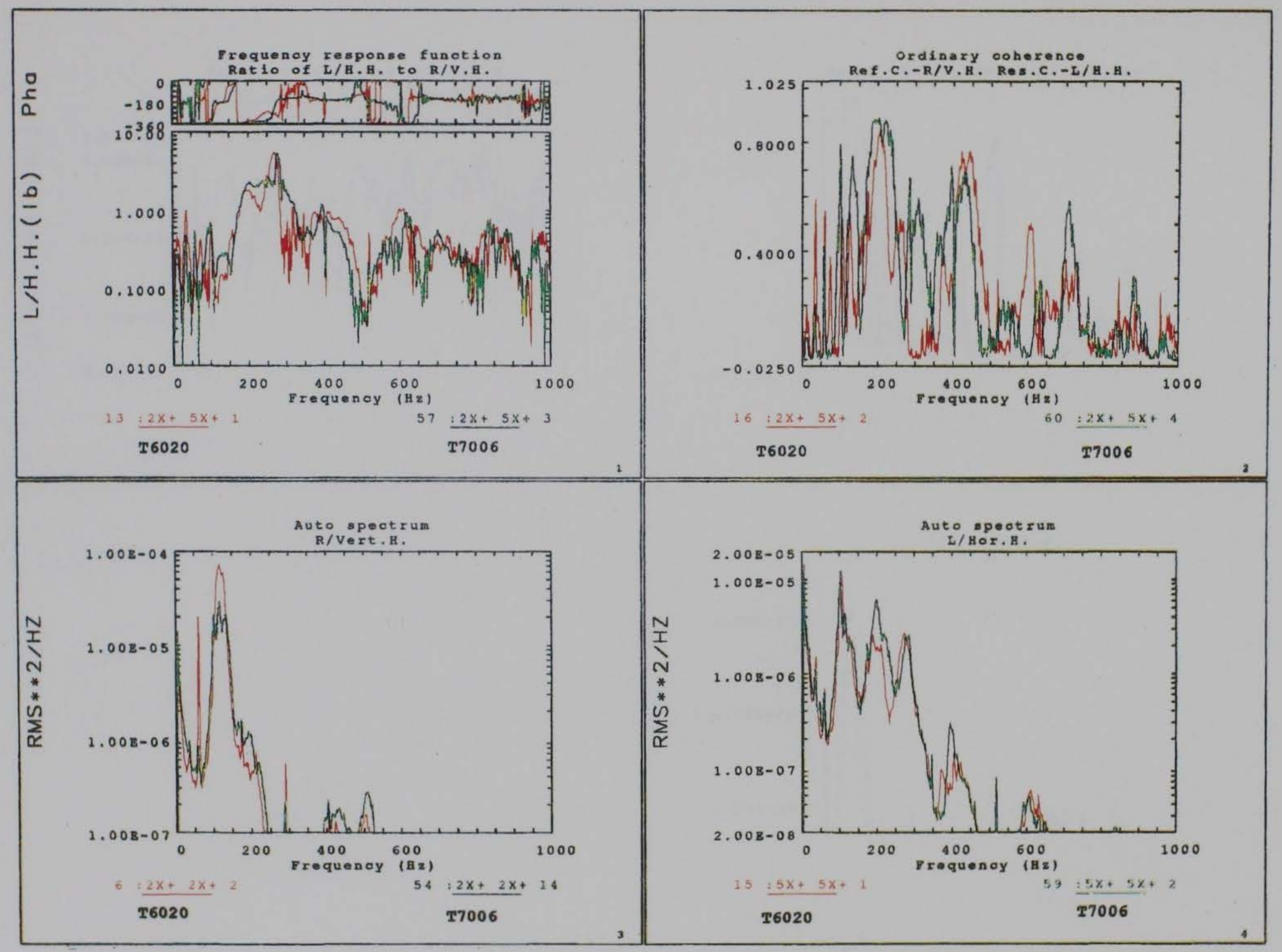

Figure $17 d$. Left horizontal to right vertical hinge (Sheet 4 of 9 ) 


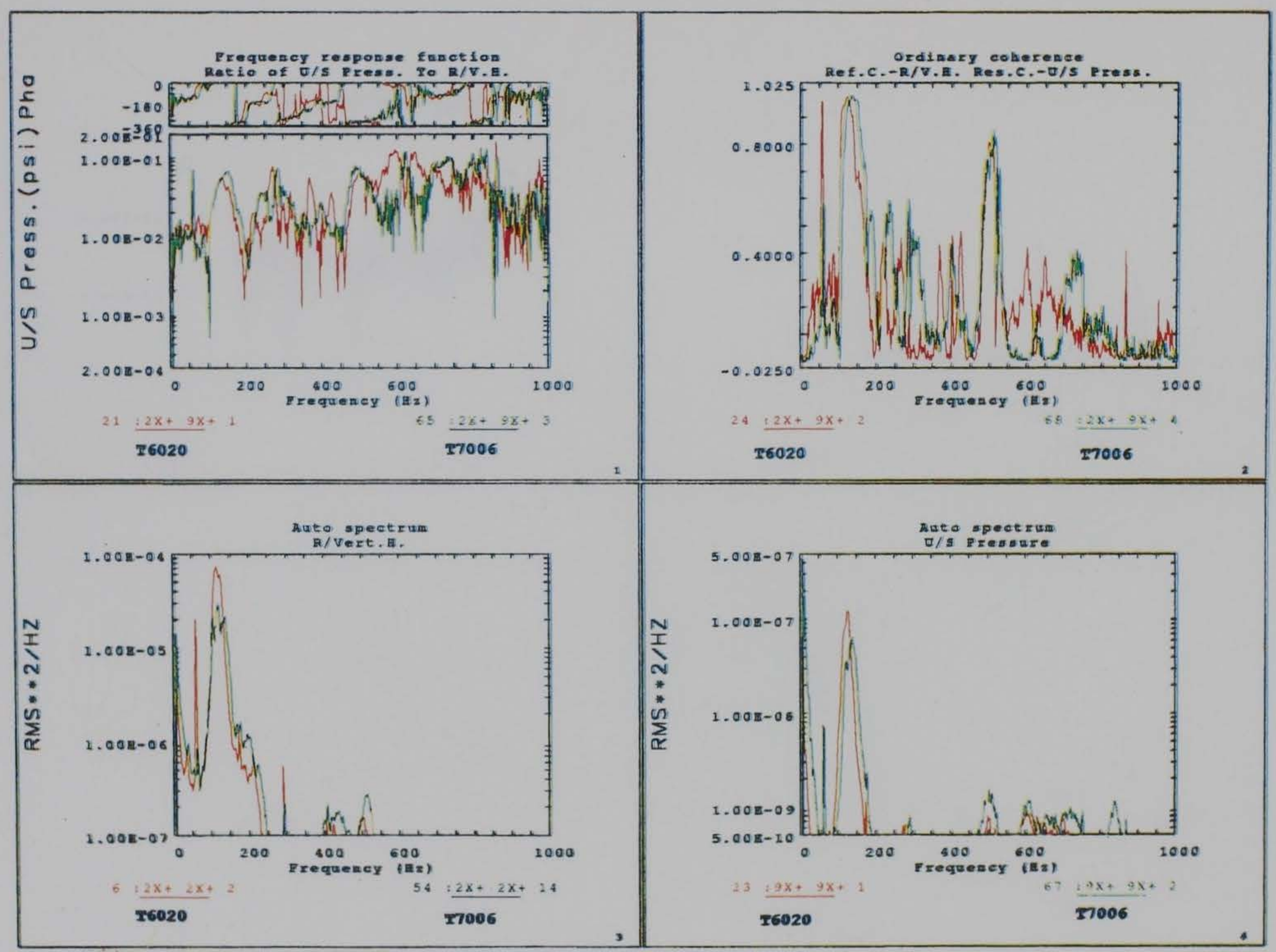

Figure 17e. Upstream pressure to right vertical hinge (Sheet 5 of 9) 


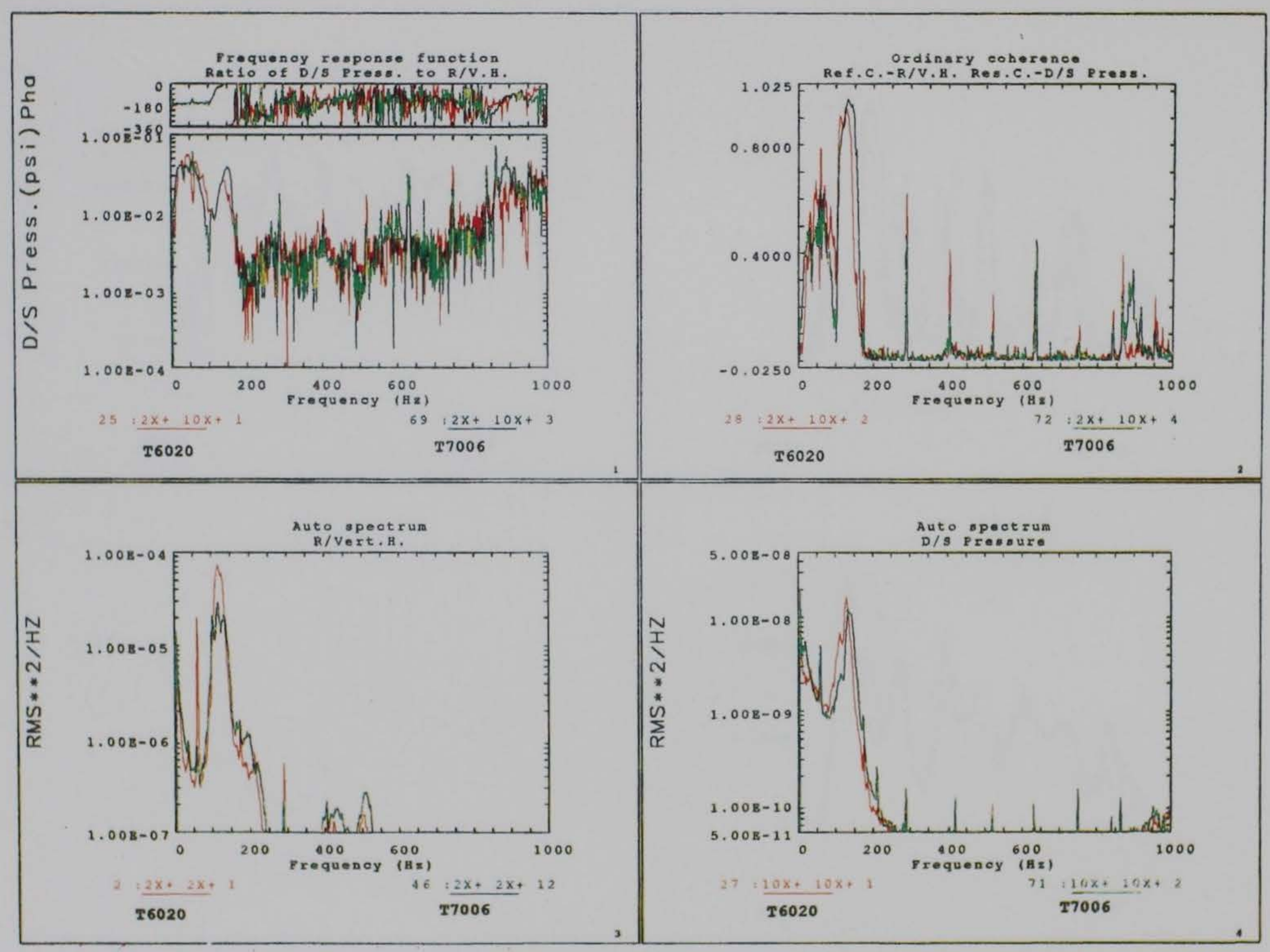

Figure 17f. Downstream pressure to right vertical hinge (Sheet 6 of 9) 


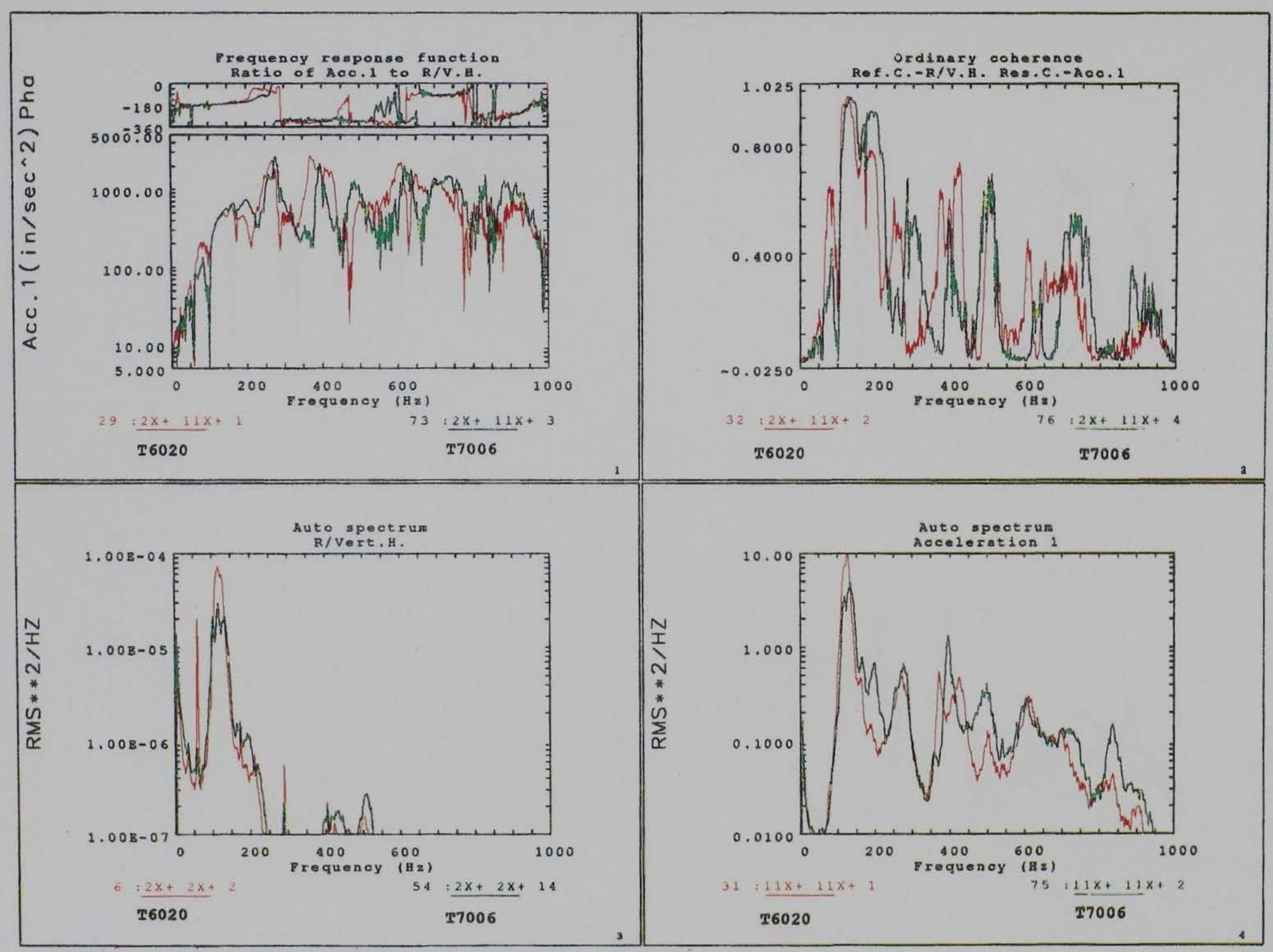

Figure $17 \mathrm{~g}$. Acceleration 1 to right vertical hinge (Sheet 7 of 9) 


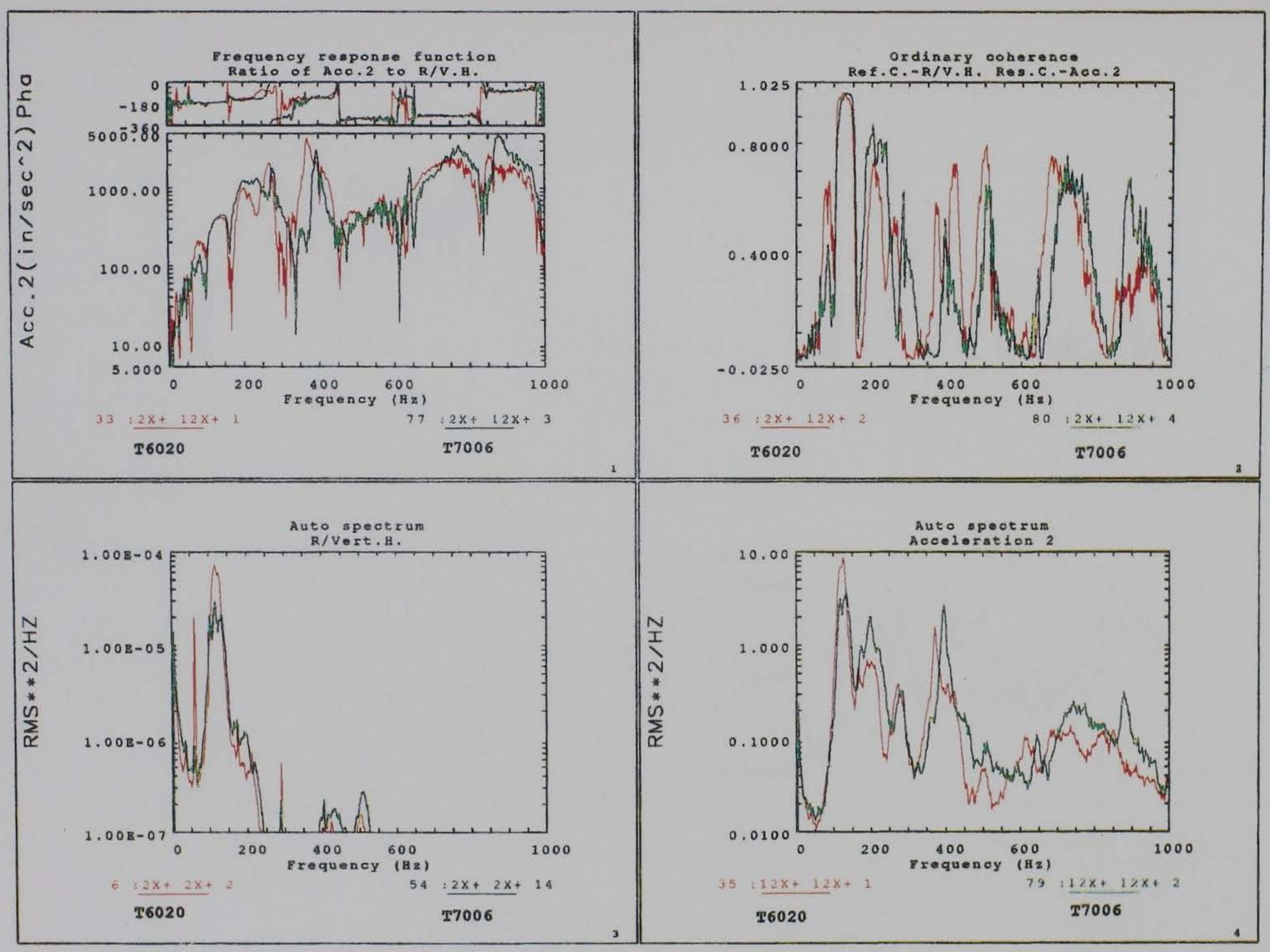

Figure 17h. Acceleration 2 to right vertical hinge (Sheet 8 of 9) 


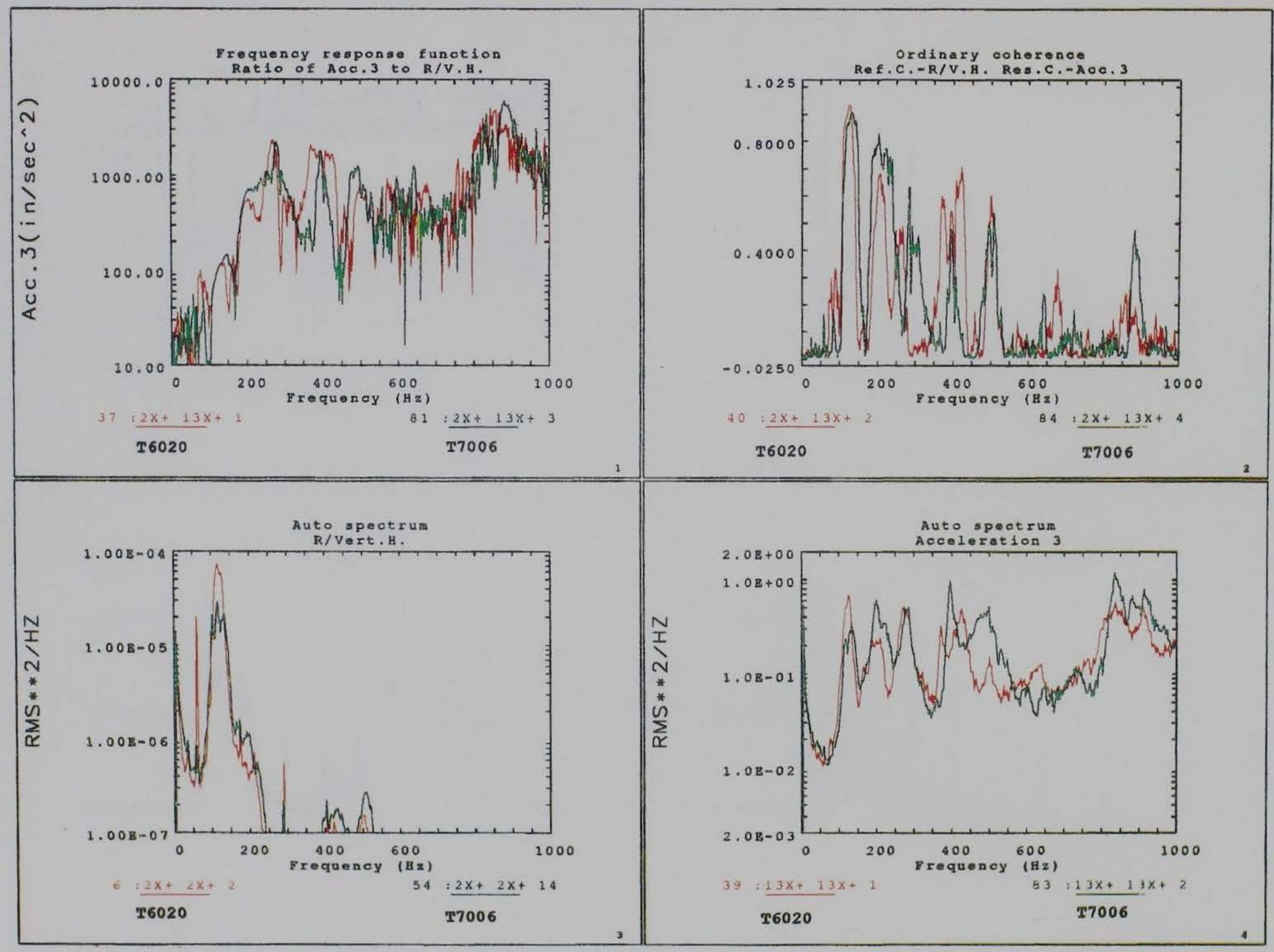

Figure 17i. Acceleration 3 to right vertical hinge (Sheet 9 of 9) 


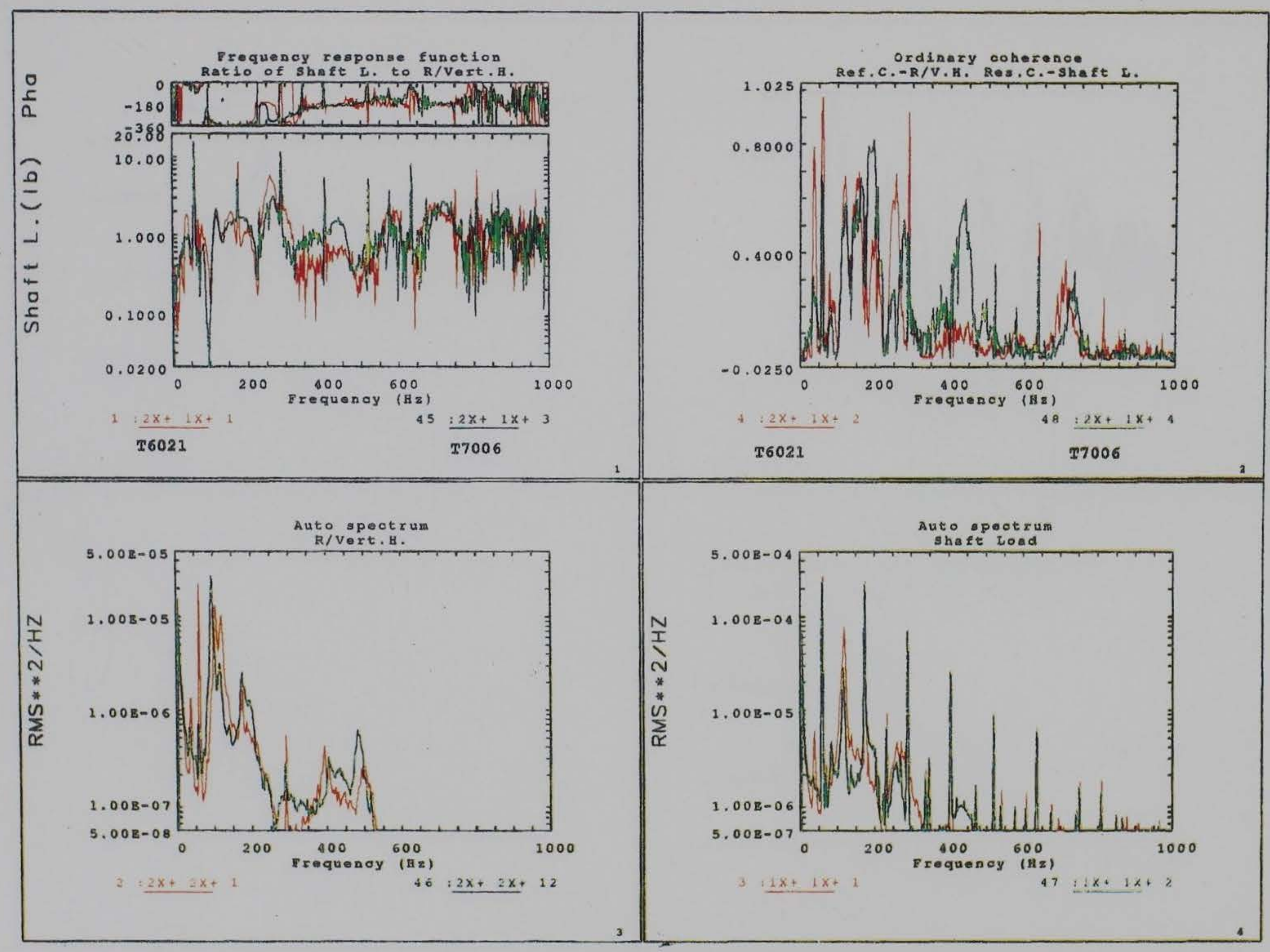

Figure 18. FRF data comparison for test set \#3 $\left(60^{\circ}\right.$ position). a. Shaft load to right vertical hinge (Sheet 1 of 9 ) 


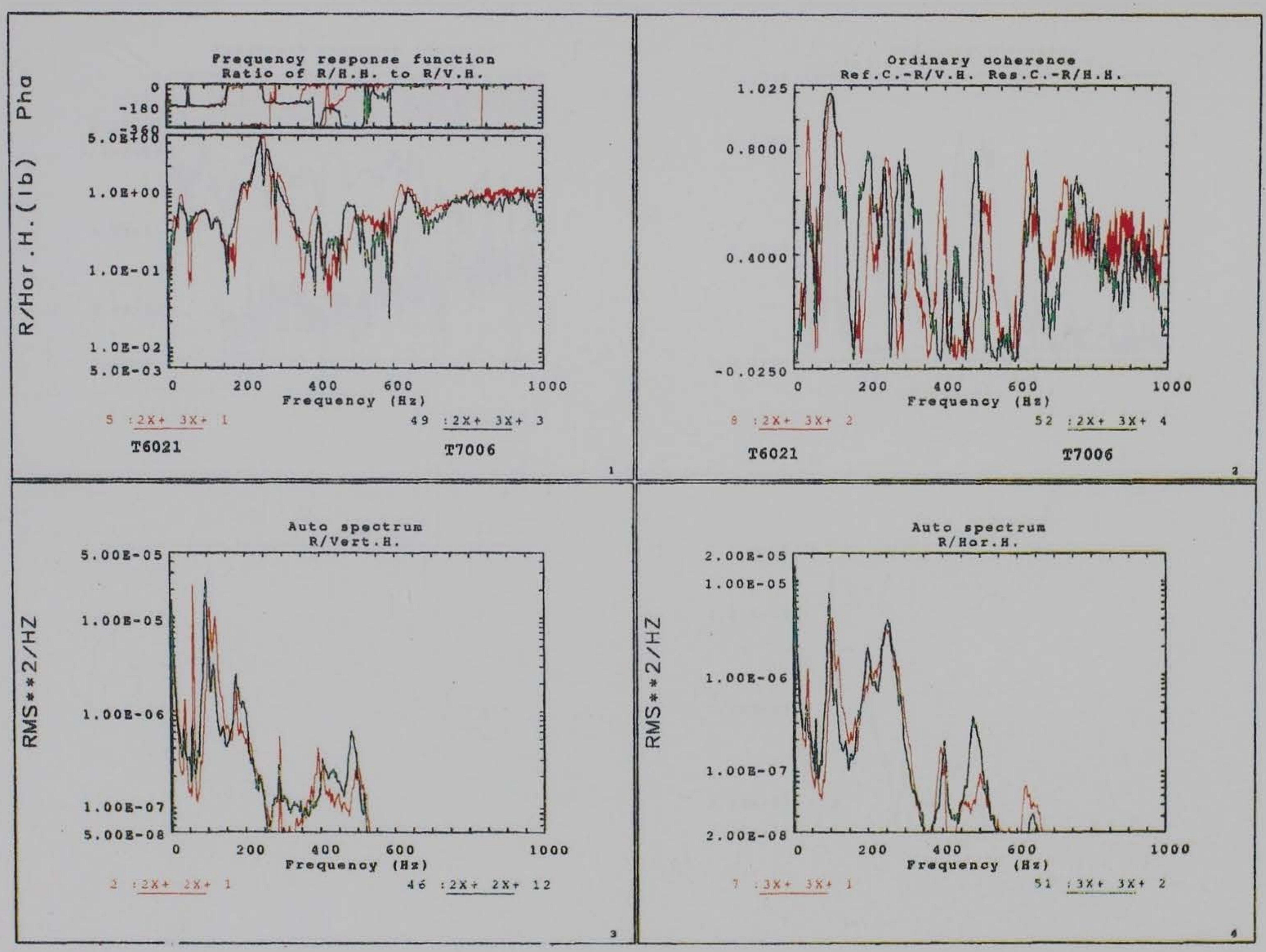

Figure 18b. Right horizontal to right vertical hinge (Sheet 2 of 9) 


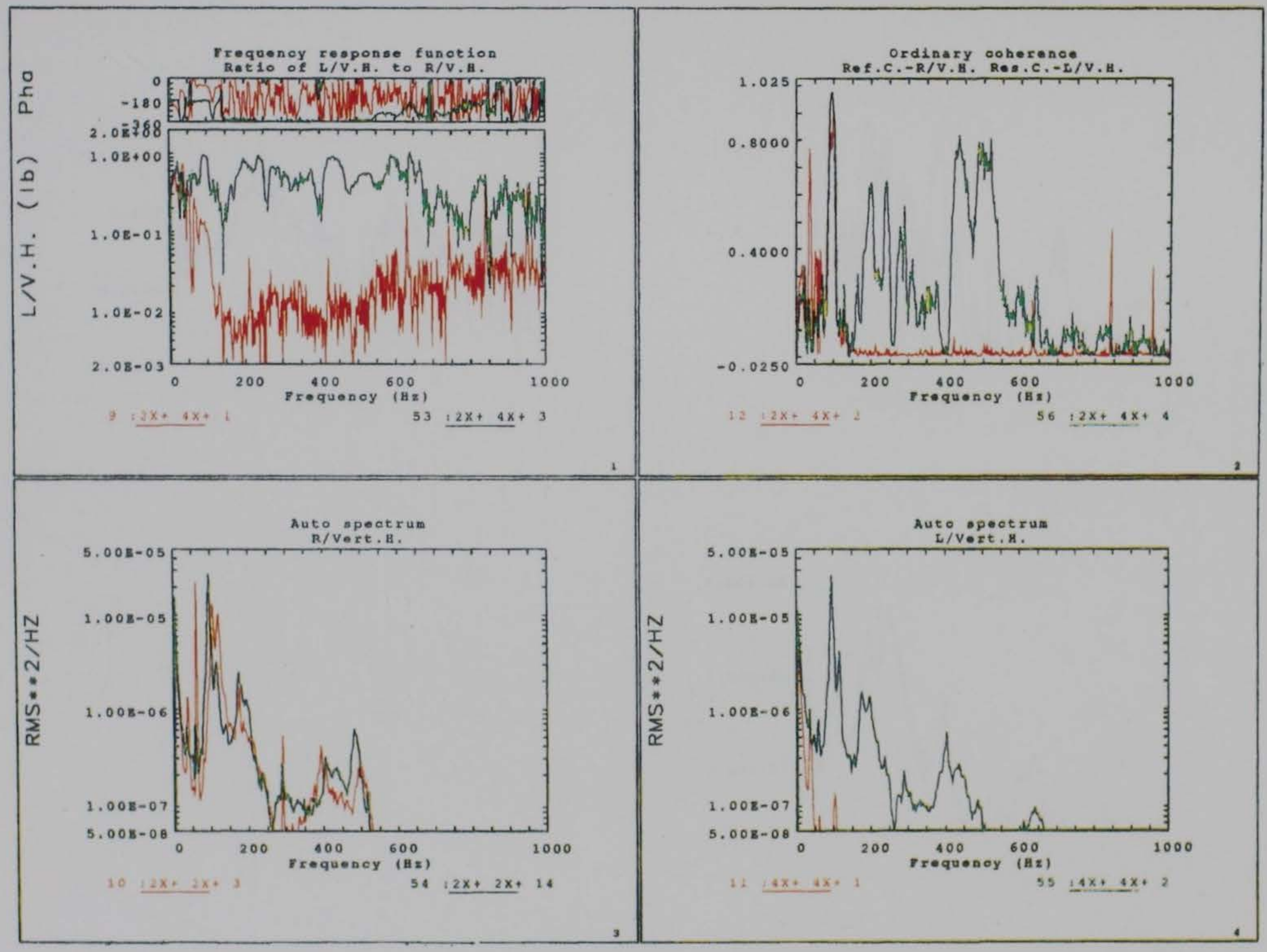

Figure 18c. Left vertical to right vertical hinge (Sheet 3 of 9) 


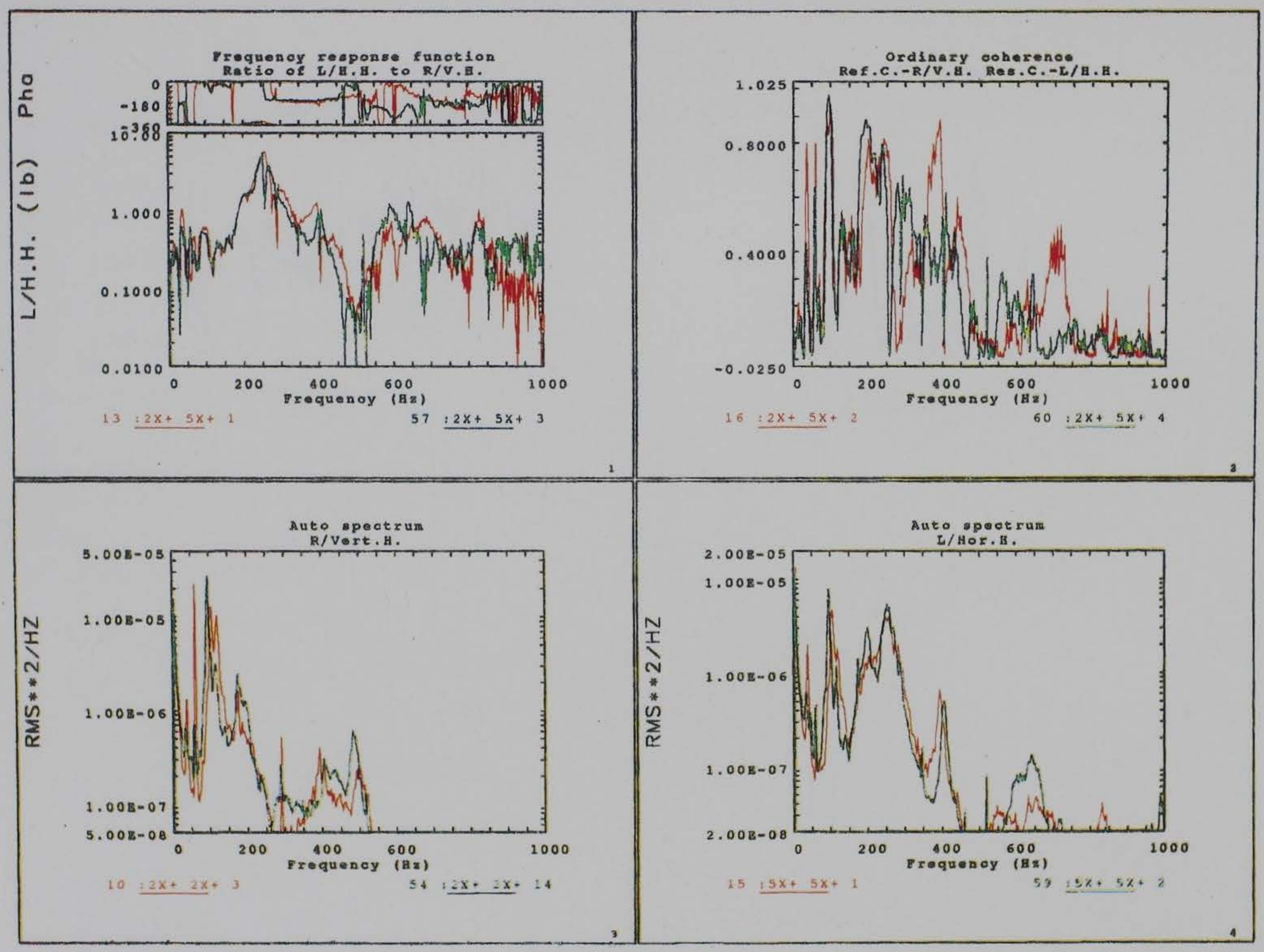

Figure 18d. Left horizontal to right vertical hinge (Sheet 4 of 9) 


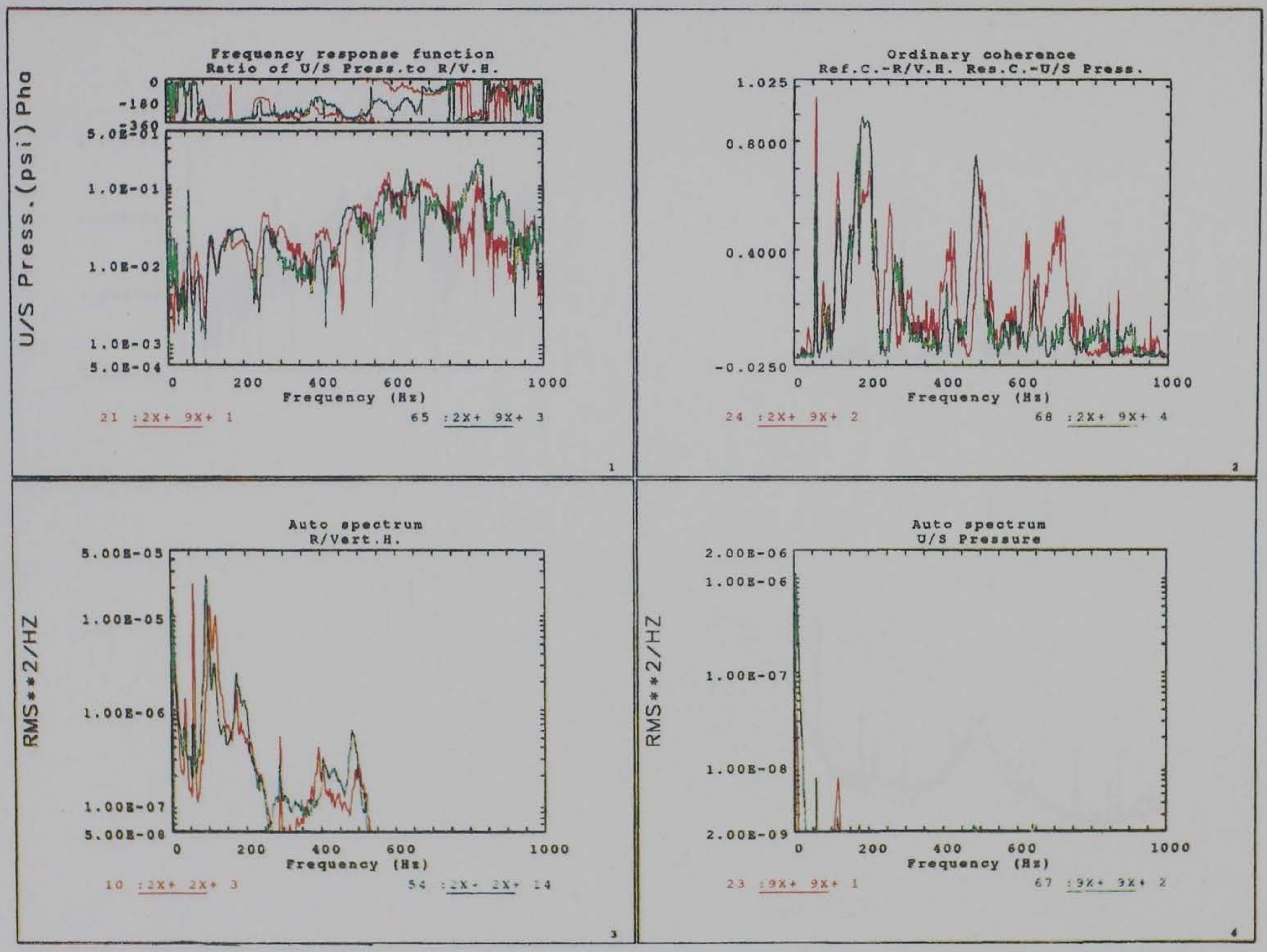

Figure $18 \mathrm{e}$. Upstream pressure to right vertical hinge (Sheet 5 of 9) 


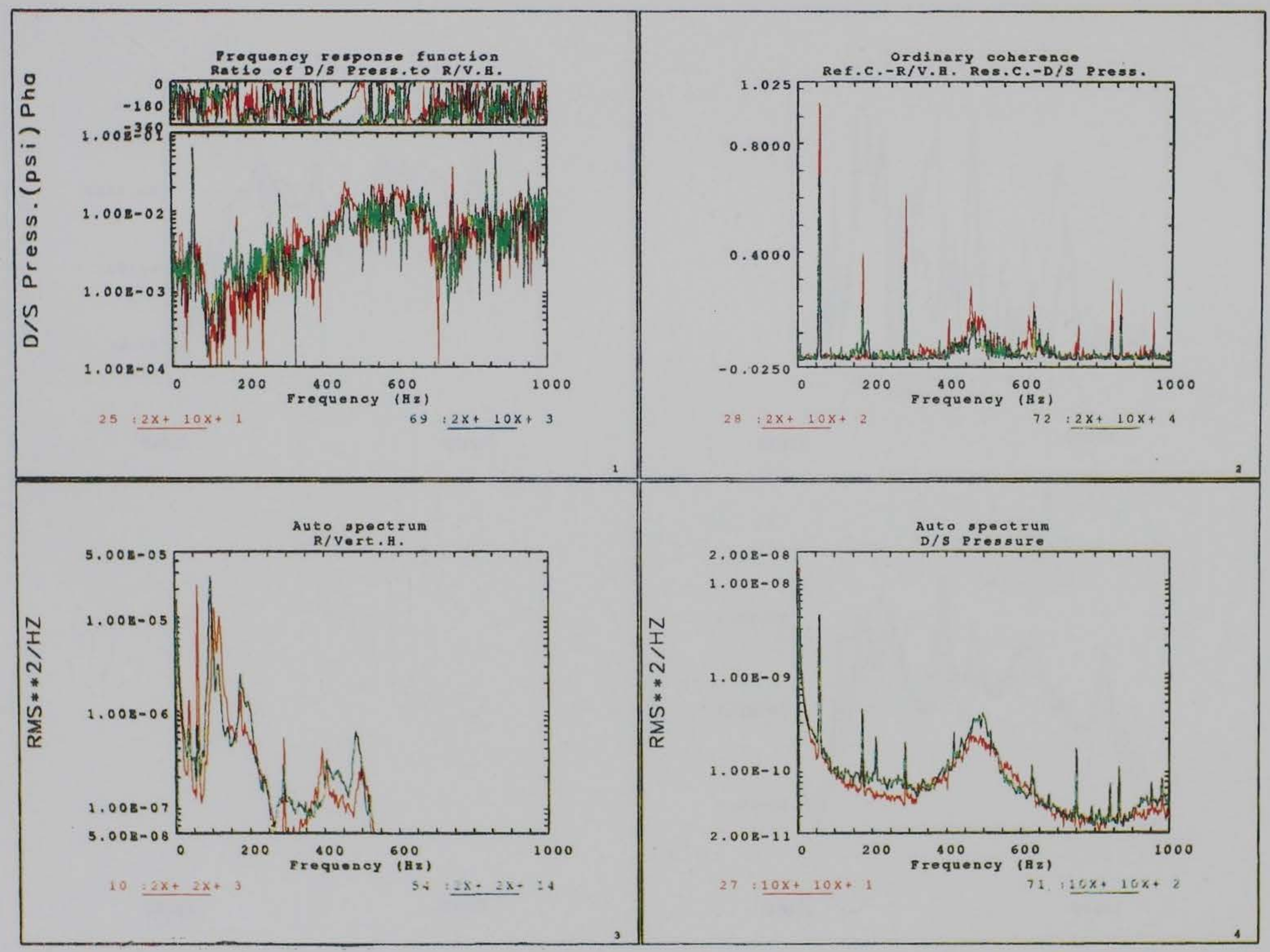

Figure 18f. Downstream pressure to right vertical hinge (Sheet 6 of 9) 


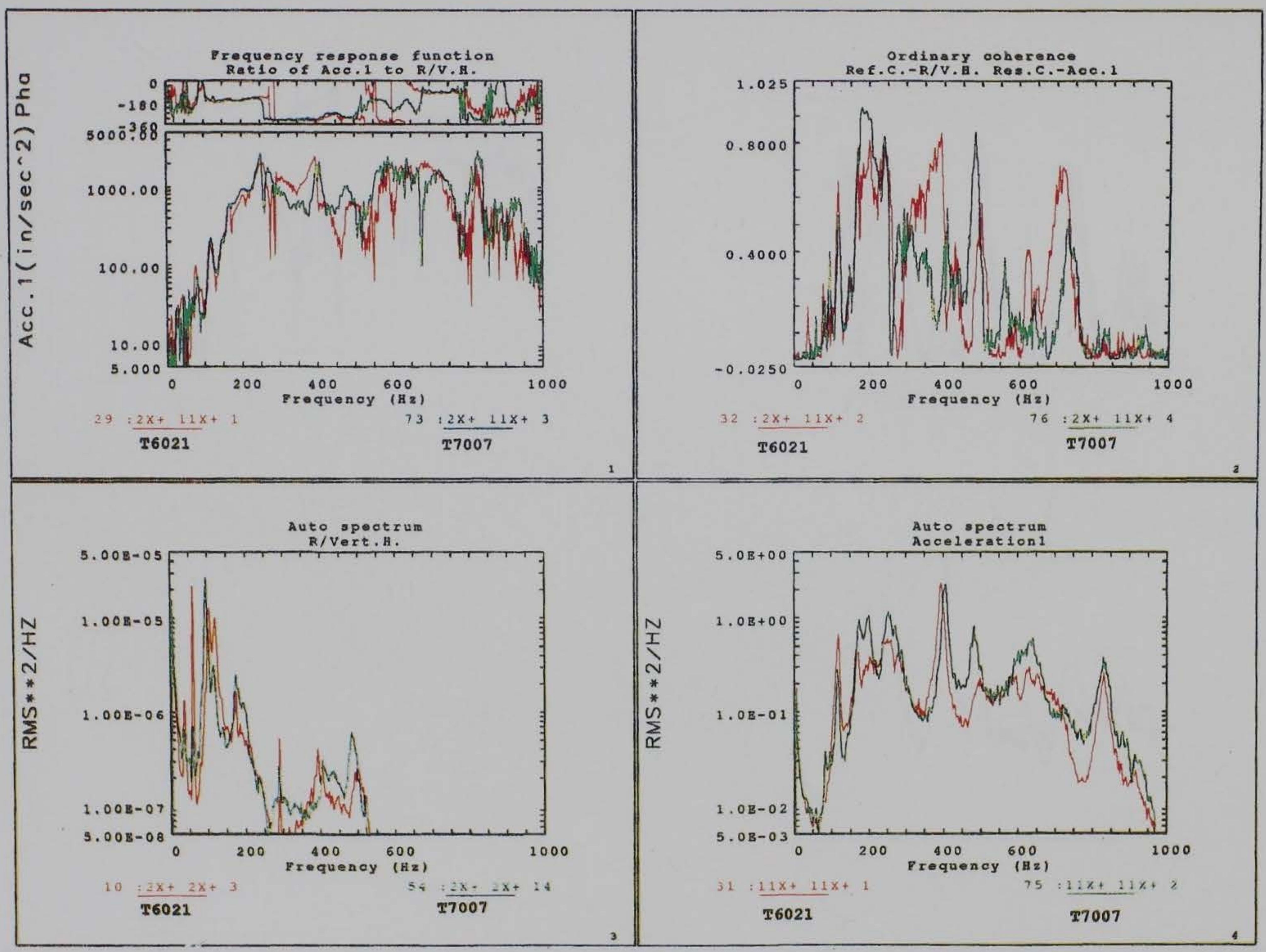

Figure $18 \mathrm{~g}$. Acceleration 1 to right vertical hinge (Sheet 7 of 9) 


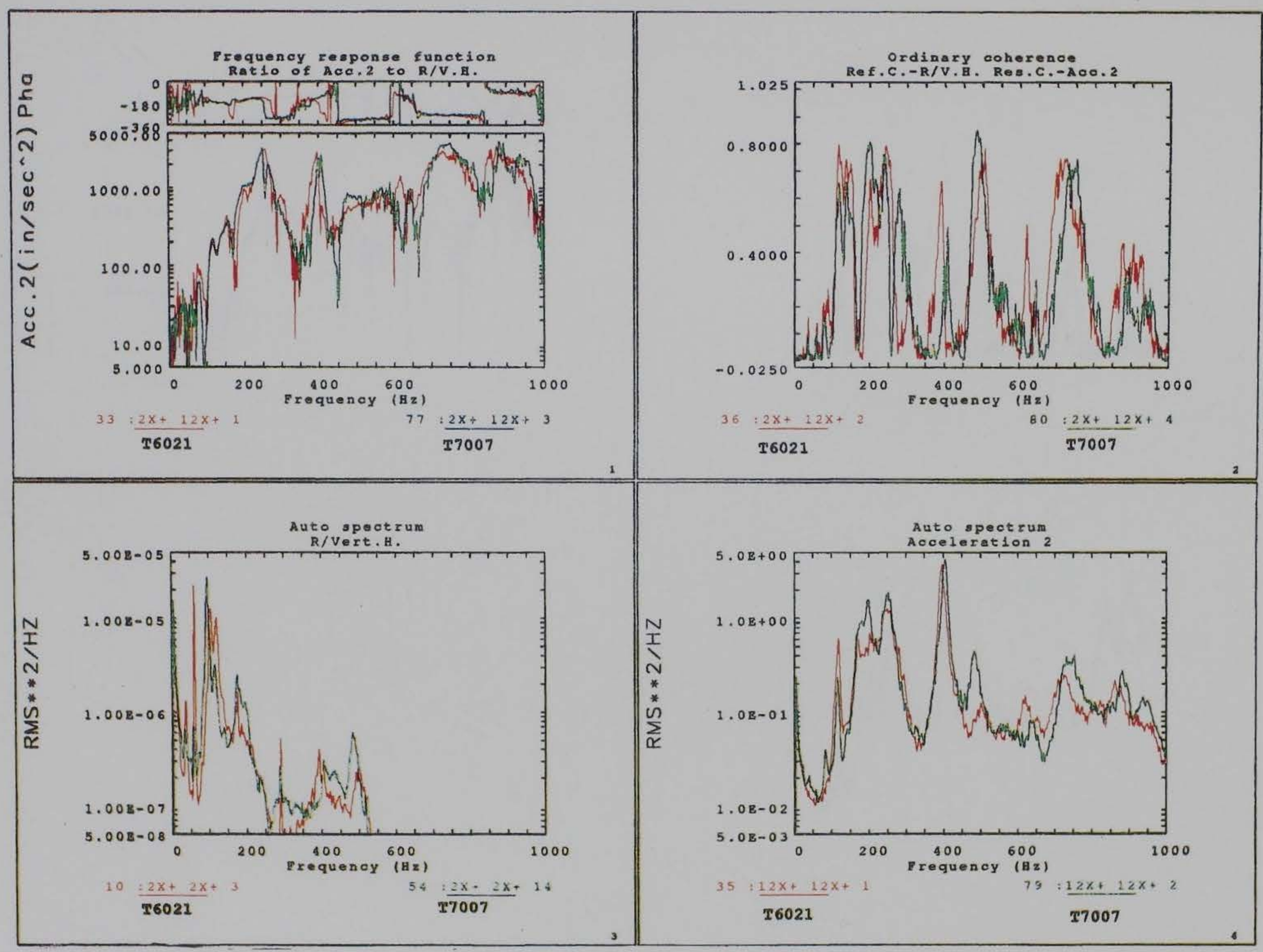

Figure $18 \mathrm{~h}$. Acceleration 2 to right vertical hinge (Sheet 8 of 9) 


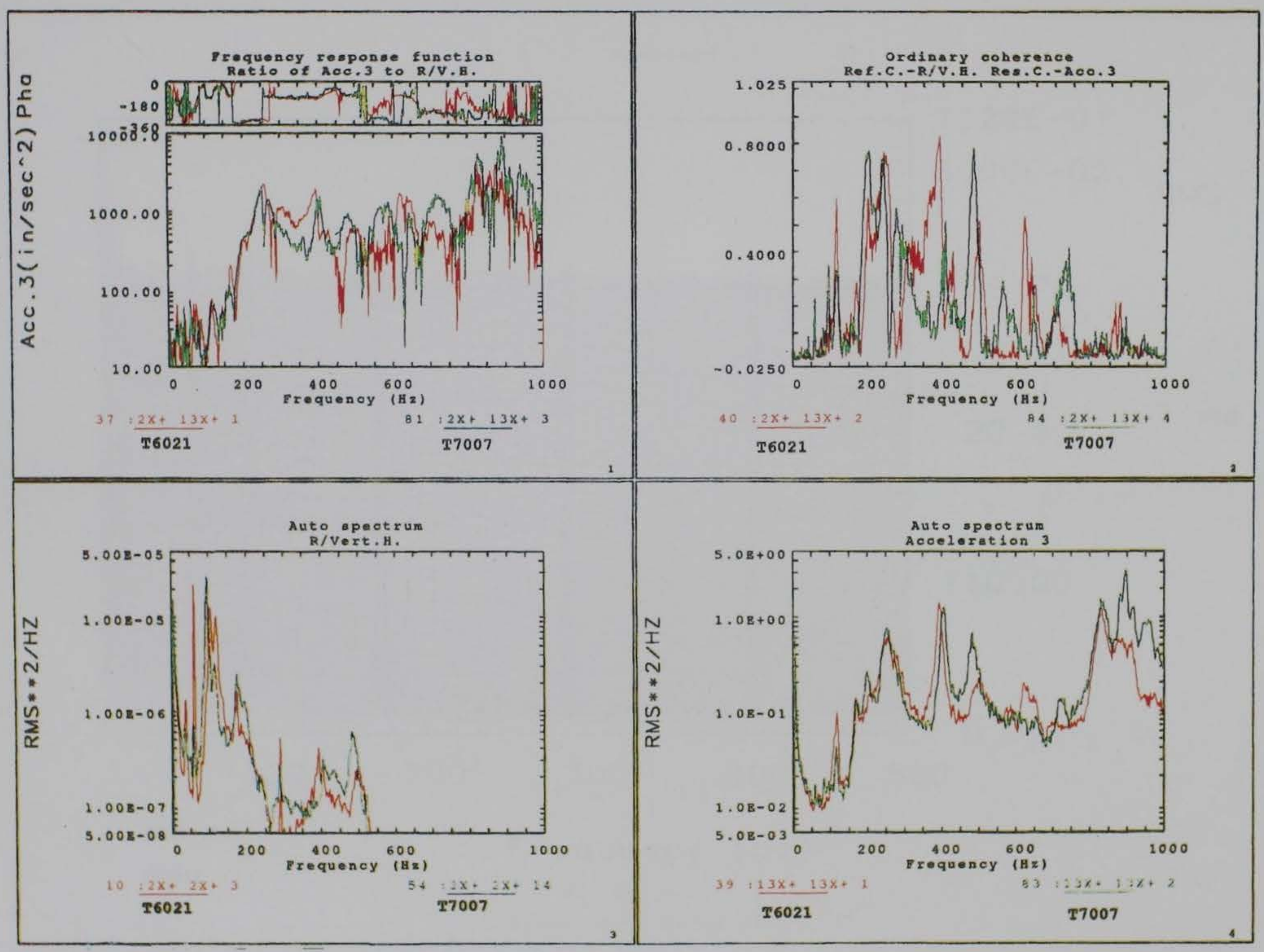

Figure 18i. Acceleration 3 to right vertical hinge (Sheet 9 of 9) 


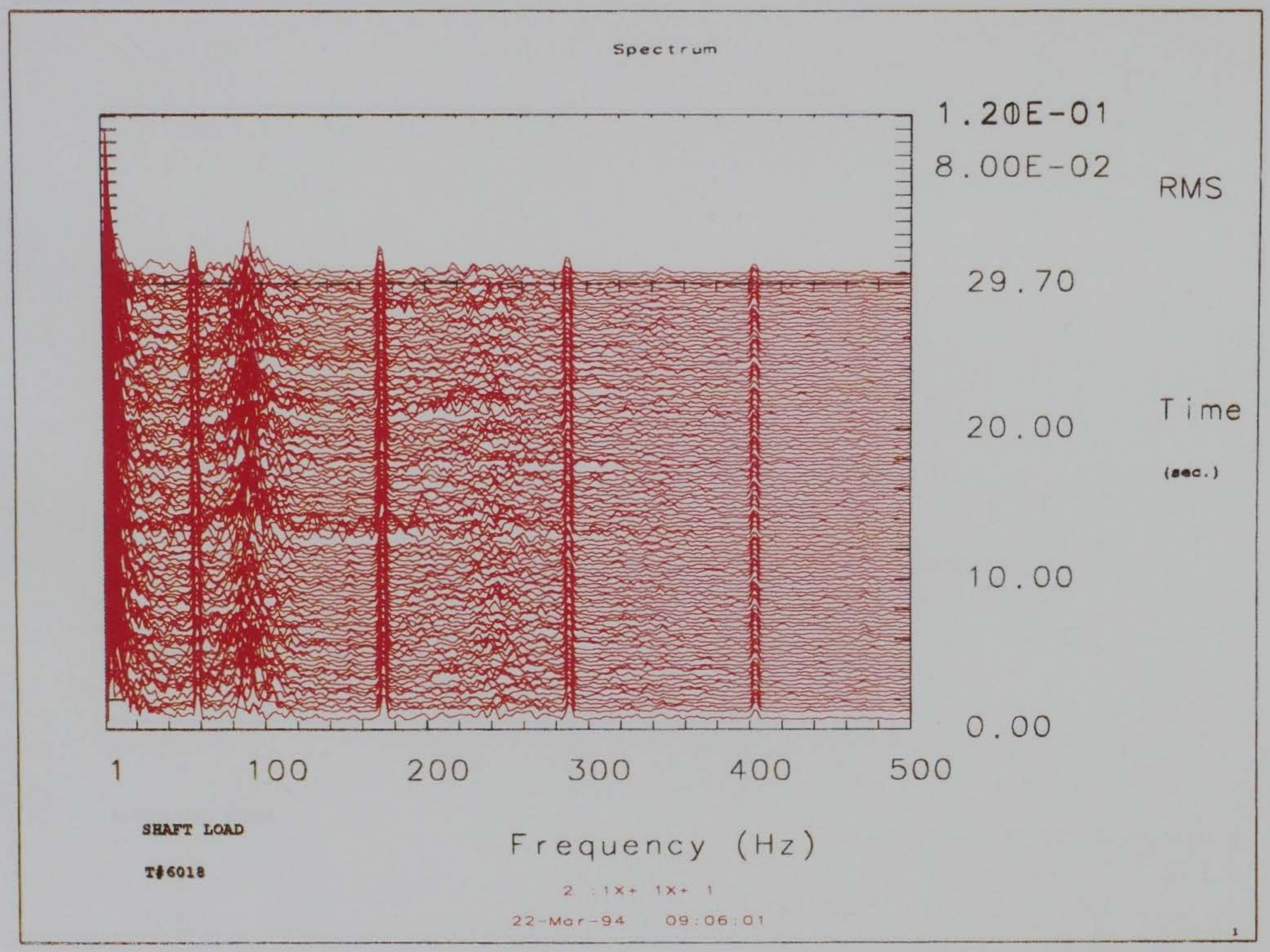

Figure 19. Time-spectral map for test set \#3 (Open channel @ $27^{\circ}$ position). a. Shaft load (Sheet 1 of 10) 


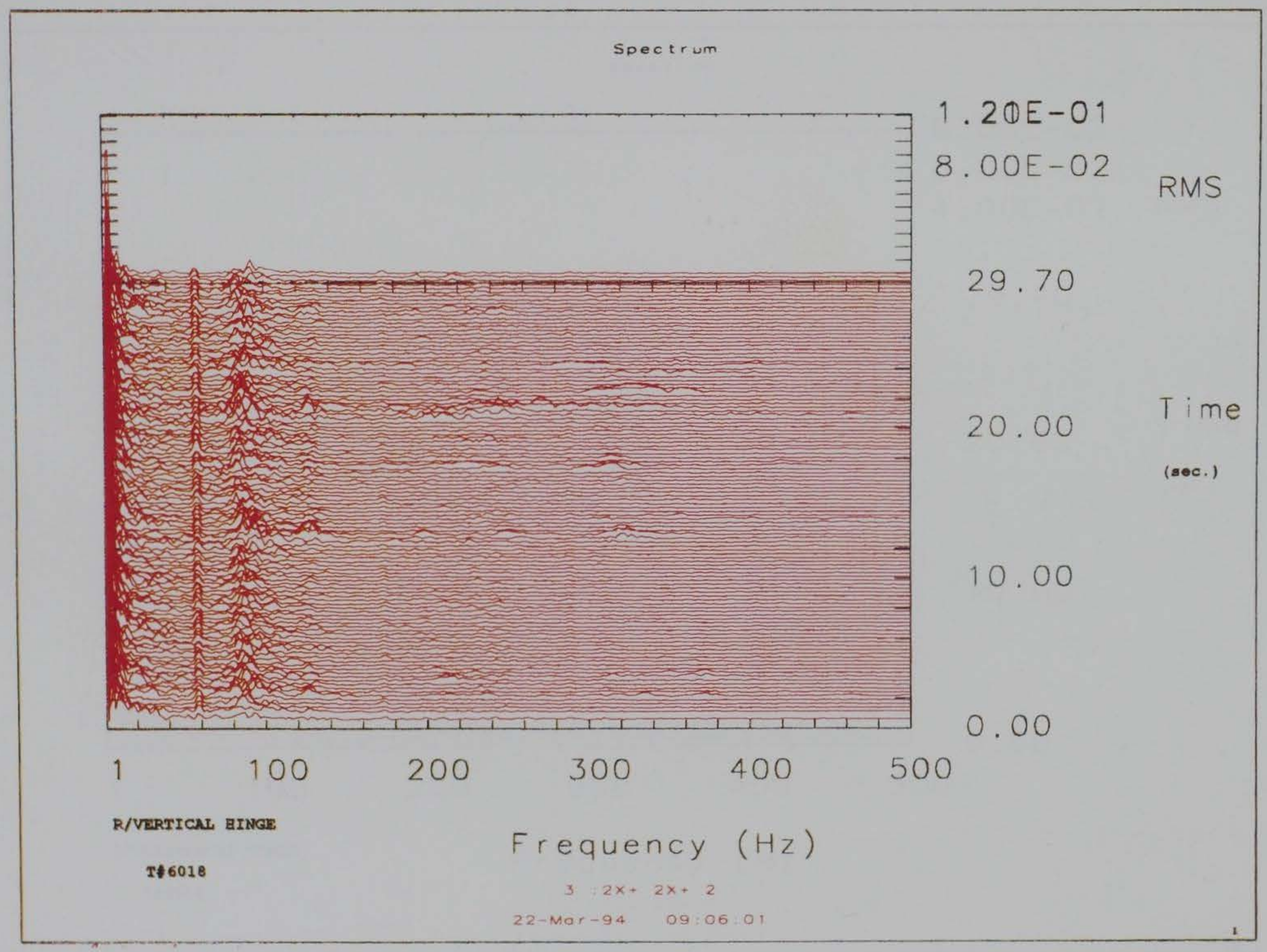

Figure 19b. Right vertical hinge (Sheet 2 of 10) 


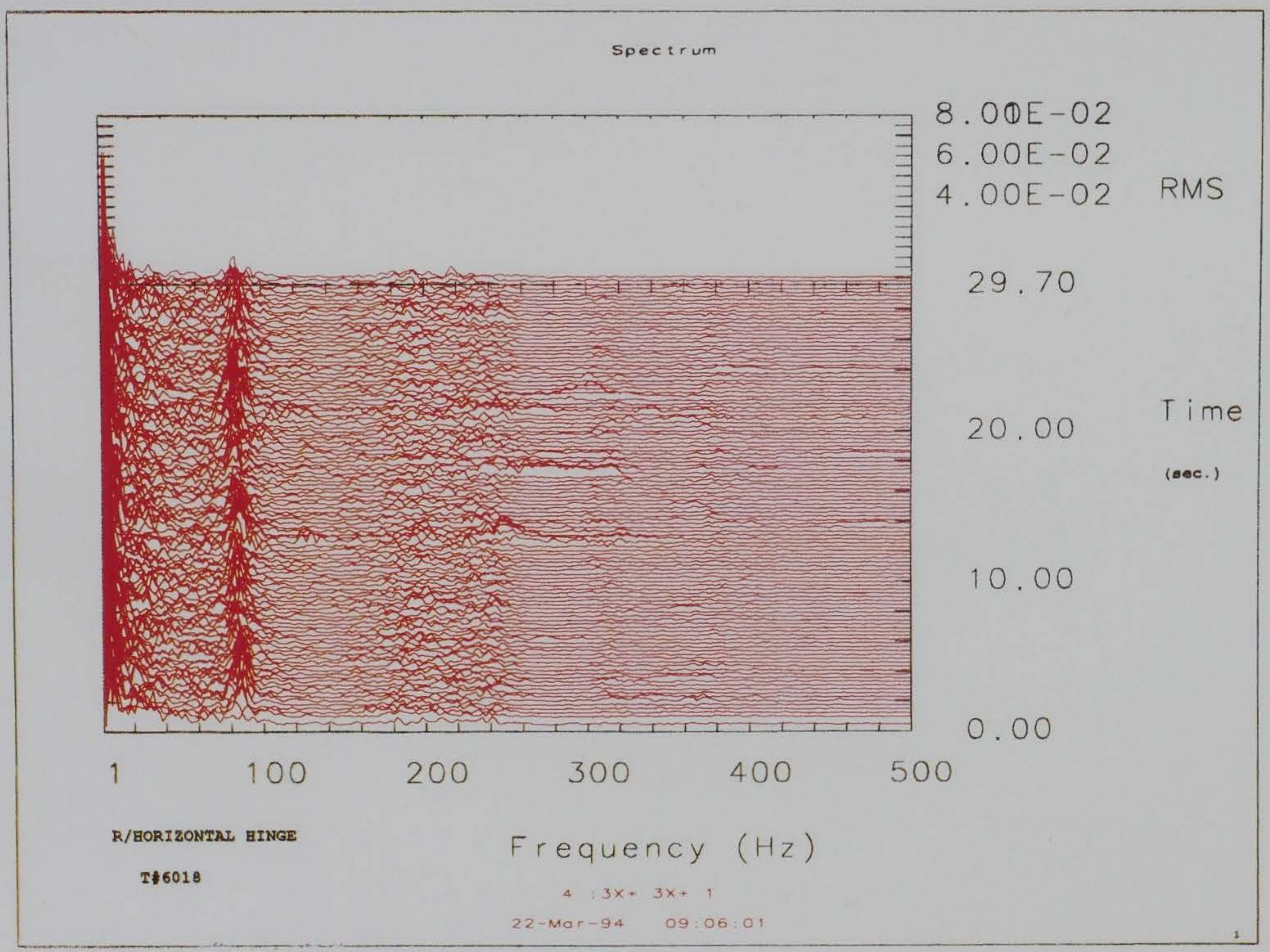

Figure 19c. Right horizontal hinge (Sheet 3 of 10) 


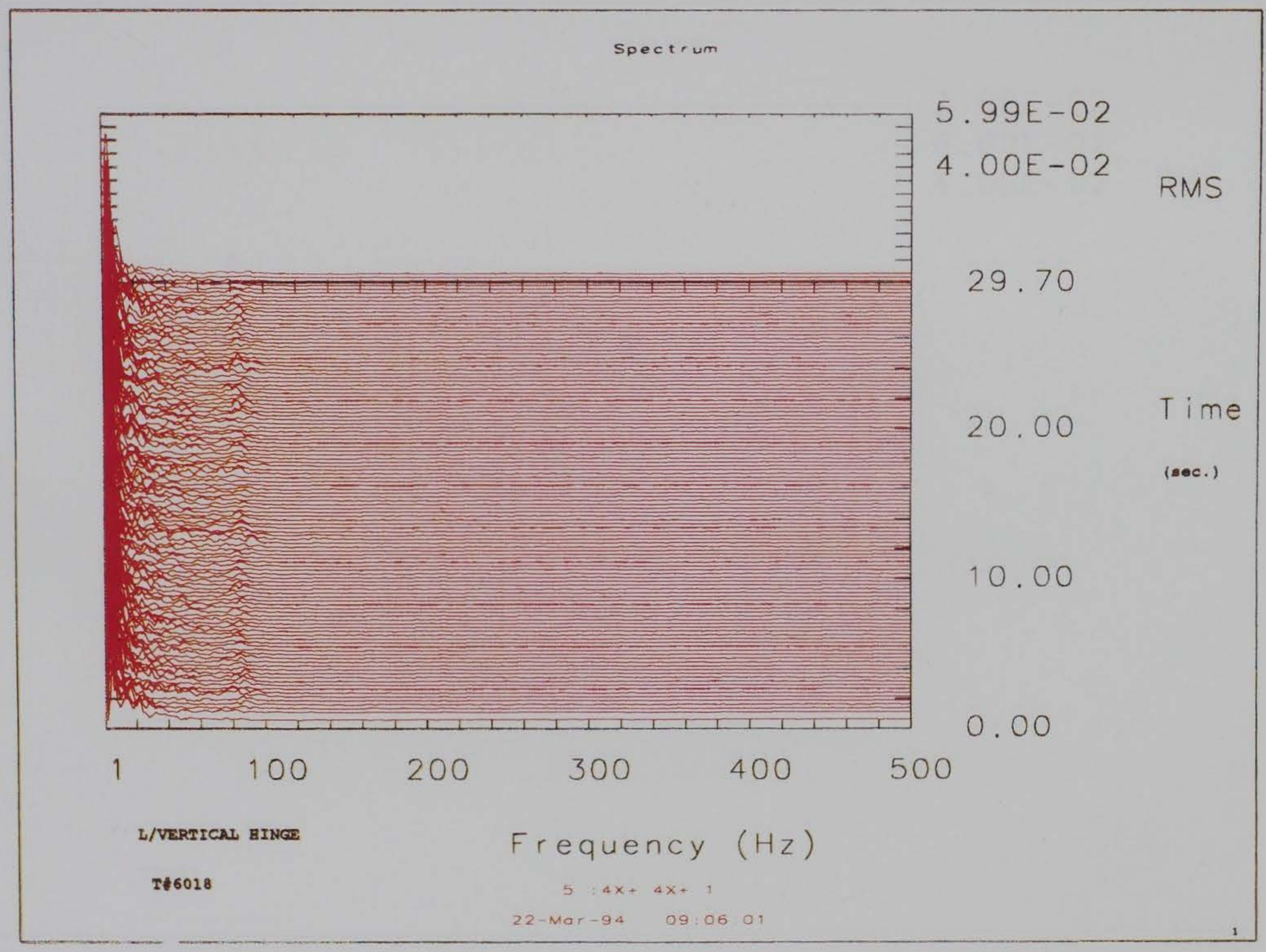

Figure 19d. Left vertical hinge (Sheet 4 of 10) 


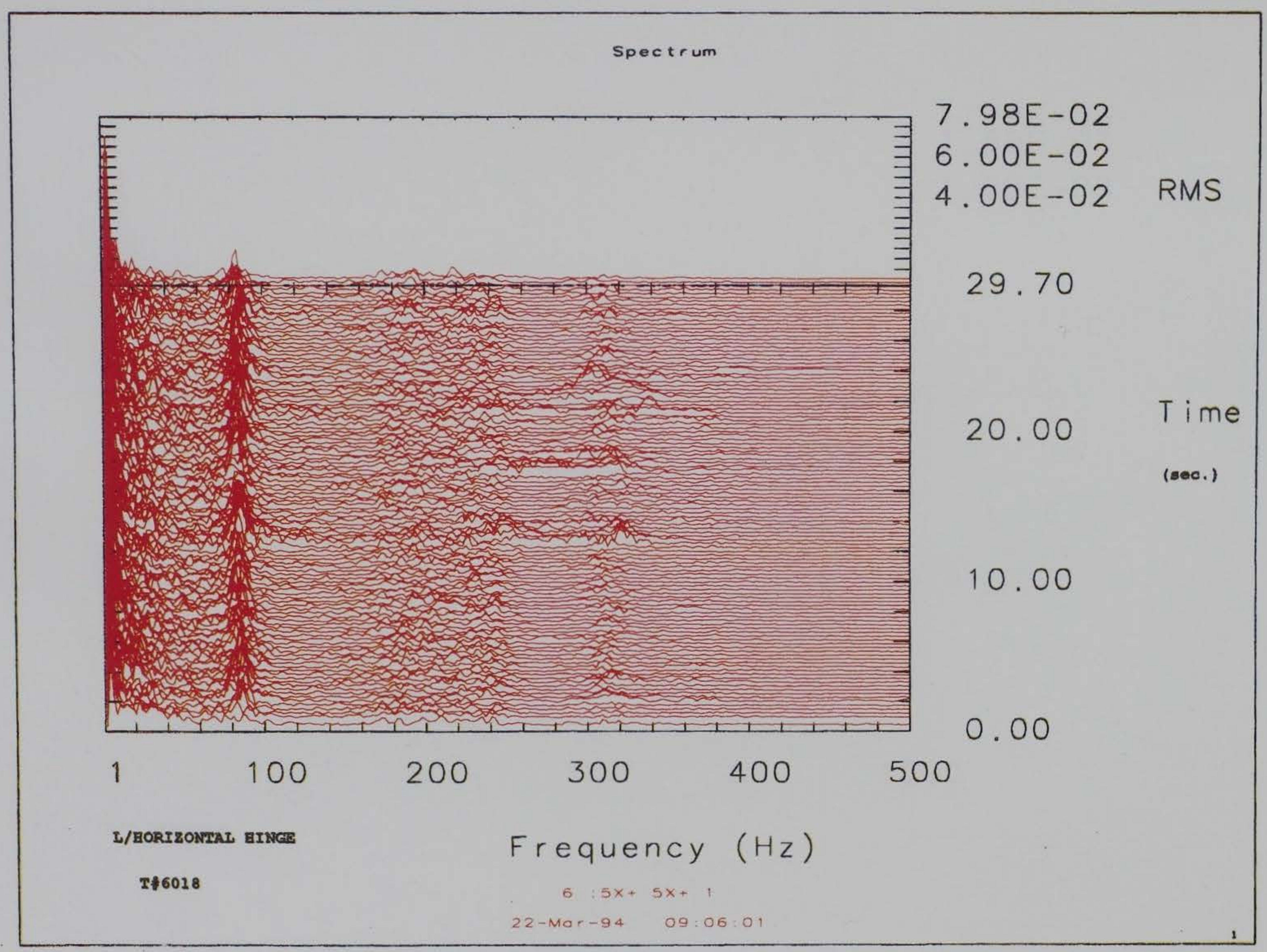

Figure $19 \mathrm{e}$. Left horizontal hinge (Sheet 5 of 10) 
Spectrum

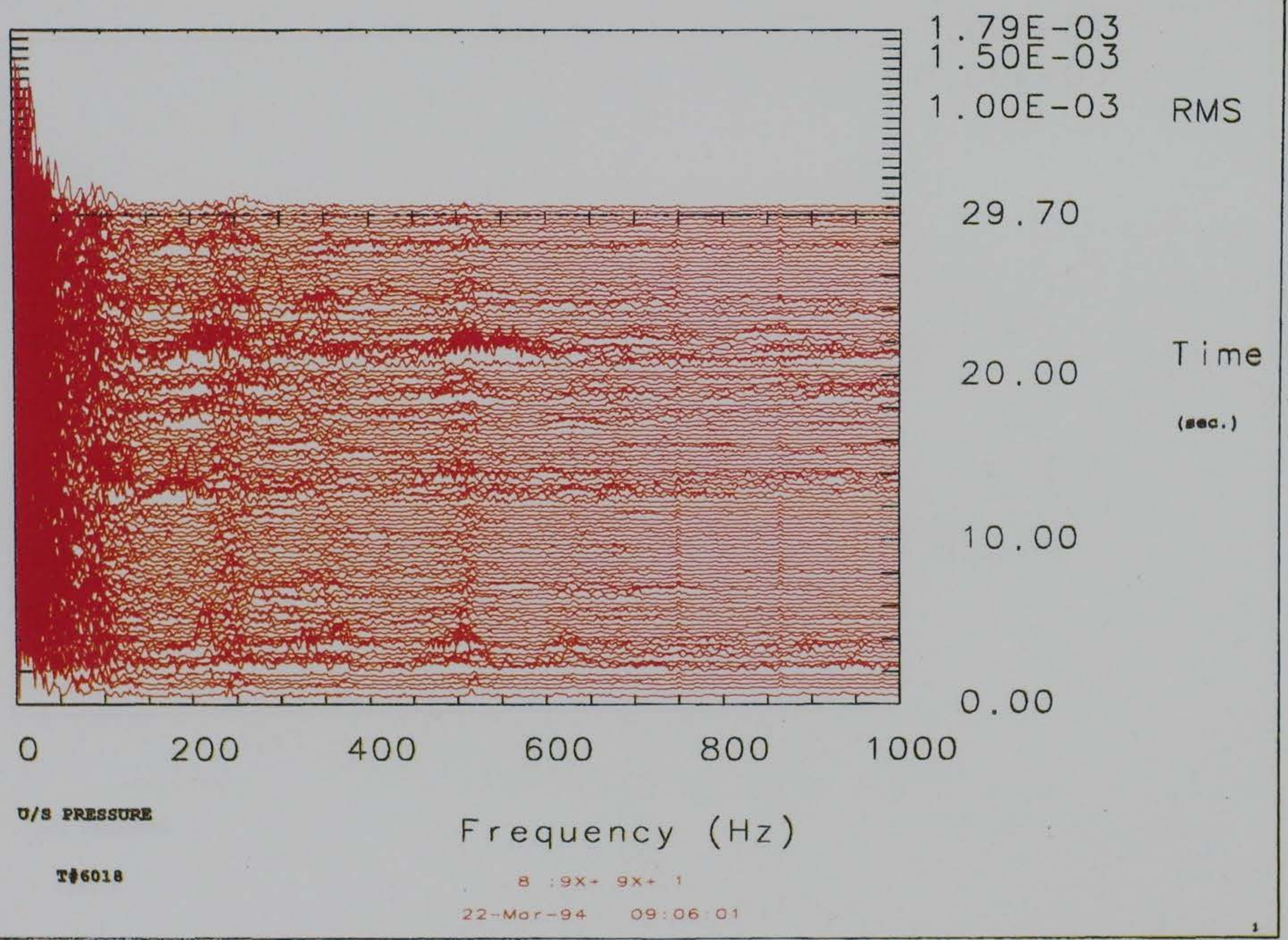

Figure 19f. Upstream pressure (Sheet 6 of 10) 


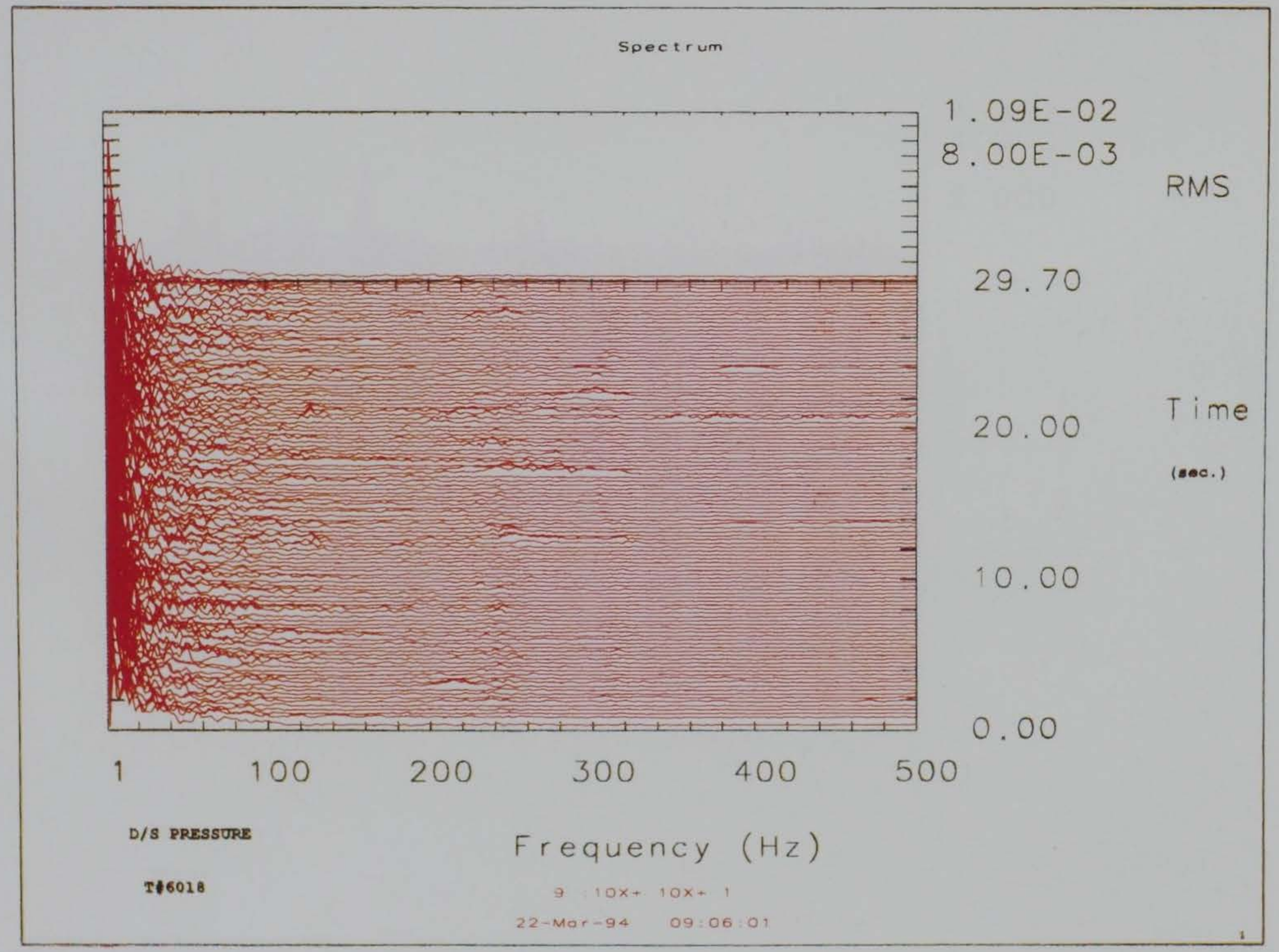

Figure $19 \mathrm{~g}$. Downstream pressure (Sheet 7 of 10) 


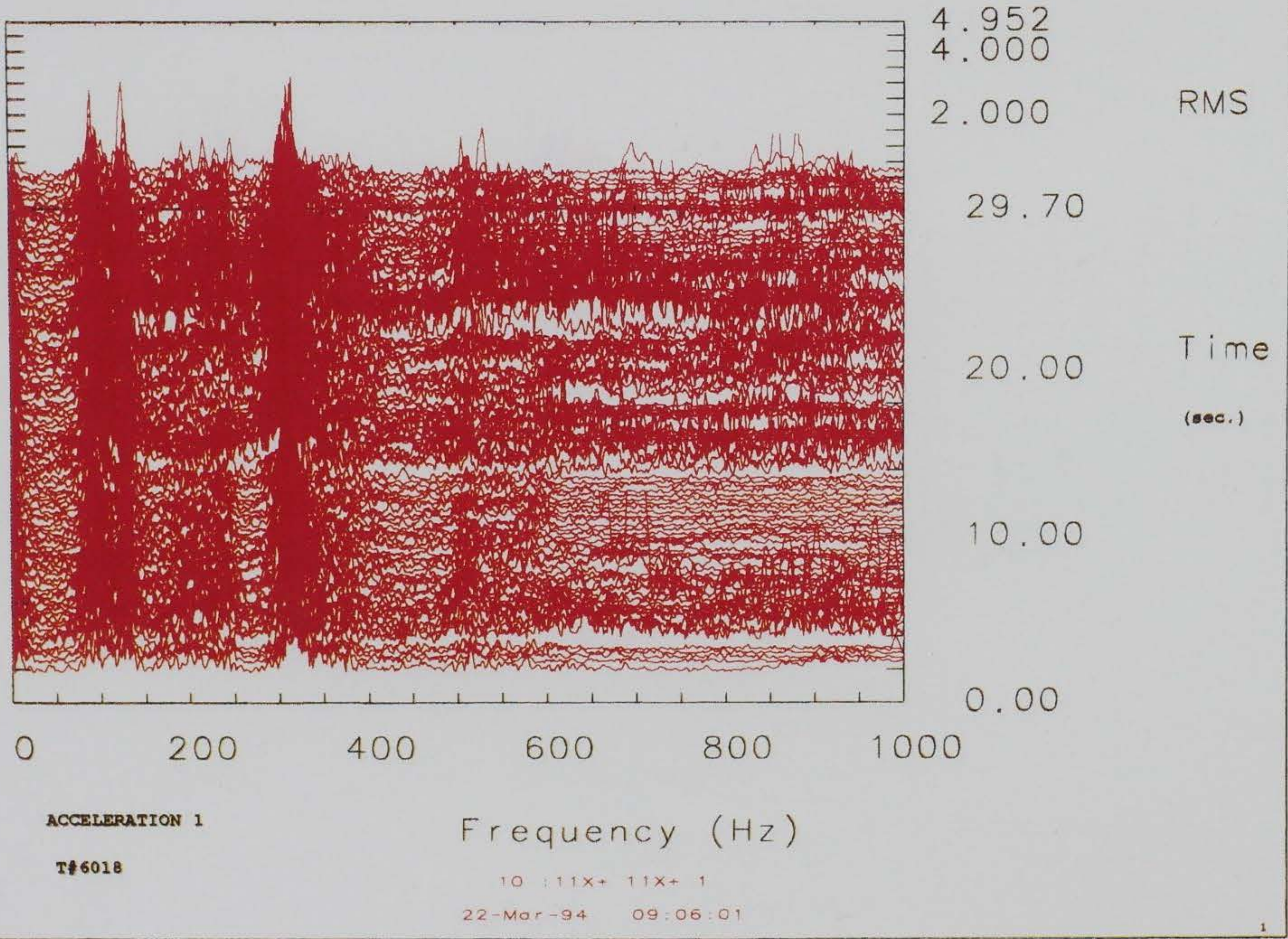

Figure 19h. Acceleration 1 (Sheet 8 of 10) 


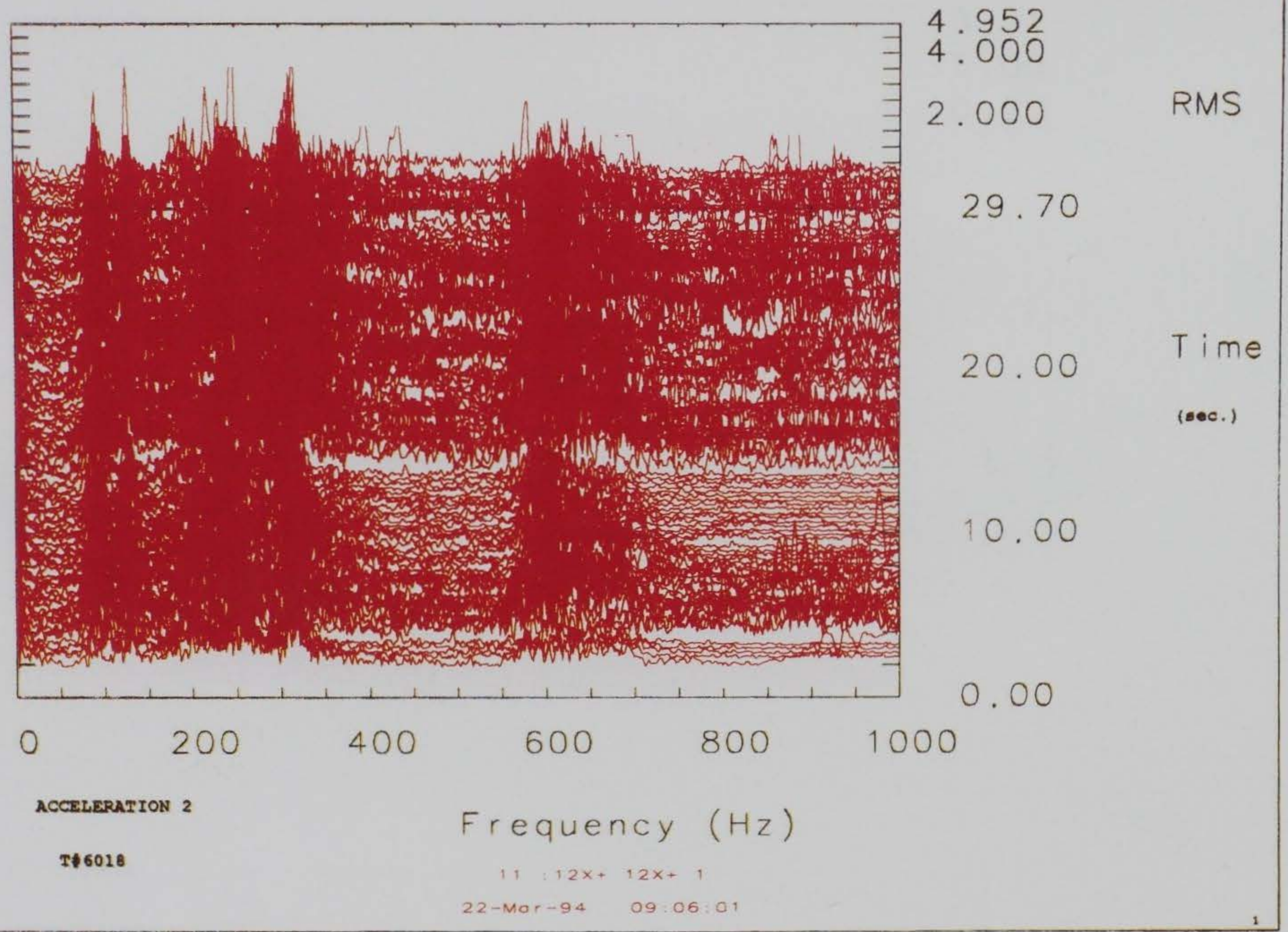

Figure 19i. Acceleration 2 (Sheet 9 of 10) 
Spectrum

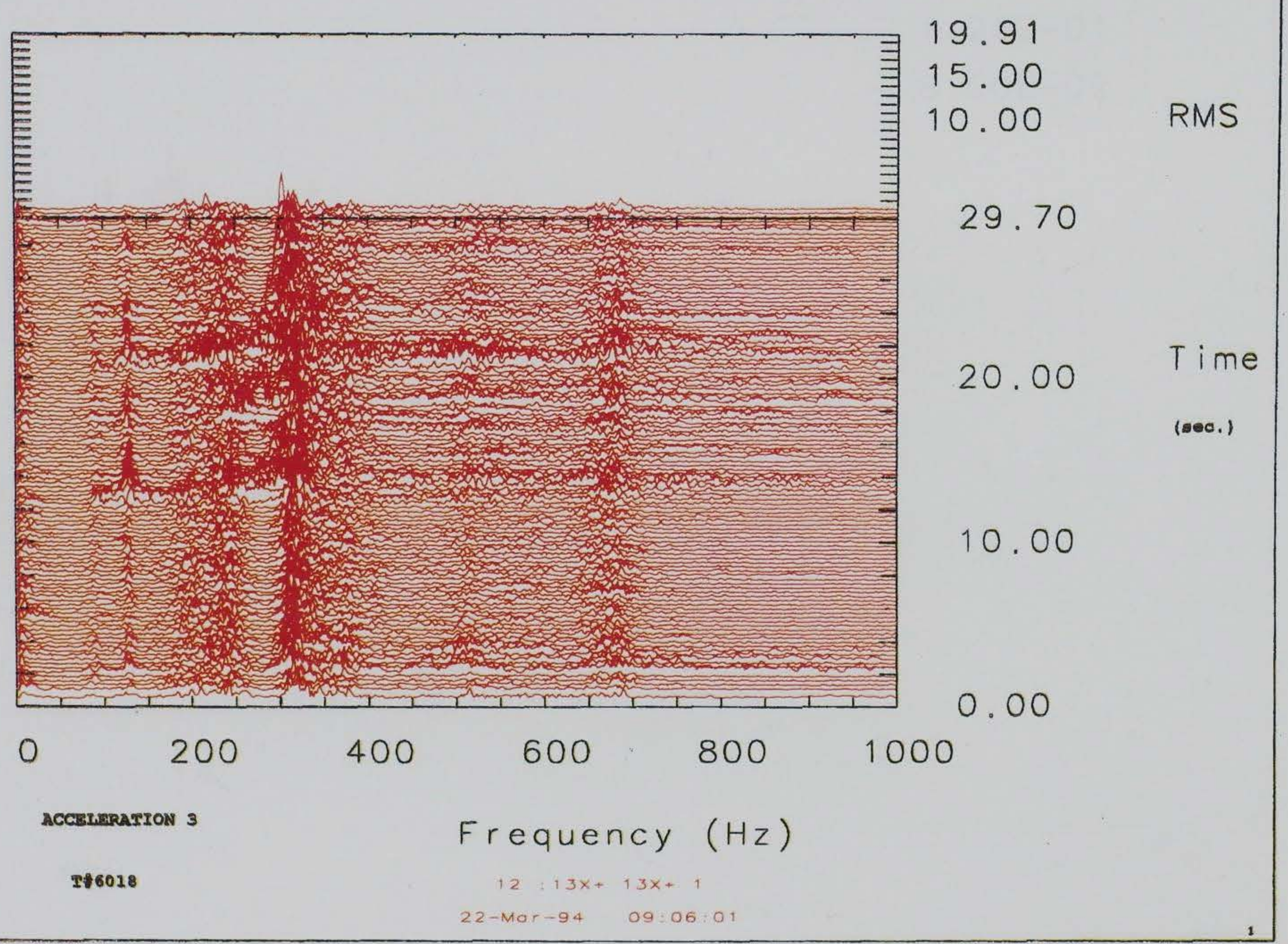

Figure 19j. Acceleration 3 (Sheet 10 of 10) 


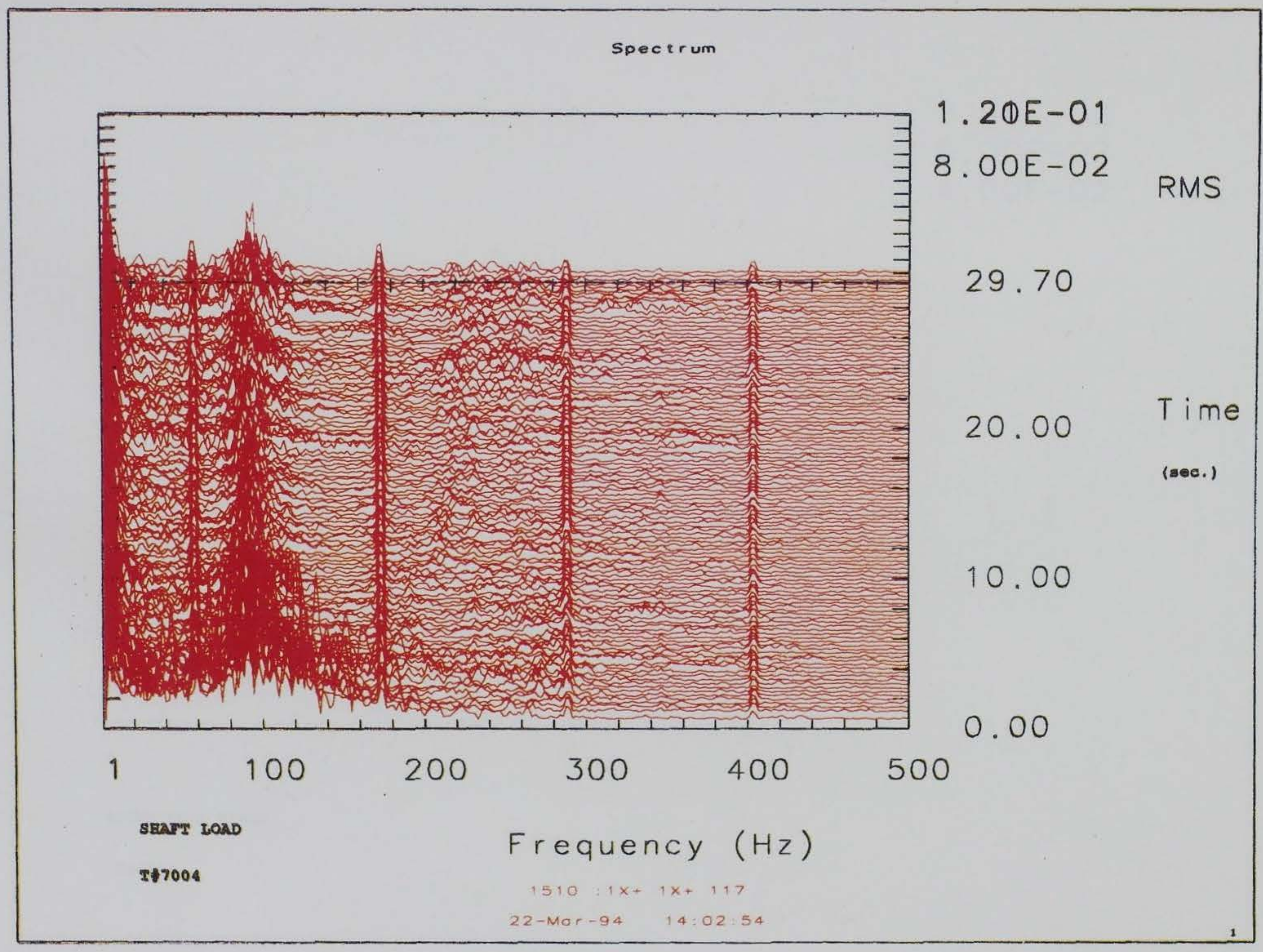

Figure 20. Time-spectral map for test set \#3 (approach channel @ $27^{\circ}$ position). a. Shaft load (Sheet 1 of 10 ) 


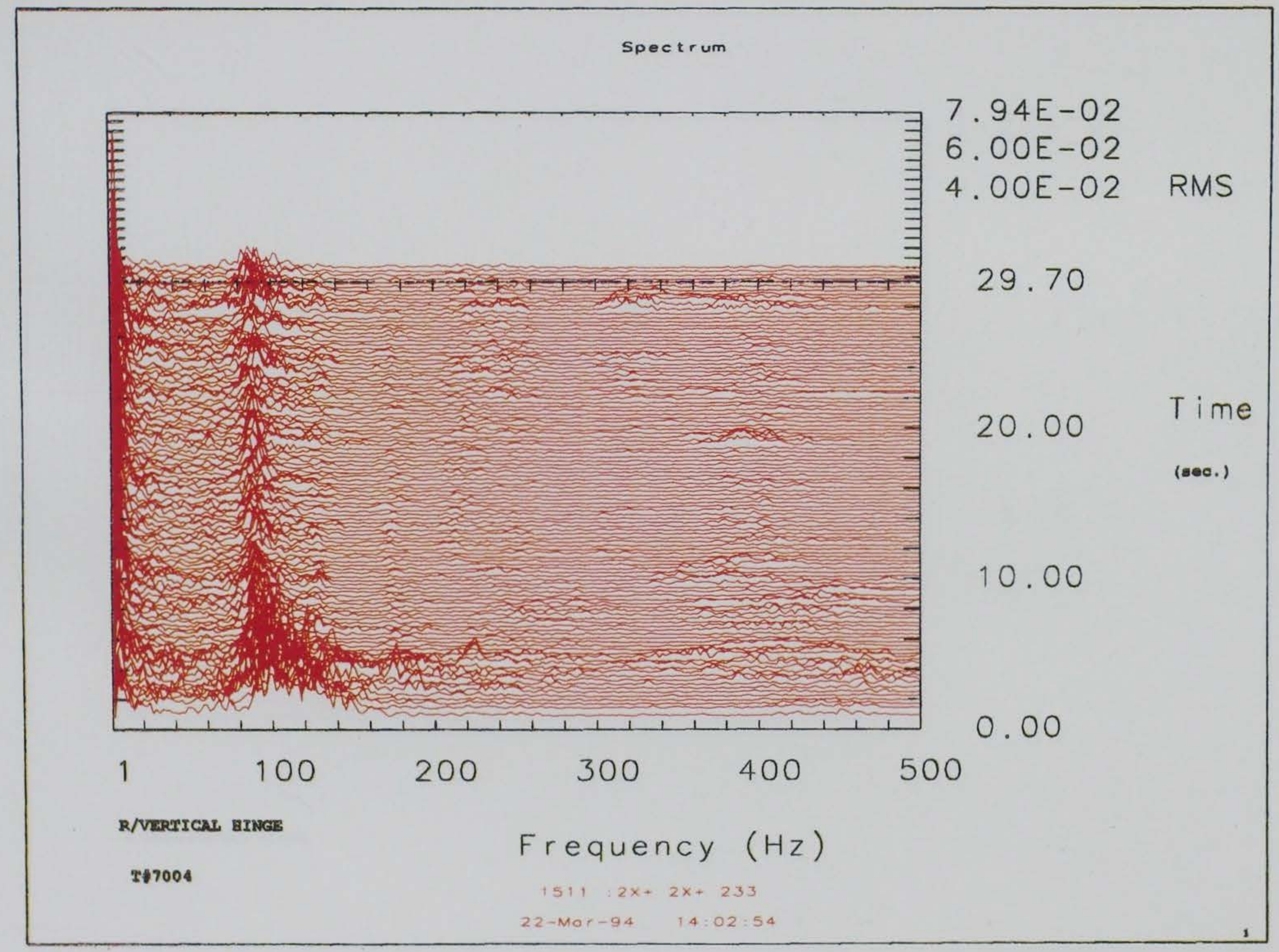

Figure 20b. Right vertical hinge (Sheet 2 of 10) 


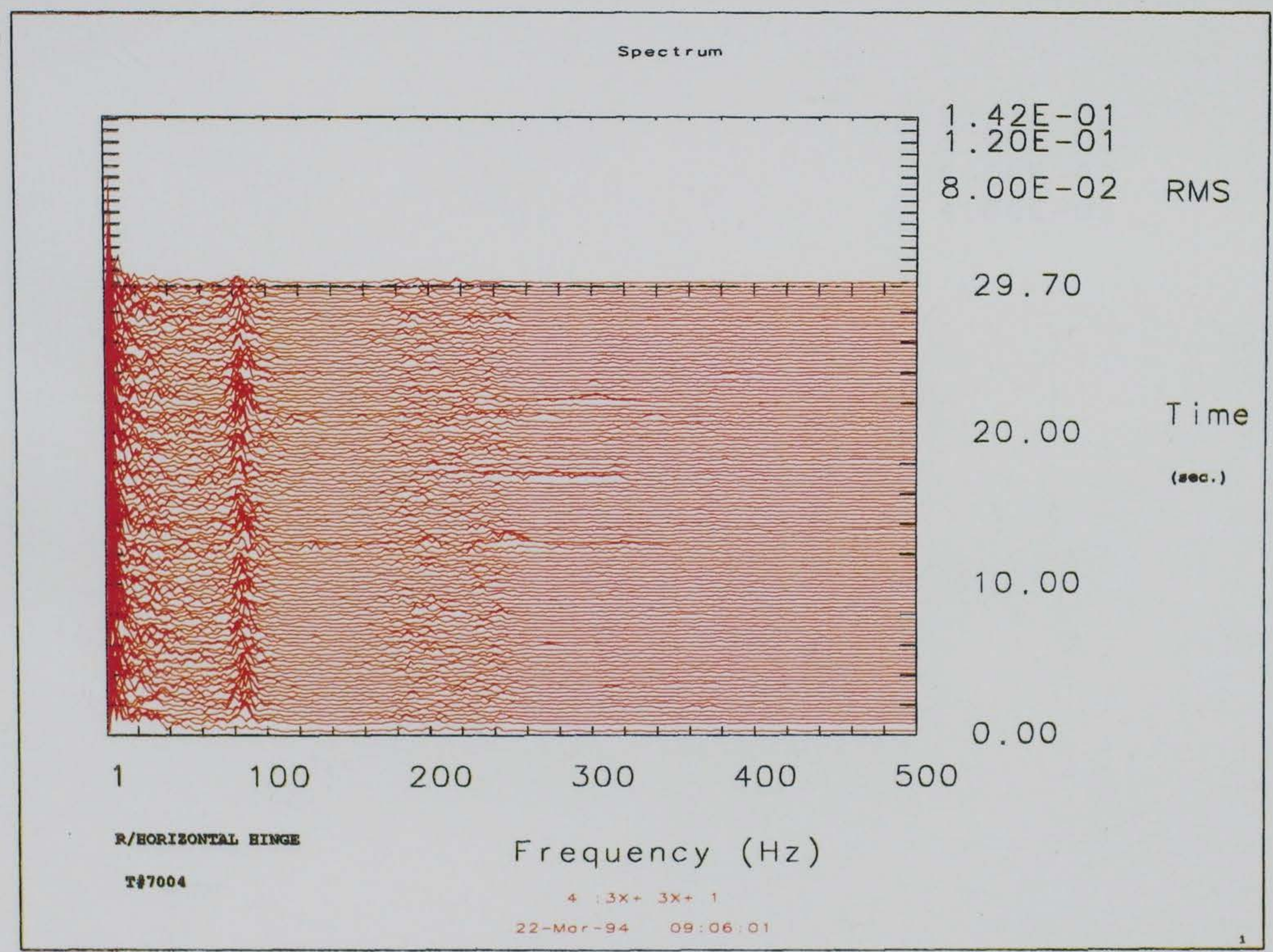

Figure 20c. Right horizontal hinge (Sheet 3 of 10) 


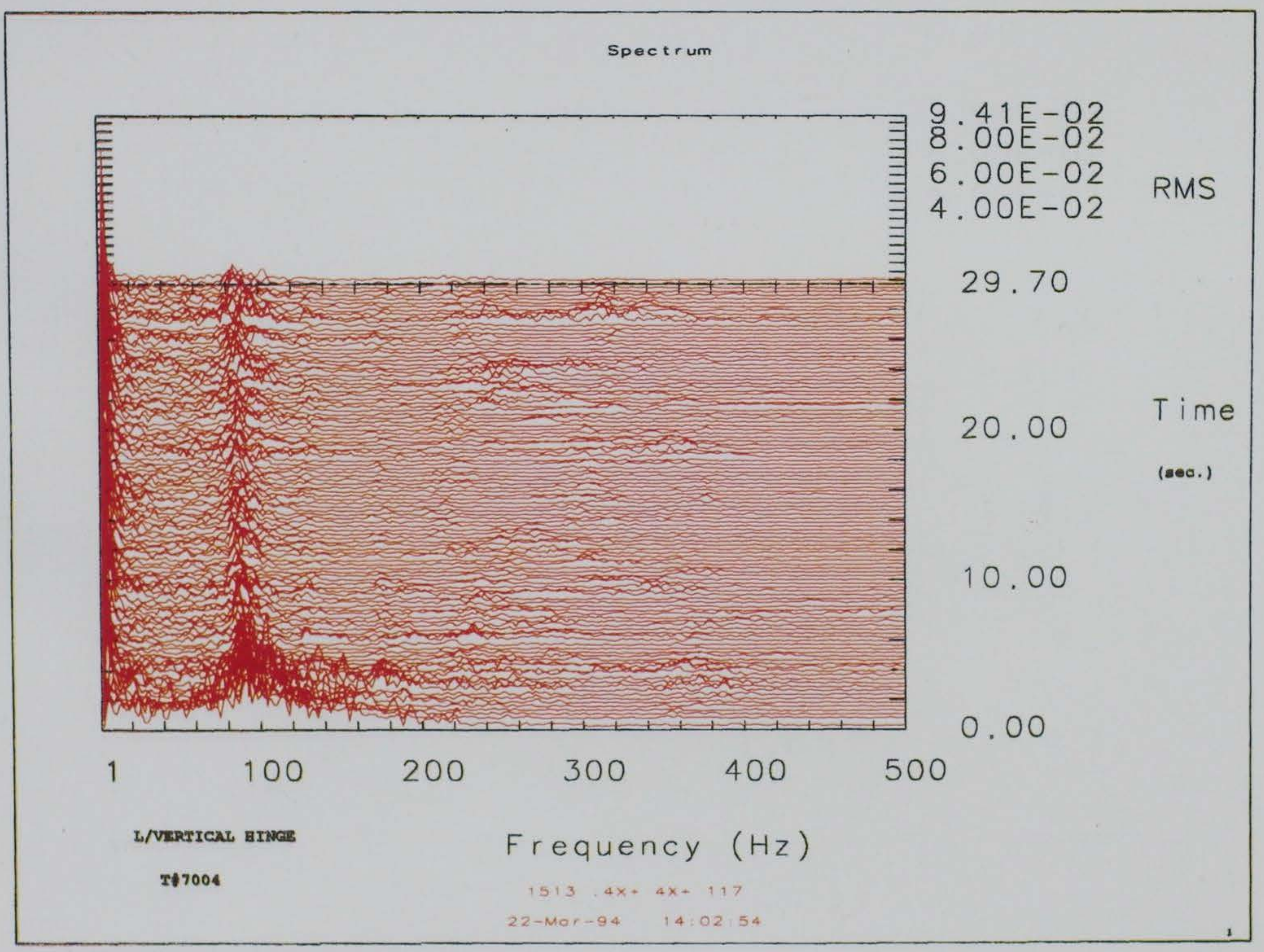

Figure 20d. Left vertical hinge (Sheet 4 of 10 ) 


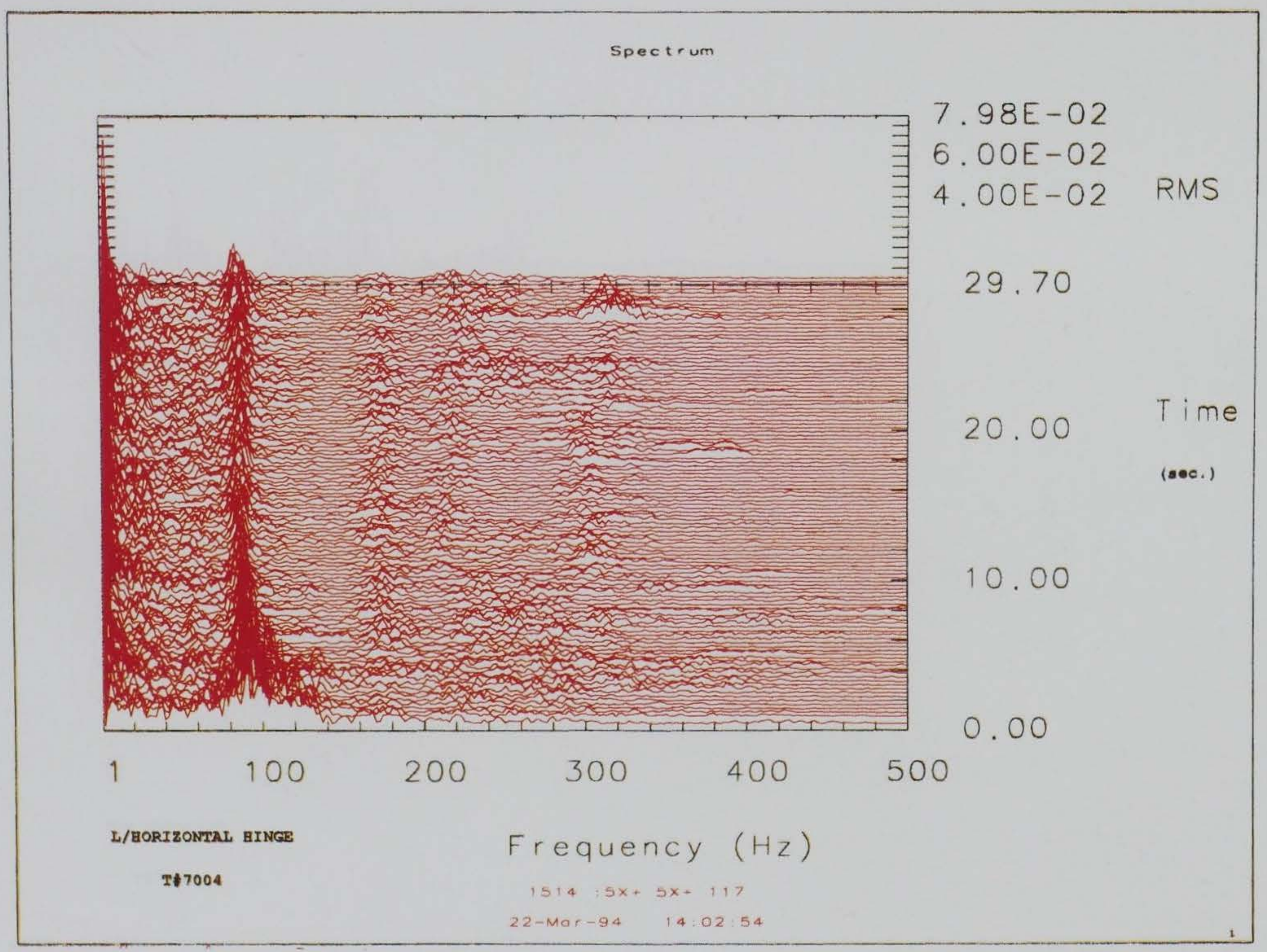

Figure 20e. Left horizontal hinge (Sheet 5 of 10) 


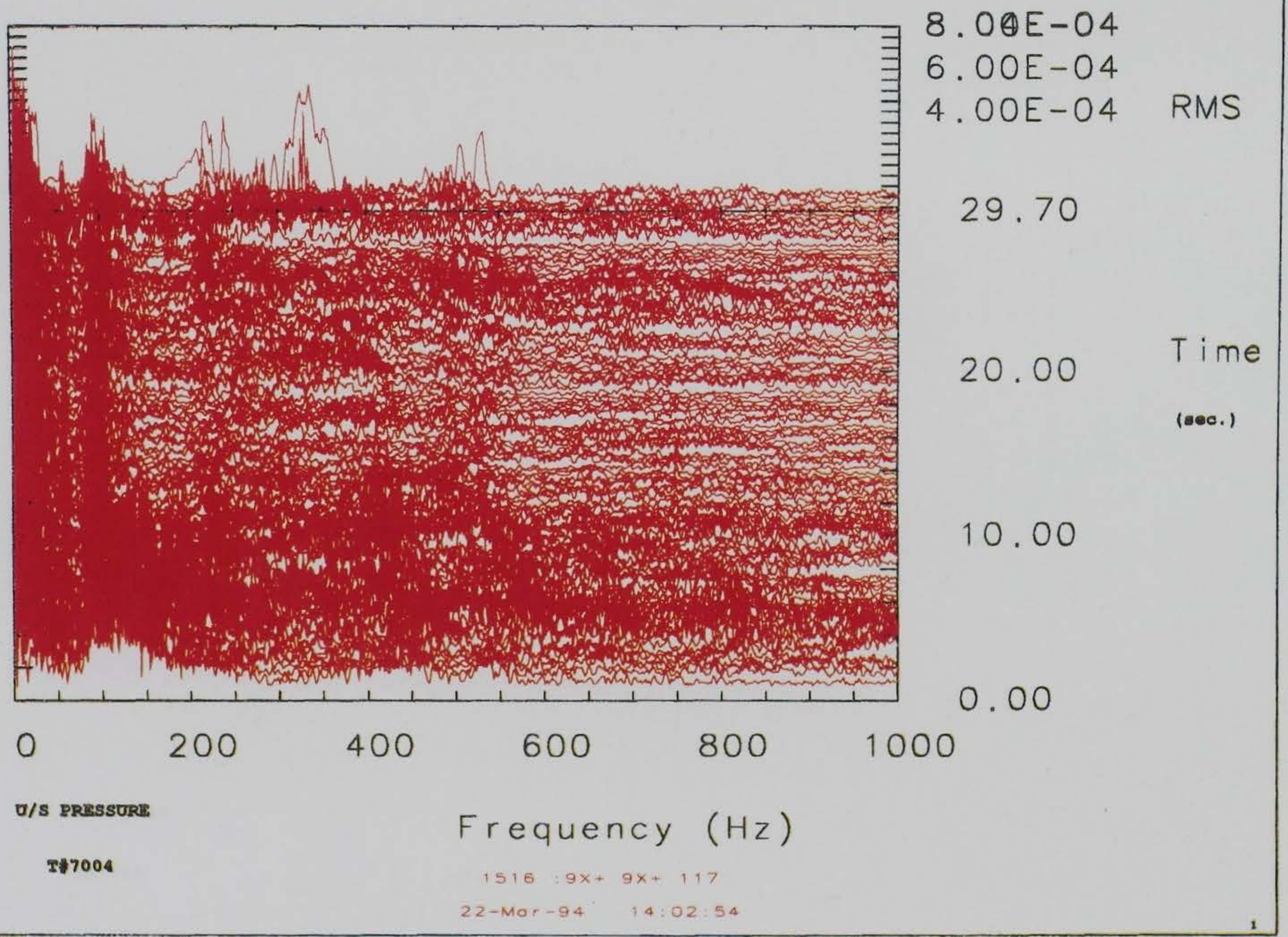

Figure 20f. Upstream pressure (Sheet 6 of 10) 


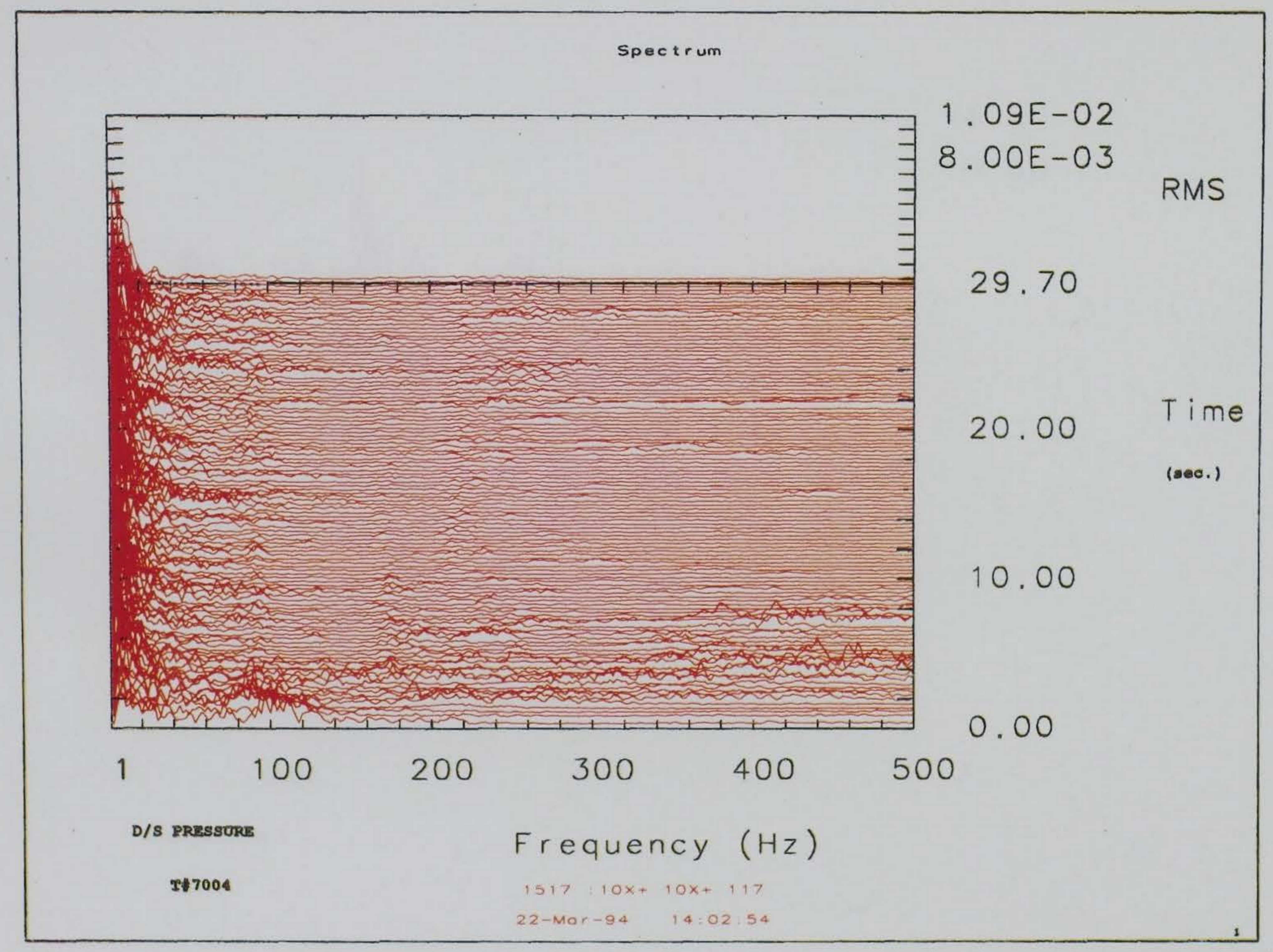

Figure 20g. Downstream pressure (Sheet 7 of 10) 


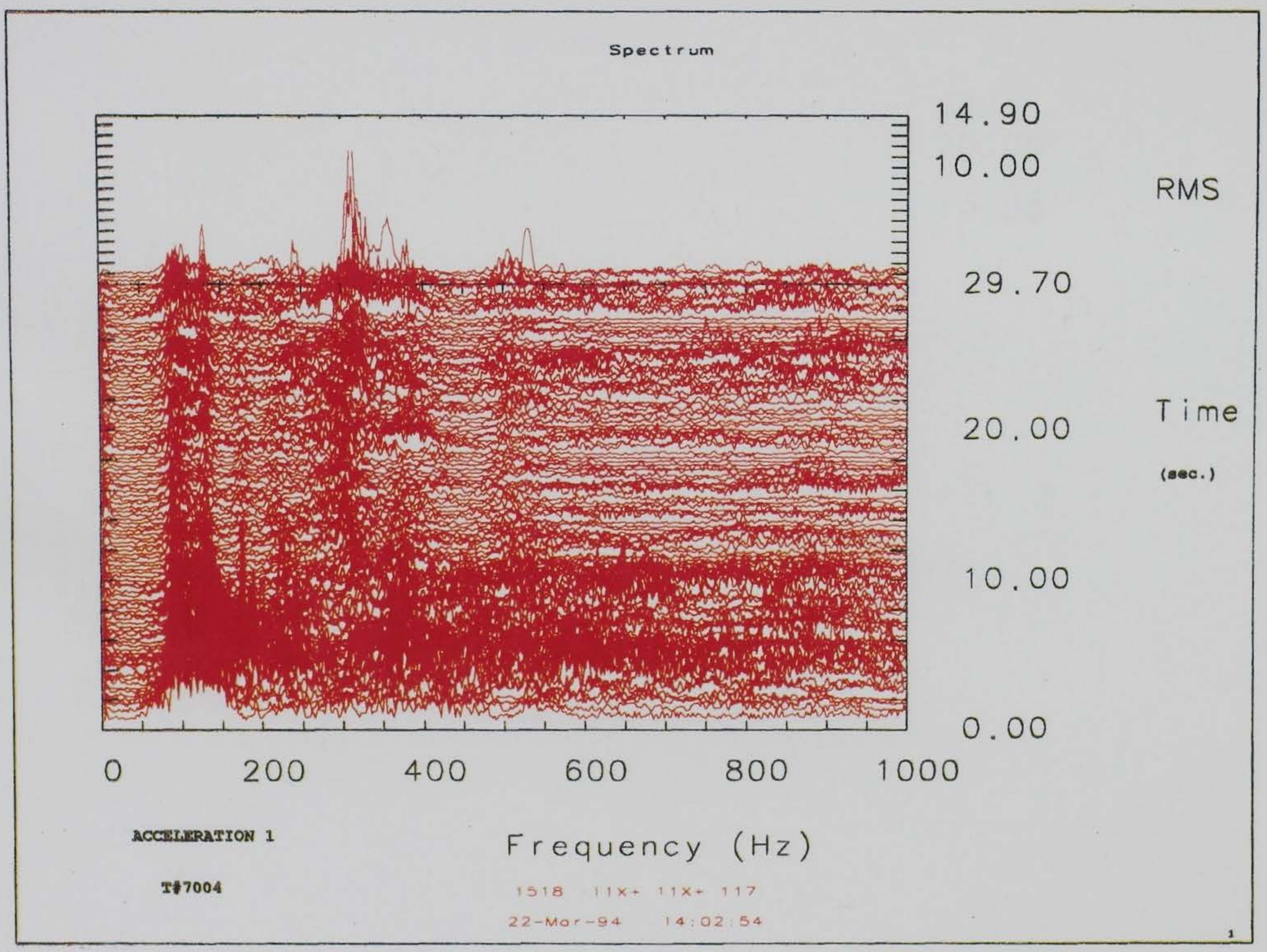

Figure 20h. Acceleration 1 (Sheet 8 of 10) 


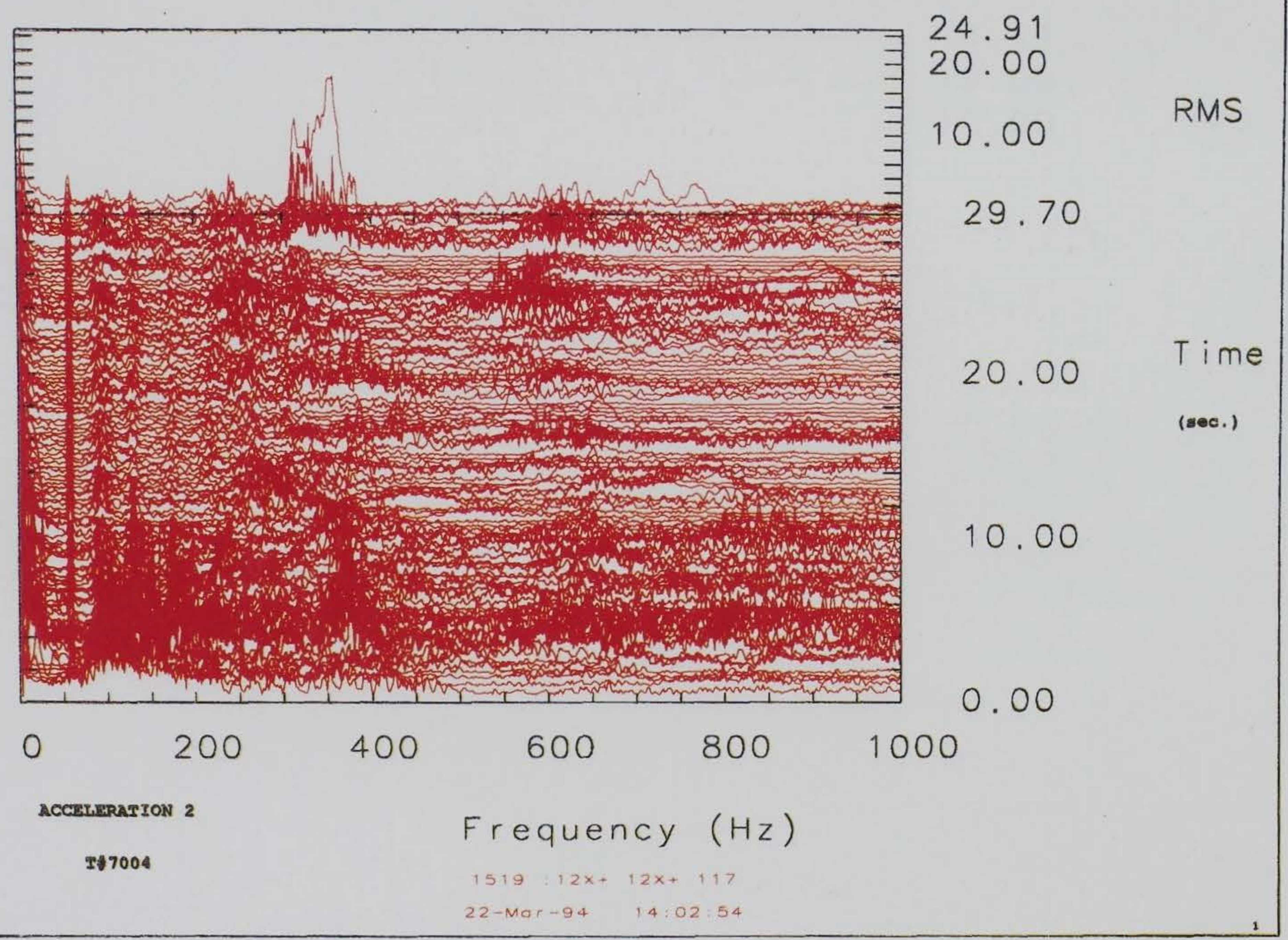

Figure 20i. Acceleration 2 (Sheet 9 of 10) 


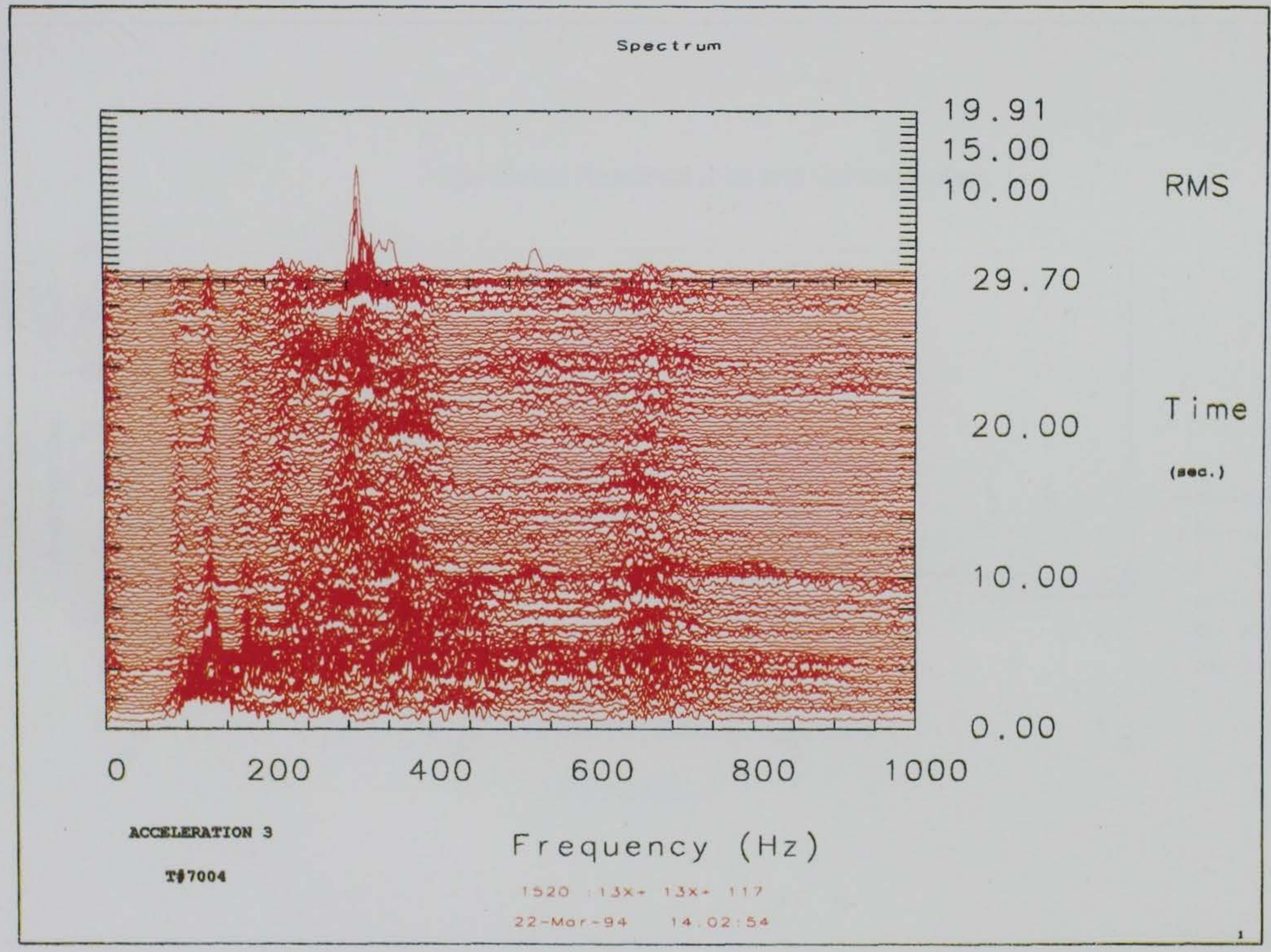

Figure 20j. Acceleration 3 (Sheet 10 of 10) 


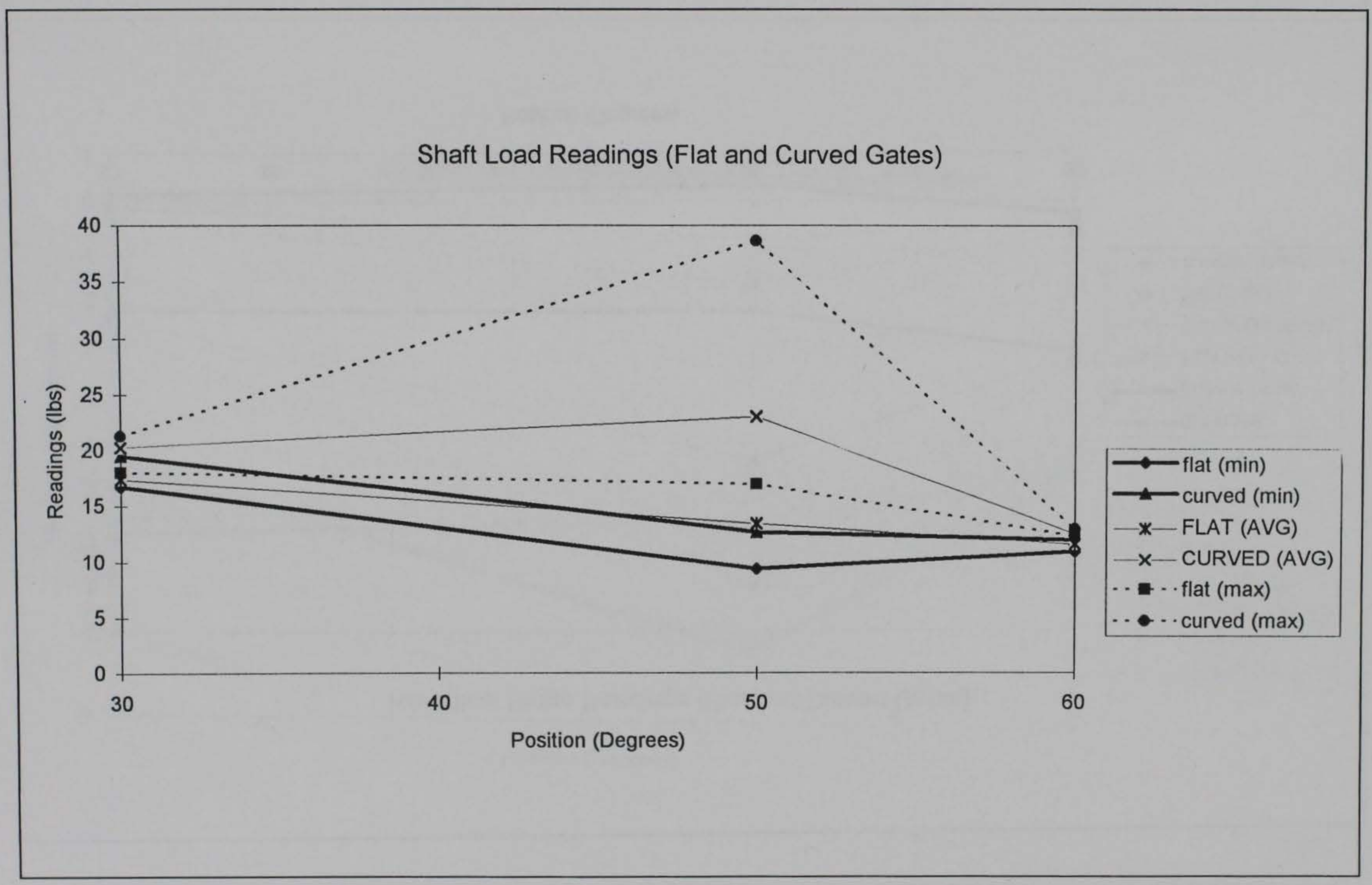

Figure 21. Time-domain data comparison for the flat and curved gates. a. Shaft load readings (Sheet 1 of 11) 
RNertical Hinge Readings (Flat and Curved Gates)

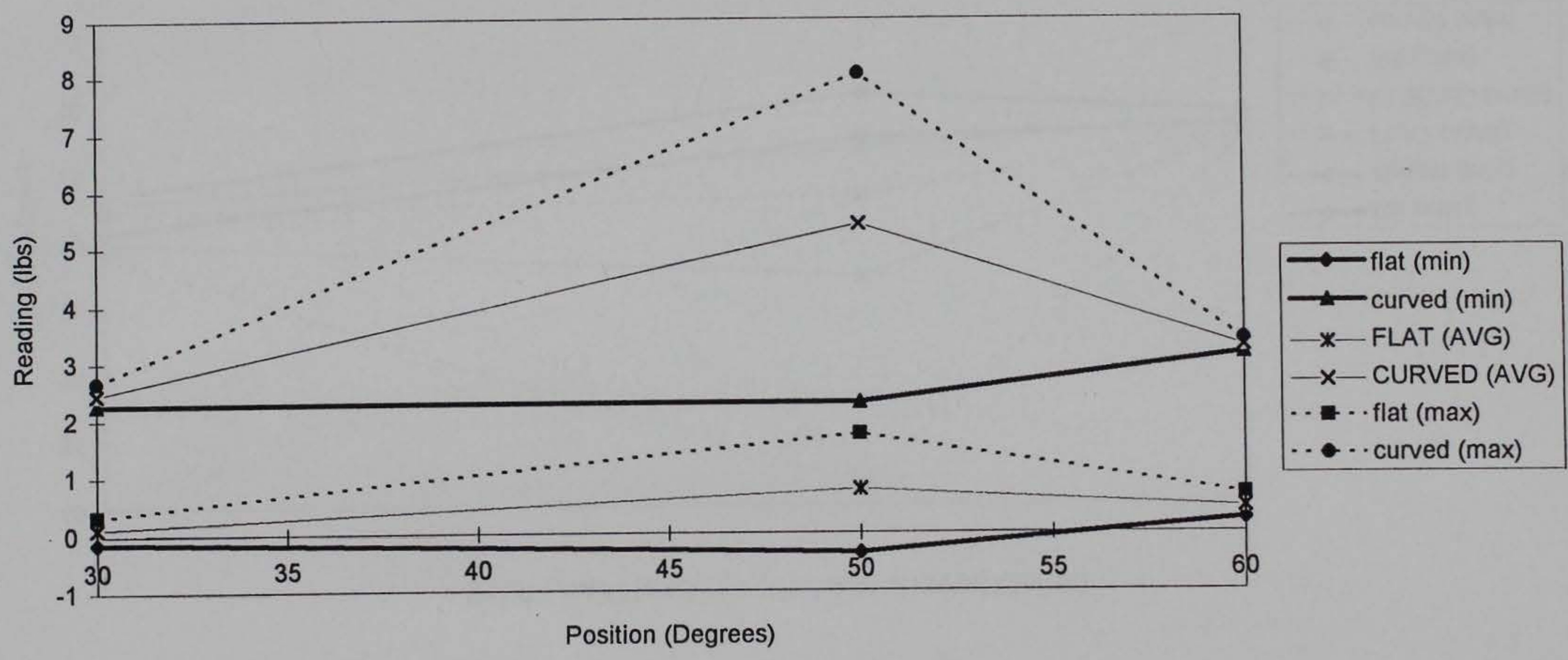

Figure $21 \mathrm{~b}$. Right vertical hinge readings (Sheet 2 of 11) 
R/Horizontal Hinge Readings (Flat and Curved Gates)

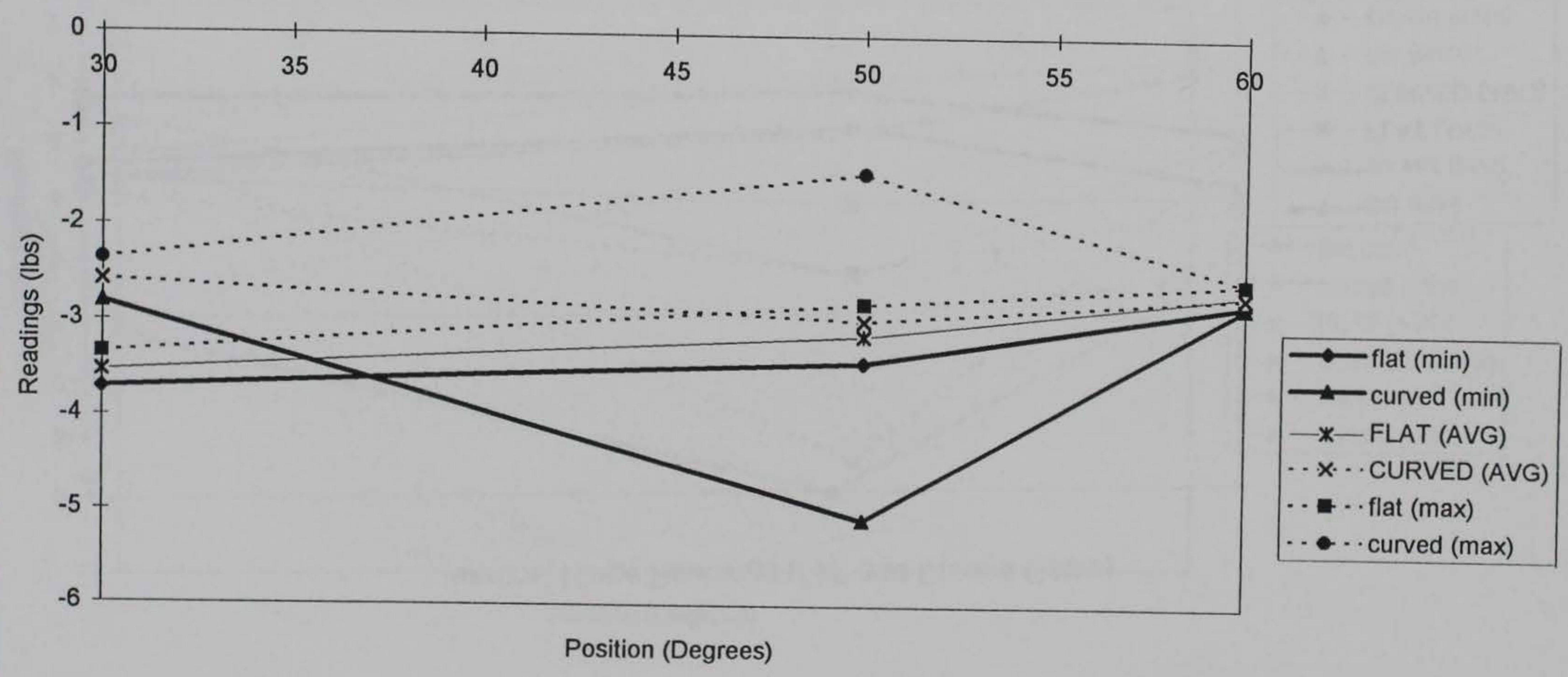

Figure 21c. Right horizontal hinge readings (Sheet 3 of 11) 


\section{LNertical Hinge Readings (Flat and Curved Gates)}

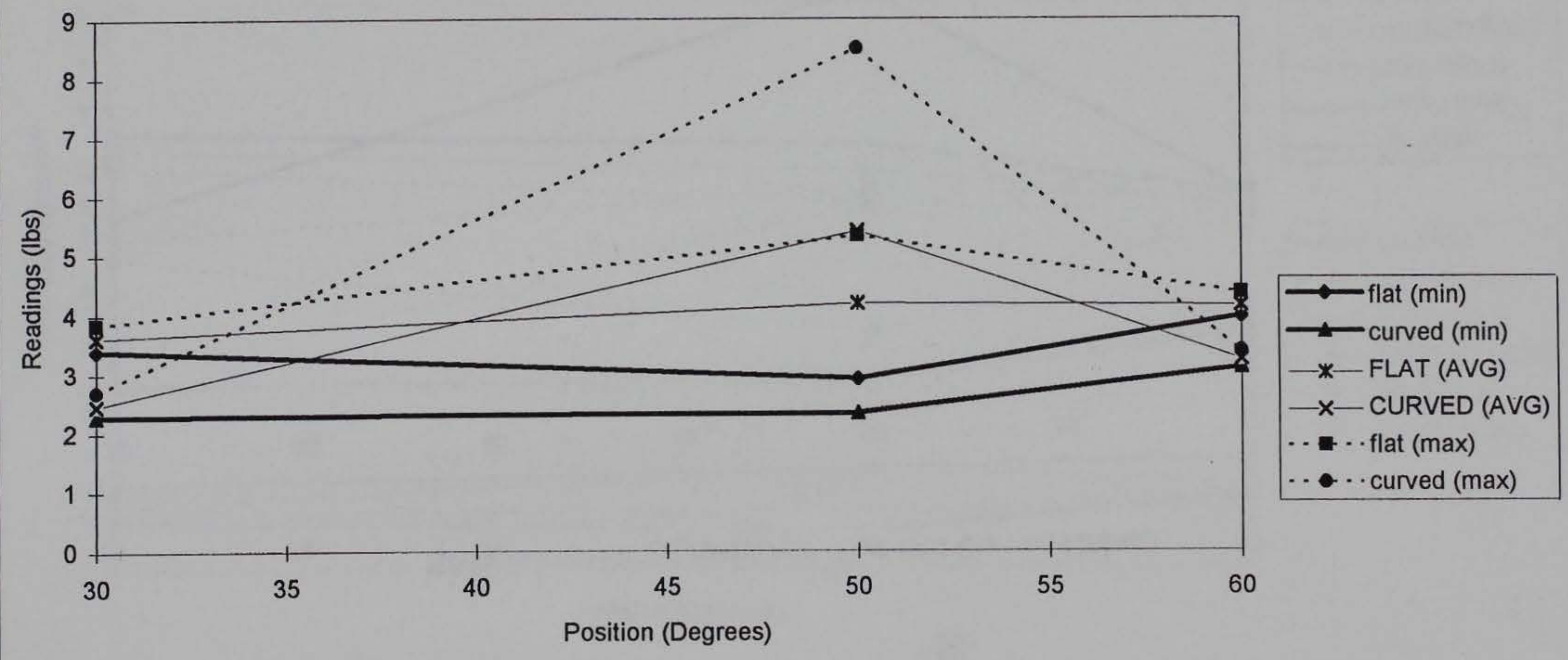

Figure $21 \mathrm{~d}$. Left vertical hinge readings (Sheet 4 of 11) 


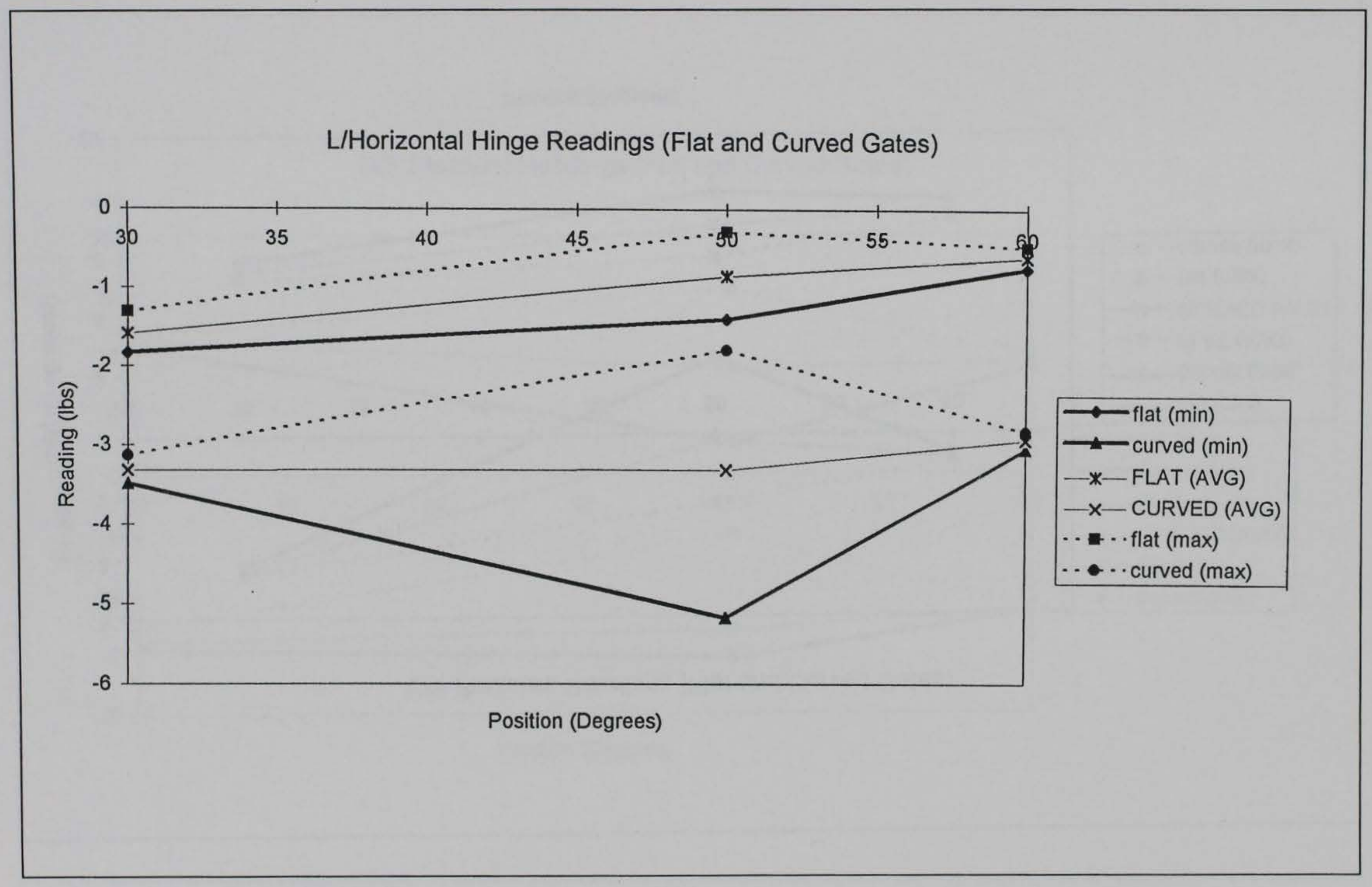

Figure 21e. Left horizontal hinge readings (Sheet 5 of 11) 


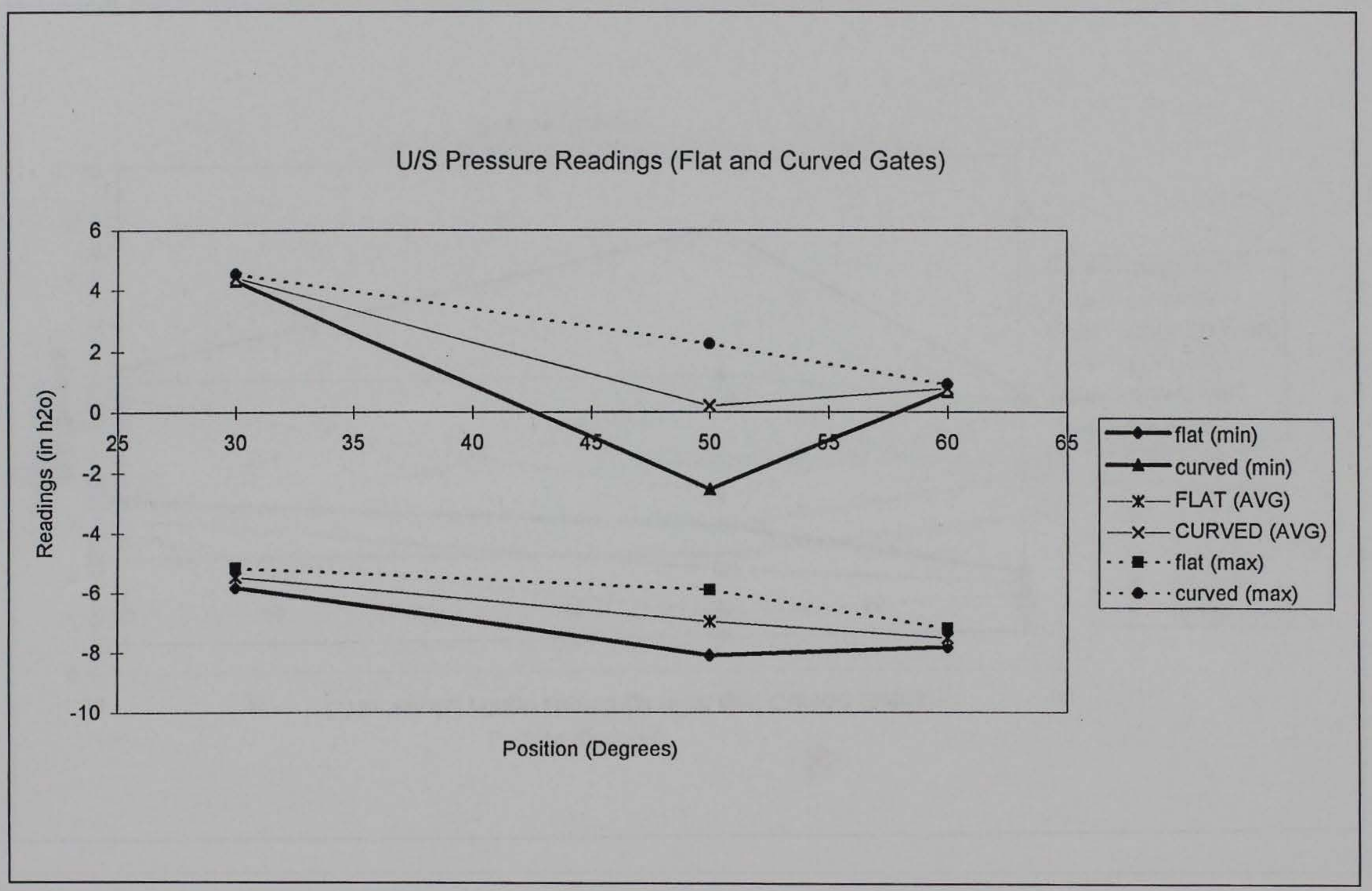

Figure $21 \mathrm{f}$. Upstream pressure readings (Sheet 6 of 11) 
D/S Pressure Readings (Flat and Curved Gates)

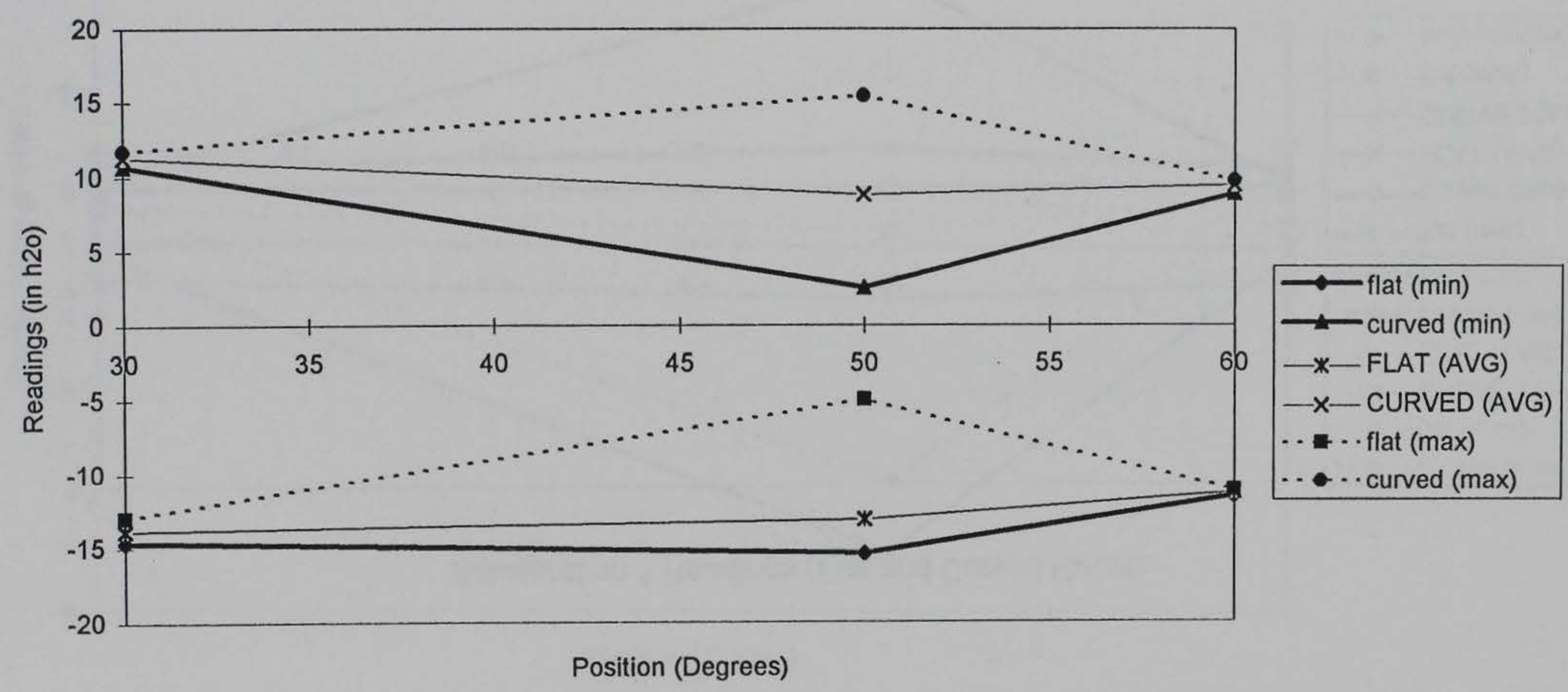

Figure $21 \mathrm{~g}$. Downstream pressure readings (Sheet 7 of 11 ) 


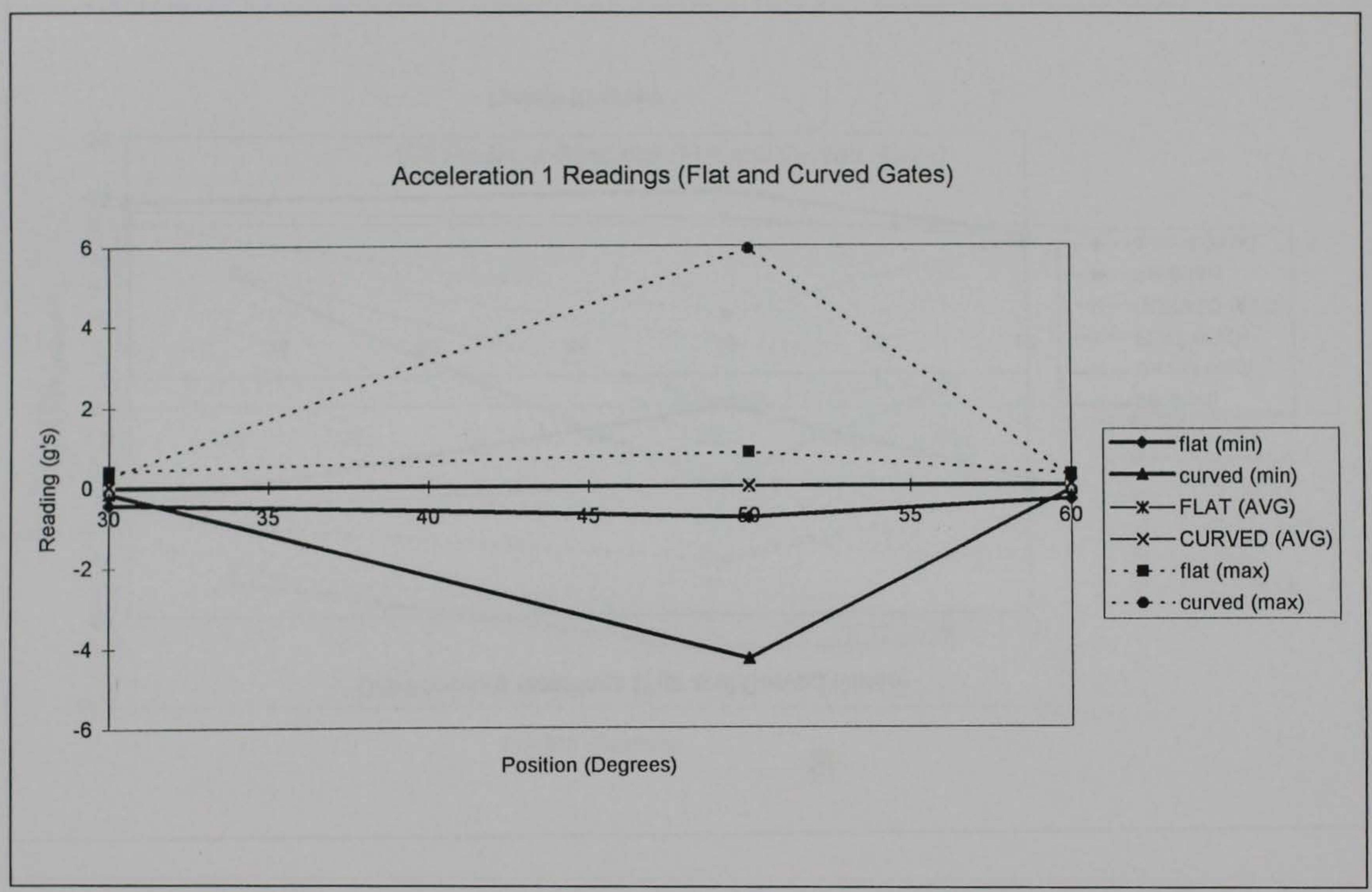

Figure $21 \mathrm{~h}$. Acceleration 1 readings (Sheet 8 of 11) 
Acceleration 2 Readings (Flat and Curved Gates)

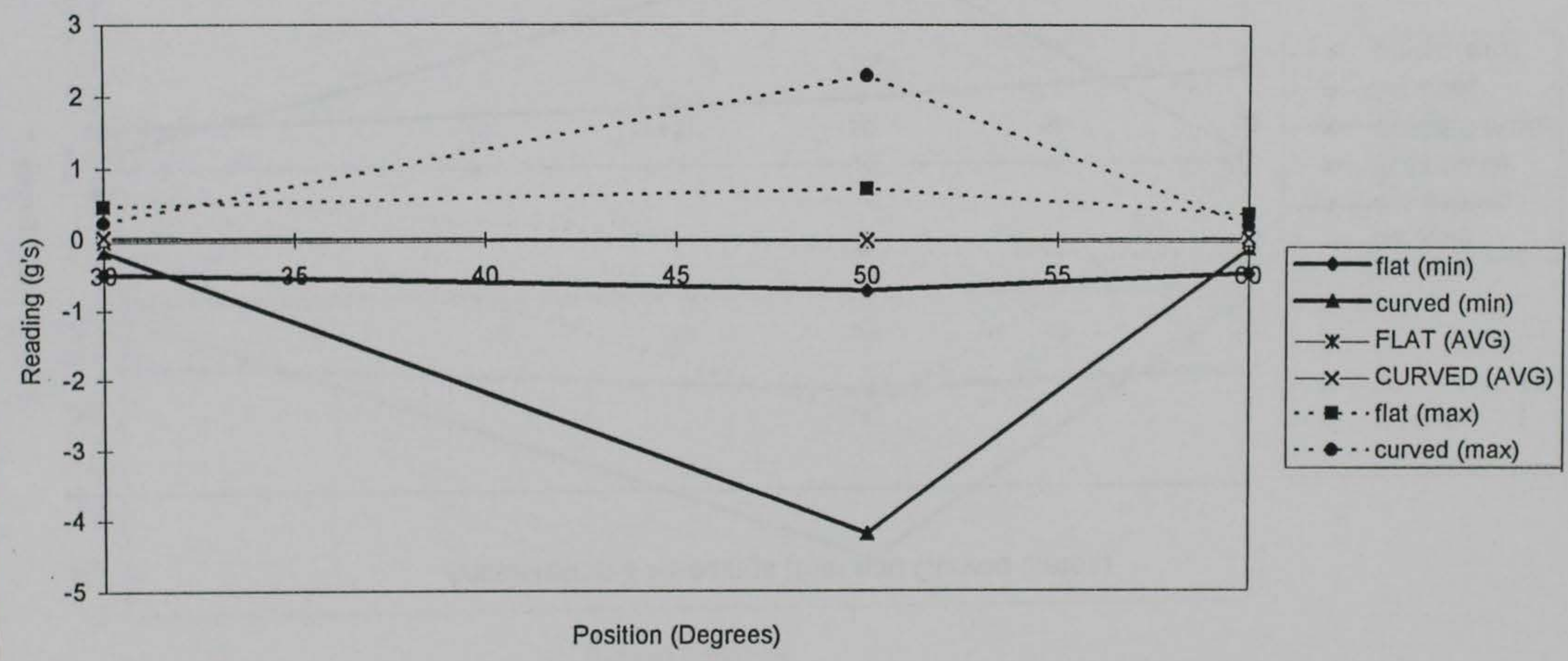

Figure 21i. Acceleration 2 readings (Sheet 9 of 11) 
Acceleration 3 Readings (Flat and Curved Gates)

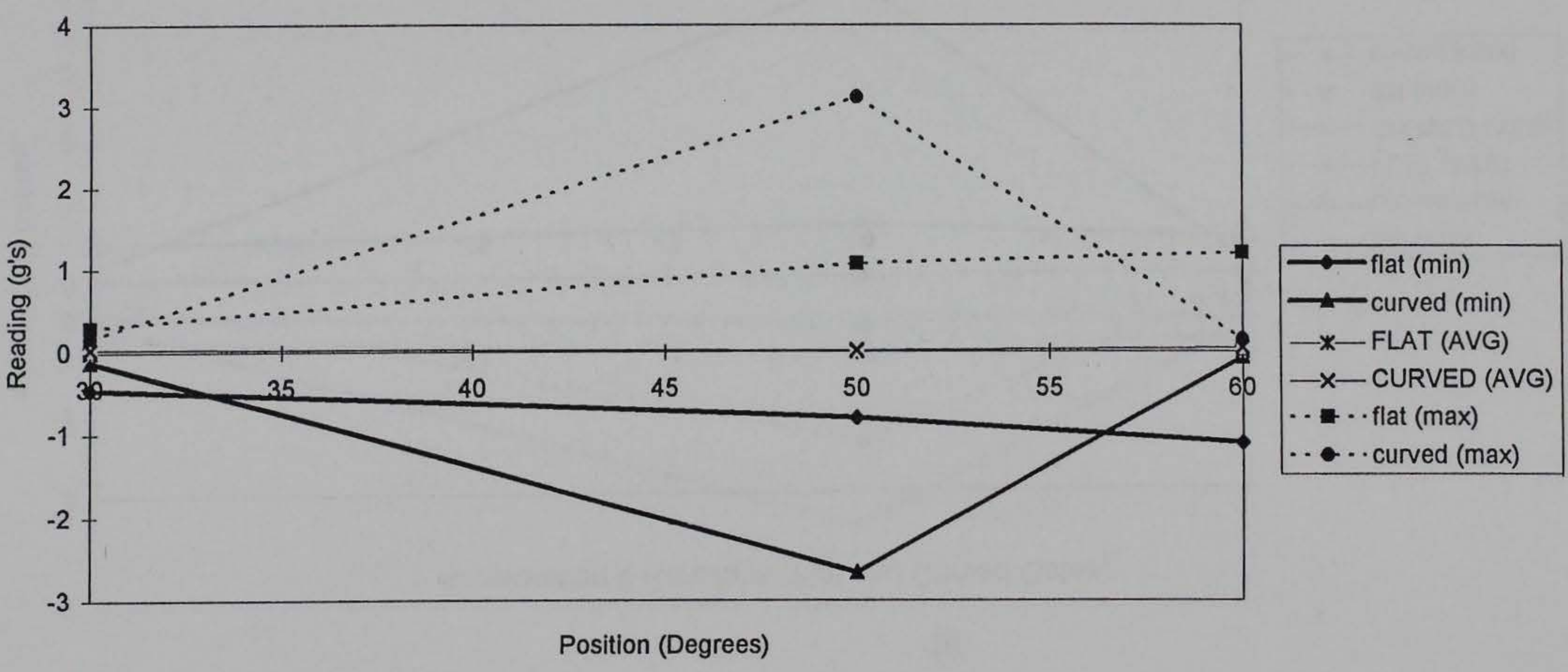

Figure $21 \mathrm{j}$. Acceleration 3 readings (Sheet 10 of 11 ) 


\section{Acceleration 4 Readings (Flat and Curved Gates)}

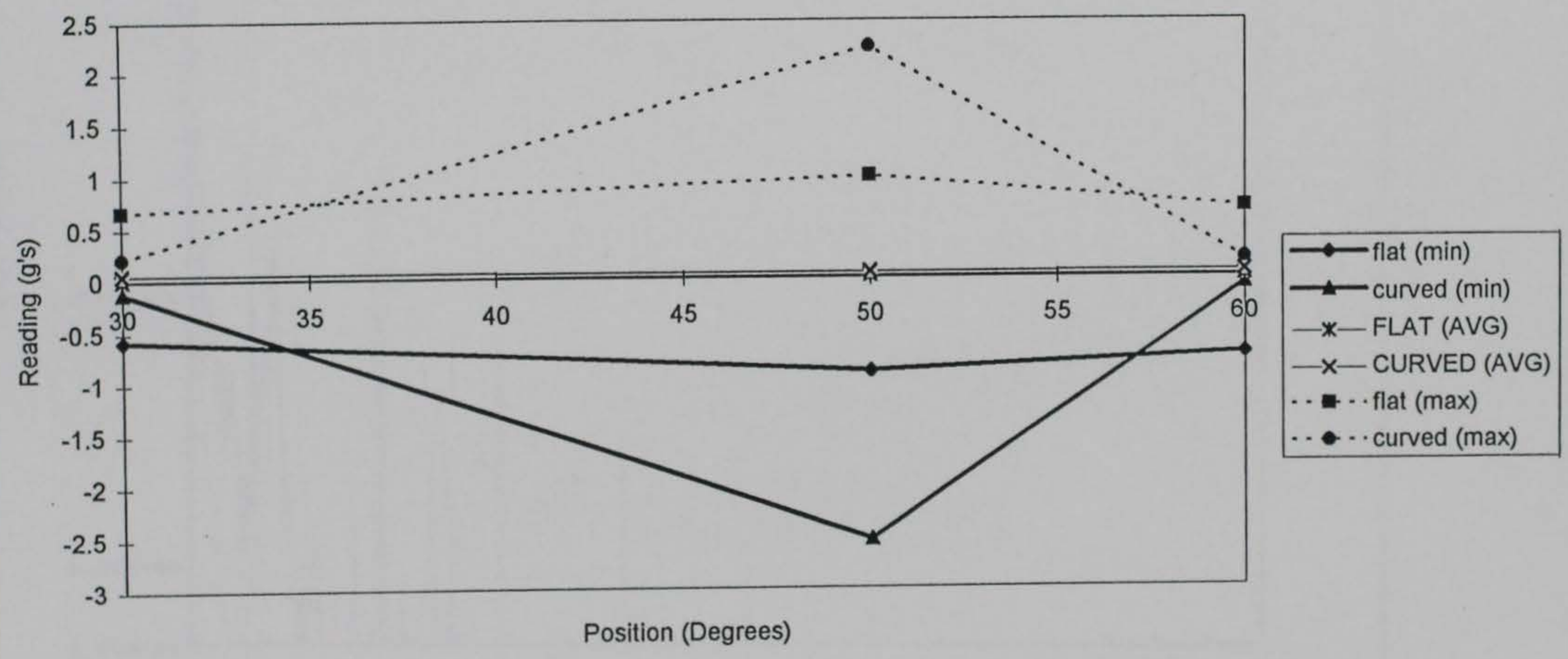

Figure $21 \mathrm{k}$. Acceleration 4 readings (Sheet 11 of 11 ) 


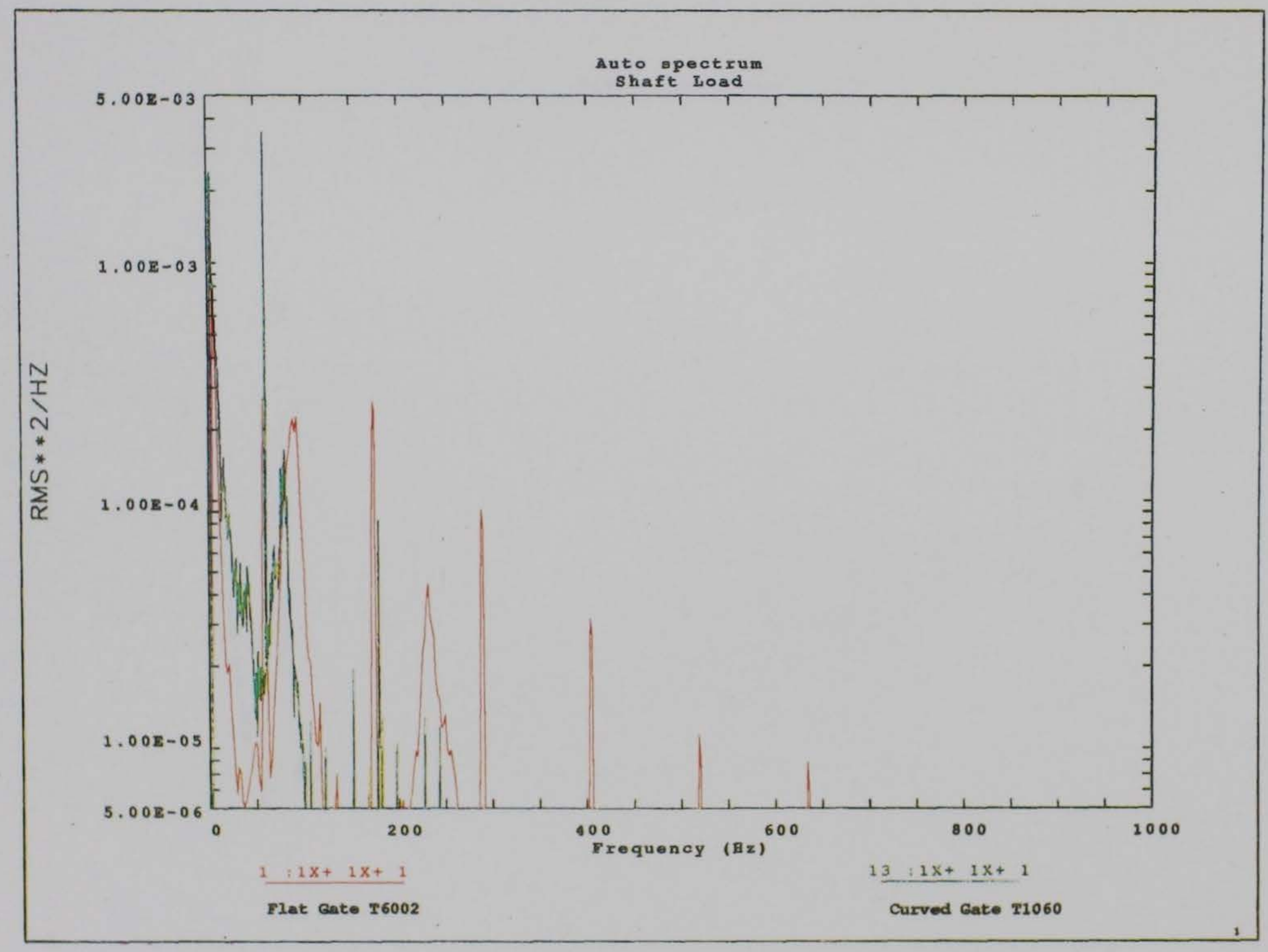

Figure 22. Auto spectra comparison for the flat and curved gates $\left(30^{\circ}\right.$ position). a. Shaft load (Sheet 1 of 11$)$ 


$$
19
$$




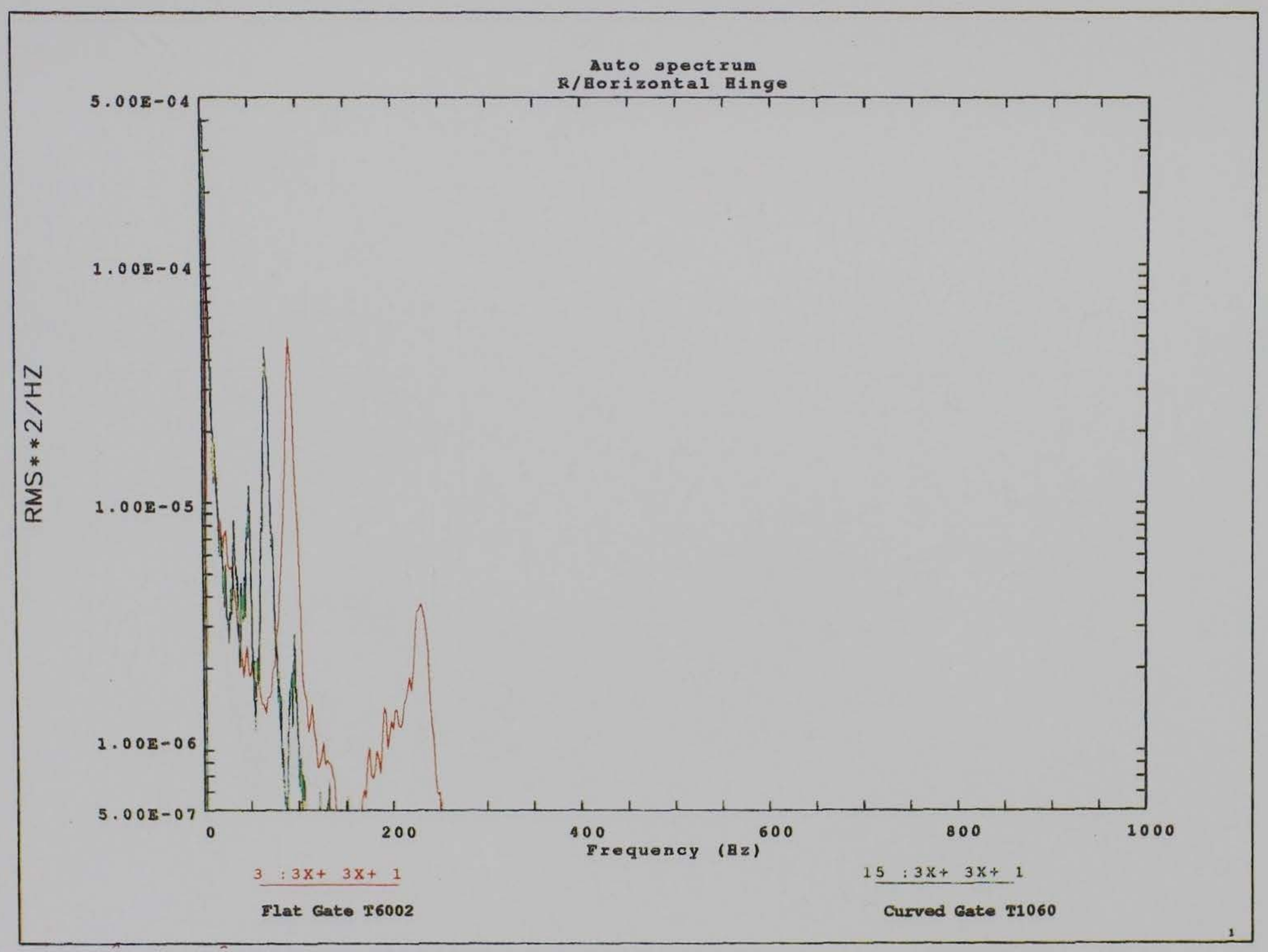

Figure 22c. Right horizontal hinge (Sheet 3 of 11) 


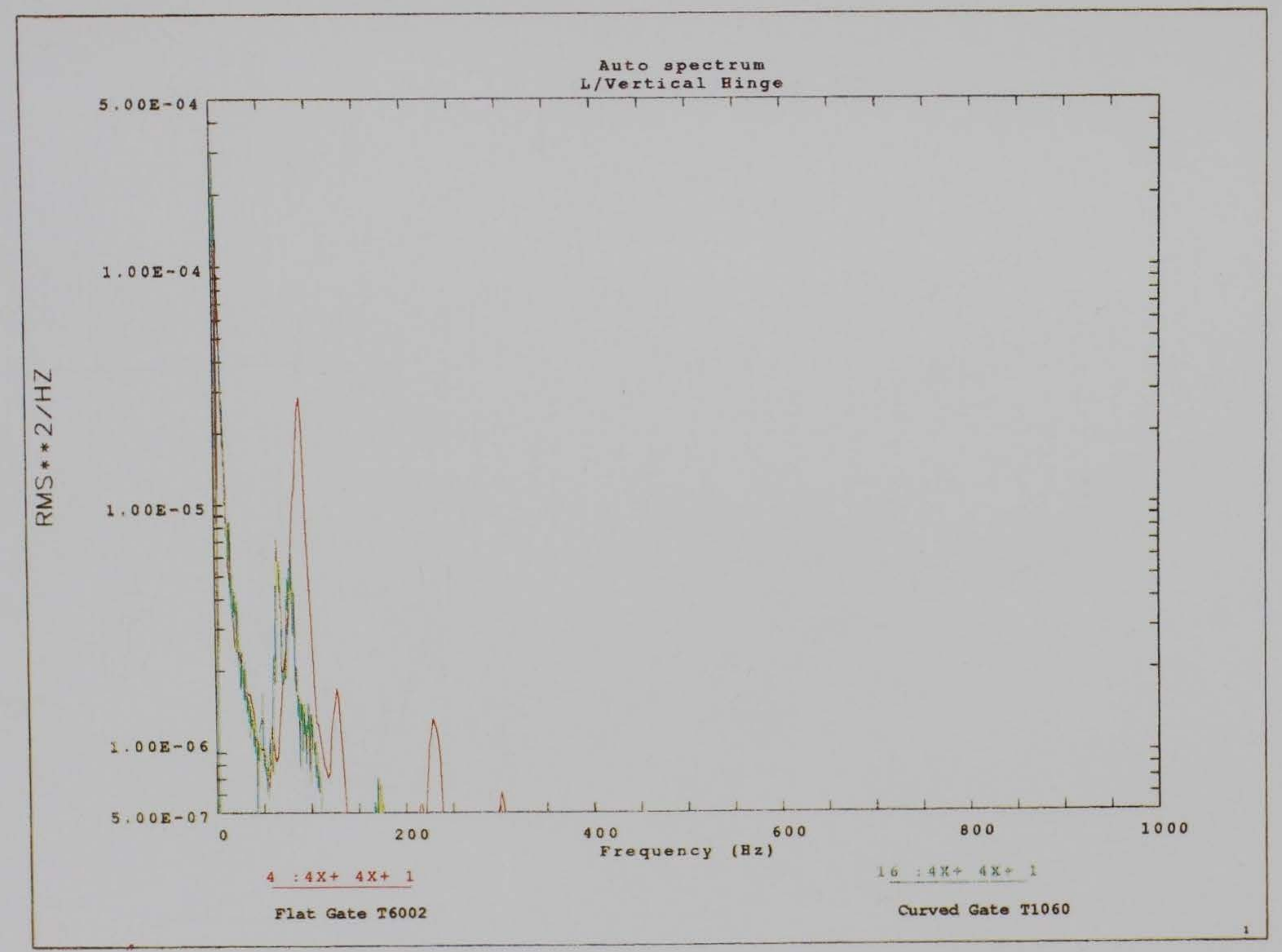

Figure 22d. Left vertical hinge (Sheet 4 of 11 ) 


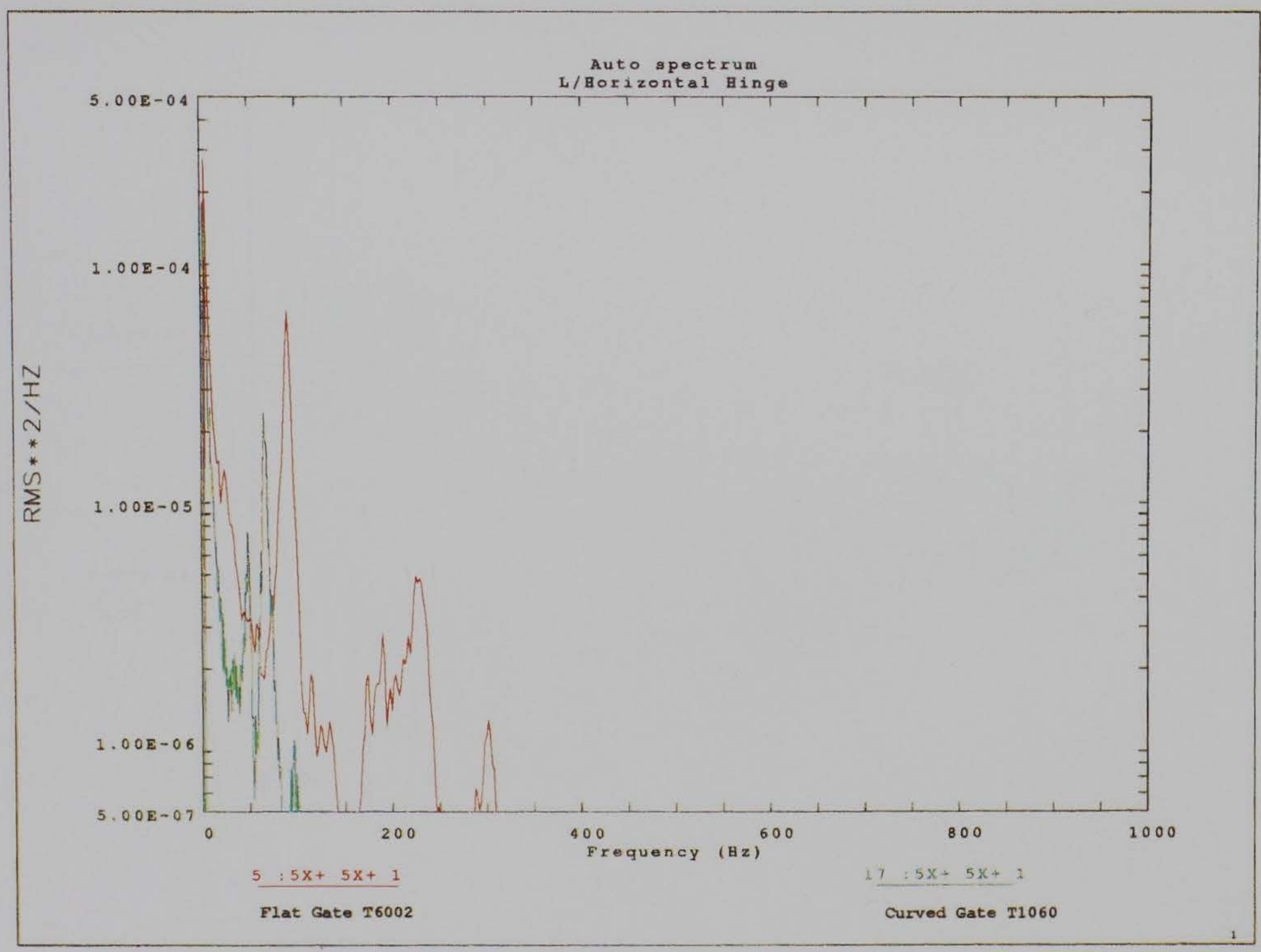

Figure 22e. Left horizontal hinge (Sheet 5 of 11) 


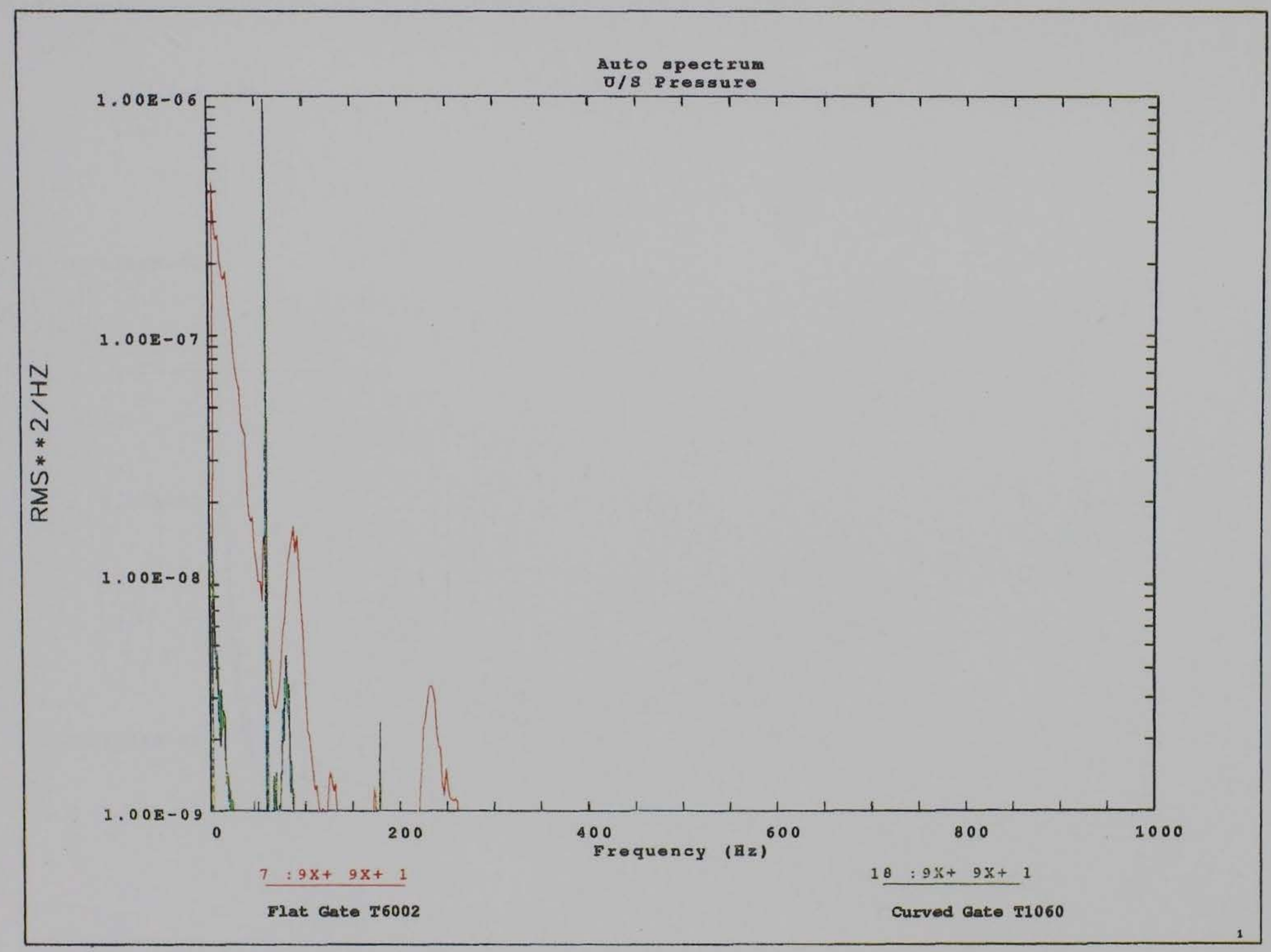

Figure 22f. Upstream pressure (Sheet 6 of 11) 


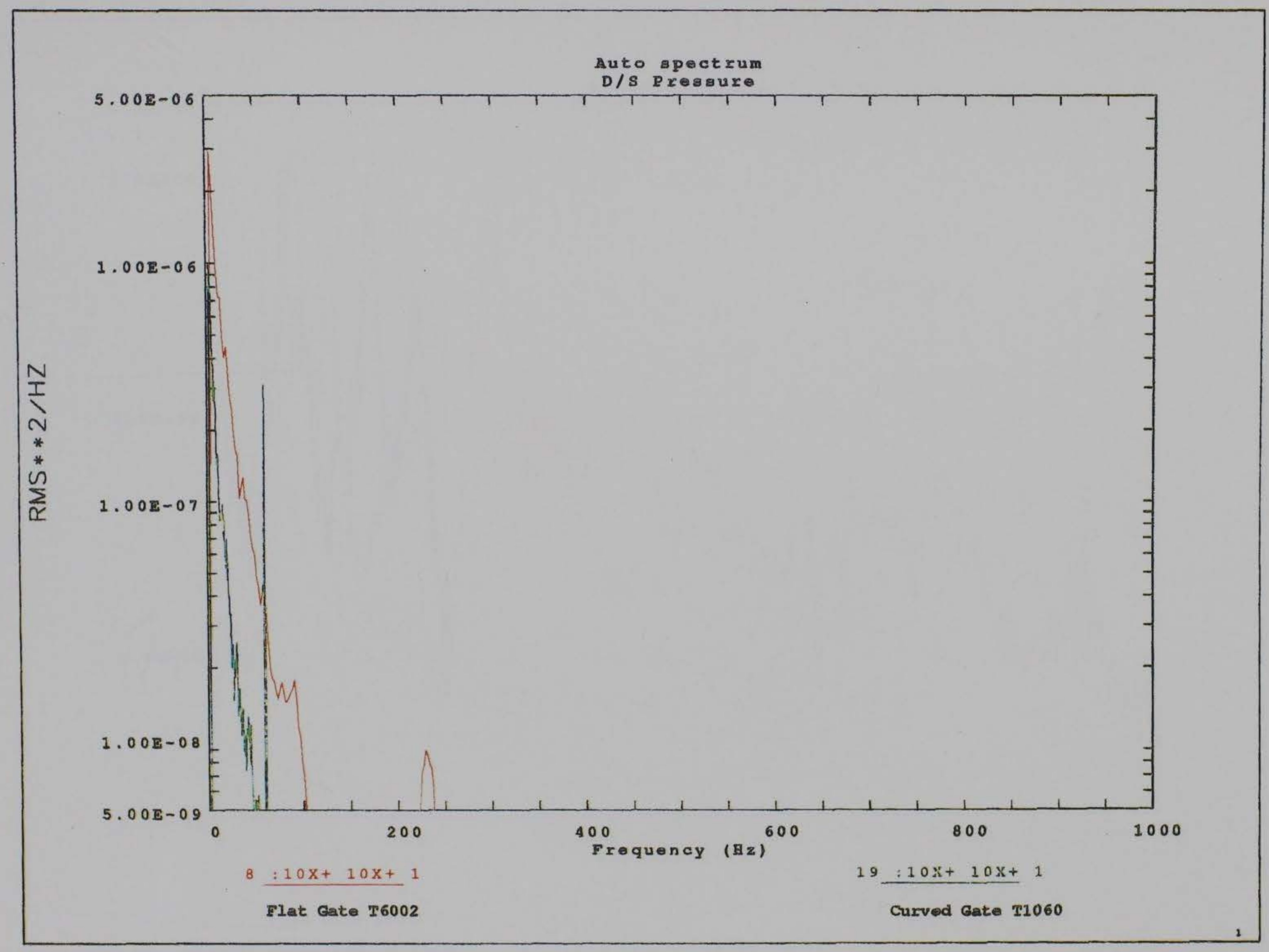

Figure 22g. Downstream pressure (Sheet 7 of 11) 


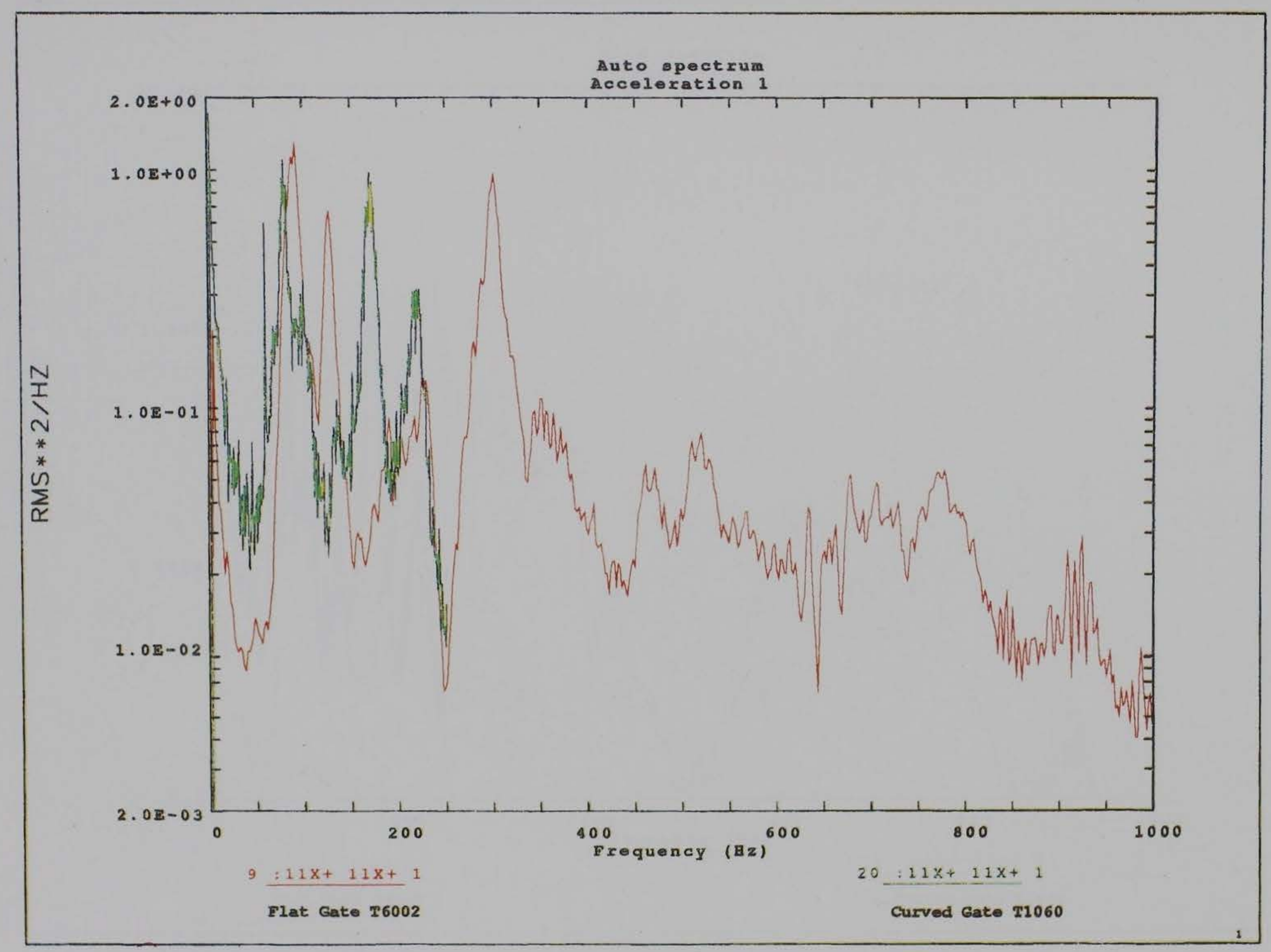

Figure 22h. Acceleration 1 (Sheet 8 of 11) 


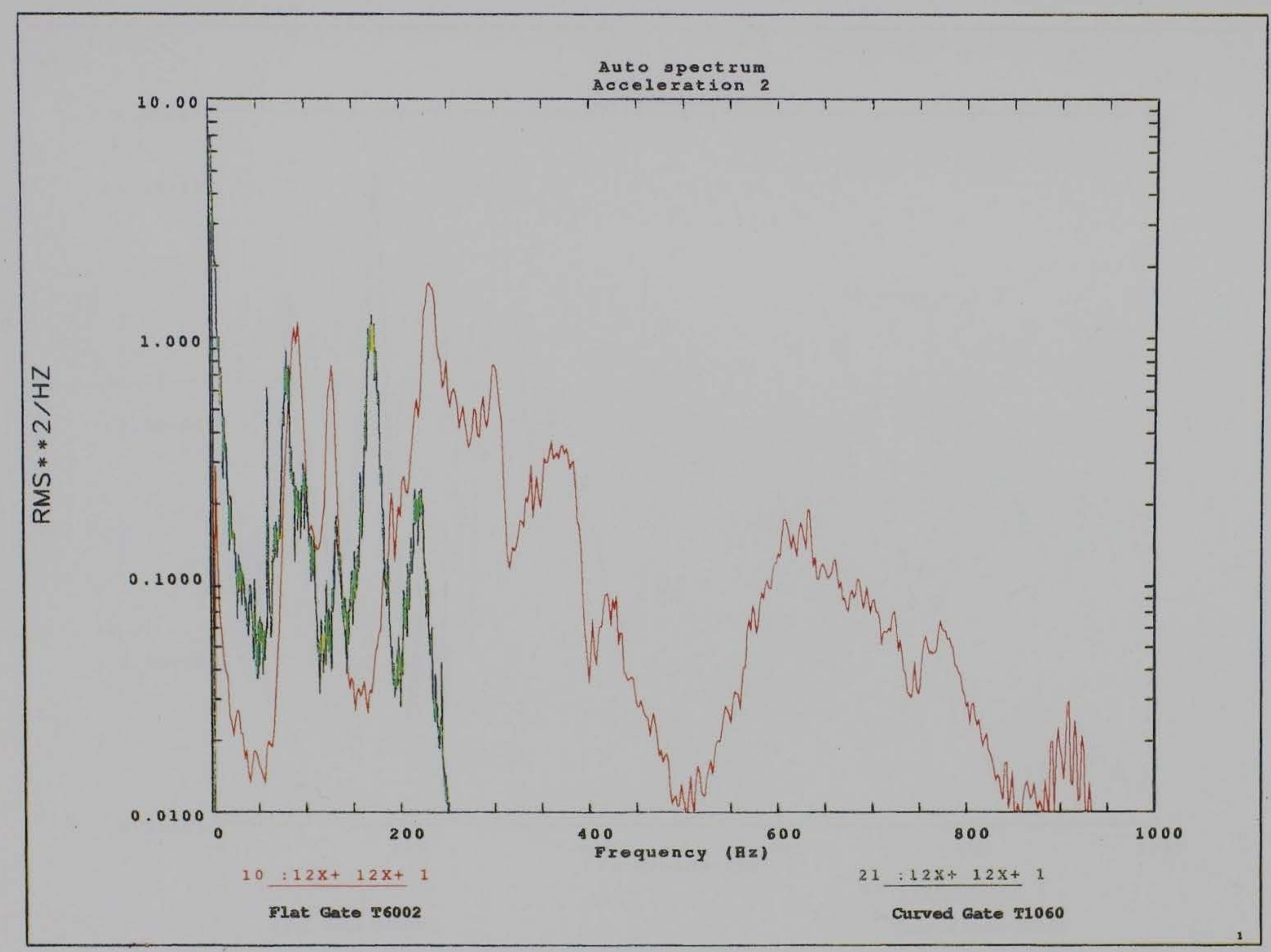

Figure 22i. Acceleration 2 (Sheet 9 of 11) 


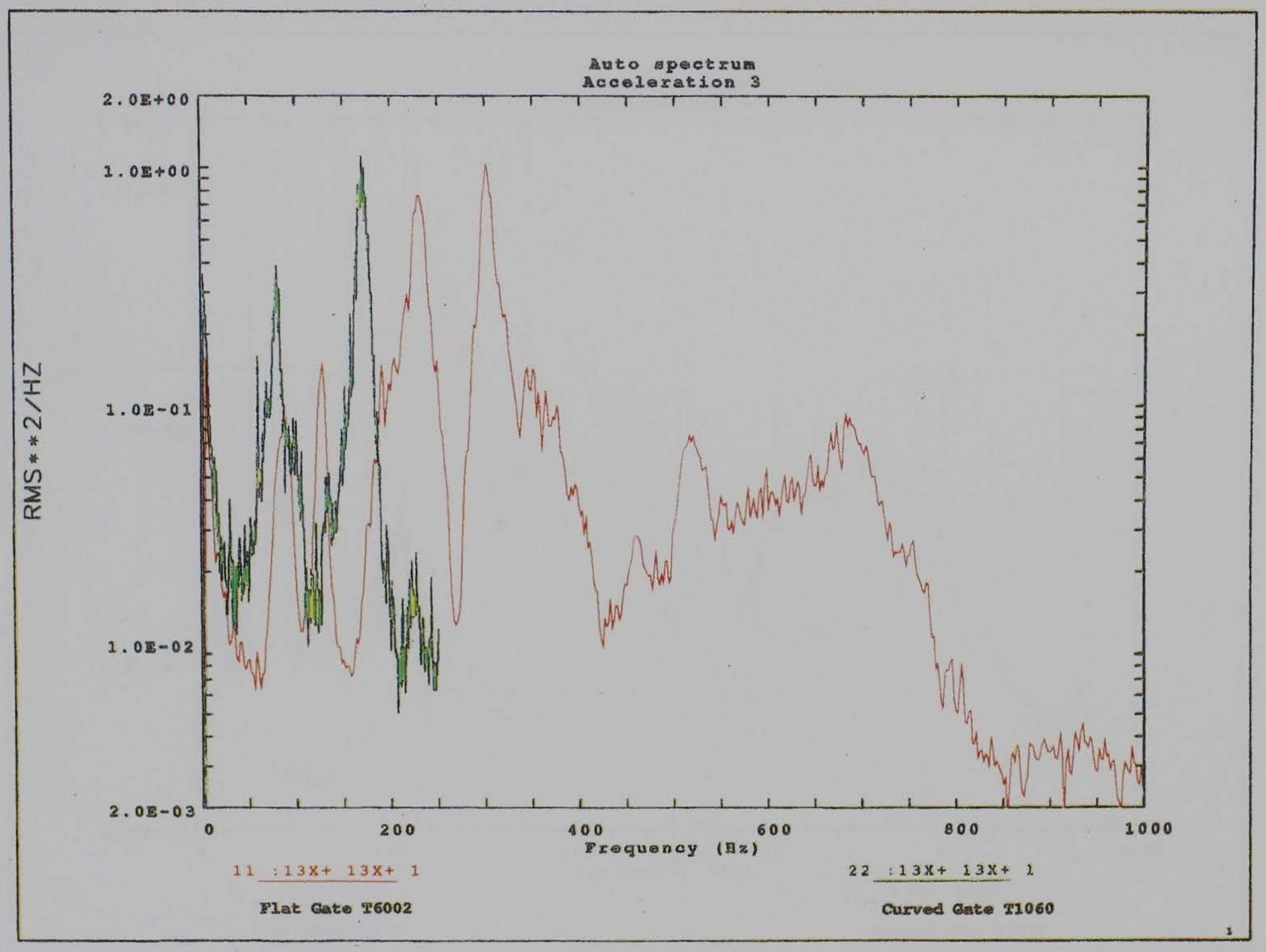

Figure 22j. Acceleration 3 (Sheet 10 of 11) 


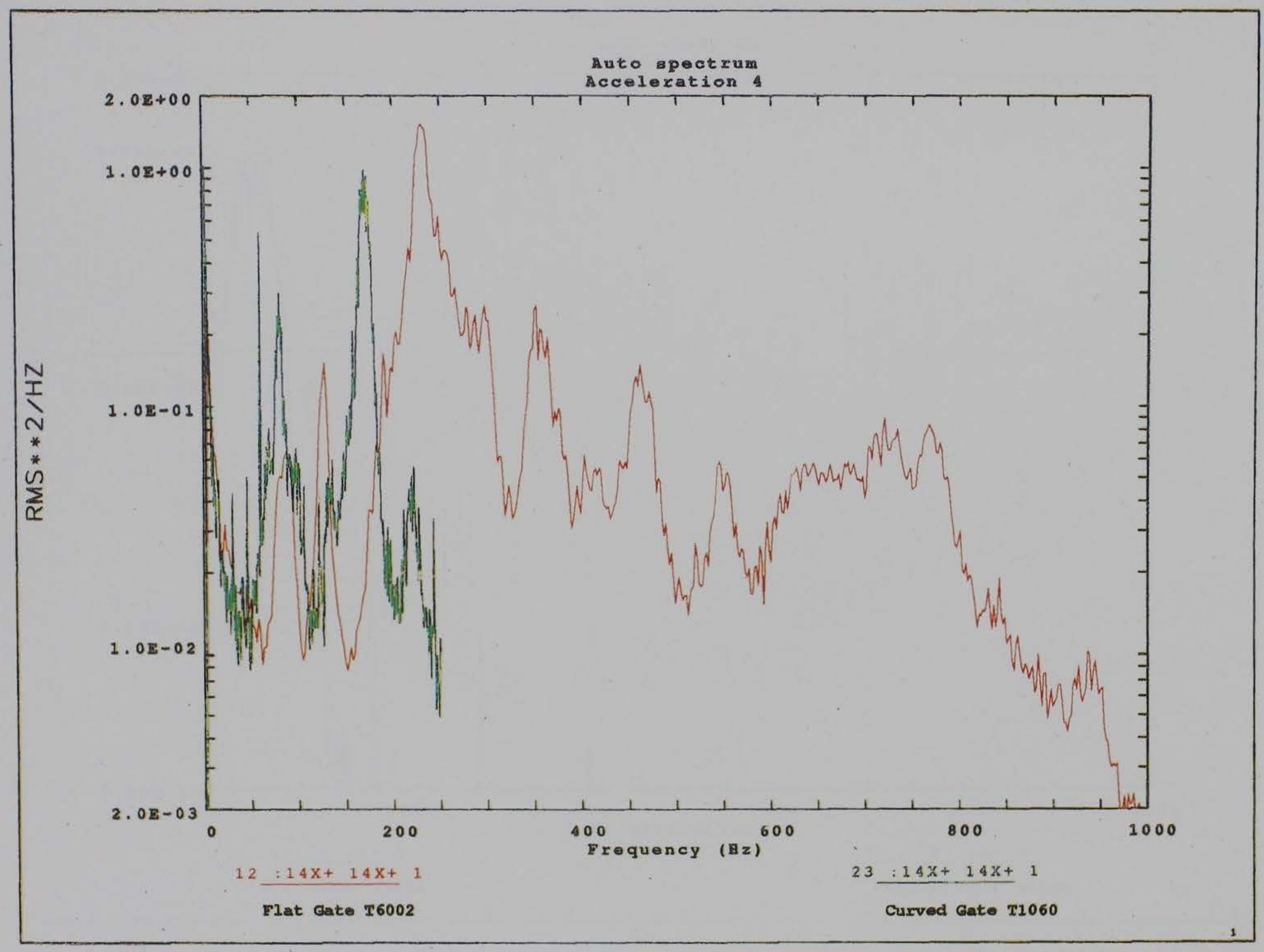

Figure 22k. Acceleration 4 (Sheet 11 of 11) 


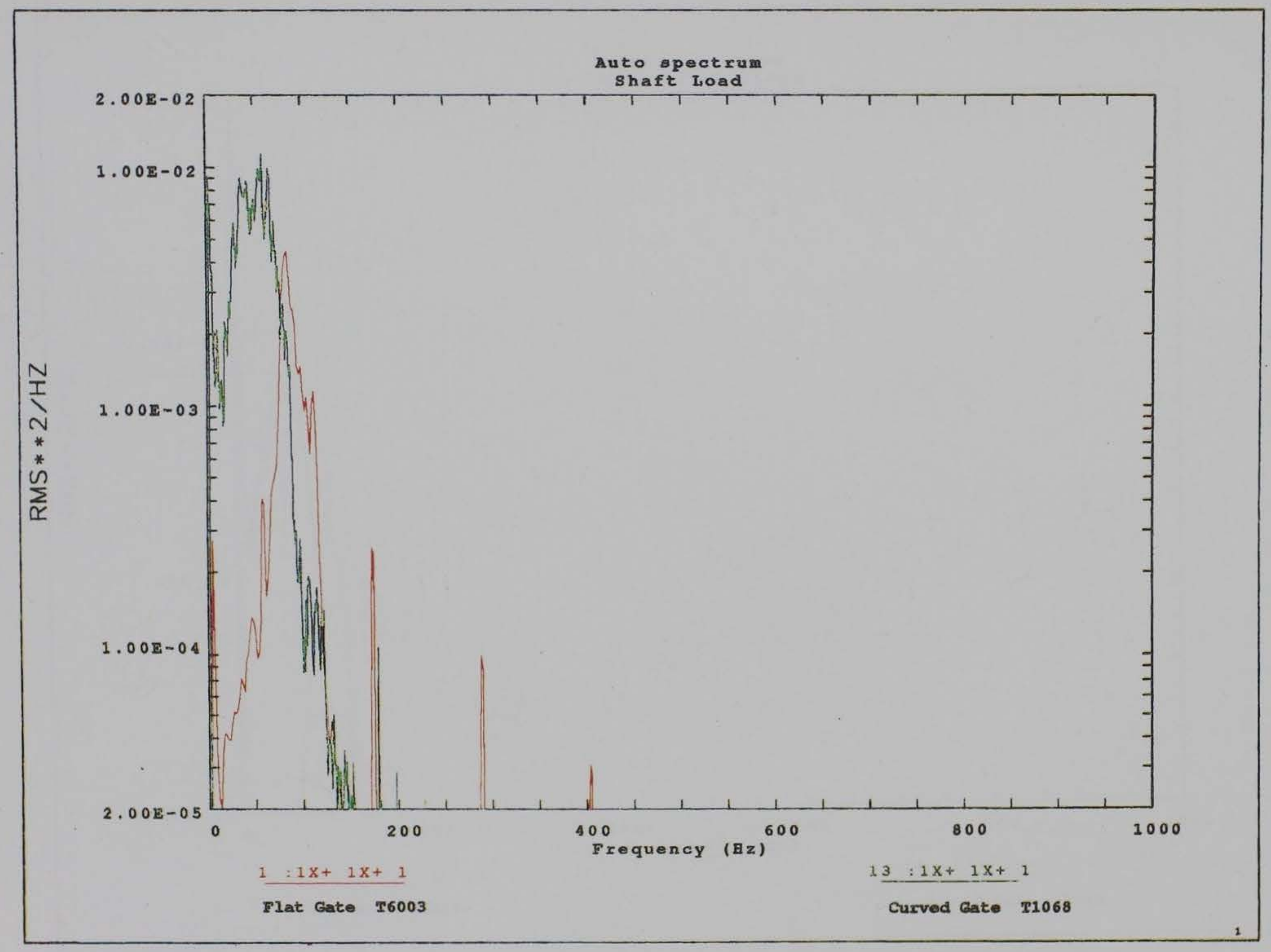

Figure 23. Auto spectra comparison for the flat and curved gates $\left(50^{\circ}\right.$ position). a. Shaft load (Sheet 1 of 11$)$ 


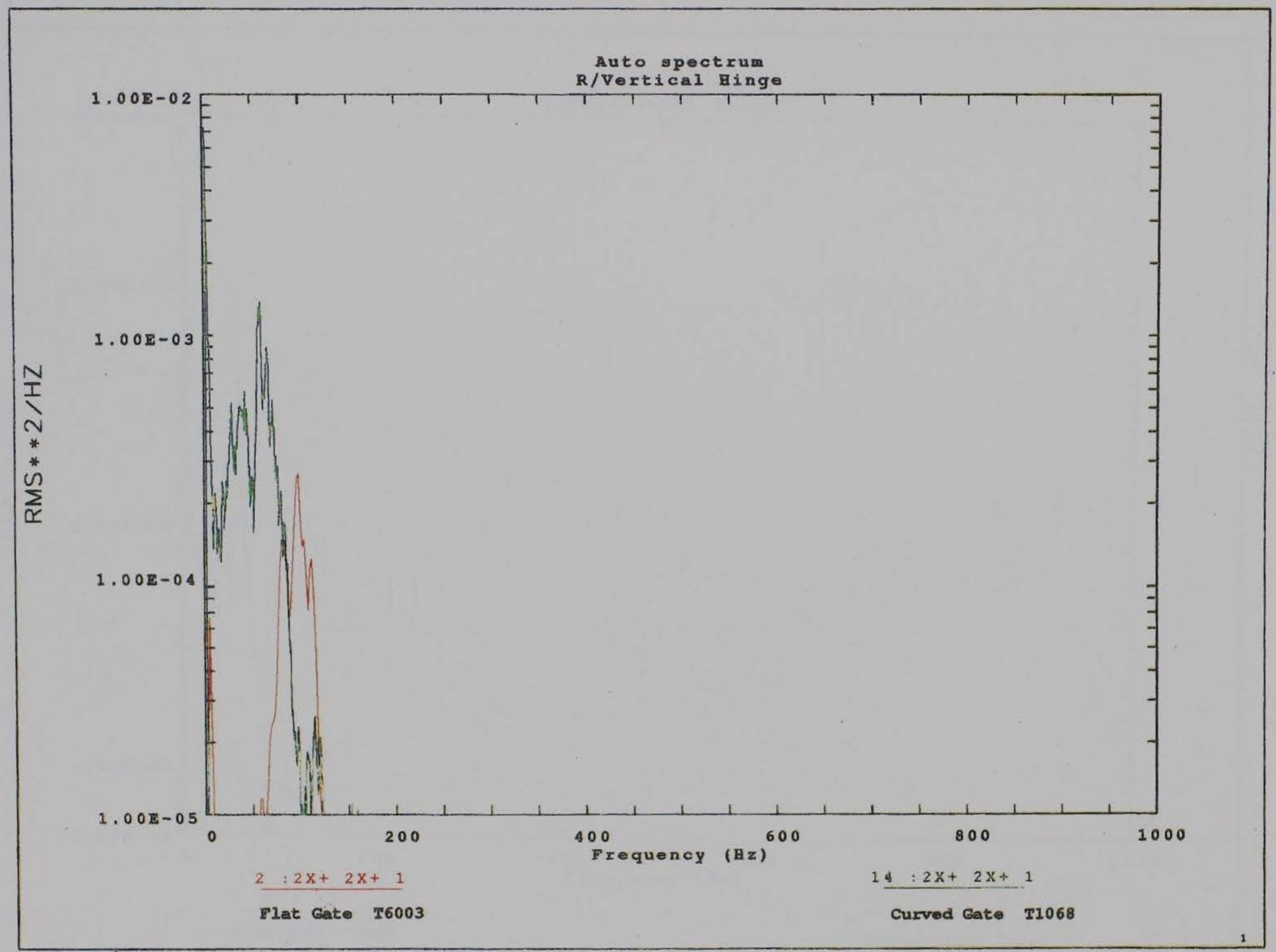

Figure 23b. Right vertical hinge (Sheet 2 of 11) 


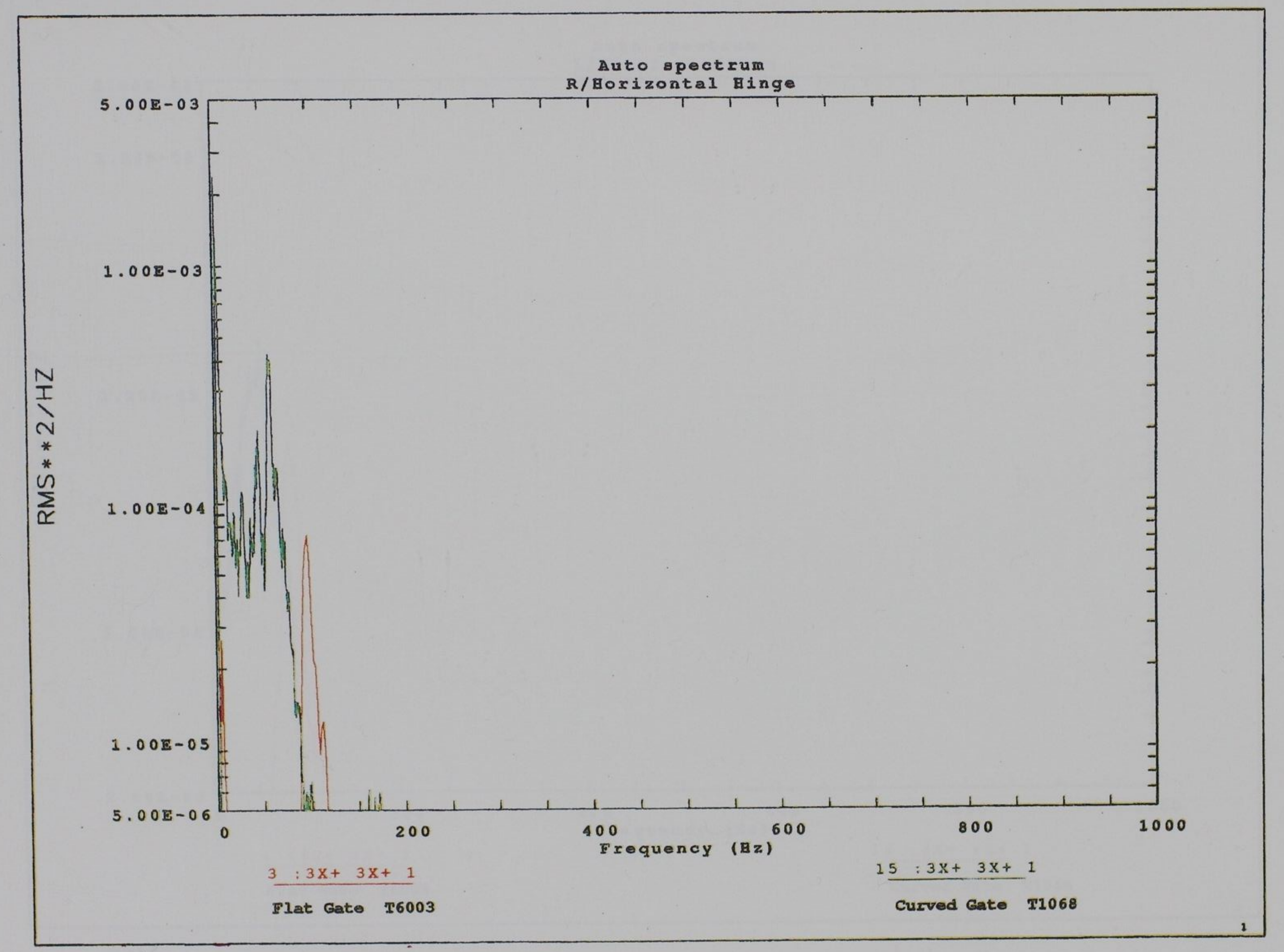

Figure 23c. Right horizontal hinge (Sheet 3 of 11) 


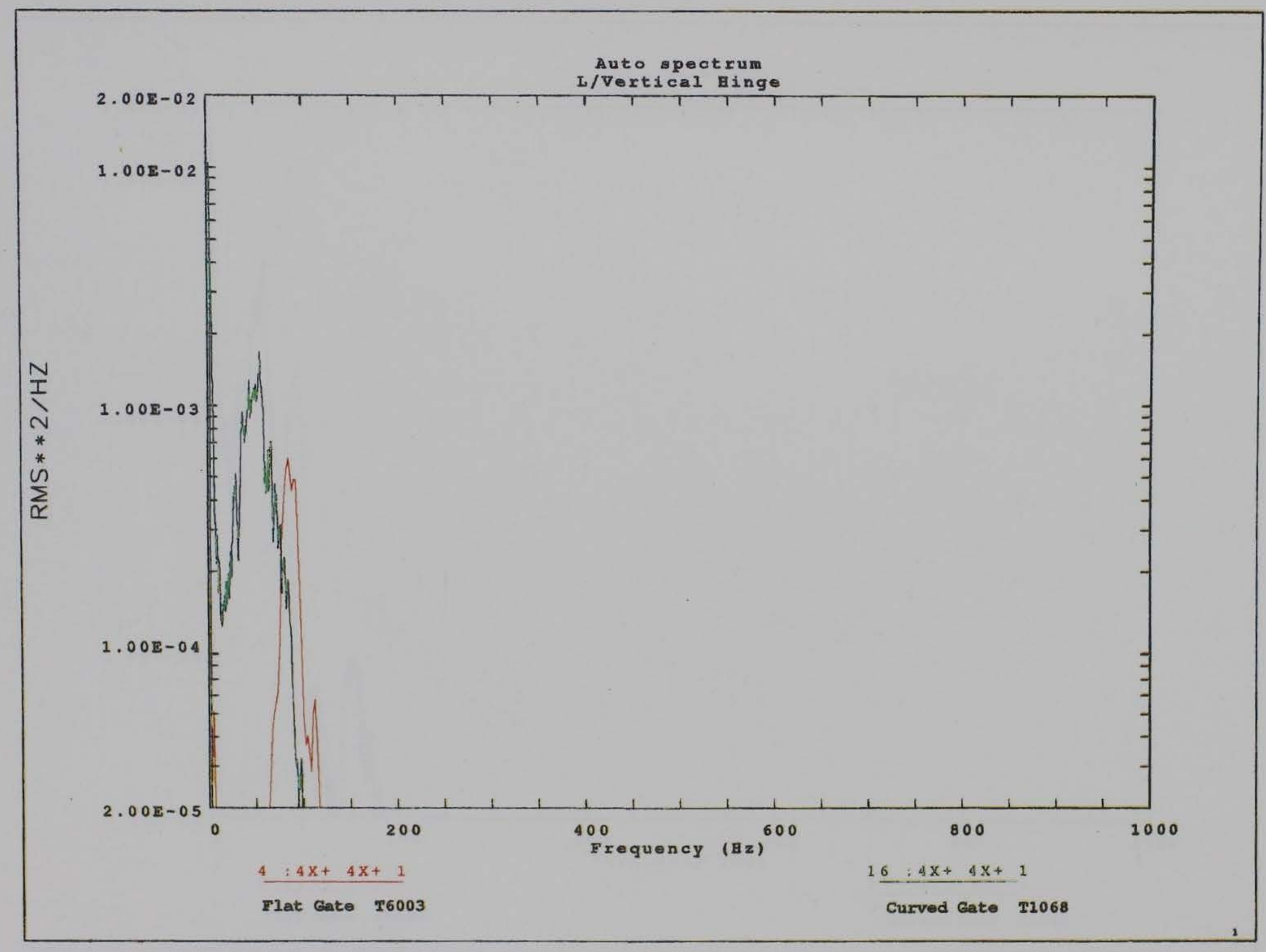

Figure 23d. Left vertical hinge (Sheet 4 of 11) 


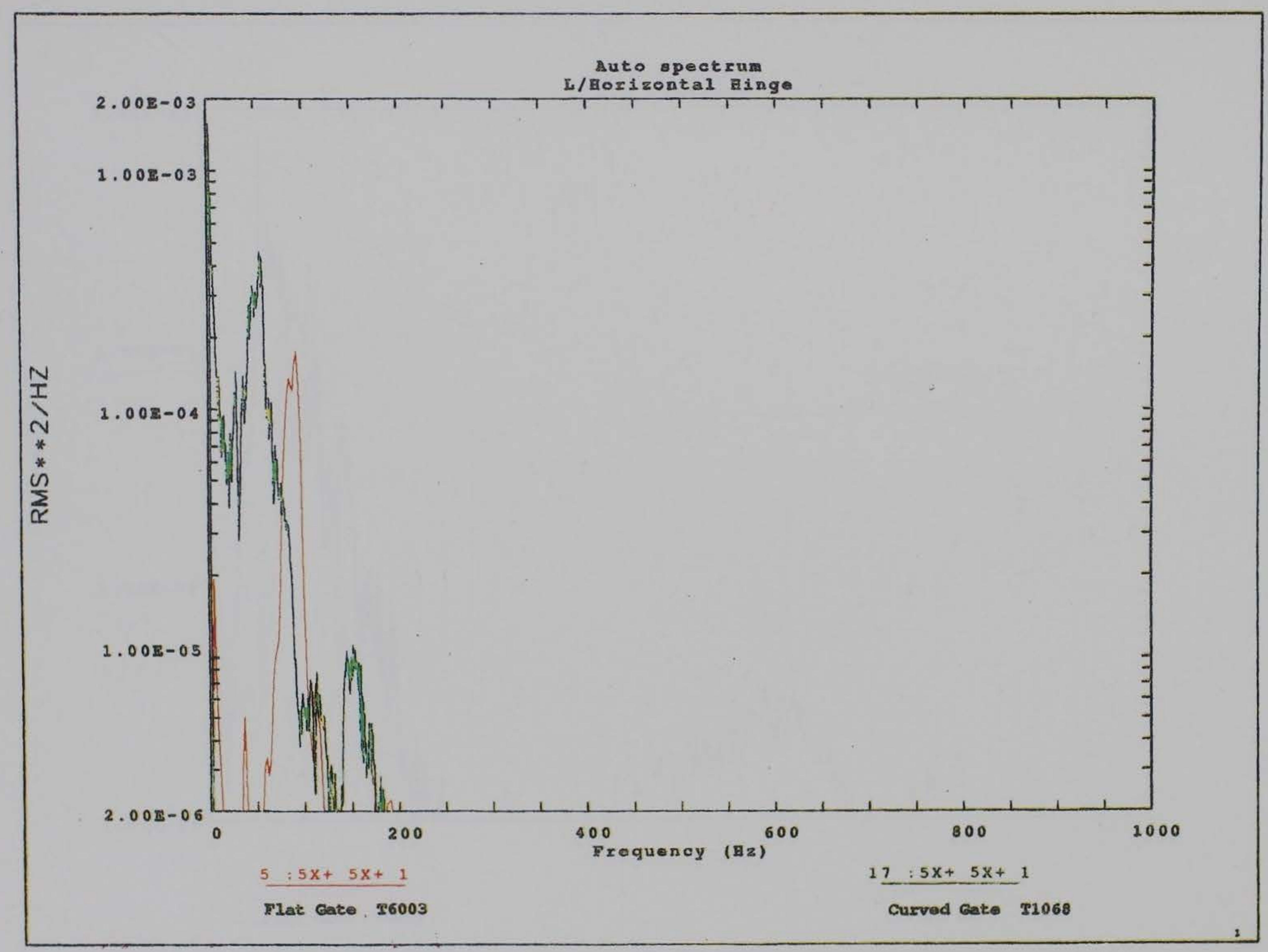

Figure 23e. Left horizontal hinge (Sheet 5 of 11) 


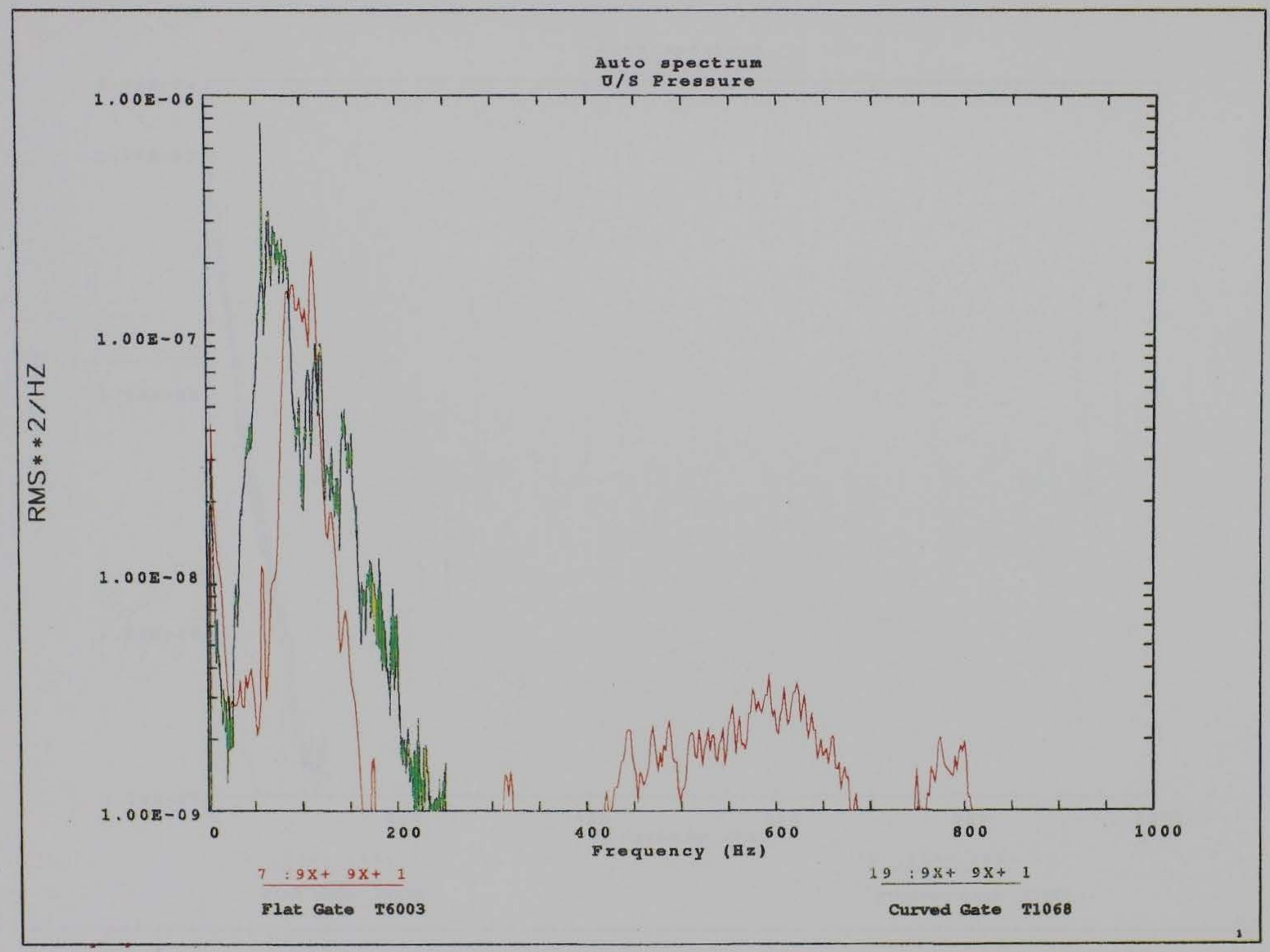

Figure 23f. Upstream pressure (Sheet 6 of 11) 


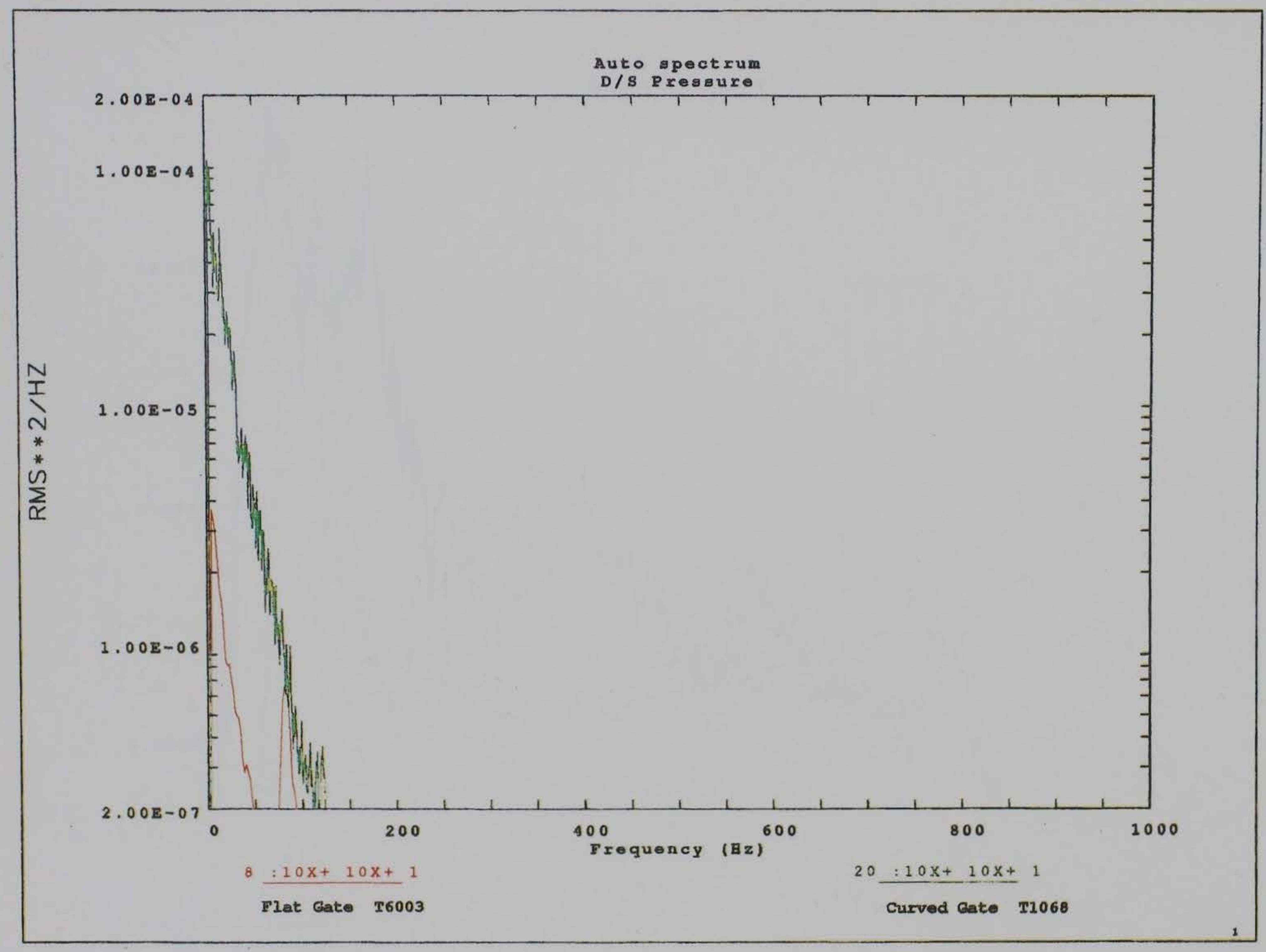

Figure 23g. Downstream pressure (Sheet 7 of 11) 


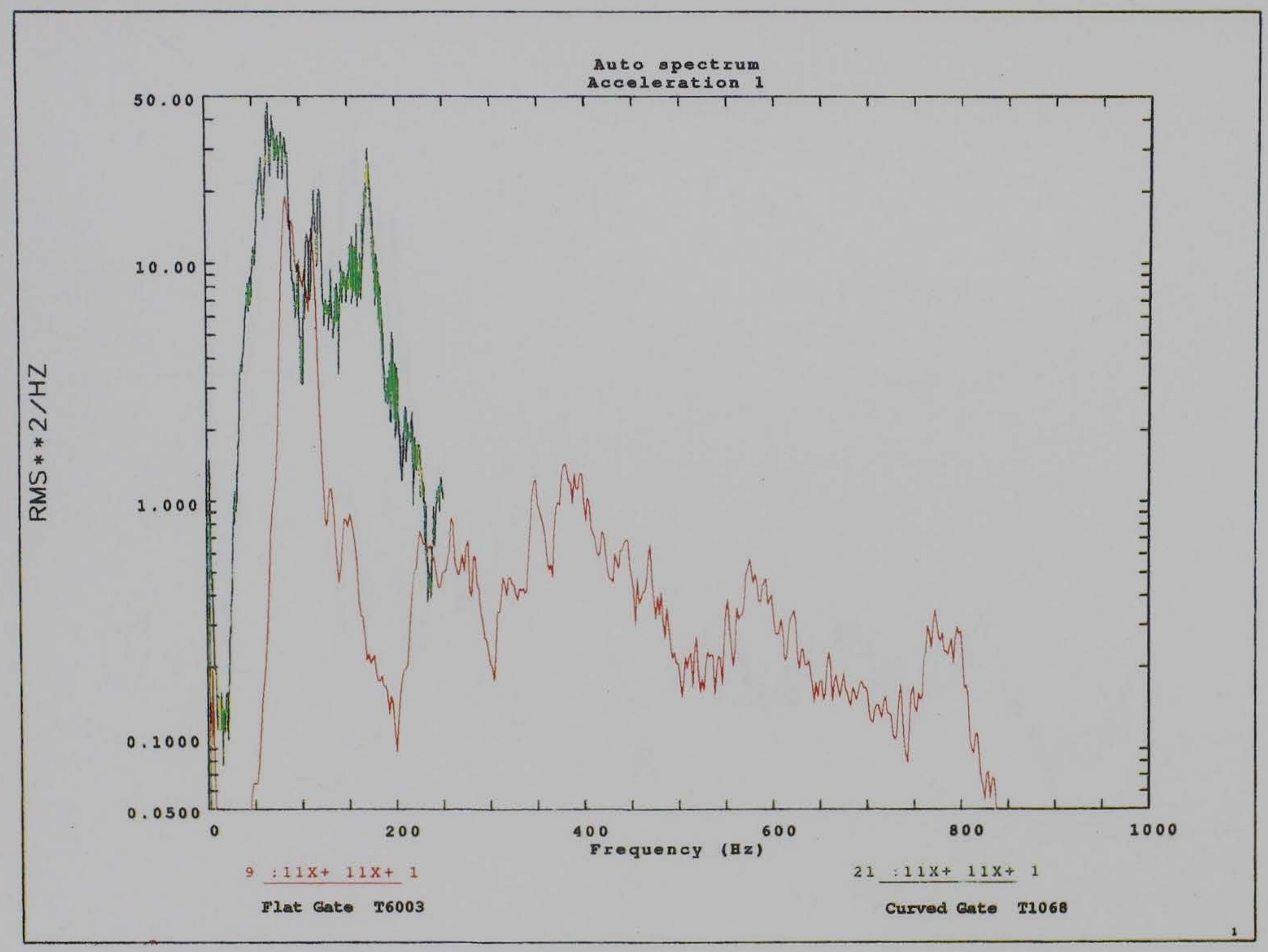

Figure 23h. Acceleration 1 (Sheet 8 of 11) 


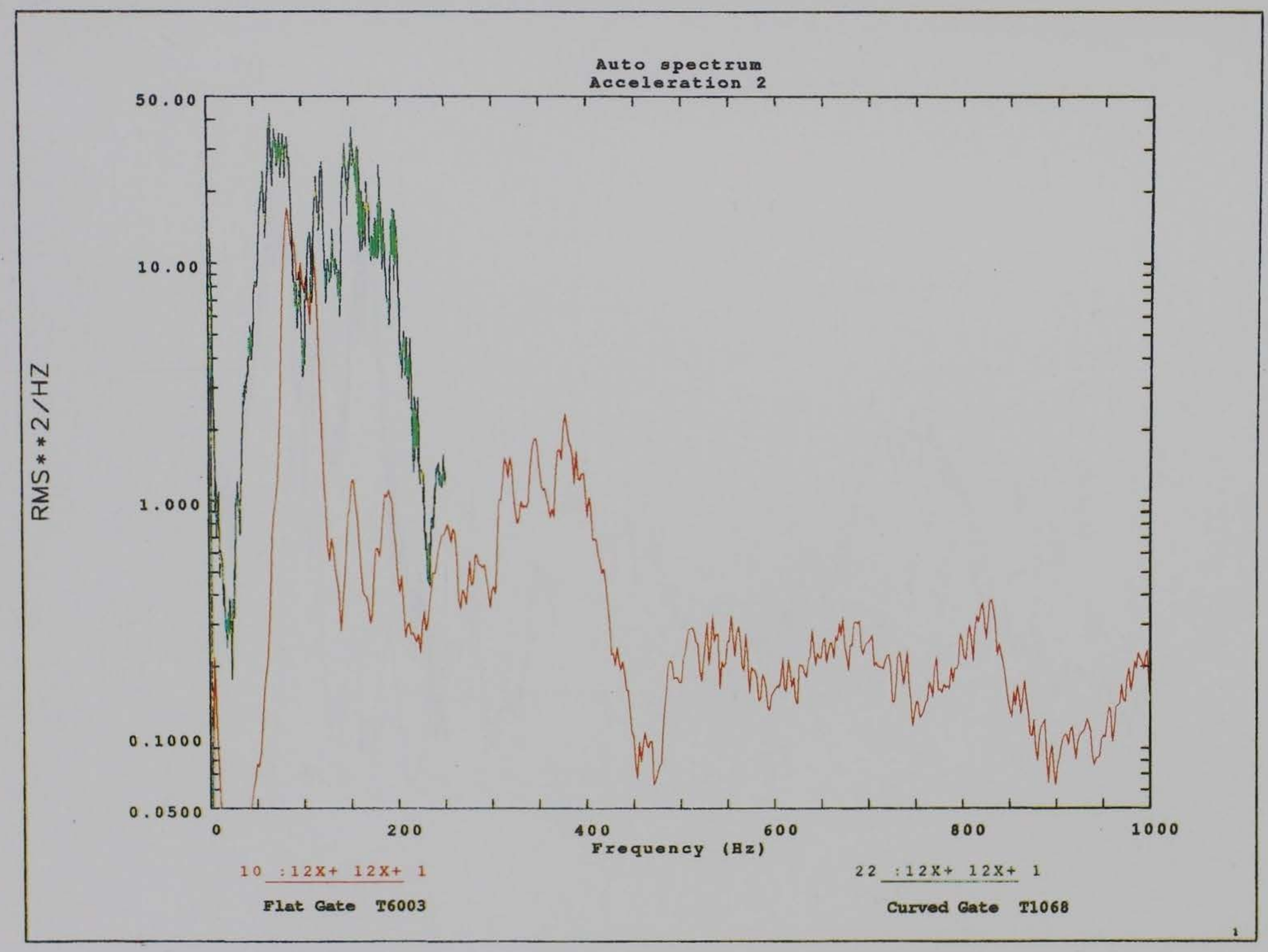

Figure 23i. Acceleration 2 (Sheet 9 of 11) 


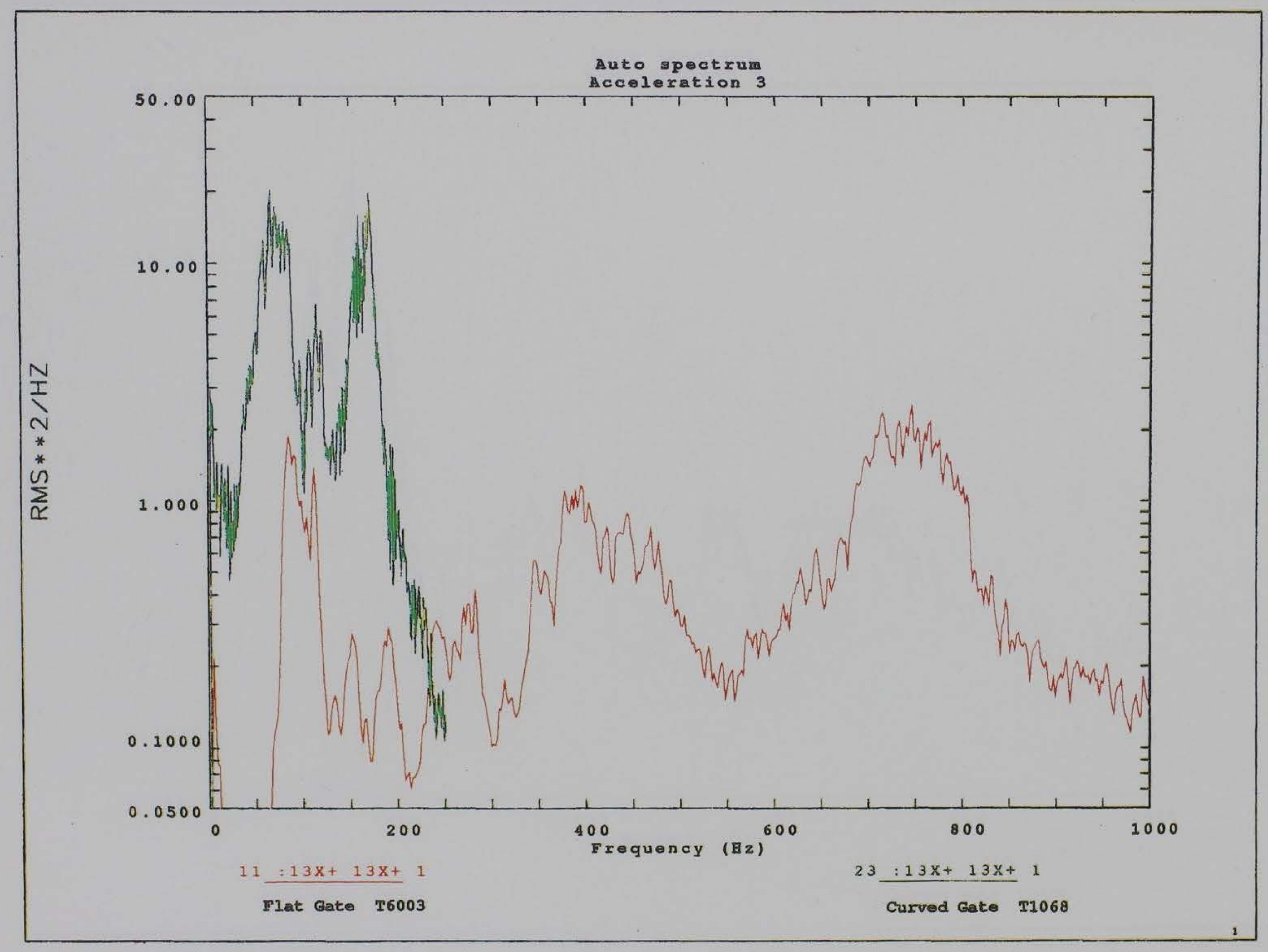

Figure 23j. Acceleration 3 (Sheet 10 of 11) 


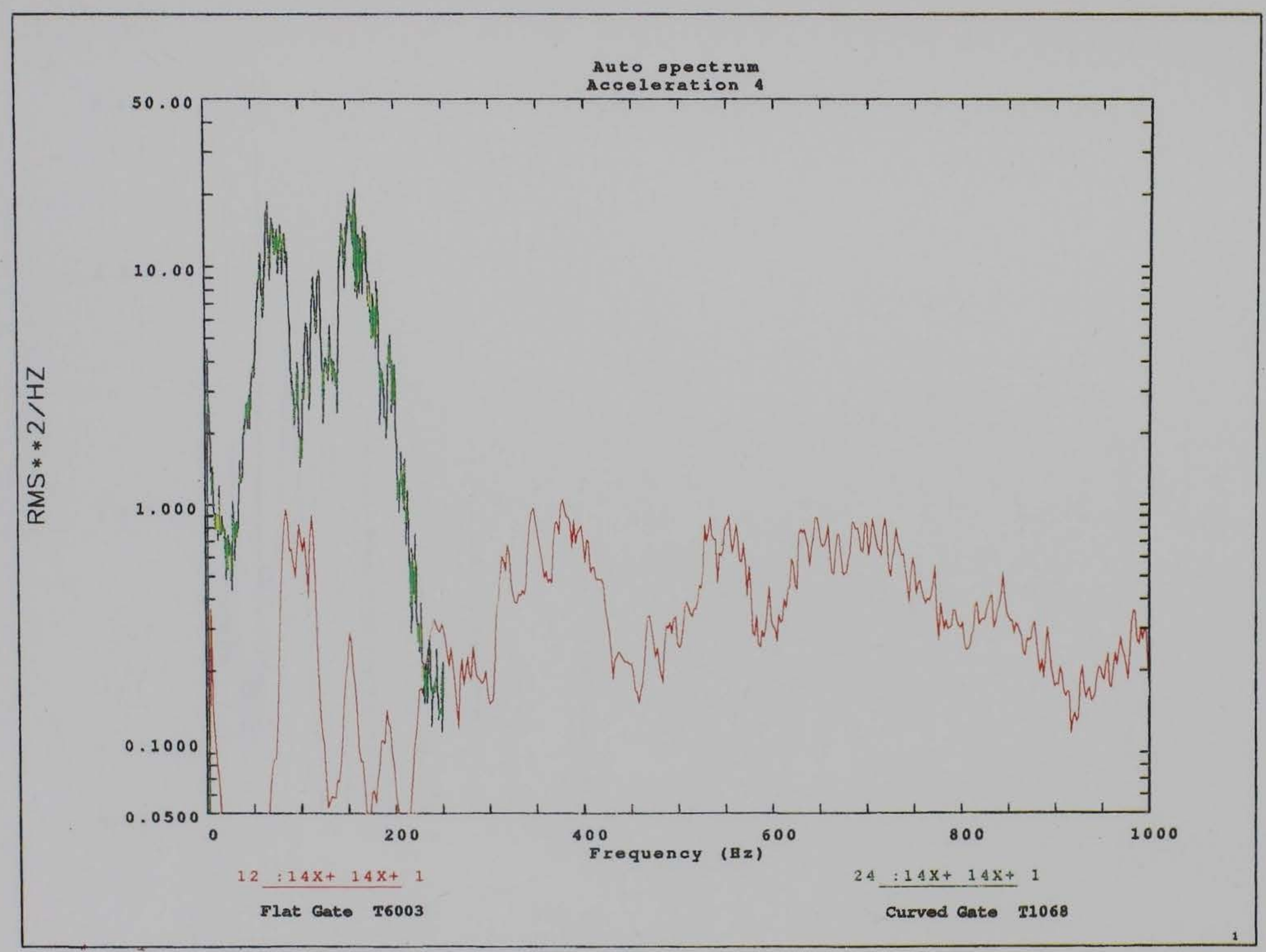

Figure 23k. Acceleration 4 (Sheet 11 of 11) 


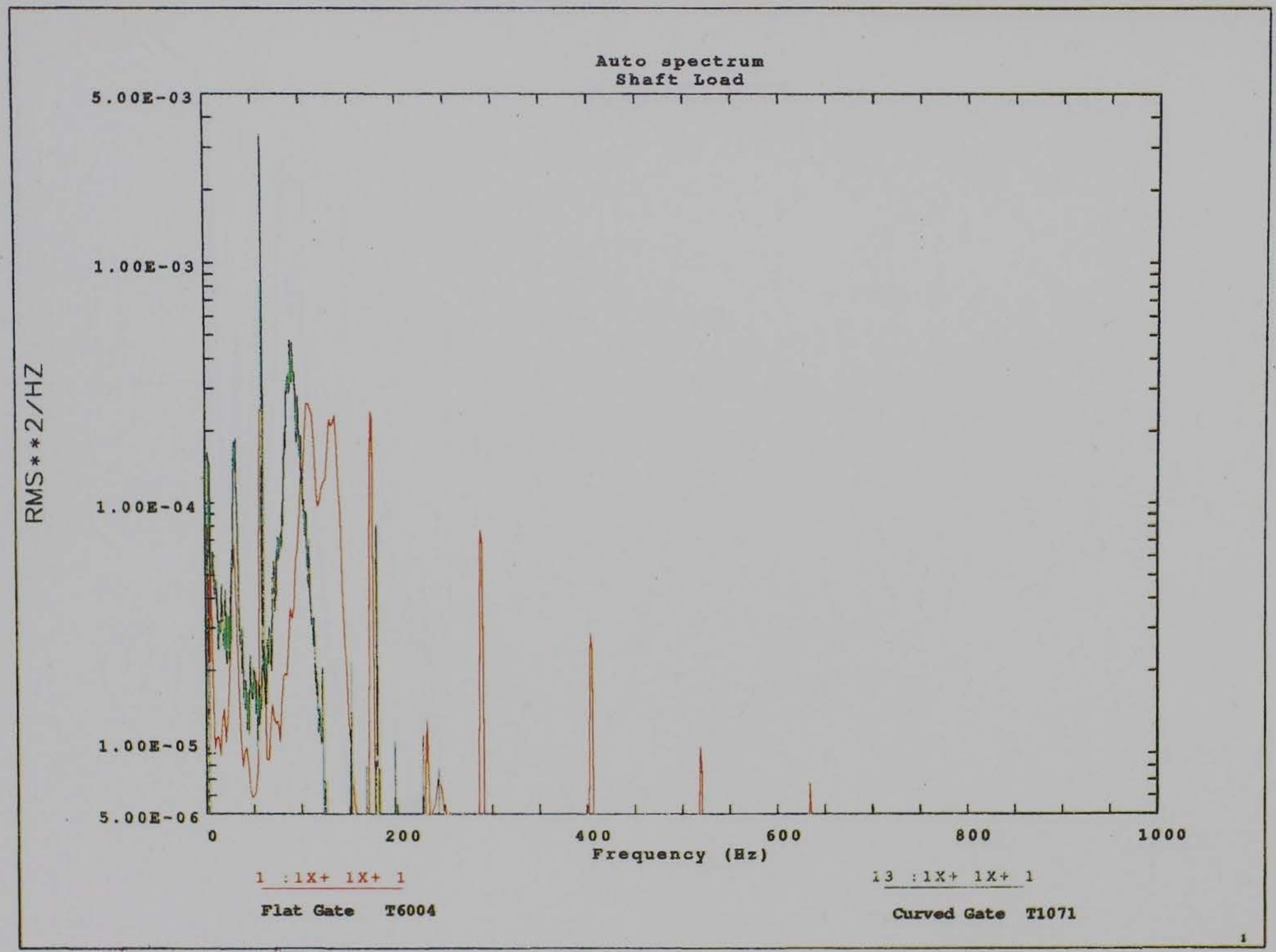

Figure 24. Auto spectra comparison for the flat and curved gates $\left(60^{\circ}\right.$ position). a. Shaft load (Sheet 1 of 11$)$ 


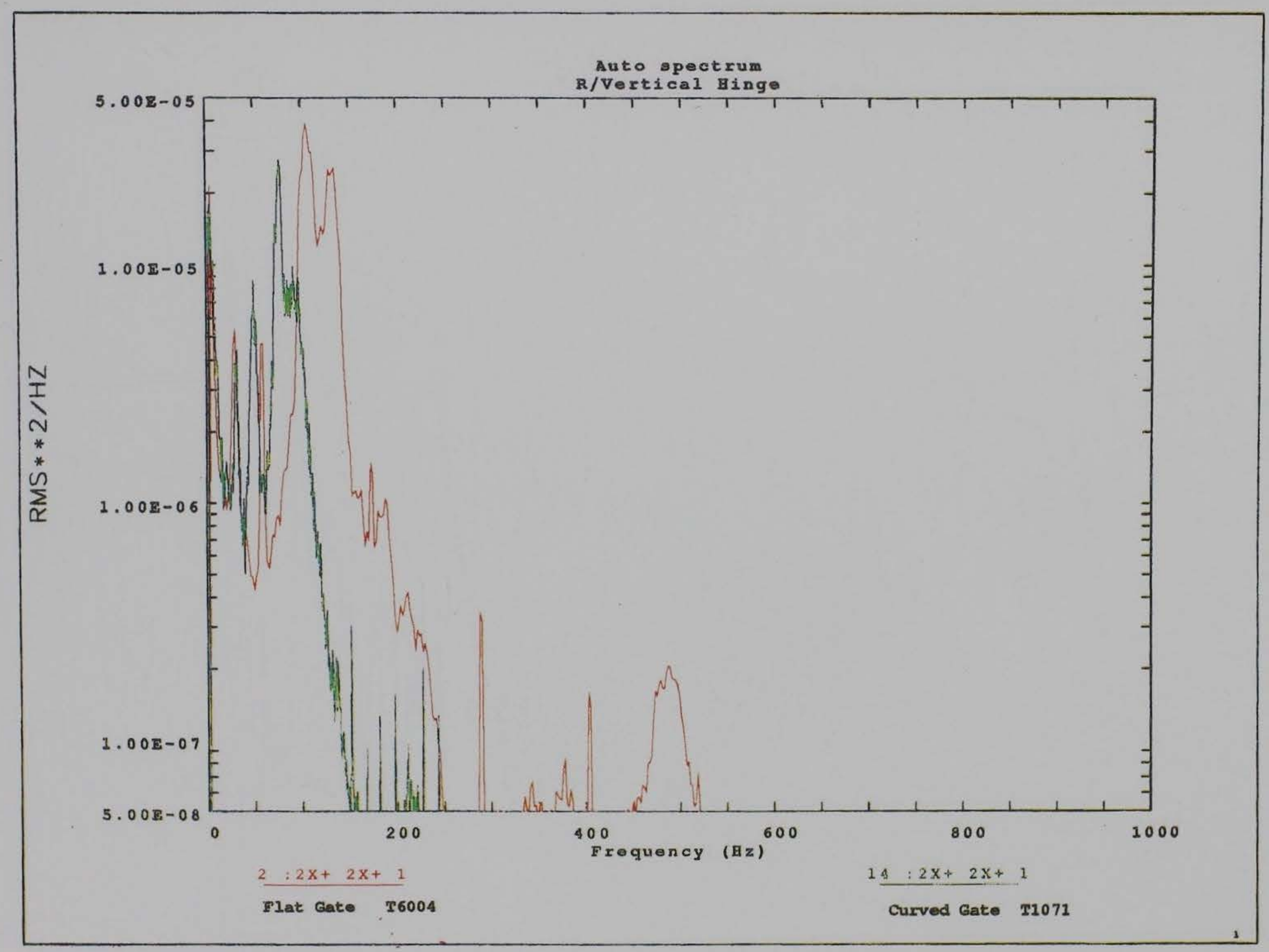

Figure 24b. Right vertical hinge (Sheet 2 of 11) 


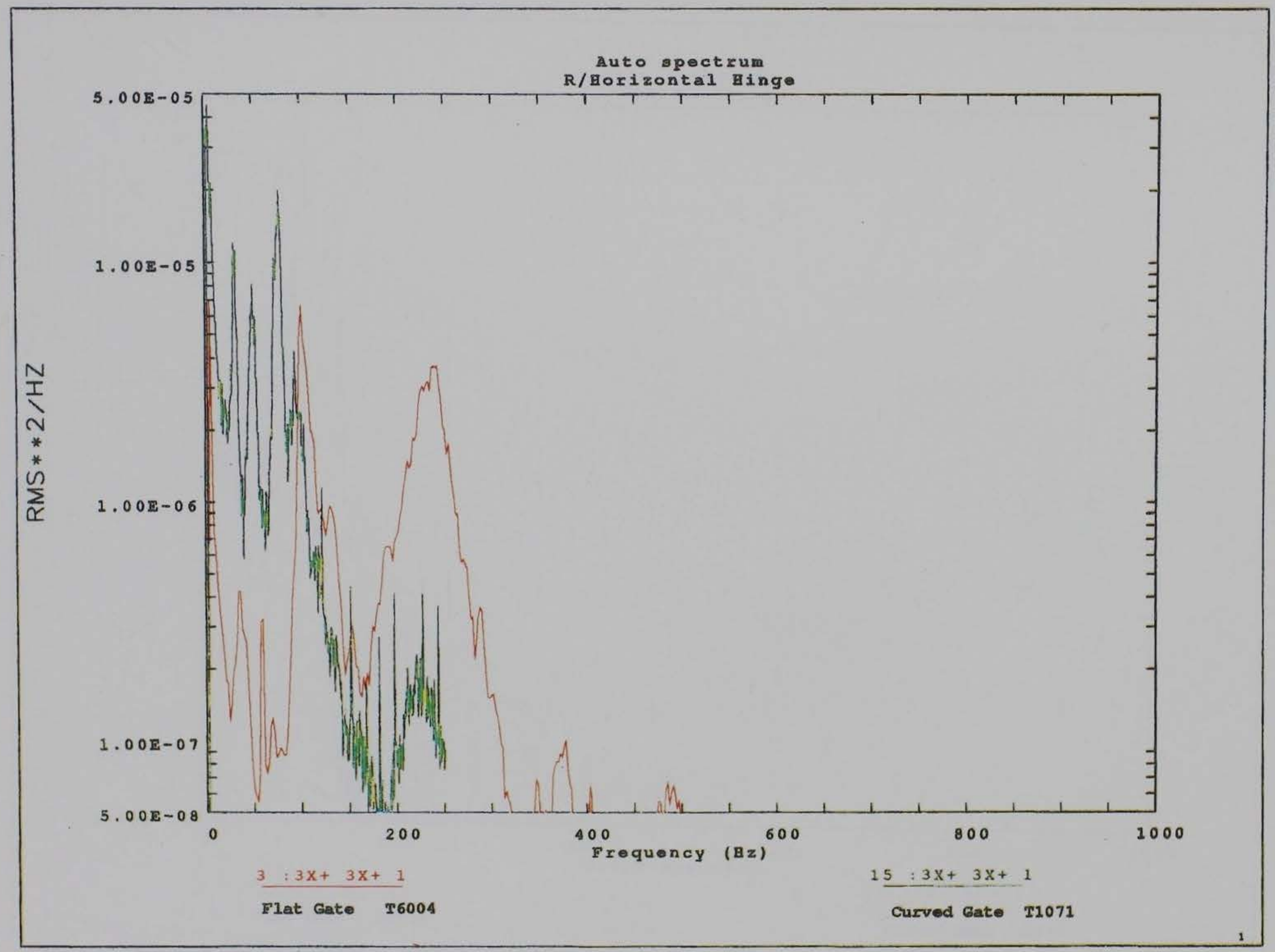

Figure 24c. Right horizontal hinge (Sheet 3 of 11) 


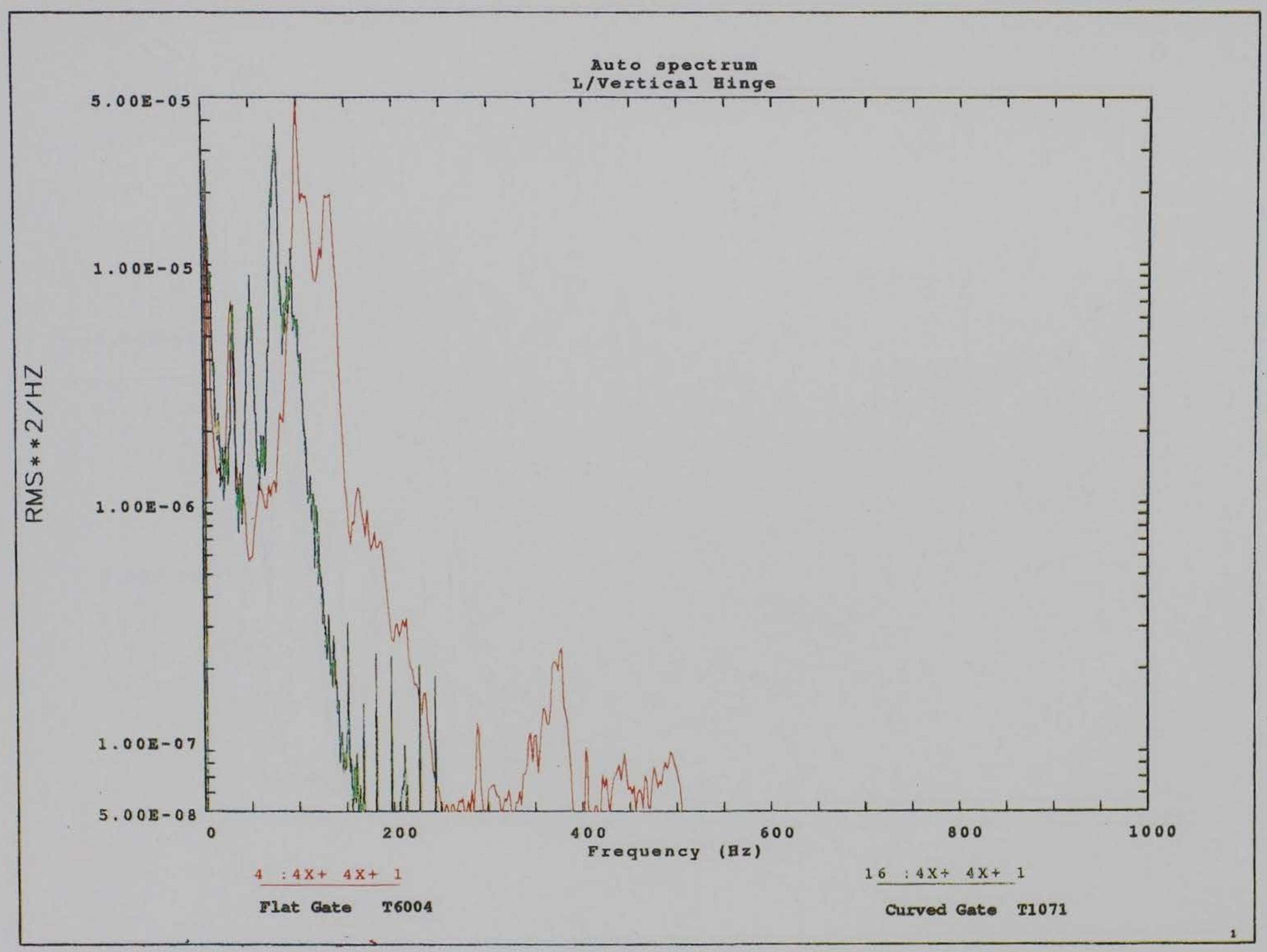

Figure 24d. Left vertical hinge (Sheet 4 of 11) 


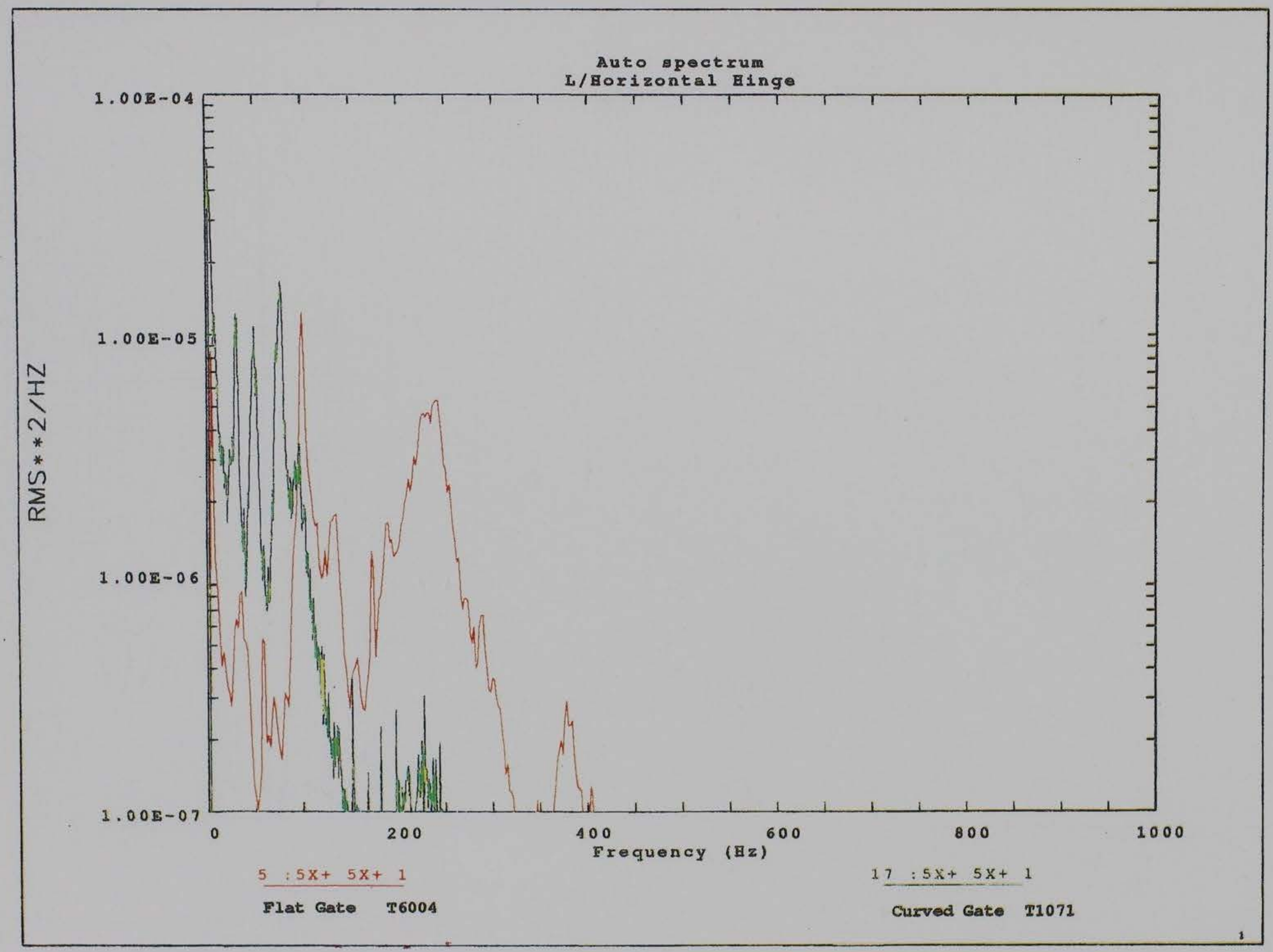

Figure 24e. Left horizontal hinge (Sheet 5 of 11) 


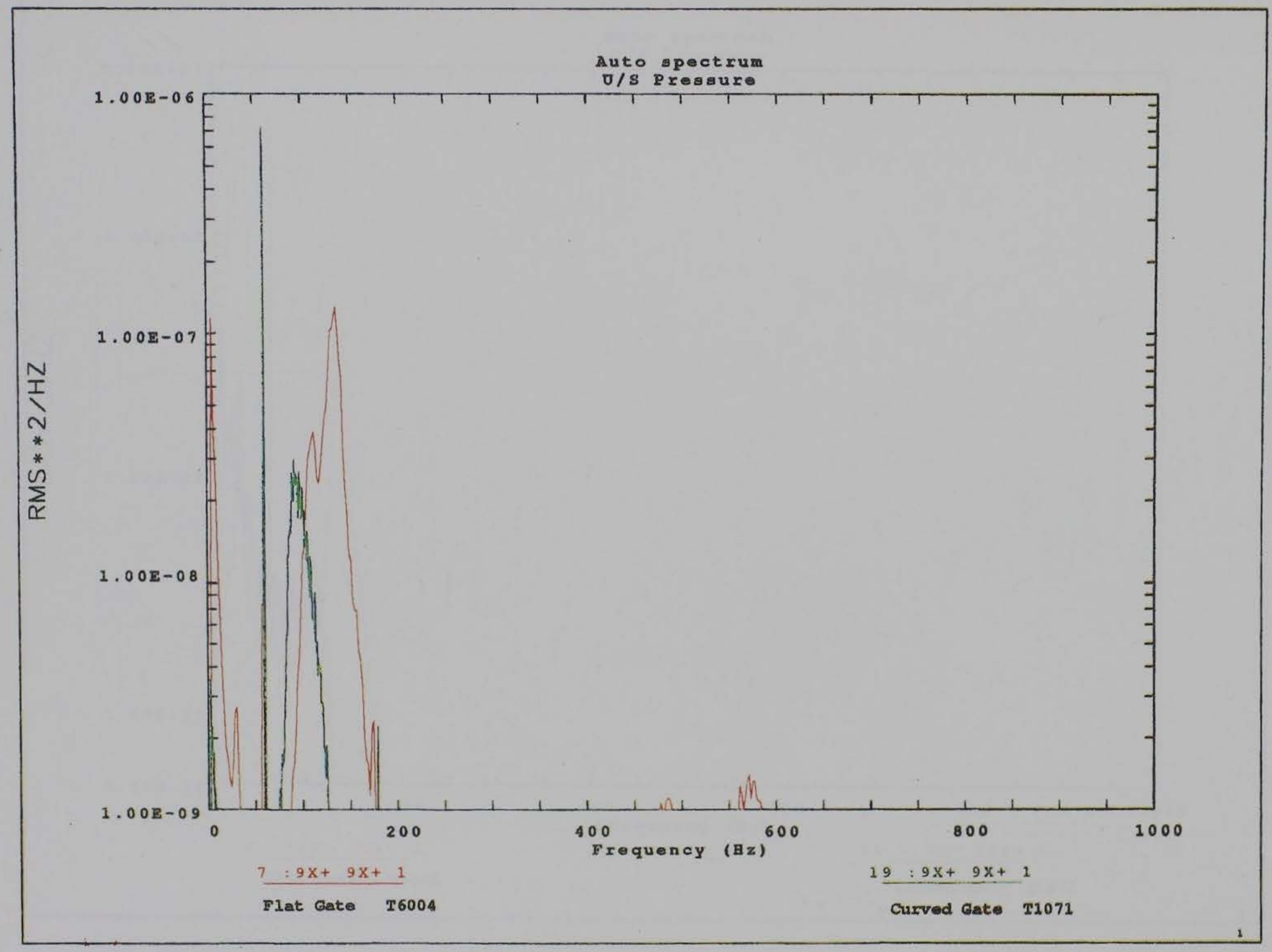

Figure 24f. Upstream pressure (Sheet 6 of 11) 


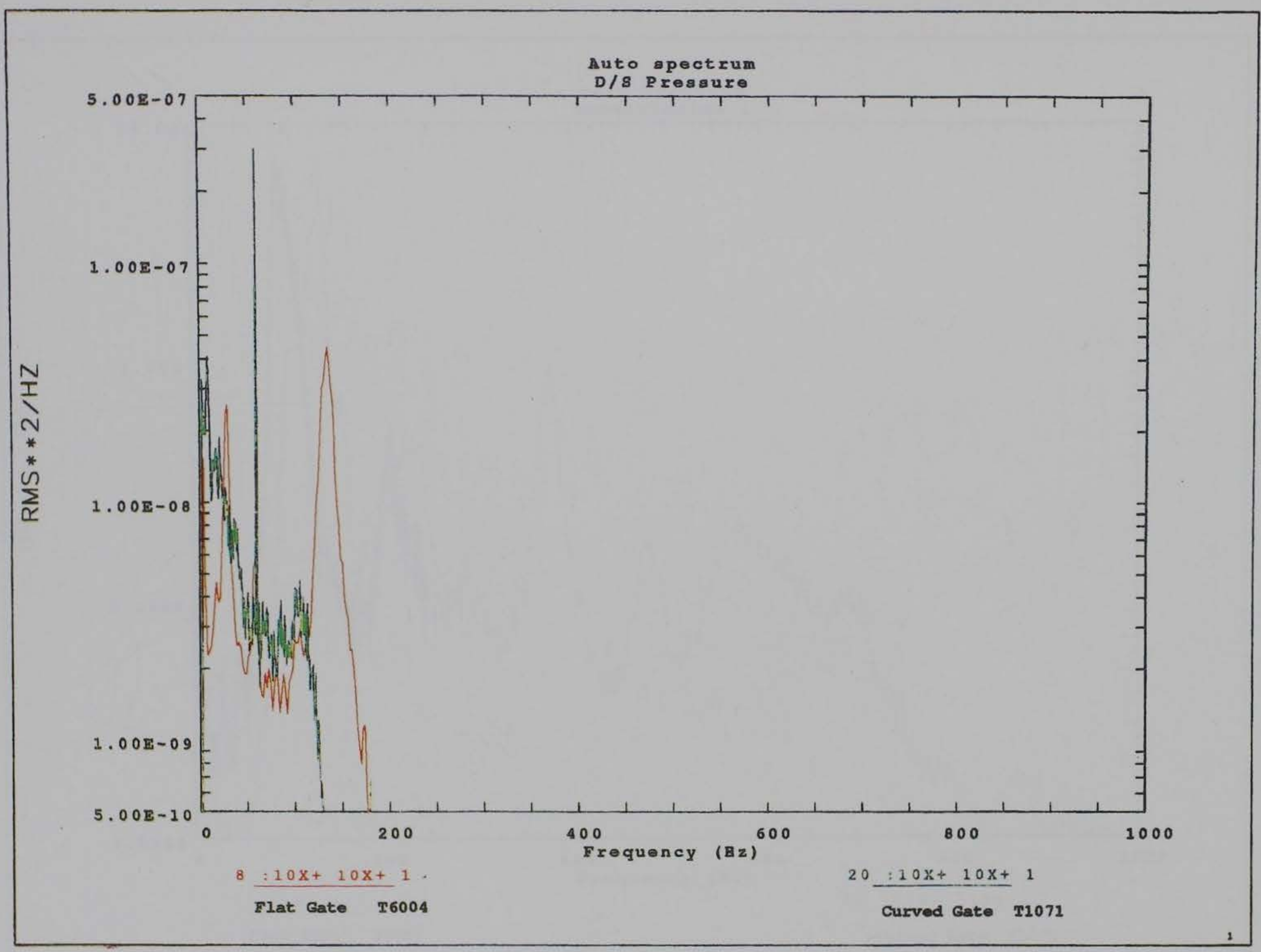

Figure $24 \mathrm{~g}$. Downstream pressure (Sheet 7 of 11) 


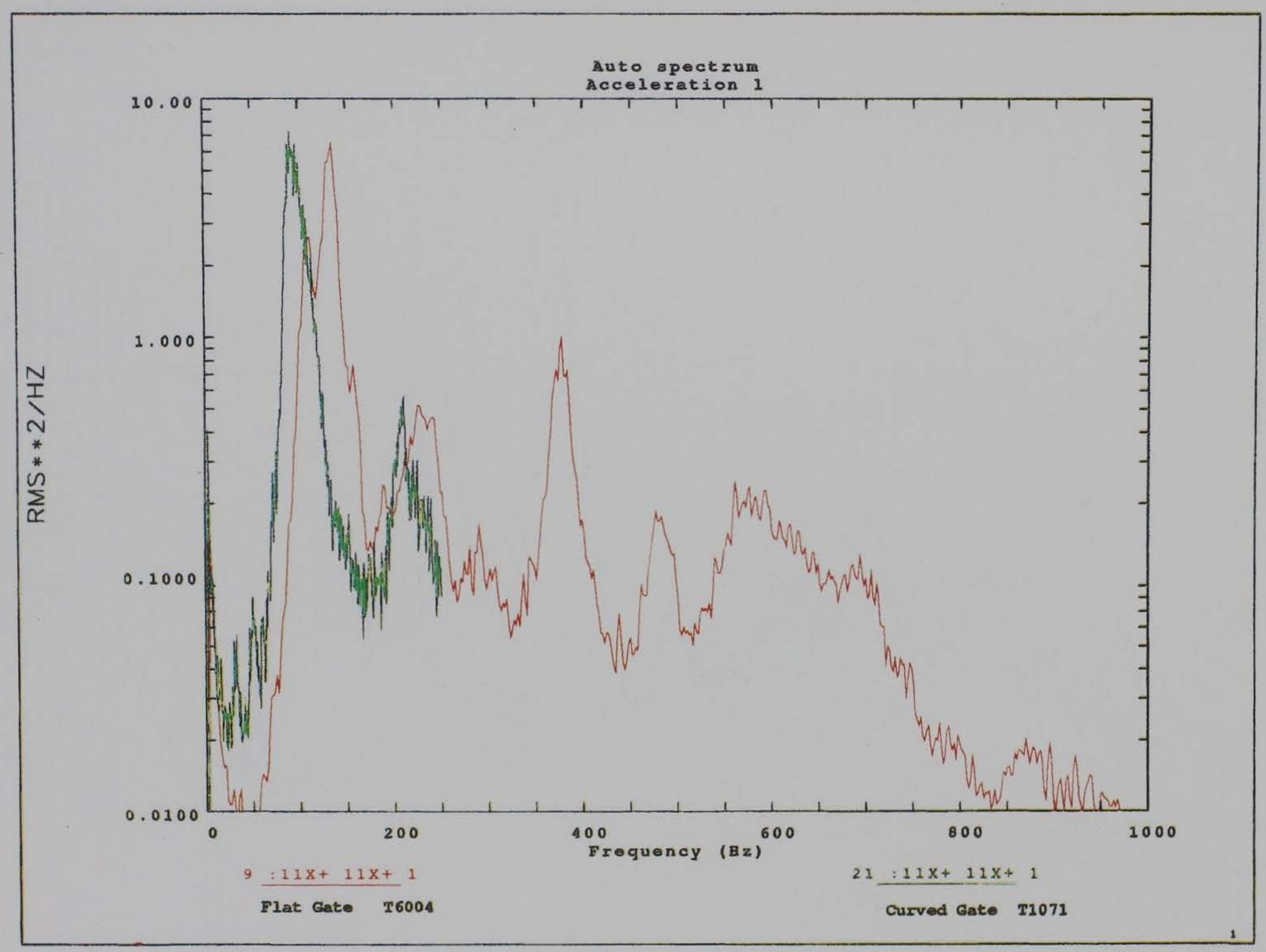

Figure 24h. Acceleration 1 (Sheet 8 of 11 ) 


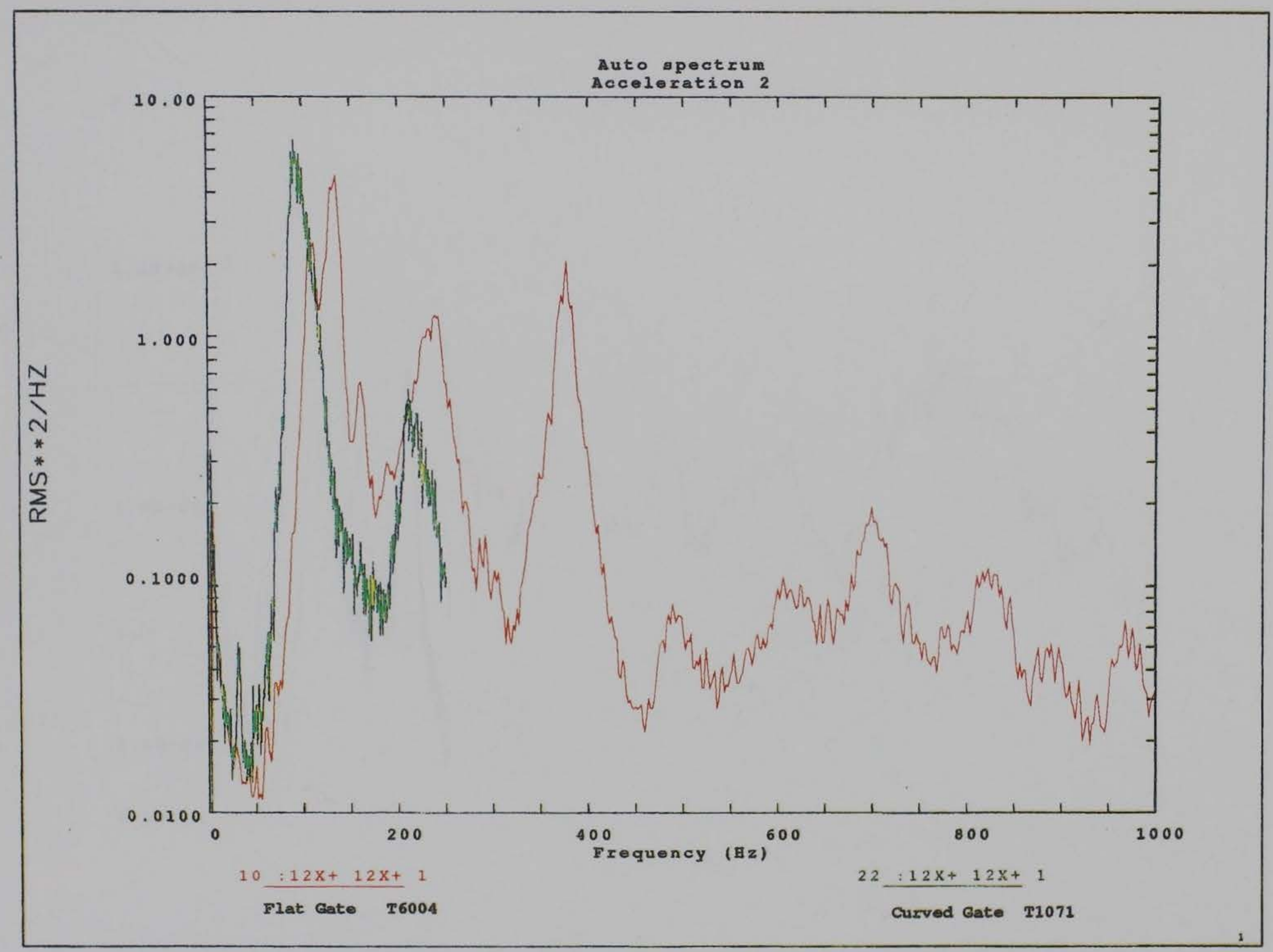

Figure 24i. Acceleration 2 (Sheet 9 of 11) 


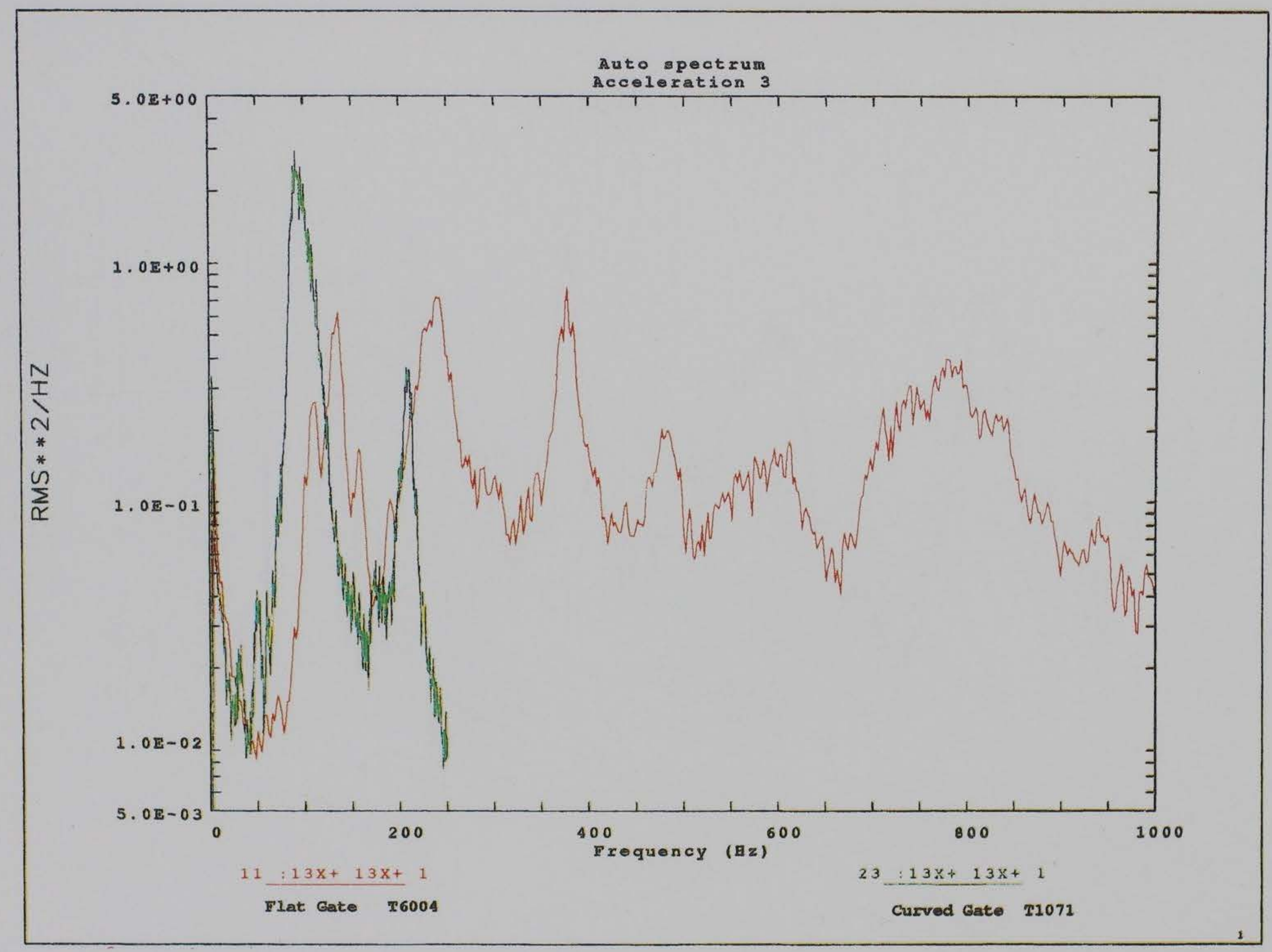

Figure $24 \mathrm{j}$. Acceleration 3 (Sheet 10 of 11) 


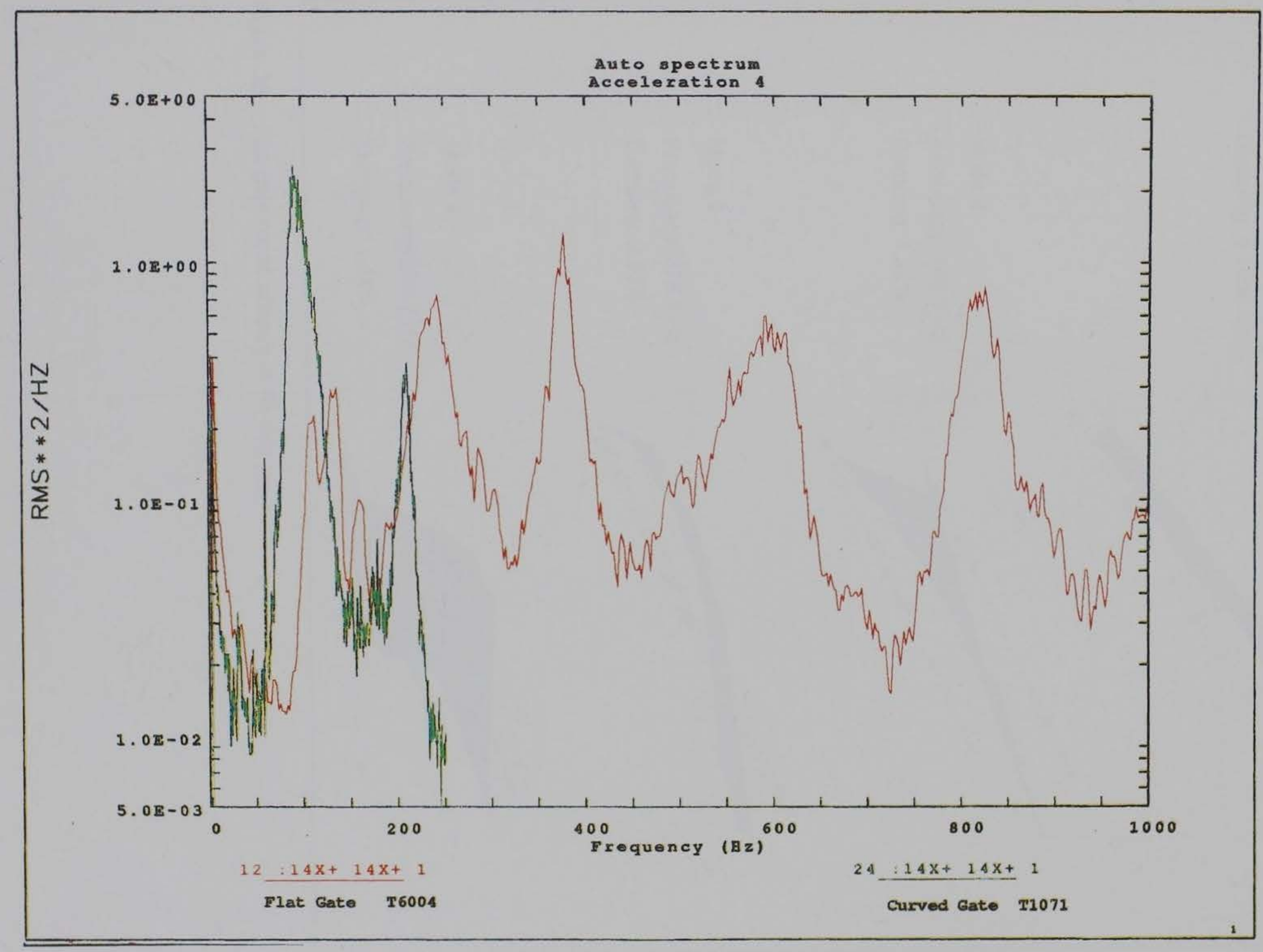

Figure 24k. Acceleration 4 (Sheet 11 of 11) 
Mode 1

Frequency: $179.1 \mathrm{~Hz}$

Damping: $4.19 \%$

Mode 2

Frequency: $242.7 \mathrm{~Hz}$

Damping: $1.26 \%$

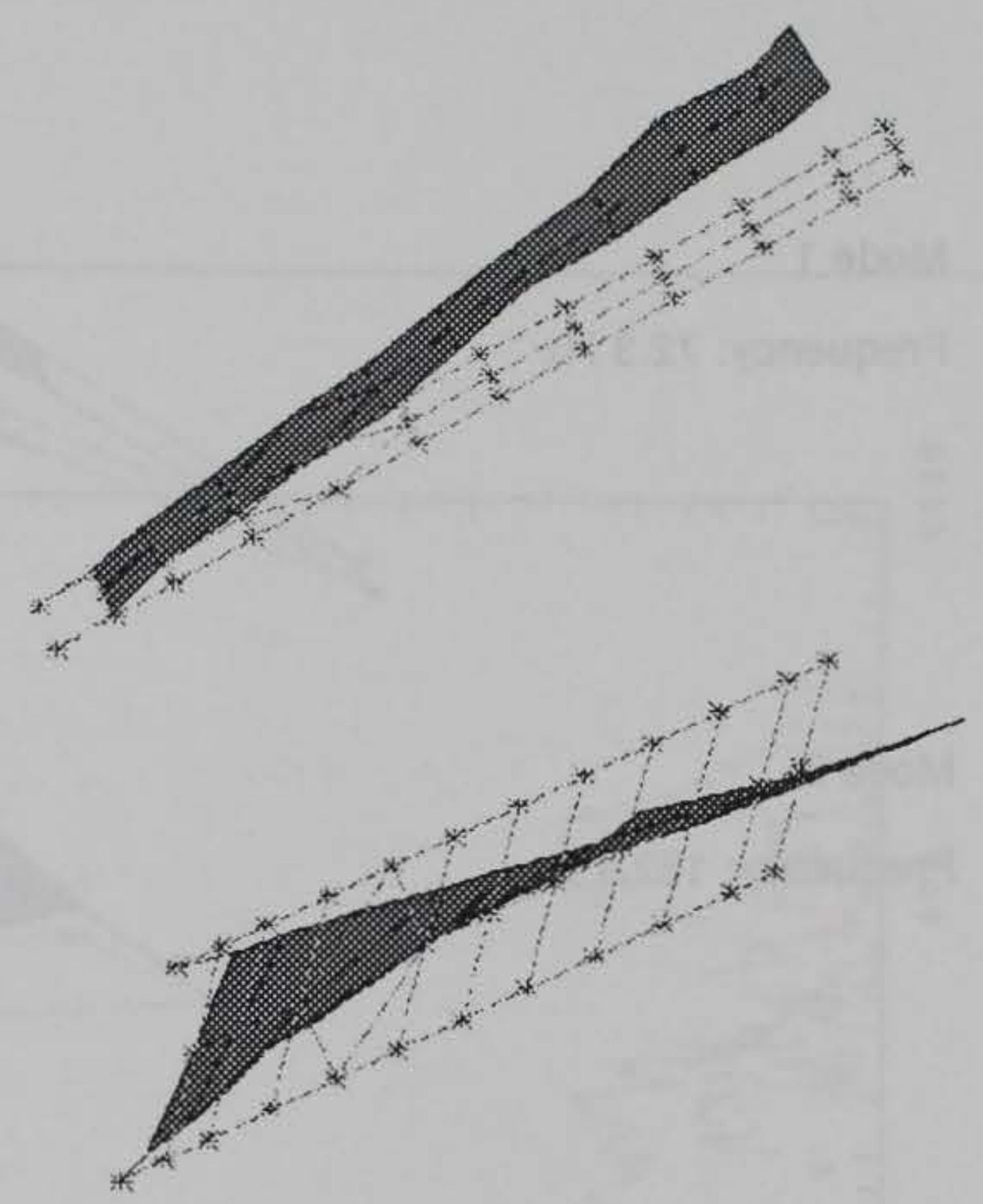

Mode 3

Frequency: $375.1 \mathrm{~Hz}$

Damping: $2.83 \%$

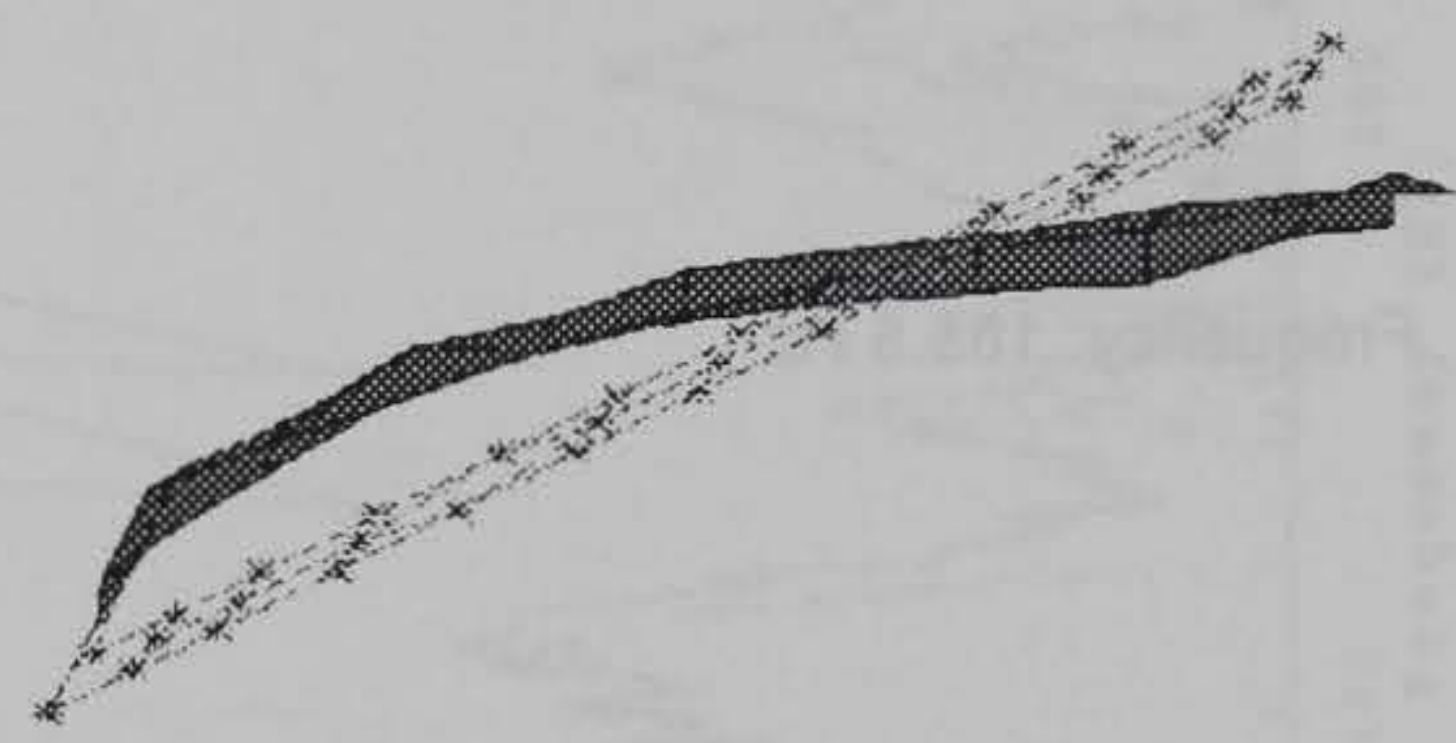

Mode 4

Frequency: $605.7 \mathrm{~Hz}$

Damping: $1.44 \%$

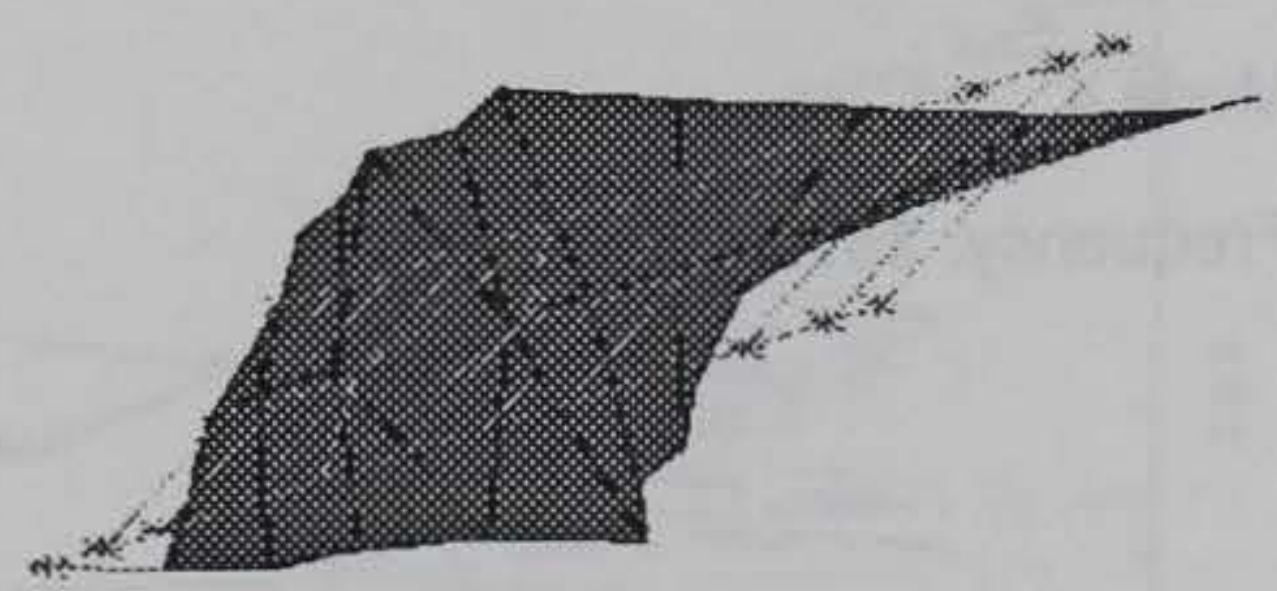

Figure 25. Flat gate mode shapes at 45-deg position 
Mode 1

Frequency: $72.3 \mathrm{~Hz}$

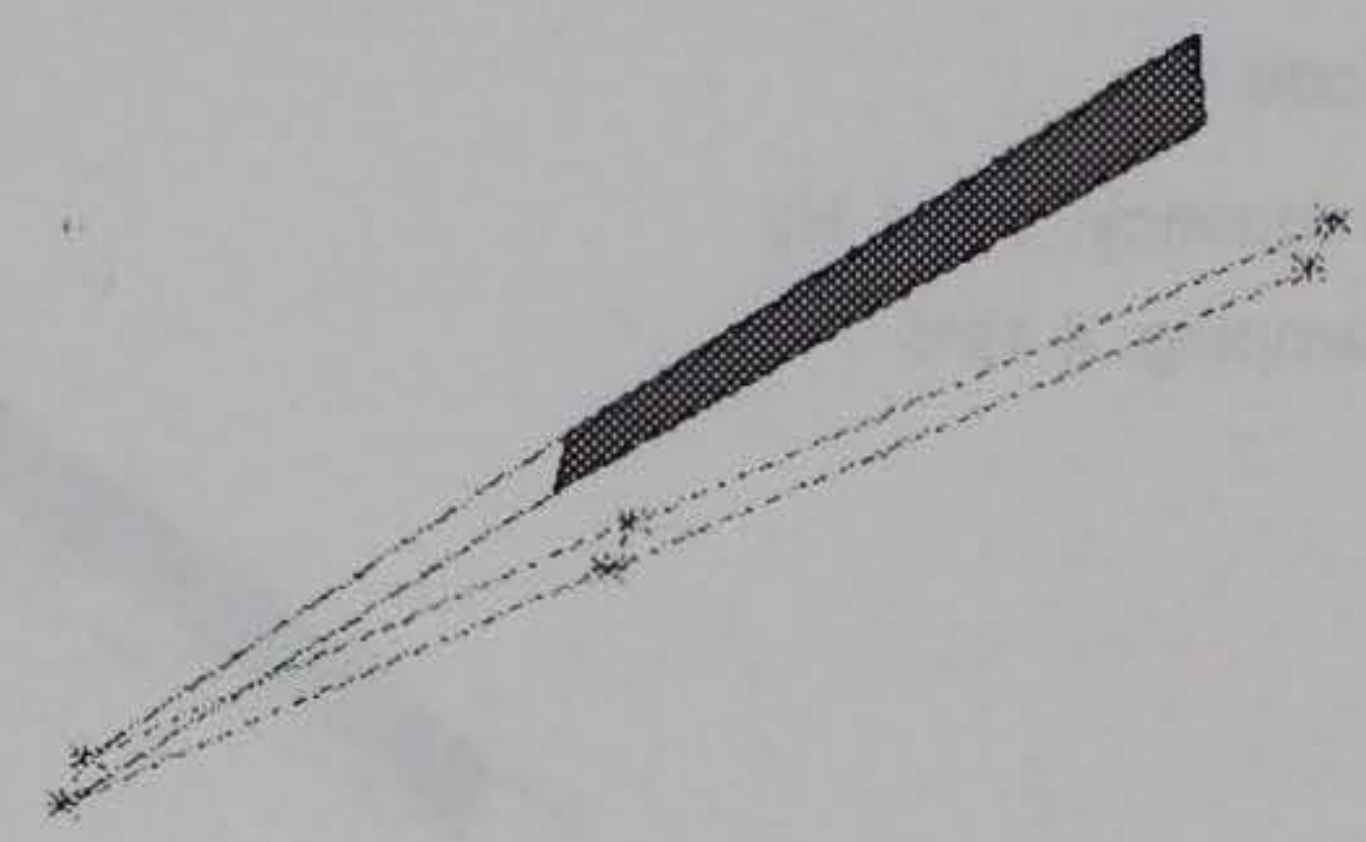

Mode 2

Frequency: $162.1 \mathrm{~Hz}$

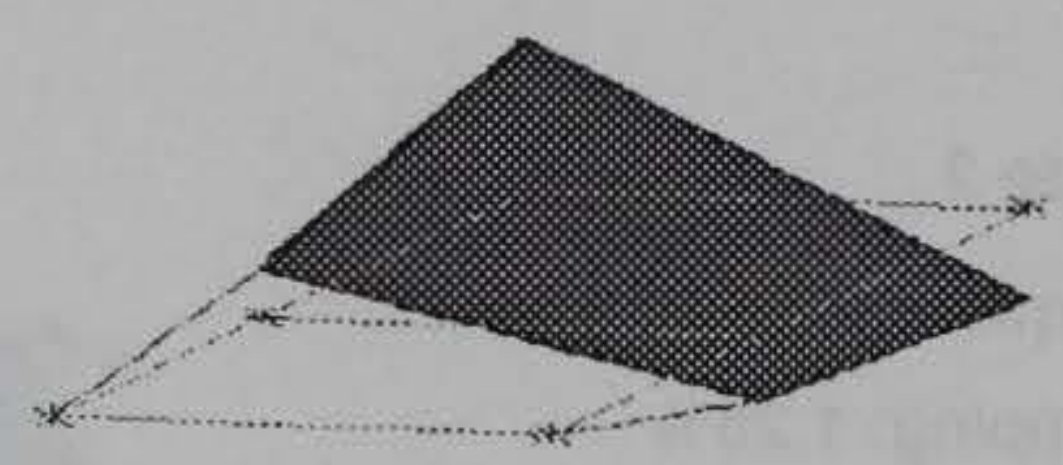

Mode 3

Frequency: $185.5 \mathrm{~Hz}$

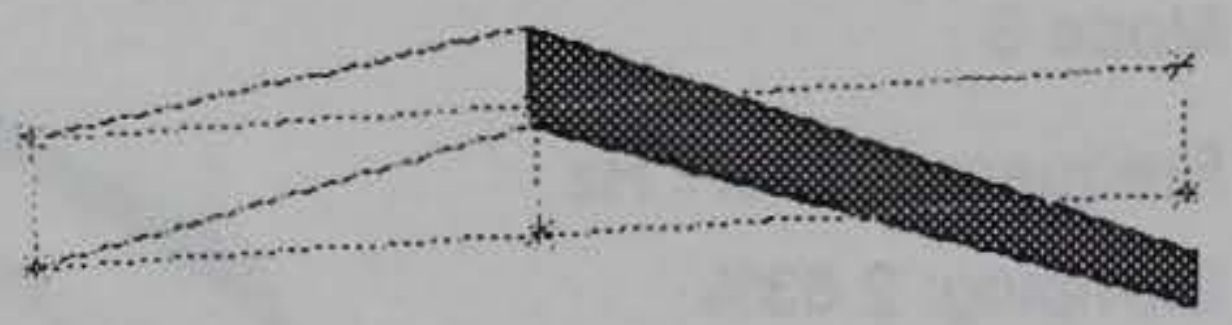

Mode 4

Frequency: $357.4 \mathrm{~Hz}$

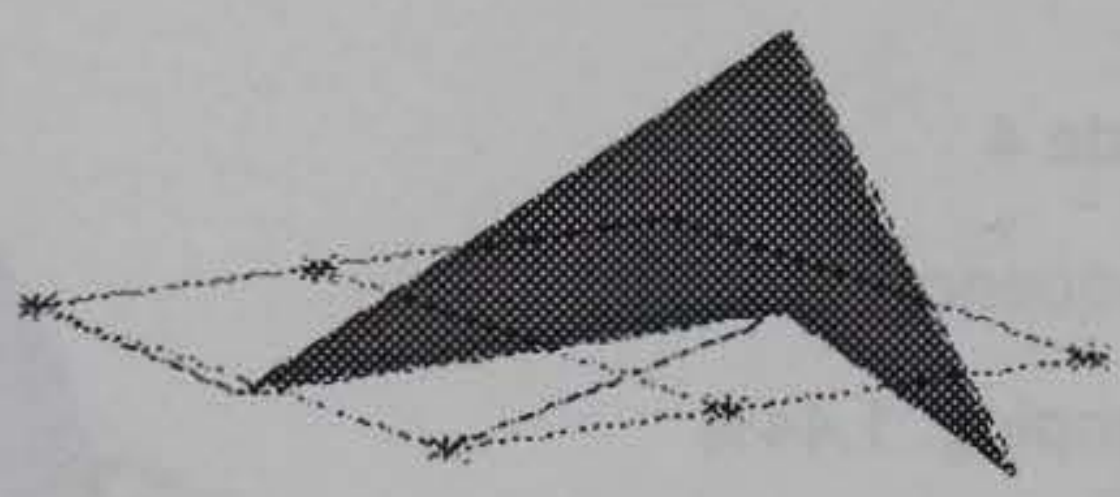

Figure 26. Operating defected shapes (Test \#6020) 


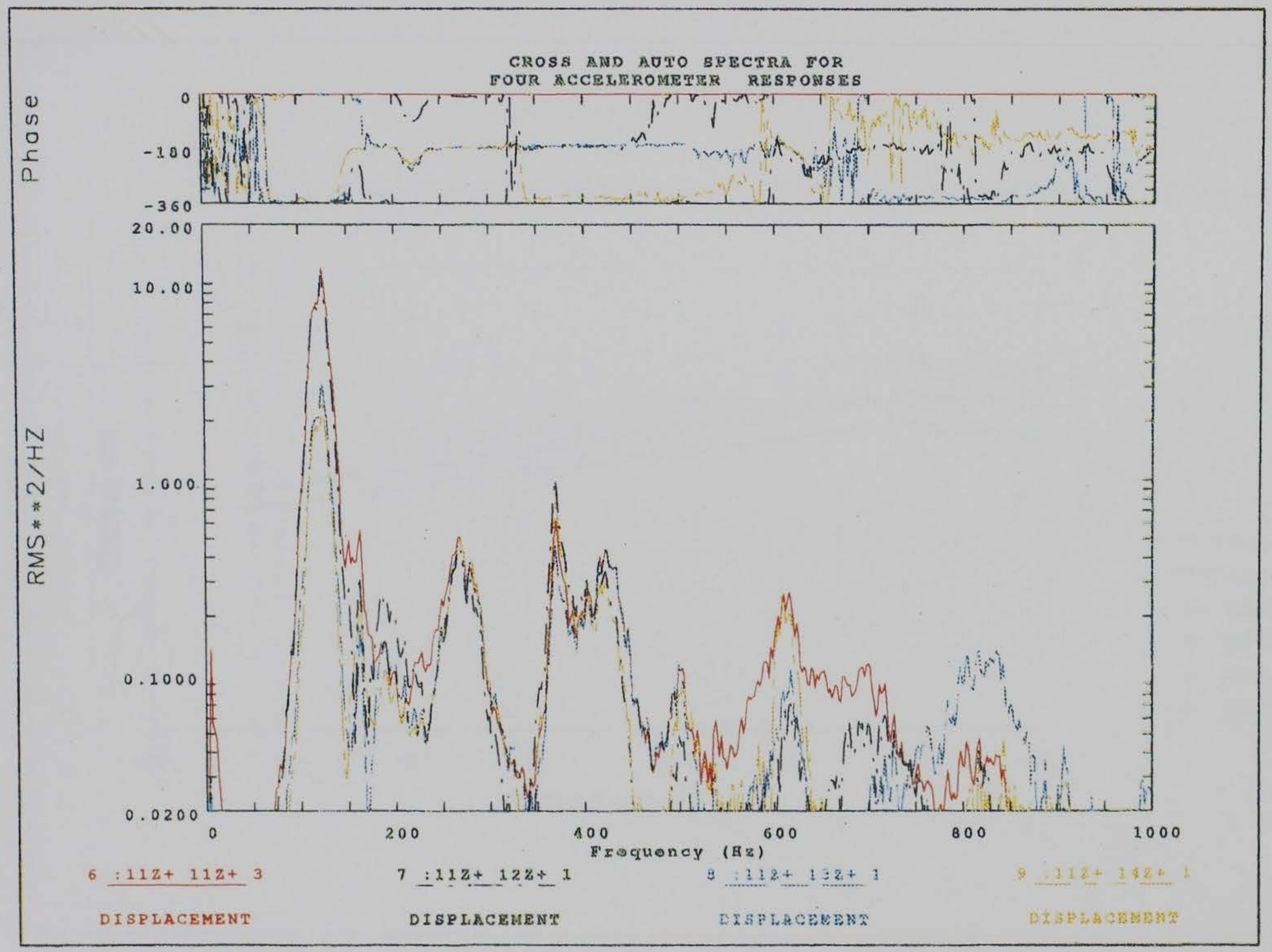

Figure 27. Transmissibility function for four accelerometer responses for the flat gate in Test No. 6020 


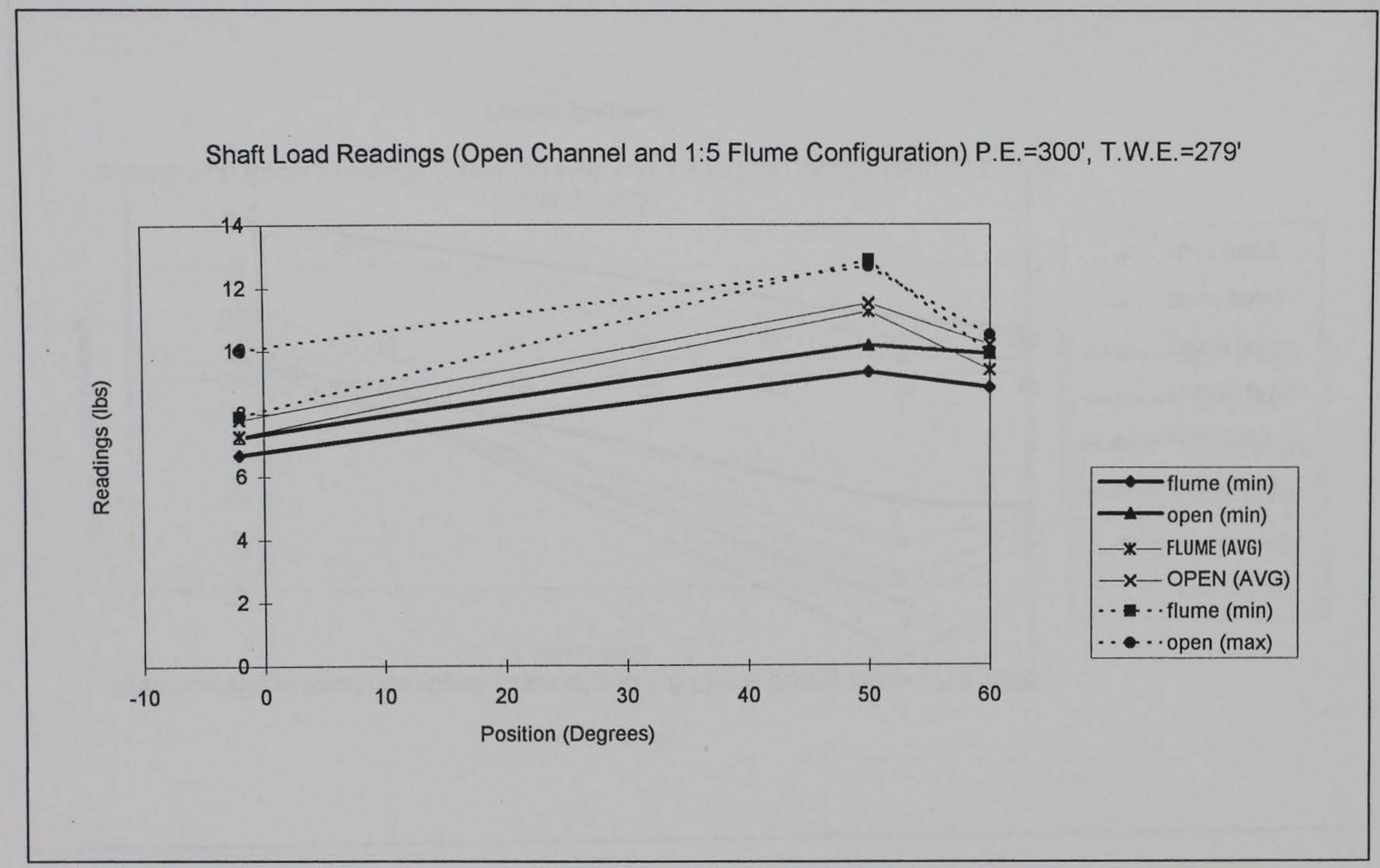

Figure 28. Time-domain data comparison for the open channel and 1:5 flume configuration flow tests for the 1:25 flat gate for test set \#5. a. Shaft load readings (Sheet 1 of 10) 
R/Vertical Hinge Readings (Open Channel and 1:5 Flume Configuration) P.E. $=300$ ',

T.W.E. $=279^{\prime}$

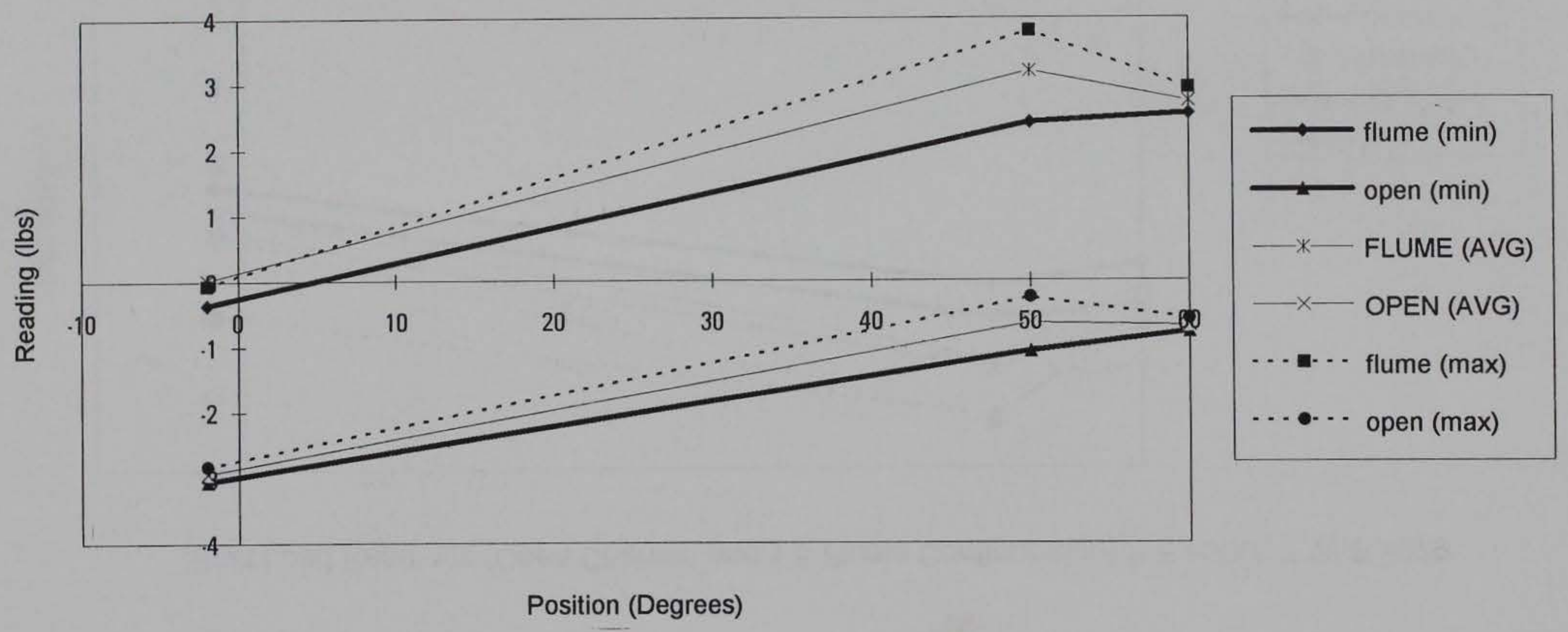

Figure 28b. Right vertical hinge readings (Sheet 2 of 10) 
R/Horizontal Hinge Readings (Open Channel and 1:5 Flume Configuration) P.E. $=300$ ',

T.W.E. $=279^{\prime}$

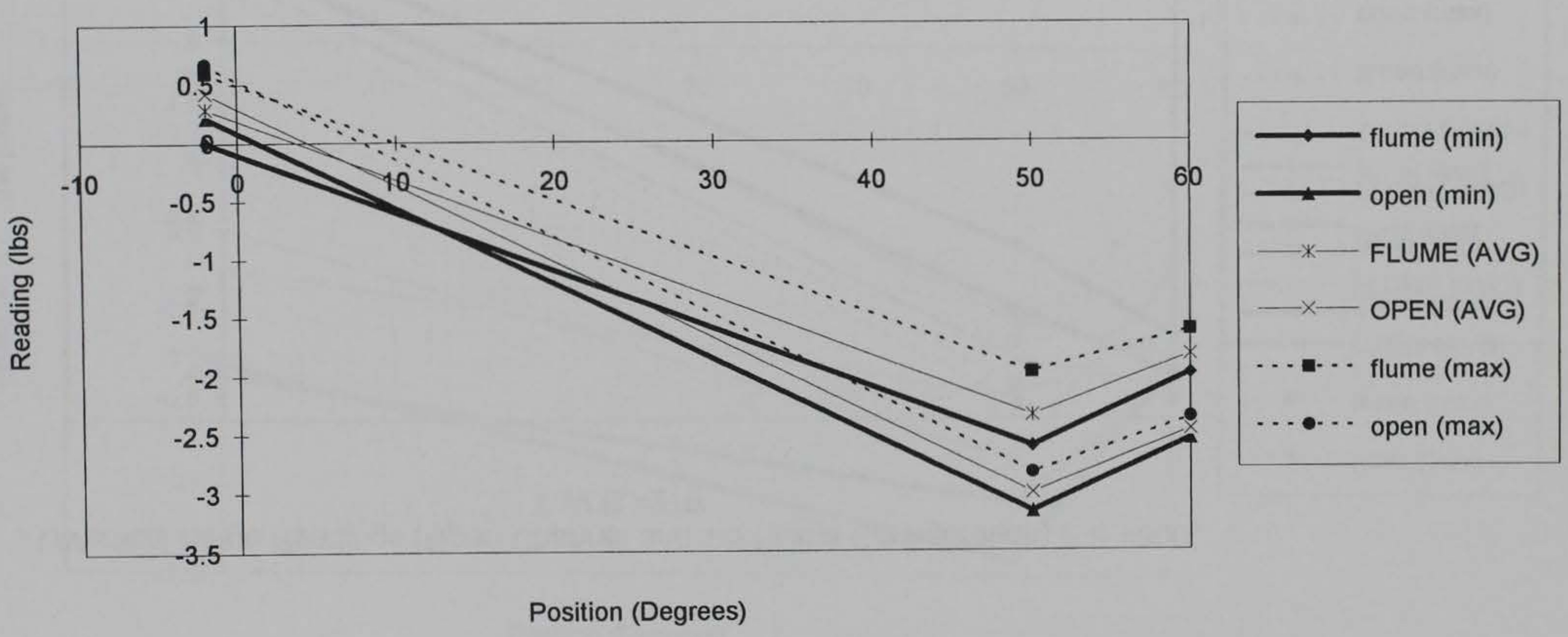

Figure 28c. Right horizontal hinge readings (Sheet 3 of 10) 
L/Nertical Hinge Readings (Open Channel and 1:5 Flume Configuration) P.E. $=300$ ',

T.W.E. $=279$

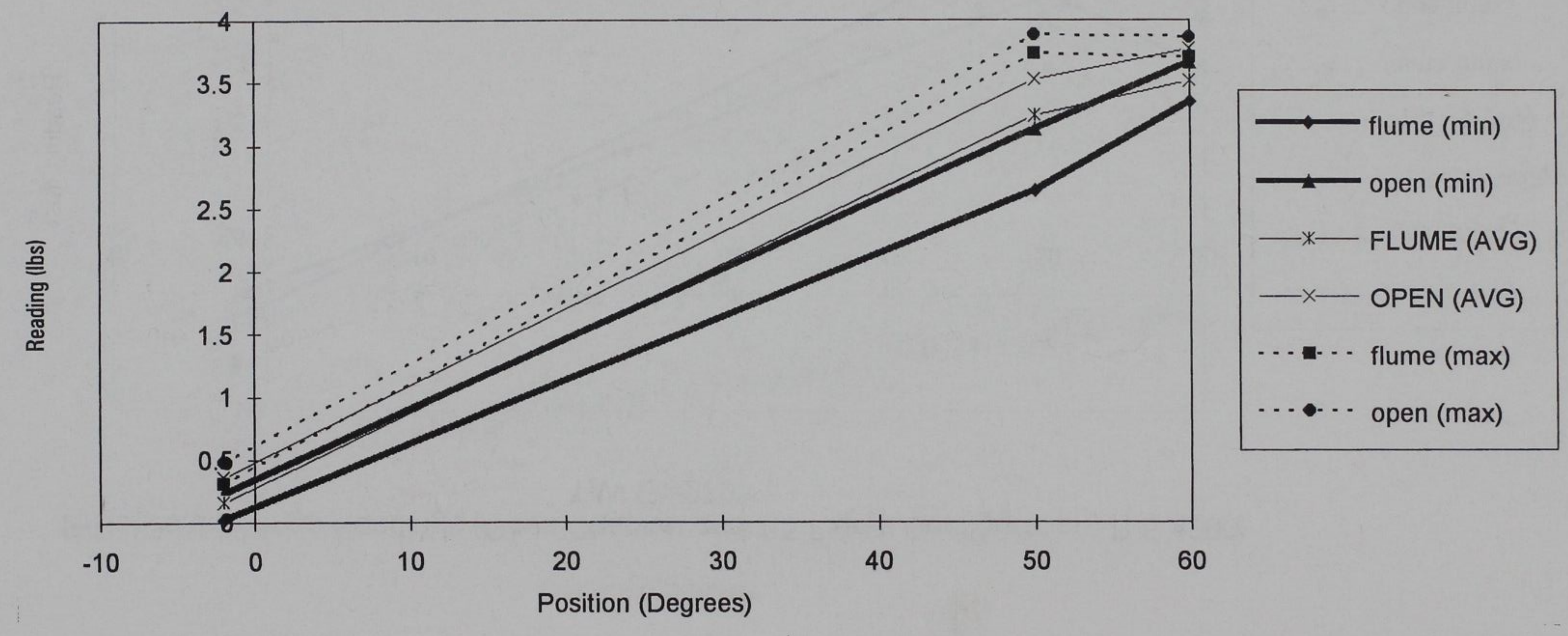

Figure $28 \mathrm{~d}$. Left vertical hinge readings (Sheet 4 of 10) 
L/Horizontal Hinge Readings (Open Channel and 1:5 Flume Configuration) P.E. $=300$ ', T.W.E. $=279$ '

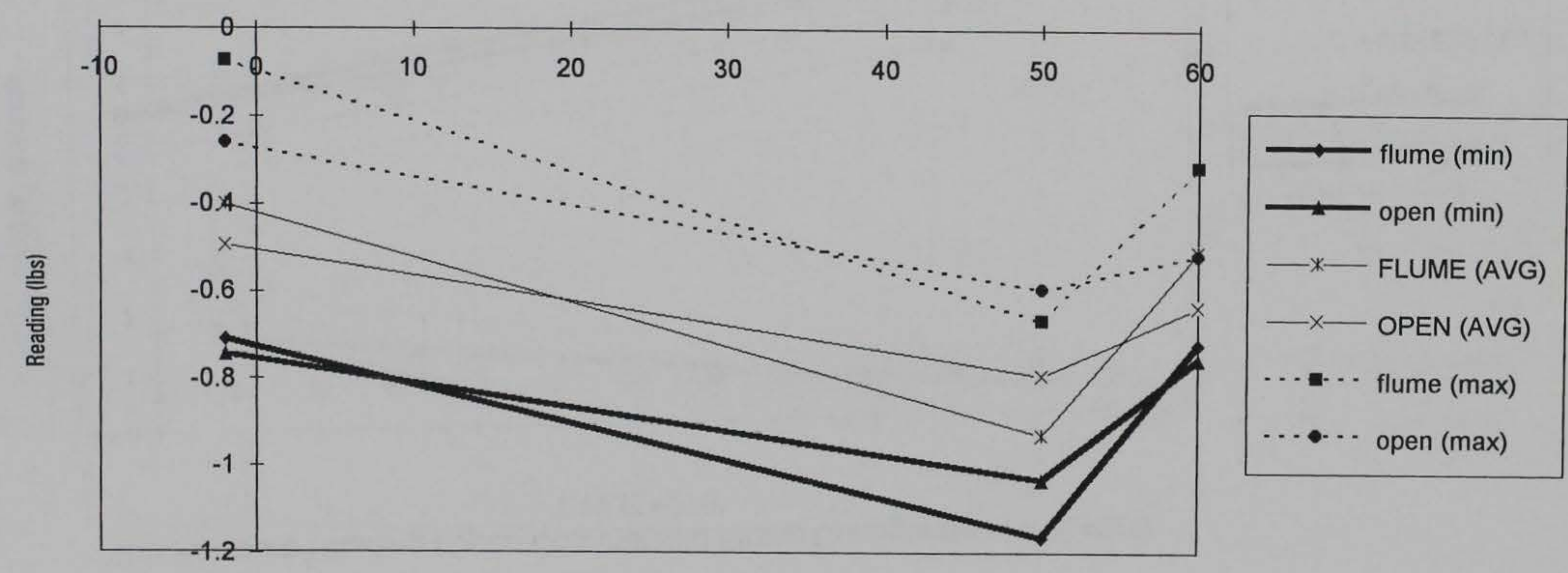

Position (Degrees)

Figure 28e. Left horizontal hinge readings (Sheet 5 of 10) 
U/S Pressure Reading (Open Channel and Flume Configuration) P.E. $=300$ ', T.W.E. $=279^{\prime}$

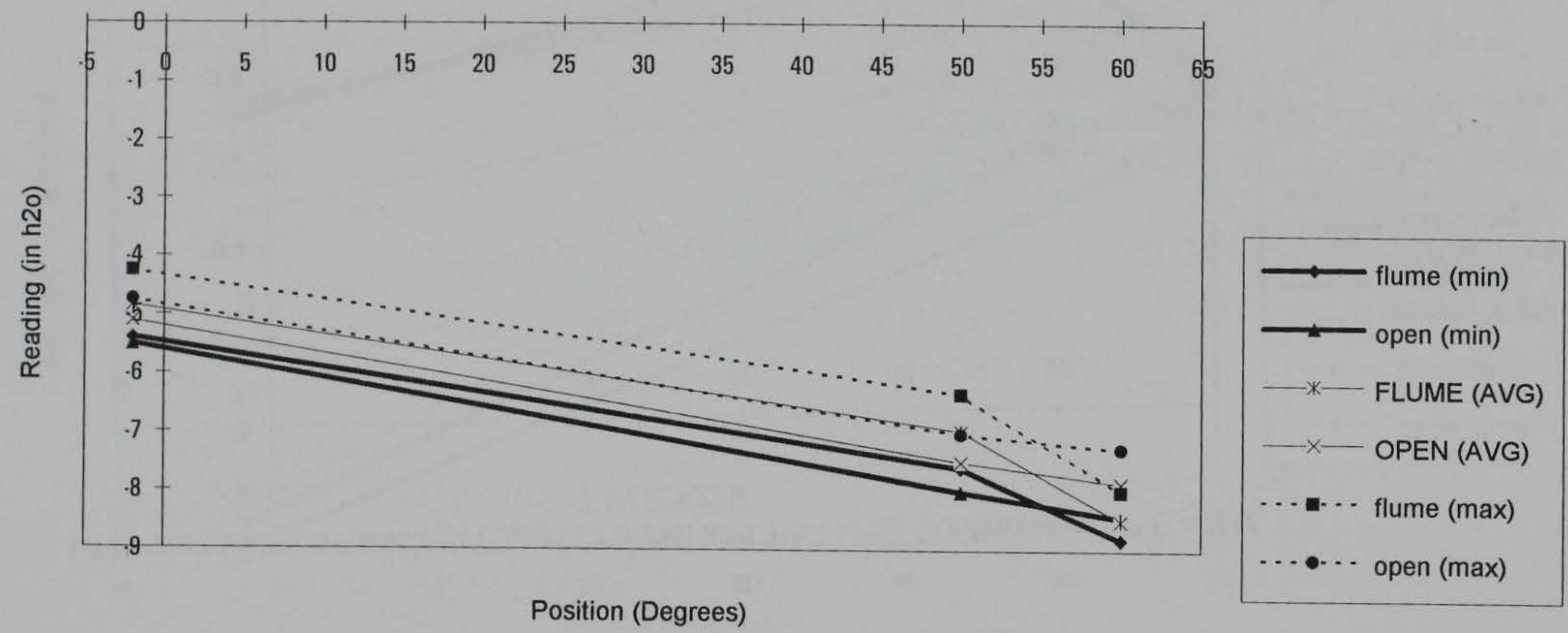

Figure 28f. Upstream pressure readings (Sheet 6 of 10 ) 
D/S Pressure Readings (Open Channel and 1:5 Flume Configuration) P.E. $=300$ ',

T.W.E. $=279^{\prime}$

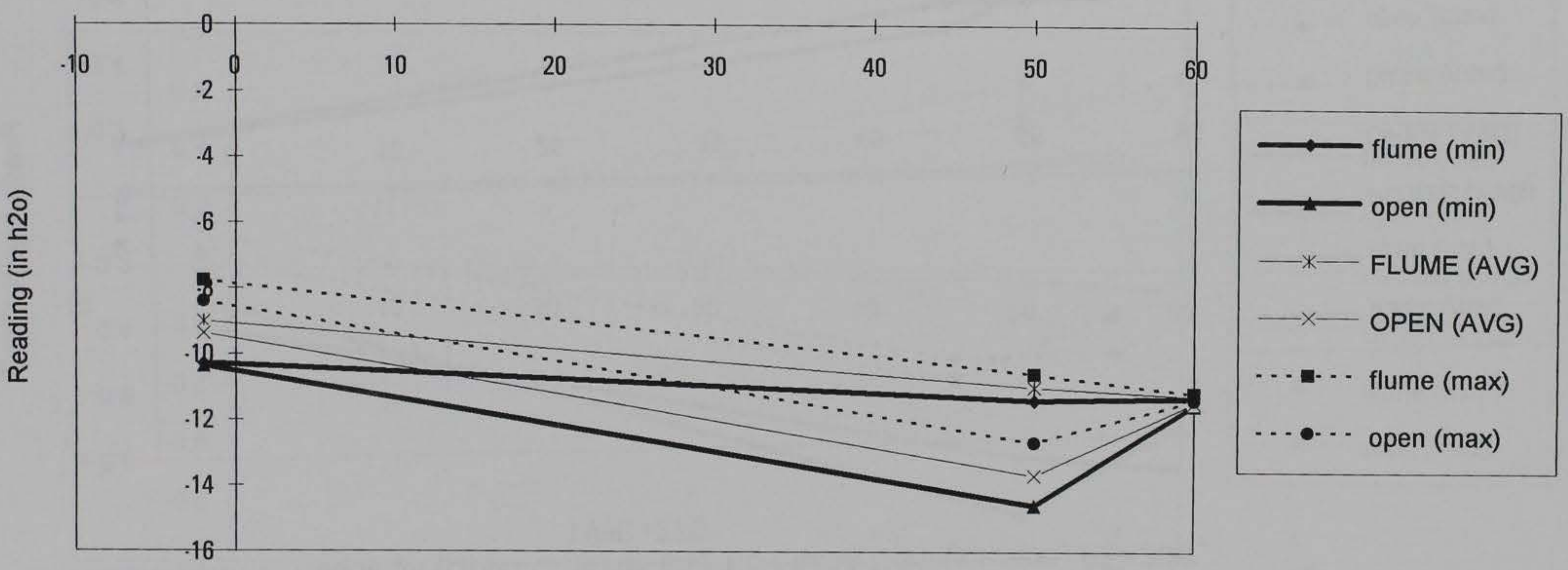

Position (Degrees) 
Acceleration 1 Readings (Open Channel and 1:5 Flume Configuration) PE=300', TWE $=279^{\prime}$

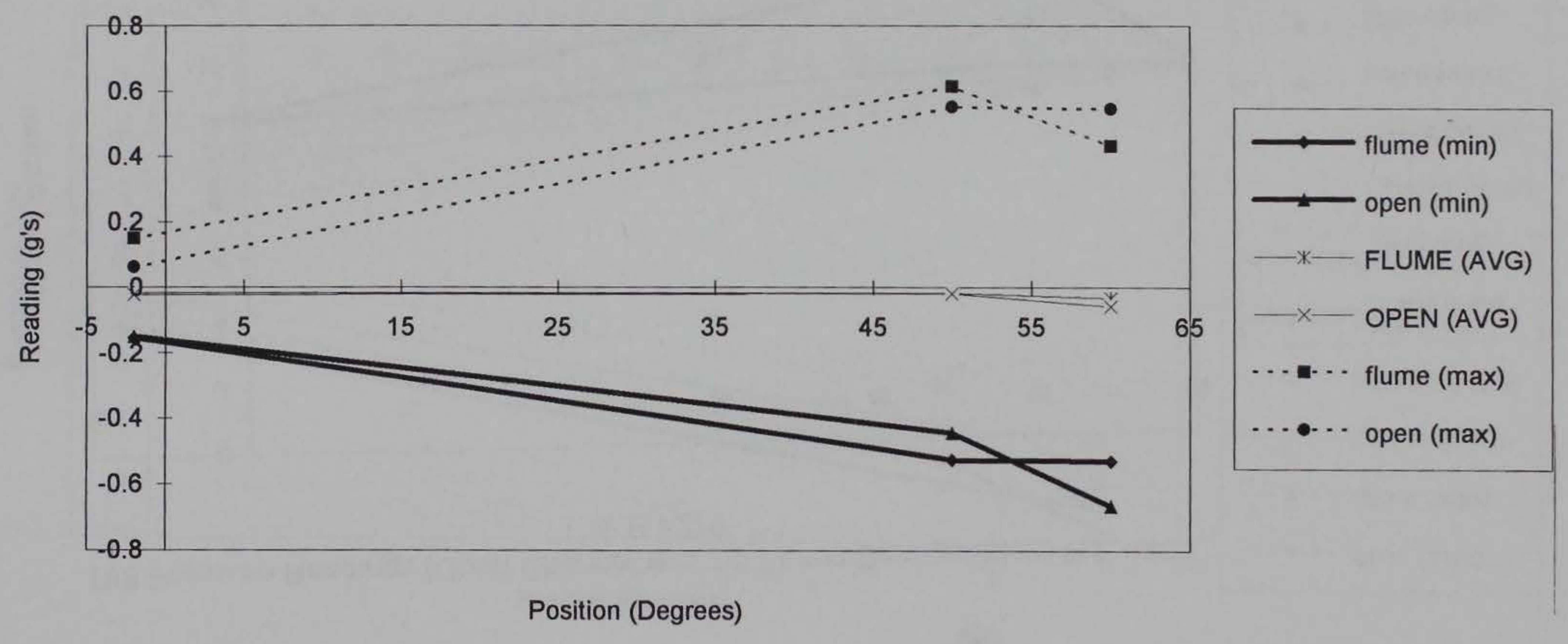

Figure $28 \mathrm{~h}$. Acceleration 1 readings (Sheet 8 of 10) 
Acceleration 2 Readings (Open Channel and 1:5 Flume Configuration) P.E. $=300$ ',

T.W.E. $=279^{\prime}$

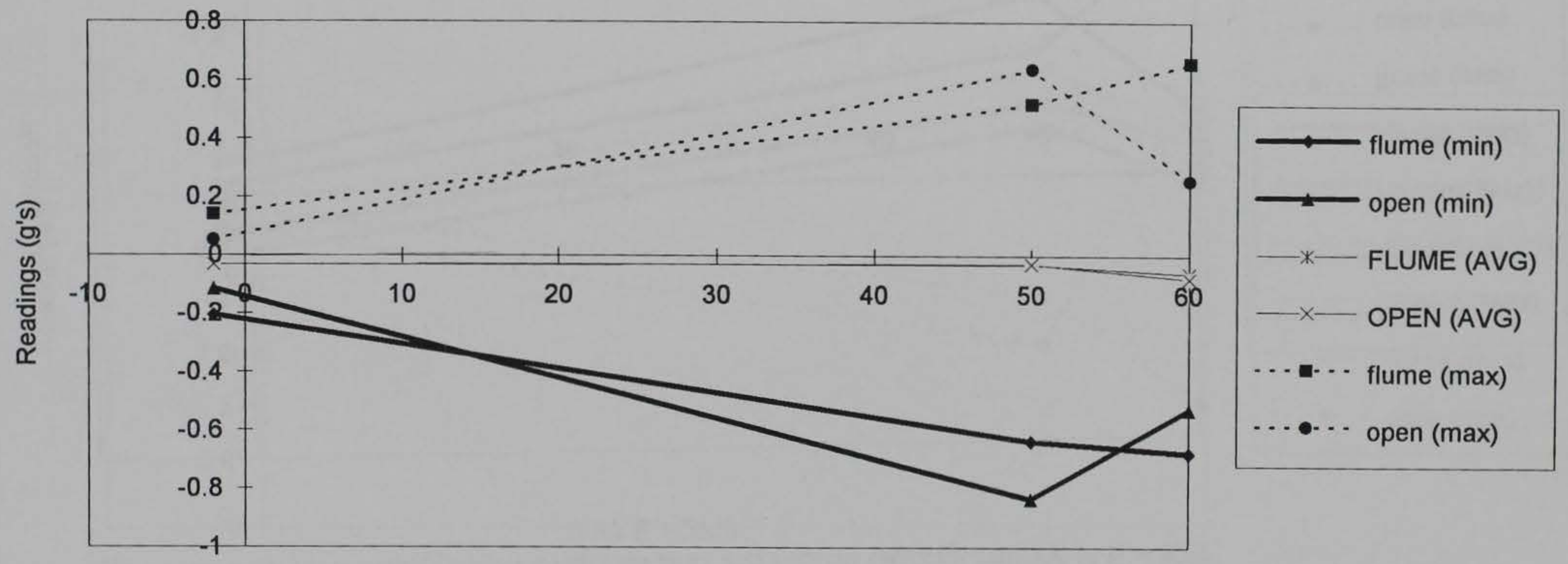

Position (Degrees) 
Acceleration 3 Readings (Open Channel and 1:5 Flume Configuration) P.E. $=300$ ',

T.W.E. $=279^{\prime}$

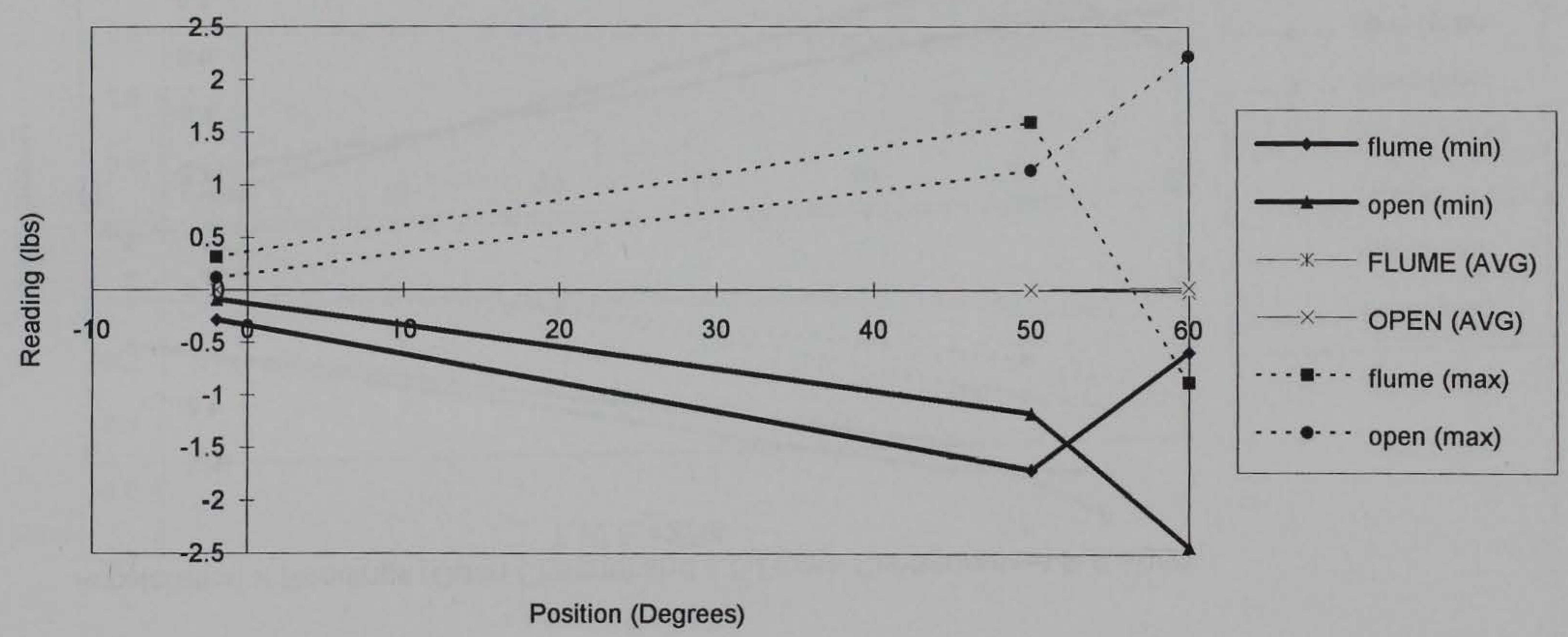

Figure 28j. Acceleration 3 readings (Sheet 10 of 10) 
Shaft Load Readings (Open Channel and 1:5 Flume Configuration) P.E.=299',

T.W.E. $=276.5^{\prime}$

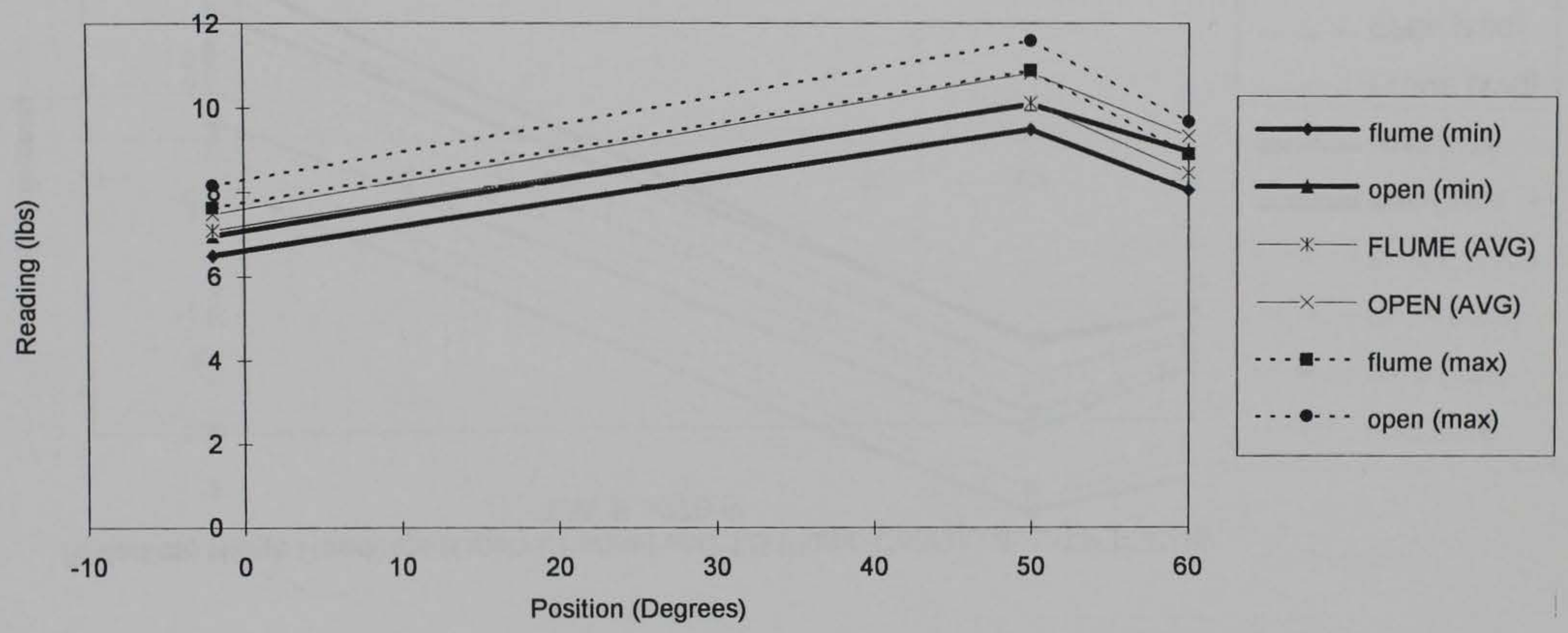

Figure 29. Time-domain data comparison for the open channel and 1:5 flume configuration flow tests for the 1:25 flat gate for test set \#6. a. Shaft load readings (Sheet 1 of 10 ) 
R/Nertical Hinge Readings (Open Channel and 1:5 Flume Configuration) P.E.=299',

T.W.E. $=276.5^{\prime}$
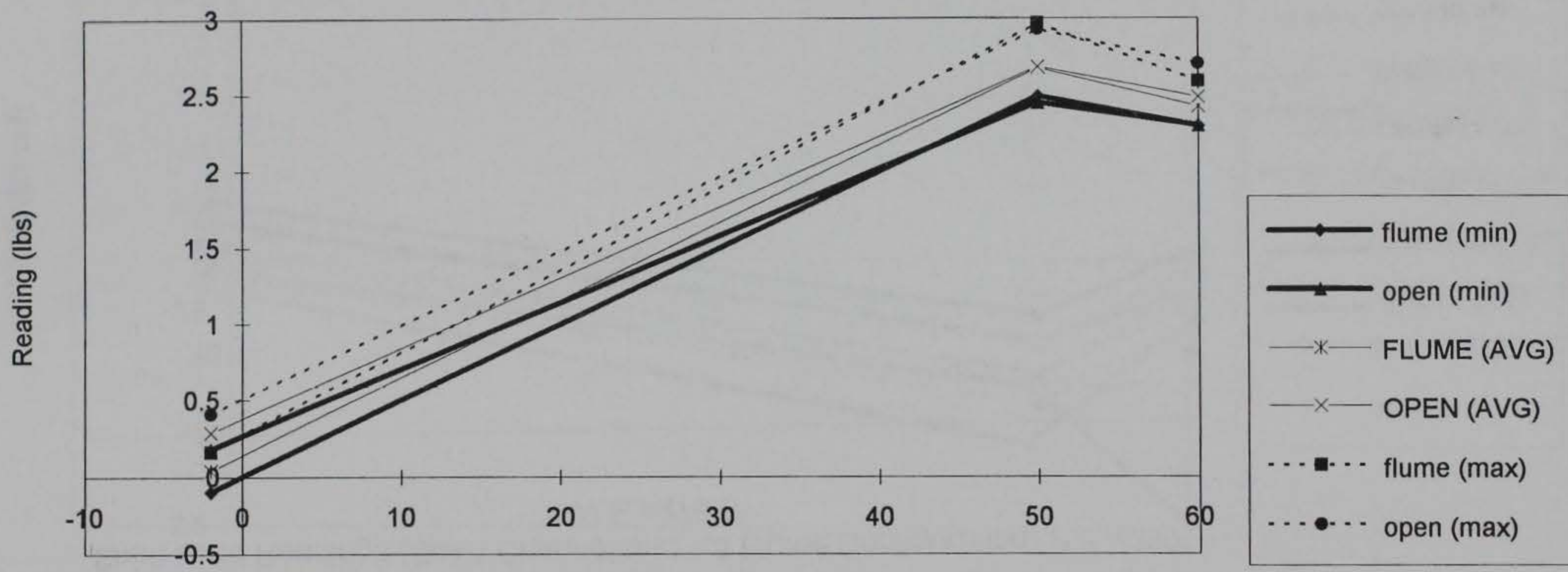

Position (Degrees)

Figure 29b. Right vertical hinge readings (Sheet 2 of 10) 
R/Horizontal Hinge Readings (Open Channel and 1:5 Flume Configuration) P.E. $=299$ ', T.W.E. $=276.5^{\prime}$

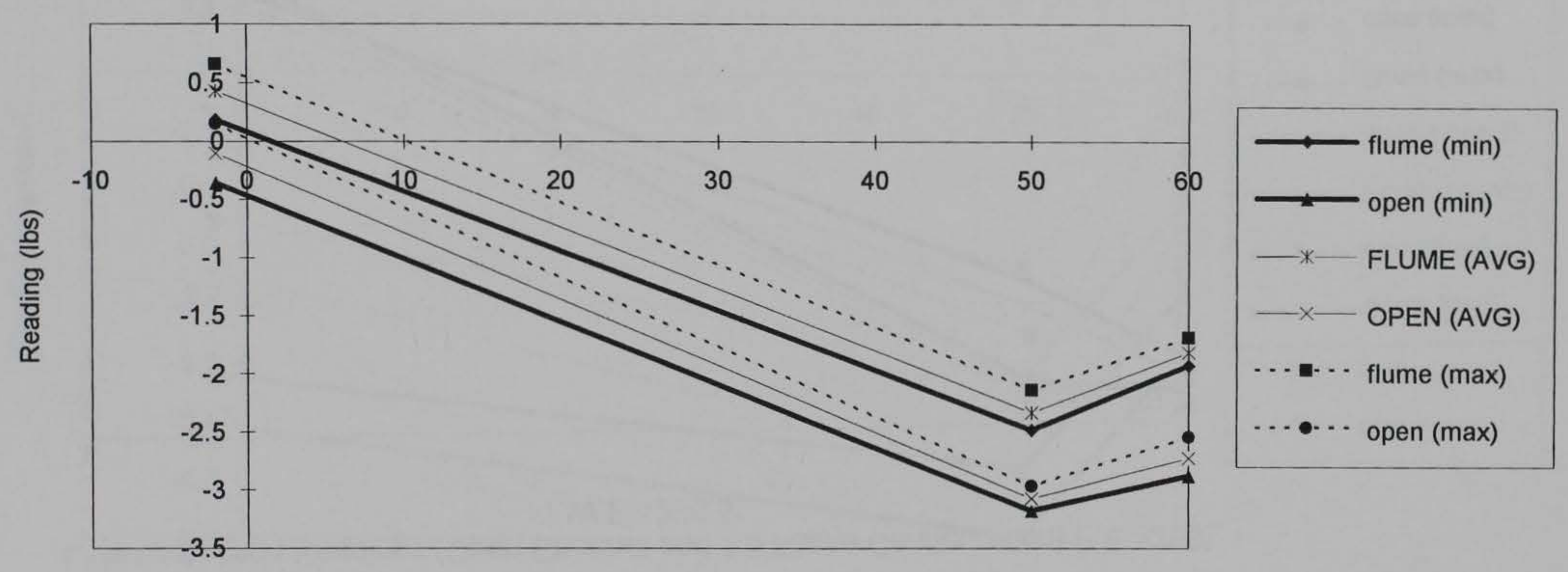

Position (Degrees) 
L/Nertical Hinge Readings (Open Channel and 1:5 Flume Configuration) P.E.=299',

T.W.E. $=276 \cdot 5^{\prime}$

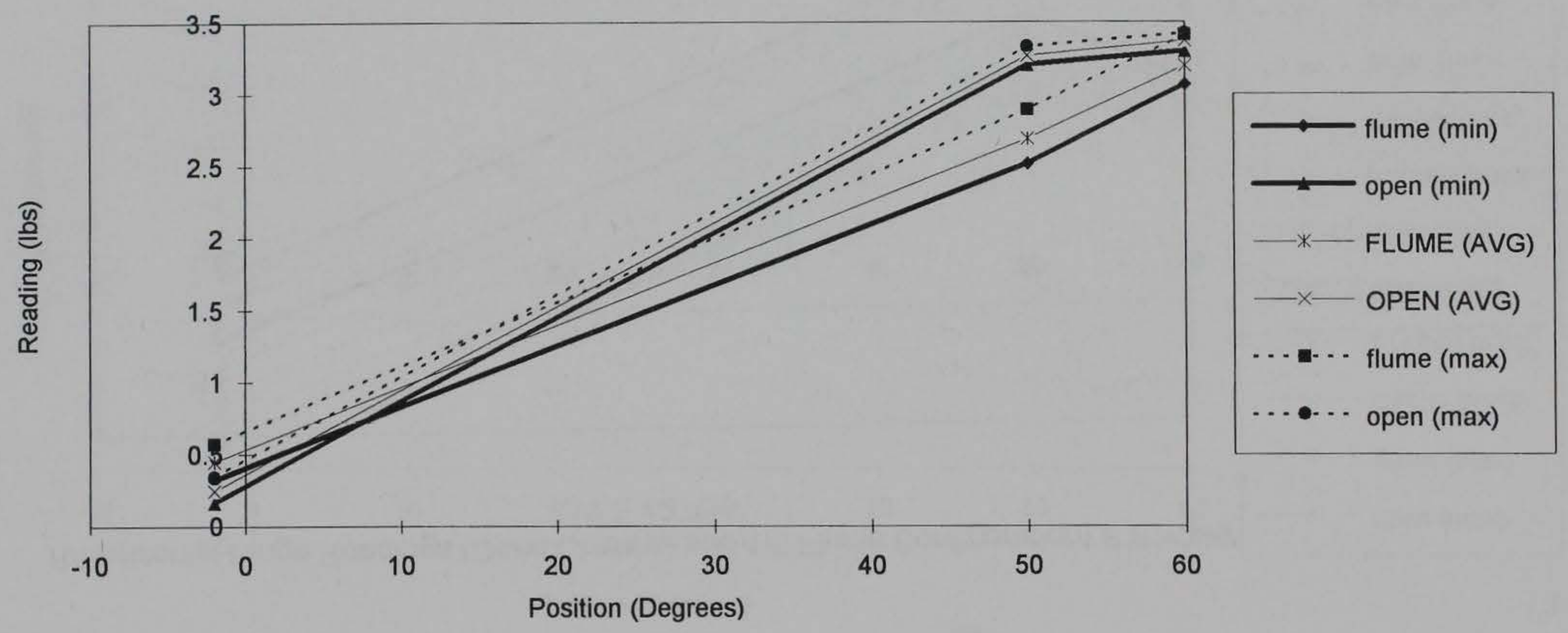

Figure 29d. Left vertical hinge readings (Sheet 4 of 10) 
L/Horizontal Hinge Readings (Open Channel and 1:5 Flume Configuration) P.E.=299', T.W.E. $=276.5^{\prime}$

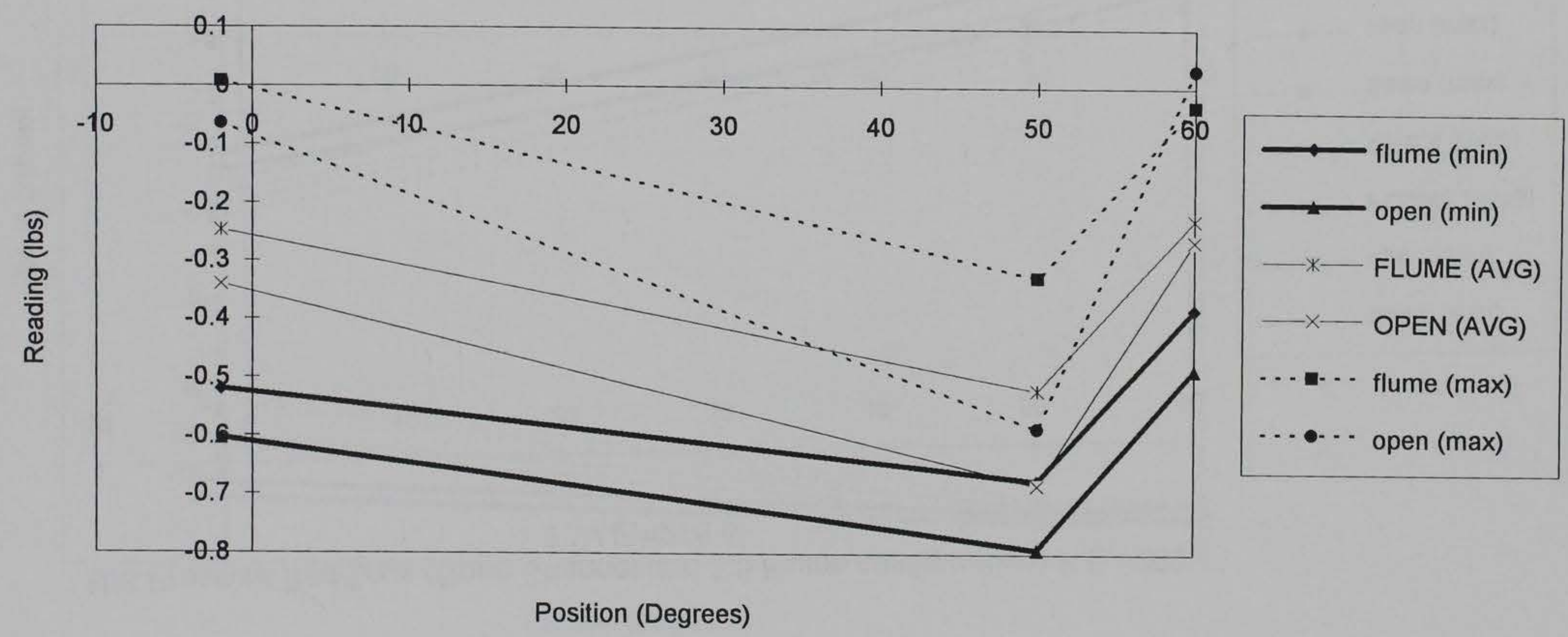


U/S Pressure Readings (Open Channel and 1:5 Flume configuration) P.E. $=299$ ', T.W.E. $=276.5^{\prime}$

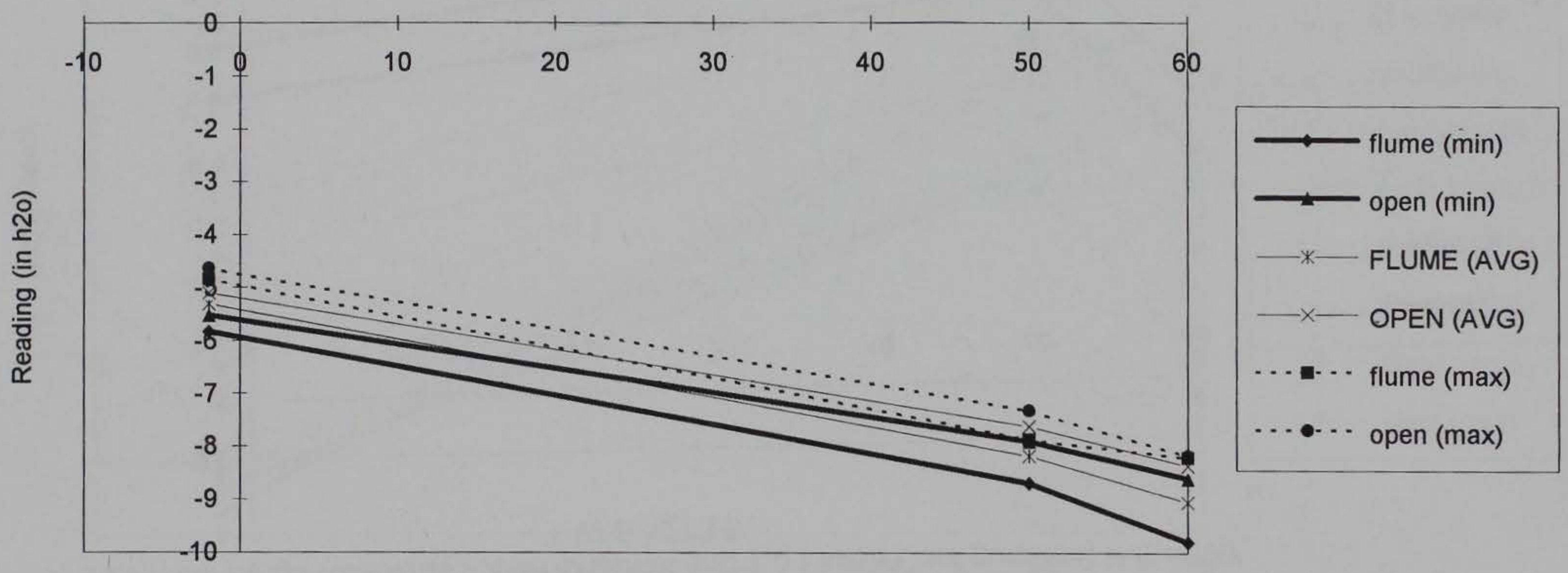

Postion (Degrees) 
D/S Pressure Readings (Open Channel and 1:5 Flume Configuration) P.E. $=299$ ',

T.W.E. $=276.5^{\prime}$

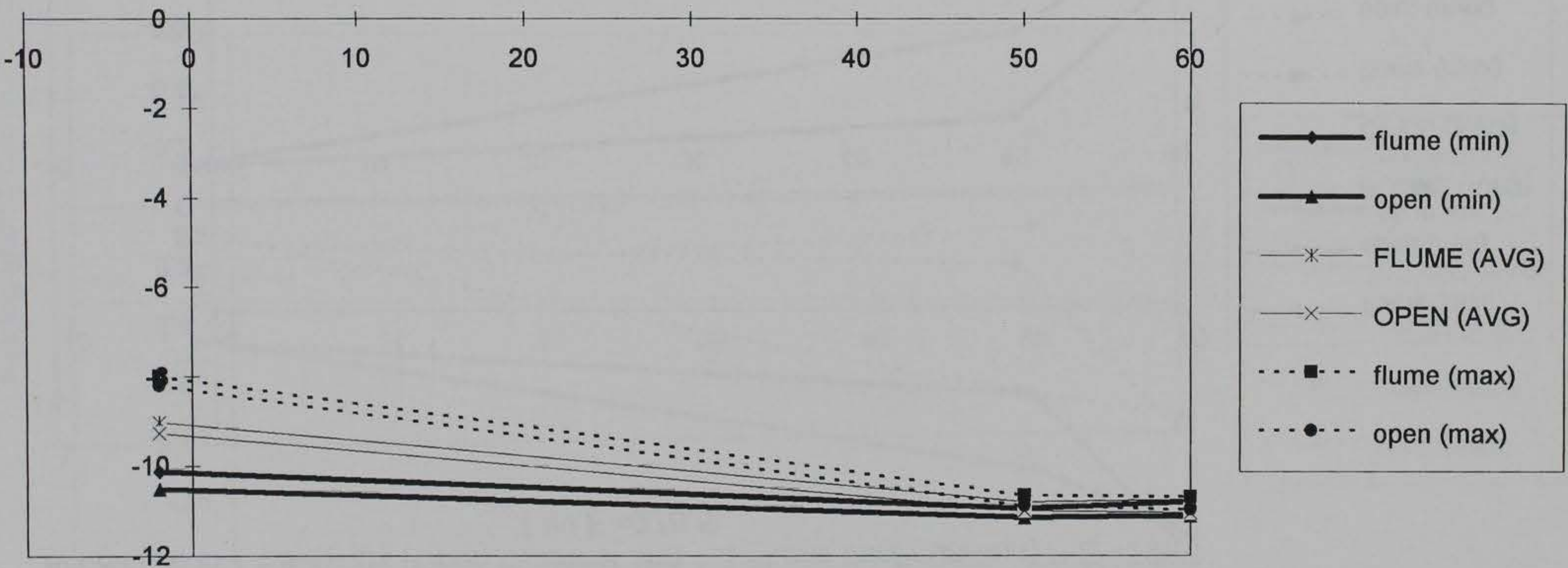

Position (Degrees) 
Acceleration 1 Readings (Open Channel and 1:5 Flume configuration) P.E.=299',

T.W.E. $=276.5^{\prime}$

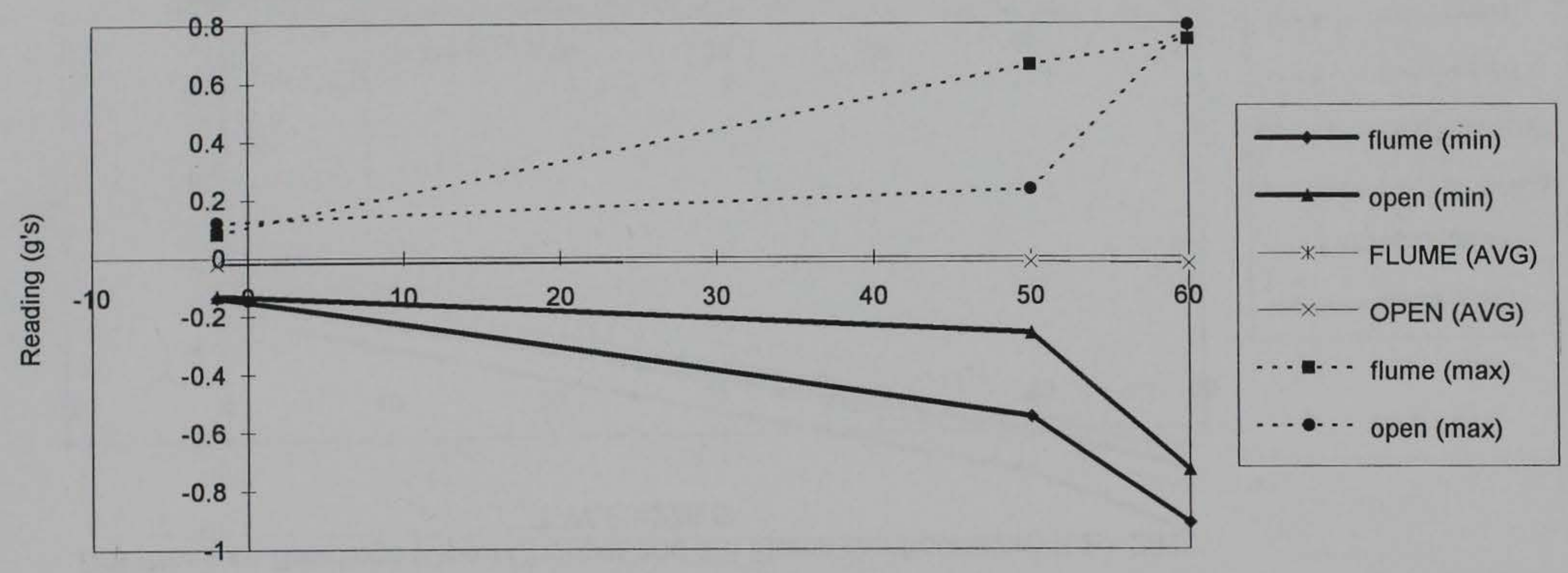

Position (Degrees)

Figure 29h. Acceleration 1 readings (Sheet 8 of 10) 
Acceleration 2 Readings (Open Channel and 1:5 Flume Configuration) P.E.=299',

T.W.E. $=276.5^{\prime}$

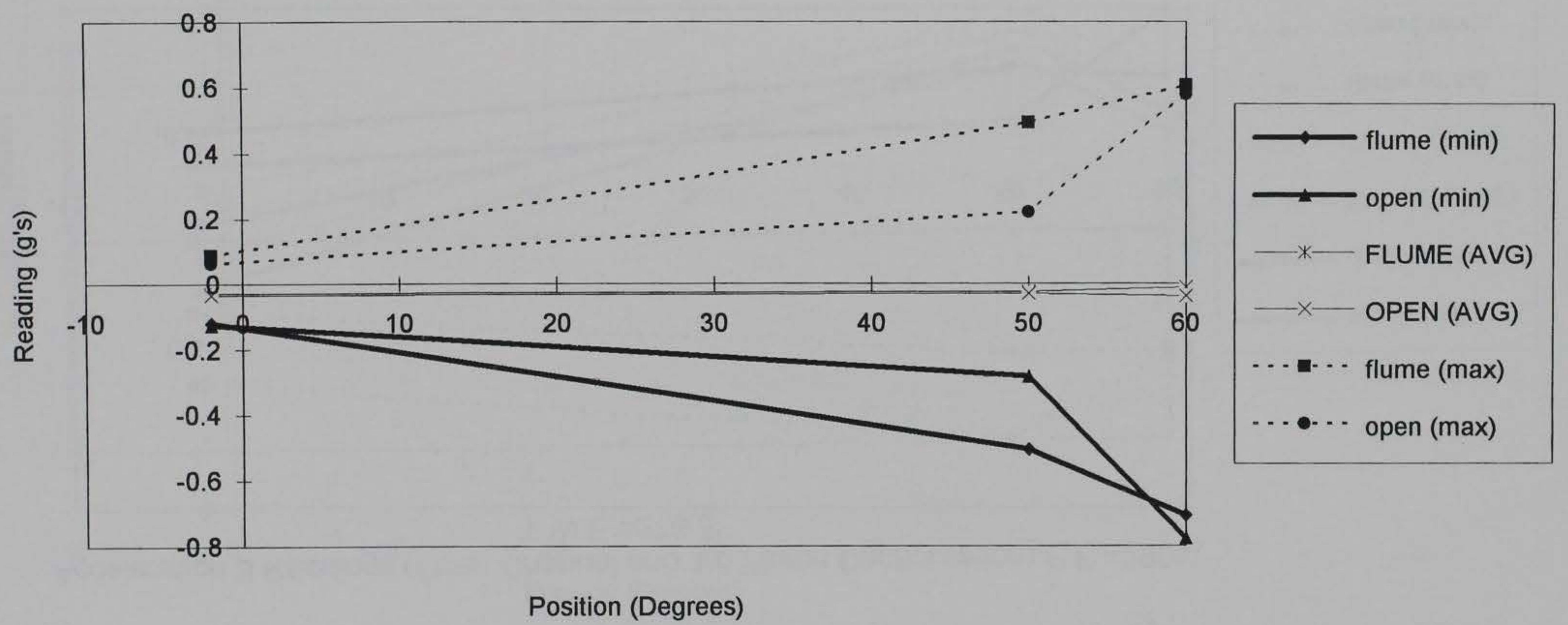

Figure 29i. Acceleration 2 readings (Sheet 9 of 10) 
Acceleration 3 Readings (Open Channel and 1:5 Flume Configuration) P.E.=299',

T.W.E. $=276.5^{\prime}$

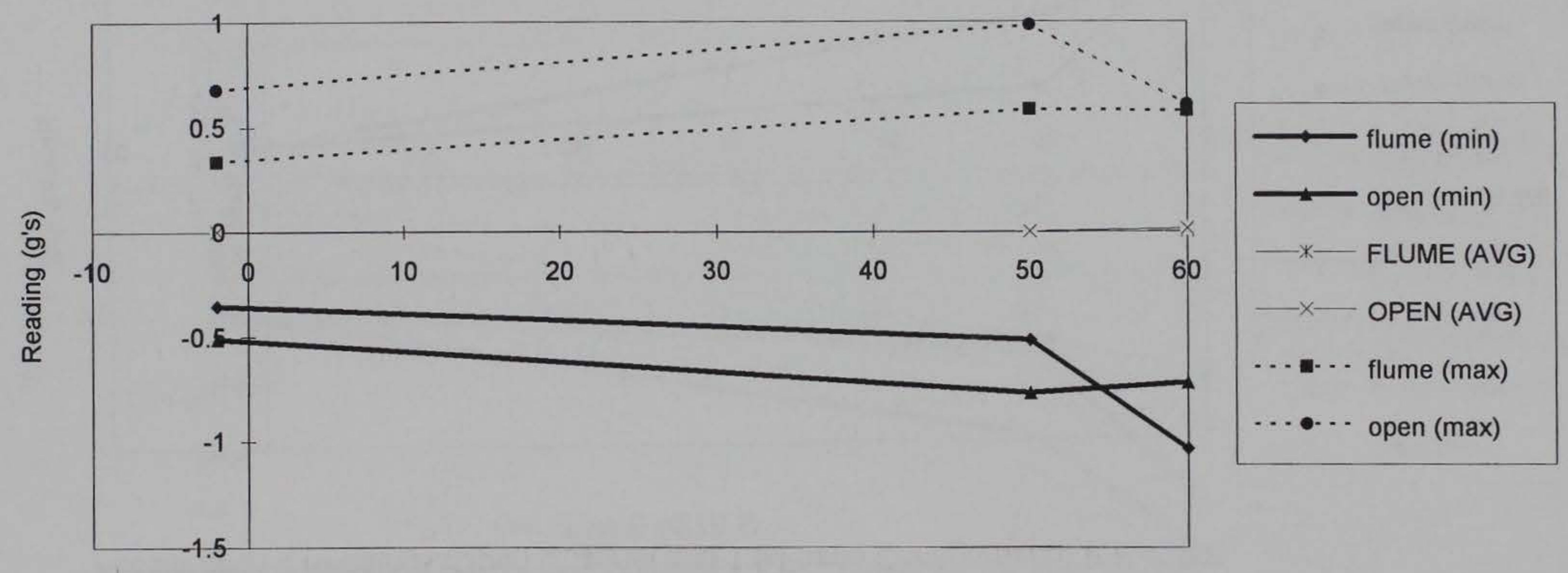

Position (Degrees)

Figure 29j. Acceleration 3 readings (Sheet 10 of 10) 
Shaft Load Readings (Open Channel and 1:5Flume Configuration) P.E. $=296.5^{\prime}$,

T.W.E. $=285.5^{\prime}$

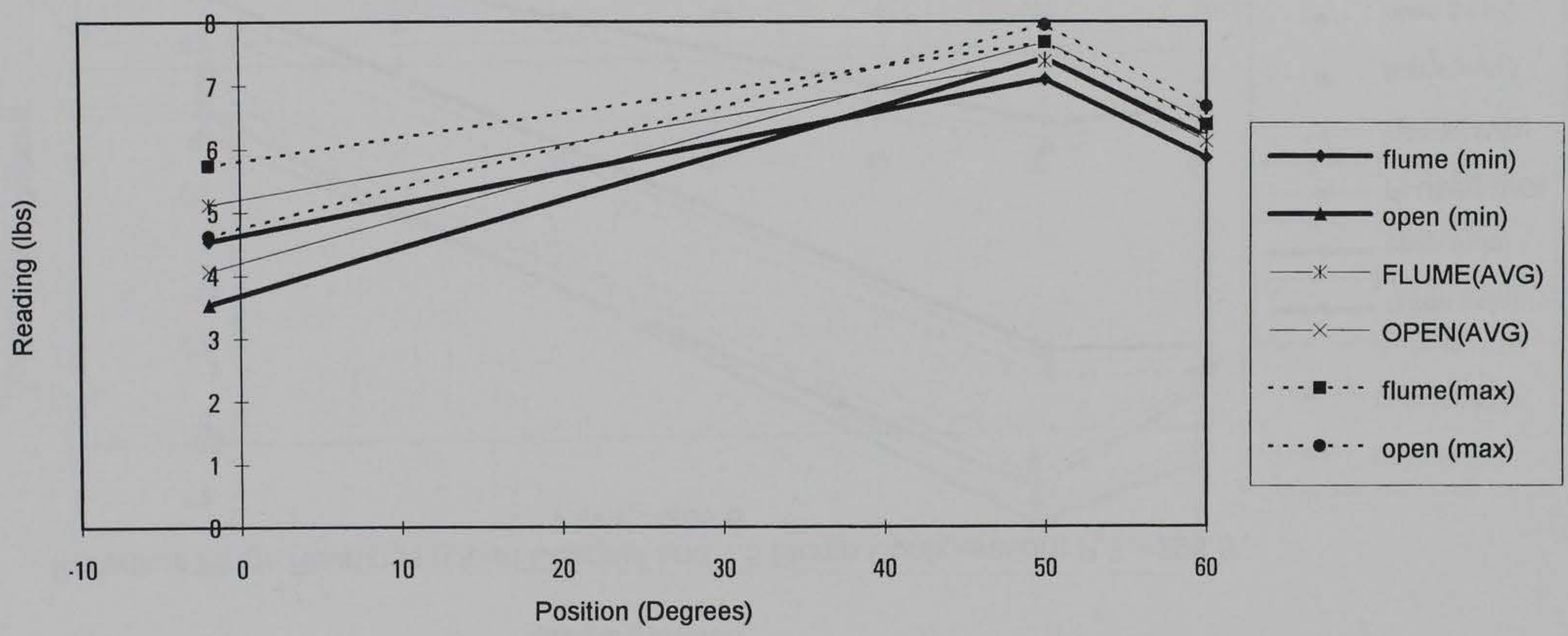

Figure 30. Time-domain data comparison for the open channel and 1:5 flume configuration flow tests for the 1:25 flat gate for test set \#7. a. Shaft load readings (Sheet 1 of 10) 
R/Nertical Hinge Readings (Open Channel and 1:5 Flume Configuration) P.E. $=296.5^{\prime}$,

T.W.E. $=285.5^{\prime}$

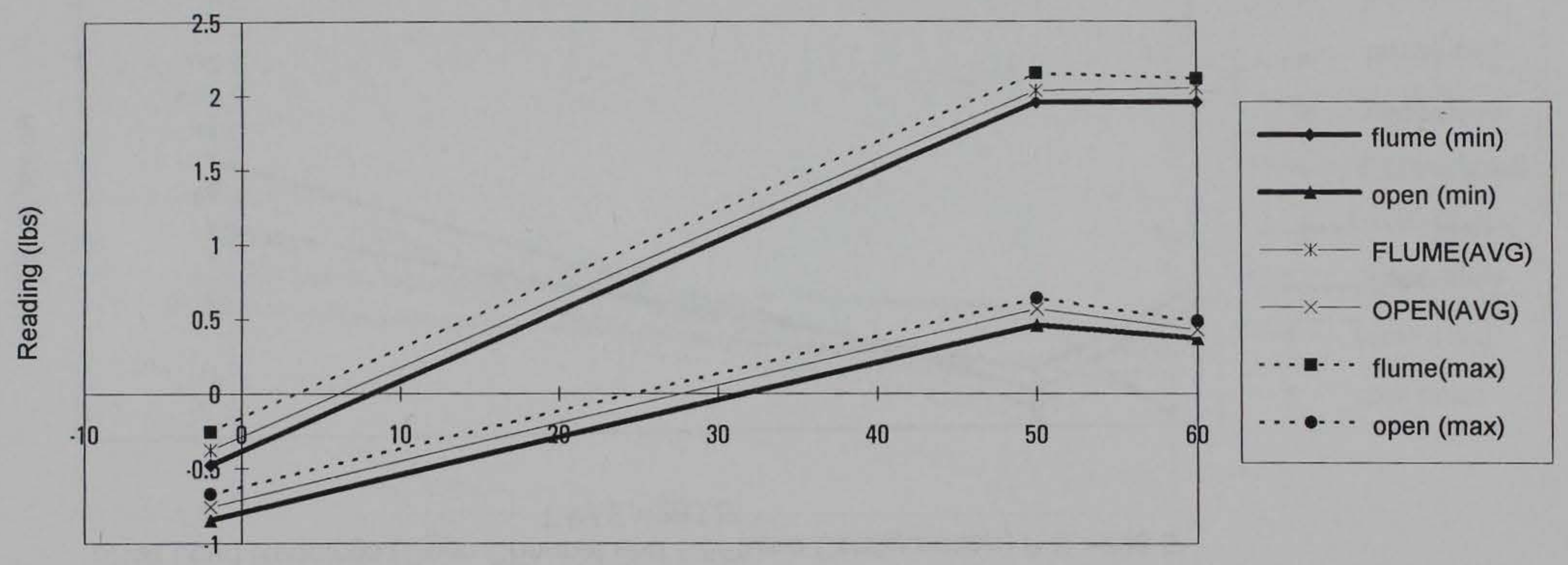

Position (Degrees) 
R/Horizontal Hinge Readings (Open Channel and 1:5 Flume Configuration) P.E. $=296.5^{\prime}$, T.W.E. $=285.5^{\prime}$

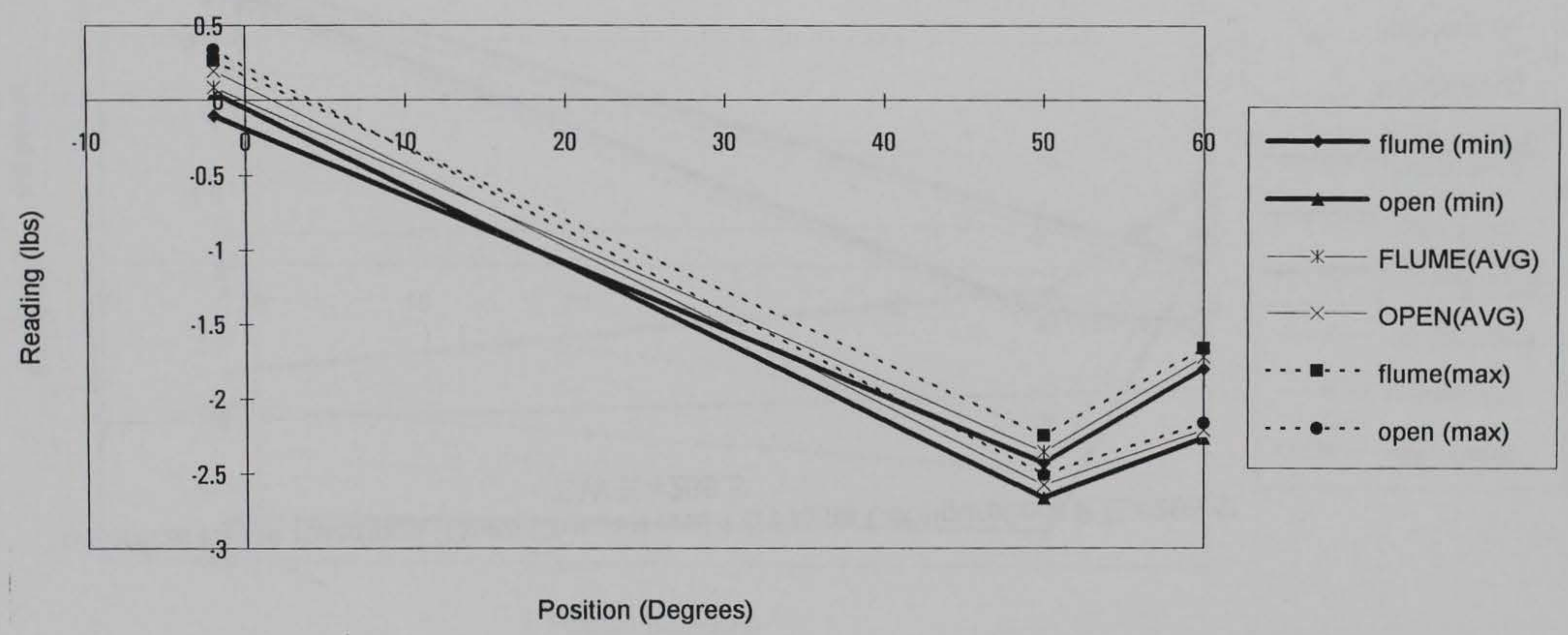

Figure 30c. Right horizontal hinge readings (Sheet 3 of 10) 
L/Nertical Hinge Readings (Open Channel and 1:5 Flume Configuration) P.E. $=296.5$ ',

T.W.E. $=285.5^{\prime}$

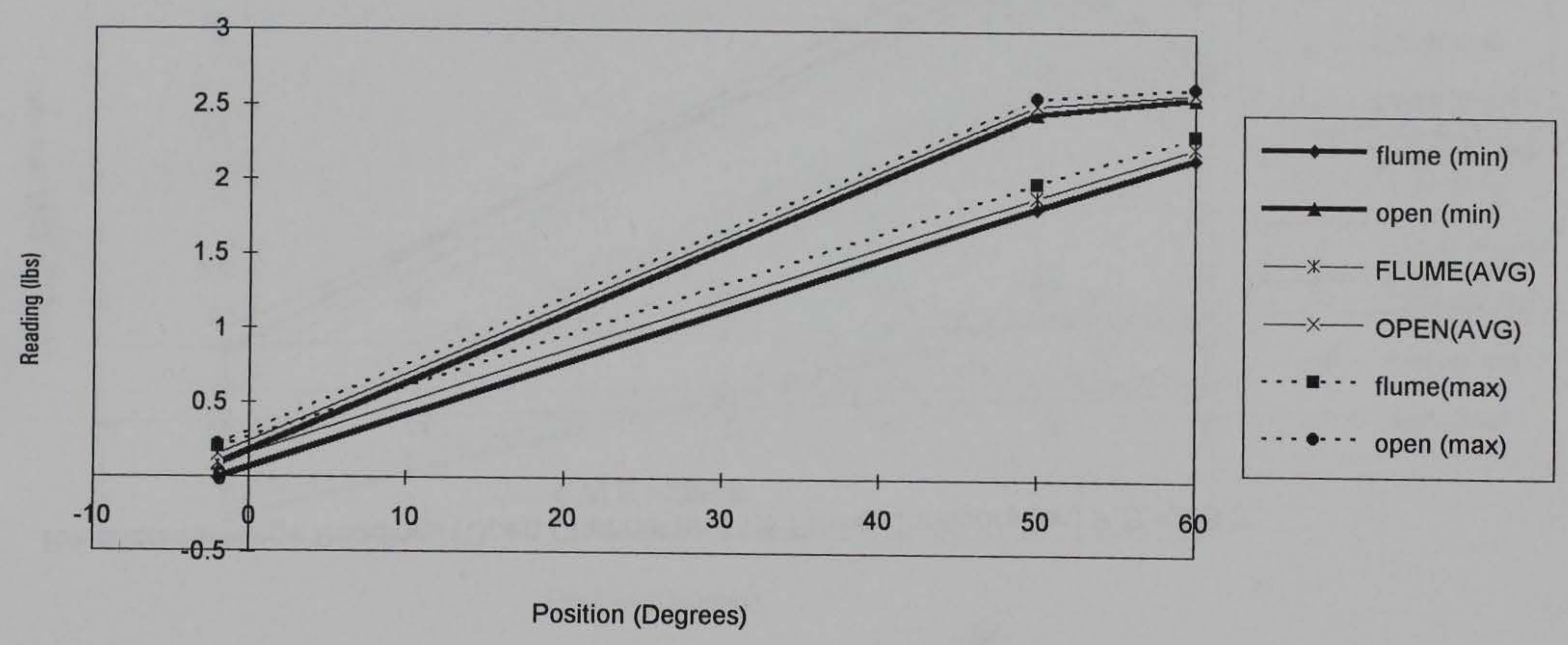

Figure $30 \mathrm{~d}$. Left vertical hinge readings (Sheet 4 of 10) 
L/Horizontal Hinge Readings (Open Channel and 1:5 Flume Configuration) P.E. $=296.5$ ', T.W.E. $=285.5^{\prime}$

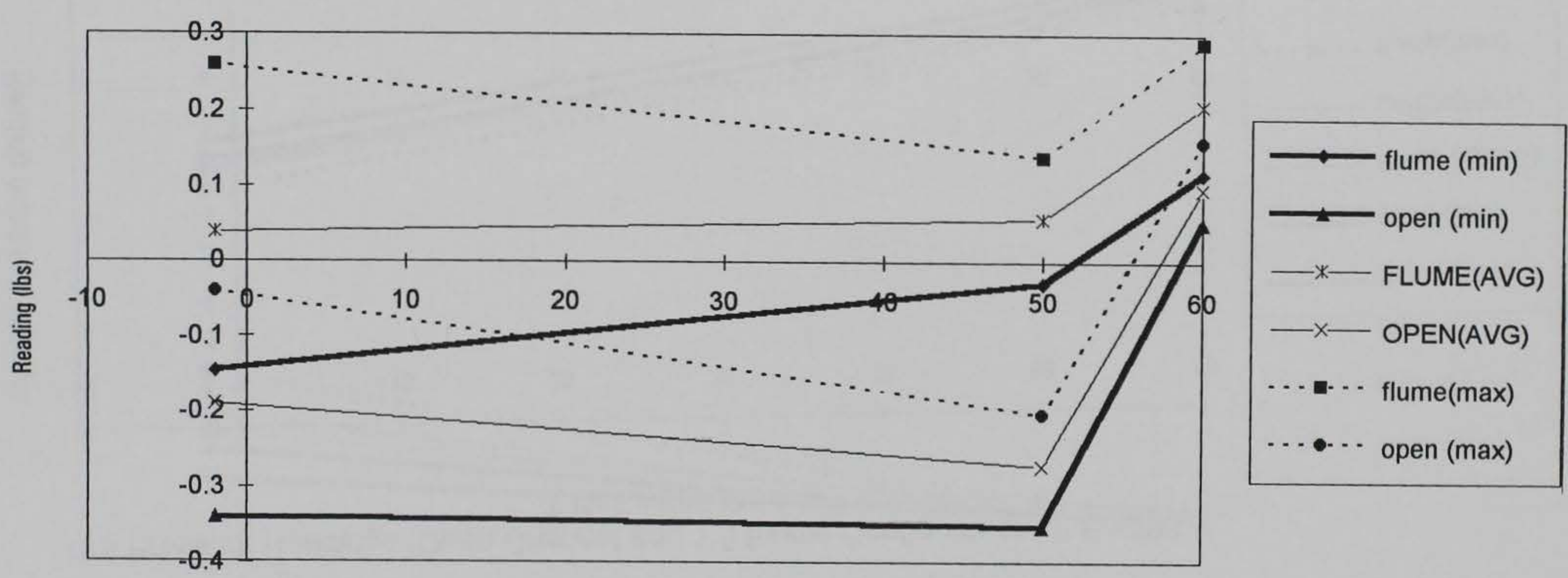

Position (Degrees) 
U/S Pressure Readings (Open Channel and 1:5 Flume Configuration) P.E. $=296.5^{\prime}$,

T.W.E. $=285.5^{\prime}$

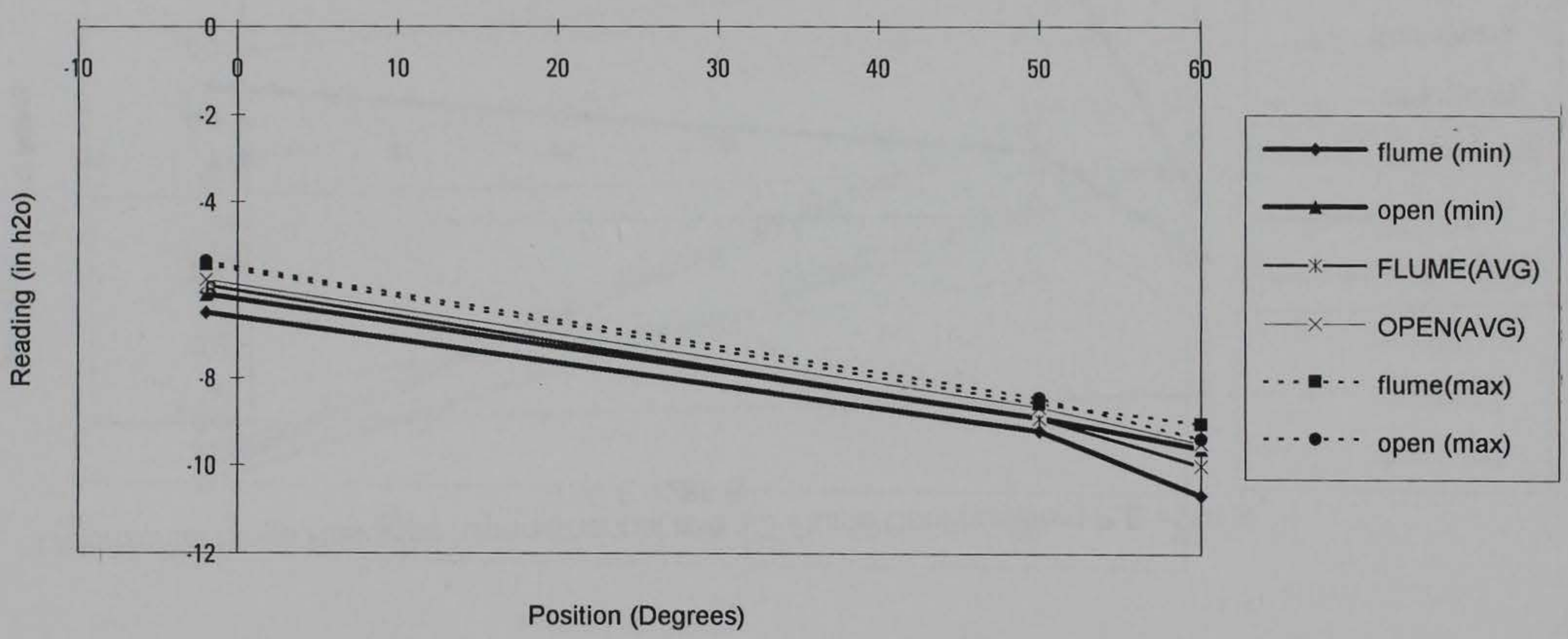

Figure 30f. Upstream pressure readings (Sheet 6 of 10) 
D/S Pressure Readings (Open Channel and 1:5 Flume Configuration) P.E.=296.5', T.W.E. $=285.5^{\prime}$

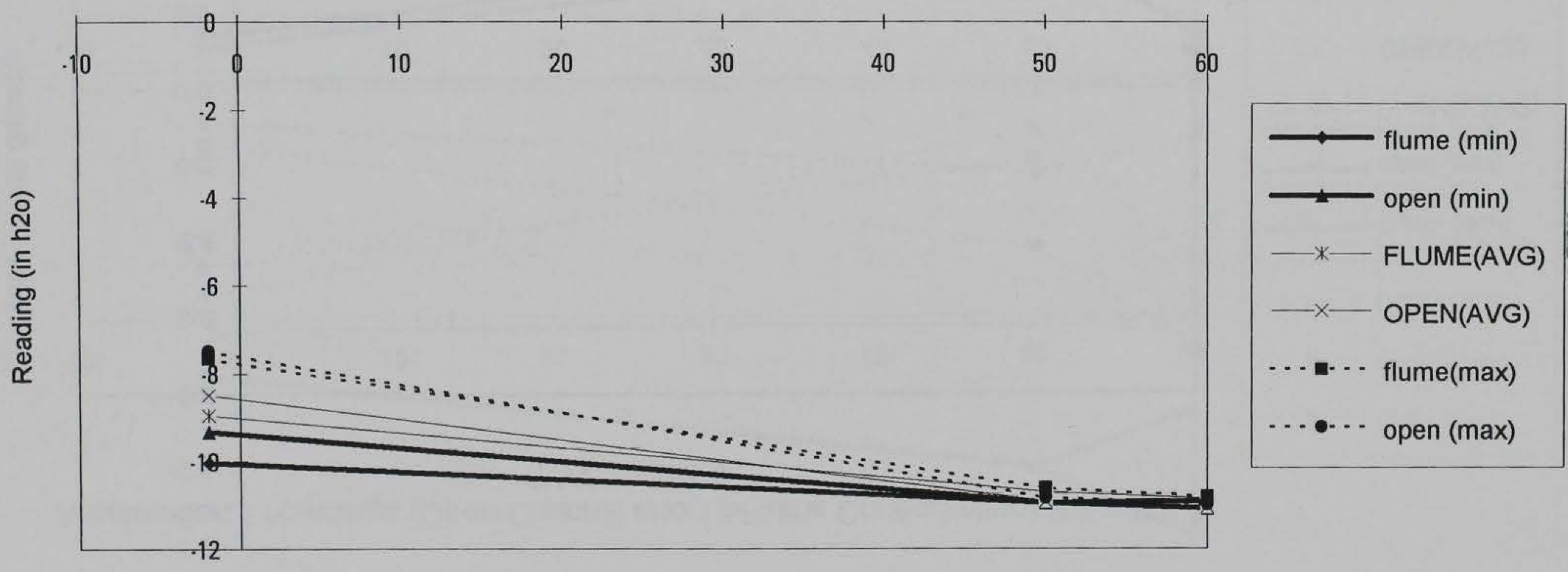

Position (Degrees) 
Acceleration 1 Readings (Open Channel and 1:5Flume Configuration) P.E. $=296.5^{\prime}$,

T.W.E. $=285.5^{\prime}$

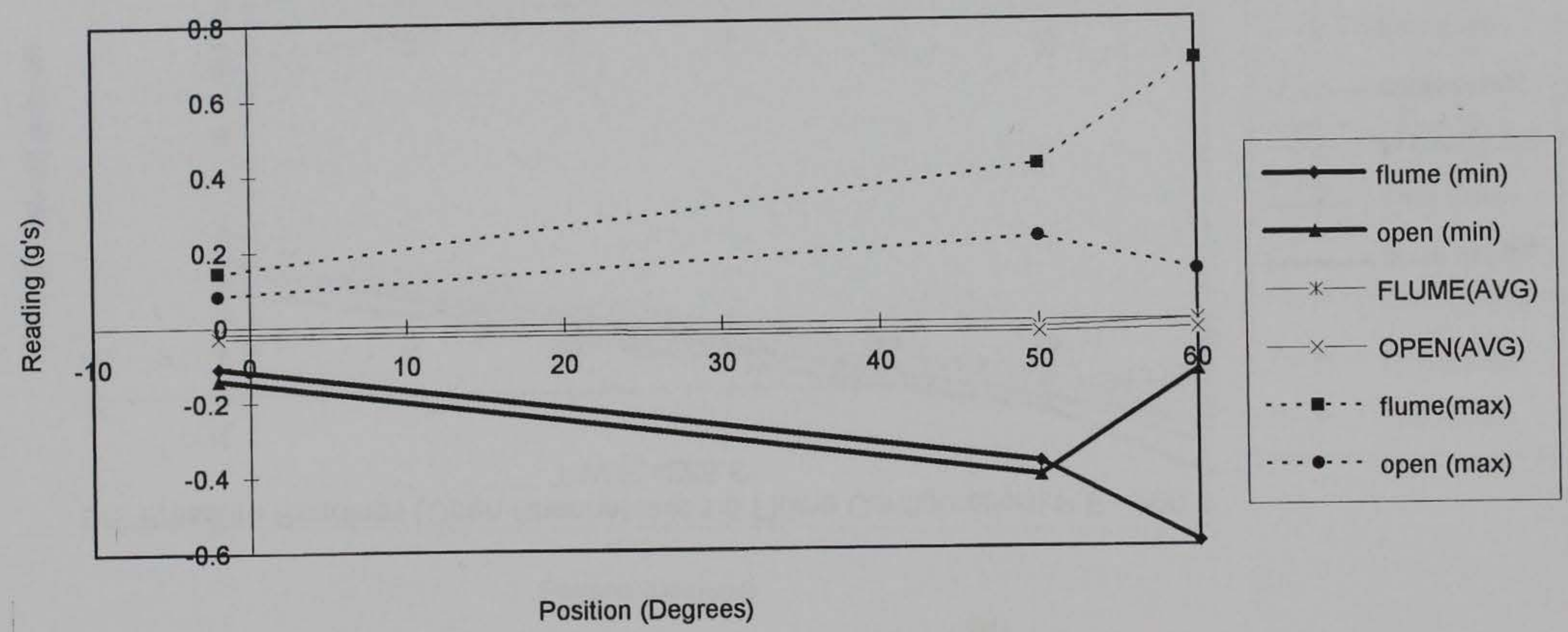

Figure $30 \mathrm{~h}$. Acceleration 1 readings (Sheet 8 of 10) 
Acceleration 2 Readings (Open Channel and 1:5 Flume Configuration ) P.E. $=296.5^{\prime}$,

T.W.E. $=285.5^{\prime}$

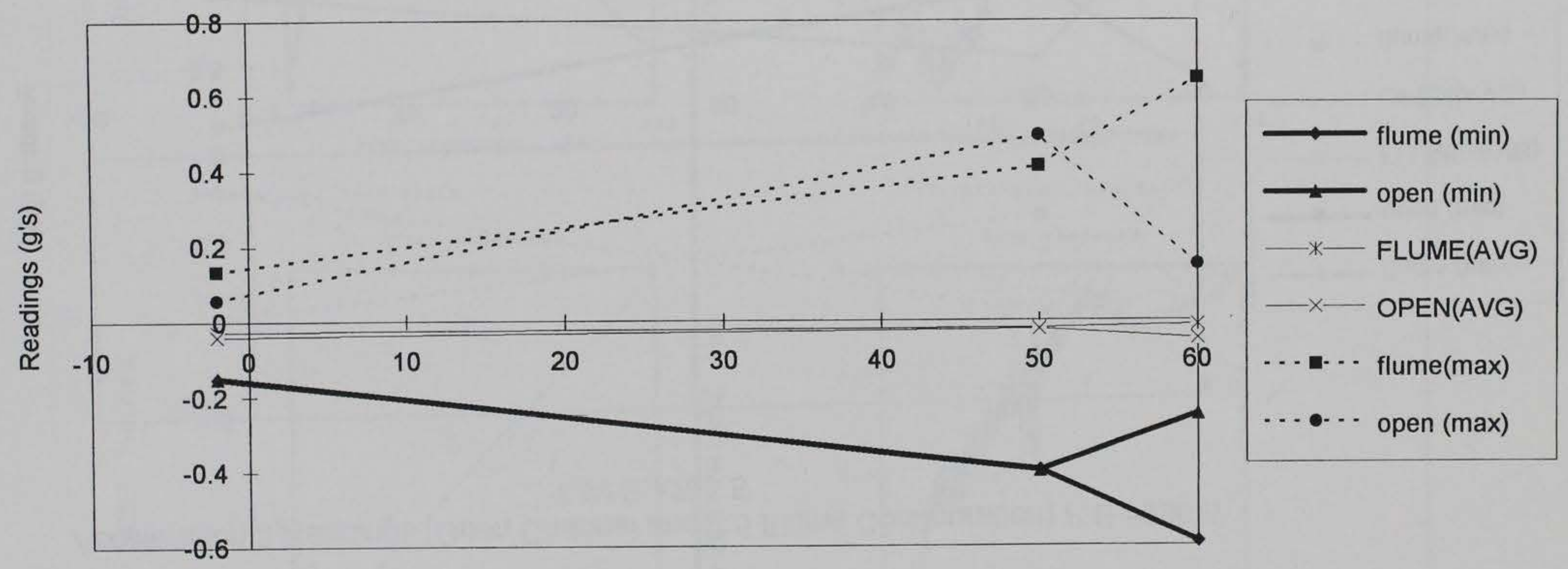

Position (Degrees) 
Acceleration 3 Readings (Open Channel and 1:5 Flume Configuration) P.E. $=296.5^{\prime}$,

T.W.E. $=285.5^{\prime}$

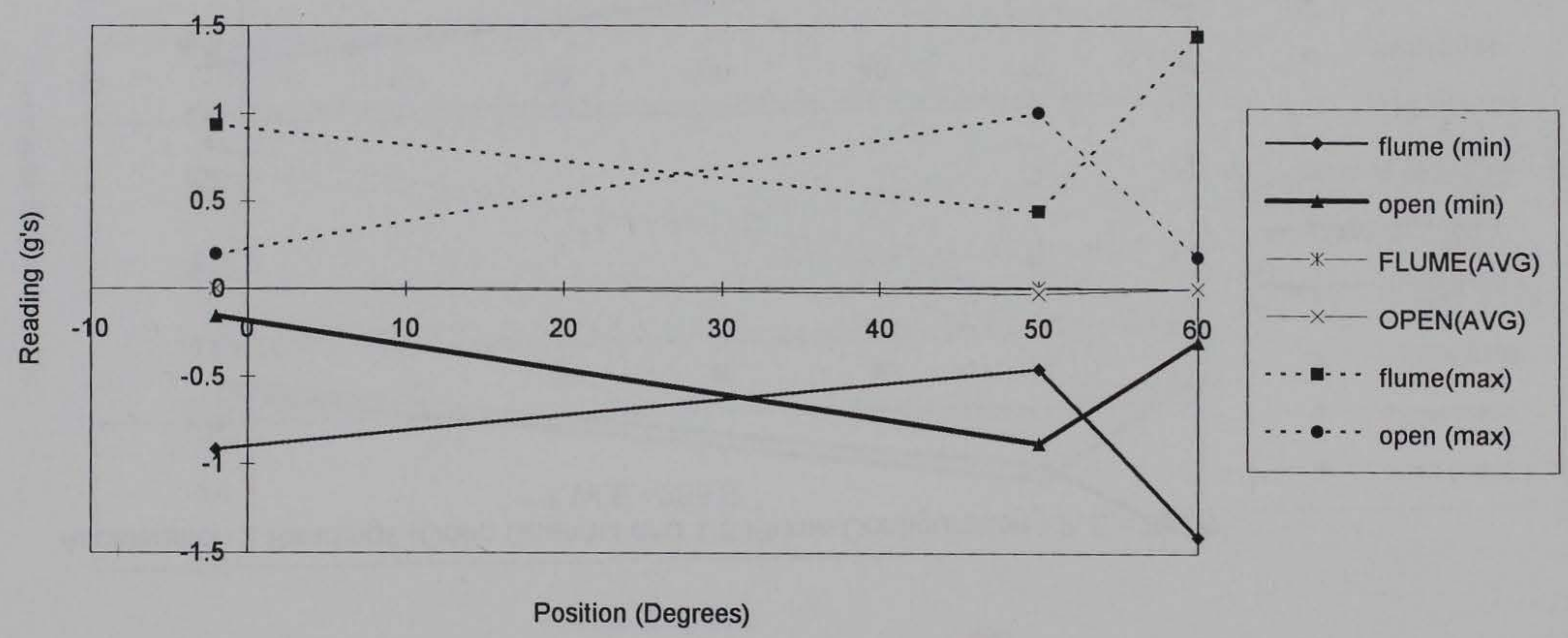

Figure 30j. Acceleration 3 readings (Sheet 10 of 10) 


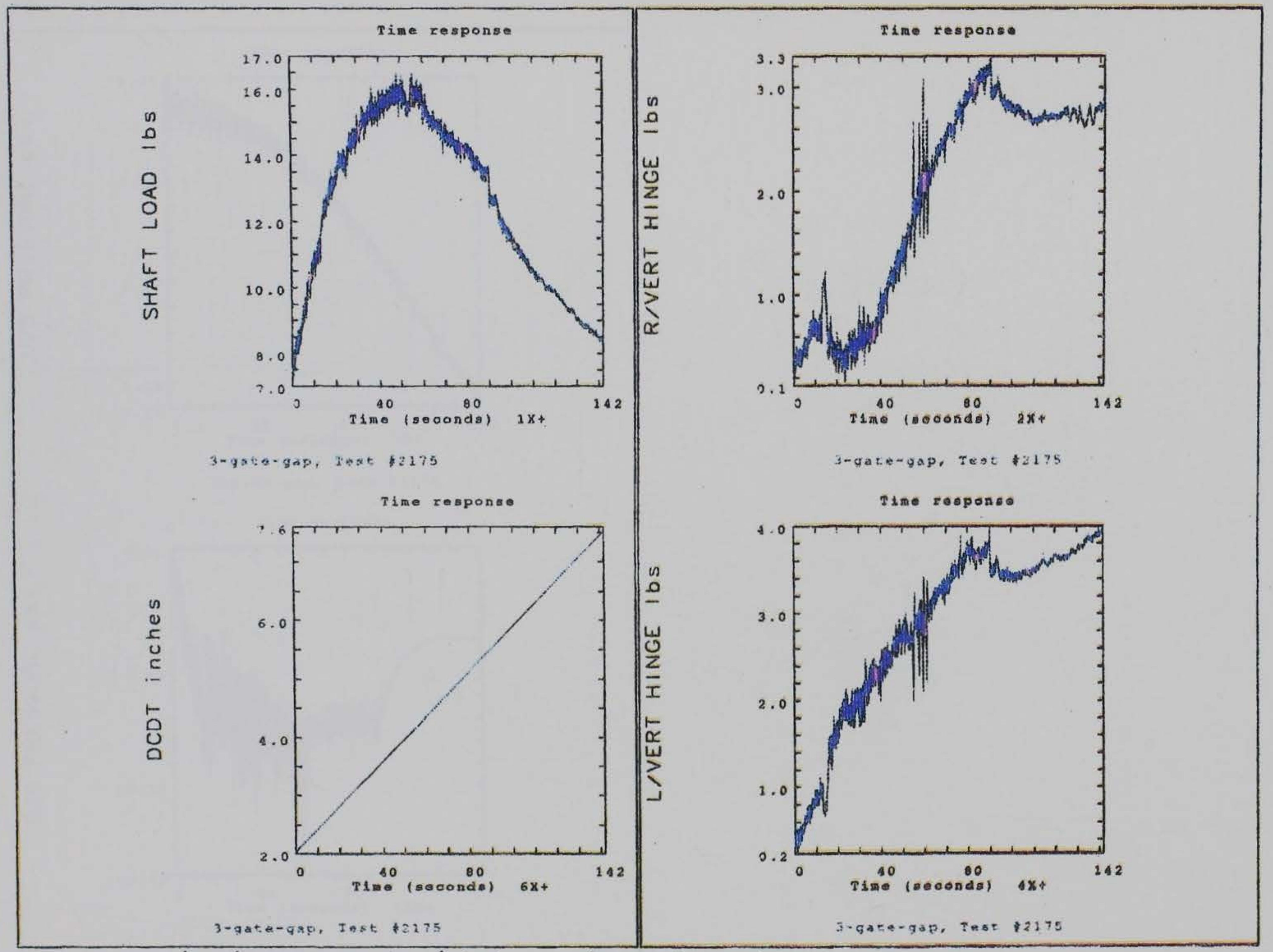

Figure 31. Flow-induced time-domain responses for the test gate while raised from -2 to $67 \mathrm{deg}$. a. Shaft load, right vertical hinge, left vertical hinge, and DCDT (Continued) 


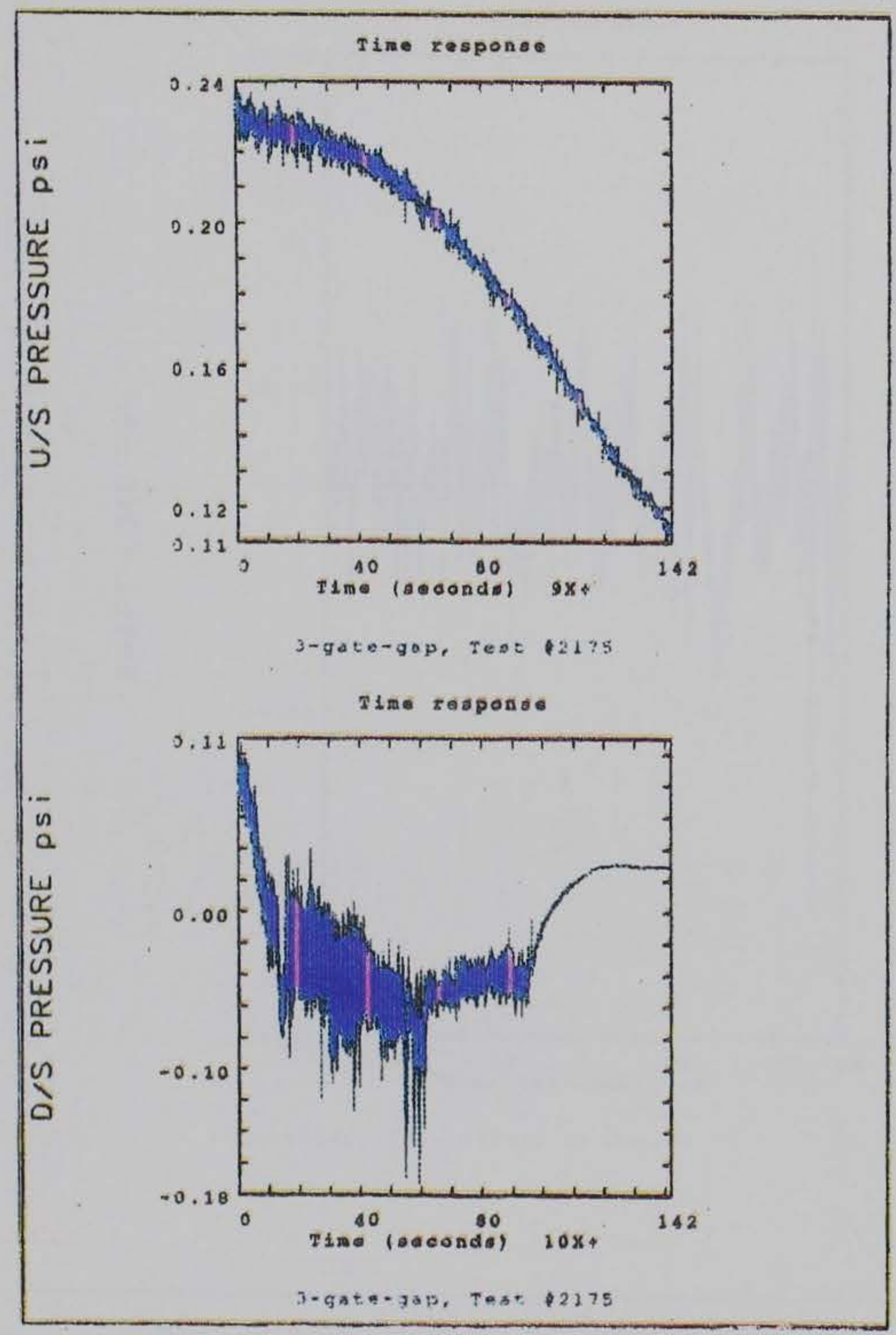

Figure 31b. Upstream and downstream pressures (Concluded) 


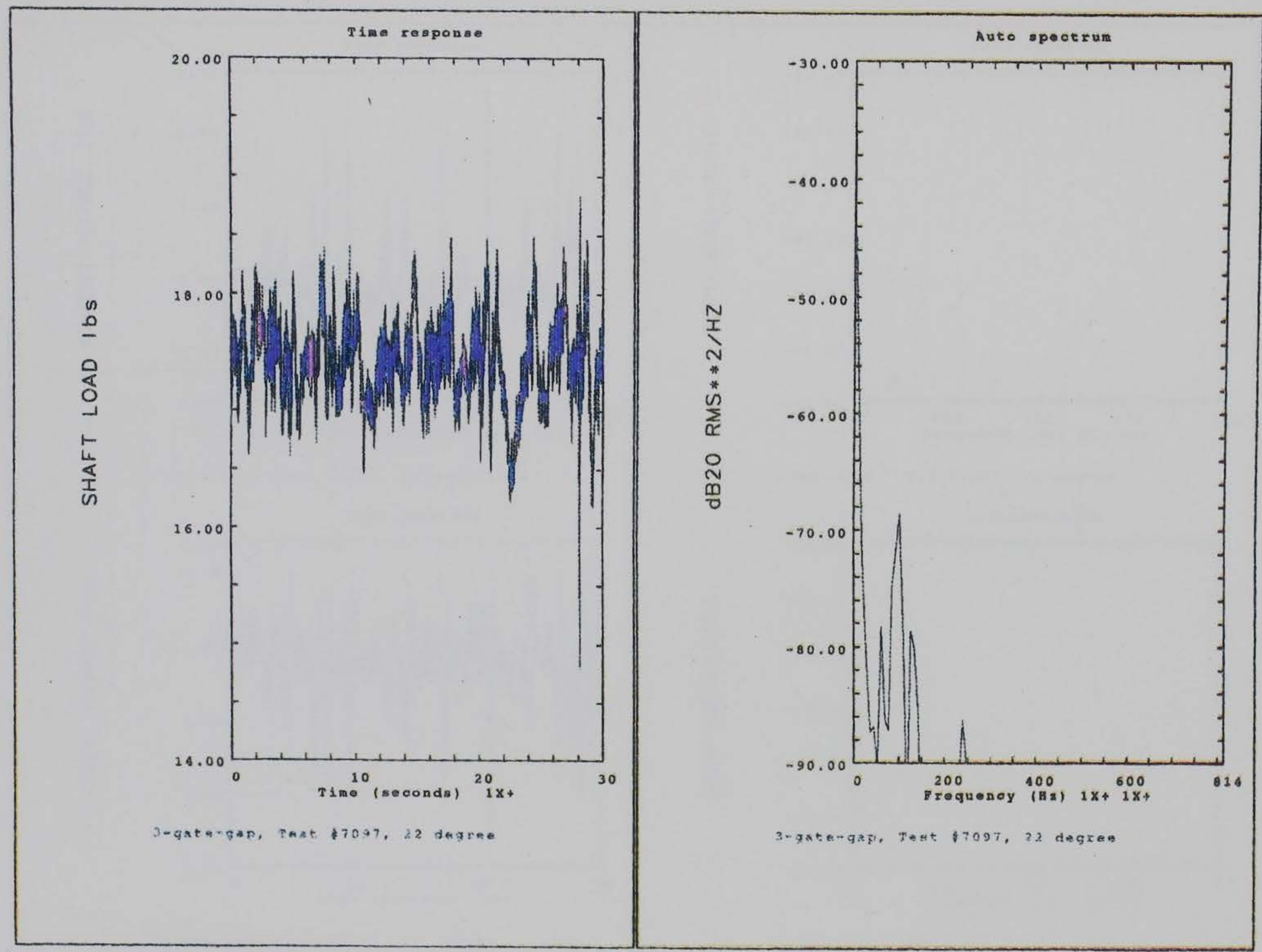

Figure 32. Time-domain responses and the corresponding auto spectra for the test gate at $22^{\circ}$ fixed position (head difference $21 \mathrm{ft}$ ). a. Shaft load (Sheet 1 of 5) 


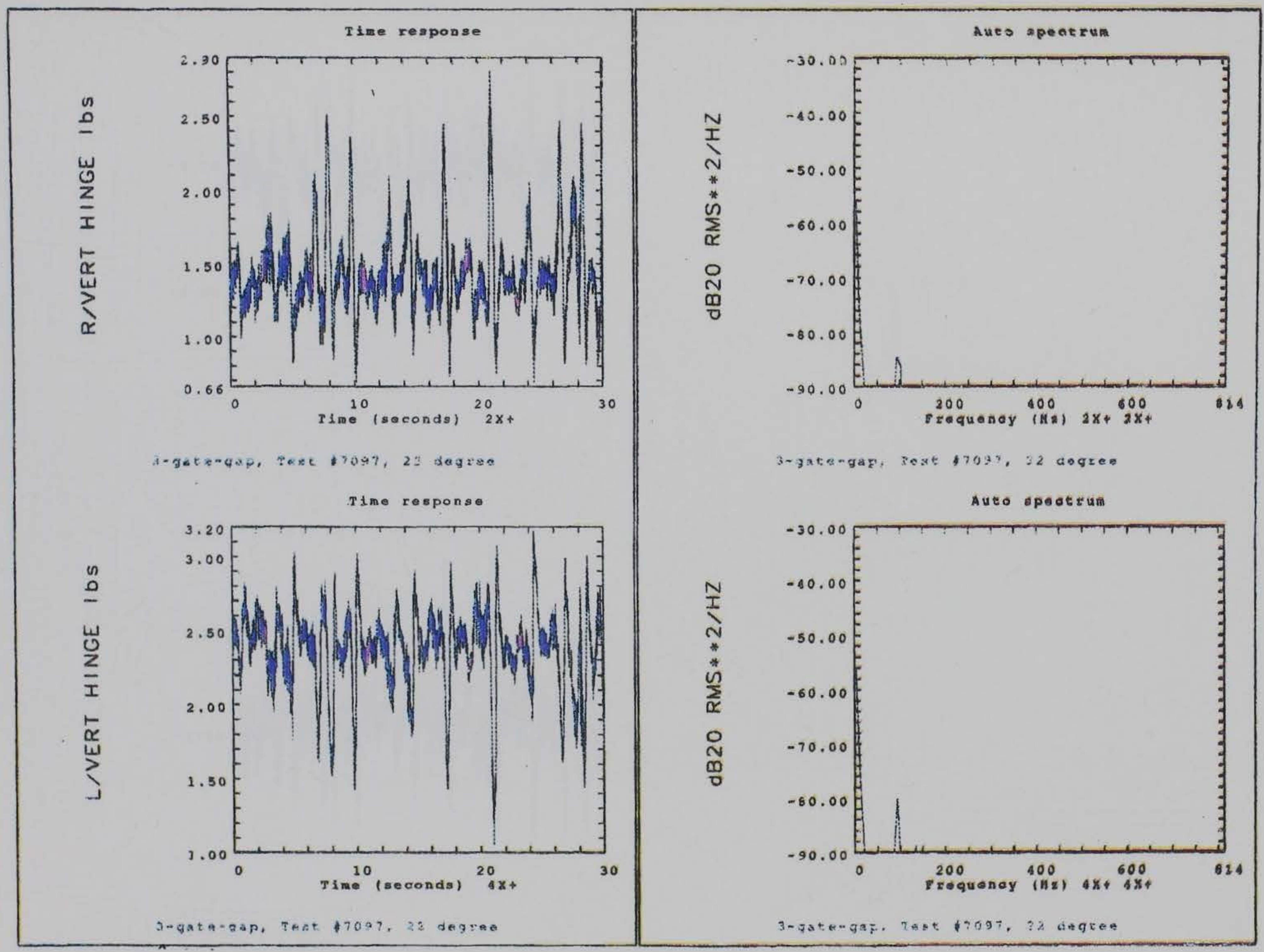

Figure 32b. Right vertical and left vertical hinges (Sheet 2 of 5) 


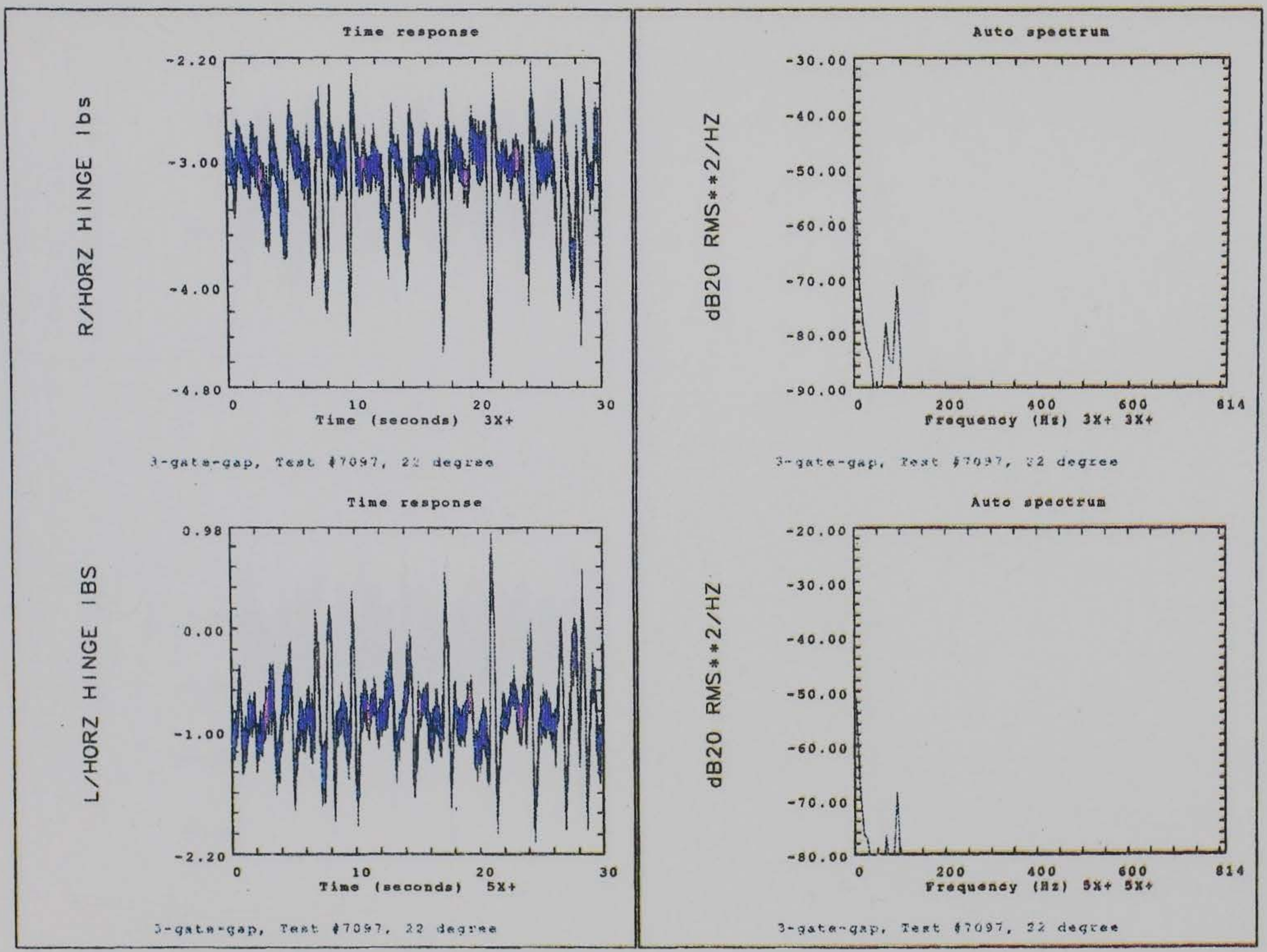

Figure 32c. Right and left horizontal hinges (Sheet 3 of 5) 


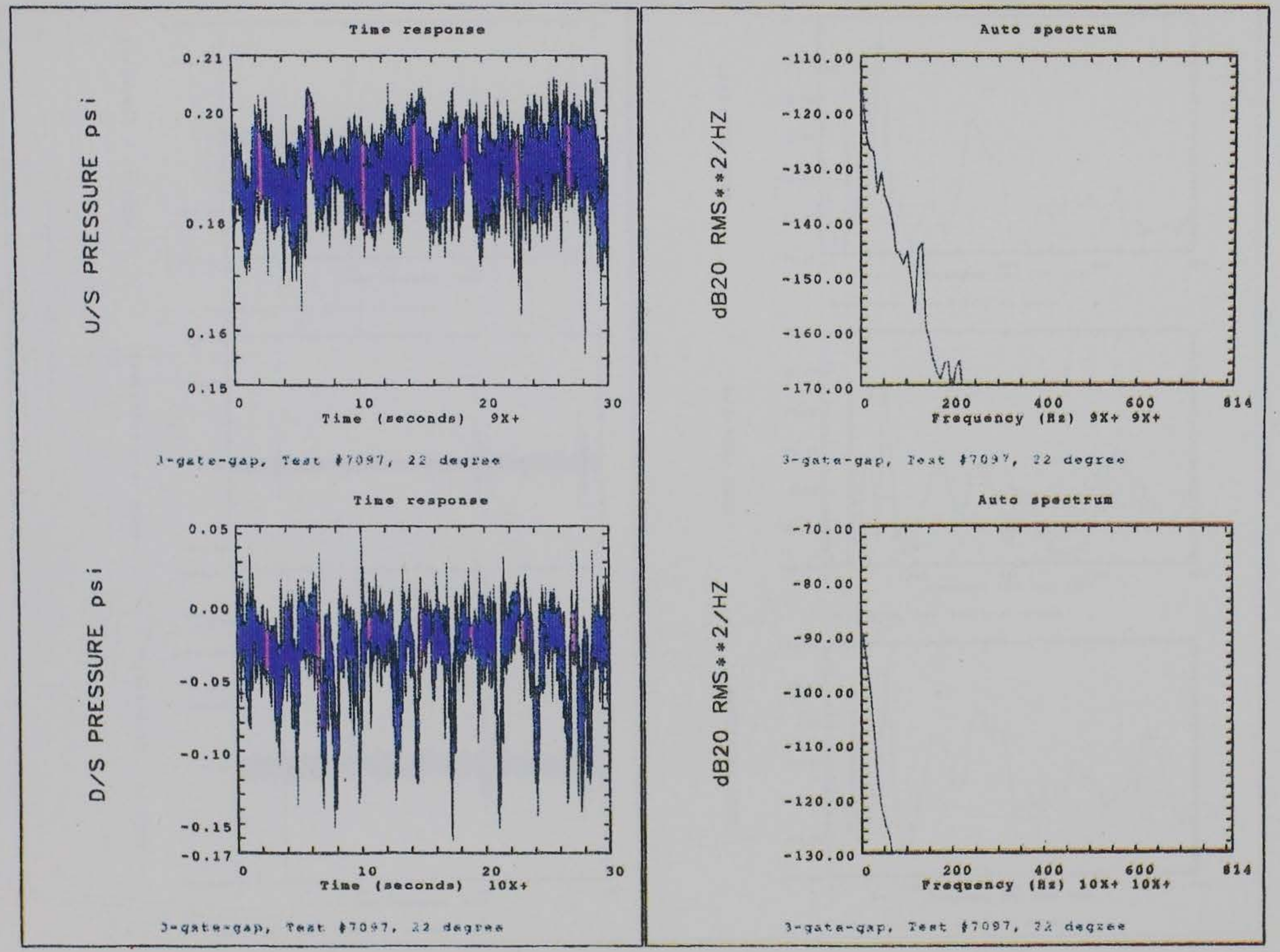

Figure 32d. Upstream and downstream pressures (Sheet 4 of 5) 


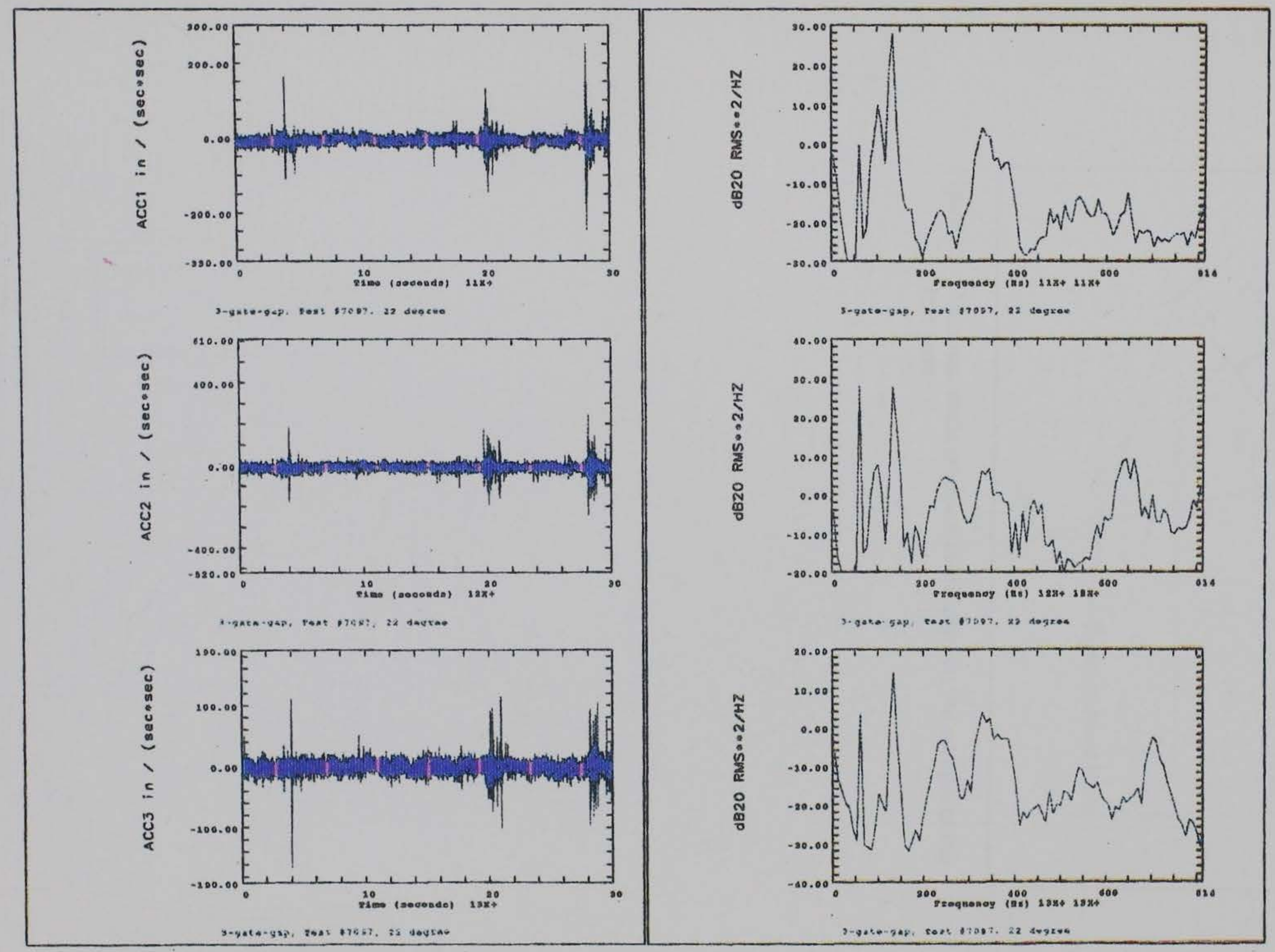

Figure 32e. Accelerations 1, 2, and 3 (Sheet 5 of 5) 


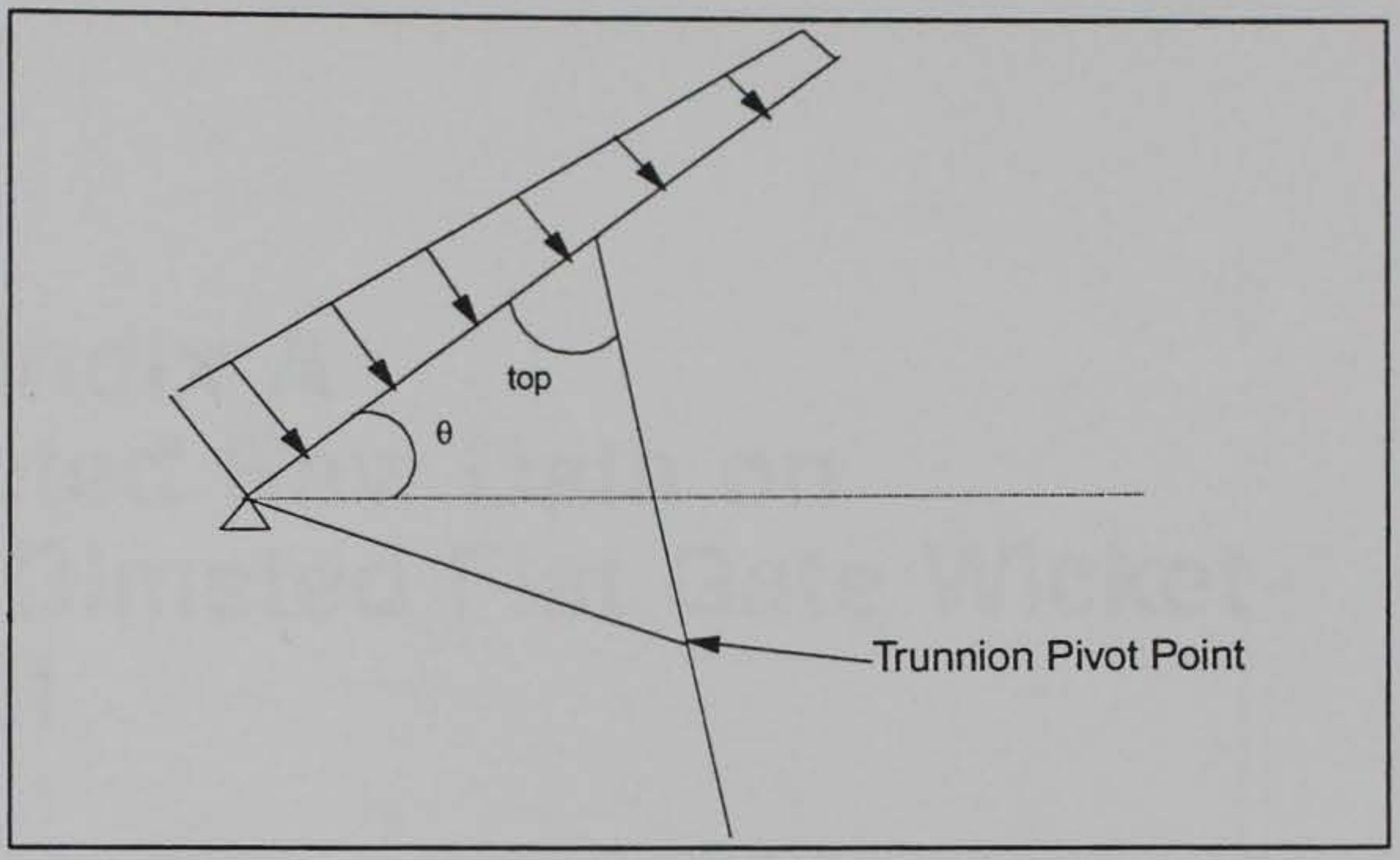

Figure 33. Assumed static pressure distribution on the surface of the test gate 
Appendix A

Selected Raw Data on

1:25 Olmsted Flat Gate Wicket

Model 


\section{A1. Test \#2370, Static Load Test Raw Data}


Test Number: 2370

Channel List: 1-6, 9-13

Sampling Rate: 50 samples/sec/channel

Length of Time Sampled: $34.00 \mathrm{sec}$

Gate Rotation Measurement Channel: 6

Gate Rotation Angle, Start of Test: 0.00 degrees

Gate Rotation Angle, End of Test: 0.00 degrees

CHAN. 1-5,9-13 FILTERED @ $1000 \mathrm{~Hz}$,

1-GATE GAP, DOWN GATE $=47$

POOL ELEV. $=0$, TAIL WATER ELEV. $=0$

PRE-TEST GATE WEIGHT REFERENCE TEST, STILI POOL $=0$

1:5 FLUME CONFIGURATION

Date: 7-7-1994 Time: 12:57:26

$\begin{array}{llllcl}\text { PROBE } & \text { MINIMUM } & \text { AVERAGE } & \text { MAXIMUM } & \text { TYPE OF } & \text { UNITS OF } \\ \text { NUMBER } & \text { READING } & \text { READING } & \text { READING } & \text { GAGE } & \text { MEASURE }\end{array}$

$\begin{array}{rrrrll}1 & -.196 & .542 & 2.079 & \text { SHAFT LOAD } & \text { Ibs } \\ 2 & -.944 & -.258 & .036 & \text { R/VERT HINGE } & \text { lbs } \\ 3 & -.207 & -.003 & .174 & \text { R/HORZ HINGE } & \text { lbs } \\ 4 & -.759 & -.215 & .029 & \text { L/VERT HINGE } & \text { lbs } \\ 5 & -.277 & .001 & .284 & \text { L/HORZ HINGE } & \text { IBS } \\ 6 & -.393 & -.365 & -.285 & \text { Gate Rotatio } & \text { degrees } \\ 9 & -.018 & .011 & .054 & \text { U/S PRESSURE } & \text { in h20 } \\ 10 & -.052 & -.011 & .026 & \text { D/S PRESSURE } & \text { in h20 } \\ 11 & -.127 & -.010 & .031 & \text { ACC1 } & \text { g's } \\ 12 & -.160 & -.037 & .092 & \text { ACC2 } & \text { g's } \\ 13 & -.045 & .000 & .038 & \text { ACC3 } & g^{\prime} \mathrm{s}\end{array}$




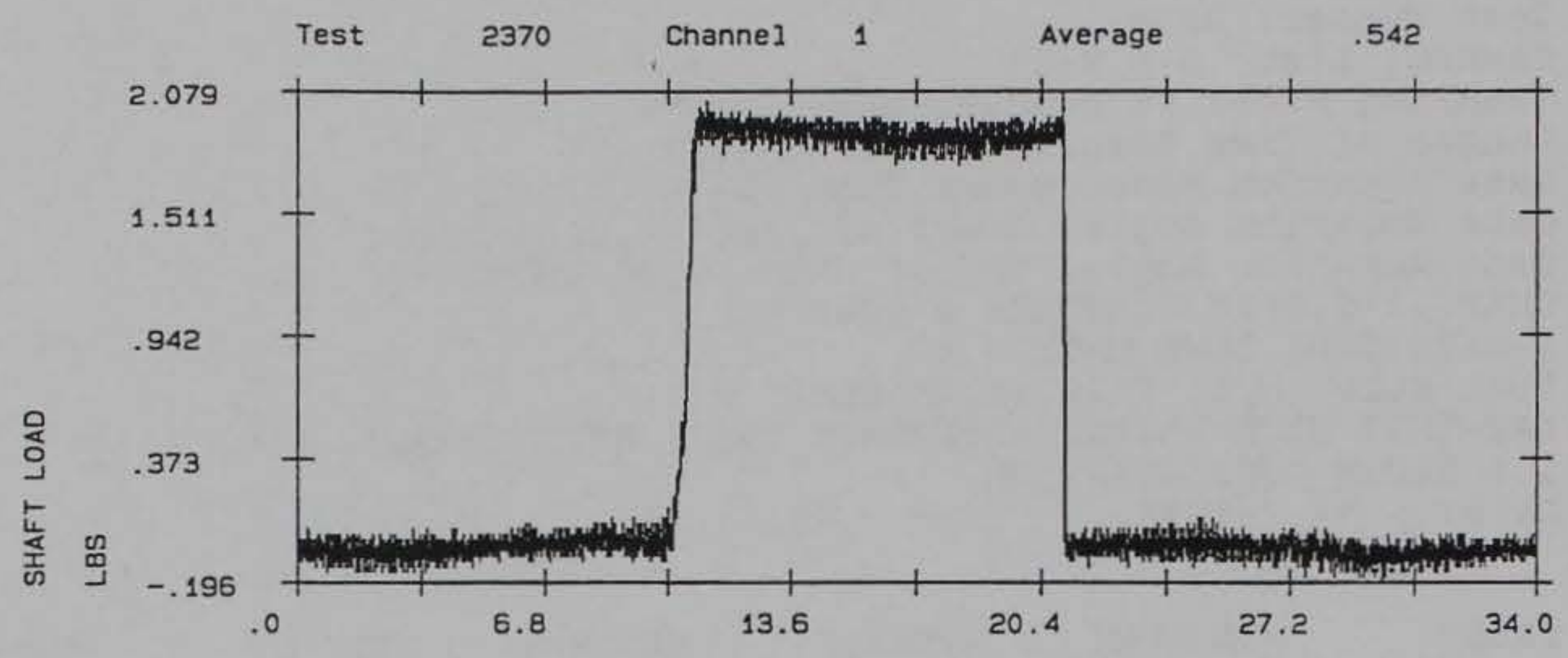

Time, in sec.

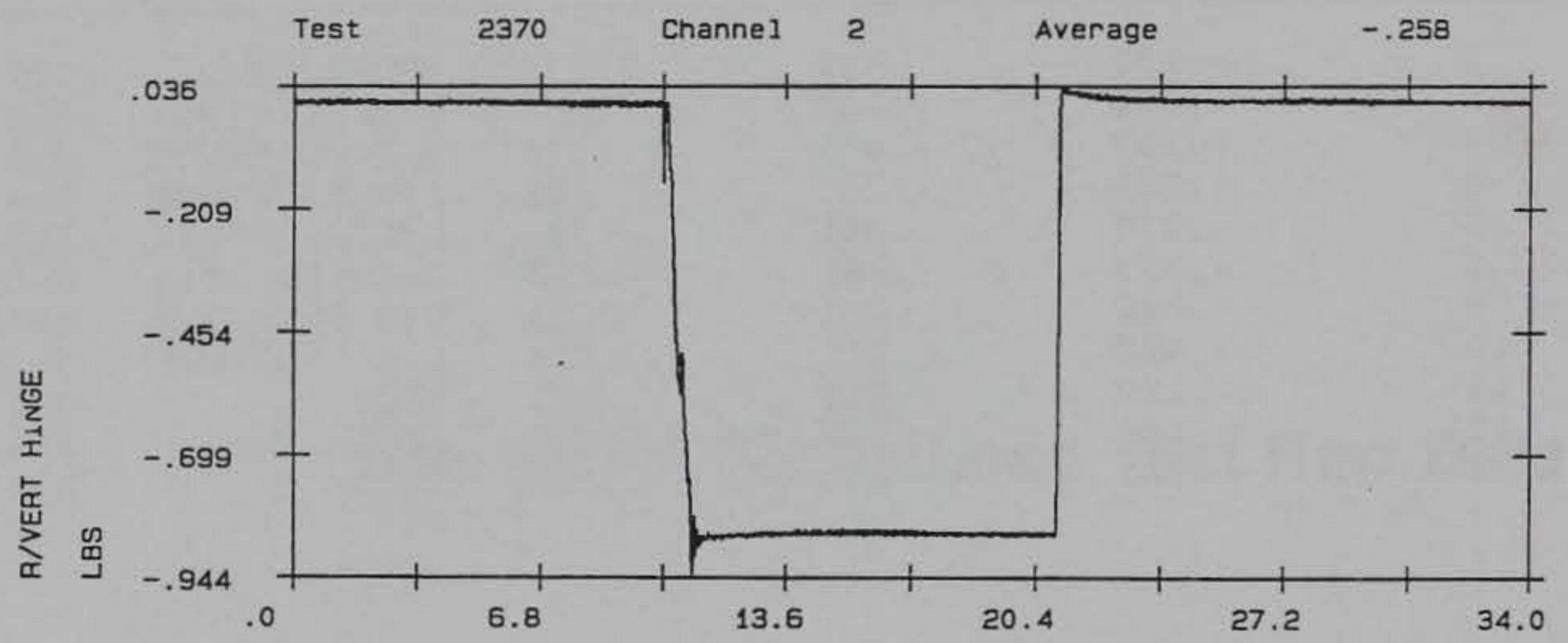

Time, in sec.

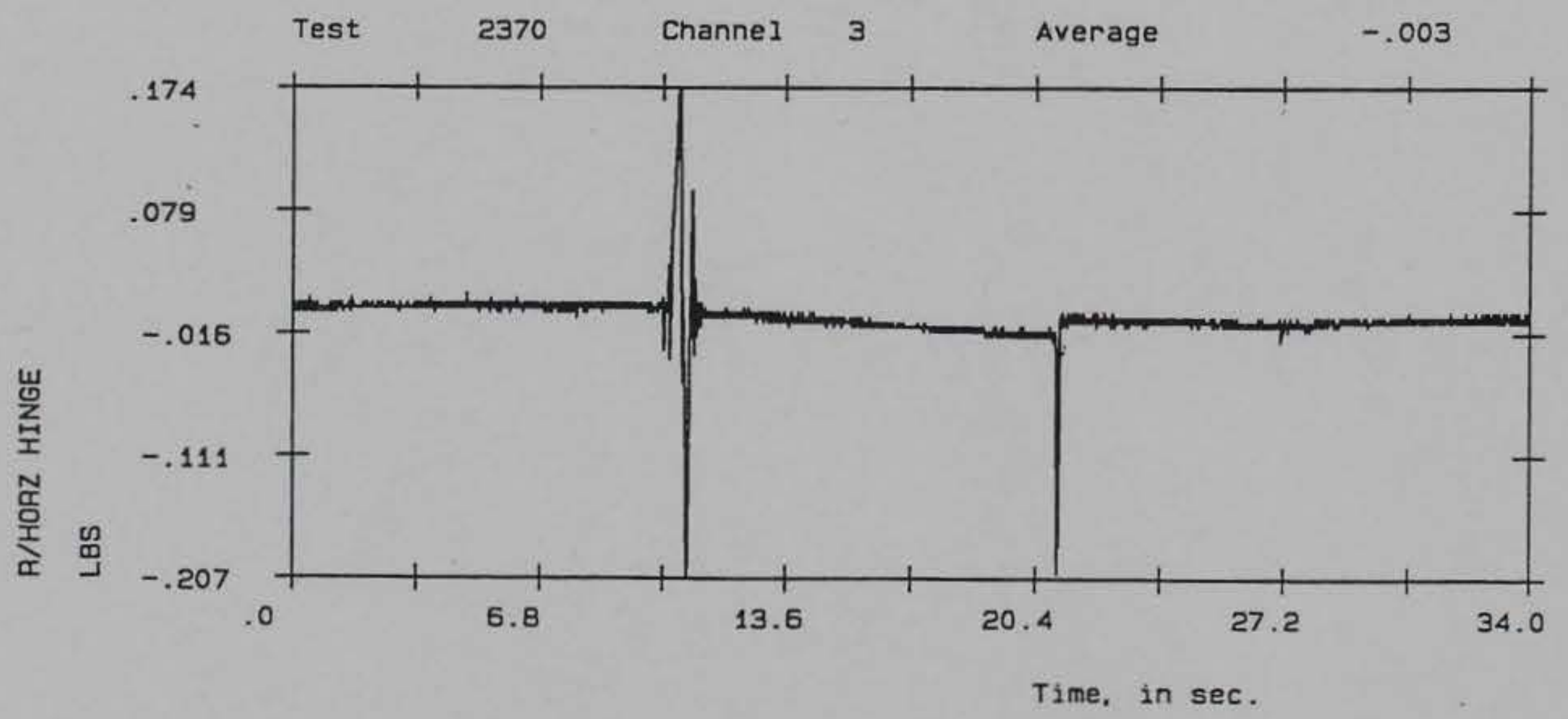




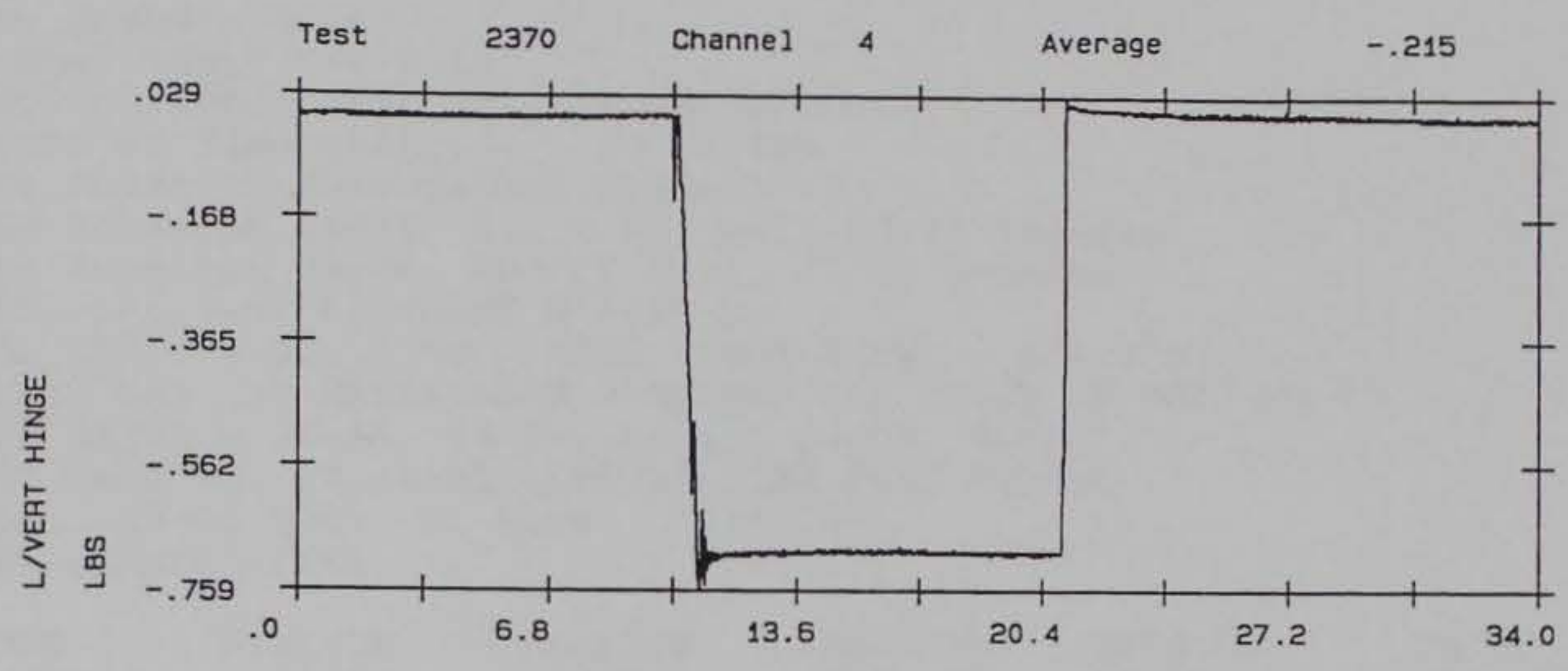

Time, in sec.

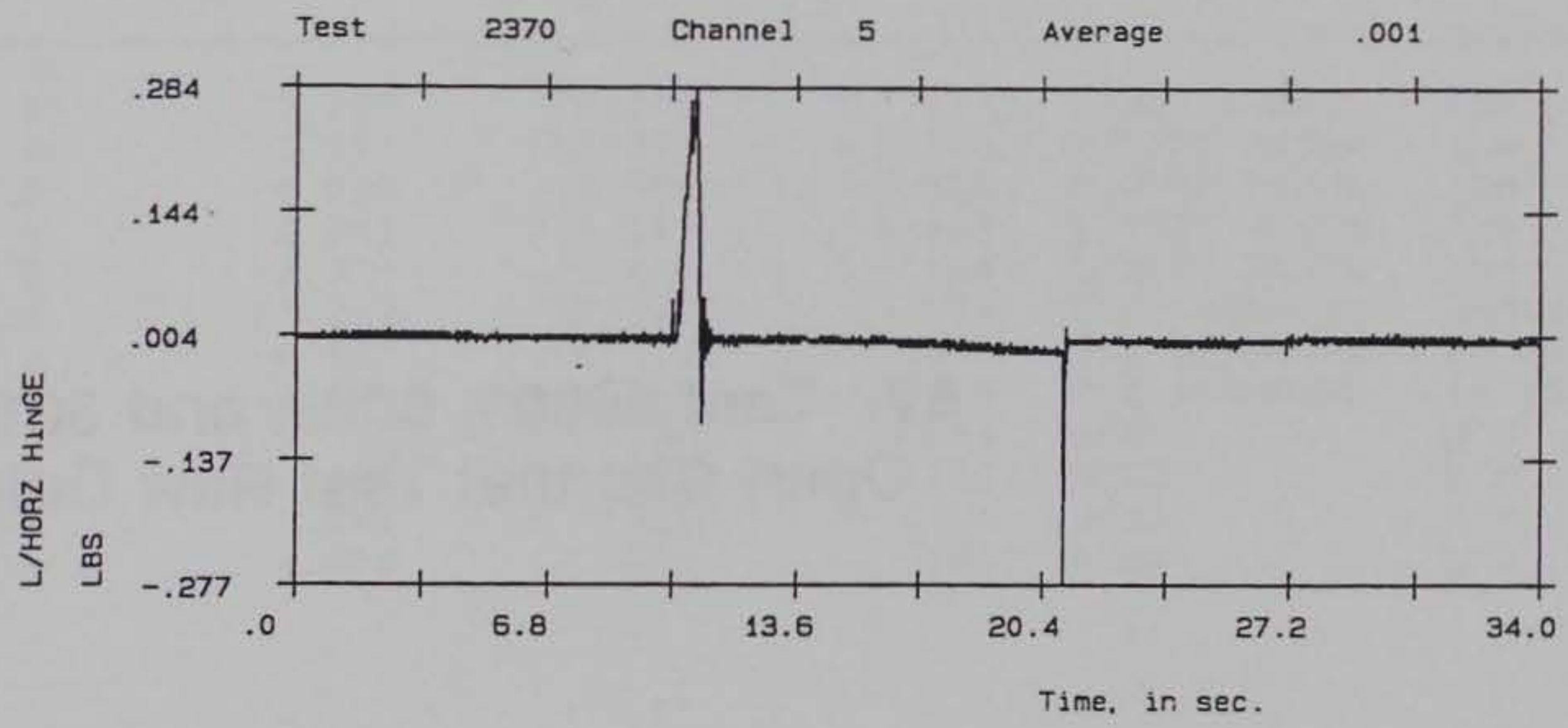


A2. Test \#6006, 6009, and 6013,
Open Channel Test Raw Data 
Test Number: 6006

Channel List: $1-6,9-14$

Sampling Rate: 2000 samples/sec/channel

Length of Time Sampled: $30.00 \mathrm{sec}$

Gate Rotation Measurement Channel: 6

Gate Rotation Angle, Start of Test: 27.00 degrees

Gate Rotation Angle, End of Test: 27.00 degrees

CHAN. 1-5, 9-14 FILTERED @ $1000 \mathrm{~Hz}$

POOL ELEV. $=300.0 \mathrm{FT}$. TAIL WATER ELEV. $=279.0 \mathrm{FT}$.

3 GATE GAP, 15 GATES DOWN ( ZEROED ALL GAGES AT 302 SWL )

DOWN GATES $=26-28,36-38,46-48,56-58,66-68$

TEST GATE NO. 47 ( $1: 25$ OLMSTED FLAT GATE MODEL)

Date: 10-13-1993 Time: 15:59:59

OPEN CHANNEL TEST

$\begin{array}{llllcc}\text { PROBE } & \text { MINIMUM } & \text { AVERAGE } & \text { MAXIMUM } & \text { TYPE OF } & \text { UNITS OF } \\ \text { NUMBER } & \text { READING } & \text { READING } & \text { READING } & \text { GAGE } & \text { MEASURE }\end{array}$

$\begin{array}{rrrrll}1 & 15.427 & 16.320 & 17.873 & \text { SHAFT LOAD } & \text { Ibs } \\ 2 & -1.873 & -1.251 & -.556 & \text { R/VERT HINGE } & \text { Ibs } \\ 3 & -4.090 & -3.300 & -2.716 & \text { R/HORZ HINGE } & \text { lbs } \\ 4 & 2.381 & 3.169 & 3.997 & \text { L/VERT HINGE } & \text { lbs } \\ 5 & -2.379 & -1.444 & -.648 & \text { L/HORZ HINGE } & \text { IBS } \\ 6 & 27.293 & 27.327 & 27.374 & \text { Gate Rotatio } & \text { degrees } \\ 9 & -6.442 & -6.072 & -5.648 & \text { U/S PRESSURE } & \text { in h20 } \\ 10 & -17.274 & -14.297 & -12.666 & \text { D/S PRESSURE } & \text { in h20 } \\ 11 & -.332 & -.022 & .233 & \text { ACC1 } & g^{\prime} \mathrm{s} \\ 12 & -.357 & -.034 & .171 & \text { ACC2 } & g^{\prime} \mathrm{s} \\ 13 & -.104 & .002 & .111 & \text { ACC3 } & g^{\prime} \mathrm{s} \\ 14 & -.232 & .014 & .198 & \text { ACC4 } & \mathrm{g}^{\prime} \mathrm{s}\end{array}$



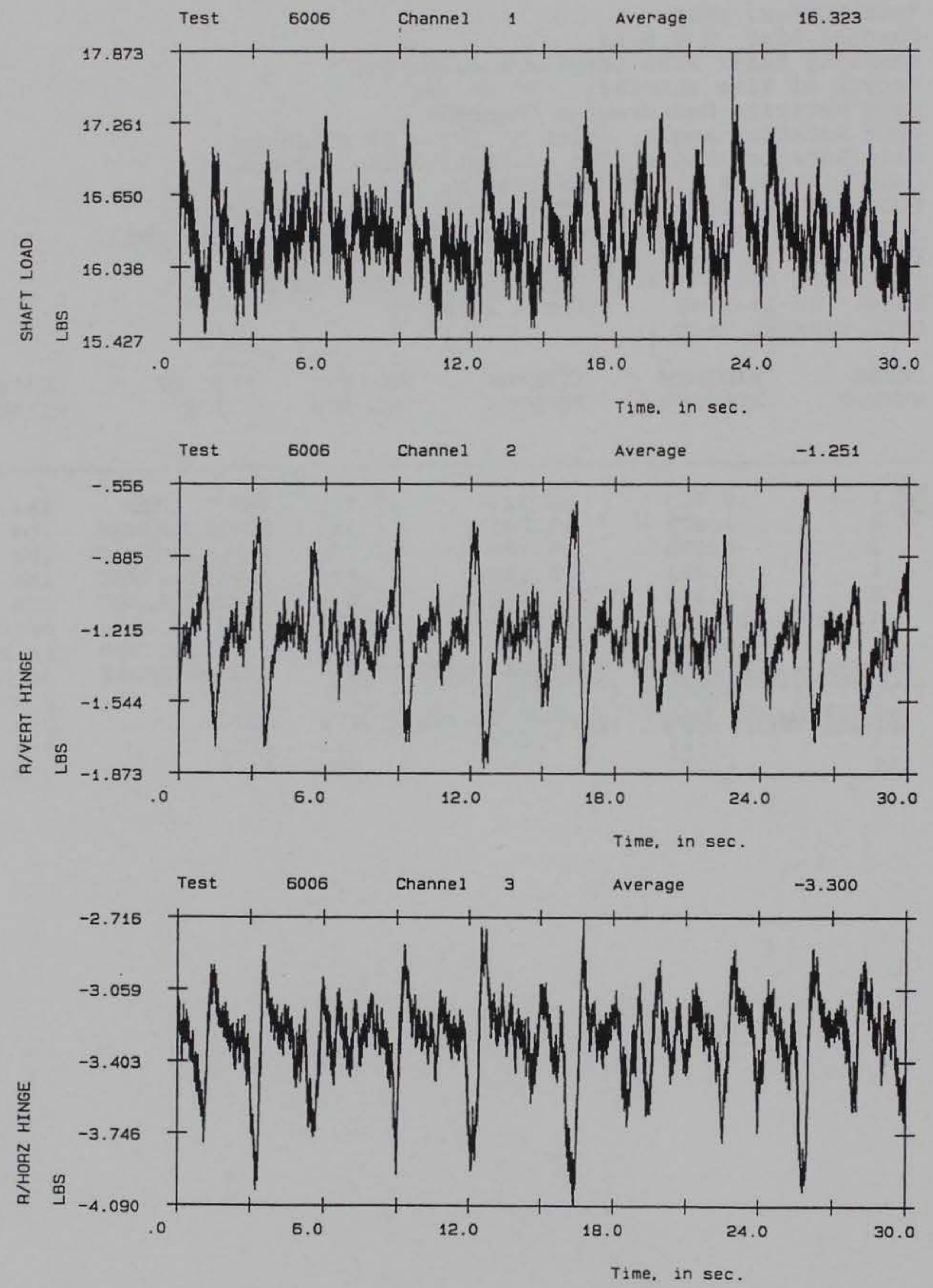

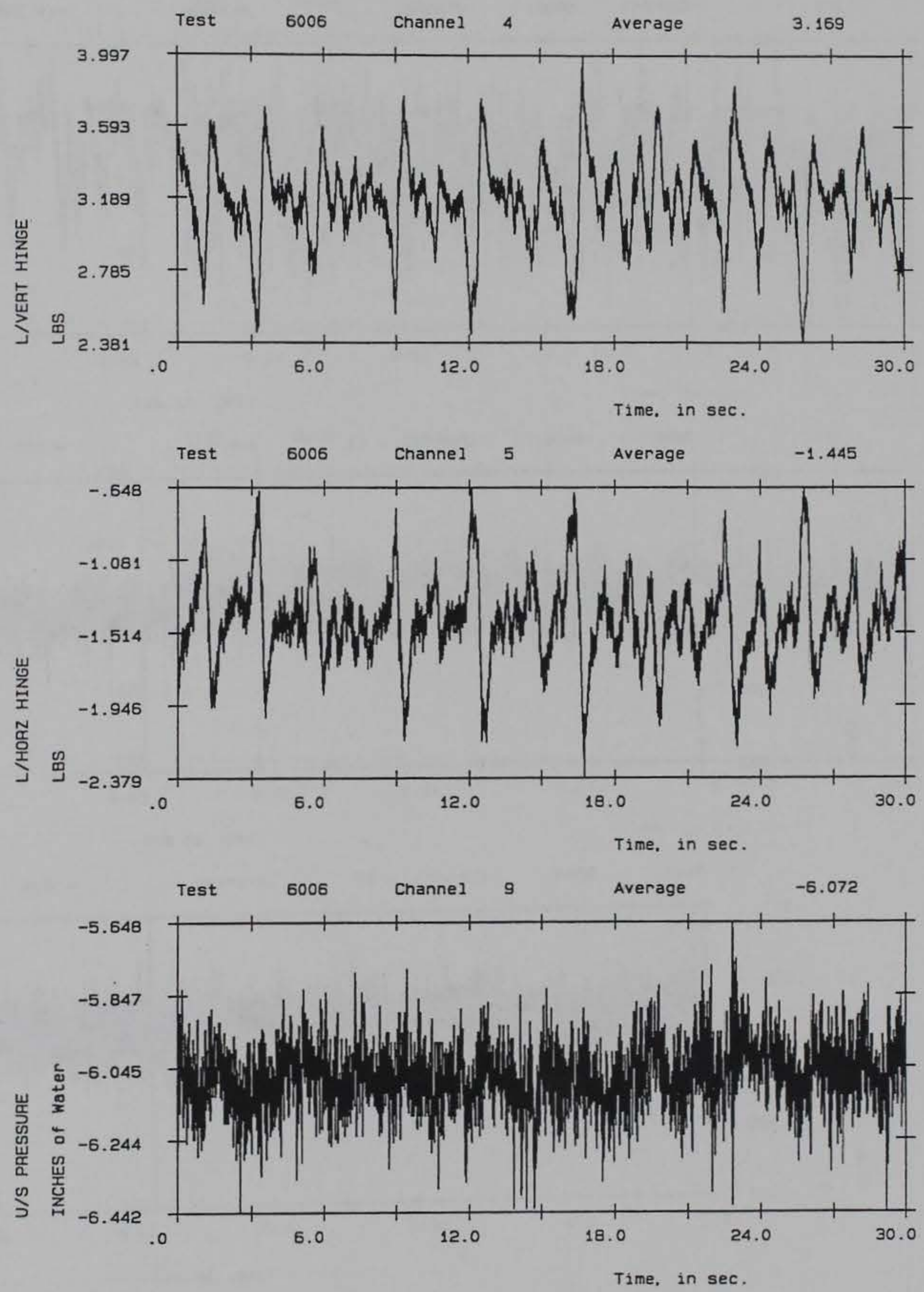

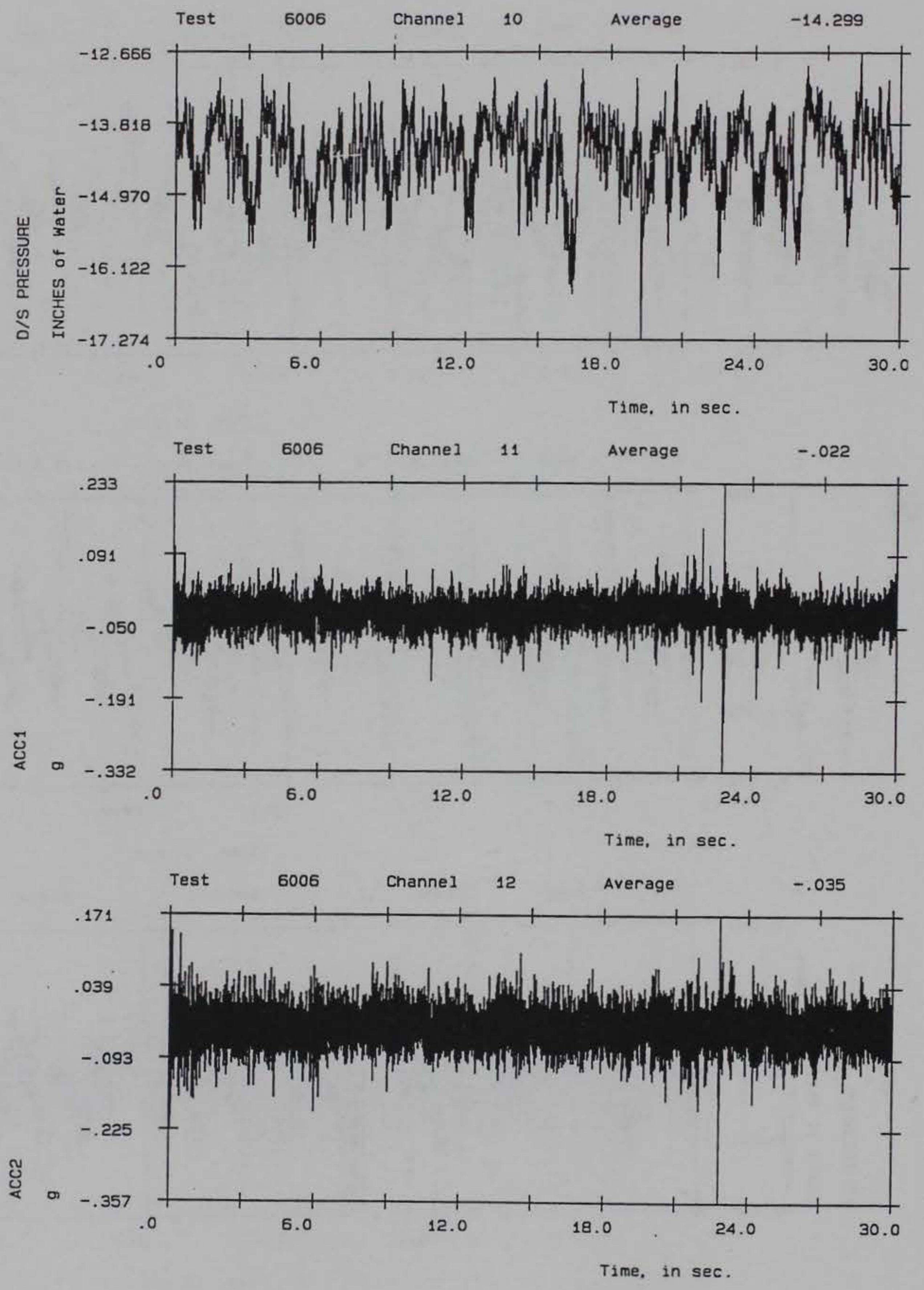

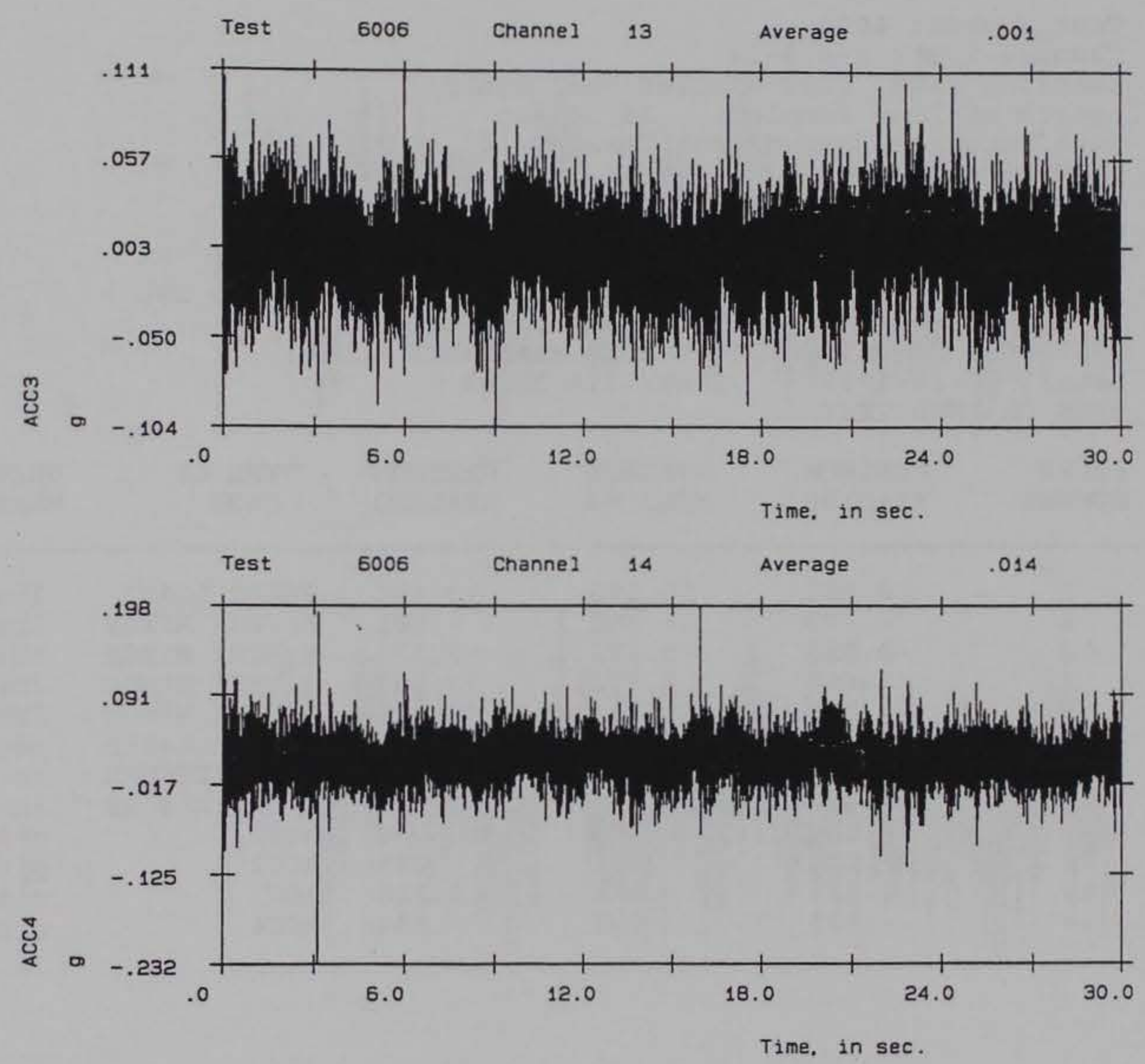
Test Number: 6009

Channel List: $1-6,9-14$

Sampling Rate: 2000 samples/sec/channel

Length of Time Sampled: $30.00 \mathrm{sec}$

Gate Rotation Measurement Channel: 6

Gate Rotation Angle, Start of Test: 60.00 degrees

Gate Rotation Angle, End of Test: 60.00 degrees

CHAN.1-5,9-14 FILTERED@1000 Hz

POOL ELEV. $=300.0 \mathrm{FT} .$, TAIL WATER ELEV. $=279.0 \mathrm{FT}$.

3 GATE GAP, 15 GATES DOWN ( ZEROED ALL GAGES AT 302 SWL)

DOWN GATES $=26-28,36-38,46-48,56-58,66-68$

TEST GATE NO. 47 ( $1: 25$ OLMSTED FLAT GATE MODEL)

Date: 10-13-1993 Time: 16:26:49

OPEN CHANNEL TEST

$\begin{array}{llllcl}\text { PROBE } & \text { MINIMUM } & \text { AVERAGE } & \text { MAXIMUM } & \text { TYPE OF } & \text { UNITS OF } \\ \text { NUMBER } & \text { READING } & \text { READING } & \text { READING } & \text { GAGE } & \text { MEASURE }\end{array}$

$\begin{array}{rrrrll}1 & 9.881 & 10.180 & 10.486 & \text { SHAFT LOAD } & \text { Ibs } \\ 2 & -.779 & -.682 & -.581 & \text { R/VERT HINGE } & \text { Ibs } \\ 3 & -2.553 & -2.473 & -2.371 & \text { R/HORZ HINGE } & \text { Ibs } \\ 4 & 3.668 & 3.772 & 3.867 & \text { L/VERT HINGE } & \text { Ibs } \\ 5 & -.753 & -.633 & -.514 & \text { L/HORZ HINGE } & \text { IBS } \\ 6 & 60.904 & 60.944 & 61.002 & \text { Gate Rotatio } & \text { degrees } \\ 9 & -8.441 & -7.851 & -7.273 & \text { U/S PRESSURE } & \text { in h20 } \\ 10 & -11.525 & -11.441 & -11.366 & \text { D/S PRESSURE } & \text { in h20 } \\ 11 & -.666 & -.056 & .546 & \text { ACC1 } & g^{\prime} \mathrm{s} \\ 12 & -.528 & -.077 & .258 & \text { ACC2 } & g^{\prime} \mathrm{s} \\ 13 & -2.431 & .026 & 2.218 & \text { ACC3 } & g^{\prime} \mathrm{s} \\ 14 & -.835 & .023 & .984 & \text { ACC4 } & g^{\prime} \mathrm{s}\end{array}$



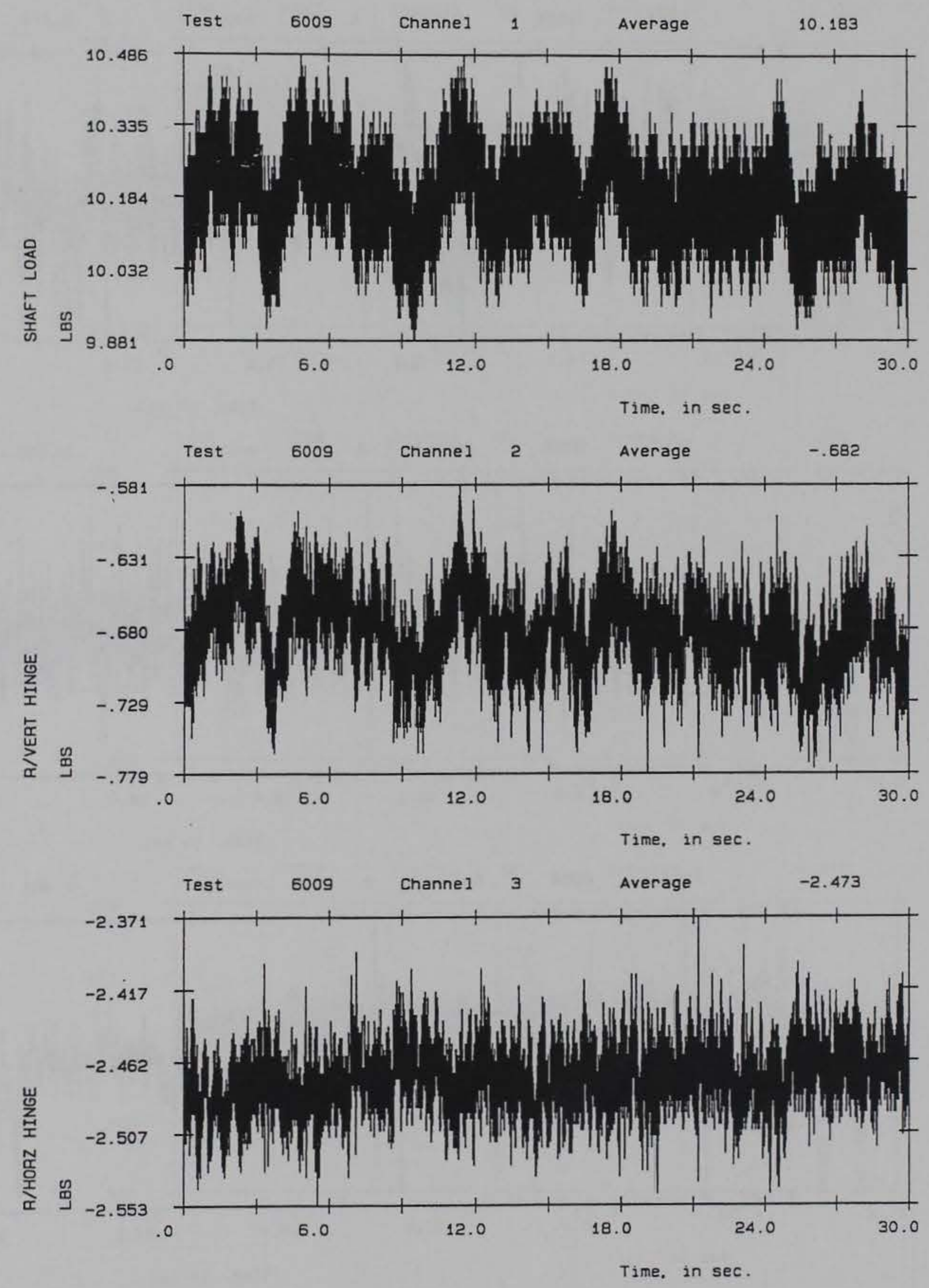

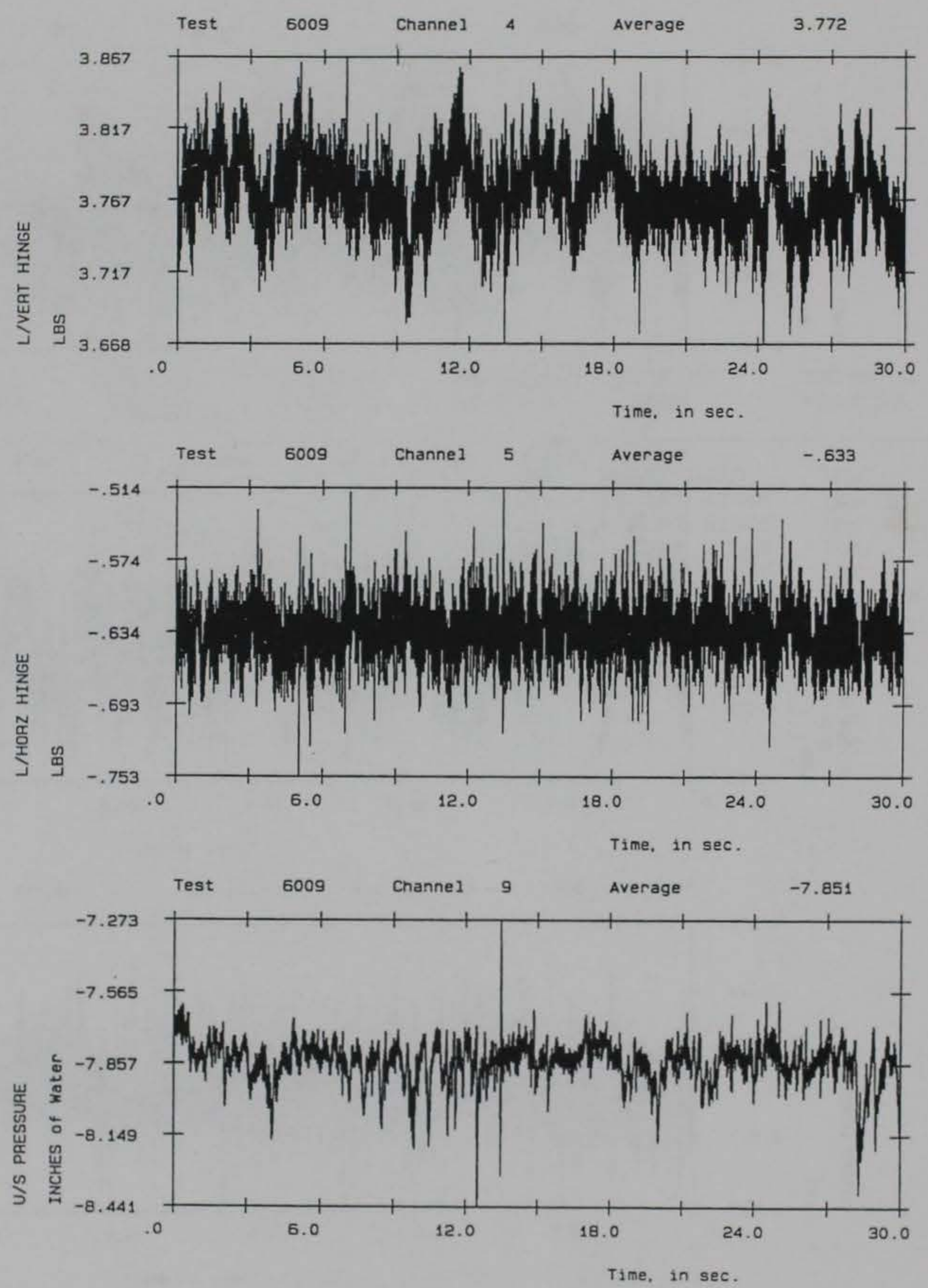

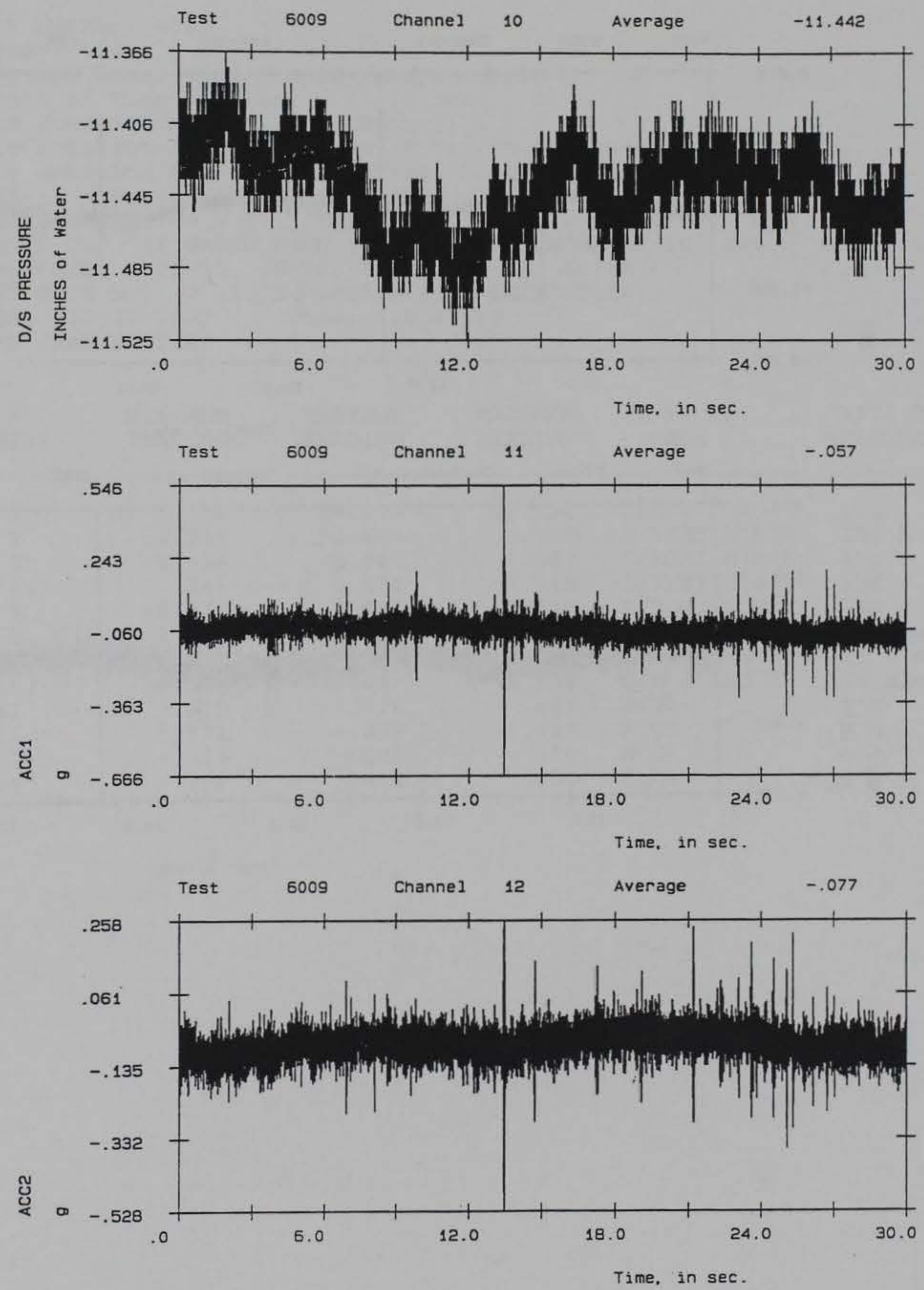

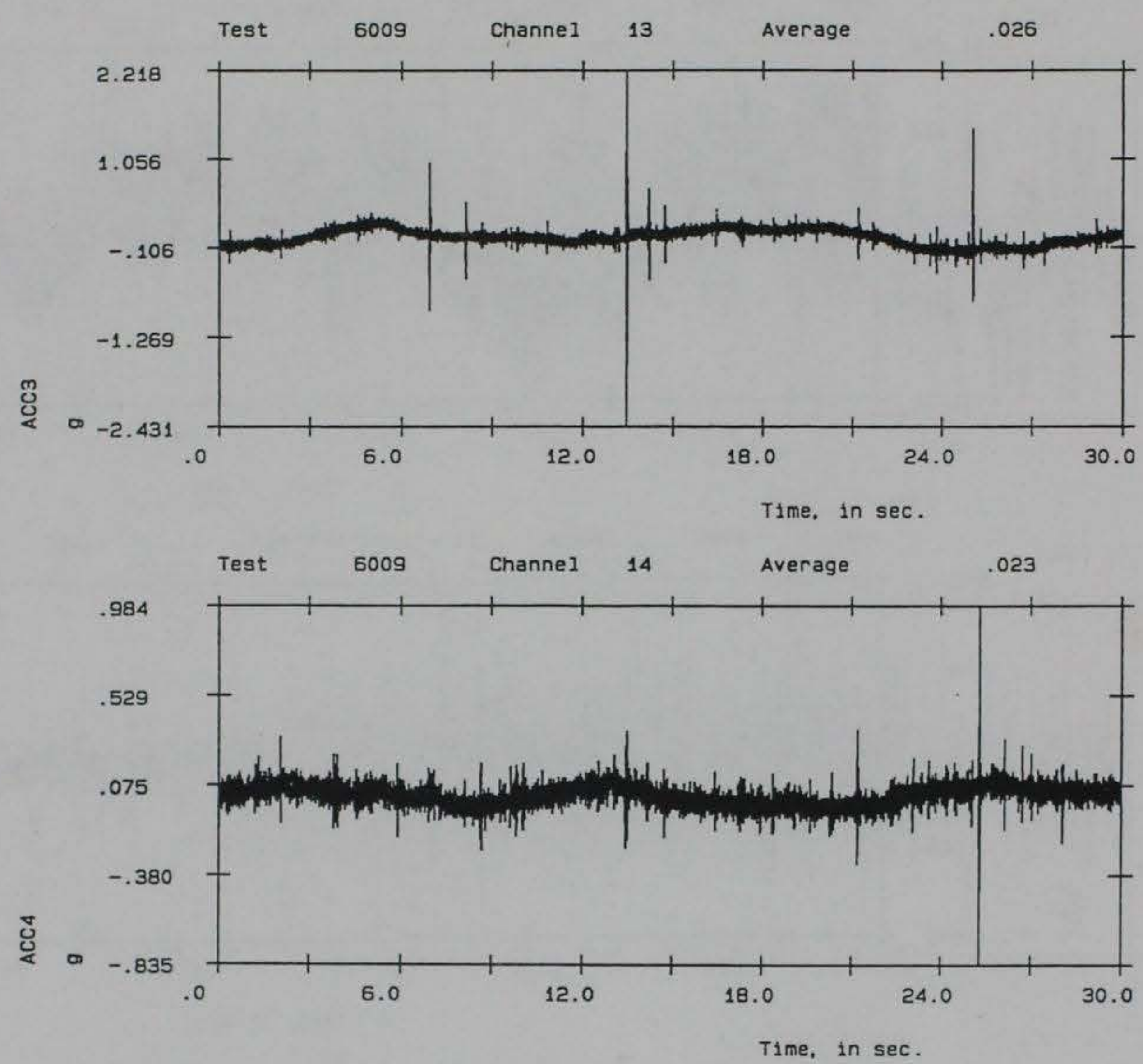
Test Number: 6013

Channel List: $1-6,9-14$

Sampling Rate: 2000 samples/sec/channel

Length of Time Sampled: $30.00 \mathrm{sec}$

Gate Rotation Measurement Channel: 6

Gate Rotation Angle, Start of Test: -2.00 degrees

Gate Rotation Angle, End of Test: 30.00 degrees

CHAN. 1-5, 9-14 FILTERED@1000 Hz

POOL ELEV. $=300.0 \mathrm{FT} .$, TAIL WATER ELEV. $=279.0 \mathrm{FT}$.

3 GATE GAP, 15 GATES DOWN ( ZEROED ALL GAGES AT 302 SWL)

DOWN GATES $=26-28,36-38,46-48,56-58,66-68$

TEST GATE NO. 47 ( $1: 25$ OLMSTED FLAT GATE MODEL)

Date: 10-13-1993 Time: 16:49:33

OPEN CHANNEL TEST

$\begin{array}{llllcl}\text { PROBE } & \text { MINIMUM } & \text { AVERAGE } & \text { MAXIMUM } & \text { TYPE OF } & \text { UNITS OF } \\ \text { NUMBER } & \text { READING } & \text { READING } & \text { READING } & \text { GAGE } & \text { MEASURE }\end{array}$

$\begin{array}{rrrrll}1 & 7.532 & 14.773 & 18.188 & \text { SHAFT LOAD } & \text { Ibs } \\ 2 & -3.736 & -2.694 & -.789 & \text { R/VERT HINGE } & \text { lbs } \\ 3 & -4.634 & -1.900 & .827 & \text { R/HORZ HINGE } & \text { Ibs } \\ 4 & -246 & 2.001 & 3.849 & \text { L/VERT HINGE } & \text { Ibs } \\ 5 & -2.850 & -.986 & 1.180 & \text { L/HORZ HINGE } & \text { lBS } \\ 6 & -2.155 & 13.208 & 28.810 & \text { Gate Rotatio } & \text { degrees } \\ 9 & -6.543 & -5.711 & -4.754 & \text { U/S PRESSURE } & \text { in h20 } \\ 10 & -18.132 & -13.512 & -8.960 & \text { D/S PRESSURE } & \text { in h20 } \\ 11 & -.510 & -.025 & .444 & \text { ACC1 } & g^{\prime} \mathrm{s} \\ 12 & -.671 & -.036 & .517 & \text { ACC2 } & g^{\prime} \mathrm{s} \\ 13 & -.339 & .005 & .410 & \text { ACC3 } & g^{\prime} \mathrm{s} \\ 14 & -.390 & .013 & .334 & \text { ACC4 } & g^{\prime} \mathrm{s}\end{array}$



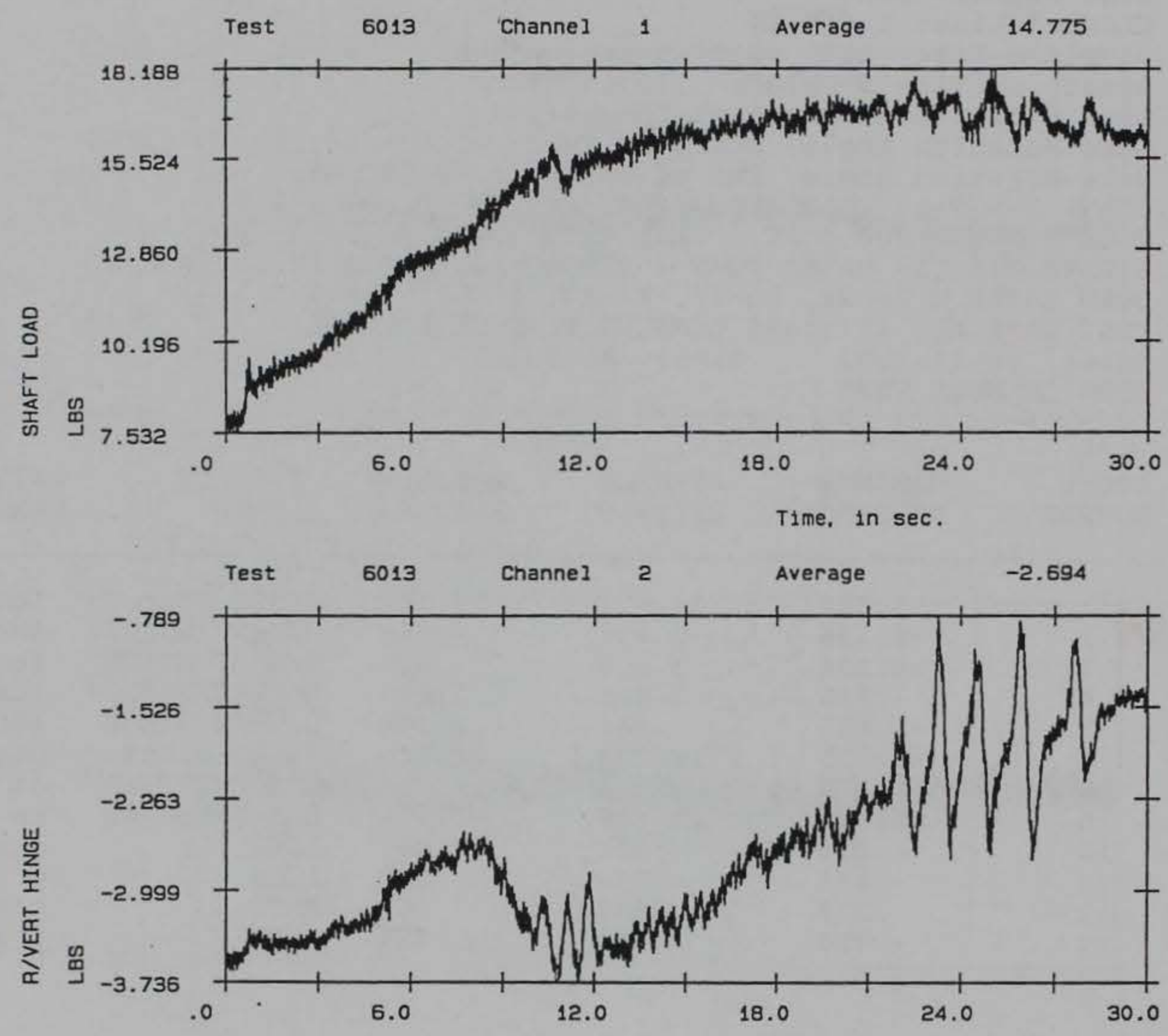

Time, in sec.

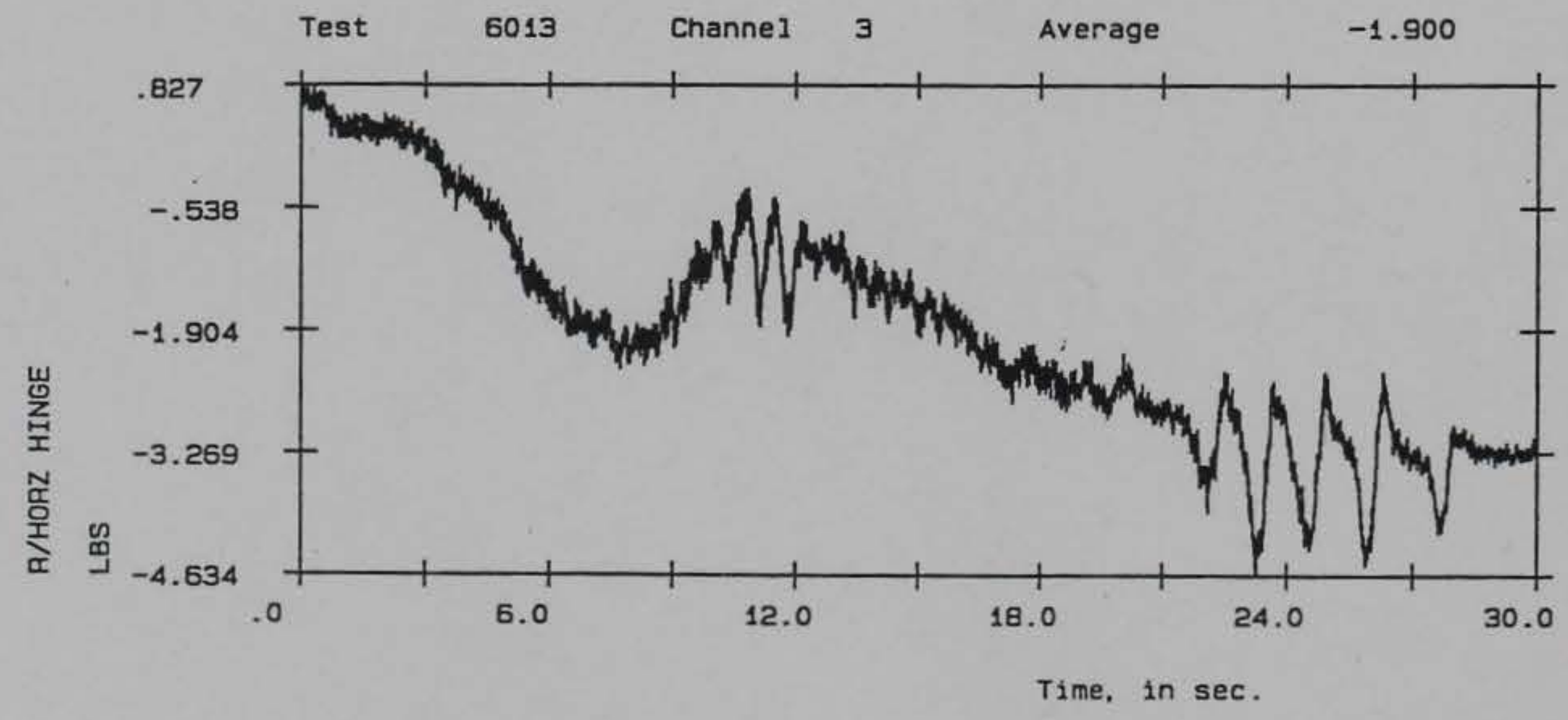



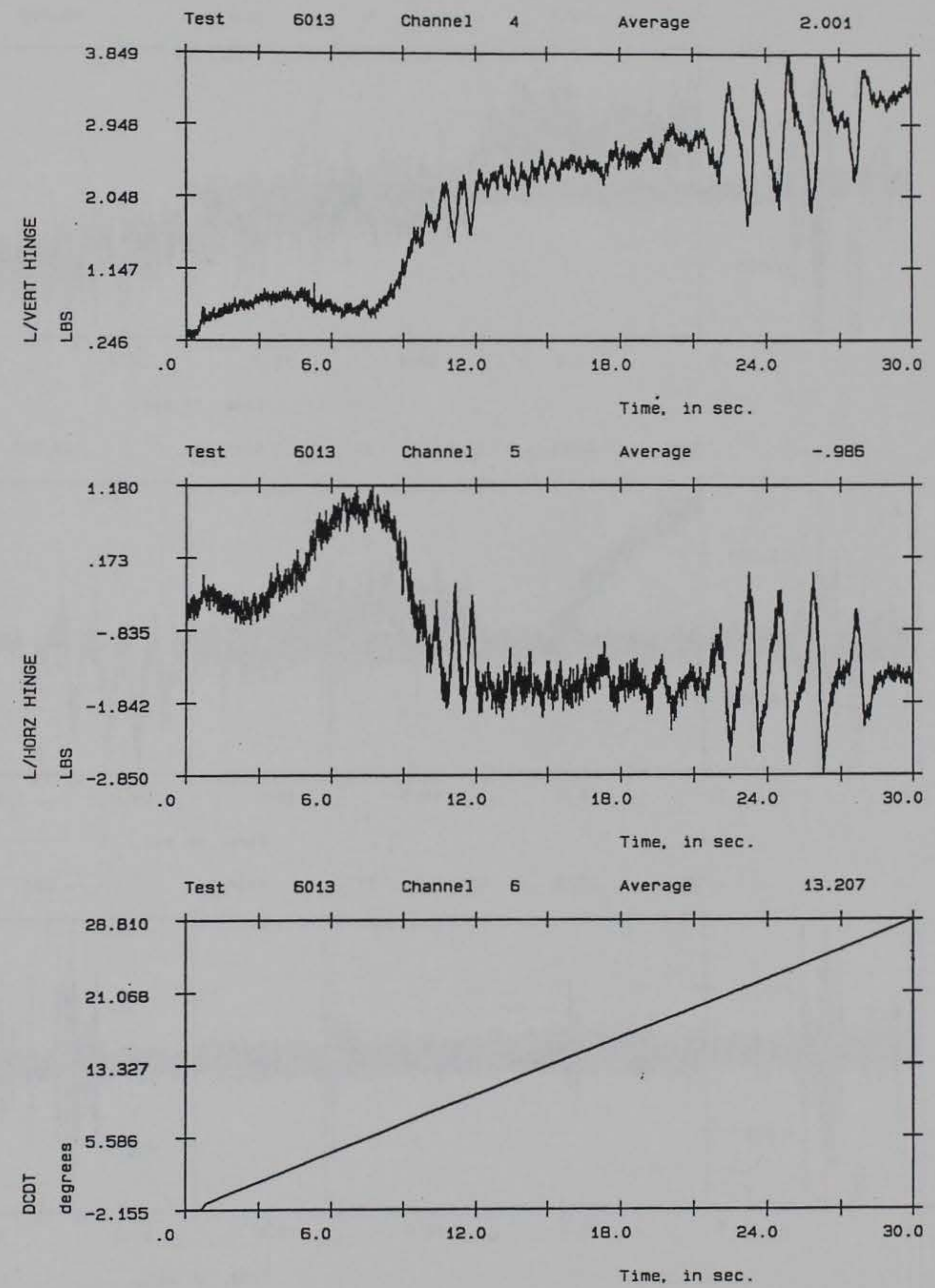

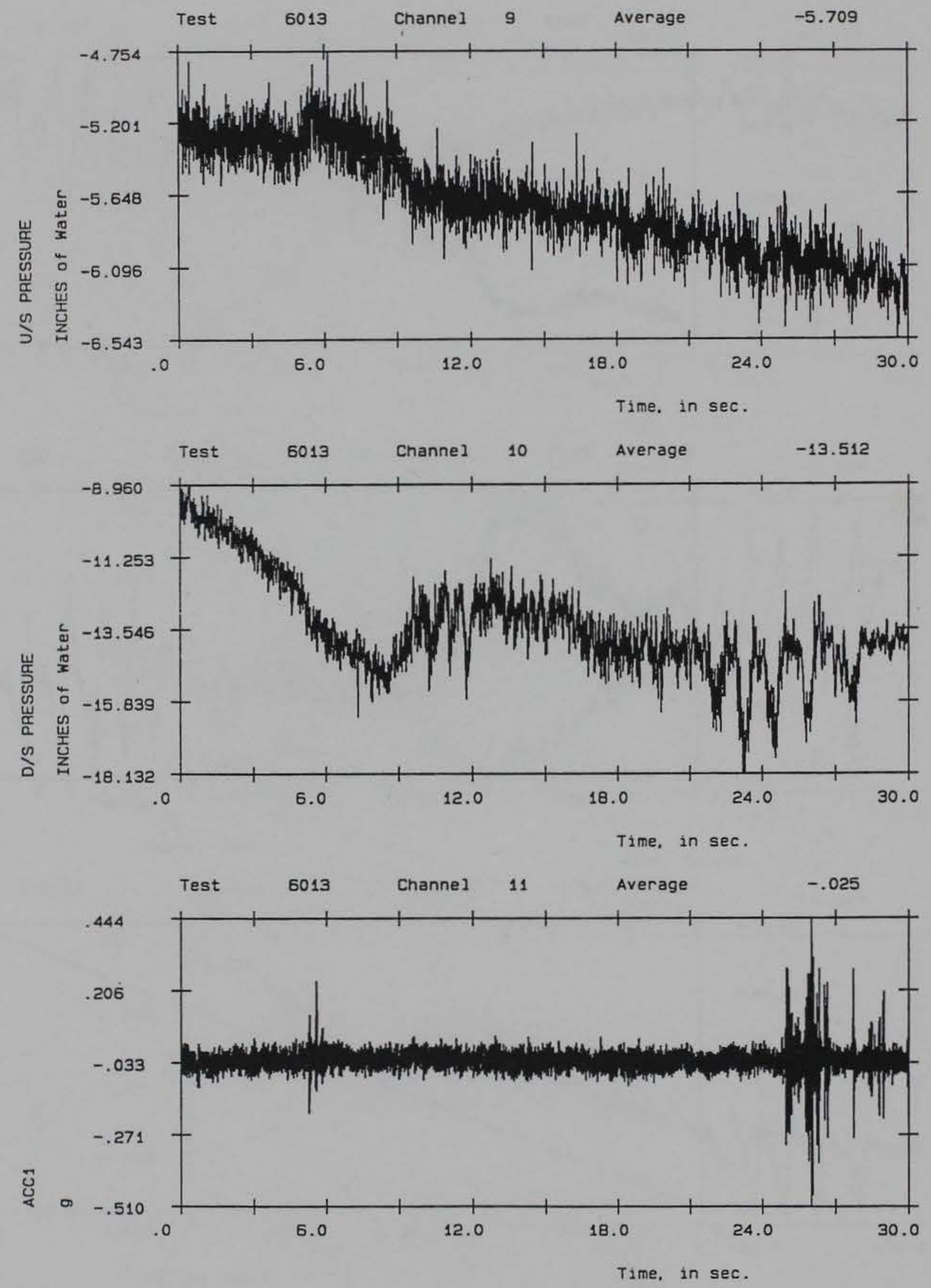

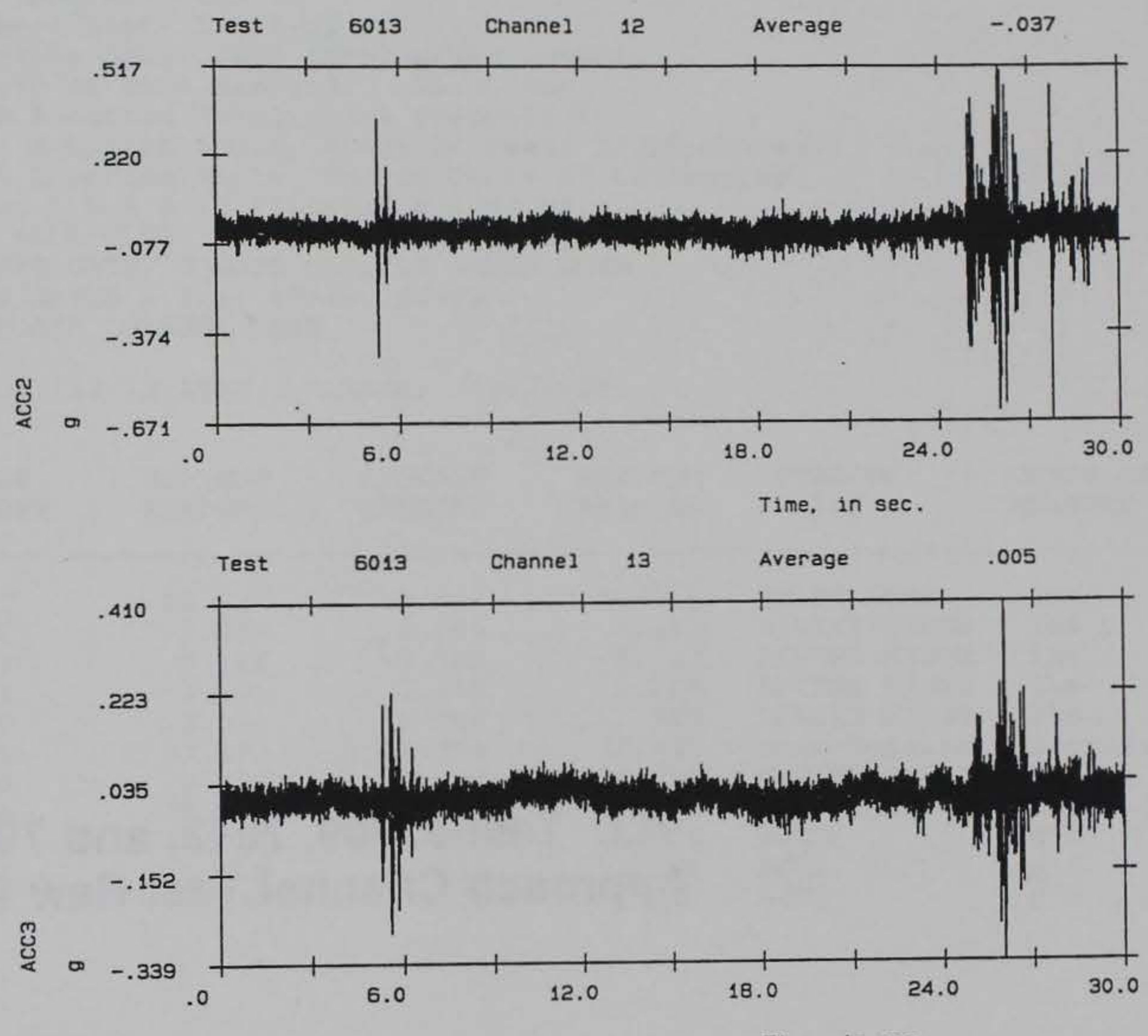

Time, in sec.

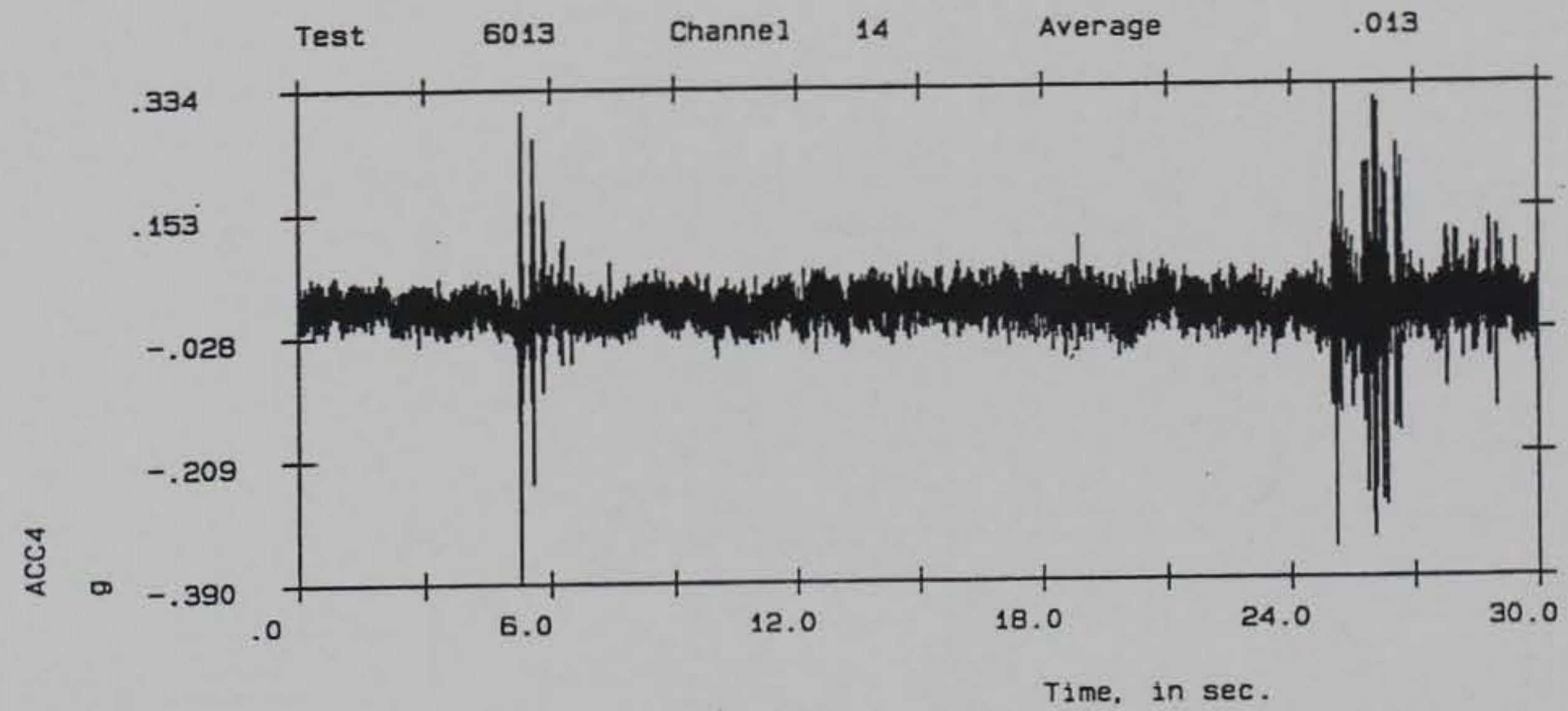


A3. Test \#7009, 7013, and 7017, Approach Channel Test Raw Data 
Test Number: 7009

Channel List: $1-6,9-13$

Sampling Rate: 2000 samples/sec/channel

Length of Time Sampled: $30.00 \mathrm{sec}$

Gate Rotation Measurement Channel: 6

Gate Rotation Angle, Start of Test: 27.00 degrees

Gate Rotation Angle, End of Test: 27.00 degrees

CHAN. $1-5,9 \& 10$ FILTERED @ $1000 \mathrm{~Hz}$,

300 POOL ELEV. 279 TAIL WATER ELEV

CENTER GATE, 3 GATE GAP, 15 GATES DOWN

DOWN GATES $=1-6,46-48,87-92$

APPROACH CHANNEL TEST

Date: 12-13-1993 Time: $12: 28: 24$

PROBE MINIMUM AVERAGE MAXIMUM TYPE OF UNITS OF

$\begin{array}{rrrrll}1 & 10.627 & 15.684 & 18.415 & \text { SHAFT LOAD } & \text { Ibs } \\ 2 & 1.286 & 2.365 & 3.239 & \text { R/VERT HINGE } & \text { lbs } \\ 3 & -5.186 & -3.522 & -2.722 & \text { R/HORZ HINGE } & \text { lbs } \\ 4 & 1.001 & 2.918 & 3.865 & \text { L/VERT HINGE } & \text { lbs } \\ 5 & -2.518 & -1.346 & .509 & \text { L/HORZ HINGE } & \text { lBS } \\ 6 & 27.293 & 27.354 & 27.401 & \text { Gate ROtatio } & \text { degree } \\ 9 & -6.830 & -5.696 & -4.526 & \text { U/S PRESSURE } & \text { in h20 } \\ 10 & -15.937 & -13.714 & -11.673 & \text { D/S PRESSURE } & \text { in h20 } \\ 11 & -1.532 & -.033 & 1.525 & \text { ACC1 } & \text { g's } \\ 12 & -1.519 & -.043 & 1.546 & \text { ACC2 } & g^{\prime} \mathrm{s} \\ 13 & -1.449 & .009 & 1.387 & \text { ACC3 } & g^{\prime} \mathrm{s}\end{array}$




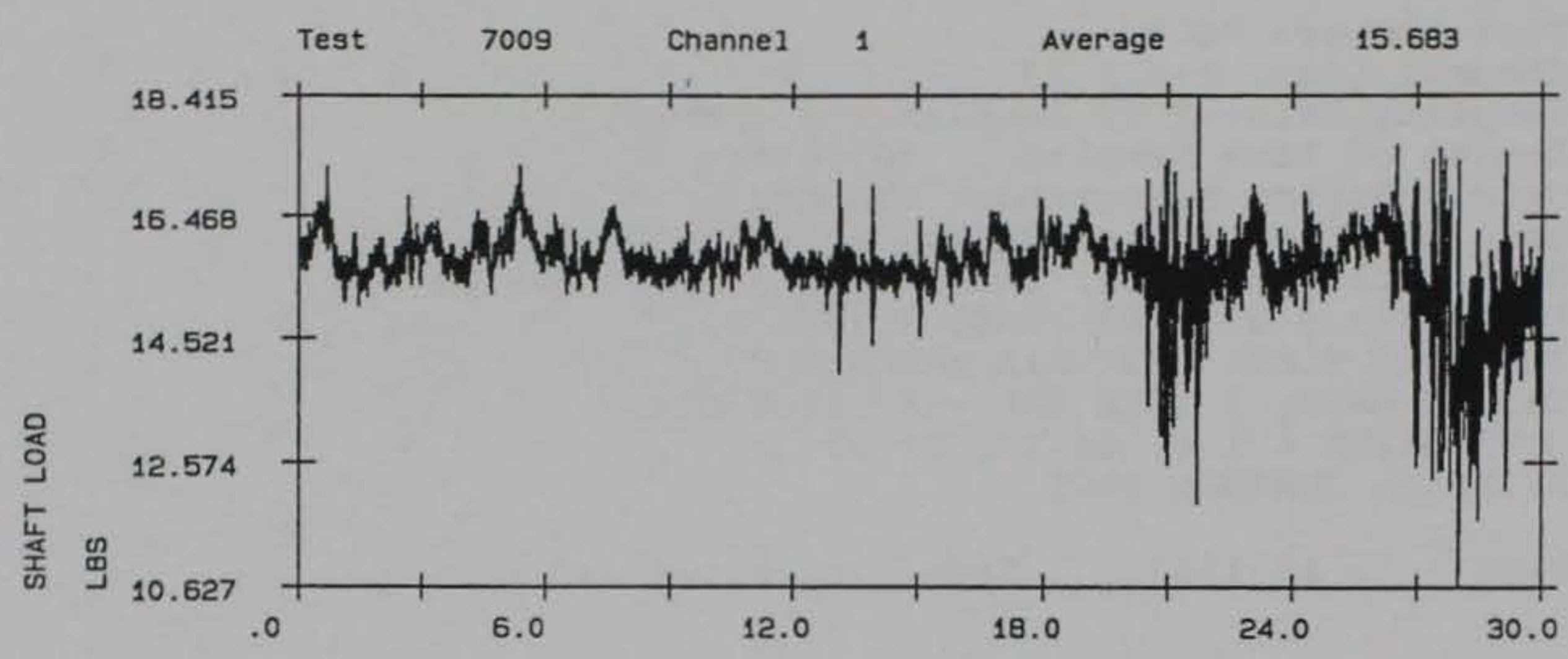

Time, in sec.

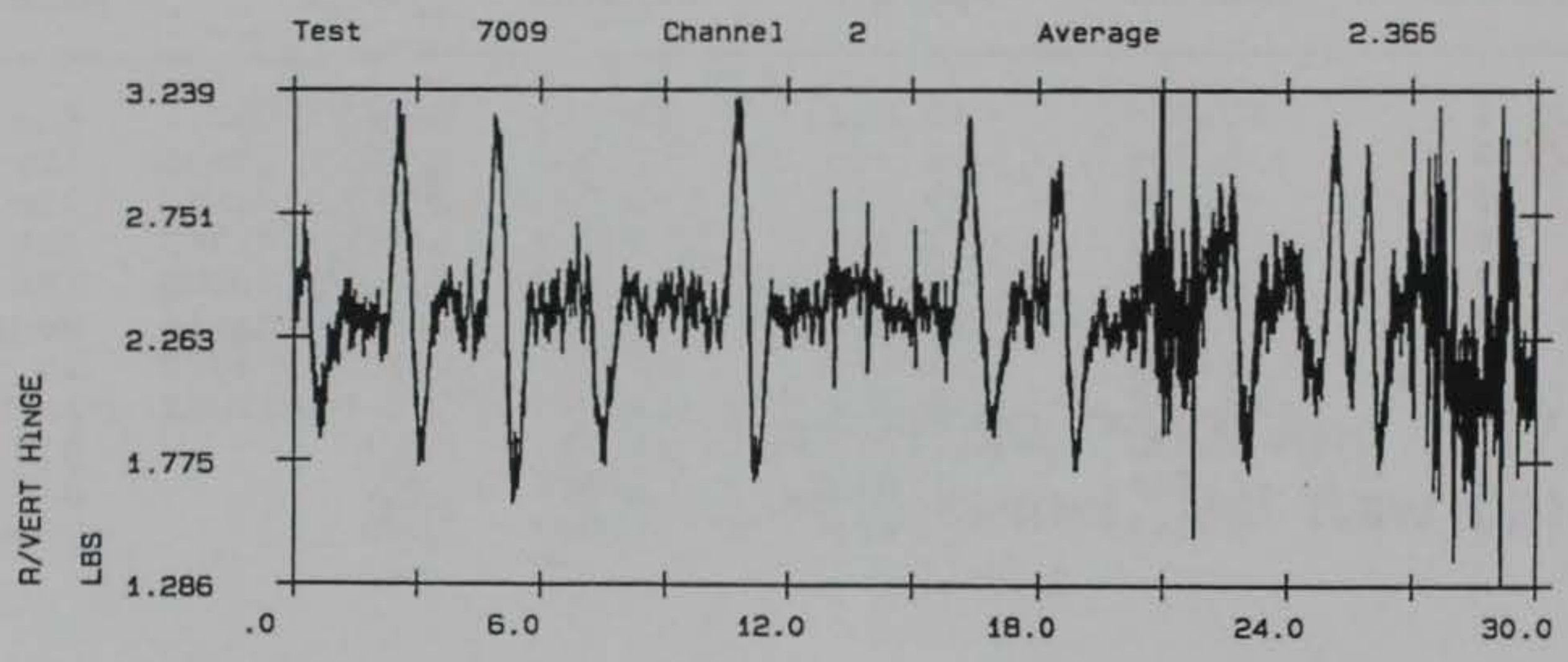

Time, in sec.

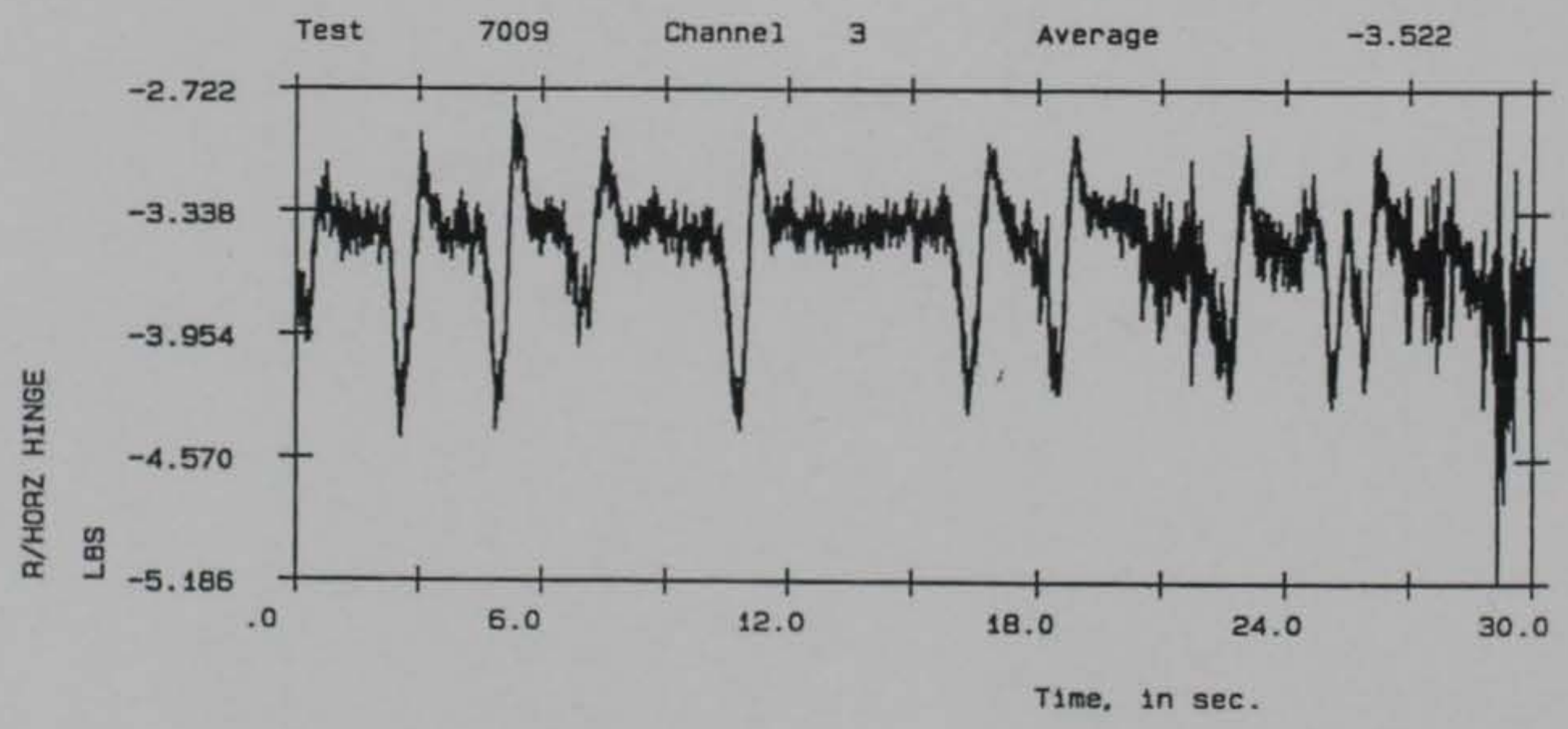



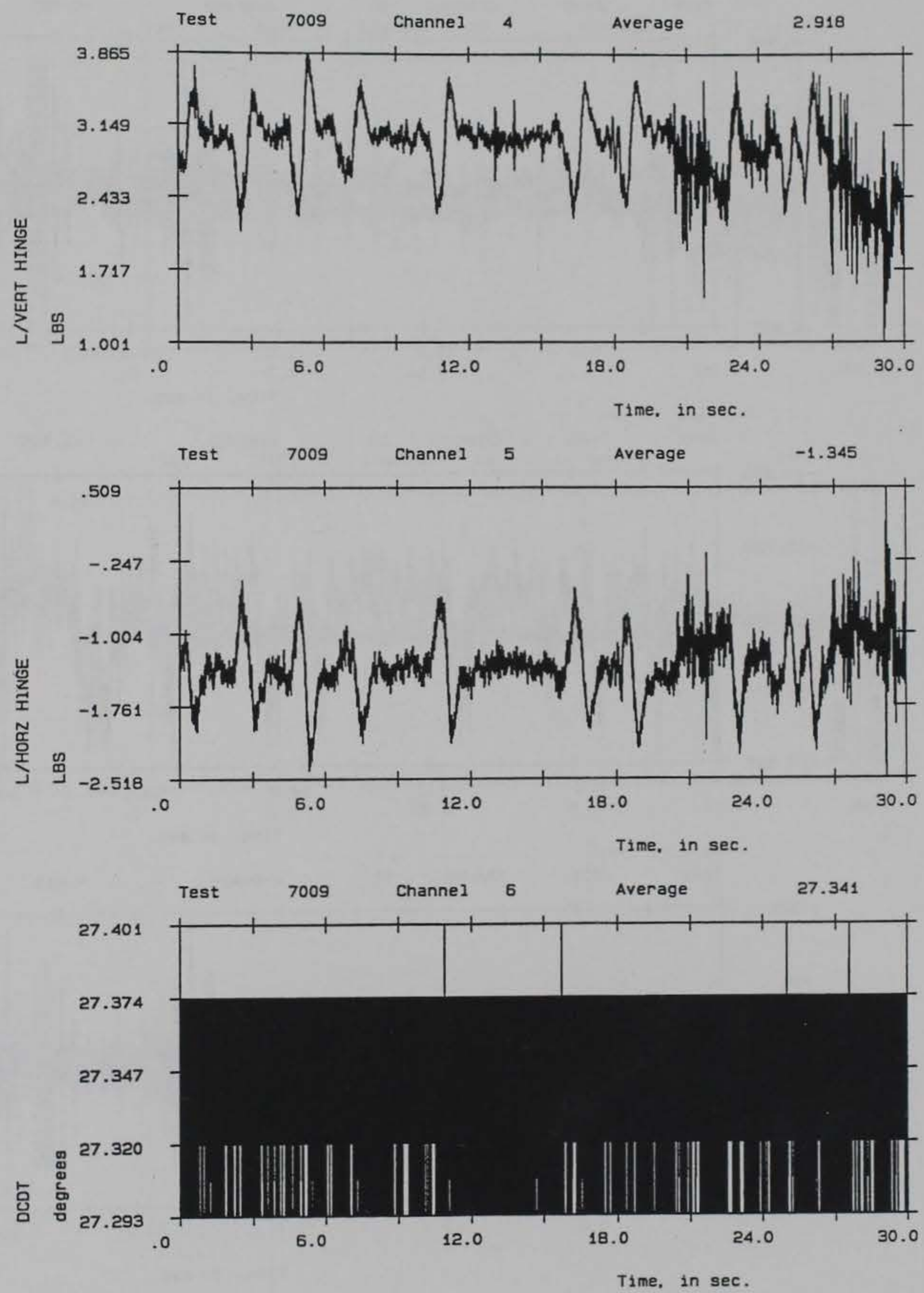

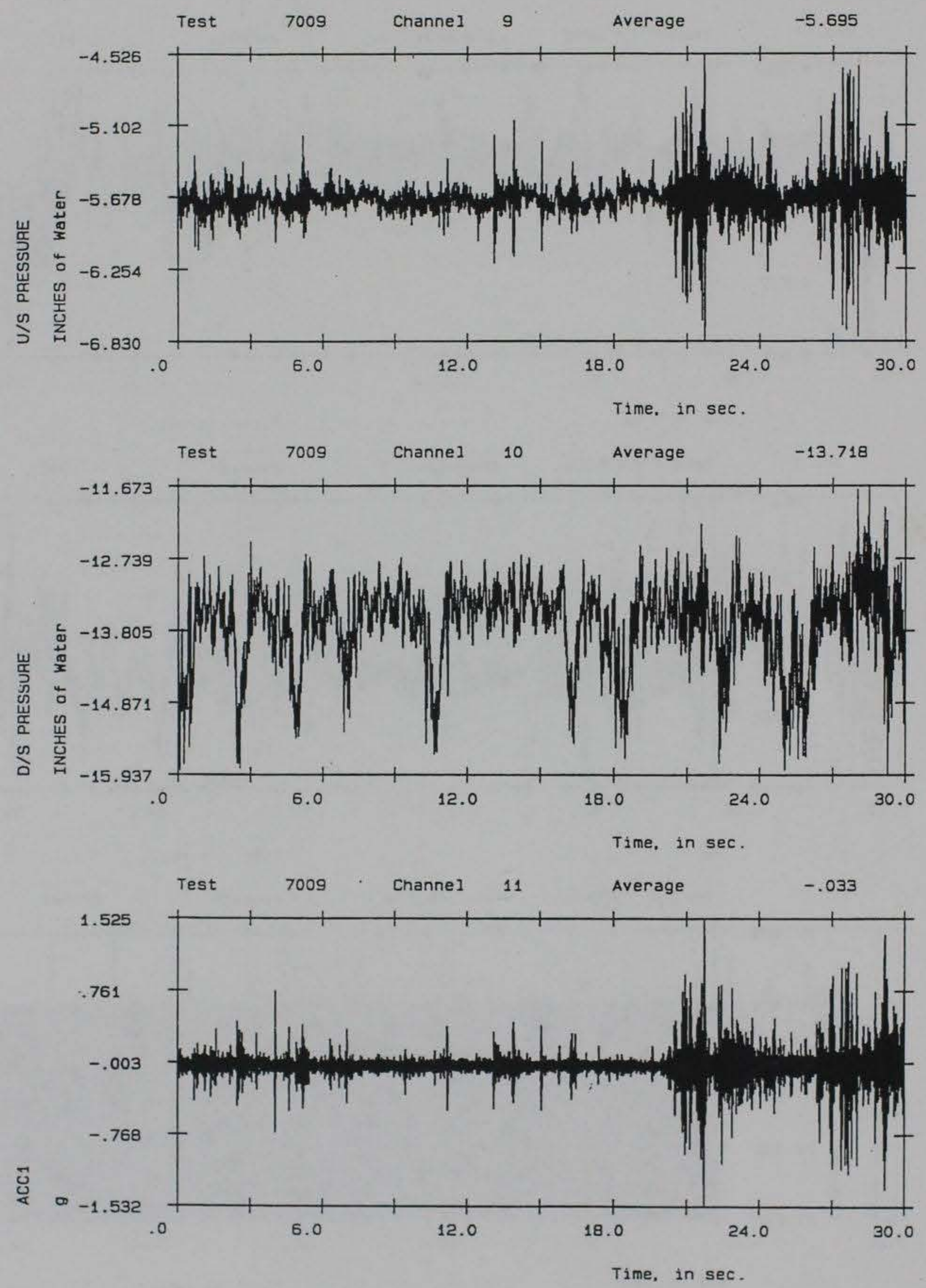

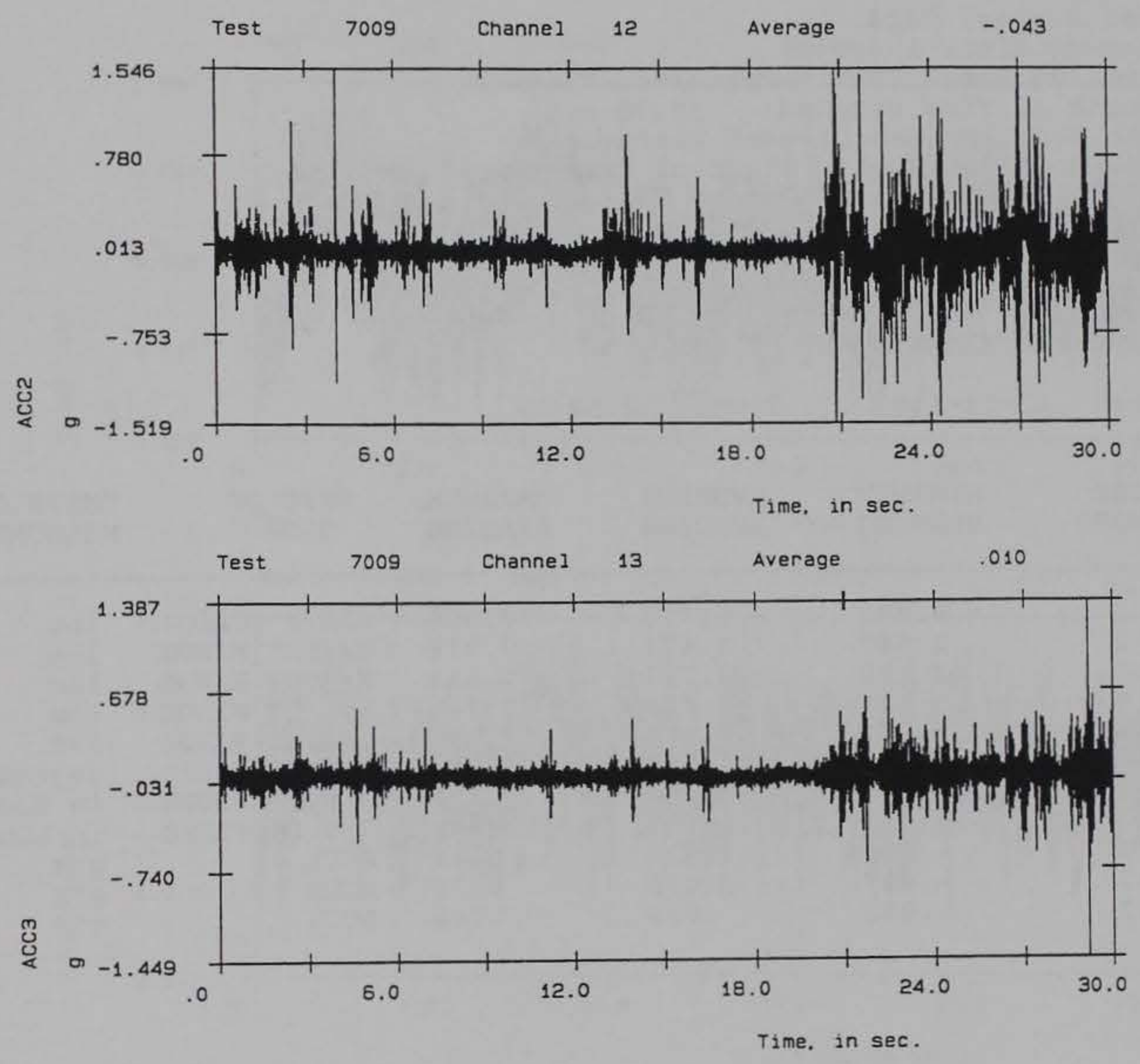
Test Number: 7013

Channel List: 1-6,9-13

Sampling Rate: 2000 samples/sec/channel

Length of Time Sampled: $30.00 \mathrm{sec}$

Gate Rotation Measurement Channel: 6

Gate Rotation Angle, Start of Test: 60.00 degrees

Gate Rotation Angle, End of Test: 60.00 degrees

CHAN. 1-5,9\&10 FILTERED@1000 Hz,

300 POOL ELEV. 279 TAIL WATER ELEV

CENTER GATE, 3 GATE GAP, 15 GATES DOWN

DOWN GATES $=1-6,46-48,87-92$

APPROACH CHANNEL TEST

Date: 12-13-1993 Time: 12:58:13

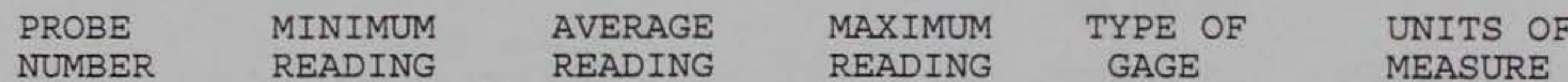

\begin{tabular}{rrrrll}
\hline 1 & 9.389 & 9.702 & 9.996 & SHAFT LOAD & Ibs \\
2 & 2.547 & 2.677 & 2.777 & R/VERT HINGE & Ibs \\
3 & -2.839 & -2.723 & -2.611 & R/HORZ HINGE & lbs \\
4 & 3.523 & 3.638 & 3.745 & L/VERT HINGE & Ibs \\
5 & -.582 & -.440 & -.222 & L/HORZ HINGE & IBS \\
6 & 60.904 & 60.989 & 61.034 & Gate ROtatio & degree \\
9 & -8.131 & -7.840 & -7.471 & U/S PRESSURE & in h20 \\
10 & -11.112 & -11.033 & -10.963 & D/S PRESSURE & in h20 \\
11 & -.389 & -.019 & .343 & ACC1 & $g^{\prime} \mathrm{s}$ \\
12 & -.407 & -.039 & .236 & ACC2 & $g^{\prime} \mathrm{s}$ \\
13 & -.852 & .031 & .706 & ACC3 & $g^{\prime} \mathrm{s}$
\end{tabular}



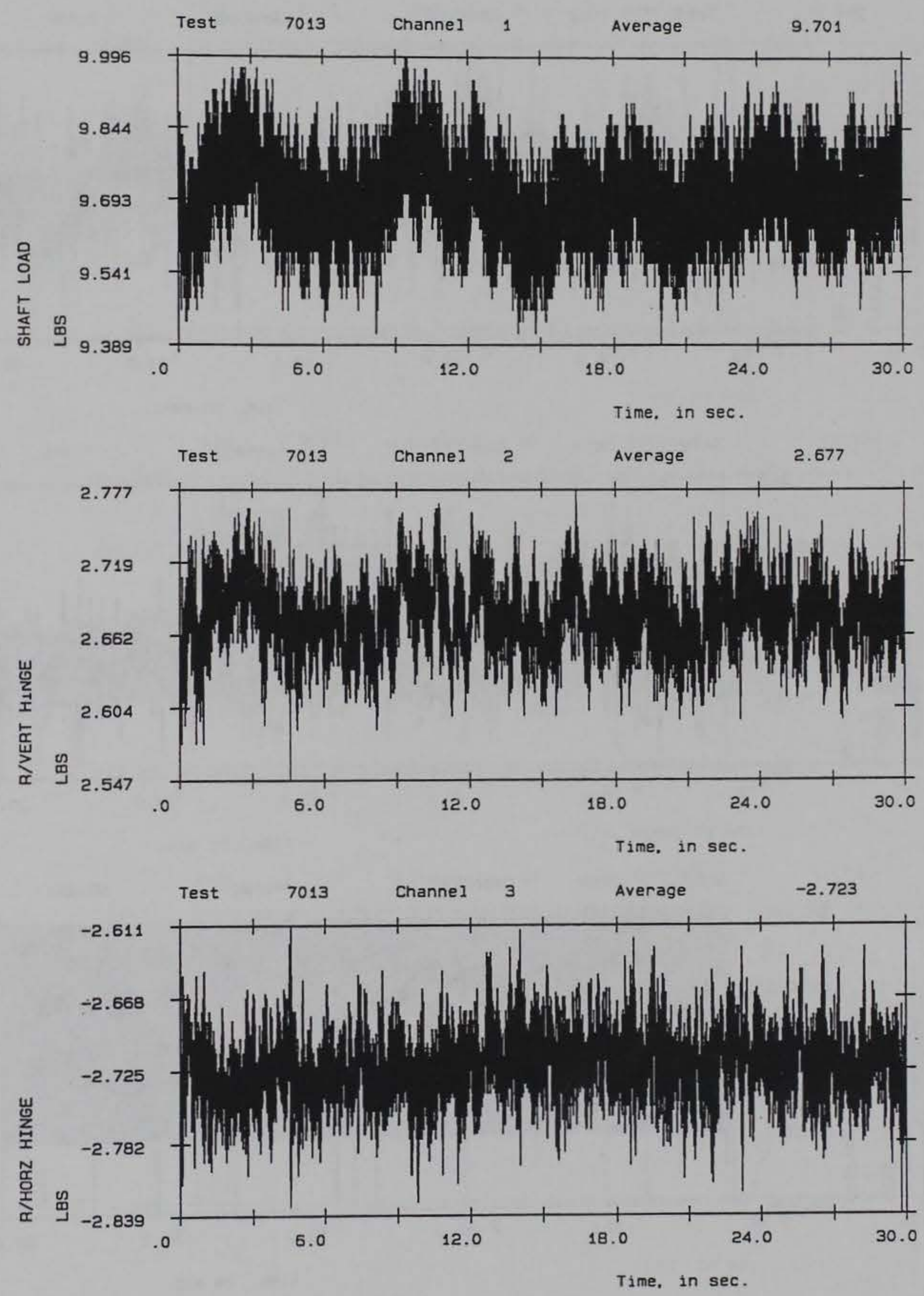

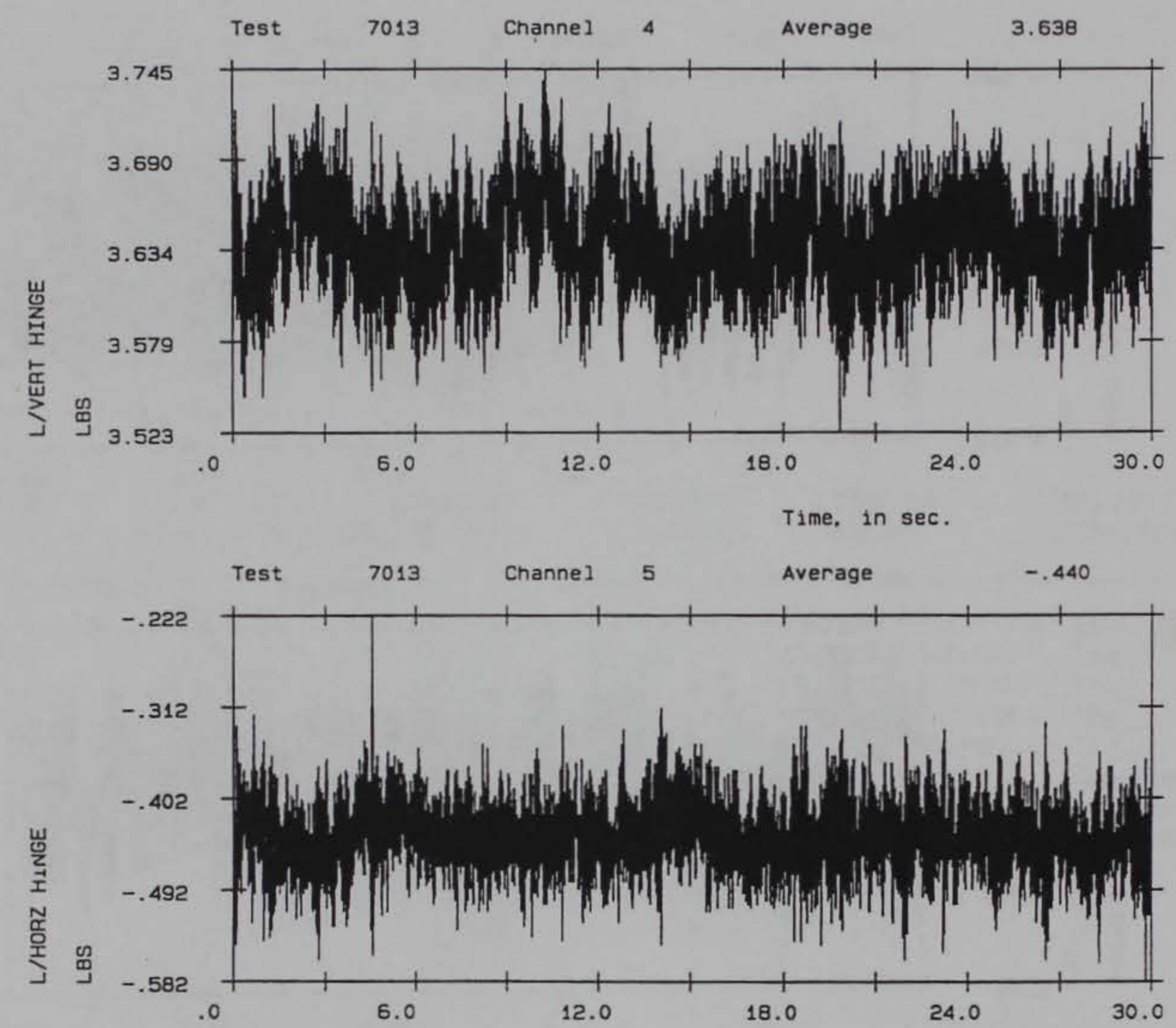

Time, in sec.

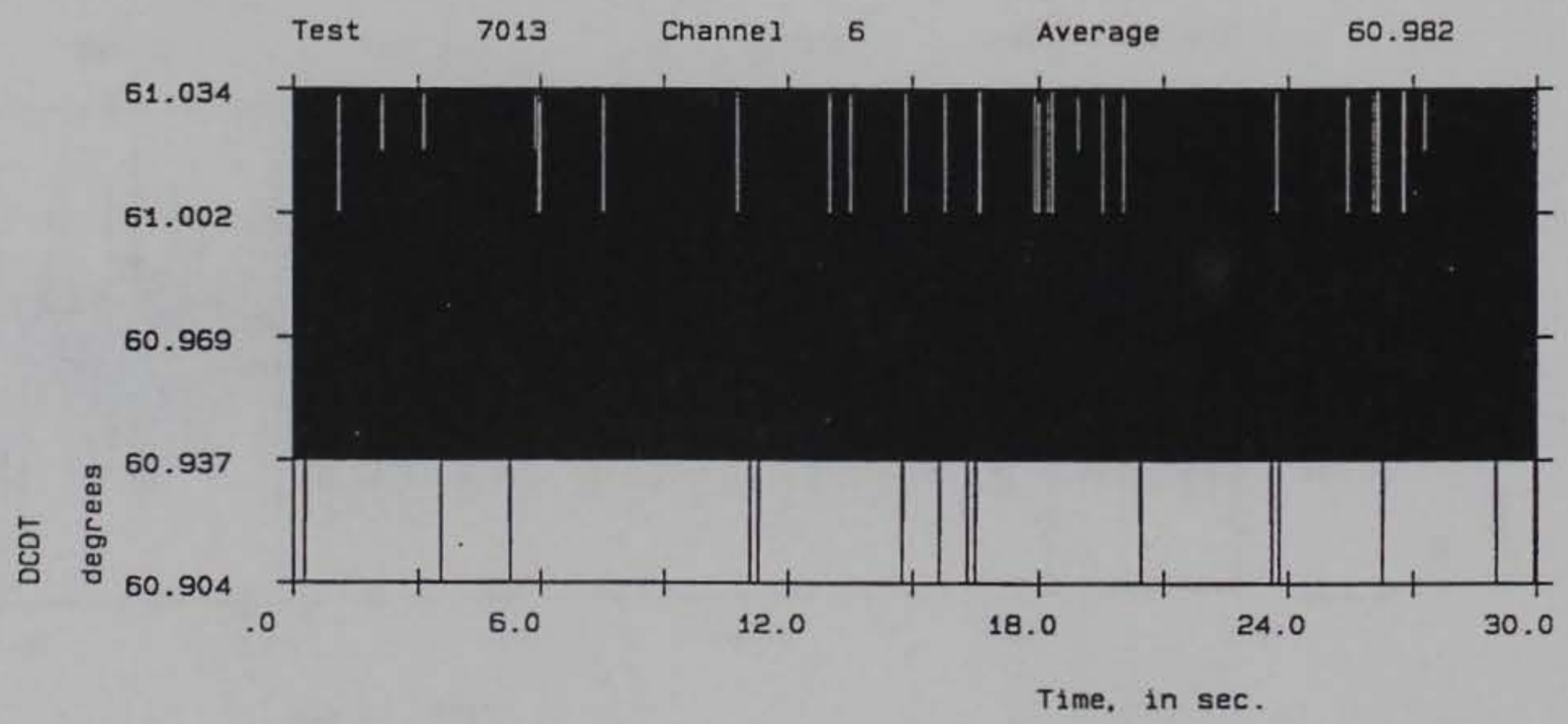



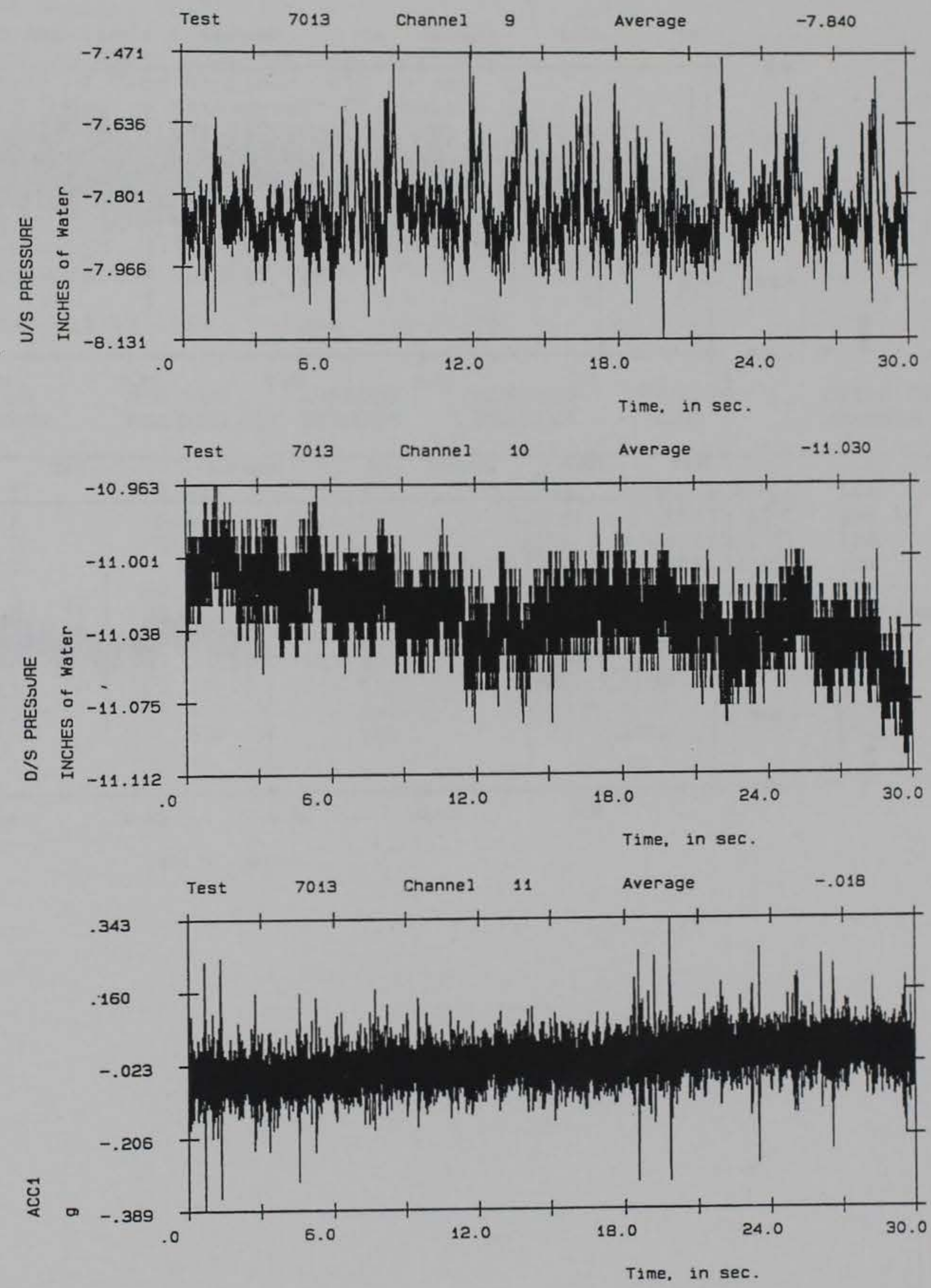

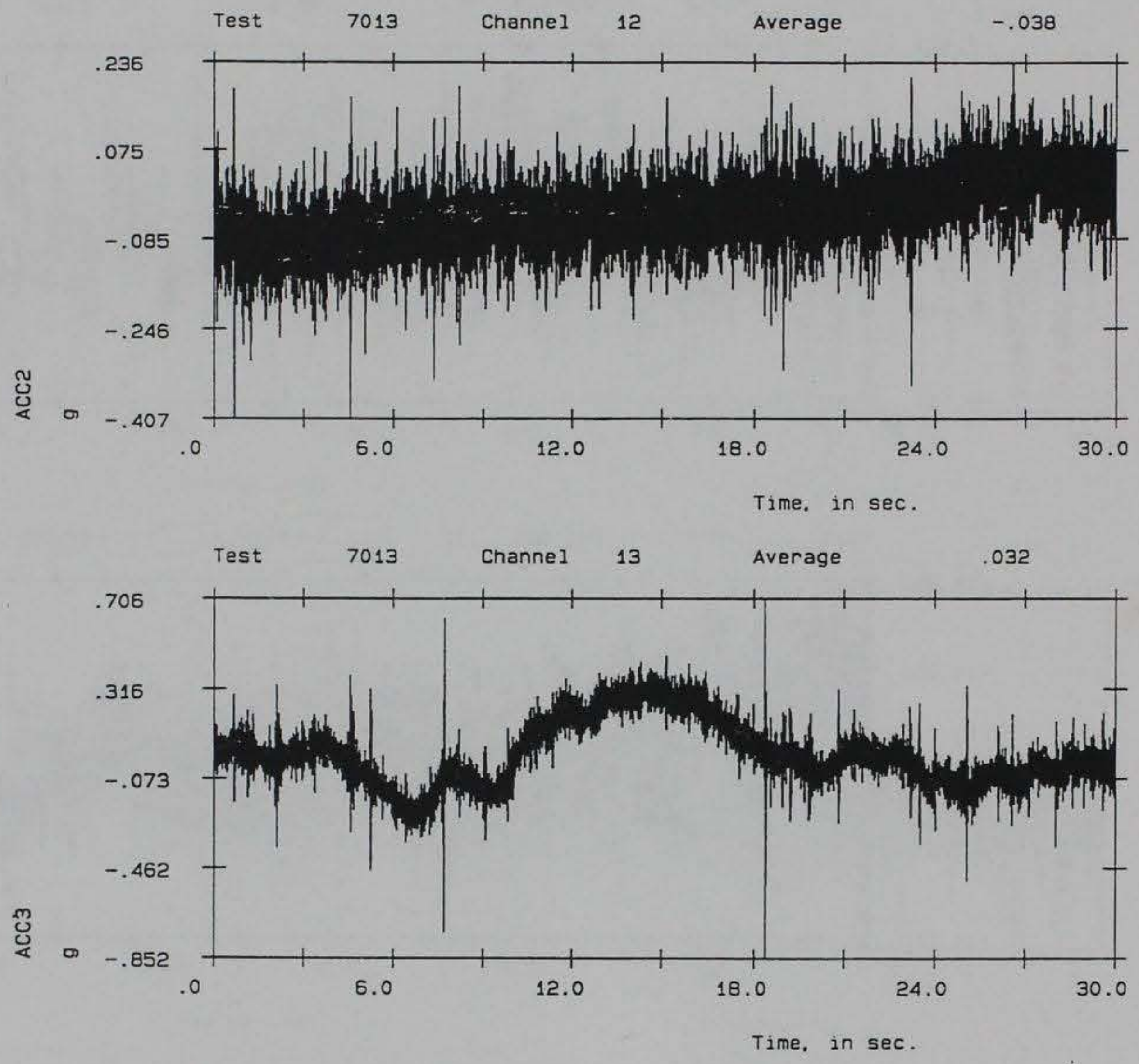
Test Number: 7017

Channel List: $1-6,9-13$

Sampling Rate: 2000 samples/sec/channel

Length of Time Sampled: $30.00 \mathrm{sec}$

Gate Rotation Measurement Channel: 6

Gate Rotation Angle, Start of Test: -2.00 degrees

Gate Rotation Angle, End of Test: 30.00 degrees

CHAN. 1-5,9\&10 FILTERED@1000 Hz,

300 POOL ELEV. 279 TAIL WATER ELEV

CENTER GATE, 3 GATE GAP, 15 GATES DOWN

DOWN GATES $=1-6,46-48,87-92$

GATE ROTATION CHANNEL TEST

Date: 12-13-1993 Time: 14:41:35

$\begin{array}{llllcl}\text { PROBE } & \text { MINIMUM } & \text { AVERAGE } & \text { MAXIMUM } & \text { TYPE OF } & \text { UNITS OF } \\ \text { NUMBER } & \text { READING } & \text { READING } & \text { READING } & \text { GAGE } & \text { MEASURE }\end{array}$

$\begin{array}{rrrrll}1 & 7.546 & 14.970 & 18.391 & \text { SHAFT LOAD } & \text { Ibs } \\ 2 & -1.279 & -.054 & 2.026 & \text { R/VERT HINGE } & \text { Ibs } \\ 3 & -5.308 & -2.513 & .471 & \text { R/HORZ HINGE } & \text { Ibs } \\ 4 & -284 & 2.071 & 4.262 & \text { L/VERT HINGE } & \text { lbs } \\ 5 & -2.696 & -.828 & 1.274 & \text { L/HORZ HINGE } & \text { lBS } \\ 6 & -2.128 & 13.241 & 28.864 & \text { Gate Rotatio } & \text { degree } \\ 9 & -6.477 & -5.322 & -4.725 & \text { U/S PRESSURE } & \text { in h20 } \\ 10 & -17.951 & -13.304 & -8.380 & \text { D/S PRESSURE } & \text { in h20 } \\ 11 & -2.396 & -.030 & 2.169 & \text { ACC1 } & g^{\prime} \mathrm{s} \\ 12 & -1.915 & -.032 & 1.387 & \text { ACC2 } & g^{\prime} \mathrm{s} \\ 13 & -1.094 & .013 & 1.357 & \text { ACC3 } & g^{\prime} \mathrm{s}\end{array}$




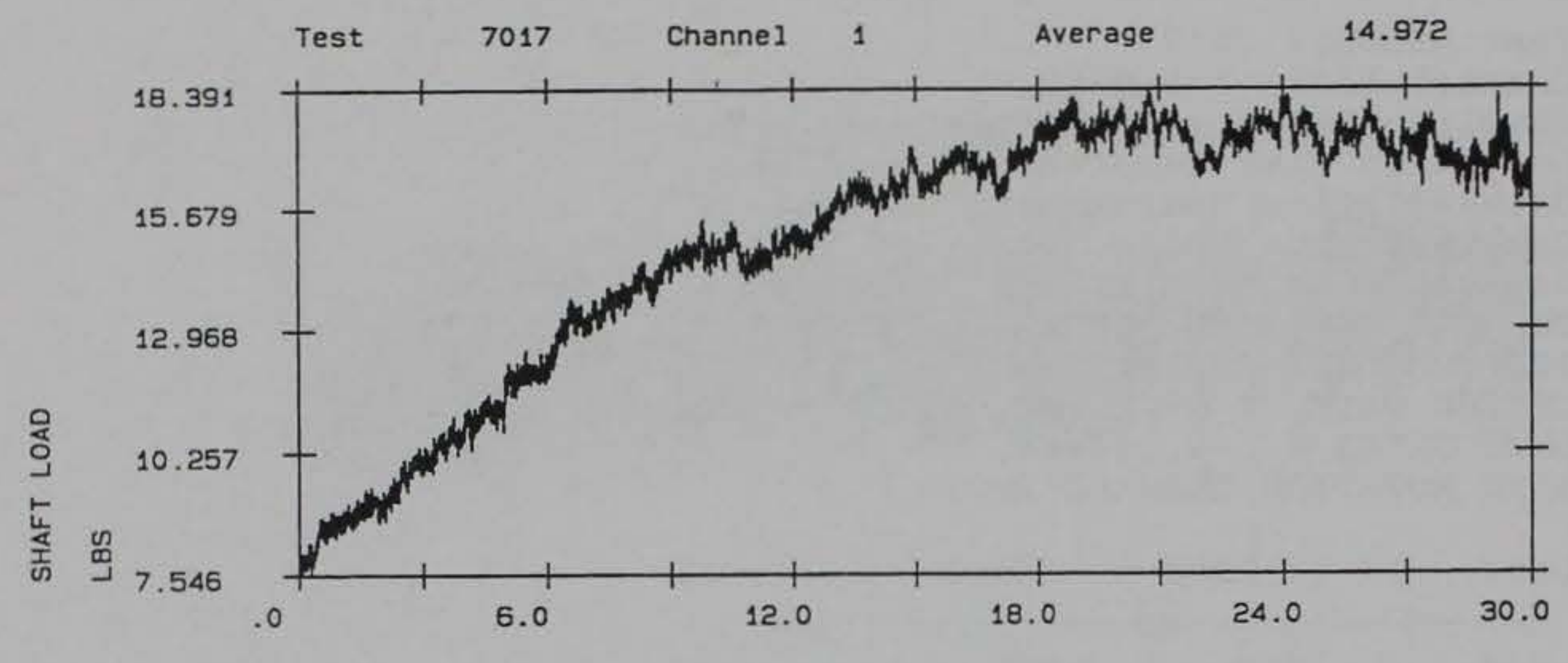

Time. in sec.
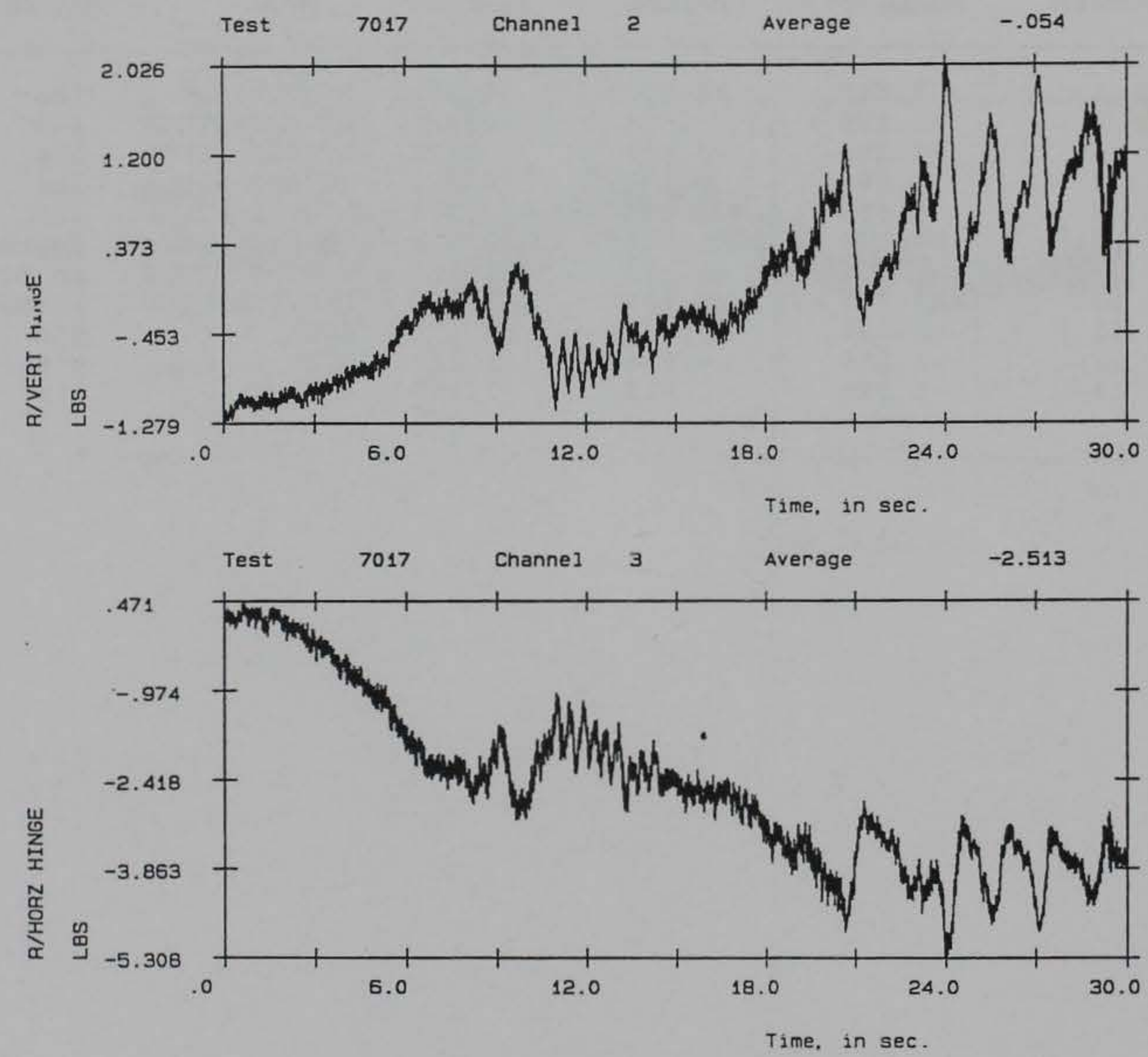

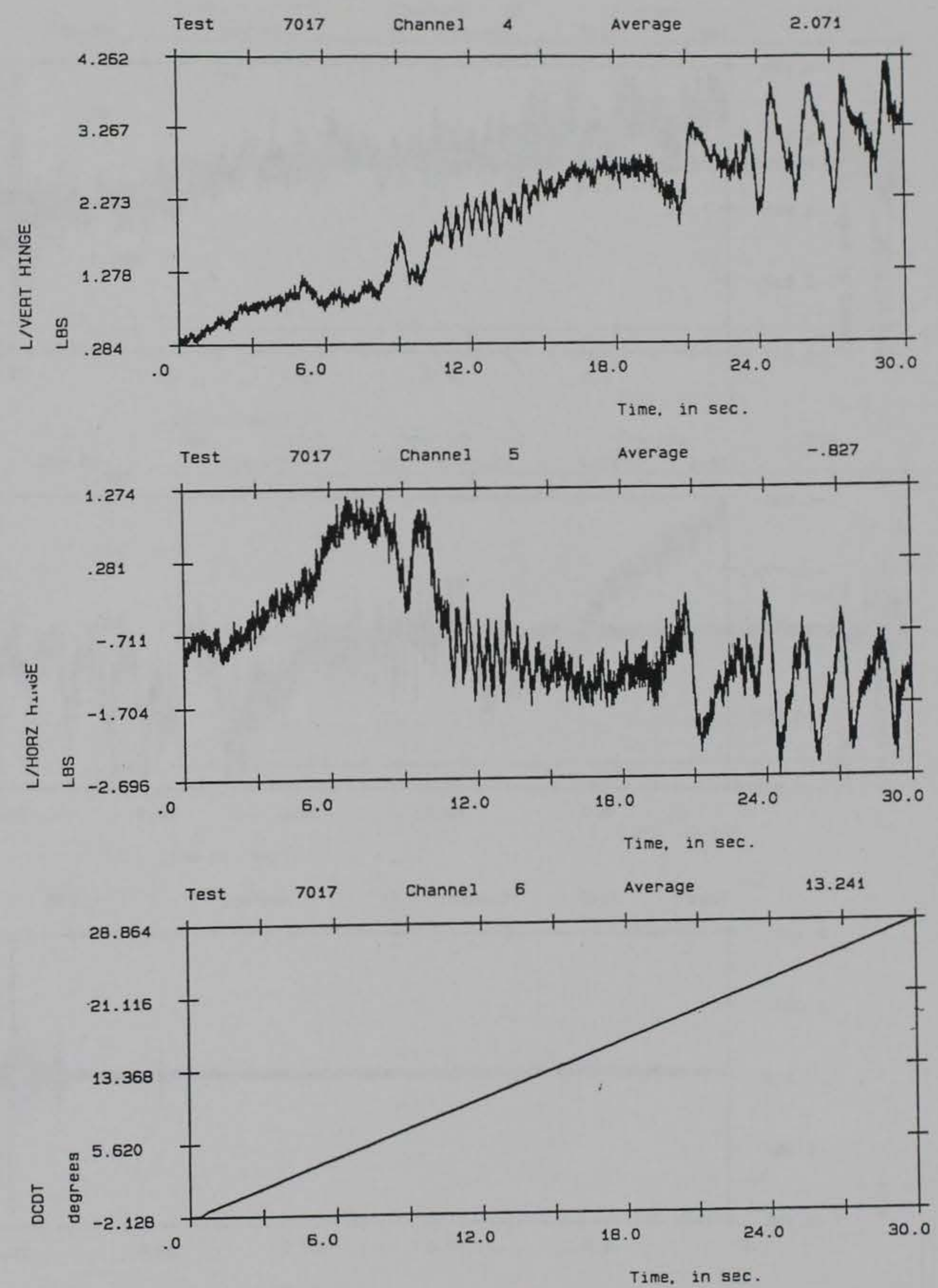

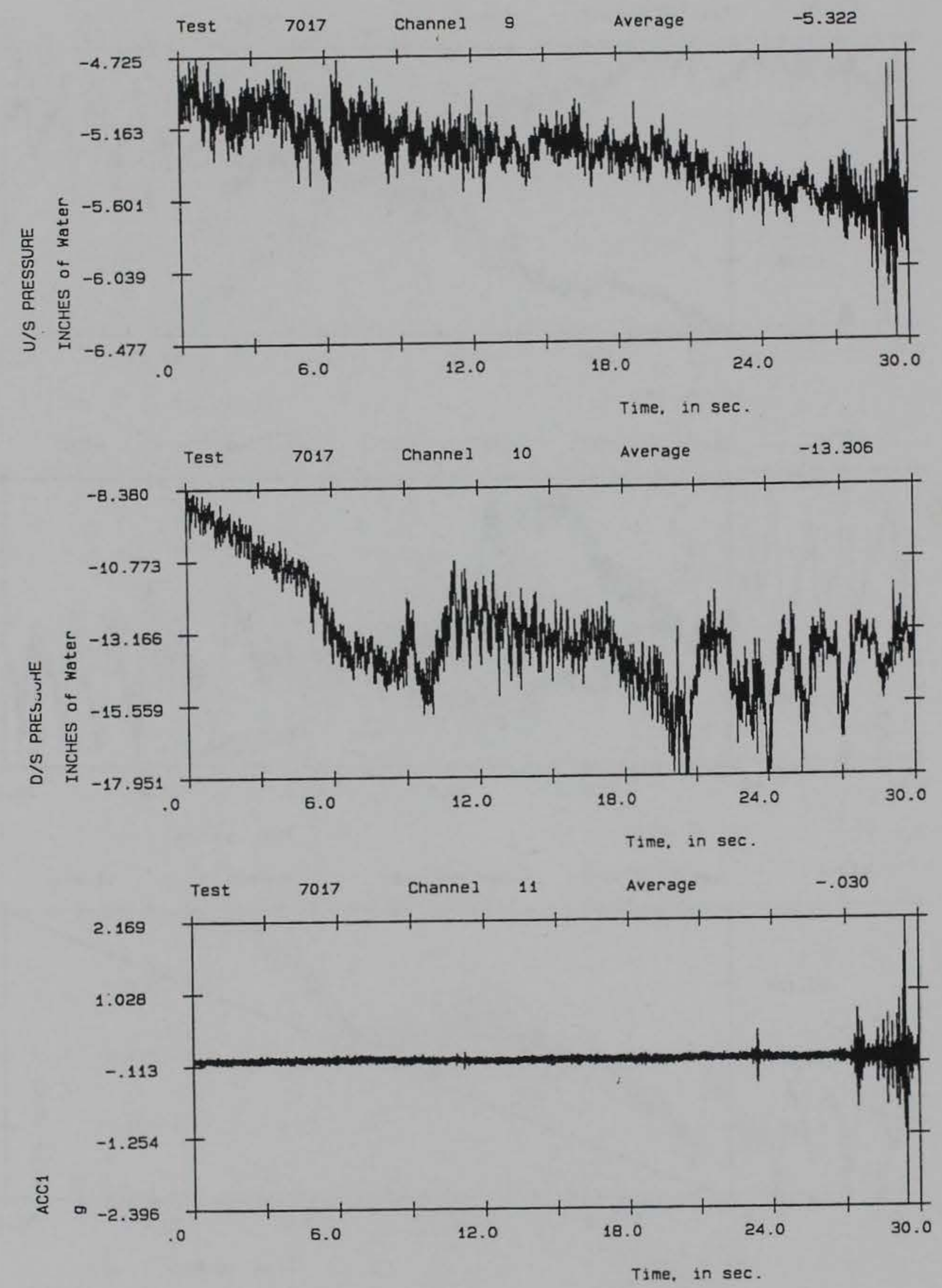

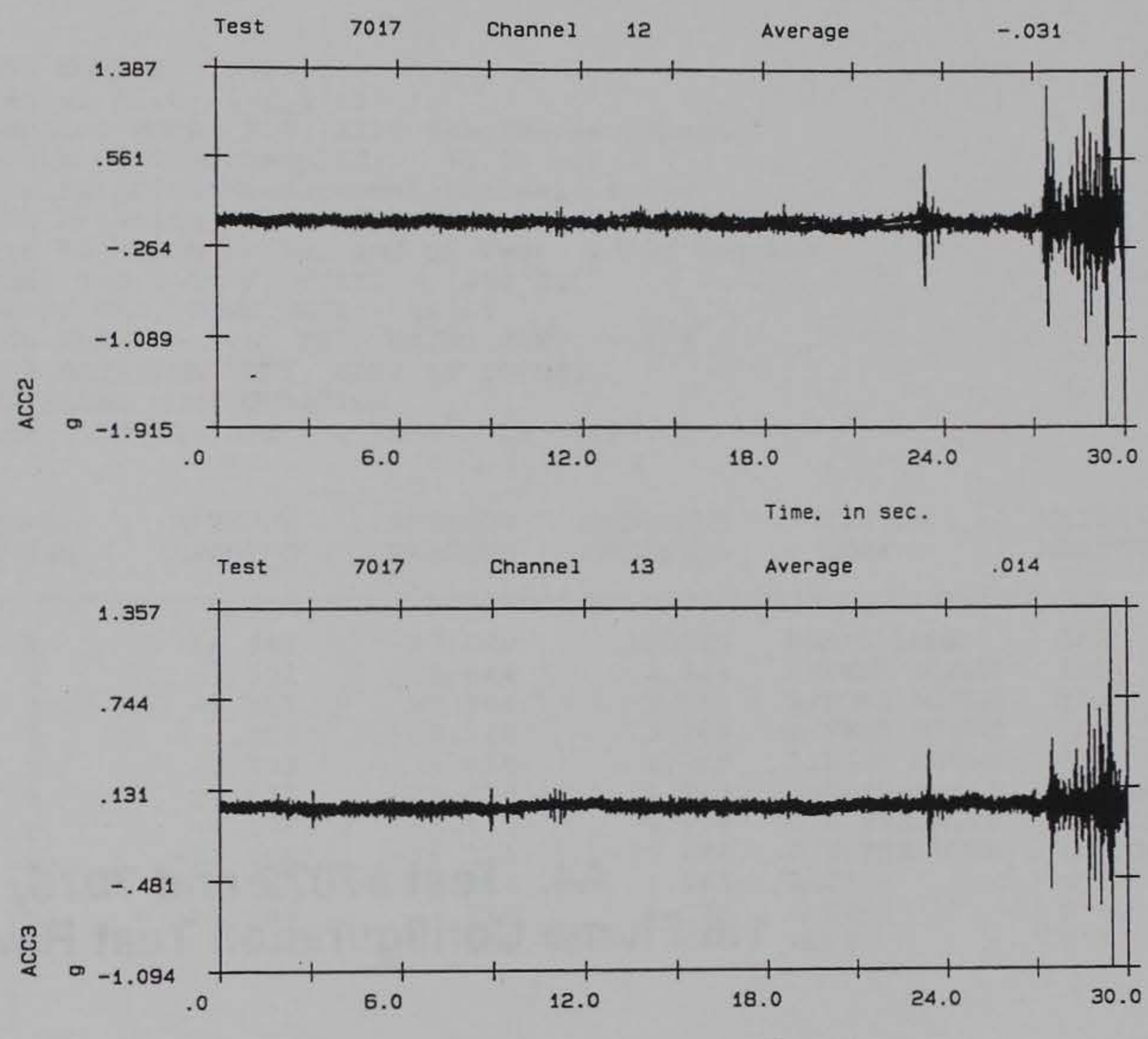

Time, in sec. 


\section{A4. Test \#7072 and 7075,}

1:5 Flume Configuration Test Raw Data 
Test Number: 7072

Channel List: $1-6,9-13$

Sampling Rate: 2083.3330 samples/sec/channel

Length of Time Sampled:

$30.00 \mathrm{sec}$

Gate Rotation Measurement Channel: 6

Gate Rotation Angle, Start of Test: 20.00 degrees

Gate Rotation Angle, End of Test: 20.00 degrees

CHAN. 1-5,9-13 FILTERED @ $1000 \mathrm{~Hz}$,

3-GATE GAP, DOWN GATE $=46-48$

POOL ELEV. $=300$, TAIL WATER ELEV. $=279$

GATE ROTATION TEST, GATE AT 20 DEG.

1:5 FLUME CONFIGURATION

Date: 7-11-1994 Time: 13: 1:57

PROBE MINIMUM AVERAGE MAXIMUM TYPE OF UNITS OF

$\begin{array}{rrrrll}1 & 14.943 & 17.029 & 18.826 & \text { SHAFT LOAD } & \text { Ibs } \\ 2 & .501 & 1.644 & 2.964 & \text { R/VERT HINGE } & \text { lbs } \\ 3 & -5.357 & -3.704 & -2.050 & \text { R/HORZ HINGE } & \text { lbs } \\ 4 & .926 & 2.318 & 3.706 & \text { L/VERT HINGE } & \text { Ibs } \\ 5 & -2.199 & -.018 & 1.719 & \text { L/HORZ HINGE } & \text { IBS } \\ 6 & 19.623 & 19.658 & 19.702 & \text { Gate Rotatio } & \text { degrees } \\ 9 & -6.178 & -5.410 & -4.474 & \text { U/S PRESSURE } & \text { in h20 } \\ 10 & -17.562 & -14.118 & -10.682 & \text { D/S PRESSURE } & \text { in h20 } \\ 11 & -.969 & -.014 & 1.062 & \text { ACC1 } & g^{\prime} \mathrm{s} \\ 12 & -1.207 & -.032 & 1.175 & \text { ACC2 } & \text { g's } \\ 13 & -.825 & -.001 & .867 & \text { ACC3 } & g^{\prime} \mathrm{s}\end{array}$



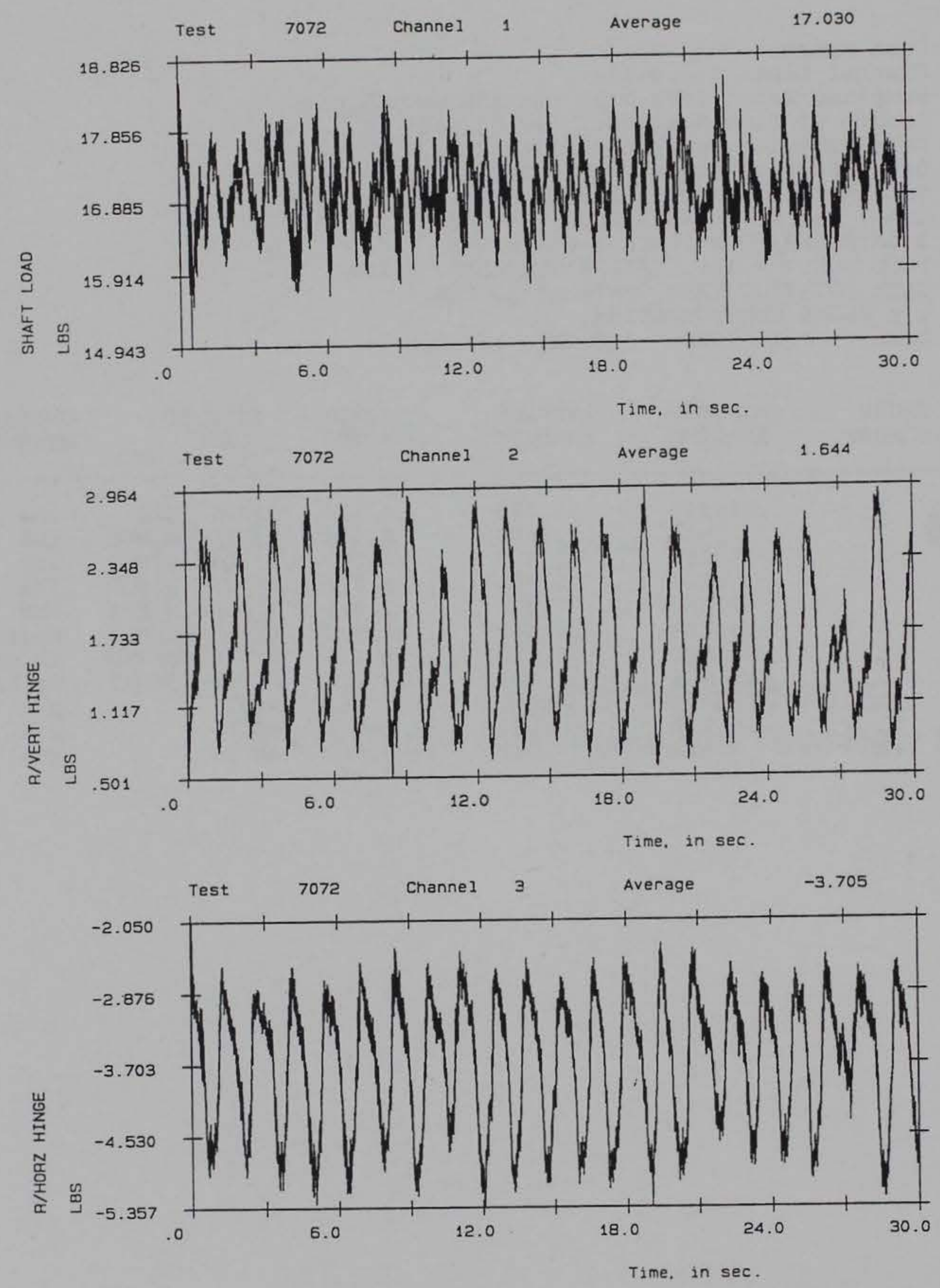

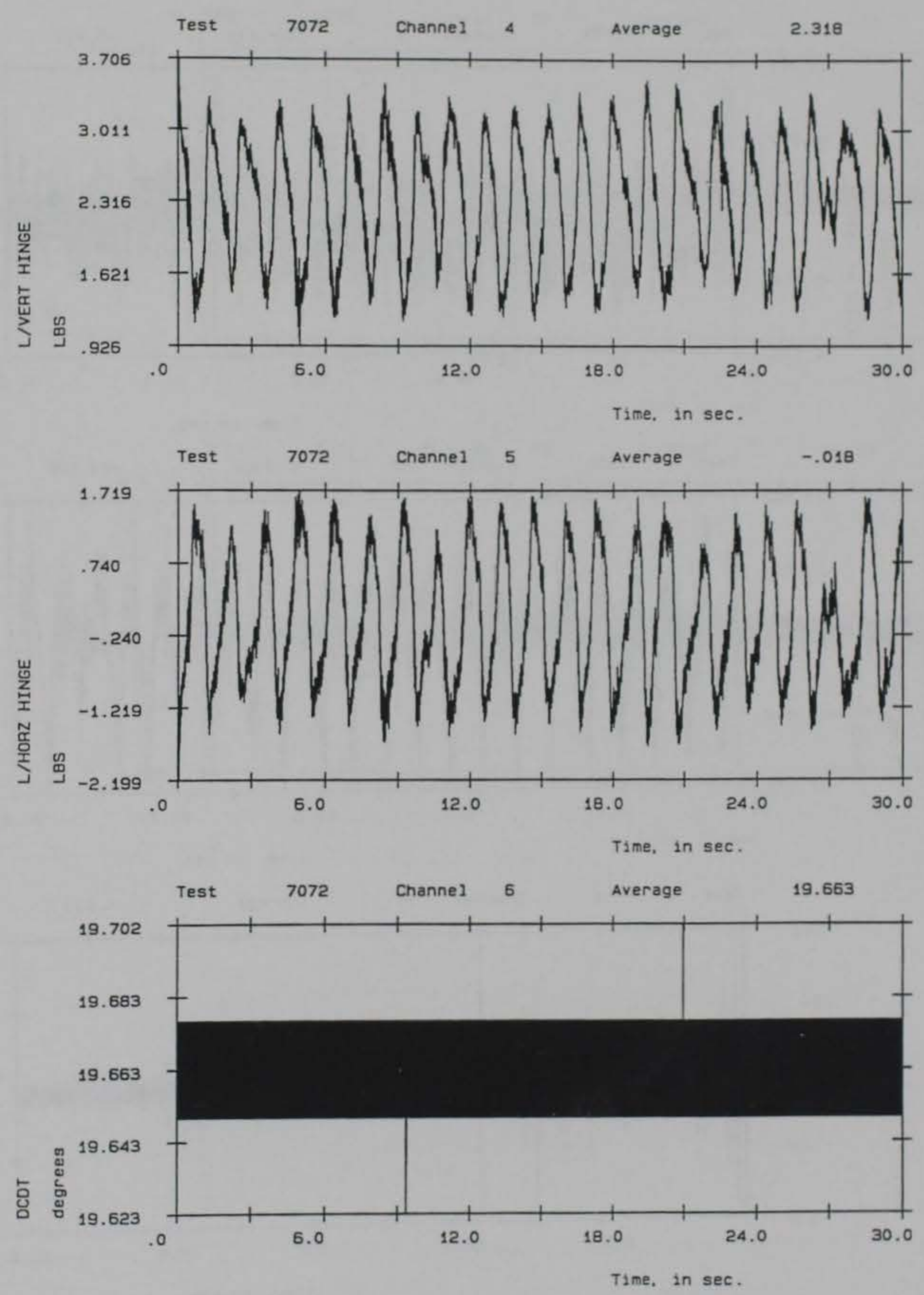

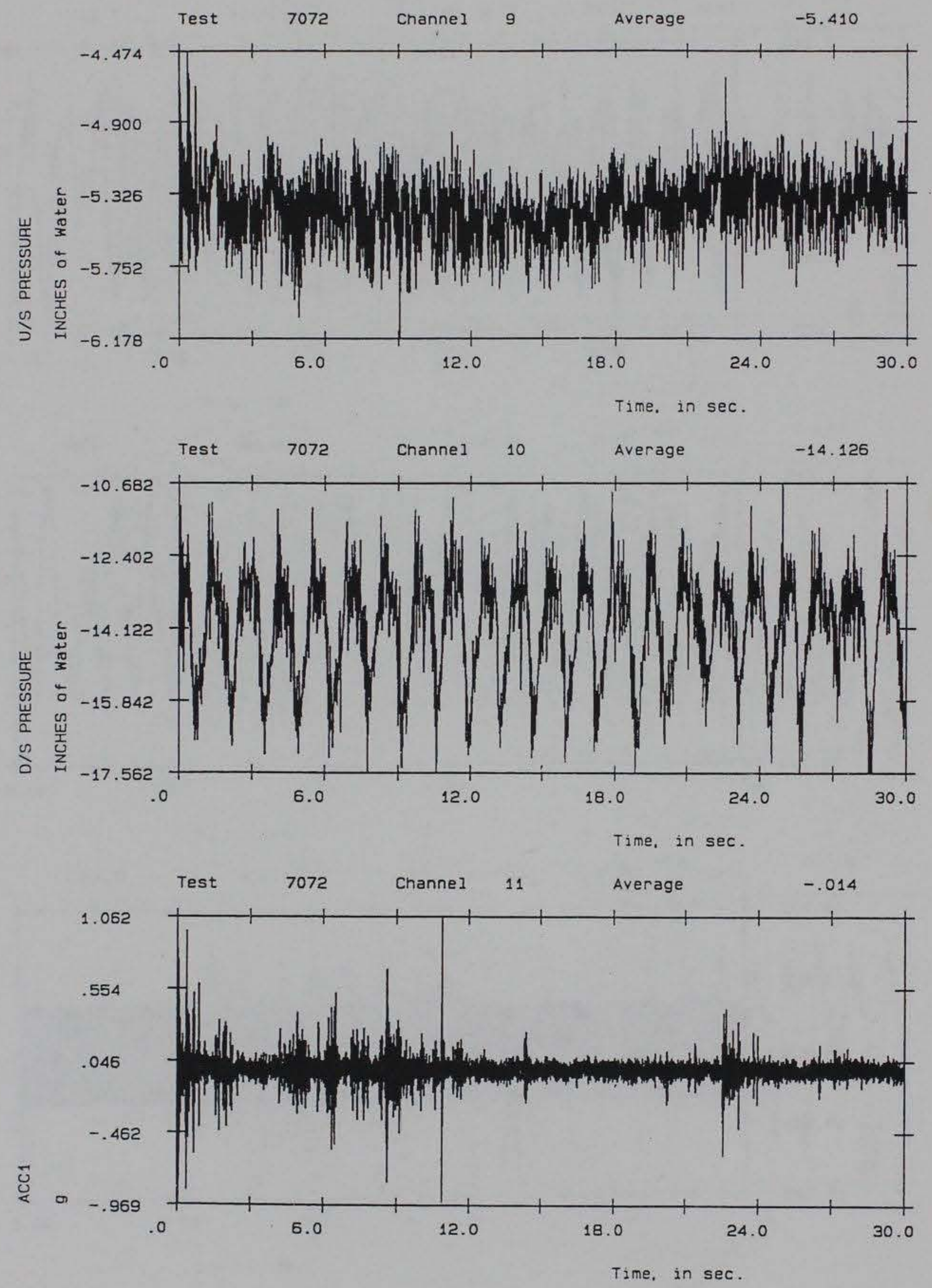

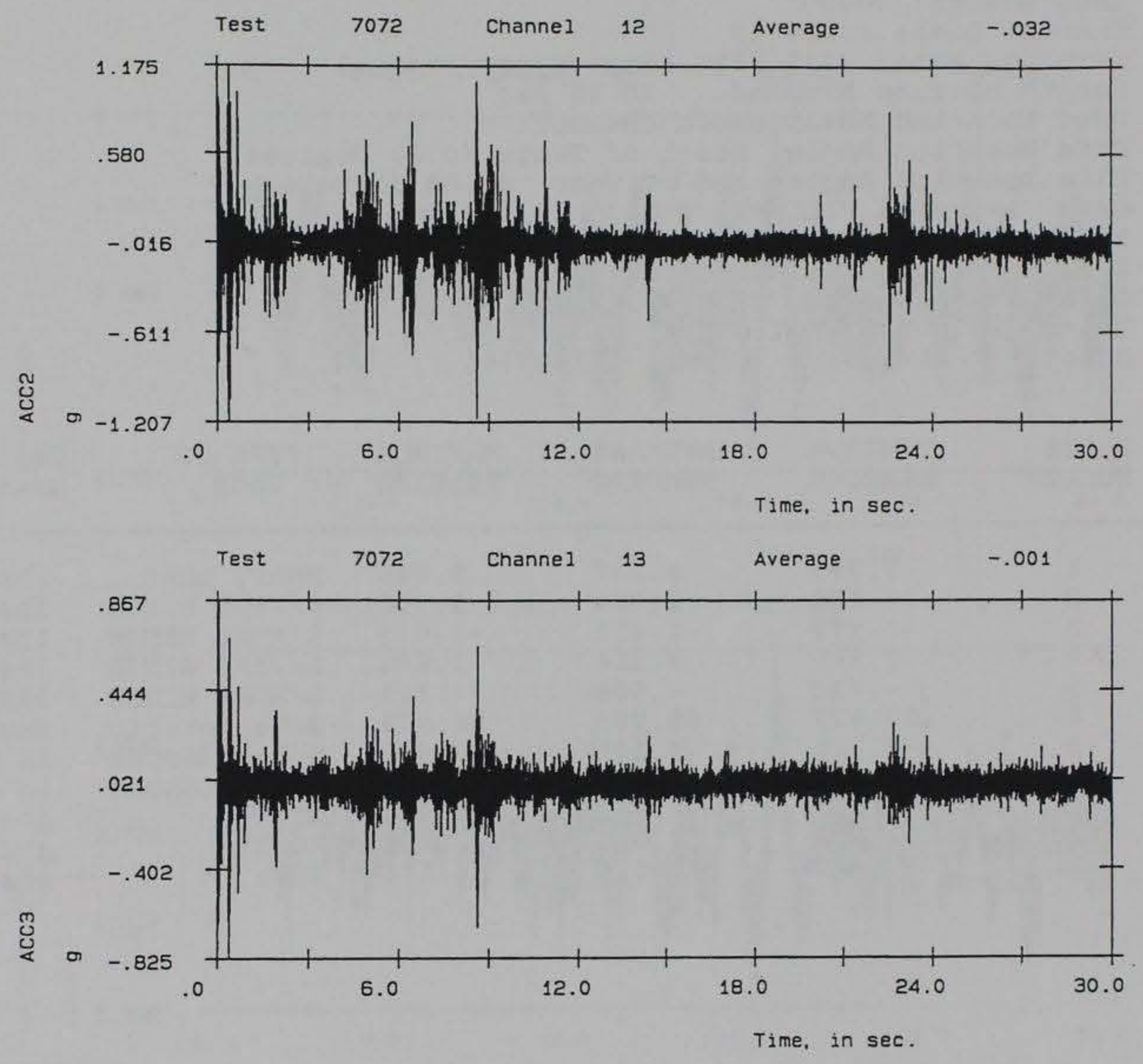
Test Number: 7075

Channel List: $1-6,9-13$

Sampling Rate: 2083.3330 samples/sec/channel

Length of Time Sampled:

$30.00 \mathrm{sec}$

Gate Rotation Measurement Channel: 6

Gate Rotation Angle, Start of Test: 60.00 degrees

Gate Rotation Angle, End of Test: 60.00 degrees

CHAN. 1-5,9-13 FILTERED @ $1000 \mathrm{~Hz}$,

3-GATE GAP, DOWN GATE $=46-48$

POOL ELEV. $=300$, TAIL WATER ELEV. $=279$

GATE ROTATION TEST, GATE AT 60 DEG.

1:5 FLUME CONFIGURATION

Date: 7-11-1994 Time: 13:17:46

$\begin{array}{llllcl}\text { PROBE } & \text { MINIMUM } & \text { AVERAGE } & \text { MAXIMUM } & \text { TYPE OF } & \text { UNITS OF } \\ \text { NUMBER } & \text { READING } & \text { READING } & \text { READING } & \text { GAGE } & \text { MEASURE }\end{array}$

$\begin{array}{rrrrll}1 & 8.799 & 9.367 & 9.929 & \text { SHAFT LOAD } & \text { lbs } \\ 2 & 2.539 & 2.729 & 2.932 & \text { R/VERT HINGE } & \text { lbs } \\ 3 & -1.992 & -1.832 & -1.623 & \text { R/HORZ HINGE } & \text { lbs } \\ 4 & 3.341 & 3.518 & 3.699 & \text { L/VERT HINGE } & \text { lbs } \\ 5 & -.720 & -.508 & -.313 & \text { L/HORZ HINGE } & \text { lBS } \\ 6 & 59.777 & 59.768 & 59.873 & \text { Gate ROtatio } & \text { degrees } \\ 9 & -8.814 & -8.491 & -7.989 & \text { U/S PRESSURE } & \text { in h20 } \\ 10 & -11.316 & -11.248 & -11.162 & \text { D/S PRESSURE } & \text { in h20 } \\ 11 & -.530 & -.031 & .433 & \text { ACC1 } & g^{\prime} \mathrm{s} \\ 12 & -.679 & -.061 & .661 & \text { ACC2 } & g^{\prime} \mathrm{s} \\ 13 & -.589 & -.015 & .874 & \text { ACC3 } & \mathrm{g}^{\prime} \mathrm{s}\end{array}$



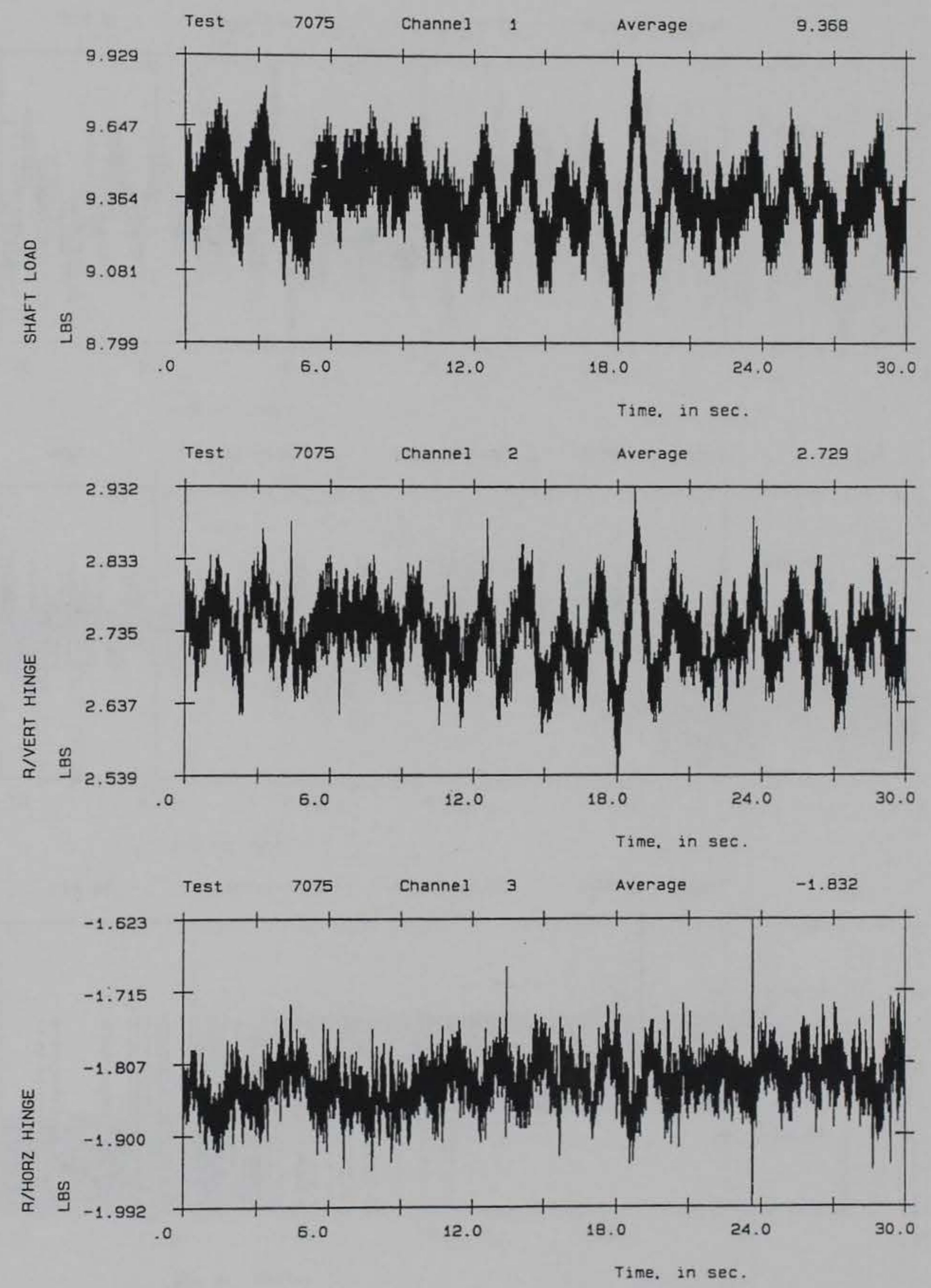

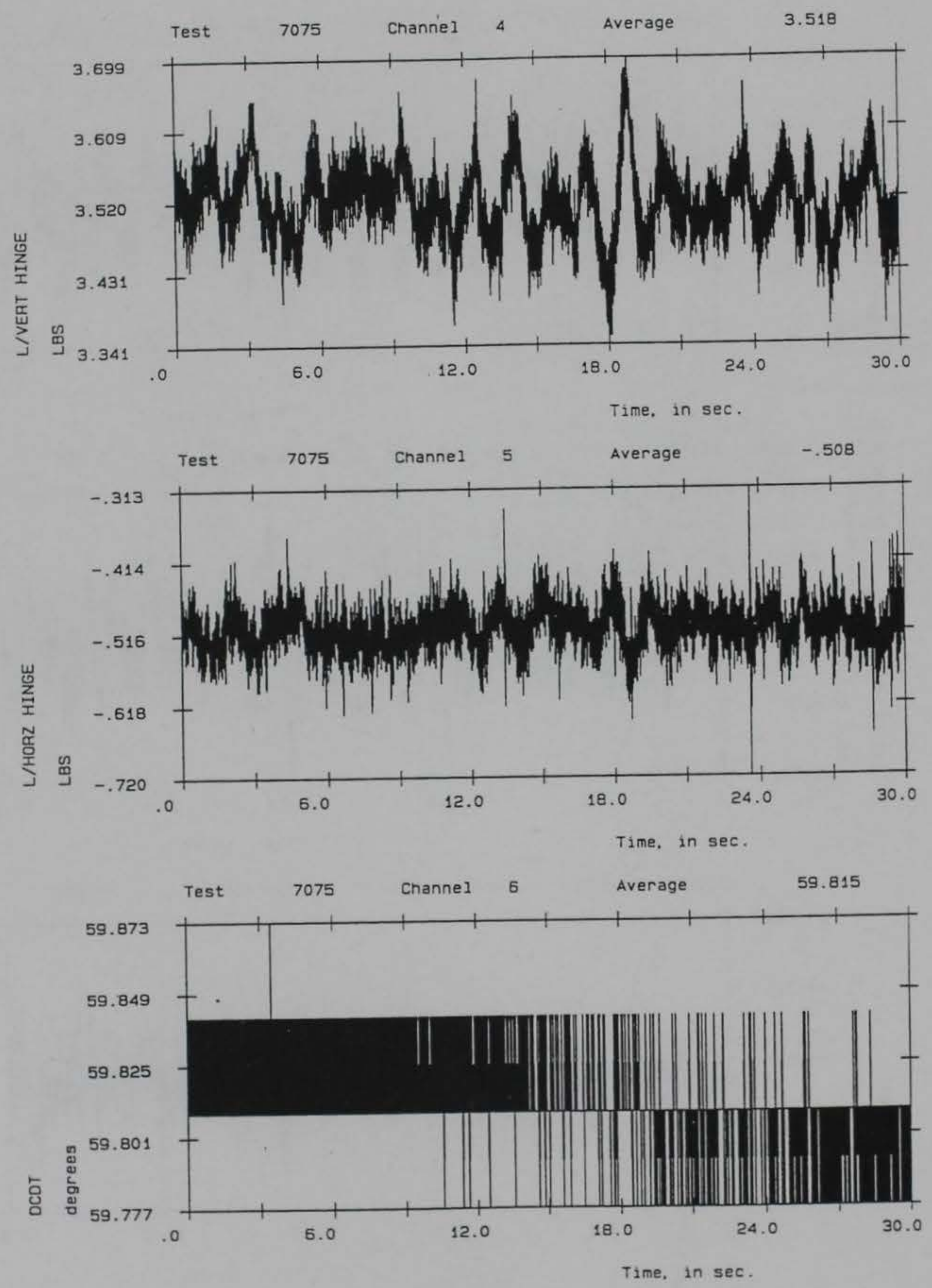

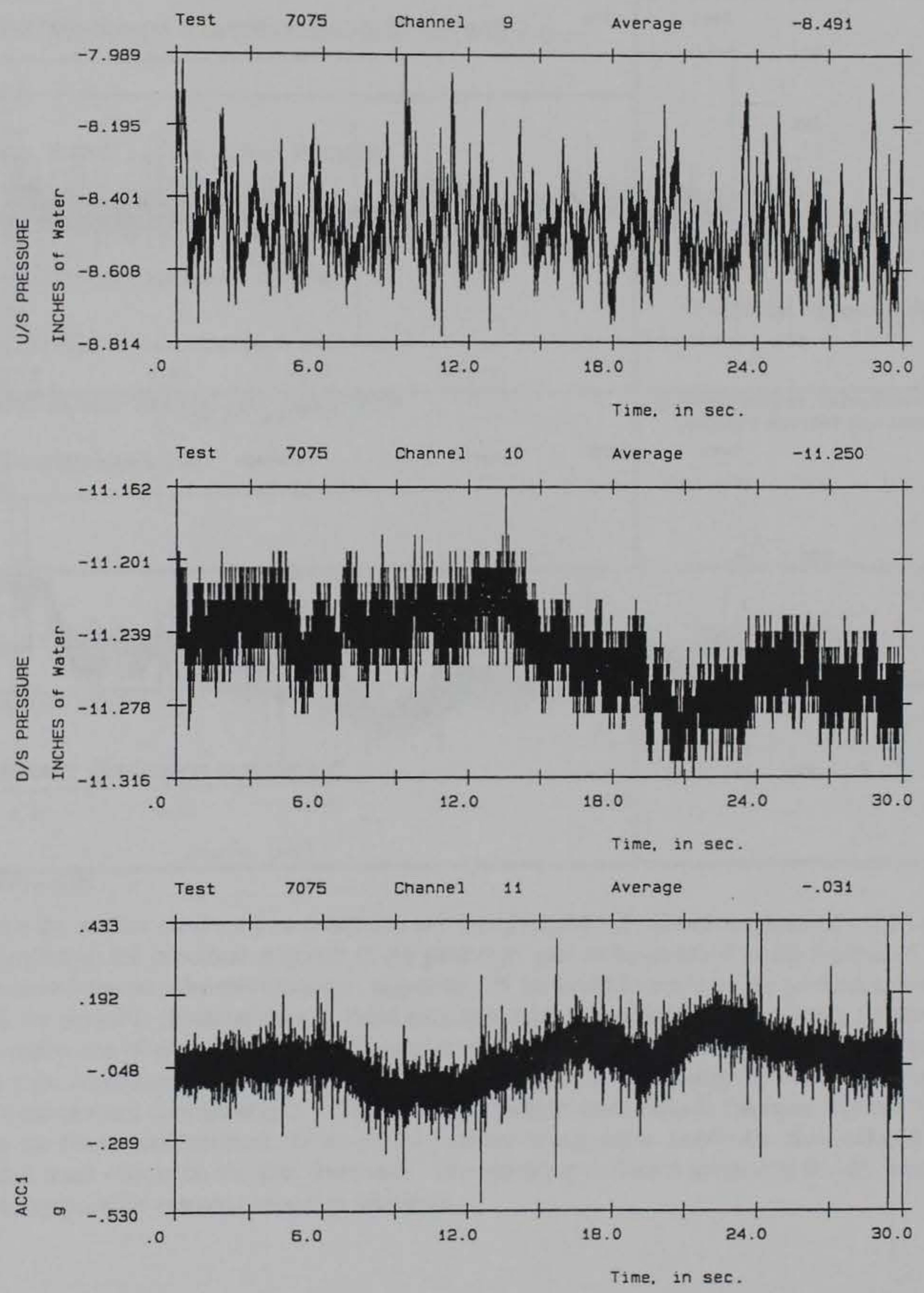


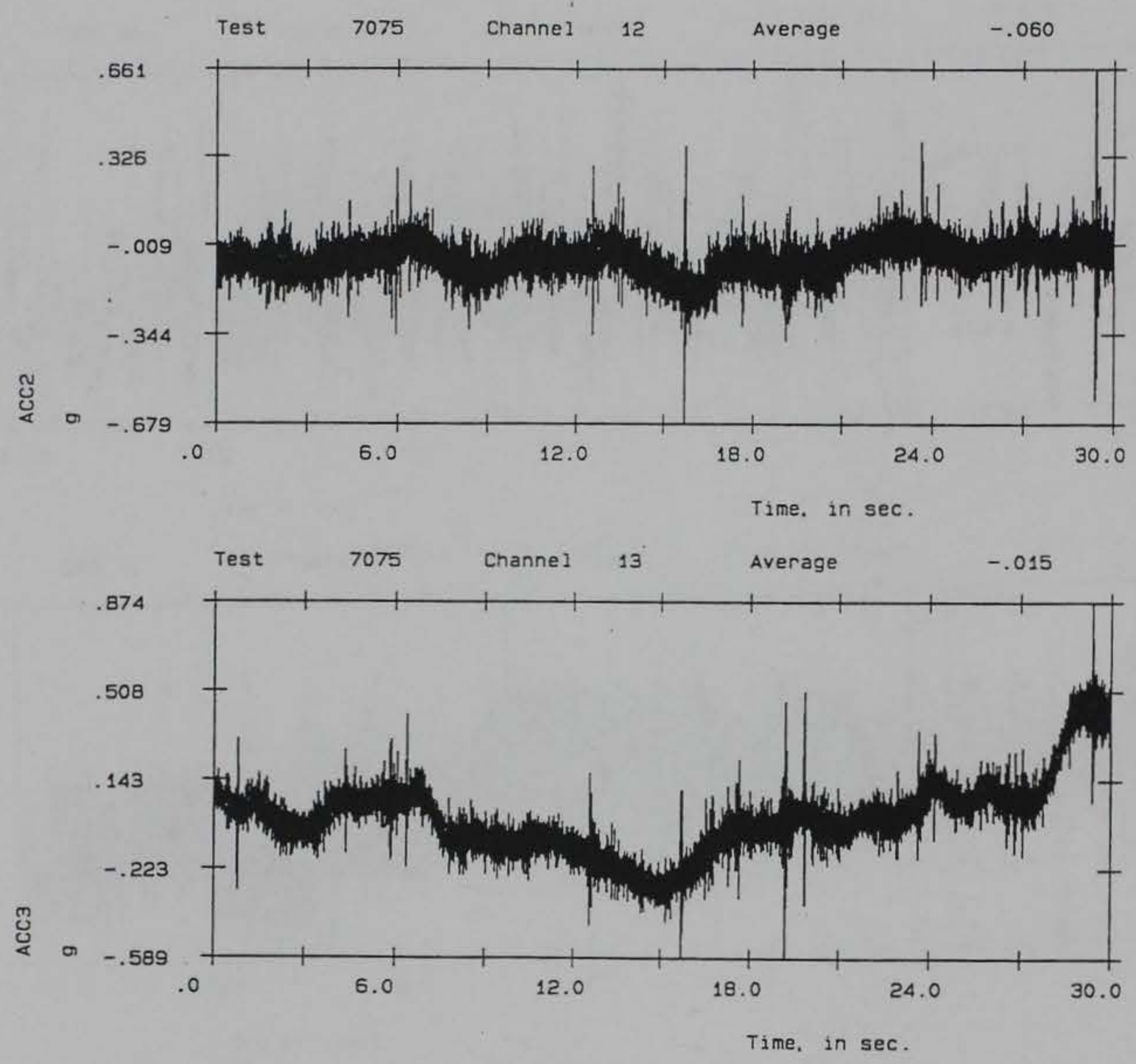

A48

Appendix A Selected Raw Data 
Public reporting burden for this collection of information is estimated to average 1 hour per response, including the time for reviewing instructions, searching existing data sources, gathering and maintaining the data needed, and completing and reviewing the collection of information. Send comments regarding this burden estimate or any other aspect of this

Davis Highway. Suite 1204, Arlington, VA 22202-4302, and to the Office of Management and Budget, Paperwork Reduction Project (0704-0188), Washington, DC 20503.

\begin{tabular}{|l|l|l}
\hline 1. AGENCY USE ONLY (Leave blank) & 2. REPORT DATE & 3. REPORT TYPE AND DATES COVERED
\end{tabular}

4. TITLE AND SUBTITLE

August 1997

Final report

Flow-Induced Vibration Experiments for a 1:25-Scale-Model Flat Wicket Gate

6. AUTHOR(S)

Mostafiz R. Chowdhury, Robert L. Hall, Eileen Pesantes

U.S. Army Engineer Waterways Experiment Station

3909 Halls Ferry Road

Vicksburg, MS 39180-6199

5. FUNDING NUMBERS

U.S. Army Engineer District, Louisville

Louisville, KY 40202

\section{SUPPLEMENTARY NOTES}

Available from National Technical Information Service, 5285 Port Royal Road, Springfield, VA 22161.

12a. DISTRIBUTION/AVAILABILITY STATEMENT

12b. DISTRIBUTION CODE

Approved for public release; distribution is unlimited.

13. ABSTRACT (Maximum 200 words)

This report presents the studies conducted to determine the flow-induced vibrational response of a 1:25-scale flat gate model used for predicting the structural response of the prototype gate to be installed in the Smithland Dam on the Ohio river. Time- and frequency-domain structural responses are analyzed to evaluate the performance of the wickets, to understand the dynamic characteristics of these structures, and to predict the design loads for the prototype wickets. The effectiveness of river channel models used in the prototype and in the physical models to represent the open channel flow conditions in the actual river is also determined by comparing the vibrational response of wickets for three different channel configurations. These channel configurations include the open channel, the approach channel, and the flume configuration. Scale model tests are conducted to isolate the flow-induced forced response from the added mass effects on the gate dynamics. The operating deflected shape and the dry mode shapes are extracted to detect any possible resonant vibration problems.

\begin{tabular}{|c|c|c|c|c|}
\hline \multirow{2}{*}{\multicolumn{2}{|c|}{$\begin{array}{l}\text { 14. SUBJECT TERMS } \\
\text { Flow-induced vibration } \\
\text { Hydraulically operated wickets } \\
\text { Modal parameters }\end{array}$}} & \multirow{2}{*}{\multicolumn{2}{|c|}{$\begin{array}{l}\text { Operating deflected shape } \\
\text { Similitude model } \\
\text { Wicket gate }\end{array}$}} & $\begin{array}{l}\text { 15. NUMBER OF PAGES } \\
247\end{array}$ \\
\hline & & & & 16. PRICE CODE \\
\hline $\begin{array}{l}\text { 17. SECURITY CLASSIFICATION } \\
\text { OF REPORT } \\
\text { UNCLASSIFIED }\end{array}$ & & $\begin{array}{l}\text { SECURITY CLASSIFICATION } \\
\text { OF THIS PAGE } \\
\text { UNCLASSIFIED }\end{array}$ & $\begin{array}{l}\text { 19. SECURITY CLASSIFICATION } \\
\text { OF ABSTRACT }\end{array}$ & 20. LIMITATION OF ABSTRACT \\
\hline NSN $7540-01-280-5500$ & & & & $\begin{array}{l}\text { andard Form } 298 \text { (Rev. 2-89) } \\
\text { scribed by ANSI sid 239-18 } \\
3-102\end{array}$ \\
\hline
\end{tabular}

